Felipe Costa Magazoni

\title{
Modelagem computacional do desempenho térmico de trocadores de calor de fluxo cruzado e casco e tubos
}

São Carlos 

Felipe Costa Magazoni

\title{
Modelagem computacional do desempenho térmico de trocadores de calor de fluxo cruzado e casco e tubos
}

Tese de doutorado apresentada à Escola de Engenharia de São Carlos da Universidade de São Paulo para obtenção do título de Doutor em Engenharia Mecânica. Área de concentração: Térmico e Fluidos

\author{
Universidade de São Paulo \\ Departamento de Engenharia Mecânica \\ Programa de Pós-Graduação
}

Orientador: Prof. Dr. Luben Cabezas Gómez

\begin{tabular}{|c|c|}
\cline { 2 - 2 } & ESTE EXEMPLAR TRATA-SE DA \\
VERSÃO CORRIGIDA. \\
A VERSÃO ORIGINAL ENCONTRA- \\
A VE DISPONIVEL JUNTO AO \\
DEPARTAMENTO DE \\
ENGENHARIA MECÂNICA DA \\
EESC-USP.
\end{tabular}


AUTORIZO A REPRODUÇÃO TOTAL OU PARCIAL DESTE TRABALHO, POR QUALQUER MEIO CONVENCIONAL OU ELETRÔNICO, PARA FINS DE ESTUDO E PESQUISA, DESDE QUE CITADA A FONTE.

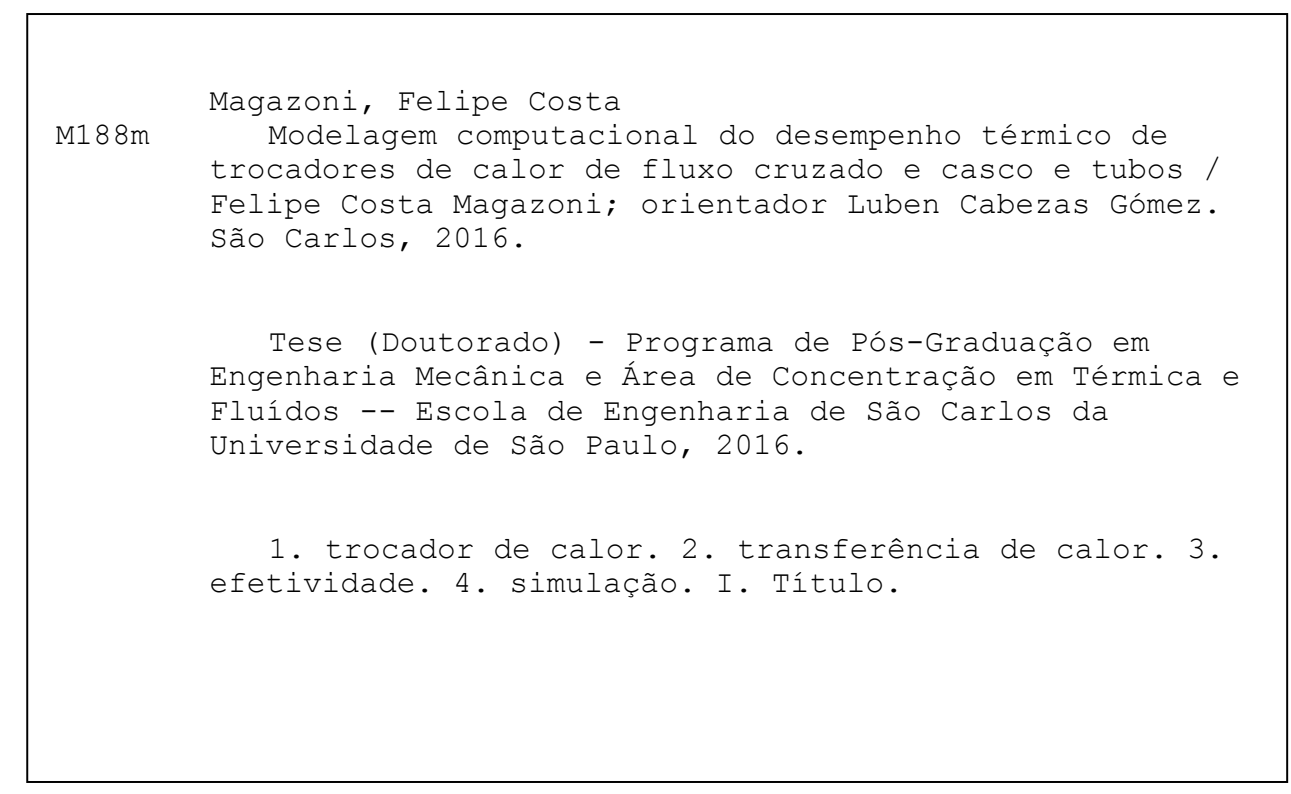




\section{FOLHA DE JULGAMENTO}

Candidato: Engenheiro FELIPE COSTA MAGAZONI.

Título da tese: "Modelagem computacional do desempenho térmico de trocadores de calor de fluxo cruzado e casco e tubos".

Data da defesa: 18/11/2016.

Comissão Julgadora:

Prof. Dr. Luben Cabezas Gómez

(Orientador)

(Escola de Engenharia de São Carlos/EESC)

Prof. Dr. Cristiano Bigonha Tibiriça

(Escola de Engenharia de São Carlos/EESC)

Prof. Associado Alberto Hernandez Neto

(Escola Politécnica/EP-USP)

Prof. Dr. Fabio Toshio Kanizawa

(Universidade Federal Fluminense/UFF)

Prof. Associado Leandro Franco de Souza

(Instituto de Ciências Matemáticas e de Computação/ICMC-USP)
Resultado:

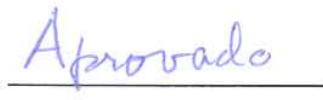

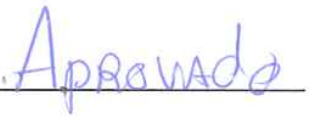
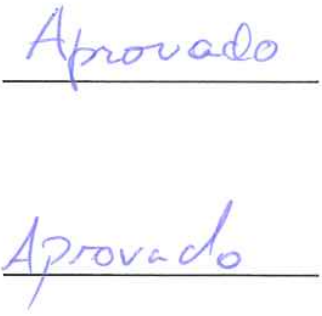

Coordenador do Programa de Pós-Graduação em Engenheira Mecânica: Prof. Associado Gherhardt Ribatski

Presidente da Comissão de Pós-Graduação:

Prof. Associado Luis Fernando Costa Alberto 



\section{Agradecimentos}

Aos professores Luben Cabezas Gómez e Gherhardt Ribatski pela amizade, oportunidade, orientação e acompanhamento concedido para a realizaçõ do presente trabalho.

Aos demais professores e servidores técnicos da Escola de Engenharia de São Carlos da Universidade de São Paulo.

Às empresas TGM Turbinas, General Motors e Thermax pela disponibilidade de tempo, ajuda e incentivo no desenvolvimento deste projeto.

À minha família pelo apoio e ajuda durante o período de doutorado.

À Ana Luiza Bassanetto pelo amor, companheirismo e amizade. 

"Nobody climbs mountains for scientific reasons. Science is used to raise money for the expeditions, but you really climb for the hell of it."

(Edmund Hillary) 



\section{Resumo}

MAGAZONI, Felipe Costa. Modelagem computacional do desempenho térmico de trocadores de calor de fluxo cruzado e casco e tubos. 2016. 240 páginas. Tese (doutorado) - Escola de Engenharia de São Carlos, Universidade de São Paulo, São Carlos, 2016.

O presente trabalho descreve e introduz uma metodologia numérica de simulação térmica de trocadores de calor de fluxo cruzado e de casco e tubo. A metodologia computacional é utilizada para simular doze configurações de arranjos de escoamento de trocadores de calor de fluxo cruzado com número de passes e tubos por passe arbitrários, assim como diversas condições de mistura de ambos os fluidos. O procedimento computacional é desenvolvido, baseado em diversos trabalhos da literatura, para calcular a efetividade de temperatura e o fator de correção da diferença média logarítmica de temperatura para trocadores de calor de fluxo cruzado em escoamentos contracorrente e paralelo. Novos dados da efetividade de temperatura e do fator de correção para configurações complexas de trocadores de calor são apresentados em diversas tabelas e figuras. As condições de mistura do fluido interno depois de cada passe são analisadas e caracterizadas por três configurações: misturado, não misturado com uma ordem idêntica das fileiras e não misturado com uma ordem inversa das fileiras. A influência da mistura do fluido externo entre os tubos do trocador de calor também é analisada. A metodologia computacional também é utilizada para trocadores de calor de casco e tubo tipo TEMA E com um passe de ambos os fluidos (fluidos do casco e dos tubos) em escoamentos contracorrente e paralelo de acordo com as entradas do trocador de calor. O algoritmo é baseado em diversas hipóteses e considerações de modelagem adotadas em diversos trabalhos de trocadores de calor de fluxo cruzado e de casco e tubo. Cada seção entre as chicanas é idealizada como um trocador de calor não misturado - não misturado. Além disso, este estudo fornece um sumário de correlações matemáticas exatas e aproximadas para algumas configurações de trocadores de calor de fluxo cruzado e de casco e tubo, que são muito apropriadas para análises computacionais e que facilitam o cálculo de efetividade de temperatura e do fator de correção. Os resultados encontrados são comparados com o algoritmo HETE e com soluções e relações matemáticas disponíveis em outras literaturas e mostram a capacidade dos algoritmos desenvolvidos.

Palavras-chaves: trocador de calor, fluxo cruzado, casco e tubo, efetividade, fator de correção, metodologia, simulação. 



\section{Abstract}

MAGAZONI, Felipe Costa. Numerical methodologies for thermal performance of crossflow and shell-and-tube heat exchangers. 2016. 240 pages. Thesis (doctoral degree) - Escola de Engenharia de São Carlos, University of São Paulo, São Carlos, 2016.

The present thesis describes and introduces the numerical simulation methodologies for thermal modeling of crossflow and shell-and-tube heat exchangers. The computational methodology is used for simulating twelve general flow arrangement configurations of crossflow heat exchangers with arbitrary number of passes and tubes per pass, as well as, several mixture conditions of both fluids. The computational procedures are developed, based on some works from literature, to calculate the temperature effectiveness and the mean logarithm temperature difference (MLTD) correction factor for crossflow and parallel and counter-crossflow heat exchangers. New temperature effectiveness and correction factor data for the treated complex flow arrangements configurations are provided and showed in various tables and plots. Tube fluid mixing conditions after each pass, characterized by three types of configuration: tube fluid mixed; tube fluid unmixed keeping identical order of the rows; and tube fluid unmixed with inverted order of the rows, are analyzed. The influence of external fluid mixing between tube rows along the heat exchanger configurations is also addressed. The computational methodology is also addressed to TEMA E shell-andtube heat exchangers type with one-pass of both fluids (in-tube and shell side) flowing in counterflow and parallel regarding the heat exchangers inlets. The algorithm is based on various assumptions and modelling considerations adopted in several works of crossflow and shell-and-tube heat exchangers. Each section between two baffles is idealized as an unmixed-unmixed crossflow heat exchanger. In addition, this study provides a summary of exact and approximate correlations for some configurations of crossflow and shell-and-tube heat exchangers, that are very appropriate for computerized analysis and that facilitate the computation of both parameters, the temperature effectiveness and the mean logarithmic temperature difference correction factor. The results found are compared to algorithm HETE and with available relations and solutions of other works and show the capability of the developed algorithm.

Keywords: heat exchanger, crossflow, shell-and-tube, effectiveness, correction factor, methodology, simulation. 



\section{Lista de ilustrações}

Figura 1 - Tipos de trocadores de calor (CENGEL[ 2008)] . . . . . . . . . . . . 4

Figura 2 - Variação das temperaturas quente e fria ao longo de um trocador de

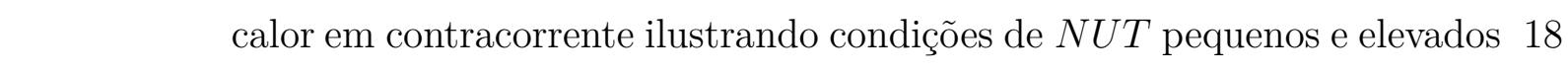

Figura 3 - Variação das temperaturas nas direções transversal e longitudinal em

\begin{tabular}{|r|}
\hline um trocador de calor de fluxo cruzado de um passe misturado - não \\
\hline
\end{tabular}

misturado . . . . . . . . . . . . . . . . . . 20

Figura 4 - Ilustração de um elemento com as temperaturas de entrada e saída

(CABEZAS-GÓMEZ; NAVARRO; SAIZ-JABARDO, 2015)] . . . . . . 35

Figura 5 - Ilustração de um trocador de calor cruzado misturado - não mistu-

rado e do elemento de análise (CABEZAS-GÓMEZ; NAVARRO; SAIZ-

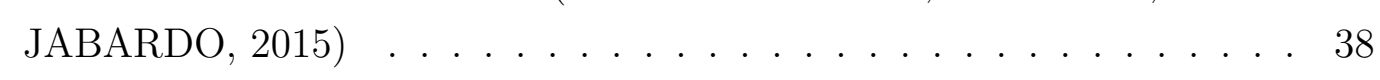

Figura 6 - Diagrama de blocos do programa principal do código HETE (CABEZASGÓMEZ; NAVARRO; SAIZ-JABARDO, 2015] . . . . . . . . . . . . . 40

Figura 7 - Diagrama de blocos da sub-rotina numérica ComputeE (CABEZASGÓMEZ; NAVARRO; SAIZ-JABARDO, 2015)] . . . . . . . . . . . . . 41

Figura 8 - Diagrama de blocos da sub-rotina numérica TEMPERATURE (CABEZASGÓMEZ; NAVARRO; SAIZ-JABARDO, 2015] . . . . . . . . . . . . . 42

Figura 9 - Diagrama de blocos da sub-rotina numérica TEMPERATURE1 (CABEZASGÓMEZ; NAVARRO; SAIZ-JABARDO, 2015] . . . . . . . . . . . . . 44

Figura 10 - Configurações de trocadores de calor de fluxo cruzado de acordo com Pignotti e Cordero $[(1983 a)] \ldots$. . . . . . . . . . . . . . . 49

Figura 11 - Superfície de controle para balanço de energia local no fluido quente. . 50

Figura 12 - Caso 1A: Trocador de calor de fluxo cruzado em escoamento paralelo

\begin{tabular}{|c|}
\hline com dois passes e dois tubos (2-2) com os fluidos quente e frio comple- \\
\hline
\end{tabular}
tamente misturados entre os passes . . . . . . . . . . . . 53

Figura 13 - Fluxograma para calcular a efetividade de temperatura e o fator de correção para o caso $1 \mathrm{~A} \ldots \ldots \ldots \ldots$. . . . . . . . . . . . 5 53

Figura 14 - Casos 1B e 1C: Trocador de calor de fluxo cruzado em escoamento paralelo com fluido frio completamente misturado entre os passes e com fluido quente não misturado com uma ordem idêntica das fileiras (caso 1B) e não misturado com uma ordem inversa das fileiras (caso 1C). . . 54

Figura 15 - Fluxograma para calcular a efetividade de temperatura e o fator de correção para os casos 1B e 1C . . . . . . . . . . . . . . 56

Figura 16 - Caso 2A: Trocador de calor de fluxo cruzado em escoamento contracorrente com dois passes e dois tubos (2-2) com os fluidos quente e frio completamente misturados entre os passes . . . . . . . . . . . 56 
Figura 17 - Fluxograma para calcular a efetividade de temperatura e o fator de

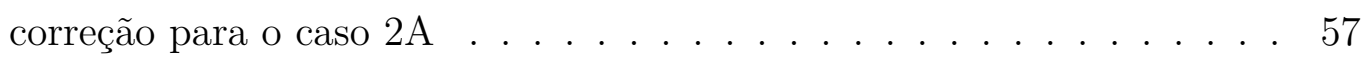

Figura 18 - Casos 2B e 2C: Trocador de calor de fluxo cruzado em escoamento contracorrente com fluido frio não misturado entre os passes e com fluido quente não misturado com uma ordem idêntica das fileiras (caso 2B) e não misturado com uma ordem inversa das fileiras (caso 2C)]. . . 58

Figura 19 - Fluxograma para calcular a efetividade de temperatura e o fator de correção para os casos $2 \mathrm{~B}$ e $2 \mathrm{C} \ldots$. . . . . . . . . . . . . . 60

Figura 20 - Casos 3A, 3B e 3C: Trocador de calor de fluxo cruzado em escoamento

\begin{tabular}{|c|}
\hline paralelo com fluido frio não misturado entre os passes e com fluido \\
\hline quente misturado (caso 3A), não misturado com uma ordem idêntica \\
\hline das fileiras (caso 3B) e não misturado com uma ordem inversa das \\
\hline fileiras (caso $3 \mathrm{C})$
\end{tabular}
fileiras (caso 3C) . . . . . . . . . . . . . . . . 6 61

Figura 21 - Fluxograma para calcular a efetividade de temperatura e o fator de correção para os casos 3A, 3B e 3C . . . . . . . . . . . . . 65

Figura 22 - Caso 4A: Trocador de calor de fluxo cruzado em escoamento contracor-

\begin{tabular}{|c|}
\hline rente com dois passes e dois tubos (2-2) com os fluidos quente e frio \\
\hline
\end{tabular}
completamente misturados entre os passes . . . . . . . . . . . 66

Figura 23 - Fluxograma para calcular a efetividade de temperatura e o fator de correção para o caso $4 \mathrm{~A}$. . . . . . . . . . . . . . . . . . 68

Figura 24 - Casos 4B e 4C: Trocador de calor de fluxo cruzado em escoamento contracorrente com dois passes e dois tubos (2-2) com os fluidos frio não misturado entre os passes e fluido quente não misturado com uma ordem idêntica das fileiras (caso 4B) e não misturado com uma ordem inversa das fileiras (caso 4C) . . . . . . . . . . . . . . . . . 69

Figura 25 - Fluxograma para calcular a efetividade de temperatura e o fator de correção para os casos $4 \mathrm{~B}$ e $4 \mathrm{C} \ldots \ldots . . \ldots 71$

Figura 26 - Procedimento complementar 1 e 2 dos casos 4B e 4C . . . . . . . . . . 72

Figura 27 - Fator de correção para trocadores de calor de fluxo cruzado em escoa-

\begin{tabular}{|c|}
\hline mento contracorrente com fluido quente misturado e fluido frio mistu- \\
\hline rado
\end{tabular}

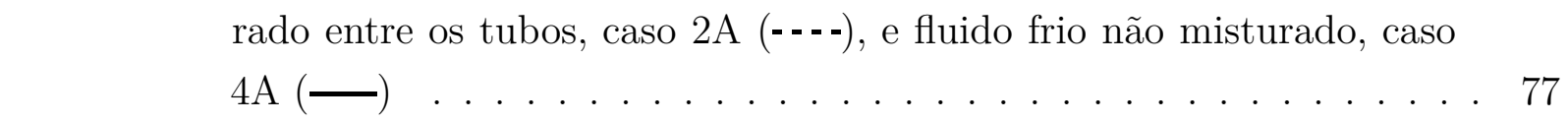

Figura 28 - Comportamento da razão $P / P_{c c}$ em função de $N U T$ para um trocador \begin{aligned} \hline de calor de fluxo cruzado em escoamento contracorrente com fluido \\ \hline\end{aligned} quente misturado e fluido frio misturado entre os tubos, caso 2A (- - - -),

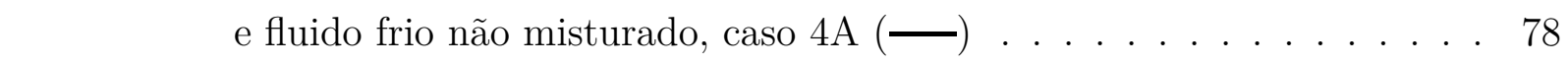

Figura 29 - Fator de correção para trocadores de calor de fluxo cruzado em escoamento paralelo com fluido quente misturado e fluido frio misturado entre os tubos, caso 1A (-), e fluido frio não misturado, caso 3A (----) 79 
Figura 30 - Fator de correção para trocadores de calor de fluxo cruzado em esco-

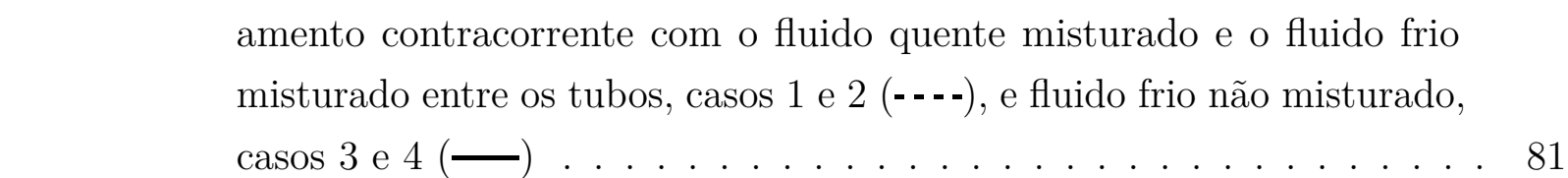

Figura 31 - Comportamento da efetividade de temperatura em função do fator de correção e da razão de temperatura para trocador de calor de fluxo

\begin{tabular}{|c|c|}
\hline & cruzado em escoamento paralelo com dois passes e quatro tubos por \\
\hline & passe (2-4) considerando três condições de mistura do fluido quente: \\
\hline & caso 3A (-), caso 3B (----) e caso 3C (……) - trocadores de calor \\
\hline & 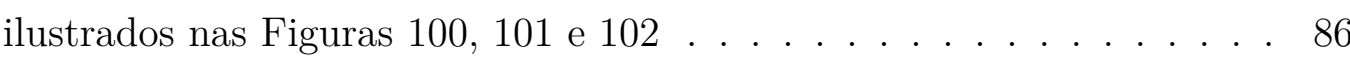 \\
\hline igura $32-$ & Comportamento da efetividade de temperatura em função do fator de \\
\hline & correção e da razão de temperatura para trocador de calor de fluxo \\
\hline
\end{tabular}

Figura 33 - Comportamento da razão $P / P_{c c}$ em função de $N U T$ para o caso 4B

\begin{tabular}{|c|}
\hline considerando um trocador de fluxo cruzado com dois passes e vinte \\
\hline
\end{tabular}

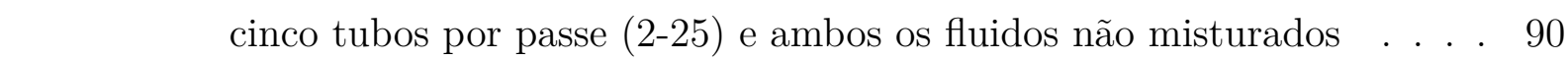

Figura 34 - Fator de correção em função de $P$ e $R$ de um trocador de calor de

\begin{tabular}{|c|}
\hline fluxo cruzado com um passe e infinitos tubos $(1-\infty)$ com o fluido frio \\
\hline
\end{tabular}
misturado e o quente não misturado - Caso 3A . . . . . . . . . . . . . 93

Figura 35 - Efetividade de temperatura em função de $N U T$ e $R$ de um trocador

\begin{tabular}{|c|}
\hline de calor de fluxo cruzado com um passe e infinitos tubos (1- $\infty$ ) com o \\
\hline
\end{tabular}

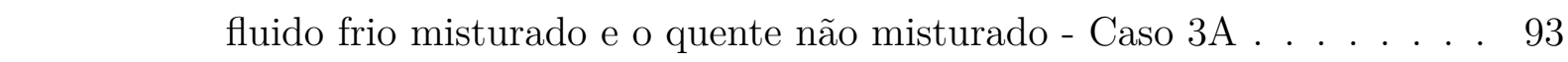

Figura 36 - Comportamento da razão $P / P_{c c}$ em função de $N U T$ para o caso $3 \mathrm{~A}$

considerando um trocador de calor de fluxo cruzado com um passe e

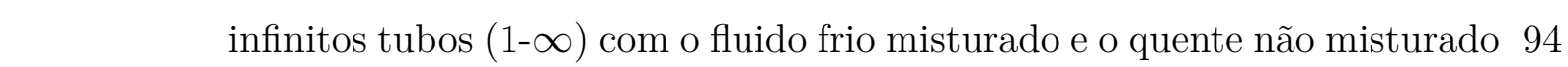

Figura 37 - Esquema de um trocador de calor tipo Plate Fin Heat Exchanger . . . 121

Figura 38 - Trocador de calor de casco e tubo tipo TEMA E com uma chicana . . 123

Figura 39 - Número de tubos em função do número de chicanas para trocadores de calor de casco e tubo 1-1 tipo TEMA E . . . . . . . . . . . . . . 126

Figura 40 - Comportamento do fator de correção de trocador de calor de casco e tubo 1-1 tipo TEMA E em escoamento contracorrente em função da efetividade de temperatura e do número de chicanas para $R=1,0$. . . 128

Figura 41 - Comportamento da razão $P / P_{c c}$ em função de $N U T$ e do número de

\begin{tabular}{|c|}
\hline chicanas para $R=1,0$ de um trocador de calor de casco e tubo 1-1 tipo \\
\hline
\end{tabular}

TEMA E em escoamento contracorrente . . . . . . . . . . . . . . . . 129

Figura 42 - Fator de correção de um trocador de calor de casco e tubo 1-1 tipo TEMA E em escoamento contracorrente considerando três condições de grau de mistura do fluido do casco: misturado entre as chicanas (-), não misturado entre as chicanas (----) e completamente misturado (.........) 135 
Figura 43 - Casos 1 e 2: desenho esquemático de um trocador de calor de fluxo cruzado com um passe e um tubo por passe (1-1) . . . . . . . . . . . . 149

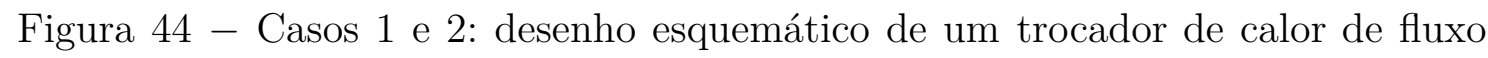
cruzado com um passe e dois tubos por passe (1-2) . . . . . . . . . . 149

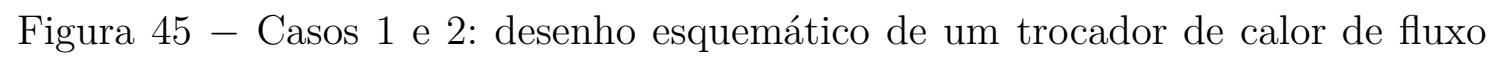
cruzado com um passe e três tubos por passe (1-3) . . . . . . . . . . 149

\begin{tabular}{|l|l|l|l|l|}
\hline Figura & 46 & - Casos 1 e 2: desenho esquemático de um trocador de calor de fluxo \\
\hline
\end{tabular} cruzado com um passe e quatro tubos por passe (1-4) . . . . . . . . . 149

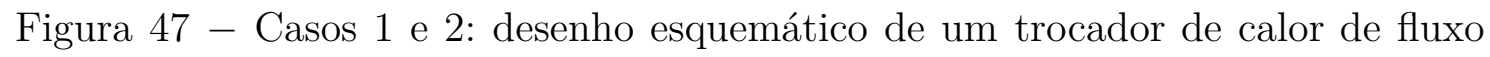
cruzado com um passe e cinco tubos por passe (1-5) . . . . . . . . . . 150

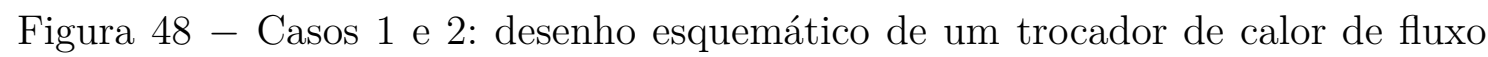
cruzado com um passe e seis tubos por passe (1-6) . . . . . . . . . 150

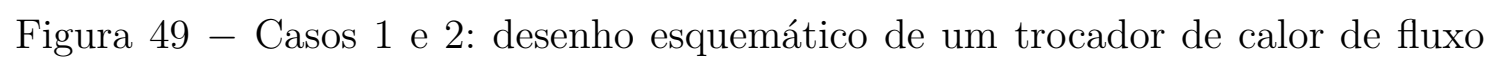
cruzado com um passe e sete tubos por passe (1-7) . . . . . . . . . 150

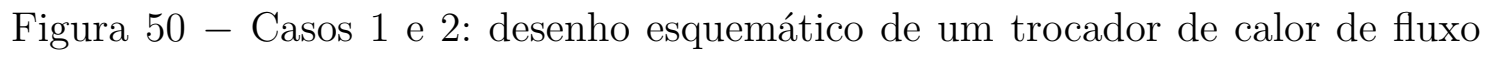
cruzado com um passe e oito tubos por passe (1-8) . . . . . . . . . . 151

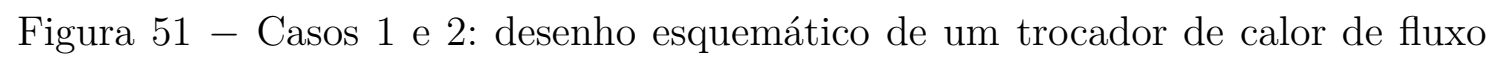
cruzado com um passe e nove tubos por passe (1-9) . . . . . . . . . . 151

\begin{tabular}{|l|l|l|l|l|}
\hline Figura & 52 & - Casos 1 e 2: desenho esquemático de um trocador de calor de fluxo \\
\hline
\end{tabular} cruzado com um passe e dez tubos por passe (1-10) . . . . . . . . . . . 152

\begin{tabular}{|l|l|l|l|}
\hline Figura & 53 & - Caso 1: desenho esquemático de um trocador de calor de fluxo cruzado \\
\hline
\end{tabular} com dois passes e um tubo por passe (2-1) em escoamento paralelo . . 152

Figura 54 - Caso 1: desenho esquemático de um trocador de calor de fluxo cruzado com três passes e um tubo por passe (3-1) em escoamento paralelo. . . 152

\begin{tabular}{|l|l|l|l|}
\hline Figura & 55 & - Caso 1: desenho esquemático de um trocador de calor de fluxo cruzado \\
\hline
\end{tabular} com quatro passes e um tubo por passe (4-1) em escoamento paralelo . 152

Figura 56 - Caso 1: desenho esquemático de um trocador de calor de fluxo cruzado com cinco passes e um tubo por passe (5-1) em escoamento paralelo . . 153

Figura 57 - Caso 1: desenho esquemático de um trocador de calor de fluxo cruzado com seis passes e um tubo por passe (6-1) em escoamento paralelo. . . 153

Figura 58 - Caso 1: desenho esquemático de um trocador de calor de fluxo cruzado com sete passes e um tubo por passe (7-1) em escoamento paralelo . . 153

Figura 59 - Caso 1: desenho esquemático de um trocador de calor de fluxo cruzado com oito passes e um tubo por passe (8-1) em escoamento paralelo . . 154

Figura 60 - Caso 1: desenho esquemático de um trocador de calor de fluxo cruzado com nove passes e um tubo por passe (9-1) em escoamento paralelo . . 154

Figura 61 - Caso 1: desenho esquemático de um trocador de calor de fluxo cruzado com dez passes e um tubo por passe (10-1) em escoamento paralelo . . 155 
\begin{tabular}{|l|l|l|}
\hline Figura & 62 & - Caso 2: desenho esquemático de um trocador de calor de fluxo cruzado \\
\hline
\end{tabular} com dois passes e um tubo por passe (2-1) em escoamento contracorrente 155

\begin{tabular}{|l|l|l|l|}
\hline Figura & - Caso 2: desenho esquemático de um trocador de calor de fluxo cruzado \\
\hline
\end{tabular} com três passes e um tubo por passe (3-1) em escoamento contracorrente 155

\begin{tabular}{|l|l|l|l|}
\hline Figura & - Caso 2: desenho esquemático de um trocador de calor de fluxo cru-
\end{tabular} \begin{tabular}{|c|}
\hline zado com quatro passes e um tubo por passe (4-1) em escoamento \\
\hline
\end{tabular} contracorrente . . . . . . . . . . . . . . . . . . 155

\begin{tabular}{|l|l|l|}
\hline Figura & - Caso 2: desenho esquemático de um trocador de calor de fluxo cruzado \\
\hline
\end{tabular} com cinco passes e um tubo por passe (5-1) em escoamento contracorrente 156

\begin{tabular}{|l|l|l|}
\hline Figura & 66 & - Caso 2: desenho esquemático de um trocador de calor de fluxo cruzado \\
\hline
\end{tabular} com seis passes e um tubo por passe (6-1) em escoamento contracorrente 156

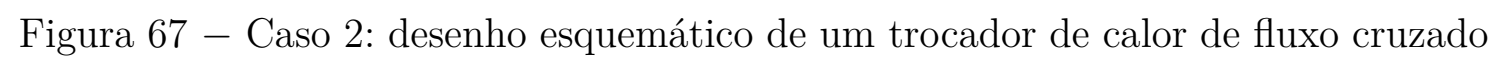
com sete passes e um tubo por passe (7-1) em escoamento contracorrente 156

Figura 68 - Caso 2: desenho esquemático de um trocador de calor de fluxo cruzado com oito passes e um tubo por passe (8-1) em escoamento contracorrente 157

Figura 69 - Caso 2: desenho esquemático de um trocador de calor de fluxo cruzado com nove passes e um tubo por passe (9-1) em escoamento contracorrente 157

\begin{tabular}{|l|l|l|l|}
\hline Figura & 70 & - Caso 2: desenho esquemático de um trocador de calor de fluxo cruzado \\
\hline
\end{tabular} com dez passes e um tubo por passe (10-1) em escoamento contracorrente 158

\begin{tabular}{|l|l|l|l|l|}
\hline Figura & - Casos 3 e 4: desenho esquemático de um trocador de calor de fluxo \\
\hline
\end{tabular} cruzado com um passe e um tubo por passe (1-1) . . . . . . . . . . . . 158

\begin{tabular}{|l|l|l|l|}
\hline Figura & 72 & - Casos 3 e 4: desenho esquemático de um trocador de calor de fluxo \\
\hline
\end{tabular} cruzado com um passe e dois tubos por passe (1-2) . . . . . . . . . 158

Figura 73 - Casos 3 e 4: desenho esquemático de um trocador de calor de fluxo cruzado com um passe e três tubos por passe (1-3) . . . . . . . . . 158

\begin{tabular}{|l|l|l|l|l|}
\hline Figura & 74 & - Casos 3 e 4: desenho esquemático de um trocador de calor de fluxo \\
\hline
\end{tabular} cruzado com um passe e quatro tubos por passe (1-4) . . . . . . . . . . 159

\begin{tabular}{|l|l|l|l|l|}
\hline Figura & 75 & - Casos 3 e 4: desenho esquemático de um trocador de calor de fluxo \\
\hline
\end{tabular} cruzado com um passe e cinco tubos por passe (1-5) . . . . . . . . . . . 159

\begin{tabular}{|l|l|l|l|l|}
\hline Figura & 76 & - Casos 3 e 4: desenho esquemático de um trocador de calor de fluxo \\
\hline
\end{tabular} cruzado com um passe e seis tubos por passe (1-6) . . . . . . . . . . 159

\begin{tabular}{|l|l|l|l|}
\hline Figura & 77 & - Casos 3 e 4: desenho esquemático de um trocador de calor de fluxo \\
\hline
\end{tabular} cruzado com um passe e sete tubos por passe (1-7) . . . . . . . . . 159

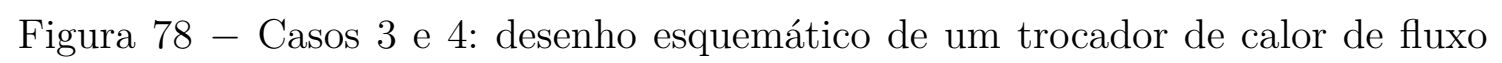
cruzado com um passe e oito tubos por passe (1-8) . . . . . . . . . . 160

\begin{tabular}{|l|l|l|l|l|}
\hline Figura & 79 & - Casos 3 e 4: desenho esquemático de um trocador de calor de fluxo \\
\hline
\end{tabular} cruzado com um passe e nove tubos por passe (1-9) . . . . . . . . . . 160

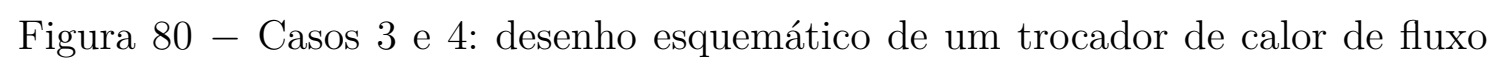
cruzado com um passe e dez tubos por passe (1-10). 
Figura 81 - Caso 3: desenho esquemático de um trocador de calor de fluxo cruzado com dois passes e um tubo por passe (2-1) em escoamento paralelo . . 161

\begin{tabular}{|l|l|l|l|l|}
\hline Figura & - Caso 3: desenho esquemático de um trocador de calor de fluxo cruzado
\end{tabular} com três passes e um tubo por passe (3-1) em escoamento paralelo. . . 161

Figura 83 - Caso 3: desenho esquemático de um trocador de calor de fluxo cruzado com quatro passes e um tubo por passe (4-1) em escoamento paralelo . 161

Figura 84-Caso 3: desenho esquemático de um trocador de calor de fluxo cruzado com cinco passes e um tubo por passe (5-1) em escoamento paralelo . . 162

Figura 85 - Caso 3: desenho esquemático de um trocador de calor de fluxo cruzado com seis passes e um tubo por passe (6-1) em escoamento paralelo . . . 162

Figura $86 \mid$ - Caso 3: desenho esquemático de um trocador de calor de fluxo cruzado com sete passes e um tubo por passe (7-1) em escoamento paralelo . . 162

Figura 87 - Caso 3: desenho esquemático de um trocador de calor de fluxo cruzado com oito passes e um tubo por passe (8-1) em escoamento paralelo . . 163

\begin{tabular}{|l|l|l|l|}
\hline Figura & - Caso 3: desenho esquemático de um trocador de calor de fluxo cruzado
\end{tabular} com nove passes e um tubo por passe (9-1) em escoamento paralelo . . 163

Figura 89 - Caso 3: desenho esquemático de um trocador de calor de fluxo cruzado com dez passes e um tubo por passe (10-1) em escoamento paralelo . . 164

Figura 90 - Caso 4: desenho esquemático de um trocador de calor de fluxo cruzado com dois passes e um tubo por passe (2-1) em escoamento contracorrente164

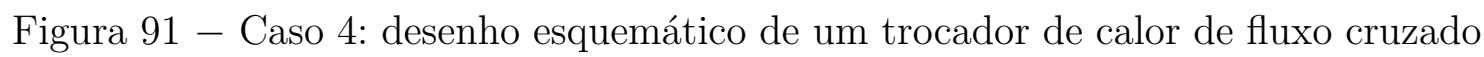
com três passes e um tubo por passe (3-1) em escoamento contracorrentel 64

Figura 92 - Caso 4: desenho esquemático de um trocador de calor de fluxo cruzado com quatro passes e um tubo por passe (4-1) em escoamento contracorrente . . . . . . . . . . . . . . . . . 164

Figura - Caso 4: desenho esquemático de um trocador de calor de fluxo cruzado com cinco passes e um tubo por passe (5-1) em escoamento contracorrente 165

Figura 94 - Caso 4: desenho esquemático de um trocador de calor de fluxo cruzado com seis passes e um tubo por passe (6-1) em escoamento contracorrente 165

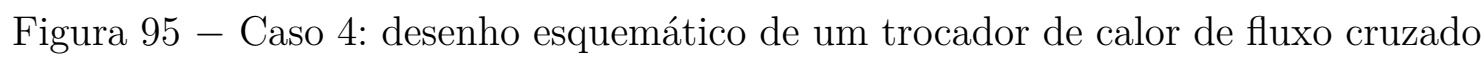
com sete passes e um tubo por passe (7-1) em escoamento contracorrente 165

\begin{tabular}{|l|l|l|l|}
\hline Figura & 96 & - Caso 4: desenho esquemático de um trocador de calor de fluxo cruzado \\
\hline
\end{tabular} com oito passes e um tubo por passe (8-1) em escoamento contracorrente 166

Figura $97 \mid$ - Caso 4: desenho esquemático de um trocador de calor de fluxo cruzado com nove passes e um tubo por passe (9-1) em escoamento contracorrente 166

Figura 98 - Caso 4: desenho esquemático de um trocador de calor de fluxo cruzado com dez passes e um tubo por passe (10-1) em escoamento contracorrente 167

Figura 99 - Caso 4A: desenho esquemático de um trocador de calor de fluxo cruzado com dois passes e dois tubos por passe (2-2) em escoamento contracorrente 167 
Figura 100 - Caso 3A: desenho esquemático de um trocador de calor de fluxo cruzado com dois passes e quatro tubos por passe (2-4) em escoamento

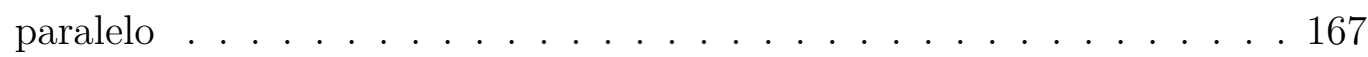

Figura 101 - Caso 3A: desenho esquemático de um trocador de calor de fluxo cruzado com dois passes e quatro tubos por passe (2-4) em escoamento

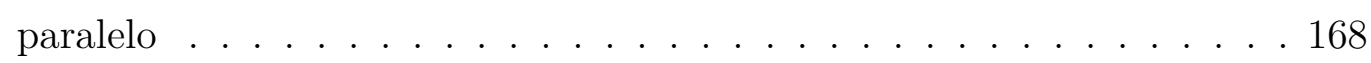

Figura 102 - Caso 3A: desenho esquemático de um trocador de calor de fluxo cruzado com dois passes e quatro tubos por passe (2-4) em escoamento paralelo . . . . . . . . . . . . . . . . . . . . . . . 168

Figura 103 - Caso 4A: desenho esquemático de um trocador de calor de fluxo cruzado com dois passes e quatro tubos por passe (2-4) em escoamento contracorrente . . . . . . . . . . . . . . . . . . . 168

Figura 104 - Caso 4B: desenho esquemático de um trocador de calor de fluxo cruzado com dois passes e quatro tubos por passe (2-4) em escoamento contracorrente . . . . . . . . . . . . . . . . . . 169

Figura 105 - Caso 4A: desenho esquemático de um trocador de calor de fluxo cruzado com três passes e dois tubos por passe (3-2) em escoamento contracorrente. . . . . . . . . . . . . . . . . 169

Figura 106 - Caso 4B: desenho esquemático de um trocador de calor de fluxo cruzado com três passes e dois tubos por passe (3-2) em escoamento contracorrente. . . . . . . . . . . . . . . . . . 169 



\section{Lista de tabelas}

Tabela 1 - Relações $\varepsilon$-NUT para configurações de fluxo cruzado com um passe dos fluidos e uma a várias fileiras de tubos (STEVENS; FERNANDEZ;

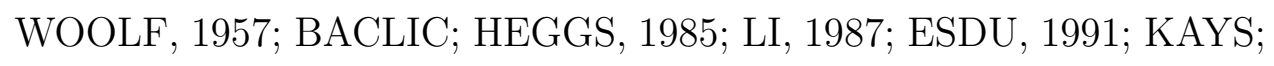
LONDON, 1998] . . . . . . . . . . . . . . . . . 23

Tabela 2 - Relações $\varepsilon$-NUT para configuração paralelo-cruzado com vários passes

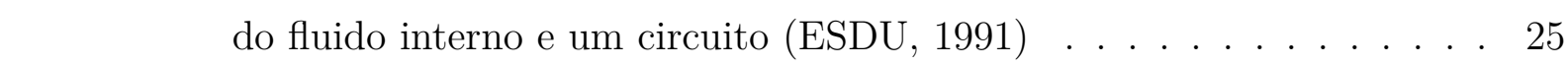

Tabela 3 - Relações $\varepsilon$-NUT para configuração contracorrente-cruzado com vários

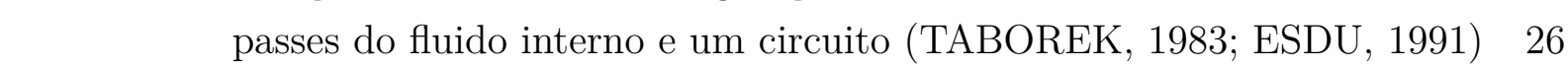
Tabela 4 - Relações analíticas diretas para cálculo do número de unidades de transferência, NUT (SHAH; SEKULIC $[2003)]$. . . . . . . . . . . . . . 26 Tabela 5 - Relações analíticas diretas para cálculo do fator de correção $F$, (SHAH; SEKULIC][2003)] . . . . . . . . . . . . . . . . 34

Tabela 6 - Efetividade de temperatura e fator de correção para trocador de calor \begin{tabular}{|c|}
\hline de fluxo cruzado em escoamento contracorrente com dois passes e um \\
\hline tubo por passe (2-1) com o fluido frio não misturado e o fluido quente \\
\hline
\end{tabular} misturado - Caso 4A . . . . . . . . . . . . . . . . 74

Tabela 7 - Efetividade de temperatura e fator de correção para trocador de calor \begin{tabular}{|c|}
\hline de fluxo cruzado em escoamento contracorrente com cinco passes e um \\
\hline tubo (5-1) com o fluido frio não misturado e o fluido quente misturado \\
\hline
\end{tabular}

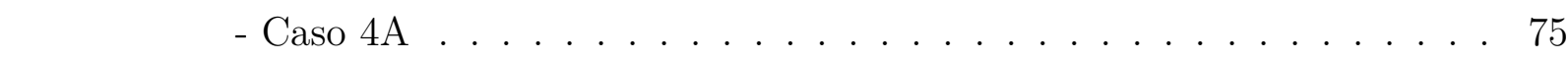

Tabela 8 - Efetividade de temperatura e fator de correção para trocador de calor

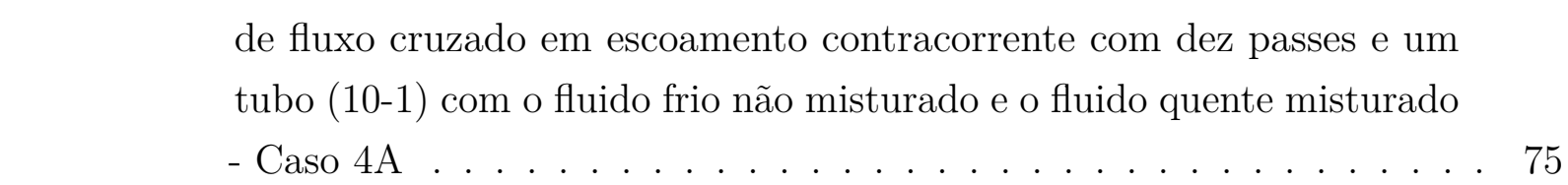

Tabela 9 - Efetividade de temperatura e fator de correção para trocadores de calor \begin{tabular}{|l|}
\hline de fluxo cruzado em escoamentos paralelo e cruzado com o fluido frio \\
\hline misturado (casos 1A e 2A) e não misturado (casos 3A e 4A) entre os \\
\hline tubos para $R=1,0$
\end{tabular}

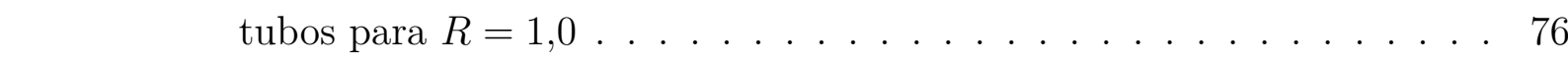

Tabela 10 - Efetividade de temperatura para trocadores de calor de fluxo cruzado

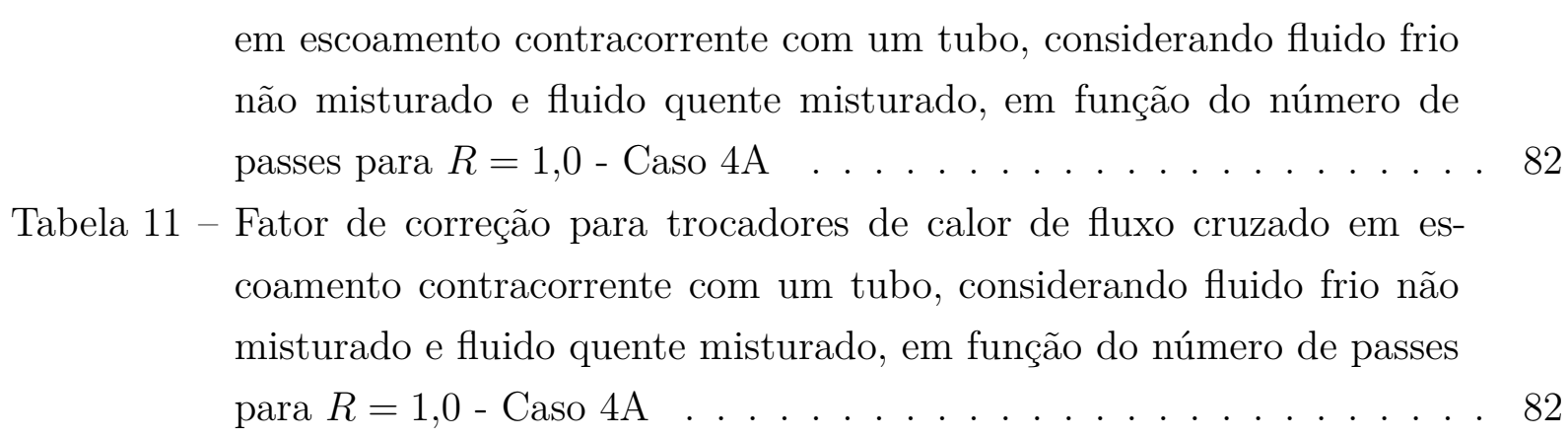


Tabela 12 - Efetividade de temperatura para trocadores de calor de fluxo cruzado em escoamento contracorrente com um tubo, considerando fluido frio não misturado e fluido quente misturado, em função do número de tubos por passe para $R=1,0-$ Caso $4 \mathrm{~A} \ldots$. . . . . . . . . . 83

Tabela 13 - Fator de correção para trocadores de calor de fluxo cruzado em escoamento contracorrente com um tubo, considerando fluido frio não misturado e fluido quente misturado, em função do número de tubos por passe para $R=1,0-$ Caso $4 \mathrm{~A}$. . . . . . . . . . . . 83

Tabela 14 - Efetividade de temperatura e fator de correção para trocadores de calor de fluxo cruzado em escoamento contracorrente com diversos passes e tubos por passe considerando fluido frio não misturado e fluido quente misturado para $R=1,0$ e $N U T=5,0$ - Caso $4 \mathrm{~A} \ldots \ldots$. . . . . 84

Tabela 15 - Efetividade de temperatura e fator de correção para trocador de calor de fluxo cruzado em escoamento paralelo com dois passes e quatro tubos por passe (2-4) considerando três tipos de configuração de mistura do fluido quente . . . . . . . . . . . . . . . . . . 85

Tabela 16 - Efetividade de temperatura e fator de correção para trocador de calor de fluxo cruzado em escoamento contracorrente com dois passes e quatro tubos por passe (2-4) com o fluido frio não misturado e o quente misturado - Caso 4B . . . . . . . . . . . . . . . 887

Tabela 17 - Efetividade de temperatura e fator de correção para trocador de calor de fluxo cruzado em escoamento contracorrente com três passes e dois tubos por passe (3-2) com o fluido frio não misturado e o quente misturado - Caso 4B . . . . . . . . . . . . . . . . 887

Tabela 18 - Efetividade de temperatura e erro relativo $\left(\times 10^{4}\right)$ do presente algoritmo em relação ao trabalho de Baclic e Heggs $[1985)$ para trocador de calor de fluxo cruzado com um passe e infinitos tubos $(1-\infty)$ com o fluido

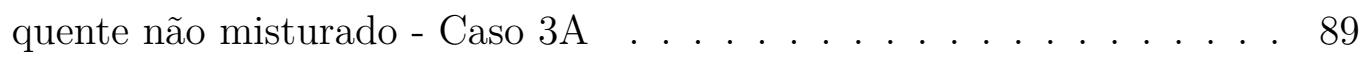

Tabela 19 - Efetividade de temperatura e erro relativo $\left(\times 10^{2}\right)$ do presente algoritmo em relação ao trabalho de Gvozdenac (1986) para trocadores de calor de fluxo cruzado com dois passes e infinitos tubos (2- $\infty)$ com o fluido quente não misturado - Caso 4B . . . . . . . . . . . . . . . . . 90

Tabela 20 - Fator de correção e erro relativo $\left(\times 10^{7}\right)$ do presente algoritmo em relação ao trabalho de Bowman, Mueller e Nagle $[$ (1940) para trocador de calor de fluxo cruzado com um passe e um tubo (1-1) com o fluido quente não misturado - Caso 3A . . . . . . . . . . . . . . . . . 91 
Tabela 21 - Fator de correção e erro relativo $\left(\times 10^{1}\right)$ do presente algoritmo em fluido quente não misturado - Caso 3A . . . . . . . . . . . . . . . 92

Tabela 22 - Fator de correção e erro relativo do presente algoritmo em relação ao \begin{tabular}{|c|}
\hline trabalho de Roetzel e Spang $(2010)$ para trocador de calor de fluxo \\
\hline cruzado com um passe e um tubo por passe (1-1) com o fluido quente \\
\hline
\end{tabular} não misturado . . . . . . . . . . . . . . . . . . . . . . . . . . . . . . . . 95

Tabela 23 - Fator de correção e erro relativo do presente algoritmo em relação ao

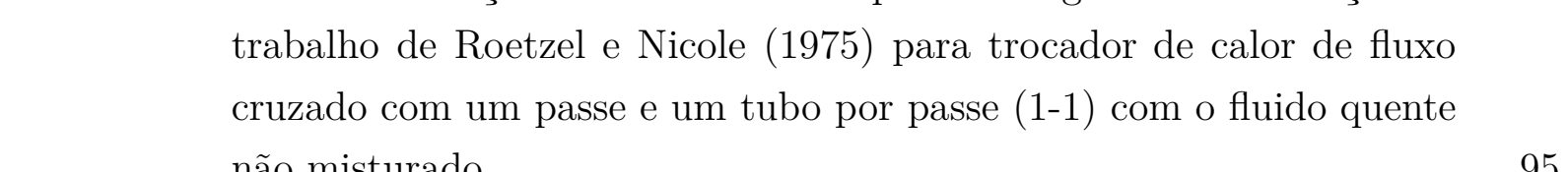

Tabela 24 - Fator de correção e erro relativo do presente algoritmo em relação ao

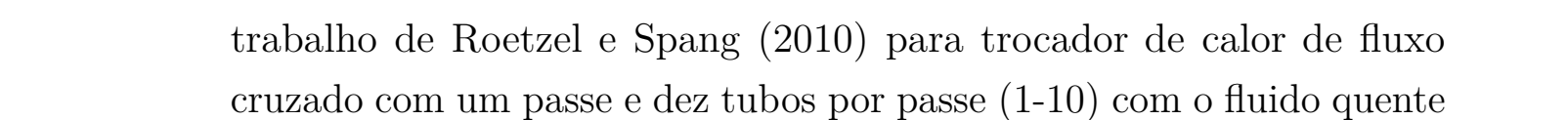

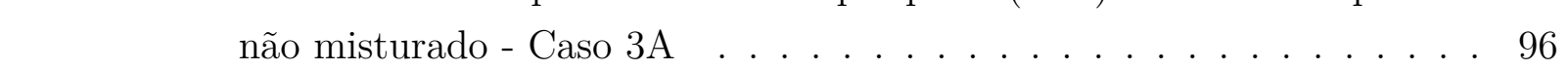

Tabela 25 - Fator de correção e erro relativo do presente algoritmo em relação ao

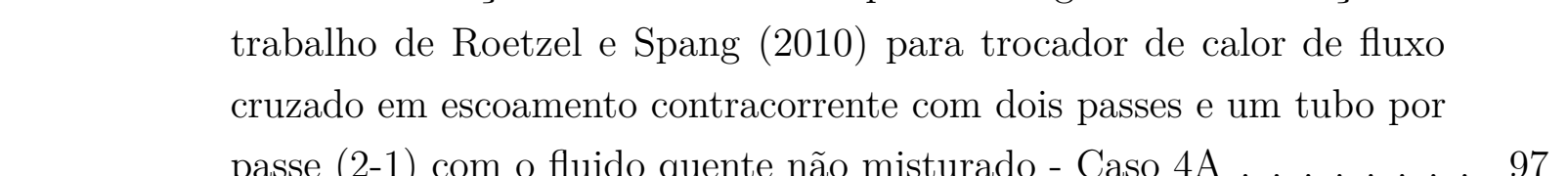

Tabela 26 - Fator de correção e erro relativo do presente algoritmo em relação ao \begin{tabular}{|r|r|}
\hline trabalho de & Roetzel e Nicole \\
\hline
\end{tabular} cruzado em escoamento contracorrente com dois passes e um tubo por

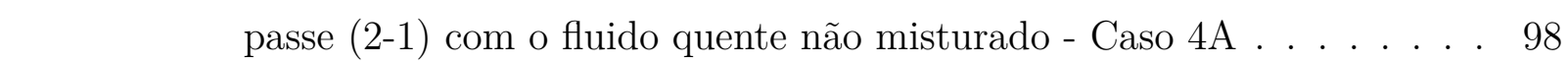

Tabela 27 - Sumário do erro relativo médio e do intervalo de confiança $95 \%$ para diversas configurações de trocadores de calor de fluxo cruzado . . . . . 99

Tabela 28 - Sumário do erro relativo médio e do intervalo de confiança $95 \%$ do algoritmo HETE para diversas configurações de trocadores de calor de fluxo cruzado . . . . . . . . . . . . . . . . . . . 101

Tabela 29 - Relação matemática teórica da efetividade de trocadores de calor de fluxo cruzado com um passe e o fluido quente misturado - Casos 1A, 1B, 1C, 2A, 2B, 2C - trocadores de calor ilustrados nas Figuras $|43 \| 52|$ do AnexolA . . . . . . . . . . . . . . . . . . 102

Tabela 30 - Relação matemática teórica da efetividade de trocadores de calor de fluxo cruzado em escoamento paralelo com múltiplos passes com o fluido quente misturado - Casos 1A, 1B, 1C - trocadores de calor ilustrados nas Figuras $|53 \| 61|$ do Anexo $\mid \mathrm{A}$. . . . . . . . . . . . . . . . . . . 105 
Tabela 31 - Relação matemática teórica da efetividade de trocadores de calor de fluxo cruzado em escoamento contracorrente com múltiplos passes com o fluido quente misturado - Casos 2A, 2B, 2C - trocadores de calor ilustrados nas Figuras $62 \| 70 \mid$ do Anexo $\mid \mathrm{A}$. . . . . . . . . . . . . . . . . 107

Tabela 32 - Relação matemática teórica da efetividade de trocadores de calor de fluxo cruzado com um passe e o fluido quente não misturado - Casos 3A, 3B, 3C, 4A, 4B, 4C - trocadores de calor ilustrados nas Figuras $|71+180|$ do Anexo|A

Tabela 33 - Relação matemática teórica da efetividade de trocadores de calor de fluxo cruzado em escoamento paralelo com múltiplos passes com o fluido quente não misturado - Casos 3A, 3B, 3C - trocadores de calor ilustrados nas Figuras 81|| $89 \mid$ do Anexo $\mid \mathrm{A}$. . . . . . . . . . . . . . . . . 113

Tabela 34 - Relação matemática teórica da efetividade de trocadores de calor de fluxo cruzado em escoamento contracorrente com múltiplos passes com o fluido quente não misturado - Casos 4A, 4B, 4C - trocadores de calor ilustrados nas Figuras $90 \| 98$ do Anexo $\mid \mathrm{A}$. . . . . . . . . . . . . . . . . 116

Tabela 35 - Dados físicos e termodinâmicos dos fluidos frio e quente . . . . . . . . 121

Tabela 36 - Efetividade de temperatura e fator de correção do trocador de calor de casco e tubo 1-1 tipo TEMA E em escoamento contracorrente com uma chicana . . . . . . . . . . . . . . . . . . . . . . . . . . . . 124

Tabela 37 - Efetividade de temperatura e fator de correção do trocador de calor de casco e tubo 1-1 tipo TEMA E em escoamento contracorrente com cinco chicanas . . . . . . . . . . . . . . . . . . . . . . . . . . . 125

Tabela 38 - Efetividade de temperatura e fator de correção do trocador de calor de casco e tubo 1-1 tipo TEMA E em escoamento contracorrente com dez chicanas . . . . . . . . . . . . . . . . . . . . 125

Tabela 39 - Efetividade de temperatura do trocador de calor de casco e tubo 1-1 tipo TEMA E em escoamento contracorrente em função do número de chicanas e $R=0,7$. . . . . . . . . . . . . . . . . . . . . . . 127

Tabela 40 - Efetividade de temperatura do trocador de calor de casco e tubo 1-1 tipo TEMA E em escoamento contracorrente em função do número de chicanas e $R=1,0$. . . . . . . . . . . . . . . . . . . . 127

Tabela 41 - Efetividade de temperatura do trocador de calor de casco e tubo 1-1 tipo TEMA E em escoamento contracorrente em função do número de

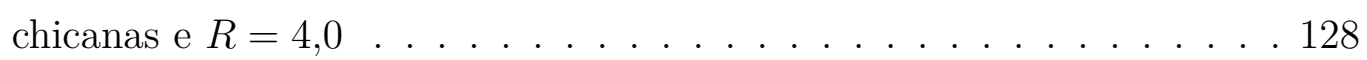

Tabela 42 - Efetividade de temperatura e fator de correção do trocador de calor de casco e tubo 1-1 tipo TEMA E em escoamento paralelo com uma chicana 129 
Tabela 43 - Efetividade de temperatura e fator de correção do trocador de calor de casco e tubo 1-1 tipo TEMA E em escoamento paralelo com cinco chicanas .

Tabela 44 - Efetividade de temperatura e fator de correção do trocador de calor de casco e tubo 1-1 tipo TEMA E em escoamento paralelo com dez chicanas 130

Tabela 45 - Comparação do fator de correção de um trocador de calor de casco e tubo 1-1 tipo TEMA E em escoamento contracorrente com diversas chicanas .

Tabela 46 - Coeficientes da expressão matemática aproximada em função da razão de temperatura e do número de chicanas para um trocador de calor de casco e tubo 1-1 tipo TEMA E em escoamento contracorrente . . . . . 132

Tabela 47 - Coeficientes da expressão matemática aproximada em função da razão de temperatura e do número de chicanas para um trocador de calor de casco e tubo 1-1 tipo TEMA E em escoamento paralelo . . . . . . . . . 133

Tabela 48 - Sumário do erro relativo médio e do intervalo de confiança $95 \%$ das

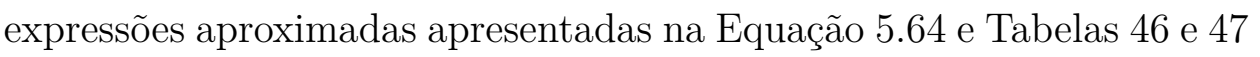
para trocadores de calor de casco e tubo em escoamentos contracorrente e paralelo . . . . . . . . . . . . . . . . . . . 133

Tabela 49 - Fator de correção de um trocador de calor de casco e tubo 1-1 tipo TEMA E em escoamento contracorrente em função do número de chicanas, efetividade de temperatura e razão de temperatura considerando fluido do casco misturado entre as chicanas . . . . . . . . . . . . . . . 136

Tabela 50 - Fator de correção de um trocador de calor de casco e tubo 1-1 tipo TEMA E em escoamento contracorrente em função do número de chicanas, efetividade de temperatura e razão de temperatura considerando fluido do casco não misturado entre as chicanas . . . . . . . . . . . . . 137

Tabela 51 - Fator de correção de um trocador de calor de casco e tubo 1-1 tipo TEMA E em escoamento contracorrente em função do número de chicanas, efetividade de temperatura e razão de temperatura considerando fluido do casco completamente misturado nos compartimentos . . . . . 138

Tabela 52 - Desenhos esquemáticos dos trocadores de calor de fluxo cruzado . . . . 149

Tabela 53 - Efetividade de temperatura para trocador de calor de fluxo cruzado com um passe e um tubo por passe (1-1) - Caso 3 ou 4 - trocador de calor ilustrado na Figura $|71|$ do Anexo $\mid \mathrm{A}$. . . . . . . . . . . . . . . . . 171

Tabela 54 - Fator de correção para trocador de calor de fluxo cruzado com um passe e um tubo por passe (1-1) - Caso 3 ou 4 - trocador de calor ilustrado

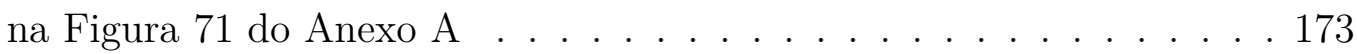


Tabela 55 - Efetividade de temperatura para trocador de calor de fluxo cruzado com um passe e dois tubos por passe (1-2) - Caso 3 ou 4 - trocador de calor ilustrado na Figura $\mid 72$ do Anexo $\mid \mathrm{A}$. . . . . . . . . . . . . . . 175

Tabela 56 - Fator de correção para trocador de calor de fluxo cruzado com um passe e dois tubos por passe (1-2) - Caso 3 ou 4 - trocador de calor ilustrado na Figura $\mid 72$ do Anexo $\mid \mathrm{A}$. . . . . . . . . . . . . . . . . 177

Tabela 57 - Efetividade de temperatura para trocador de calor de fluxo cruzado com um passe e três tubos por passe (1-3) - Caso 3 ou 4 - trocador de calor ilustrado na Figura $|73|$ do Anexo $\mid \mathrm{A}$. . . . . . . . . . . . . . . . . 179

Tabela 58 - Fator de correção para trocador de calor de fluxo cruzado com um passe e três tubos por passe (1-3) - Caso 3 ou 4 - trocador de calor ilustrado na Figura $|73|$ do Anexo $\mid \mathrm{A}$. . . . . . . . . . . . . . . . . . . . . 181

Tabela 59 - Efetividade de temperatura para trocador de calor de fluxo cruzado com um passe e quatro tubos por passe (1-4) - Caso 3 ou 4 - trocador de calor ilustrado na Figura $74 \mid$ do Anexo|A $\ldots$. . . . . . . . . . . . . 183

Tabela 60 - Fator de correção para trocador de calor de fluxo cruzado com um passe e quatro tubos por passe (1-4) - Caso 3 ou 4 - trocador de calor ilustrado na Figura $|74|$ do Anexo $\mid \mathrm{A}$. . . . . . . . . . . . . . . . . . 185

Tabela 61 - Efetividade de temperatura para trocador de calor de fluxo cruzado com um passe e cinco tubos por passe (1-5) - Caso 3 ou 4 - trocador de calor ilustrado na Figura $|75|$ do Anexo $\mid \mathrm{A}$. . . . . . . . . . . . . . . 187

Tabela 62 - Fator de correção para trocador de calor de fluxo cruzado com um passe e cinco tubos por passe (1-5) - Caso 3 ou 4 - trocador de calor ilustrado

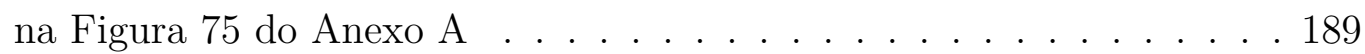

Tabela 63 - Efetividade de temperatura para trocador de calor de fluxo cruzado com um passe e dez tubos por passe (1-10) - Caso 3 ou 4 - trocador de calor ilustrado na Figura $|80|$ do Anexo $\mid \mathrm{A}]$. . . . . . . . . . . . . . . . . 191

Tabela 64 - Fator de correção para trocador de calor de fluxo cruzado com um passe e dez tubos por passe (1-10) - Caso 3 ou 4 - trocador de calor ilustrado na Figura $|80|$ do Anexo $\mid \mathrm{A}$. . . . . . . . . . . . . . . . . . . 193

Tabela 65 - Efetividade de temperatura para trocador de calor de fluxo cruzado com um passe e infinitos tubos por passe $(1-\infty)$ - Caso 3A . . . . . . 195

Tabela 66 - Fator de correção para trocador de calor de fluxo cruzado com um passe e infinitos tubos por passe $(1-\infty)$ - Caso 3A . . . . . . . . . . 197

Tabela 67 - Efetividade de temperatura para trocador de calor de fluxo cruzado com dois passes e um tubo por passe (2-1) - Caso 4A - trocador de calor ilustrado na Figura $|90|$ do Anexo $\mid \mathrm{A}$. . . . . . . . . . . . . . . . . 199 
Tabela 68 - Fator de correção para trocador de calor de fluxo cruzado com dois passes e um tubo por passe (2-1) - Caso 4A - trocador de calor ilustrado na Figura $90 \mid$ do Anexo $\mid \mathrm{A}$. . . . . . . . . . . . . . . . . . . . . . 202

Tabela 69 - Efetividade de temperatura para trocador de calor de fluxo cruzado com dois passes e dois tubos por passe (2-2) - Caso 4A - trocador de calor ilustrado na Figura 99 do Anexo|A . . . . . . . . . . . . . . . . . 204

Tabela 70 - Fator de correção para trocador de calor de fluxo cruzado com dois passes e dois tubos por passe (2-2) - Caso 4A - trocador de calor ilustrado na Figura $|99|$ do Anexo $\mid \mathrm{A}$. . . . . . . . . . . . . . . . . 206

Tabela 71 - Efetividade de temperatura para trocador de calor de fluxo cruzado com dois passes e quatro tubos por passe (2-4) - Caso 4A - trocador de calor ilustrado na Figura $103 \mid$ do Anexo $\mid \mathrm{A}$. . . . . . . . . . . . . . . . 208

Tabela 72 - Fator de correção para trocador de calor de fluxo cruzado com dois passes e quatro tubos por passe (2-4) - Caso 4A - trocador de calor ilustrado na Figura $|103|$ do Anexo|A $\ldots 210$

Tabela 73 - Efetividade de temperatura para trocador de calor de fluxo cruzado com três passes e um tubo por passe (3-1) - Caso 4A - trocador de calor

\begin{tabular}{|r|l|l|l}
\hline ilustrado na Figura & 91 & do Anexo & $\mathrm{A}$ \\
\hline
\end{tabular} . . . . . . . . . . . . . 212

Tabela 74 - Fator de correção para trocador de calor de fluxo cruzado com três passes e um tubo por passe (3-1) - Caso 4A - trocador de calor ilustrado na Figura $|91|$ do Anexo $\mid \mathrm{A}$. . . . . . . . . . . . . . . . . . . . . . . . . 214

Tabela 75 - Efetividade de temperatura para trocador de calor de fluxo cruzado com três passes e dois tubos por passe (3-2) - Caso 4A - trocador de calor ilustrado na Figura $105 \mid$ do Anexo $\mid \mathrm{A}$. . . . . . . . . . . . . . . . 216

Tabela 76 - Fator de correção para trocador de calor de fluxo cruzado com três passes e dois tubos por passe (3-2) - Caso 4A - trocador de calor

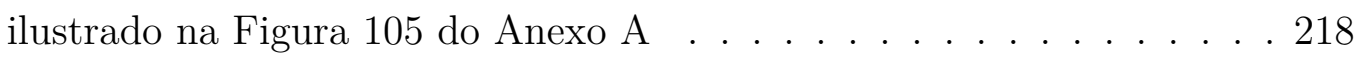

Tabela 77 - Efetividade de temperatura para trocador de calor de fluxo cruzado com quatro passes e um tubo por passe (4-1) - Caso 4A - trocador de calor ilustrado na Figura $|92|$ do Anexo $\mid \mathrm{A}$. . . . . . . . . . . . . . . . . 220

Tabela 78 - Fator de correção para trocador de calor de fluxo cruzado com quatro passes e um tubo por passe (4-1) - Caso 4A - trocador de calor ilustrado

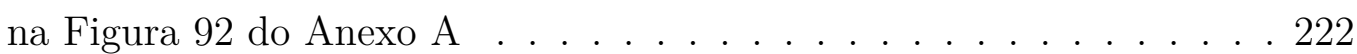

Tabela 79 - Efetividade de temperatura para trocador de calor de fluxo cruzado com cinco passes e um tubo por passe (5-1) - Caso 4A - trocador de

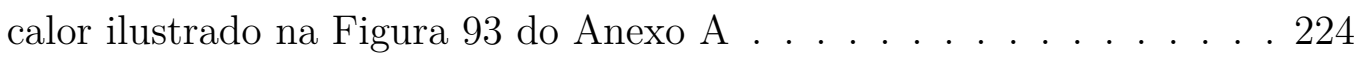

Tabela 80 - Fator de correção para trocador de calor de fluxo cruzado com cinco passes e um tubo por passe (5-1) - Caso 4A - trocador de calor ilustrado na Figura $|93|$ do Anexo $\mid \mathrm{A}$. . . . . . . . . . . . . . . . . . . . . . . 226 
Tabela 81 - Efetividade de temperatura para trocador de calor de fluxo cruzado com dez passes e um tubo por passe (10-1) - Caso 4A - trocador de calor ilustrado na Figura $|98|$ do Anexo $\mid \mathrm{A}$. . . . . . . . . . . . . . . . . 228

Tabela 82 - Fator de correção para trocador de calor de fluxo cruzado com dez passes e um tubo por passe (10-1) - Caso 4A - trocador de calor ilustrado na Figura $|98|$ do Anexo $\mid \mathrm{A}$. . . . . . . . . . . . . . . . . . . . . . . . 230 


\section{Lista de abreviaturas e siglas}

$\begin{array}{ll}\text { ASME } & \text { American Society of Mechanical Engineers } \\ \text { CAE } & \text { Computer Aided Engineering } \\ \text { HETE } & \text { Heat Exchanger Thermal Efficiency } \\ \text { LMTD } & \text { Diferença média logarítmica de temperaturas } \\ \text { PFHE } & \text { Plate Fin Heat Exchanger } \\ \text { TEMA } & \text { Tubular Exchanger Manufacturers Association }\end{array}$





\section{Nomenclatura}

$a, a^{\prime}, a^{\prime \prime}$

A

$b, b^{\prime}, b^{\prime \prime}$

$c, c^{\prime}, c^{\prime \prime}$

cp

C

$C^{*}$

D

$D_{h}$

$f$

F

$g$

h

$i$

L

$k$

K

$\dot{m}$

$N$

$N_{a}, N_{b}, N_{c}, N_{\alpha}, N_{\beta}, N_{\gamma}$

NUT

$P$

Pr

PR

$\dot{q}$

$\dot{Q}$

$R$

$R e$

T

U

V coeficientes definidos pelas Equações 4.59 e 4.80

área, $\mathrm{m}^{2}$

coeficientes definidos pelas Equações 4.63 , 4.64 e 4.81

coeficientes definidos pelas Equações 4.65 e 4.82

calor específico, $\mathrm{J} \mathrm{kg}^{-1} \mathrm{~K}^{-1}$

capacitância térmica, $\mathrm{W} \mathrm{K}^{-1}$

razão de capacitância térmica

diâmetro, $m$

diâmetro hidráulico, $\mathrm{m}$

fator de atrito de Darcy-Weisbach

coeficiente definido pela Equação 4.89

fator de correção do método de diferença de temperatura logarítmica definido pela Equação 4.1

coeficiente definido pela Equação 4.90

coeficiente de transferência de calor por convecção, $\mathrm{W} \mathrm{m}^{-2} \mathrm{~K}^{-1}$

coeficiente definido pela Equação 4.52

comprimento do tubo, $\mathrm{m}$

condutividade térmica, $\mathrm{W} \mathrm{m}^{-1} \mathrm{~K}^{-1}$

coeficiente definido nas Tabelas 29 a 34

vazão mássica, $\mathrm{kg} \mathrm{s}^{-1}$

número

limites superiores das somatórias definidos pelas Equações 4.53, 4.54, 4.56 e 4.57

número de unidades de transferência

efetividade de temperatura

número de Prandtl

razão de pressão

taxa de transferência de calor por área, $\mathrm{W} \mathrm{m}^{-2}$

taxa de transferência de calor, W

razão de temperatura ou capacitância

número de Reynolds

temperatura, ${ }^{\circ} \mathrm{C}$

coeficiente global de transferência de calor, $\mathrm{W} \mathrm{m}^{-2} \mathrm{~K}^{-1}$

velocidade, $\mathrm{m} \mathrm{s}^{-1}$ 
Letras gregas

$\alpha$

$\chi$

$\delta$

$\Delta$

$\varepsilon$

$\gamma$

$\Gamma$

$\lambda$

$\Lambda$

$\mu$

$\omega$

$\rho$

$\tau$

$\theta$

\section{Subscritos}

$c c$

ch

$d$

$e$

ent

$f$

F

fr

I

LMTD

$m$

$\max$

min

$p$

$q$

$r$ coeficiente definido pelas Equações 4.60 e 4.68

coeficiente definido pelas Equação 4.61

coeficiente definido pela Equação 4.2

erro relativo de acordo com as Equações 5.1 e 5.2

diferença

efetividade

coeficiente definido pela Equação 4.62

efetividade térmica local

função definida pela Equação 4.16

função definida pela Equação 3.105

viscosidade dinâmica, $\mathrm{kg} \mathrm{m}^{-1} \mathrm{~s}^{-1}$

ângulo do tubo em relação ao seu centro

massa específica, $\mathrm{kg} \mathrm{m}^{-3}$

coeficiente definido pela Equação 4.12

temperatura adimensional do fluido quente

temperatura adimensional do fluido frio

relação adimensional $P / N U T$

contracorrente

chicana

dados

elemento

entrada

frio

final

frontal

inicial

diferença de temperatura média logarítmica

média

máximo

mínimo

passe

quente

tubo

fileira de tubos 
saída

total

Sobrescritos

e

elemento 



\section{Sumário}

$1 \quad$ INTRODUÇÃO $\ldots \ldots \ldots \ldots \ldots$

$1.1 \quad$ Justificativa $\ldots \ldots \ldots \ldots \ldots \ldots \ldots$

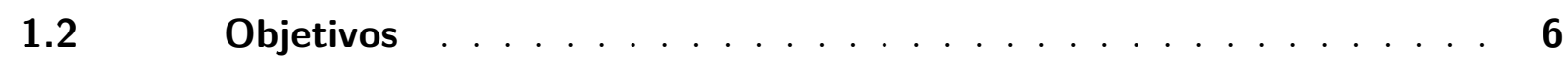

$1.3 \quad$ Estruturação do trabalho $\ldots \ldots \ldots \ldots \ldots$

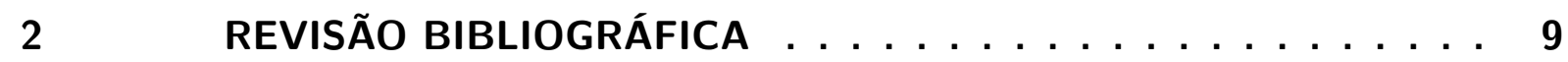

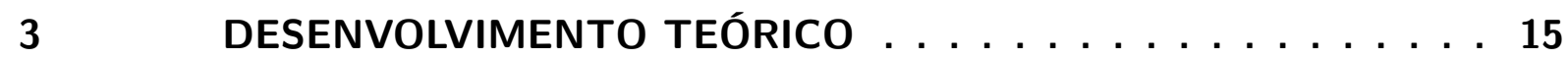

$3.1 \quad$ Fundamentos do Método $\varepsilon$-NUT . . . . . . . . . . . . . . . . 15

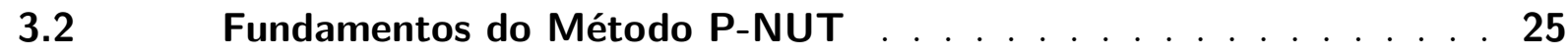

3.3 Fundamentos do Método de LMTD . . . . . . . . . . . . . . . . 29

$3.4 \quad$ Código HETE $\ldots \ldots \ldots \ldots$

$3.4 .1 \quad$ Equações governantes discretas $\ldots \ldots \ldots \ldots . \ldots . \ldots . \ldots 34$

$3.4 .2 \quad$ Procedimento numérico . . . . . . . . . . . . . . . . 38

$3.4 .3 \quad$ Algoritmo para o cálculo do fator de correção . . . . . . . . . . . . . 39

$4 \quad$ MÉTODO DE CÁLCULO . . . . . . . . . . . . . . 47

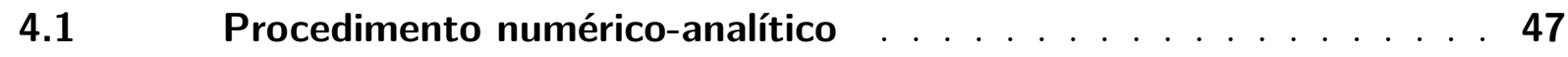

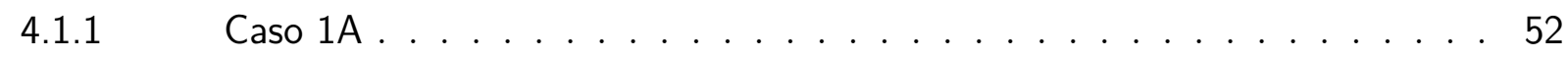

$4.1 .2 \quad$ Casos $1 \mathrm{~B} \mathrm{e} 1 \mathrm{C} \ldots \ldots \ldots \ldots \ldots$

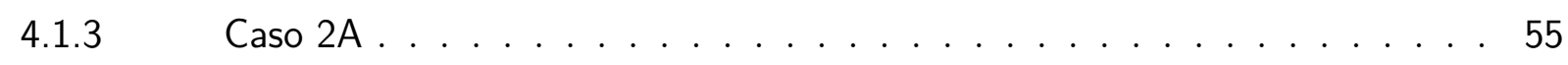

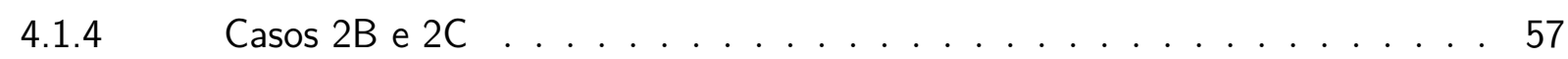

$4.1 .5 \quad$ Casos $3 \mathrm{~A}, 3 \mathrm{~B}$ e $3 \mathrm{C} \ldots \ldots \ldots \ldots$

$4.1 .6 \quad$ Caso $4 \mathrm{~A} \ldots \ldots \ldots \ldots \ldots$

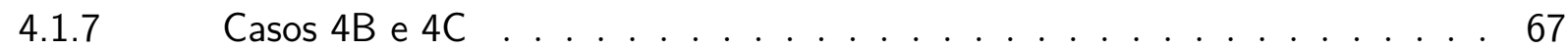

5 RESULTADOS E DISCUSSÕES $\ldots \ldots \ldots \ldots \ldots$

$5.1 \quad$ Trocador de Calor de Fluxo Cruzado . . . . . . . . . . 73

$5.2 \quad$ Trocador de Calor de Casco e Tubo . . . . . . . . . . . . 122

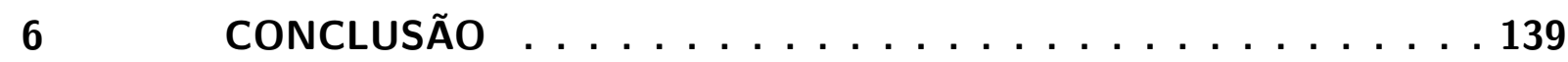

$6.1 \quad$ Recomendações para trabalhos futuros $\ldots \ldots \ldots \ldots 14$

REFERÊNCIAS . . . . . . . . . . . . . . . 143

A ESQUEMA DOS TROCADORES DE CALOR $\ldots \ldots \ldots \ldots 149$ 
B DADOS DE EFETIVIDADE DE TEMPERATURA E FATOR DE CORREÇÃO ......................... 171

C ALGORITMOS . . . . . . . . . . . . . . 233

C.1 Caso 1A . . . . . . . . . . . . . . . . 233

C.2 Casos 1B e 1C . . . . . . . . . . . . . . . . . . . . . 234

C.3 Caso 2A . . . . . . . . . . . . . . . . . . . . 235

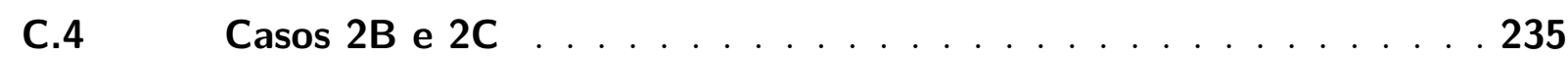

C.5 Casos 3A, 3B e 3C . . . . . . . . . . . . . . . 237 



\section{Introdução}

Trocadores de calor são equipamentos comumente utilizados na prática em uma enorme gama de aplicações industriais, onde o processo de transferência de calor entre dois fluidos a diferente temperatura é necessário. Alguns exemplos podem ser dados como aquecimento e resfriamento de ambientes, condicionamento de ar, recuperação de calor residual, produção de energia elétrica, indústria automobilística, entre outros.

Para o desenvolvimento de projetos e otimização de trocadores de calor, diversos trabalhos foram realizados e têm sido publicados por vários autores ao longo dos anos, como Nusselt (1911), Nusselt (1930), Colburn e Pont (1933), Nagle (1933), Underwood (1934), Smith (1934), Fischer (1938) e Bowman, Mueller e Nagle (1940). Estes métodos são utilizados até hoje no cálculo das diferenças de temperaturas de trocadores de calor (GUIMARAES, 2015).

Neste presente trabalho são estudados dois tipos de trocadores de calor: (i) fluxo cruzado; e (ii) casco e tubo tipo TEMA E (Tubular Exchanger Manufacturers Association). O primeiro se caracteriza pelo escoamento transversal entre os fluidos quente e frio. Já os trocadores de calor de casco e tubo tipo TEMA E se caracterizam por tubos paralelos por onde um dos fluidos circula, montados em uma casco cilíndrico no qual o outro fluido circula. Usualmente, em trocadores de calor de casco e tubo existem chicanas que têm como objetivo conduzir o escoamento e ocasionar uma turbulência, aumentando o tempo de residência do fluido no interior do trocador de calor e provocando um aumento da taxa de transferência de calor. Os trocadores de calor de casco e tubo tipo TEMA E se caracterizam pela presença de somente um passe no casco. Na Figura 1 são apresentados esquematicamente os dois tipos de trocadores de calor (CENGEL, 2008). No caso do trocador de calor de fluxo cruzado um dos fluidos não está misturado (escoamento de ar). A definição de fluidos misturado e não misturado é um importante conceito em trocadores de calor. Segundo Taborek (1983), um escoamento não misturado implica que a diferença de temperaturas em um fluido pode existir na direção normal ao escoamento. Por sua vez, um escoamento misturado implica que a temperatura é uniforme em um determinado plano normal ao escoamento do fluido.

Segundo Pignotti e Shaw (1992), Sekulic, Shah e Pignotti (1999) e Cabezas-Gómez, Navarro e Saiz-Jabardo (2015), o projeto e análise de trocadores de calor de dois fluidos, incluindo os trocadores de fluxo cruzado e de casco e tubo, podem ser realizados por alguns procedimentos de cálculo numérico: (i) método da efetividade-número de unidades de transferência $(\varepsilon-N U T)$; (ii) método da diferença média logarítmica de temperaturas (LMTD); (iii) método da efetividade de temperatura e número de unidades de transferência 


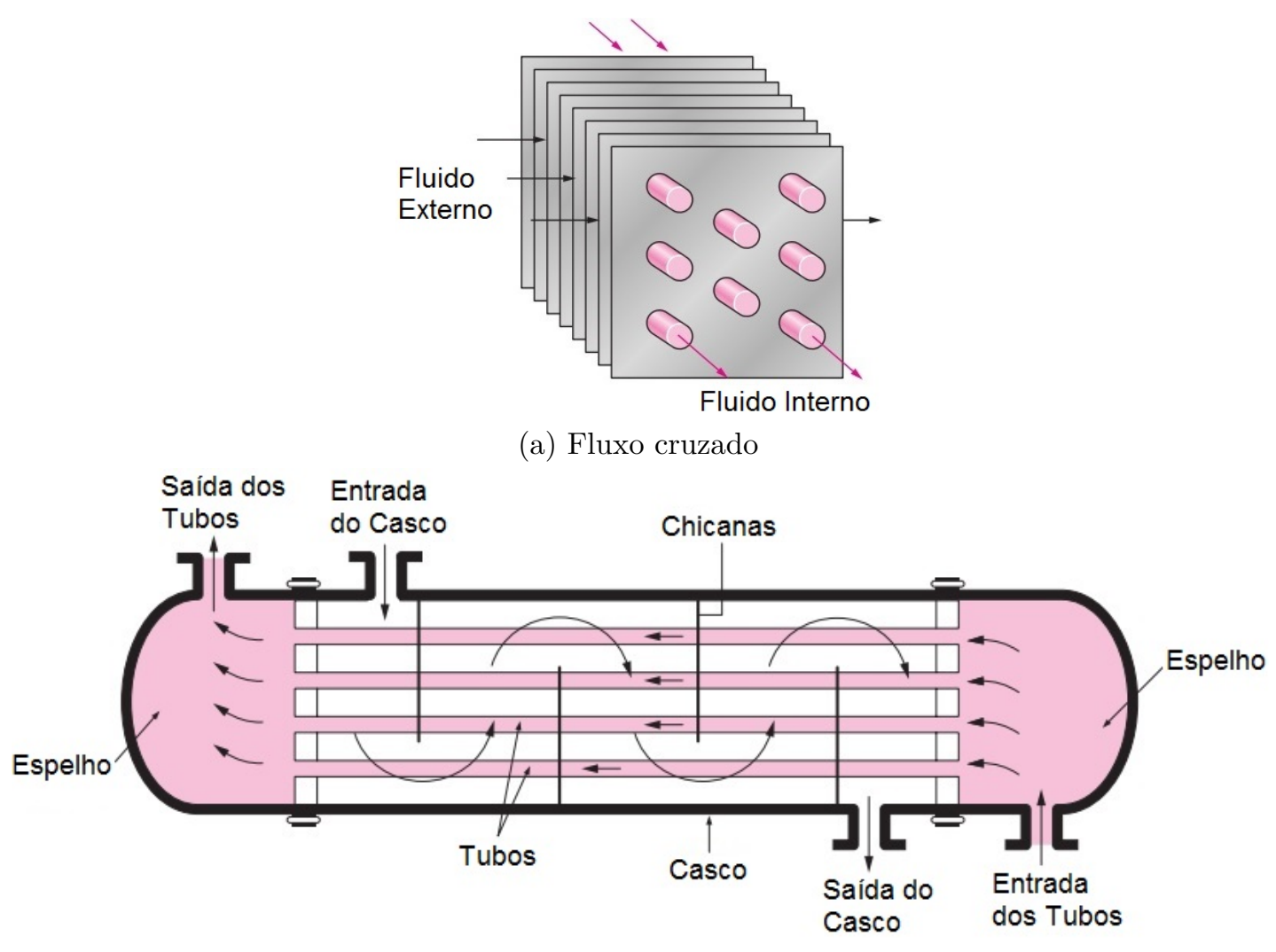

(b) Casco e tubo tipo TEMA E

Figura 1 - Tipos de trocadores de calor (CENGEL, 2008)

( $P$-NUT); (iv) uma versão modificada de qualquer um desses métodos tal como as cartas de Mueller e Roetzel; e (v) método de diferenças e volumes finitos (CAE). Basicamente, estes métodos de cálculo numérico exploram a razão entre as taxas de transferência de calor real e a máxima, onde uma particularidade é realizada para cada um destes métodos.

Neste trabalho o método da diferença média logarítmica de temperaturas (LMTD) é estudado empregando os métodos $\varepsilon-N U T$ e $P$-NUT. O método LMTD se baseia no uso de um fator de correção, denotado por $F$, que se define costumeiramente como a razão entre a diferença de temperaturas real e a diferença média logarítmica para o arranjo contracorrente.

Para muitos arranjos de trocadores de calor, usualmente diagramas e expressões matemáticas aproximadas estão disponíveis na literatura, que são muito efetivas no cálculo manual de trocadores de calor. Bowman, Mueller e Nagle (1940) propuseram relações matemáticas baseadas nos resultados de Nagle (1933), Underwood (1934) e Fischer (1938). As configurações de trocadores de calor consideradas no presente trabalho são as de fluxo cruzado e de casco e tubo. Apesar da importância dos resultados, a ausência de relações analíticas para diversos tipos de arranjos dificultam a utilização dos resultados e implicam em erros na determinação final da taxa de transferência de calor, o que pode influenciar o dimensionamento de trocadores. 


\subsection{Justificativa}

A originalidade do presente trabalho consiste em três realizações: (i) a obtenção de expressões matemáticas analíticas para o cálculo da efetividade de temperatura e do fator de correção para trocadores de calor de fluxo cruzado baseado no procedimento proposto por Pignotti e Cordero (1983a) e detalhado por Magazoni e Cabezas-Gómez (2016); (ii) a obtenção de expressões matemáticas aproximadas para o cálculo da efetividade de temperatura e do fator de correção para trocadores de calor de casco e tubo tipo TEMA E utilizando o mesmo procedimento citado anteriormente; e (iii) o desenvolvimento de ferramentas computacionais atuais nos softwares Matlab e Maple que permitem obter estas relações analíticas originais e simular diversos arranjos de trocadores de calor de fluxo cruzado e de casco e tubo.

O método proposto neste trabalho tem como objetivo obter relações teóricas e aproximadas da efetividade de temperatura e consequentemente do fator de correção para diversas configurações de trocadores de calor de fluxo cruzado e de casco e tubo com números variáveis de chicanas. As relações analíticas encontradas são comparadas com equações teóricas e aproximadas disponíveis na literatura, apresentando assim os erros dos procedimentos da literatura. Em razão disso, diversas tabelas e curvas da efetividade de temperatura e do fator de correção para vários arranjos complexos de trocadores de calor são construídas e apresentadas no presente trabalho. As condições de mistura do tubo depois de cada passe são analisadas, assim como a influência do tipo de mistura do fluido externo ao longo do trocadores de calor.

A metodologia utilizada baseia-se nos estudos desenvolvidos por Pignotti e Cordero (1983a) e Cabezas-Gómez, Navarro e Saiz-Jabardo (2015). Os primeiros autores desenvolveram um complexo procedimento matemático para a obtenção dos resultados de efetividade de temperatura e do fator de correção para diversos arranjos de trocadores de calor de fluxo cruzado com diversas condições de mistura dos fluidos frio e quente. Esta metodologia também é explicada com maiores detalhes em Magazoni e Cabezas-Gómez (2016), onde foi apresentado o desenvolvimento teórico publicado por Pignotti e Cordero (1983a), incluindo todos os detalhes dos códigos computacionais. Por sua vez, CabezasGómez, Navarro e Saiz-Jabardo (2015) desenvolveram uma nova abordagem para o cálculo da efetividade de temperatura de trocadores de calor de fluxo cruzado, que é resumida no código Heat Exchanger Thermal Efficiency (HETE), pelo método $\varepsilon$-NUT. Para o cálculo do fator de correção faz-se uma associação entre os dois métodos, baseado no procedimento apresentado por Kays e London (1998).

A metodologia desenvolvida no presente trabalho para o cálculo da efetividade de temperatura e do fator de correção para trocadores de calor de fluxo cruzado pode ser estendida e empregada no cálculo de trocadores de calor casco e tubo tipo TEMA E com um passe no casco e um no tubo (1-1) em escoamentos contracorrente e paralelo. 
Desta forma, a principal contribuição deste trabalho é apresentar e detalhar a metodologia desenvolvida por Pignotti e Cordero (1983a) e Magazoni e Cabezas-Gómez (2016), possibilitando assim a obtenção de expressões analíticas para o cálculo da efetividade de temperatura e consequentemente do fator de correção.

\subsection{Objetivos}

Este trabalho tem como objetivo principal implementar a metodologia de cálculo de trocadores de calor de fluxo cruzado realizada por Pignotti e Cordero (1983a) e detalhada por Magazoni e Cabezas-Gómez (2016) para a determinação da efetividade de temperatura e do fator de correção. Neste trabalho a metodologia é aplicada também em trocadores de calor de casco e tubo 1-1 tipo TEMA E com um número de chicanas variável.

Neste trabalho, os objetivos específicos são:

- Análise da condição de mistura dos fluidos quente e frio de trocador de calor de casco e tubo;

- Obtenção de expressões matemáticas analíticas para trocadores de calor de fluxo cruzado;

- Obtenção de equações aproximadas para trocadores de calor de casco e tubo 1-1 tipo TEMA E;

- Comparação dos resultados encontrados em trocadores de calor de fluxo cruzado e de casco e tubo com as equações analíticas e aproximadas da literatura aberta;

- Comparação dos resultados encontrados com as soluções obtidas pelo programa computacional HETE;

- Apresentação de dados de efetividade de temperatura e de fator de correção para trocadores de calor de fluxo cruzado e de casco e tubo.

\subsection{Estruturação do trabalho}

O presente trabalho é estruturado em capítulos descritos brevemente a seguir.

No Capítulo 2 é apresentada uma revisão bibliográfica de modelos de cálculos de trocadores de calor de fluxo cruzado e de casco e tubo.

Já no Capítulo 3 são apresentados os fundamentos teóricos dos diferentes métodos de cálculo e projeto de trocadores de calor, mostrando assim o estado da arte de alguns dos métodos de cálculo de relações de desempenho térmico para trocadores de fluxo cruzado e os fundamentos teóricos do programa computacional HETE. 
O método de cálculo apresentado no presente trabalho, que foi desenvolvido a partir do estudo de Pignotti e Cordero (1983a) e Magazoni e Cabezas-Gómez (2016), é apresentado no Capítulo 4.

No Capítulo 5 são mostrados os principais resultados do presente trabalho, dando ênfase nos trocadores de calor de fluxo cruzado e de casco e tubo. Comparações entre os resultados encontrados pelo presente trabalho com aqueles fornecidos com relações teóricas e aproximadas da literatura são também apresentados.

Finalmente, no Capítulo 6 são apresentados as conclusões do trabalho, bem como, as recomendações de trabalhos futuros.

No Anexo A são apresentados os desenhos esquemáticos dos trocadores de calor de fluxo cruzado utilizados no presente trabalho. No Anexo B são apresentados dados de efetividade de temperatura e de fator de correção para diversos arranjos de trocadores de calor de fluxo cruzado. Já no Anexo C são mostrados os algoritmos desenvolvimentos para todas as configurações de trocadores de calor de fluxo cruzado desenvolvidos por Pignotti e Cordero (1983a), detalhados por Magazoni e Cabezas-Gómez (2016) e apresentados no presente trabalho. 



\section{Revisão Bibliográfica}

O objetivo do presente capítulo é apresentar uma revisão bibliográfica de modelos de cálculos de trocadores de calor de fluxo cruzado e de casco e tubo, bem como estudos relacionados à determinação da efetividade de temperatura e do fator de correção.

De acordo com Pignotti e Shaw (1992), Sekulic, Shah e Pignotti (1999), CabezasGómez, Navarro e Saiz-Jabardo (2015), o projeto e análise de trocadores de calor de dois fluidos, incluindo os trocadores de fluxo cruzado e de casco e tubos podem ser realizados pelos seguintes procedimentos: (i) o método da efetividade-número de unidades de transferência $(\varepsilon-N U T)$; (ii) o método da diferença média logarítmica de temperaturas (LMTD); (iii) o método da efetividade de temperatura-número de unidades de transferência $(P-N U T)$; (iv) uma versão modificada de qualquer um desses métodos tal como as cartas de Mueller e Roetzel; e (v) método de diferenças e volumes finitos (CAE). Para uma listagem completa e discussão sobre os diferentes métodos podem-se consultar as publicações de Taborek (1983), Shah e Mueller (1985), Hewitt, Shires e Bott (1994), Kays e London (1998), Shah e Sekulic (2003) e Thulukkanam (2013) e os relatórios de ESDU (1991), entre outras.

Diferenças entre os diversos procedimentos e afirmações sobre as vantagens de um método em particular em relação aos outros tem sido reportados na literatura aberta. Kays e London (1998) apresentaram argumentos em favor do método $\varepsilon$-NUT com respeito ao método LMTD. A principal vantagem do primeiro está relacionada com a solução de problemas de desempenho. Nestes problemas o método $\varepsilon$-NUT permite uma solução direta para a avaliação do desempenho térmico do trocador de calor sem a necessidade de sucessivas aproximações requeridas pelo procedimento da média logarítmica. Como regra geral, as relações $\varepsilon-N U T$, além de serem muito úteis para o dimensionamento e o cálculo do desempenho de trocadores de calor, também são úteis no tratamento de dados experimentais para a determinação dos coeficientes de transferência de calor externos de trocadores de calor compactos. Kays e London (1998) e Webb e Kim (2005) apresentam um resumo desses tipos de investigações.

Roetzel e Nicole (1975) e Roetzel e Neubert (1979) apresentaram uma expressão aproximada para o cálculo da diferença média logarítmica de temperaturas e do fator de correção de diversos arranjos de trocadores de calor de fluxo cruzado. Na obtenção dos valores apropriados para os coeficientes das expressões aproximadas, os autores utilizaram a solução das séries infinitas duplas de Nusselt (1930).

Por sua vez, Gardner e Taborek (1977) examinaram o erro relacionado à adoção de algumas hipóteses simplificadoras teóricas para a determinação de LMTD e do fator 
de correção. Assim, as três hipóteses principais abordadas foram: (i) coeficiente global de transferência de calor constante ao longo do trocador de calor, principalmente para fluidos com características de viscosidades particulares; (ii) condição de bypassing, que trata da partilha do fluxo dentro dos diversos ramais do trocador de calor, que pode produzir um valor distorcido da temperatura de saída; e (iii) alto número de chicanas em um trocador de calor de casco e tubo. Segundo Perussi (2010), para as duas primeiras hipóteses abordadas, os autores apresentaram uma revisão crítica das condições que conduzem aos erros potenciais. A terceira consideração, de que o número de chicanas em um trocador de calor casco e tubo é grande, é avaliada pela comparação da média da diferença de temperaturas convencional para um trocador sintetizado de elementos de fluxo cruzado puro com ambos fluidos não misturados com todas outras considerações convencionais permanecendo válidas.

Tucker (1996) apresentou alguns diagramas do fator de correção para trocadores de calor de fluxo cruzado de simples passe, assim como uma solução iterativa para reproduzir os valores obtidos por Bowman, Mueller e Nagle (1940) e Mason (1955). O novo diagrama encontrado, que deveria ser idêntico ao original, apresentou uma discrepância considerável devido ao erro relacionado aos valores numéricos obtidos por Nusselt (1930) e adotados por Bowman, Mueller e Nagle (1940), fato este atribuído aos recursos limitados disponíveis em 1930 e ao erro atribuído à interpolação de valores.

Nagle (1933) apresentou diagramas para o cálculo do fator de correção para trocadores de calor de casco e tubo em função da efetividade de temperatura $P$ e da razão de temperaturas $R$. Inicialmente, foram apresentados diagramas do fator de correção para arranjos de trocadores de calor 1-2, 1-4 e 1-6 (um passe no casco e dois, quatro e seis passes nos tubos). Resultados adicionais, na forma de diagramas, para arranjos 2-4 foram também apresentados.

Bowman, Mueller e Nagle (1940) apresentaram um estudo de trocadores de calor em variados arranjos e propuseram relações matemáticas para o cálculo do fator de correção. As configurações de trocadores de calor consideradas pelos autores estão incluídas os de fluxo cruzado e os de casco e tubo. Foram apresentados os resultados do cálculo do fator de correção propostos por Nagle (1933), Underwood (1934) e Fischer (1938). Apesar da importância dos resultados, esses são limitados à hipótese de infinitas chicanas no trocador de calor de casco e tubo, podendo gerar resultados errôneos para condições fora desta consideração.

Outro procedimento empregado na literatura e similar ao $\varepsilon$-NUT é o $P$-NUT, onde $P$ é uma efetividade definida para o fluido quente ou para o frio (fluido 1 ou fluido 2 ), em contraste com a efetividade $\varepsilon$ que é definida em termos do fluido com a capacitância térmica mínima, $C_{m i n}$. Pignotti e Shaw (1992) enfatizaram o fato de que o método $P$-NUT evita a necessidade de duas expressões da efetividade para trocadores de calor de dois 
fluidos assimétricos, requeridas pelo método $\varepsilon-N U T$, em função de qual dos dois fluidos é o que possui a capacitância térmica mínima.

Hewitt, Shires e Bott (1994) argumentaram que os gráficos obtidos pelo método $P-N U T$ apresentam curvas muito comprimidas que dificultam uma interpolação adequada. Como alternativa esses autores optaram pelo procedimento iterativo apresentado em $\mathrm{Ta}$ borek (1983), o qual é uma combinação do método da LMTD, com o fator de correção $F$, com o método $\theta-N U T$, sendo o parâmetro $\theta$ definido como $\theta=P / N U T$. Dos desenvolvimentos teóricos apresentados na literatura se deve notar que todos os procedimentos são inter-relacionados, e podem ser aplicados conhecendo-se a distribuição do campo de temperaturas no trocador de calor, produzindo os mesmos resultados para o mesmo conjunto de dados de entrada.

$\mathrm{Na}$ presente tese se empregam principalmente os métodos $\varepsilon-N U T$ e $P-N U T$, isto devido à sua ampla aplicação em trocadores de calor, assim como ao seu extenso uso em programas computacionais. Shah e Sekulic (2003) fornecem um suporte para essa escolha com base nas vantagens computacionais desses dois métodos em relação aos outros.

Sekulic, Shah e Pignotti (1999) apresentaram uma revisão abrangente dos métodos de solução empregados na determinação das relações $\varepsilon$-NUT para trocadores de calor de dois fluidos com arranjos de escoamento simples e complexos. Os métodos disponíveis foram separados nas seguintes categorias: métodos analíticos exatos, métodos aproximados (analíticos e ajuste de curvas), métodos numéricos, métodos empregando o formalismo matricial, e métodos baseados nas propriedades da configuração do trocador de calor. Apesar de sua detalhada investigação, Sekulic, Shah e Pignotti (1999) afirmaram que novas relações $\varepsilon$-NUT ainda não reportadas na literatura são requeridas para contribuir com os esforços correntes para projetar sistemas mais eficientes com menor fator de segurança, trocadores mais compactos, e sistemas operando sob condições de operação mais específicas.

Pignotti e Shaw (1992), empregando os métodos de formalismo matricial e com base nas configurações dos trocadores de calor, desenvolveram expressões $\varepsilon-N U T$ para dezoito arranjos novos com configurações complexas, dezesseis dos quais foram trocadores de calor de fluxo cruzado. Os autores usaram métodos tais como: o tratamento algébrico introduzido por Domingos (1969), também conhecido como as regras de Domingos (Domingos rules); a regra da cadeia; e as regras previamente publicadas por Pignotti e Tamborenea (1988) para trocadores com um fluido misturado. Nesse último artigo, o autor introduziu o formalismo matricial usado para a avaliação da efetividade de trocadores de calor com configurações complexas, que podem ser divididos em partes constitutivas simples, juntas entre si por correntes não misturadas.

Shah e Pignotti (1993) trataram com configurações complexas de trocadores de calor relacionando as mesmas a configurações simples para as quais existem soluções 
analíticas exatas ou podem ser obtidas soluções aproximadas. Usando esse procedimento os autores forneceram relações $\varepsilon$-NUT para sete configurações diferentes de trocadores de fluxo cruzado de tubos aletados construídos empregando o mesmo feixe de tubos com seis fileiras.

Trabalhos anteriores, tais como os de Stevens, Fernandez e Woolf (1957), Taborek (1983) e Baclic (1990), relacionados com a avaliação de efetividade térmica de configurações de múltiplos passes em arranjos paralelo-cruzado ou contracorrente-cruzado, devem ser citados. Stevens, Fernandez e Woolf (1957) determinaram numericamente a distribuição de temperaturas para distribuições de trocadores de calor com um, dois e três passes paralelo-cruzado e contracorrente-cruzado com o lado do fluido dos tubos misturados e o lado do fluido externo não misturado. No total os autores estudaram 40 configurações, fornecendo em alguns casos expressões fechadas para o cálculo da efetividade, $\varepsilon$, do trocador de calor. O mesmo procedimento foi empregado por Chen, Conklin e Baxter (1998) para desenvolver uma expressão fechada para a efetividade de um trocador de calor de quatro fileiras de tubos em arranjo contracorrente-cruzado. De acordo com esses autores, o estudo desenvolvido por Fernandez (1956), Stevens, Fernandez e Woolf (1957) é uma contribuição significativa à teoria dos trocadores de calor de fluxo cruzado de múltiplos passes. Eles calcularam a distribuição de temperatura para um, dois e três tubos de trocadores de calor de fluxo cruzado em escoamentos contracorrente e paralelo.

Nicole (1972) estudou a diferença de temperatura média em trocadores de calor de fluxo cruzado com até seis tubos por passe. Entretanto, devido a alguns erros das expressões matemáticas da efetividade, os resultados não puderam ser comparados. Domingos (1969) apresentou um método para calcular a efetividade e as temperaturas intermediárias de configurações de trocadores de calor. A expressão matemática utilizada para predizer a efetividade de trocadores de calor de fluxo cruzado é complexa para algumas geometrias simples.

Em relação ao estudo dos trocadores de calor de fluxo cruzado de apenas um passe com ambos os fluidos não misturados, denominados de fluxo cruzado puro, as investigações realizadas por Nusselt (1911), Nusselt (1930) e Mason (1955) devem ser citadas. Os autores forneceram soluções analíticas para esse tipo de trocador de calor até hoje empregadas. De acordo com Sekulic, Shah e Pignotti (1999), Nusselt em seu artigo de 1911 usou o método de integração de Riemann para resolver uma equação diferencial de segunda ordem e obter a distribuição de temperatura no trocador de calor. Depois disso, na sua segunda tentativa em 1930, Nusselt resolveu o mesmo problema transformando o modelo analítico numa equação integral de Volterra. Esta equação foi resolvida assumindo uma solução teste na forma de series de potência, da qual ele obteve uma expressão explícita complicada para o cálculo da efetividade.

Mason (1955) usou a transformada de Laplace para o mesmo problema e obteve uma 
solução comumente empregada por outros autores (STEVENS; FERNANDEZ; WOOLF 1957; KAYS; LONDON, 1998). A solução analítica do problema endereçado inicialmente por Nusselt motivou a procura por outros procedimentos de solução, em conjunto com ajustes da expressão complexa obtida por Nusselt para sua simplificação. O artigo de Baclic e Heggs (1985) apresentaram uma explanação muito detalhada dos diversos métodos empregados e de sua equivalência. Alguns dos trabalhos citados por estes autores são Binnie e Poole (1937), Smith (1934), Baclic (1978), Hausen (1983), e outros. Após a publicação de Baclic e Heggs (1985) e Li (1987) apresentaram uma solução simplificada, obtida pela modificação da solução das series duplas de Nusselt (1930). Enfatiza-se que o estudo de Nusselt (1911) foi o primeiro do gênero em trocadores de calor de fluxo cruzado e se considera uma das contribuições importantes desse cientista na área de transferência de calor. Baclic (1978) apresentou uma solução aproximada de trocadores de calor de fluxo cruzado com ambos os fluidos não misturados baseados nas funções modificadas de Bessel de primeira ordem.

Recentemente, Triboix (2009) apresentou uma nova solução exata, que pode ser resolvida de forma mais eficiente usando a integração da função de Bessel, para trocadores de calor de fluxo cruzado com um único passe. O autor apresentou relações aproximadas tanto para o cálculo da efetividade de temperatura, quanto para o cálculo direto do $N U T$ que merecem ser destacadas. Porém, as relações matemáticas aproximadas possuem ao menos $2 \%$ de erro relativo, o que pode prejudicar o cálculo final da efetividade.

Diversas relações para a efetividade térmica de trocadores de calor podem ser encontradas em Martin (1990). O autor desenvolveu essas relações da solução de duas equações diferenciais fornecendo a distribuição da temperatura adimensional para cada fluido. Martin (1990) aplicou a solução de Nusselt (1930) com algumas posteriores simplificações num trocador de calor de fluxo cruzado puro (trocador de fluxo cruzado com ambas as correntes não misturadas). Em configurações de arranjos combinados, tais como arranjos, paralelo-cruzado e contracorrente-cruzado, foi empregado o método das células. Este método consiste na divisão do trocador de calor em células que correspondem à uma seção que cobre todo o comprimento de um passe do fluido misturado por dentro dos tubos e a porção correspondente do fluido externo no misturado. Dessa forma para cada célula se obtém um par de equações algébricas para o cálculo da distribuição da temperatura adimensional de cada fluido. Assim, o trocador de calor se simula através de um sistema global de equações algébricas, cuja solução permite a avaliação da efetividade global do trocador.

Por sua vez, Pignotti e Cordero (1983a) desenvolveram um procedimento para o cálculo da efetividade de temperatura e do fator de correção em trocadores de calor de fluxo cruzado com números arbitrários de passes e de tubos por passe. A influência das misturas dos fluidos quente e frio foi analisada para trocadores em escoamentos contracorrente 
e paralelo. Esta metodologia também é explicada com maiores detalhes em Magazoni e Cabezas-Gómez (2016), onde foi apresentado o desenvolvimento teórico, incluindo todos os detalhes dos códigos computacionais. Novas tabelas e figuras de efetividade de temperatura e do fator de correção para complexos arranjos de trocadores de calor foram apresentadas. Pignotti e Cordero (1983b) utilizaram este procedimento para o desenvolvimento de gráficos do fator de correção e da efetividade de temperatura para diversas configurações de trocadores de calor de interesse industrial.

Para muitos arranjos de trocadores de calor, usualmente diagramas e expressões matemáticas aproximadas estão disponíveis na literatura, que são muito efetivas no cálculo manual de trocadores de calor (ROETZEL; NICOLE, 1975; PIGNOTTI; CORDERO, 1983b; SPANG; ROETZEL, 1995; ROETZEL; SPANG, 2010). Um resumo excelente das relações da efetividade para diferentes arranjos de escoamento também se apresenta em detalhes em VDI (2010). Entretanto, a utilização destes diagramas e expressões podem levar a erros consideráveis no desenvolvimento final de trocadores de calor. Isto será evidenciado no presente trabalho, conforme apresentado no Capítulo 5.

Ainda no campo computacional, Navarro e Cabezas-Gómez (2005), Cabezas-Gómez, Navarro e Saiz-Jabardo (2006), Cabezas-Gómez et al. (2009) e Cabezas-Gómez et al. (2012) apresentaram uma nova metodologia para o cálculo térmico de trocadores de calor de fluxo cruzado baseado na discretização do trocador de calor em pequenas inúmeras células de trocadores de calor de um passe. O código gerado a partir desta metodologia é utilizado no programa computacional HETE, que será empregado neste trabalho para comparação com os resultados encontrados. Os resultados apresentados por estes autores utilizando o código computacional HETE foram validados com diversas metodologias e soluções analíticas para trocadores de calor de fluxo cruzado com um número de fileiras de um a quatro.

Guimaraes (2015) estendeu a metodologia do código computacional HETE, primeiramente idealizado para trocadores de calor de fluxo cruzado, para trocadores de calor de casco e tubo. São apresentados resultados numéricos inéditos do fator de correção para trocadores de calor de casco e tubo tipo E, que ajudam a complementar as relações analíticas existentes na literatura aberta.

Desta maneira, o presente trabalho tem com o objetivo obter expressões matemáticas para o cálculo da efetividade de temperatura e do fator de correção para trocadores de calor de fluxo cruzado e casco e tubo tipo TEMA E utilizando o procedimento proposto por Pignotti e Cordero (1983a) e detalhado por Magazoni e Cabezas-Gómez (2016). Dados de efetividade de temperatura e de fator de correção para trocadores de calor de fluxo cruzado e de casco e tubo também são apresentados no presente trabalho. 


\section{Desenvolvimento Teórico}

Neste capítulo se apresentam os fundamentos teóricos dos diferentes métodos de cálculo e projeto de trocadores de calor. Dá-se ênfase ao desenvolvimento das principais relações empregadas para caracterização do desempenho térmico de trocadores de calor em geral, de fluxo cruzado em particular. No fim do capítulo se apresenta parcialmente o estado da arte de alguns dos métodos de cálculo de relações de desempenho térmico para trocadores de fluxo cruzado.

\subsection{Fundamentos do Método $\varepsilon$-NUT}

O método $\varepsilon$-NUT foi formalmente introduzido em 1942 em um relatório não publicado por London e Seban, que veio ser publicado em 1980 (LONDON; SEBAN, 1980). Posteriormente, Kays e London em 1952 usaram extensivamente esse procedimento e publicaram os resultados no seu conhecido livro Compact Heat Exchangers (KAYS; LONDON, 1998). Nesse livro dados experimentais dos coeficientes de atrito e de transferência de calor para diferentes geometrias e configurações podem ser encontrados. Também se apresentam diversas relações teóricas da efetividade, $\varepsilon$, para muitos dos arranjos dos trocadores de calor mais comuns encontrados na prática. A partir desse momento, a aplicação do método $\varepsilon$-NUT tem aumentado até o ponto que no presente esse método pode ser considerado o procedimento mais aceito para projeto e análise de trocadores de calor.

No método $\varepsilon$-NUT, a efetividade do trocador de calor, $\varepsilon$, desempenha um papel central, embora o seu conceito seja relativamente simples. A ideia da efetividade do trocador de calor tem a ver com a conservação de energia, já que é definida como a razão entre a taxa de transferência de calor real, $\dot{Q}$, e a máxima taxa de transferência de calor, $\dot{Q}_{\text {max }}$, que pode ser obtida em um trocador de calor com área infinita, onde a máxima troca de calor é realizada entre as temperaturas de entrada dos fluidos frio e quente. A efetividade é assim definida como,

$$
\varepsilon=\frac{\dot{Q}}{\dot{Q}_{\max }}
$$

As taxas de transferência de calor dos fluidos frio e quente $\dot{Q}_{f}$ e $\dot{Q}_{q}$, são determinadas através da conservação de energia no trocador de calor. Considerando as capacidades térmicas constantes e sem mudança de fase, pode-se escrever a taxa de transferência de calor em função da capacitância térmica dos fluidos, $C$, e das temperaturas de entrada e saída do trocador de calor, $T_{\text {ent }}$ e $T_{\text {sai }}$, 


$$
\begin{gathered}
\dot{Q}_{f}=\dot{m}_{f}\left(h_{f, s a i}-h_{f, e n t}\right)=C_{f}\left(T_{f, s a i}-T_{f, e n t}\right) \\
\dot{Q}_{q}=\dot{m}_{q}\left(h_{q, \text { ent }}-h_{q, s a i}\right)=C_{q}\left(T_{q, \text { ent }}-T_{q, s a i}\right)
\end{gathered}
$$

onde $\dot{m}$ é a vazão mássica, $h$ é a entalpia. Os subscritos $q$ e $f$ representam os fluidos quente e frio, respectivamente, enquanto os subscritos ent e sai se referem às seções de entrada e saída. Note que a taxa de transferência de calor máxima, $\dot{Q}_{\max }$, é aquela que pode ser obtida em um trocador de calor em contracorrente com as mesmas temperaturas de entrada dos fluidos quente e frio e com a capacitância térmica mínima, $C_{m i n}$, atinge a mesma temperatura de entrada do fluido com a maior capacitância térmica sendo este o fluido quente ou frio.

A taxa de transferência de calor real, $\dot{Q}$, pode ser escrita como,

$$
\dot{Q}=\varepsilon \dot{Q}_{\max }=\varepsilon C_{\min }\left(T_{q, \text { ent }}-T_{f, s a i}\right)
$$

onde $C_{\text {min }}$ é a capacidade térmica mínima do trocador de calor. Se $C_{f}<C_{q}$, o fluido frio iria experimentar a maior variação de temperatura, $\operatorname{logo} C_{\min }=C_{f}$. Similarmente, se $C_{q}<C_{f}$, o fluido quente experimentaria a maior variação de temperatura e $C_{\min }=C_{q}$.

É interessante notar que quando uma das correntes está mudando de fase à pressão constante, a capacitância térmica tende ao infinito, pois não existe diferença de temperatura do fluido. Logo, a outra corrente é a que possui o valor de capacitância térmica mínimo. Em geral, é possível expressar a efetividade do trocador de calor como função do número de unidades de transferência, $N U T$, da razão das capacitâncias térmicas, $C^{*}$, e do tipo de arranjo de escoamento do trocador de calor,

$$
\varepsilon=\Phi\left(N U T, C^{*}, \text { arranjo }\right)
$$

Os parâmetros adimensionais $N U T$ e $C^{*}$ são definidos como,

$$
\begin{gathered}
N U T=\frac{U A}{C_{\min }} \\
C^{*}=\frac{C_{\min }}{C_{\max }}
\end{gathered}
$$

Através do balanço de energia no trocador de calor, sabe-se que $\dot{Q}_{f}=\dot{Q}_{q}=\dot{Q}$ e a taxa de transferência de calor pode ser escrita em função da diferença de temperatura média apropriada $\Delta T_{m}$, do coeficiente global de transferência de calor $U$ e da área de 
troca térmica $A$. Segundo Shah e Sekulic (2003), a taxa de transferência de calor pode ser escrita em termos da diferença média de temperaturas das correntes quente e fria,

$$
\dot{Q}=U A \Delta T_{m}
$$

Assim, combinando as Equações 3.4 e 3.8, uma expressão alternativa para a efetividade térmica do trocador pode ser obtida,

$$
\varepsilon=N U T\left(\frac{\Delta T_{m}}{\Delta T_{\max }}\right)
$$

Note que $\Delta T_{m}$ é a diferença média de temperaturas efetiva também conhecida como o potencial motriz médio da temperatura (mean temperature driving potential), ver Shah e Sekulic (2003). Note também que $\Delta T_{m}$ está relacionado com a diferença média logarítmica de temperaturas, LMTD, pela seguinte expressão,

$$
\Delta T_{m}=F \Delta T_{L M T D}
$$

onde $F$ é o fator de correção do método de diferença de temperatura logarítmica. Expressões algébricas para o a fator de correção foram desenvolvidas para várias configurações de trocador de calor casco e tubo e correntes cruzadas (BOWMAN; MUELLER; NAGLE, 1940; KAYS; LONDON, 1998). O fator de correção será apresentado em detalhes na Seção 3.3 .

De acordo com Shah e Sekulic (2003), o parâmetro adimensional NUT pode ser considerado como o tamanho adimensional ou, em outras palavras, o tamanho térmico do trocador de calor, sendo assim um parâmetro de projeto. Outro ponto de vista em relação ao sentido físico deste parâmetro pode ser concebido em termos da razão das diferenças de temperaturas. De fato, rearranjando a Equação 3.9, obtém-se a seguinte expressão,

$$
N U T=\frac{\varepsilon \Delta T_{\max }}{\Delta T_{m}}
$$

Note que NUT pode ser considerado como uma razão entre temperaturas,

$$
N U T= \begin{cases}\frac{\Delta T_{f}}{\Delta T_{m}}=\frac{T_{f, e n t}-T_{f, s a i}}{\Delta T_{m}}, & C_{\text {min }}=C_{f} \\ \frac{\Delta T_{q}}{\Delta T_{m}}=\frac{T_{q, s a i}-T_{q, e n t}}{\Delta T_{m}}, & C_{\text {min }}=C_{q}\end{cases}
$$

Desta forma, NUT pode ser considerado como a razão entre a diferença máxima e a diferença média de temperaturas entre as correntes quente e fria no trocador de calor. 
Valores elevados de NUT correspondem, por exemplo, a uma diferença de temperatura pequena entre ambas as correntes. Na Figura 2 são ilustradas as condições operacionais correspondentes a valores elevados e pequenos de NUT. Note que no primeiro caso o valor da diferença média de temperaturas é relativamente elevado, correspondendo a um pequeno $N U T$, enquanto no segundo esta diferença é pequena, i.e., NUT elevado.
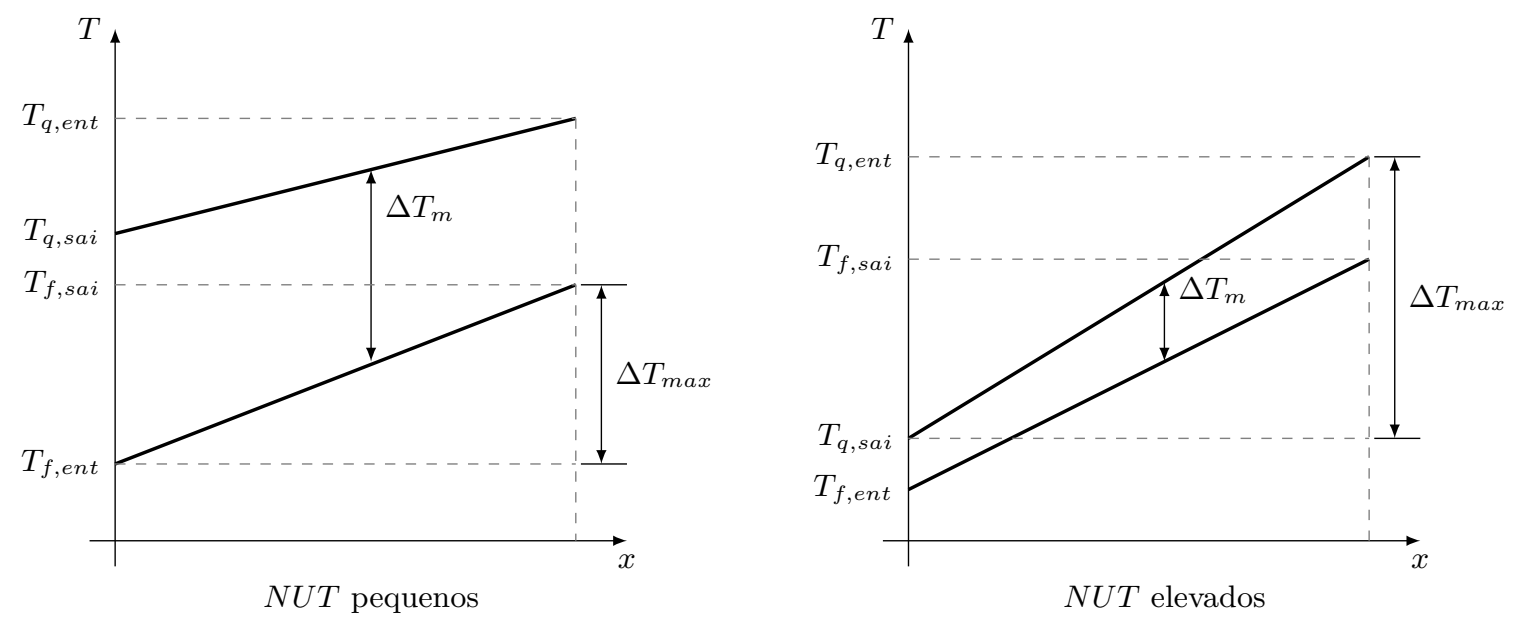

Figura 2 - Variação das temperaturas quente e fria ao longo de um trocador de calor em contracorrente ilustrando condições de $N U T$ pequenos e elevados

A relação funcional expressa pela Equação 3.5 pode ser obtida por análise dimensional, usando o teorema $\Pi$ de Buckinham. Este procedimento apenas prova que a efetividade pode ser expressa em função de $N U T, C^{*}$ e do tipo de configuração ou arranjo particular do trocador de calor. Entretanto, a função que relaciona estes parâmetros adimensionais teria que ser ainda determinada. Isto é realizado para o trocador de calor em contracorrente da Figura 2 assumindo que a capacitância térmica do fluido quente é menor que à do fluido frio, correspondendo ao gráfico da direita. Considerando inicialmente a expressão para a diferença média logarítmica de temperaturas, LMTD, sendo $F=1$ (SHAH; SEKULIC, 2003),

$$
\Delta T_{L M T D}=\frac{\left(T_{q, e n t}-T_{f, s a i}\right)-\left(T_{q, s a i}-T_{f, e n t}\right)}{\ln \left(\frac{T_{q, e n t}-T_{f, s a i}}{T_{q, s a i}-T_{f, e n t}}\right)}
$$

Com as equações de conservação da energia para os fluidos quente e frio, Equações 3.2 e 3.3 , e os componentes localizados a esquerda e direita da Equação 3.8, encontra-se a seguinte expressão matemática,

$$
\frac{\dot{Q}}{U A}=\frac{\left(T_{q, \text { ent }}-T_{f, \text { sai }}\right)-\left(T_{q, \text { sai }}-T_{f, \text { ent }}\right)}{\ln \left(\frac{T_{q, \text { ent }}-T_{f, \text { sai }}}{T_{q, \text { sai }}-T_{f, \text { ent }}}\right)}=\frac{\frac{\dot{Q}}{C_{q}}-\frac{\dot{Q}}{C_{f}}}{\ln \left(\frac{T_{q, \text { ent }}-T_{f, \text { sai }}}{T_{q, \text { sai }}-T_{f, \text { ent }}}\right)}
$$


Somando e subtraindo $T_{q, \text { ent }}$ no numerador e $T_{f, \text { ent }}$ no denominador do lado direito da equação anterior e introduzindo ainda a expressão de definição da efetividade, Equação 3.1. para $C_{\min }=C_{q}$, resulta em,

$$
\frac{-\varepsilon+1}{1-\varepsilon C^{*}}=\exp \left[-N U T\left(1-C^{*}\right)\right]
$$

Finalmente,

$$
\varepsilon=\frac{1-\exp \left[-N U T\left(1-C^{*}\right)\right]}{1-C^{*} \exp \left[-N U T\left(1-C^{*}\right)\right]}
$$

A Equação 3.16 foi obtida para a configuração correspondente ao trocador de calor em contracorrente da Figura 2. Para a configuração de um trocador de calor em paralelo se aplica o mesmo procedimento, porém considerando a relação correta para a LMTD, sendo,

$$
\Delta T_{L M T D}=\frac{\left(T_{q, e n t}-T_{f, e n t}\right)-\left(T_{q, s a i}-T_{f, s a i}\right)}{\ln \left(\frac{T_{q, e n t}-T_{f, e n t}}{T_{q, s a i}-T_{f, s a i}}\right)}
$$

Rearranjando a expressão matemática, chega-se na equação abaixo,

$$
\varepsilon=\frac{1-\exp \left[-N U T\left(1+C^{*}\right)\right]}{1+C^{*}}
$$

As expressões obtidas para os arranjos contracorrente (Equação 3.16) e paralelo (Equação 3.18 também são válidas para $C_{\text {min }}=C_{f}$, pois essas duas configurações são simétricas ( (PIGNOTTI, 1989, SHAH; SEKULIC, 2003). Expressões para estes e outros arranjos simples podem ser encontradas nos livros de transferência de calor e na literatura geral. Shah e Sekulic (2003), Nellis e Klein (2009) e Incropera e DeWitt (2014) apresentaram em detalhes a derivação das mesmas através do uso das equações de conservação de energia para ambos os fluidos e das definições da efetividade, Equação 3.1. Entretanto, antes de apresentar um resumo das mesmas se mostra a obtenção da relação para a efetividade de um trocador de calor de fluxo cruzado misturado - não misturado com apenas um passe de cada fluido.

Na Figura 3 se mostra esquematicamente um trocador de calor de fluxo cruzado misturado - não misturado com apenas um passe de cada fluido. Isso equivale a considerar apenas uma fileira de tubos com um tubo, ou seja, com apenas um circuito do fluido que escoa pelo interior dos tubos. Na Figura 3 se ilustra a distribuição de temperaturas de ambos os fluidos ao longo das direções transversal e longitudinal com respeito ao fluido interno. Ao longo da tira diferencial de comprimento $d x$ mostrada na Figura 3 , a vazão mássica do fluido externo (denotado fluido frio) é pequena. Devido à taxa de transferência 
de calor também ser pequena, espera-se que a temperatura do fluido interno (denotado fluido quente) se mantenha constante, como sugerido na figura. Segundo as relações (KAYS; LONDON, 1998), escreve-se um balanço de energia no comprimento da tira diferencial para os fluidos, quente e frio,

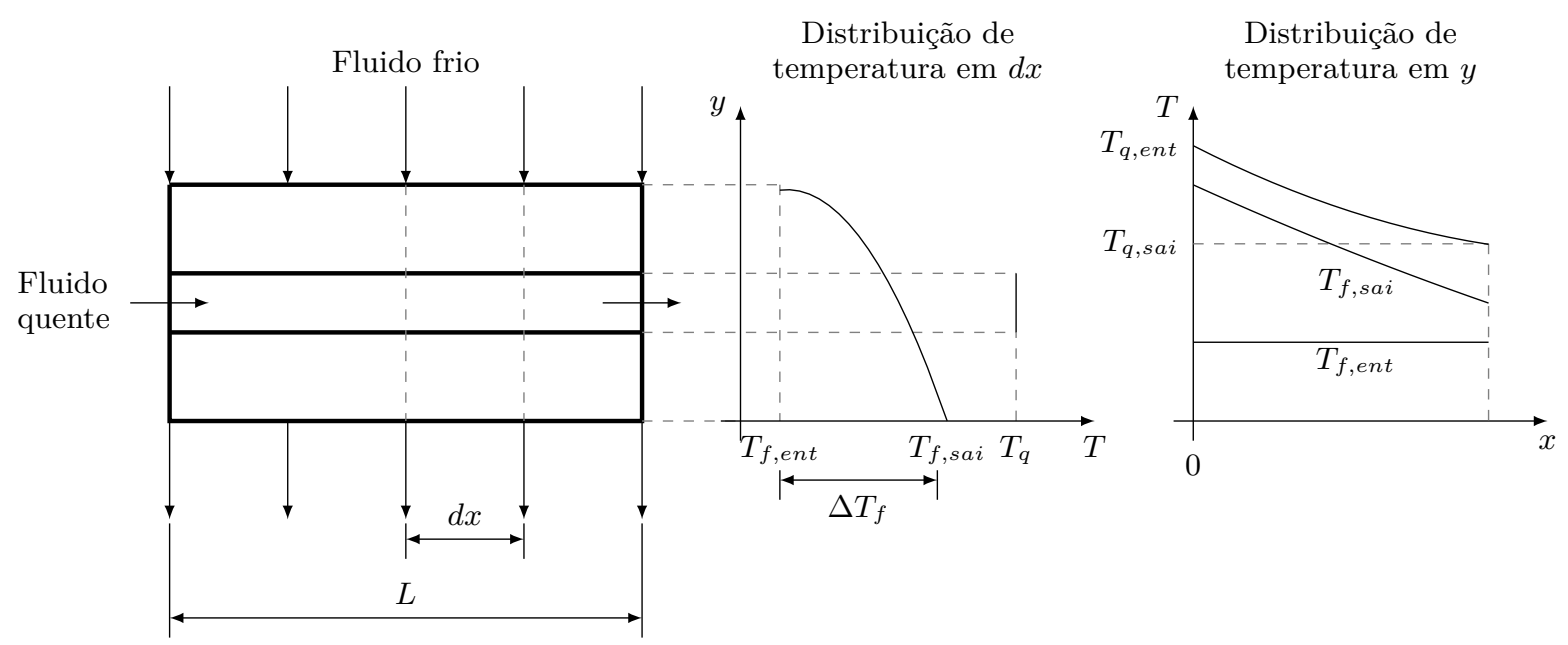

Figura 3 - Variação das temperaturas nas direções transversal e longitudinal em um trocador de calor de fluxo cruzado de um passe misturado - não misturado

$$
\delta \dot{Q}=-C_{q} d T_{q}=d C_{f} \Delta T_{f}
$$

Note que $\Delta T_{f}$ é a variação da temperatura do fluido frio no elemento diferencial, ou seja, $\Delta T_{f}=T_{f, s a i}-T_{f, e n t}$, onde os subscritos representam as temperaturas de entrada e saída do fluido externo (fluido frio) na tira diferencial.

Dado o fato de que a vazão mássica do fluido frio no elemento diferencial é pequena, conclui-se que a razão das capacitâncias térmicas para o trocador de calor diferencial é dada pela expressão,

$$
d C^{*}=\frac{d C_{f}}{C_{q}} \rightarrow 0
$$

Esta é a razão das capacitâncias térmicas diferencial, a qual tende a zero devido ao valor da vazão mássica do fluido frio também tender a zero. Fisicamente esse resultado é equivalente a considerar o trocador de calor diferencial como um condensador, já que a temperatura do fluido quente permanece essencialmente constante, como mostrado na Figura 3. Dessa forma a efetividade térmica local do trocador diferencial, $\Gamma$, pode ser determinada da Equação 3.16 que assume a seguinte expressão quando a razão das capacitâncias térmicas tende a zero (efetividade de um trocador com mudança de fase),

$$
\Gamma=\frac{\Delta T_{f}}{T_{q}-T_{f, s a i}}=1-\exp \left(-\frac{U d A}{d C_{f}}\right)
$$


Assumindo que a área frontal pelo lado do fluido frio, $A_{f r}$, e a área da superfície de transferência de calor, $A$ são uniformes em toda a largura do trocador de calor, podem ser escritas as seguintes expressões,

$$
\begin{gathered}
\frac{d C_{f}}{d A_{f r}}=\frac{C_{f}}{A_{f r}}=\text { constante } \\
\frac{d C_{f}}{d A}=\frac{C_{f}}{A}=\text { constante }
\end{gathered}
$$

Assim, introduzindo a Equação 3.23 na 3.21 , a seguinte expressão para a efetividade térmica local resulta, sendo válida em toda a largura $L$ do trocador de calor,

$$
\Gamma=1-\exp \left(-\frac{U A}{C_{f}}\right)=\text { constante }
$$

A combinação das Equações 3.19 e 3.21 em conjunto com a Equação 3.22, a seguinte equação geral é encontrada,

$$
\frac{d T_{q}}{T_{q}-T_{f, s a i}}=-\Gamma d C^{*}=-\Gamma\left(\frac{C_{f}}{C_{q}}\right)\left(\frac{d A_{f r}}{A_{f r}}\right)
$$

Note que os valores dos parâmetros físicos $C_{f}, C_{q}$ e $A_{f r}$ são características físicas e geométricas do trocador de calor e como tal são consideradas constantes. Integrando ambos os lados da Equação 3.25 a expressão é obtida,

$$
\frac{T_{q, \text { sai }}-T_{f, \text { ent }}}{T_{q, \text { ent }}-T_{f, \text { ent }}}=\exp \left(-\frac{\Gamma C_{f}}{C_{q}}\right)
$$

Somando e subtraindo $T_{q, \text { ent }}$ no numerador do lado esquerdo da equação anterior e introduzindo ainda a equação da definição da efetividade, Equação 3.1 , para $C_{\min }=C_{f}$, resulta em,

$$
1-\varepsilon C^{*}=\exp \left\{-C^{*}[1-\exp (-N U T)]\right\}
$$

Rearranjando a expressão acima, obtém-se,

$$
\varepsilon=\frac{1}{C^{*}}\left\{1-\exp \left\{-C^{*}[1-\exp (-N U T)]\right\}\right\}
$$

A Equação 3.28 é a expressão da efetividade de um trocador de fluxo cruzado misturado - não misturado de um passe para $C_{\min }=C_{f}\left(C_{f}\right.$ é o fluido não misturado neste caso). Quando o fluido misturado é o que possui o menor valor de capacitância térmica, considera-se $C_{\min }=C_{q}$ ) se obtém de forma similar a relação, 


$$
\varepsilon=1-\exp \left\{-\frac{\left[1-\exp \left(-\frac{N U T}{C^{*}}\right)\right]}{C^{*}}\right\}
$$

Trocadores de calor de fluxo cruzado para aplicações de engenharia são comumente caracterizados por arranjos de escoamentos mais complexos com vários circuitos, fileiras e linhas de tubos. Para muitos desses arranjos o conjunto de equações prévio (Equações 3.19 3.25 não possui uma solução analítica já que as condições sob as quais a Equação 3.25 tem sido obtida não são mais válidas devido à: (i) aplicação das Equações $3.23 \mathrm{e}$ 3.24 é questionável nesses casos; e (ii) a temperatura de entrada do fluido frio em cada fileira de tubos não é uniforme como mostrado na Figura 3. Uma solução adequada e exata para trocadores de calor com configurações complexas pode ser obtida através de um procedimento de cálculo numérico como o código HETE ou através do procedimento desenvolvido por Pignotti e Cordero (1983a) e detalhado por Magazoni e Cabezas-Gómez (2016). Este procedimento se baseia no conjunto de equações algébricas, que podem ser resolvidas numericamente, cujo desenvolvimento e análise são apresentados no Capítulo 4. Por outro lado muitas configurações complexas também tem sido modeladas através dos diversos métodos resumidos por Sekulic, Shah e Pignotti (1999).

As relações da efetividade até aqui obtidas e as apresentadas em todo o presente trabalho foram obtidas levando em conta as considerações básicas, comumente empregadas na literatura, Kays e London (1998), Shah e Sekulic (2003), Cabezas-Gómez, Navarro e SaizJabardo (2015): (i) o trocador de calor opera em regime permanente; (ii) as transferências de calor com o meio externo são desprezadas, ou seja, o trocador de calor é modelado como adiabático em relação ao meio externo; (iii) não há fontes ou sumidouros de energia térmica nas paredes do trocador de calor e/ou nos fluidos; (iv) o fluido que escoa por dentro dos tubos está perfeitamente misturado em toda a sua seção transversal, acontecendo uma variação linear de sua temperatura ao longo do eixo axial dos tubos; (v) os coeficientes de transferência de calor e as propriedades de transporte dos fluidos e das paredes do trocador de calor são uniformes e constantes; (vi) os efeitos da transferência de calor axial nas paredes sólidas e nos fluidos são desprezíveis; e (vii) não há mudança de fase em ambas as correntes ou fluidos.

As hipóteses (i)-(v) são necessárias para realizar análises teóricas em trocadores de calor em regime permanente. Segundo Shah e Pignotti (1993), a hipótese (vii) restringe a análise para escoamentos de uma fase em ambos os fluidos quente e frio. Para escoamentos bifásicos nos dois fluidos, muitas das hipóteses citadas anteriormente não são válidas uma vez que a transferência de massa com a mudança de fase resulta em propriedades variáveis dos fluidos e o coeficiente global de transferência de calor podem também significativamente.

Na Tabela 1 se apresenta um resumo das correlações para trocadores de calor de 
fluxo cruzado para configurações de um passe de ambos os fluidos e uma ou várias fileiras de tubos. As relações foram tomadas de Kays e London (1998), ESDU (1991), Stevens, Fernandez e Woolf (1957), Baclic e Heggs (1985). Os detalhes da derivação destas relações podem ser consultados nesses trabalhos. No Capítulo 4 se apresenta o procedimento de Pignotti e Cordero (1983a) que permite a derivação de algumas dessas relações. As relações para a configuração com ambos os fluidos não misturados merecem alguns comentários. A Equação 3.38 (Tabela 1), proposta por Mason (1955), válida para um número infinito de fileiras de tubos (i.e., circuitos de fluido), foi empregada como referência por Navarro e Cabezas-Gómez (2005) para comparação dos resultados numéricos obtidos com o código HETE. Em adição, esta relação é uma das sugeridas por Baclic e Heggs (1985) para calcular a efetividade deste tipo de arranjo de escoamento. A Equação 3.39, também válida para um número infinito de fileiras de tubos, foi obtida através de um ajuste de curva de dados da efetividade. Segundo DiGiovanni e Webb (1989) sua origem é incerta, embora aparece em uma nota de rodapé do livro de Eckert (1959, pag. 483). Navarro e Cabezas-Gómez (2005) afirmaram que a aplicação desta correlação pode resultar em erros relativos da ordem de $4 \%$ para certos valores de $N U T$ e $C^{*}$ quando comparados com resultados mais exatos tais como os obtidos com o código HETE e a Equação 3.38 , Shah e Sekulic (2003) sugerem o uso da Equação 3.40 para a mesma configuração. Essa relação foi obtida por $\operatorname{Li}(1987)$.

Tabela 1 - Relações $\varepsilon$-NUT para configurações de fluxo cruzado com um passe dos fluidos e uma a várias fileiras de tubos (STEVENS; FERNANDEZ; WOOLF, 1957; BACLIC; HEGGS, 1985; LI, 1987; ESDU, 1991; KAYS; LONDON, 1998)

\begin{tabular}{|c|c|c|c|}
\hline$N_{r}$ & $C_{\min }$ & Relações teóricas & Equação \\
\hline \multirow{2}{*}{1} & A & $\varepsilon_{A}=1-e^{-\left(1-e^{-N U T_{A} C_{A}^{*}}\right) / C_{A}^{*}}$ & $(3.30)$ \\
\hline & B & $\varepsilon_{B}=\frac{1}{C_{B}^{*}}\left[1-e^{-C_{B}^{*}\left(1-e^{-N U T_{B}}\right)}\right]$ & $(3.31)$ \\
\hline \multirow{2}{*}{2} & A & $\varepsilon_{A}=1-e^{-2 K / C_{A}^{*}}\left(1+\frac{K^{2}}{C_{A}^{*}}\right), K=1-e^{-N U T_{A} C_{A}^{*} / 2}$ & $(3.32)$ \\
\hline & B & $\varepsilon_{B}=\frac{1}{C_{B}^{*}}\left[1-e^{-2 K C_{B}^{*}}\left(1+K^{2} C_{B}^{*}\right)\right], K=1-e^{-N U T_{B} / 2}$ & $(3.33)$ \\
\hline \multirow{2}{*}{3} & A & $\begin{array}{l}\varepsilon_{A}=1-e^{-3 K / C_{A}^{*}}\left[1+\frac{K^{2}(3-K)}{C_{A}^{*}}+\frac{3 K^{4}}{2\left(C_{A}^{*}\right)^{2}}\right] \\
K=1-e^{-N U T_{A} C_{A}^{*} / 3}\end{array}$ & $(3.34)$ \\
\hline & B & $\varepsilon_{B}=\frac{1}{C_{B}^{*}}\left\{1-e^{-3 K C_{B}^{*}}\left[1+K^{2}(3-K) C_{B}^{*}+\frac{2 K^{4}\left(C_{B}^{*}\right)^{2}}{2}\right]\right\}$ & $(3.35)$ \\
\hline & & Continuação & na página \\
\hline
\end{tabular}


Tabela 1 - continuação da página anterior

\begin{tabular}{|c|c|c|c|}
\hline$N_{r}$ & $C_{\min }$ & $\begin{array}{l}\text { Relações teóxicass } \\
K=1-e_{B} / 3\end{array}$ & Equação \\
\hline \multirow{2}{*}{4} & A & 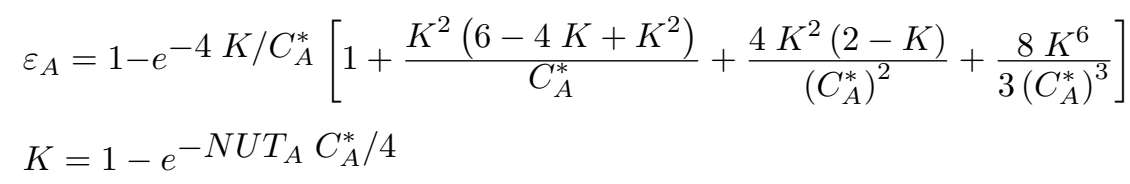 & $(3.36)$ \\
\hline & B & 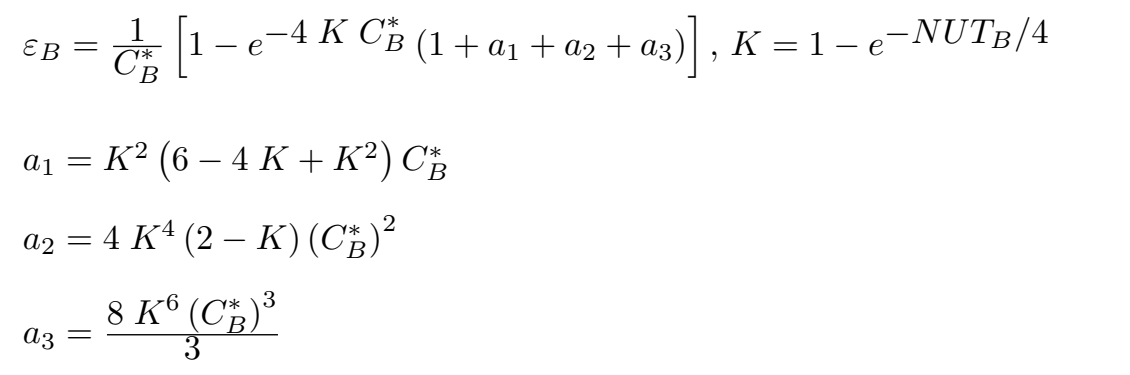 & (3.37) \\
\hline$\infty$ & $\begin{array}{l}\text { ambos } \\
\text { não mistu- } \\
\text { rados }\end{array}$ & $\begin{array}{l}\varepsilon=\frac{1}{C^{*} N U T} \sum_{n=0}^{\infty}\left(a_{1} a_{2}\right) \\
a_{1}=\left(1-e^{-N U T} \sum_{m=0}^{n} \frac{N U T^{m}}{m !}\right) \\
a_{2}=\left[1-e^{-C^{*} N U T} \sum_{m=0}^{n} \frac{\left(C^{*} N U T\right)^{m}}{m !}\right]\end{array}$ & $(3.38)$ \\
\hline$\infty$ & $\begin{array}{l}\text { ambos } \\
\text { não mistu- } \\
\text { rados }\end{array}$ & $\varepsilon=1-e^{\left[N U T^{0,22}\left(e^{-C^{*} N U T^{0,78}-1}\right) / C^{*}\right]}$ & (3.39) \\
\hline$\infty$ & $\begin{array}{l}\text { ambos } \\
\text { não mistu- } \\
\text { rados }\end{array}$ & $\begin{array}{l}\varepsilon=1-e^{-N U T}-e^{-\left(1+C^{*}\right) N U T} \sum_{n=1}^{\infty}\left(C^{*}\right)^{n} P_{n}(N U T), P_{n}(y)= \\
\frac{1}{(n+1) !} \sum_{j=1}^{n} \frac{(n+1-j)}{j !} y^{n+j}\end{array}$ & $(3.40)$ \\
\hline
\end{tabular}

Nas Tabelas 2 e 3 são apresentadas relações para diferentes arranjos considerando configurações amplamente empregadas de múltiplos passes, paralelo-cruzado e contracorrente-cruzado (TABOREK, 1983 , ESDU, 1991; CABEZAS-GÓMEZ; NAVARRO; SAIZ-JABARDO, 2006). No Capítulo 4 se apresenta o procedimento de Pignotti e Cordero (1983a) que permite a derivação de todas essas relações. As relações apresentadas posteriormente nas Tabelas 29-34 foram obtidas na plataforma Maple 18 com os códigos desenvolvidos no presente trabalho.

A relação funcional, Equação 3.5, é aplicada para cálculos de desempenho de um trocador de calor determinando a efetividade térmica para uma dada configuração. No projeto, as relações $\varepsilon-N U T$ são empregadas no dimensionamento de um trocador de calor 
Tabela 2 - Relações $\varepsilon$-NUT para configuração paralelo-cruzado com vários passes do fluido interno e um circuito (ESDU, 1991)

\begin{tabular}{|c|c|c|c|}
\hline$N_{r}$ & $C_{\min }$ & Relações teóricas & Equação \\
\hline \multirow{2}{*}{2} & A & $\varepsilon_{A}=\left(1-\frac{K}{2}\right)\left(1-e^{-2 K / C_{A}^{*}}\right), K=1-e^{-N U T_{A} C_{A}^{*} / 2}$ & $(3.41)$ \\
\hline & B & $\varepsilon_{B}=\frac{1}{C_{B}^{*}}\left(1-\frac{K}{2}\right)\left(1-e^{-2 K C_{B}^{*}}\right), K=1-e^{-N U T_{B} / 2}$ & $(3.42)$ \\
\hline \multirow{2}{*}{3} & A & $\begin{array}{l}\varepsilon_{A}=1-\left(1-\frac{K}{2}\right)^{2} e^{-3 K / C_{A}^{*}}-K\left[1-\frac{K}{4}+\frac{K}{C_{A}^{*}}\left(1-\frac{K}{2}\right)\right] e^{-K / C_{A}^{*}}, K= \\
1-e^{-N U T_{A} C_{A}^{*} / 3}\end{array}$ & $(3.43)$ \\
\hline & B & 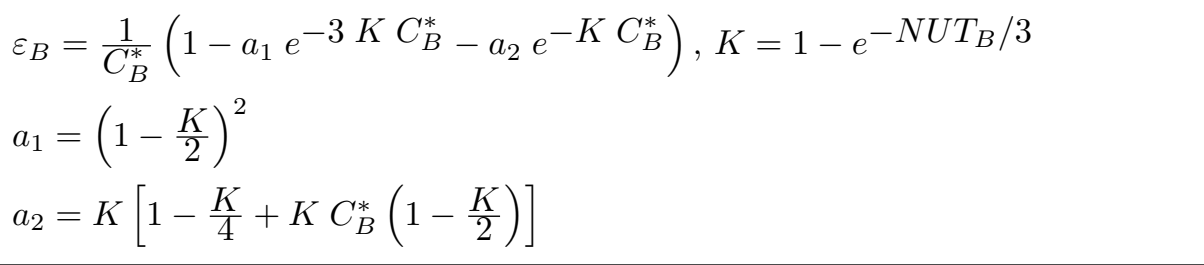 & $(3.44)$ \\
\hline \multirow{2}{*}{4} & A & $\begin{array}{l}\varepsilon_{A}=1-\frac{K}{2}\left(1-\frac{K}{2}+\frac{K^{2}}{4}\right)-K\left(1-\frac{K}{2}\right)\left[1+\frac{2 K}{C_{A}^{*}}\left(1-\frac{K}{2}\right)\right] e^{-2 K / C_{A}^{*}}- \\
\left(1-\frac{K}{2}\right)^{3}, K=1-e^{-N U T_{A} C_{A}^{*} / 4}\end{array}$ & $(3.45)$ \\
\hline & B & $\begin{array}{l}\varepsilon_{B}=1-\frac{K}{2}\left(1-\frac{K}{2}+\frac{K^{2}}{4}\right)-K\left(1-\frac{K}{2}\right)\left[1+2 K C_{B}^{*}\left(1-\frac{K}{2}\right)\right] e^{-2 K C_{B}^{*}} \\
\left(1-\frac{K}{2}\right)^{3}, K=1-e^{-N U T_{B} / 4}\end{array}$ & $(3.46)$ \\
\hline
\end{tabular}

conhecendo as temperaturas de entrada e saída das correntes de fluido. Nesse caso relações explícitas de $N U T$ são necessárias em termos de $\varepsilon$ e $C^{*}$ para uma determinada configuração. Entretanto, o número de $N U T$ pode ser calculado através de relações analíticas diretas para poucos arranjos. Estas relações são apresentadas na Tabela 4, mostrando a relação para o trocador de calor de casco e tubo com um passe no caso e dois nos tubos. O número de unidades de transferência $N U T$ é uma função implícita de $\varepsilon$ e $C^{*}$ para o restante das configurações existentes, e pode ser calculado iterativamente ou resolvendo a equação $f(N U T)=0$.

\subsection{Fundamentos do Método P-NUT}

Historicamente o método $P$-NUT tem sido usado para o projeto de trocadores de calor de casco e tubos, mesmo antes do método $\varepsilon$-NUT na década de 1940. O método se baseia no conceito da efetividade da temperatura, $P$, para cada fluido, quente ou frio, definida por,

$$
\dot{Q}=P_{1} C_{1} \Delta T_{\max }=P_{2} C_{2} \Delta T_{\max }
$$

onde $\Delta T_{\max }=T_{q, e n t}-T_{f, \text { ent }}$ é a diferença de temperaturas máxima no trocador de calor. 
Tabela 3 - Relações $\varepsilon$-NUT para configuração contracorrente-cruzado com vários passes do fluido interno e um circuito (TABOREK, 1983, ESDU, 1991)

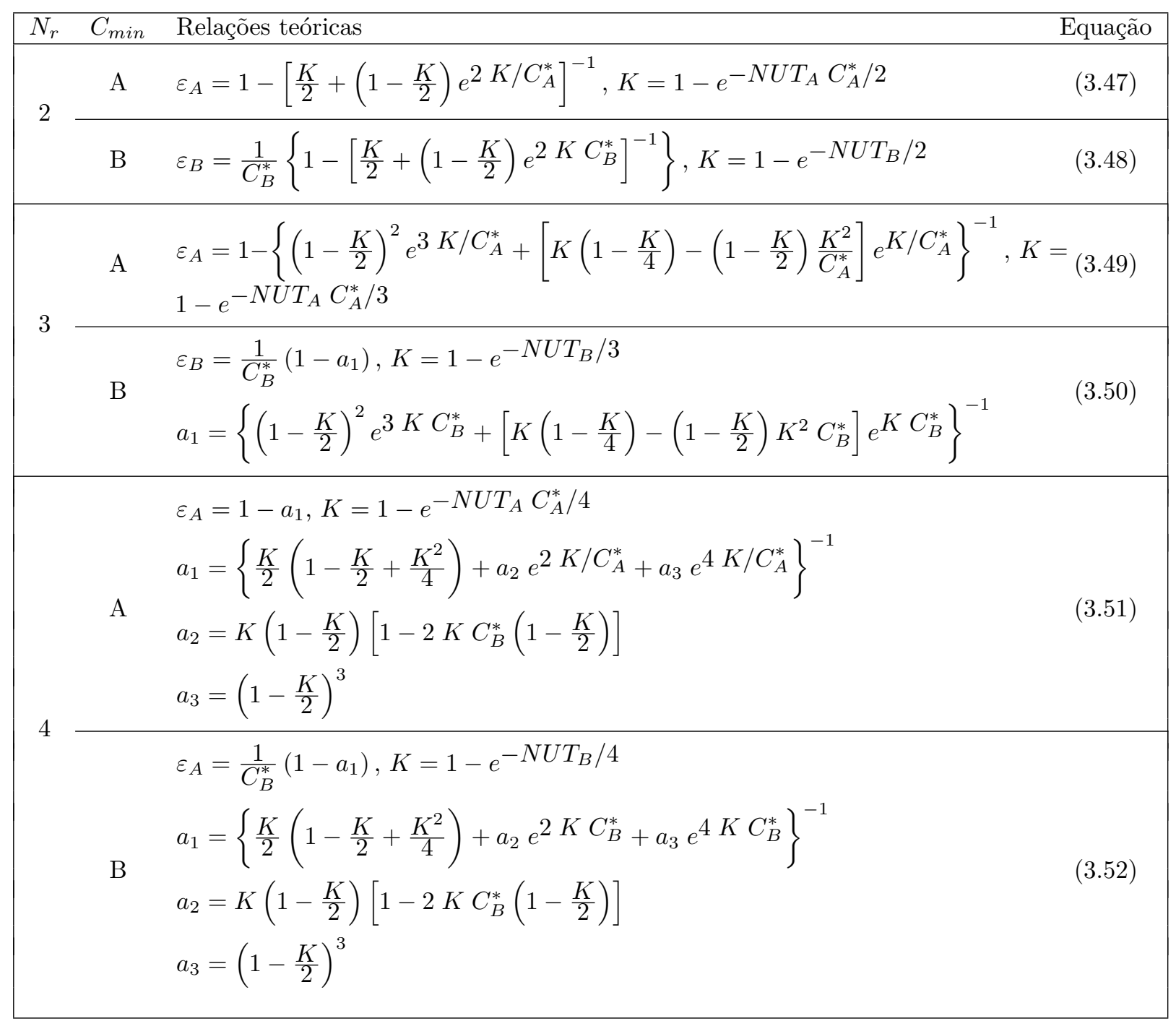

Tabela 4 - Relações analíticas diretas para cálculo do número de unidades de transferência, NUT (SHAH; SEKULIC, 2003)

\begin{tabular}{|ccc|}
\hline Arranjo & Relações teóricas & Equação \\
\hline Contracorrente & $N U T=\left(\frac{1}{1-C^{*}}\right) \ln \left(\frac{1-C^{*} \varepsilon}{1-\varepsilon}\right),\left(C^{*}<1\right)$ & $(3.53)$ \\
& $N U T=\left(\frac{\varepsilon}{1-\varepsilon}\right),\left(C^{*}=1\right)$ & $(3.54)$ \\
\hline Paralelo & $N U T=-\frac{\ln \left[1-\varepsilon\left(1+C^{*}\right)\right]}{1+C^{*}}$ & $(3.55)$ \\
\hline$C_{\text {max }}$ (misturado), $C_{\text {min }}$ (não misturado) & $N U T=-\ln \left[1+\frac{1}{C^{*}} \ln \left(1-C^{*} \varepsilon\right)\right]$ \\
$C_{\text {min }}$ (misturado), $C_{\text {max }}$ (não misturado) & $N U T=-\frac{1}{C^{*}} \ln \left[1+C^{*} \ln (1-\varepsilon)\right]$ & $(3.56)$ \\
\hline Todos os trocadores com $C^{*}=0$ & $N U T=-\ln (1-\varepsilon)$ & $(3.58)$ \\
\hline
\end{tabular}


A efetividade da temperatura, $P$, de forma similar à efetividade $\varepsilon$, é adimensional e também depende de três parâmetros: número de unidades de transferência, $N U T$, razão de temperatura ou capacitância, $R$, e arranjo de escoamento. Essa dependência se expressa pelas seguintes relações funcionais,

$$
\begin{aligned}
& P_{1}=\Phi_{1}\left(N U T_{1}, R_{1}, \text { arranjo }\right) \\
& P_{2}=\Phi_{2}\left(N U T_{2}, R_{2}, \text { arranjo }\right)
\end{aligned}
$$

Comumente na literatura (SHAH; SEKULIC, 2003), o fluido 1 designa o fluido que escoa pelo lado do casco em trocadores de calor de casco e tubos, independente do mesmo ser quente ou frio. Em outros tipos de trocadores de calor um dos fluidos se define como o fluido 1 para poder aplicar corretamente as relações expressadas pela Equações 3.60 e 3.61. No caso do uso do método P-NUT, uma vez escolhido o fluido para o qual se calcula a efetividade $P, R$ varia de zero até o infinito $(0 \leq R \leq \infty)$, não sendo necessário o uso de duas relações para calcular $P$, como se faz necessário no método $\varepsilon-N U T$ para trocadores de calor assimétricos, por exemplo, um trocador de fluxo cruzado misturado não misturado com apenas um passe dos fluidos.

Assim, nas Equações 3.59, 3.60 e 3.61, $P$ representa a efetividade de temperatura para o fluido 1 ou 2, dependendo do subscrito. O mesmo se aplica para a capacitância $C$ e para o número de unidades de transferência NUT. Os fluidos individuais 1 e 2 podem ser quente ou frio, ou os fluidos com $C_{\min }$ ou $C_{\max }$, respectivamente. Dessa forma a efetividade da temperatura $P$ é definida como a razão entre a variação da temperatura do fluido 1 ou 2 (quente ou frio) no trocador de calor e a diferença entre as temperaturas de entrada de ambos os fluidos, ou seja, o $\Delta T_{\max }$,

$$
\begin{gathered}
P_{1}=\frac{T_{1, \text { sai }}-T_{1, \text { ent }}}{T_{2, \text { ent }}-T_{1, \text { ent }}} \\
P_{2}=\frac{T_{2, \text { ent }}-T_{2, \text { sai }}}{T_{2, \text { ent }}-T_{1, \text { ent }}}
\end{gathered}
$$

Empregando a Equação 3.59 mostra-se que,

$$
\begin{aligned}
& P_{1}=P_{2} R_{2} \\
& P_{2}=P_{1} R_{1}
\end{aligned}
$$

Sendo $R_{1}$ e $R_{2}$ definidas como a razão entre as capacitâncias de cada fluido, 


$$
\begin{aligned}
& R_{1}=\frac{C_{1}}{C_{2}}=\frac{T_{2, e n t}-T_{2, s a i}}{T_{1, s a i}-T_{1, \text { ent }}} \\
& R_{2}=\frac{C_{2}}{C_{1}}=\frac{T_{1, s a i}-T_{1, \text { ent }}}{T_{2, \text { ent }}-T_{2, \text { sai }}}
\end{aligned}
$$

E, portanto,

$$
R_{1}=\frac{1}{R_{2}}
$$

Comparando a Equação 3.1 com a Equação 3.62 se verifica que a relação entre a efetividade de temperatura $P_{1}$ e a efetividade $\varepsilon$ é expressa como,

$$
P_{1}=\varepsilon\left(\frac{C_{\min }}{C_{1}}\right)= \begin{cases}\varepsilon, & C_{1}=C_{\text {min }} \\ \varepsilon C^{*}, & C_{1}=C_{\max }\end{cases}
$$

De forma similar,

$$
P_{2}=\varepsilon\left(\frac{C_{\min }}{C_{2}}\right)= \begin{cases}\varepsilon, & C_{2}=C_{\min } \\ \varepsilon C^{*}, & C_{2}=C_{\max }\end{cases}
$$

Assim, os valores de $P_{1}$ e de $P_{2}$ sempre são menores ou iguais à $\varepsilon$. Da mesma forma comparando a Equações 3.69 e 3.70 com a Equação 3.7 resulta,

$$
\begin{aligned}
& R_{1}=\left(\frac{C_{1}}{C_{2}}\right)= \begin{cases}C^{*}, & C_{1}=C_{\min } \\
\frac{1}{C^{*}}, & C_{1}=C_{\max }\end{cases} \\
& R_{2}=\left(\frac{C_{2}}{C_{1}}\right)= \begin{cases}C^{*}, & C_{2}=C_{\min } \\
\frac{1}{C^{*}}, & C_{2}=C_{\max }\end{cases}
\end{aligned}
$$

Assim, os valores de $R_{1}$ e de $R_{2}$ sempre são maiores ou iguais a $C^{*}$. Individualmente os valores de $R_{1}$ e $R_{2}$ assumem valores de 0 até $\infty$, zero indicando condensação de um vapor puro, e infinito indicando vaporização de um líquido puro (SHAH; SEKULIC, 2003).

De forma semelhante os números de unidade de transferência $N U T_{1}$ e $N U T_{2}$ são definidos definidos como, 


$$
\begin{aligned}
& N U T_{1}=\frac{U A}{C_{1}} \\
& N U T_{2}=\frac{U A}{C_{2}}
\end{aligned}
$$

Resultando,

$$
\begin{aligned}
& N U T_{1}=N U T_{2} R_{2} \\
& N U T_{2}=N U T_{1} R_{1}
\end{aligned}
$$

Os número de unidades de transferência, NUT definidos pelas Equações 3.73 e 3.74, se relacionam com o $N U T$ definido pela Equação 3.6 com base em $C_{\min }$ por,

$$
\begin{aligned}
& N U T_{1}=\operatorname{NUT}\left(\frac{C_{\text {min }}}{C_{1}}\right)= \begin{cases}N U T, & C_{1}=C_{\text {min }} \\
N U T C^{*}, & C_{1}=C_{\max }\end{cases} \\
& N T_{2}=\operatorname{NUT}\left(\frac{C_{\text {min }}}{C_{2}}\right)= \begin{cases}N U T, & C_{2}=C_{\min } \\
N U T C^{*}, & C_{2}=C_{\max }\end{cases}
\end{aligned}
$$

Assim, $N U T_{1}$ e $N U T_{2}$ sempre são menores ou iguais à $N U T$.

Diversas relações analíticas para o cálculo da efetividade da temperatura $P$ são apresentadas em Shah e Sekulic (2003). As Equações 3.69, 3.71 e 3.77 podem ser empregadas para obter relações analíticas para $P$ através daquelas mostradas nas Tabelas 1 , 2 e 3 para a efetividade $\varepsilon$. No Seção 4.1 são mostradas diversas relações analíticas para cálculo da efetividade de temperatura $P$ obtidas pelo procedimento de Pignotti e Cordero (1983a) através dos códigos computacionais desenvolvidos neste presente trabalho. No mesmo capítulo se mostra a obtenção da expressão para o cálculo de $P$ para um arranjo de fluxo cruzado de um passe misturado - não misturado.

\subsection{Fundamentos do Método de LMTD}

Uma expressão para a diferença média logarítmica de temperaturas LMTD foi empregada na Seção 3.1. O método LMTD se define genericamente por, 


$$
\Delta T_{L M T D}=\frac{\Delta T_{I}-\Delta T_{I I}}{\ln \left(\frac{\Delta T_{I}}{\Delta T_{I I}}\right)}
$$

Na Equação 3.79, $\Delta T_{I}$ e $\Delta T_{I I}$ representam as diferenças de temperaturas entre os dois fluidos em cada extremo do trocador de calor. Para um trocador de calor em contracorrente,

$$
\begin{gathered}
\Delta T_{I}=\left(T_{q, \text { ent }}-T_{f, s a i}\right) \\
\Delta T_{I I}=\left(T_{q, s a i}-T_{f, e n t}\right)
\end{gathered}
$$

E para um trocador de calor em paralelo,

$$
\begin{gathered}
\Delta T_{I}=\left(T_{q, e n t}-T_{f, e n t}\right) \\
\Delta T_{I I}=\left(T_{q, s a i}-T_{f, s a i}\right)
\end{gathered}
$$

Para todos os outros arranjos de escoamento se assume hipoteticamente que o trocador de calor é uma unidade em contracorrente operando com os mesmos valores de $R$ (ou $C^{*}$ ) e as mesmas temperaturas nos terminais (ou a mesma efetividade). Dessa forma a LMTD para todas as outras configurações se determina da Equação 3.79 usando as diferenças de temperatura $\Delta T_{I}$ e $\Delta T_{I I}$ das Equações 3.80 e 3.81. Dessa forma a LMTD representa o potencial máximo de temperatura para a transferência de calor que pode ser obtido apenas numa configuração em contracorrente.

O método LMTD normalizado em relação à diferença de temperatura de entrada, $\Delta T_{\text {max }}$, pode ser escrito em termos das efetividades $P$ e $\varepsilon$, considerando as suas definições de $C^{*}$,

$$
\frac{\Delta T_{\text {LMTD }}}{\Delta T_{\text {max }}=T_{q, \text { ent }}-T_{f, \text { ent }}}=\frac{P_{1}-P_{2}}{\ln \left(\frac{1-P_{2}}{1-P_{1}}\right)}=\frac{\left(1-C^{*}\right) \varepsilon}{\ln \left(\frac{1-C^{*} \varepsilon}{1-\varepsilon}\right)}
$$

As relações apresentadas na Equação 3.84 são válidas para todos os arranjos de escoamento. Duas formas limite das expressões acima são apresentadas,

$$
\frac{\Delta T_{L M T D}}{T_{q, \text { ent }}-T_{f, \text { ent }}}= \begin{cases}\frac{\Delta T_{L M T D}}{\Delta T_{\max }}=1-\varepsilon, & C^{*} \rightarrow 1 \\ \frac{\Delta T_{L M T D}}{\Delta T_{\max }} \rightarrow 1, & \varepsilon \rightarrow 1\end{cases}
$$


As relações apresentadas na Equação 3.85 mostram que $\Delta T_{\max } \rightarrow 0$, quando $\varepsilon \rightarrow 1$. Assim um decréscimo da $\Delta T_{L M T D}$ significa um aumento da efetividade do trocador de calor para uma unidade dada. Uma forma alternativa de interpretar é que o parâmetro $\Delta T_{L M T D}$ decresce com o aumento de NUT e por tanto da área de transferência de calor, A.

O método LMTD se baseia no uso de fator de correção da LMTD, denotado por $F$. A razão principal para o uso desse fator se baseia no fato de que a $\Delta T_{L M T D}$ não varia em função da configuração, sendo sempre calculada pela Equação 3.79. Já a diferença média de temperaturas, $\Delta T_{m}$, assume valores diferentes para as várias configurações possíveis. Como a taxa de transferência de calor depende da diferença média de temperaturas, $\Delta T_{m}$, ver Equação 3.8, e a mesma varia em função da configuração modelada, então é necessário introduzir o fator $F$ para empregar o método LMTD no projeto das diversas configurações de trocadores de calor utilizados nas inúmeras aplicações industriais, comerciais e de pesquisa.

O fator de correção $F$ se define costumeiramente como a razão entre a diferença de temperatura real e a diferença média logarítmica, sendo adimensional,

$$
F=\frac{\Delta T_{m}}{\Delta T_{L M T D}}=\frac{\dot{Q}}{U A \Delta T_{L M T D}}
$$

Na obtenção da relação da Equação 3.86 se emprega a Equação 3.8. De forma geral, $F$ se denomina como fator de correção da diferença média logarítmica de temperaturas, ou fator de correção da diferença de temperaturas média, ou ainda como fator de correção da configuração do trocador de calor.

$$
F=\Phi_{1}\left(P_{1}, R_{1}, \text { arranjo }\right)=\Phi_{2}\left(P_{2}, R_{2}, \text { arranjo }\right)
$$

As relações expressas pela Equação 3.87 se aplicam tanto para trocadores de calor simétricos, quanto para os assimétricos.

Empregando as equações de balanço de energia num volume de controle elementar e a Equação 3.8 se obtém as relações funcionais de $F$ para diversas configurações de trocadores de calor. Para os casos das configurações em contracorrente e paralelo, o fator de correção $F$ assume um valor unitário, $F=1$. A derivação desse resultado é bem conhecida na literatura, ver Shah e Sekulic (2003), Nellis e Klein (2009).

A relação funcional geral expressa pela Equação 3.87 (lado direito) pode ser derivada de forma explícita em função de $N U T_{1}$ como grupo adimensional adicional. Para tanto se emprega a Equação 3.86 e as Equações 3.9 e 3.11 para $\Delta T_{m}$ com algumas considerações. Considerando essas duas equações e a definição de $P_{1}$ pelas Equações 3.62 e 3.69 resulta, 


$$
\Delta T_{m}=\frac{\Delta T_{\max } \varepsilon}{N U T}=\frac{\Delta T_{\max } P_{1}}{N U T_{1}}
$$

Utilizando a relação anterior (Equação 3.88 ) e a definição do fator $F$ pela Equação 3.86 se obtém,

$$
F=\frac{\Delta T_{m}}{\Delta T_{L M T D}}=\frac{\Delta T_{m}}{\left(\Delta T_{m}\right)_{c c}}=\left(\frac{\Delta T_{\max } P_{1}}{N U T_{1}}\right)\left(\frac{N U T_{1}}{\Delta T_{\max } P_{1}}\right)_{c c}
$$

onde o subscrito $c c$ representa o arranjo contracorrente.

Para avaliar $F$, compara-se o trocador de calor real com qualquer configuração de interesse com um trocador de calor contracorrente de referência que possui as mesmas capacitâncias e temperaturas nos seus terminais, e, portanto, os mesmos valores de $P_{1}$, $\Delta T_{\max }$, e $R_{1}$. Consequentemente devido ao fato que $P_{1}=P_{1, c c}$ e $\Delta T_{\max }=\Delta T_{\max , c c}$, a Equação 3.89 se reduz à,

$$
F=\frac{N U T_{1, c c}}{N U T_{1}}
$$

sendo $N U T_{1}$ o número de unidades de transferência real para o trocador de calor e $N U T_{1, c c}$ o número de unidades de transferência para o mesmo trocador de calor operando em contracorrente. $N U T_{1, c c}$ é defino por (SHAH; SEKULIC, 2003) como,

$$
N U T_{1, c c}= \begin{cases}\frac{\ln \left(\frac{1-R_{1} P_{1}}{1-P_{1}}\right)}{1-R_{1}}, & R_{1} \neq 1 \\ \frac{P_{1}}{1-P_{1}}, & R_{1}=1\end{cases}
$$

Com ajuda da relação anterior, o fator de correção $F$ resulta em,

$$
F=\left\{\begin{array}{cc}
\frac{\ln \left(\frac{1-R_{1} P_{1}}{1-P_{1}}\right)}{N U T_{1}\left(1-R_{1}\right)}, & R_{1} \neq 1 \\
\frac{P_{1}}{N U T_{1}\left(1-P_{1}\right)}, & R_{1}=1
\end{array}\right.
$$

A Equação 3.92 é válida para todos os arranjos, com exceção do paralelo. Da Equação 3.88 também se pode obter uma relação geral do fator de correção $F$ e a efetividade

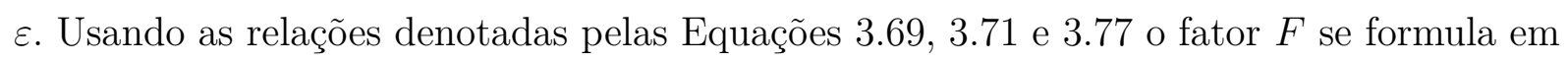
função de $N U T$, $\varepsilon$ e $C^{*}$ como segue, 


$$
F=\left\{\begin{array}{cc}
\frac{\ln \left(\frac{1-C^{*} \varepsilon}{1-\varepsilon}\right)}{N U T\left(1-C^{*}\right)}, & C^{*} \neq 1 \\
\frac{\varepsilon}{N U T(1-\varepsilon)}, & C^{*}=1
\end{array}\right.
$$

A Equação 3.90 significa fisicamente que para atingir a mesma efetividade de um trocador de calor em contracorrente o produto $F N U T_{1}$ deve ser igual a $N U T_{1, c c}$, assim pequenos valores do fator de correção $F$ implicam em valores maiores de $N U T_{1}$. Também observa-se que a diferença de temperatura $\Delta T_{L M T D}$ será maior que a $\Delta T_{L M T D}$ para um trocador de calor em contracorrente para os mesmos valores de $N U T_{1}$ e $R_{1}$. Quando o fator de correção $F$ para uma determinada configuração é menor que o de outra configuração, significa que a efetividade da temperatura $P_{1}$ também será menor, considerando que $N U T_{1}$, $R_{1}$ e $\Delta T_{\text {max }}$ assumem os mesmos valores. Isso significa que uma redução no valor de $F$ também implica em uma redução de $P_{1}$ ou $\varepsilon$, e vice-versa.

Embora $F$ seja uma função dos três grupos adimensionais $P_{1}, R_{1}$ e $N U T_{1}$, ver Equação 3.92 , sabe-se que $N U T_{1}$ também é função de $P_{1}$ e $R_{1}$. Assim o fator de correção $F$ pode ser expresso como uma relação de dois parâmetros adimensionais independentes ( $P_{1}$ e $\left.R_{1}\right)$ como sugerido na Equação 3.87, ou $P_{1}$ e $N U T_{1}$, ou $N U T_{1}$ e $R_{1}$, para uma dada configuração.

Relações analíticas explícitas do tipo $P_{1}\left(N U T_{1}, R_{1}\right)$ existem para muitas configurações, entretanto relações analíticas do tipo $N U T_{1}\left(P_{1}, R_{1}\right)$ estão disponíveis apenas para poucos arranjos, como se mostra na Tabela 3 para o método $\varepsilon-N U T$. Por essa razão existem relações analíticas explícitas para o fator de correção $F$ em função de $P_{1}$ e $R_{1}$, ou de $\varepsilon$ e $C^{*}$, apenas para poucas configurações. Para todas as outras configurações é necessário calcular $N U T_{1}$ e consequentemente o fator de correção $F$ de forma iterativa com os valores conhecidos de $P_{1}$ e $R_{1}$, ou de $\varepsilon$ e $C^{*}$, e com o uso das Equações 3.90 ou 3.92 .

A metodologia de cálculo do fator de correção $F$ baseada no procedimento mostrada em Pignotti e Cordero (1983a) e detalhada em Magazoni e Cabezas-Gómez (2016) é apresentada na Seção 4.1. A mesma pode ser utilizada para calcular $F$ iterativamente em função de $R$ e $P$, e também de forma direta em função de $R$ e NUT.

Na Tabela 5 se apresentam as relações analíticas explícitas disponíveis para o cálculo do fator de correção $F$, com exceção daquelas usadas para um trocador de calor casco e tubos com um passe no caso e dois nos tubos. 
Tabela 5 - Relações analíticas diretas para cálculo do fator de correção $F$, (SHAH; SEKULIC, 2003)

\begin{tabular}{|llc|}
\hline Arranjo & Relações teóricas & Equação \\
\hline Contracorrente & $F=1$ & $(3.94)$ \\
\hline Paralelo & $F=1$ & $(3.95)$ \\
\hline $\begin{array}{l}\text { Cruzado (com um passe) } \\
\begin{array}{l}\text { Fluido 1 (não mistu- } \\
\text { rado), Fluido 2 (mistu- } \\
\text { rado) }\end{array}\end{array}$ & $F=\frac{\ln \left(\frac{1-R_{1} P_{1}}{1-P_{1}}\right)}{\left(R_{1}-1\right) \ln \left[1-\left(\frac{1}{R_{1}}\right) \ln \left(1-R_{1} P_{1}\right)\right]}$ \\
$\begin{array}{l}\text { Fluido 1 (misturado), } \\
\text { Fluido 2 (não mistu- } \\
\text { rado) }\end{array}$ & $F=\frac{\ln \left(\frac{1-R_{1} P_{1}}{1-P_{1}}\right)}{\left(1-\frac{1}{R_{1}}\right) \ln \left[1+R_{1} \ln \left(1-P_{1}\right)\right]}$ \\
\hline $\begin{array}{l}\text { Todos os arranjos com } \\
R_{1}=0 \text { ou } \infty\end{array}$ & $F=1$ & $(3.97)$ \\
\hline
\end{tabular}

\subsection{Código HETE}

O procedimento computacional do código HETE é apresentado nesta seção para explicação de sua metodologia. Este procedimento já foi introduzido em diversos artigos, entre eles Navarro e Cabezas-Gómez (2005), Navarro e Cabezas-Gómez (2007), CabezasGómez, Navarro e Saiz-Jabardo (2007), Navarro et al. (2010) e Perussi (2010), e em maiores detalhes publicado no livro de Cabezas-Gómez, Navarro e Saiz-Jabardo (2015). O material apresentado nesta seção se baseia amplamente nesses trabalhos. O código HETE constitui uma metodologia numérica muito útil para o cálculo de parâmetros de desempenho térmico para trocadores de calor de fluxo cruzado com diversas configurações e recentemente para trocadores de calor de casco e tubos (GUIMARAES, 2015). A partir do código computacional HETE é possível calcular a efetividade, $\varepsilon$, e consequentemente a efetividade de temperatura, $P$, e o fator de correção, $F$, através das Equações 4.1 e 4.2 .

\subsubsection{Equações governantes discretas}

A metodologia numérica de solução do código HETE se baseia em um modelo matemático discreto cujas equações governantes serão apresentadas nesta seção. O modelo se baseia no procedimento apresentado por Kays e London (1998). As equações governantes consistem na equação de conservação de energia aplicada a um trocador de calor de fluxo cruzado com um tubo apenas, sendo o fluido do tubo misturado e o fluido externo não misturado. Estas equações na sua forma diferencial estão apresentadas na Seção 3.1. O procedimento aqui apresentado se baseia no trabalho de Cabezas-Gómez, Navarro e Saiz-Jabardo (2015) e também pode ser encontrado em publicações prévias dos autores (NAVARRO; CABEZAS-GÓMEZ, 2005; NAVARRO; CABEZAS-GÓMEZ, 2007). 
As equações governantes discretas resolvidas no código HETE foram obtidas levando em conta as mesmas considerações básicas, já apresentadas na Seção 3.1. Porém duas hipóteses são assumidas: (i) o fluido externo não é misturado, i.e. existem aletas no lado externo da superfície de troca de calor que evitam uma mistura das correntes do fluido externo; (ii) para propósito de análise, como na Seção 3.1. o fluido por dentro dos tubos é assumido como fluido quente, embora as equações governantes possam ser aplicadas no caso contrário, ou seja, quando o fluido por dentro dos tubos é o fluido frio. Nesse caso trocam-se os subscritos $f$ e $q$.

Na Seção 3.1 as relações do modelo diferencial foram integradas analiticamente e foi obtida a solução para um trocador de calor misturado - não misturado com apenas um circuito e um passe de ambos os fluidos. Embora soluções do conjunto de equações diferenciais possam ser obtidas para outros arranjos simples, arranjos ou configurações mais complexas não são amenas à soluções simples. Nestes casos, soluções numéricas do conjunto discretizado de equações pode ser a resposta. Este é o caso do código HETE, cujas equações governantes em elementos serão obtidas nesta seção.

O elemento no código HETE é um trocador de calor de volume finito envolvendo um comprimento finito do fluido interno com sua correspondente parte do fluido externo, como se ilustra na Figura 4. As equações governantes da Seção 3.1 se baseiam na consideração de que a vazão mássica do fluido frio é pequena em comparação com à do fluido quente, como sugerido pela Equação 3.20. Este não é o caso para o elemento da Figura 4 . Assim a variação da temperatura do fluido quente ao longo do elemento não pode ser desprezada. Em vez disso assume-se que a mesma varia linearmente de forma que o seu valor médio e pode ser calculada por,

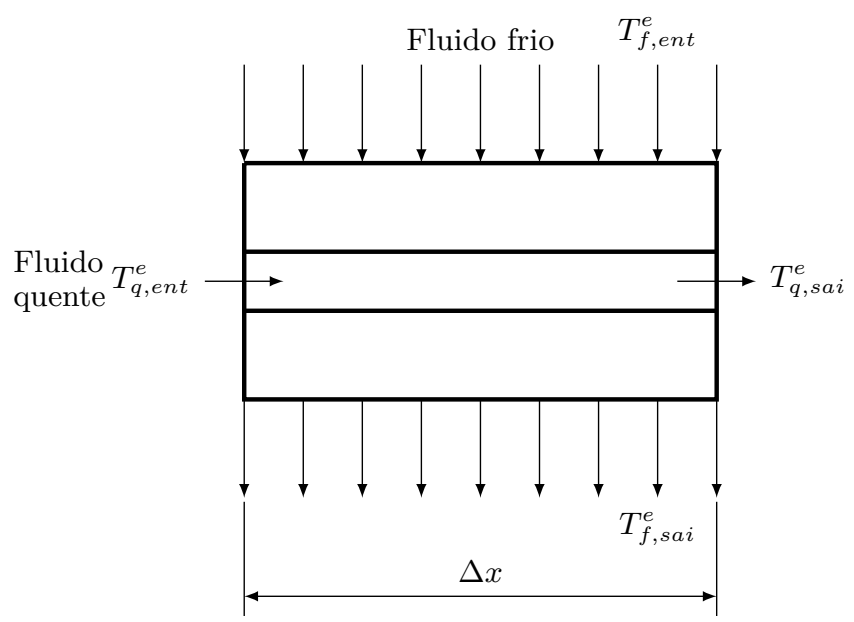

Figura 4 - Ilustração de um elemento com as temperaturas de entrada e saída (CABEZASGÓMEZ; NAVARRO; SAIZ-JABARDO, 2015)

$$
T_{h}^{e}=\frac{T_{q, e n t}^{e}+T_{q, s a i}^{e}}{2}
$$


onde o sobrescrito $e$ foi introduzido para designar um elemento cuja identificação, caracterizada pela sua localização espacial, se designa pelos subscritos $(i, j, k)$,

- $i$ : representa a posição do elemento em relação ao comprimento do tubo variando de 1 até $N_{e}$;

- $j$ : representa a altura do tubo em que se encontra o elemento em relação a uma dada fileira, variando de 1 até $N_{q}$;

- $k$ : representa a fileira de tubos em que o tubo que contém o elemento se encontra variando de 1 até $N_{r}$.

Deve-se notar que embora a temperatura do fluido quente varie linearmente pelo tamanho finito do elemento, ainda se está considerando que o mesmo deve ser pequeno em relação ao trocador de calor simulado. Isto porque o sistema de equações em cada elemento é obtido através da integração direta das equações válidas para um elemento diferencial expostas na Seção 3.1.

Integrando a equação de conservação de energia para os fluidos frio e quente ao longo do elemento finito, a expressão de cálculo da taxa de transferência de calor do elemento $\dot{Q}^{e}$ é encontrada.

$$
\dot{Q}^{e}=C_{f}^{e}\left(T_{f, s a i}^{e}-T_{f, \text { ent }}^{e}\right)=C_{q}^{e}\left(T_{q, \text { ent }}^{e}-T_{q, s a i}^{e}\right)
$$

A integração da equação de conservação de energia aplicada ao fluido frio, Equação 3.19, seguida pela introdução da Equação 3.22, resulta na seguinte expressão,

$$
\dot{Q}^{e}=\Delta T_{f}^{e} \int_{e} d C_{f}=\Delta T_{f}^{e} \int_{e} \frac{C_{f}}{A_{f r}}=\Delta T_{f}^{e} C_{f}^{e}
$$

Como observado previamente, $C_{f}$ e $A_{f r}$ são a capacitância térmica do fluido frio e a área frontal do trocador de calor. Neste ponto é importante salientar que já que as temperaturas de entrada e saída da corrente fria podem variar ao longo do elemento, a variação da temperatura do fluido frio ao longo do elemento, $\Delta T_{c}^{e}=T_{f, s a i}^{e}-T_{f, \text { ent }}^{e}$, se determina em termos das temperaturas médias de entrada e saída do fluido frio, ou seja, $T_{f, \text { ent }}^{e}$ e $T_{f, s a i}^{e}$.

O fechamento do conjunto de equações algébricas requer uma equação adicional que é aquela da efetividade térmica dada pela integração da Equação 3.21 sobre a área total do elemento. Para este propósito, a Equação 3.23 pode ser levada em conta de forma tal que introduzindo a relação $d A^{e} / d C_{f}^{e}=A^{e} / C_{f}^{e}$ nessa mesma equação se obtém o seguinte resultado, 


$$
\Gamma^{e}=\frac{\Delta T_{c}^{e}}{T_{h}^{e}-T_{f, s a i}^{e}}=1-\exp \left(-\frac{U A^{e}}{C_{f}^{e}}\right)
$$

Note que a temperatura do fluido quente é a média do elemento, em vez da temperatura de entrada. A equação acima é formalmente idêntica aquela da Equação 3.24 embora neste caso a área e a capacitância térmica se referem ao elemento. O resultado expresso pela Equação 3.102 é fisicamente equivalente a admitir que o tamanho do elemento seja pequeno. É importante notar, como acima explicado, que enquanto menor for o elemento, mais exata será a solução do conjunto de equações governantes do elemento.

O conjunto de equações governantes, acima descrito para cada elemento, é um sistema fechado com quatro equações, Equações 3.99 até 3.102 e quatro incógnitas, $T_{q, s a i}^{e}$, $T_{f, s a i}^{e}, \dot{Q}^{e}$ e $\Gamma^{e}$. Os outros parâmetros conhecidos envolvem as temperaturas de entrada do elemento, $T_{q, e n t}^{e}$ e $T_{f, e n t}^{e}$, a área de transferência de calor do elemento, o coeficiente global de transferência de calor e as capacitâncias térmicas de ambos os fluidos no elemento. A solução numérica estendida ao trocador de calor requer um procedimento iterativo que será introduzido posteriormente.

Um procedimento alternativo para solução do conjunto de equações governantes se baseia na redução do número de incógnitas e equações através do rearranjo das quatro equações disponíveis. O rearranjo é feito de forma tal a obter expressões explícitas para as temperaturas de saída do elemento dos fluidos quente e frio através das seguintes expressões,

$$
\begin{gathered}
T_{f, s a i}^{e}=\left[\frac{\Lambda^{e}+2\left(1-\Gamma^{e}\right)}{2+\Lambda^{e}}\right] T_{f, \text { ent }}^{e}+\left(\frac{2 \Gamma^{e}}{2+\Lambda^{e}}\right) T_{q, \text { ent }}^{e} \\
T_{q, \text { sai }}^{e}=\left(\frac{2-\Lambda^{e}}{2+\Lambda^{e}}\right) T_{q, \text { ent }}^{e}+\left(\frac{2 \Lambda^{e}}{2+\Lambda^{e}}\right) T_{f, \text { ent }}^{e}
\end{gathered}
$$

O parâmetro $\Lambda^{e}$ é dado pela seguinte expressão,

$$
\Lambda^{e}=\frac{C_{f}^{e} \dot{m}^{e}}{C_{q}^{e}}
$$

Note que as temperaturas de saída podem ser diretamente determinadas das Equações 3.103 e 3.104 já que a efetividade térmica do elemento pode ser determinada da Equação 3.102 . Dessa forma, uma vez que expressões explícitas para as temperaturas de saída dos elementos estão disponíveis, são essas relações que foram programadas no código HETE. 


\subsubsection{Procedimento numérico}

A metodologia numérica empregada no código HETE para resolver o conjunto de equações governantes, Equações 3.99 a 3.102, ou equivalentemente as Equações 3.103 e 3.104. em cada elemento do trocador de calor, e posteriormente calcular a efetividade, se baseia nos passos descritos a seguir em conjunto com alguns comentários explanatórios relacionados com outros aspectos do código NAVARRO; CABEZAS-GÓMEZ, 2005; CABEZAS-GÓMEZ; NAVARRO; SAIZ-JABARDO, 2015). A partir resultados é possível calcular a efetividade de temperatura, $P$, e consequentemente o fator de correção, $F$, através das Equações $4.1 \mathrm{e} 4.2$.

(i) Inicialmente o trocador de calor se divide em um conjunto de volumes de controle tridimensionais e finitos, designados como elementos, cada um sendo um pequeno trocador de calor de fluxo cruzado misturado - não misturado, como mostrado na Figura 4. Cada elemento é identificado pelos índices $(i, j, k)$, que caracterizam a posição espacial do elemento no trocador de calor. Dessa forma, os componentes variam nos seguintes intervalos: $1 \leq i \leq N_{e}, 1 \leq j \leq N_{q}$; e $1 \leq k \leq N_{r}$, onde $N_{e}$ é o número de elementos ao longo de cada tubo, $N_{q}$ é o número de tubos por fileira e $N_{r}$ o número de fileiras de tubos. No caso da Figura 5, existem 8 tubos por fileira e 4 fileiras de tubos. O número de elementos ao longo de cada tubo é escolhido pelo usuário. O número total de elementos no trocador de calor é igual ao produto $N_{e} N_{q} N_{r}$. Estes dados são dados de entrada do código HETE.
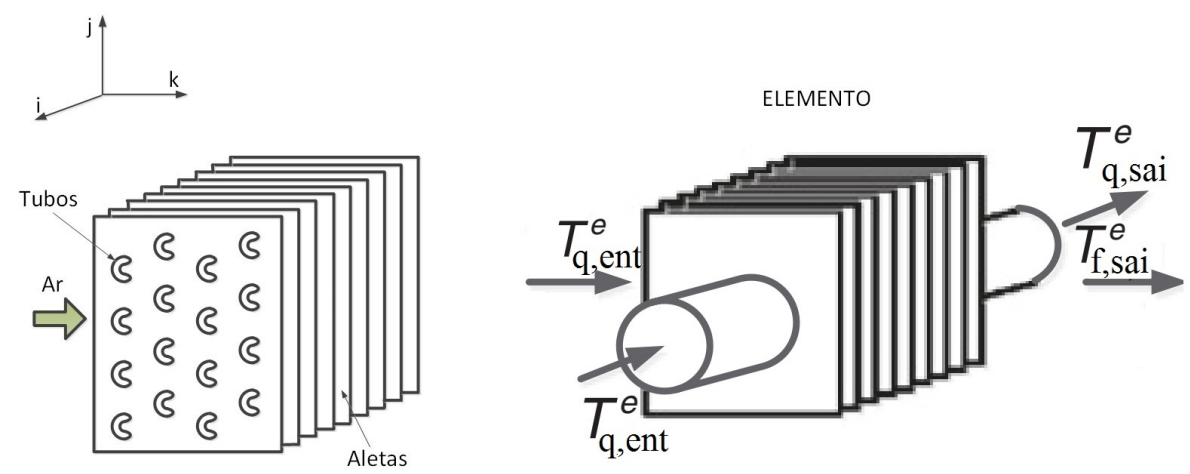

Figura 5 - Ilustração de um trocador de calor cruzado misturado - não misturado e do elemento de análise (CABEZAS-GÓMEZ; NAVARRO; SAIZ-JABARDO, 2015)

(ii) O próximo passo consiste na solução do conjunto de equações, Equações 3.99 a 3.102 ou de forma equivalente, Equações 3.103 e 3.104 para cada elemento. O conjunto de equações para todo o trocador de calor é resolvido através de um procedimento iterativo quando requerido usando o método das substituições sucessivas. A convergência é atingida quando é obtida uma distribuição de temperaturas estacionária em todo o trocador de calor. O procedimento é realizado passo por passo, começando pelo primeiro elemento do primeiro circuito, seguindo o fluido por dentro dos tubos ao longo de cada circuito, considerando o intervalo global das variáveis dos índices $(i, j, k)$. 
(iii) Finalmente, com todos os parâmetros disponíveis, como por exemplo, as temperaturas médias de saída de ambos os fluidos, se avalia a efetividade do trocador de calor pela aplicação da Equação 3.1 .

(iv) O número de elementos determina a exatidão dos resultados. Usualmente, empregam-se 1000 elementos para discretizar todo o trocador de calor. Porém esse número pode ser alterado pelo operador do programa. Devido ao pequeno tamanho de cada elemento, o fluido externo é aquele com a capacitância térmica mínima, $C_{m i n}$. Fisicamente, cada elemento opera como um trocador de calor cruzado misturado - não misturado conectado aos outros elementos pelo fluido que escoa no interior dos tubos. Assume-se que o fluido interno é perfeitamente misturado na área da seção transversal de cada elemento, enquanto o fluido externo é perfeitamente não misturado.

(v) Considerando o trocador de calor como um todo, o algoritmo do programa HETE pode ser empregado para uma configuração não misturado - não misturado, considerando um grande número de tubos. Trocadores de calor de fluxo cruzado com outras configurações, como por exemplo, paralelo-cruzadas e contracorrente-cruzadas com diferentes arranjos de mistura do fluido interno também podem ser simulados. Entretanto, a versão presente do código não contempla a mistura do fluido interno entre passes do mesmo no trocador de calor. A mistura do fluido externo entre os passes, correspondendo à distribuição de um acoplamento de ordem idêntica (SHAH; SEKULIC, 2003), pode ser simulada através da modificação da configuração do trocador como sugerido por CabezasGómez et al. (2009) e Cabezas-Gómez et al. (2012). Porém, a presente versão do código não contempla o fluido externo completamente misturado entre os passes e entre os circuitos do fluido interno.

\subsubsection{Algoritmo para o cálculo do fator de correção}

O algoritmo para resolver as equações governantes para o conjunto de elementos nos quais o trocador de calor se divide se pode efetuar através de um procedimento iterativo. O algoritmo se mostra nos diagramas de bloco das Figuras 6, 7, 8 e 9.

No diagrama de blocos da Figura 6 é apresentado o algoritmo do programa principal. Os dados de entrada da configuração são lidos inicialmente de um arquivo de texto. Depois o usuário entra com os valores dos dados térmicos de entrada no programa principal: $N U T$, $C^{*}$ e $C_{\text {min }}=\left(C_{f}\right.$ ou $\left.C_{q}\right)$. As seguintes variáveis são definidas no programa: $T_{f, e n t}, T_{q, e n t}$ e $U A$. Os valores reais destas variáveis são lidos no programa principal, Figura 6 .

Depois da leitura de todos os dados de entrada, chama-se o código na rotina ComputeE, Figura 7, para calcular a efetividade do trocador de calor. A última operação no programa principal é a impressão final dos resultados, ou seja, da efetividade calculada. Os detalhes do cálculo da efetividade pela rotina ComputeE são mostrados na Figura 7. 


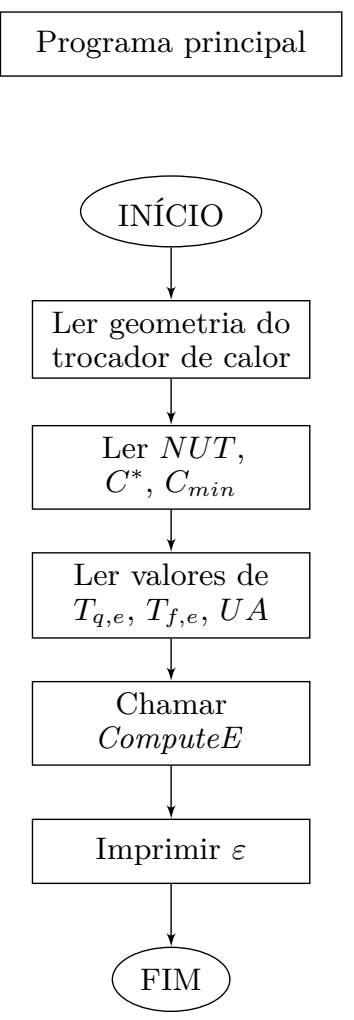

Figura 6 - Diagrama de blocos do programa principal do código HETE (CABEZAS-GÓMEZ; NAVARRO; SAIZ-JABARDO, 2015)

Após a leitura de todos os dados de entrada necessários, os parâmetros $U A^{e}, C_{f}^{e}$ e $C_{q}^{e}$ são calculados para um simples elemento. A condutância do elemento $U A^{e}$ é calculada usando o número total de elementos, ou seja,

$$
U A^{e}=\frac{U A}{N_{e} N_{q} N_{r}}
$$

As capacitâncias térmicas dos fluidos quente e frio, $C_{q}^{e}$ e $C_{f}^{e}$, são calculadas considerando a vazão mássica correspondente a cada elemento,

$$
\begin{aligned}
& C_{f}^{e}= \begin{cases}\frac{U A}{N U T N_{e} N_{q}}, & C_{f}<C_{q} \\
\frac{U A}{N U T C^{*} N_{e} N_{q}}, & C_{f}>C_{q}\end{cases} \\
& C_{q}^{e}= \begin{cases}\frac{U A}{N U T C^{*} N_{r}}, & C_{f}<C_{q} \\
\frac{U A}{N U T N_{r}}, & C_{f}>C_{q}\end{cases}
\end{aligned}
$$




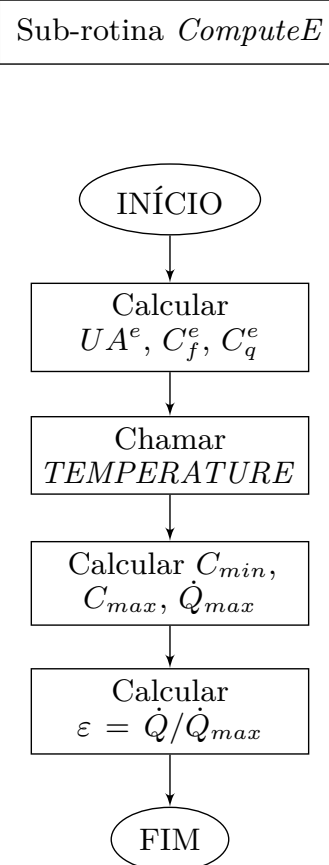

Figura 7 - Diagrama de blocos da sub-rotina numérica ComputeE (CABEZAS-GÓMEZ; NAVARRO; SAIZ-JABARDO, 2015)

Note que o cálculo dos parâmetros dos elementos $U A^{e}, C_{f}^{e}$ e $C_{q}^{e}$ se realiza nas rotinas ComputeUACminCa e ComputeUACminCr, que são chamadas pela rotina ComputeE dependendo do lado do fluido com a mínima capacitância térmica, $C_{m i n}$. Já que o procedimento de cálculo desenvolvido assume que a capacitância do fluido não misturado do elemento é a mínima, ou seja, $C_{f}^{e} / C_{q}^{e} \leq 1$; o número de elementos, $N_{e}$, deve ser escolhido o suficientemente elevado para satisfazer esta condição (NAVARRO; CABEZAS-GÓMEZ 2005; CABEZAS-GÓMEZ; NAVARRO; SAIZ-JABARDO, 2007).

A distribuição de temperaturas no trocador de calor é determinada iterativamente no próximo passo seguindo o sentido do fluido que escoa pelo interior dos tubos e aplicando as Equações 3.103 e 3.104 na rotina TEMPERATURE, mostrada em detalhes na Figura 8. O processo iterativo global é explicado a seguir. Nota-se que a distribuição da temperatura é determinada assumindo constantes as propriedades termodinâmicas e o coeficiente global de transferência de calor. Como resultado, o parâmetro $\Gamma^{e}$ permanece constante em todo o trocador de calor. Entretanto, no código consideram-se variáveis as propriedades termodinâmicas avaliando os parâmetros $U A^{e}, C_{f}^{e}, C_{q}^{e}$ e $\Gamma^{e}$ localmente. Em qualquer caso, as temperaturas dos fluidos quente e fria de saída do elemento são determinadas pelas Equações 3.103 e 3.104 (CABEZAS-GÓMEZ; NAVARRO; SAIZ-JABARDO, 2007).

A rotina ComputeE termina considerando o cálculo da efetividade do trocador de calor. Uma vez que a distribuição de temperaturas tem sido obtida pela convergência do método iterativo na rotina TEMPERATURE, as características de desempenho térmico do trocador de calor podem ser calculadas usando as suas respectivas definições. Esses são os 


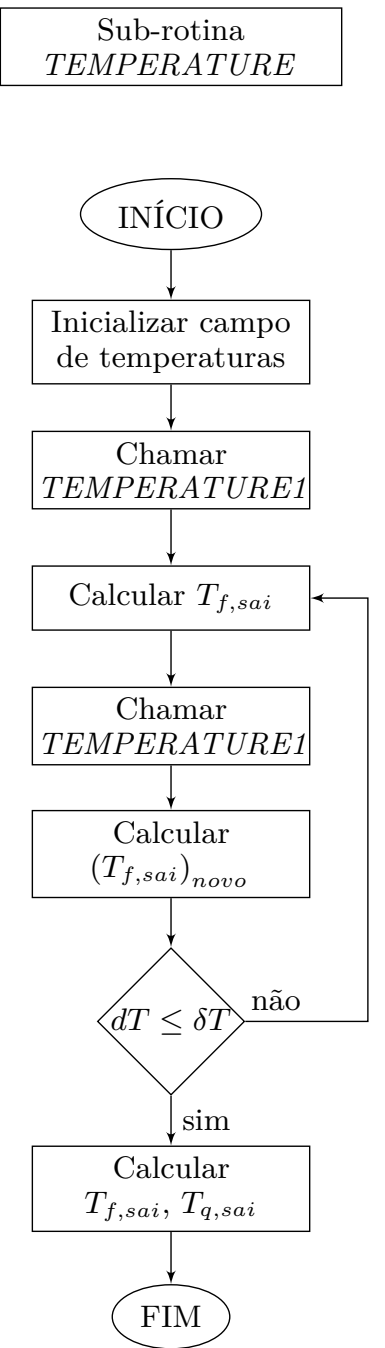

Figura 8 - Diagrama de blocos da sub-rotina numérica TEMPERATURE (CABEZAS-GÓMEZ; NAVARRO; SAIZ-JABARDO, 2015)

passos finais mostrados no diagrama de bloco da Figura 7. Note que no código HETE, os parâmetros do desempenho térmico são calculados na rotina ComputeE, fora da execução da rotina TEMPERATURE. A efetividade do trocador de calor é calculada de acordo com o seguinte conjunto de equações apresentadas abaixo e o fator de correção pode ser então calculado conforme o procedimento numérico mostrado por Pignotti e Cordero (1983a) e apresentado na Seção 4.1 .

$$
\begin{gathered}
T_{f, s a i}=\frac{1}{N_{q} N_{e}} \sum T_{f, s a i}^{e} \\
T_{q, s a i}=\frac{1}{N_{c}} \sum T_{q, s a i}^{e} \\
\dot{Q}=-C_{q}\left(T_{q, s a i}-T_{q, \text { ent }}\right)=C_{f}\left(T_{f, s a i}-T_{f, \text { ent }}\right)
\end{gathered}
$$




$$
\epsilon=\frac{\dot{Q}}{\dot{Q}_{\max }}
$$

O critério de convergência se baseia na temperatura média do fluido frio, embora a taxa de transferência de calor, $\dot{Q}$, também possa ser empregada para esse propósito.

O cálculo iterativo global é realizado através do algoritmo programado na sub-rotina principal denominada de TEMPERATURE, mostrada no diagrama de blocos da Figura 8. Note que antes de chamar pela primeira vez a rotina TEMPERATURE1, mostrada na Figura 9, o campo de temperaturas de todo o trocador de calor, i.e., as temperaturas de todos os elementos, deve ser inicializado ao menos uma vez, utilizando os valores conhecidos das temperaturas de entrada dos fluidos, frio e quente, $T_{f, e}$ e $T_{q, e}$, respectivamente. No início do processo iterativo, depois de obter a distribuição de temperaturas em todo o trocador de calor pela aplicação da rotina TEMPERATURE1, a temperatura média de saída do fluido frio (externo), $T_{f, s a i}$, pode ser determinada pela seguinte expressão, sendo chamado de $\left(T_{f, s a i}\right)_{\text {novo }}$,

$$
\left(T_{f, \text { sai }}\right)_{\text {novo }}=\frac{1}{N_{q} N_{e}} \sum T_{f, s a i}^{e}
$$

O processo iterativo começa no passo seguinte através da chamada da rotina TEMPERATURE1 repetidamente até que o erro relativo entre o valor novo, $\left(T_{f, \text { sai }}\right)_{\text {novo }}$, e o valor anterior, $T_{f, s a i}$, da temperatura média de saída do fluido frio (externo e não misturado) seja menor ou igual à uma tolerância preestabelecida, sendo a mesma igual a $\delta T=10^{-8}$.

$$
\frac{\left|\left(T_{f, s a i}\right)_{n o v o}-T_{f, s a i}\right|}{T_{f, s a i}} \leq \delta T
$$

Para desenvolver o procedimento iterativo, no início do laço iterativo, se designa à temperatura $T$ o valor de $T_{\text {novo }}$. Depois é chamada novamente a rotina TEMPERATURE1 para calcular o novo valor corrente de $T_{\text {novo }}$ e o novo valor do erro relativo. Este processo se repete até que o critério de convergência é atingido, ou seja, o erro é menor ou igual à requerida tolerância.

Como mencionado anteriormente, as temperaturas em cada circuito são calculadas seguindo a direção de escoamento do fluido interno aos tubos. Os cálculos da temperatura em cada elemento são realizados de acordo com o algoritmo programado na rotina TEMPERATURE1 mostrada no diagrama de blocos da Figura 9 . A primeira operação é o cálculo da efetividade do elemento $\Gamma^{e}$, e de $\Lambda^{e}$, de acordo com as Equações 3.102 e 3.105, respectivamente. Como esses parâmetros são constantes, os mesmos se calculam apenas uma vez. Depois disso, seguindo a direção de escoamento do fluido interno, as temperaturas de saída de cada elemento são calculadas pelas Equações 3.103 e 3.104 . 


\section{\begin{tabular}{c}
\hline Sub-rotina \\
TEMPERATURE1
\end{tabular}}

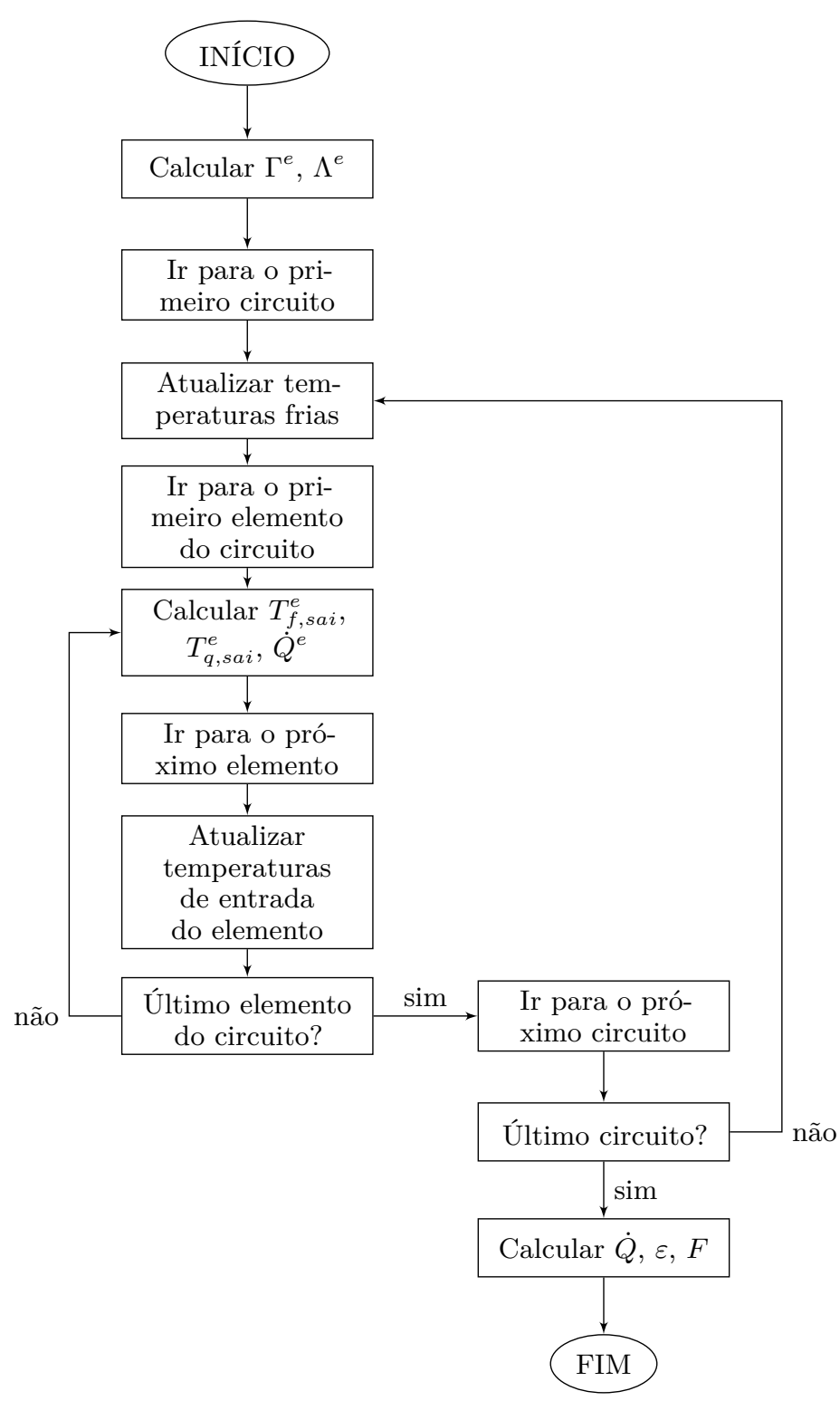

Figura 9 - Diagrama de blocos da sub-rotina numérica TEMPERATURE1 (CABEZAS-GÓMEZ; NAVARRO; SAIZ-JABARDO, 2015 
enquanto as temperaturas de entrada para ambos os fluidos são assumidas iguais às temperaturas de saída dos elementos à montante em contato com o elemento em questão. Este procedimento é repetido para todos os elementos do primeiro circuito. Posteriormente o mesmo procedimento é aplicado para os seguintes circuitos para completar o cálculo da distribuição de temperaturas em todo o trocador de calor. Devido ao fato que a ordem dos elementos no circuito não sempre segue a ordem onde os valores reais das temperaturas de entrada para um elemento em particular se conhecem, o cálculo da distribuição de temperaturas global no trocador de calor deve ser realizado iterativamente. 



\section{Método de Cálculo}

\subsection{Procedimento numérico-analítico}

Nesta seção se apresenta um procedimento computacional para calcular a efetividade de temperatura $P$ e o fator de correção $F$ para arranjos de trocadores de calor de fluxo cruzado de múltiplos passos considerando diversas hipóteses de mistura dos fluidos interno e externo. Consideram-se configurações de fluxo cruzado, contracorrente-cruzado e paralelo-cruzado com um número arbitrário de passes do fluido interno e de fileiras de tubos por passe com base no procedimento descrito por Pignotti e Cordero (1983a) e apresentado detalhadamente em Magazoni e Cabezas-Gómez (2016). A gama de configurações que podem ser modeladas inclui inclusive os trocadores de fluxo cruzado não misturado - não misturado, através da consideração de um número elevado de fileiras de tubos. O procedimento computacional adotado permite obter relações analíticas exatas que podem ser de grande aplicação no projeto de trocadores de calor de fluxo cruzado. Este procedimento é complementar à metodologia adotada no código HETE, e pode ser empregado para comprovar os resultados numéricos de simulação obtidos com o HETE.

Os procedimentos computacionais de cálculo da efetividade e do fator de correção foram obtidos levando em conta as considerações básicas, comumente empregadas na literatura (KAYS; LONDON, 1998; SHAH; SEKULIC, 2003, CABEZAS-GÓMEZ; NAVARRO; SAIZ-JABARDO, 2015): (i) o trocador de calor opera em regime permanente; (ii) as transferências de calor com o meio externo são desprezadas, ou seja, o trocador de calor é modelado como adiabático em relação ao meio externo; (iii) não há fontes ou sumidouros de energia térmica nas paredes do trocador de calor e/ou nos fluidos; (iv) o fluido que escoa por dentro dos tubos está perfeitamente misturado em toda a sua seção transversal, acontecendo uma variação linear de sua temperatura ao longo do eixo axial dos tubos; (v) os coeficientes de transferência de calor e as propriedades de transporte dos fluidos e das paredes do trocador de calor são uniformes e constantes; (vi) os efeitos da transferência de calor axial nas paredes sólidas e nos fluidos são desprezíveis; e (vii) não há mudança de fase em ambas as correntes ou fluidos.

O procedimento adotado nesta seção permite obter resultados para condições de mistura dos fluidos interno e externo, que não podem ser abordadas pelo código HETE atualmente. Estas são a consideração de mistura total do fluido externo após cada fileira de tubos, e a consideração de mistura de várias correntes de fluido interno que escoa por vários tubos após um passe do mesmo pelo trocador de calor. Como o procedimento abordado é complexo foram desenvolvidos dois códigos computacionais para seu uso, um na plataforma Matlab 2015a e o outro na plataforma Maple 18. O uso do Maple se justifica pelo fato da 
dificuldade de obter as relações analíticas para arranjos complexos ou de muitas fileiras de tubos. A seguir apresenta-se a metodologia empregada, expondo as equações de balanço essenciais e os algoritmos desenvolvidos. Entretanto, devido à complexidade envolvida na derivação de todas as relações, se recomenda consultar os trabalhos de Pignotti e Cordero (1983a), Pignotti e Cordero (1983b) e Magazoni e Cabezas-Gómez (2016) para analisar detalhadamente o procedimento aqui exposto. A novidade do trabalho desenvolvido nesta seção está relacionada com o fato de fornecer os códigos computacionais operacionais, o que não é uma tarefa trivial, e que ainda permite o uso da metodologia para modelagem de muitos arranjos de trocadores de calor de fluxo cruzado de interesse industrial.

Como apresentado anteriormente, o fator de correção pode ser calculado em função do número de unidades de transferência $N U T$, razão de temperatura $R$ e efetividade de temperatura $P$,

$$
\begin{gathered}
F=\frac{\chi}{N U T} \\
\chi= \begin{cases}\left(\frac{1}{R-1}\right) \ln \left(\frac{1-P}{1-R P}\right), & R \neq 0 \\
\frac{P}{1-P}, & R=0\end{cases}
\end{gathered}
$$

Nas relações anteriores, $P$ representa a efetividade de temperatura para o fluido externo. Dessa forma $N U T$ e $R$ também se referem ao lado externo.

Por conveniência assume-se que o fluido externo é o frio e o fluido interno é o quente. Nesse caso a temperatura do fluido externo se denota por $T_{f}$ e a do fluido frio por $T_{q}$, respectivamente. Também se empregam os subíndices ent e sai para denotar os valores de entrada e de saída da temperatura dos tubos do trocador de calor. Os subíndices $p$ e $q$ se empregam para denotar o passe e a fileira referidos. Estes valores podem variar de 1 até $N_{p}$, e de 1 até $N_{r}$, respectivamente, na direção do escoamento do fluido externo. Dessa forma, definem-se a razão de temperatura $R$ e a efetividade de temperatura $P$,

$$
\begin{gathered}
R=\frac{C_{f}}{C_{q}}=\frac{T_{q, \text { ent }}-T_{q, \text { sai }}}{T_{f, \text { sai }}-T_{f, \text { ent }}} \\
R_{r}=N_{r} R \\
P=\frac{T_{f, \text { sai }}-T_{f, \text { ent }}}{T_{q, \text { ent }}-T_{f, \text { ent }}}
\end{gathered}
$$


Conforme Pignotti e Cordero (1983a), os tubos são organizados em $N_{p}$ passes conectados em série, cada qual consistindo de $N_{r}$ fileiras conectadas em paralelo, conforme ilustrado na Figura 10 e nos trocadores de calor de fluxo cruzado esquemáticos no Anexo A O fluido no tubo é completamente misturado em cada seção transversal e sua temperatura varia continuamente ao longo da coordenada $x$ de cada fileira, $T_{(p, q, x)}$, e uma função discreta dos índices do passe e da fileira, $p$ e $q$. Os casos extremos de mistura do fluido interno, completamente misturado e não misturado dentro de cada passe se determinam pelas soluções para $N_{r}$ igual a 1 e a infinito, respectivamente.

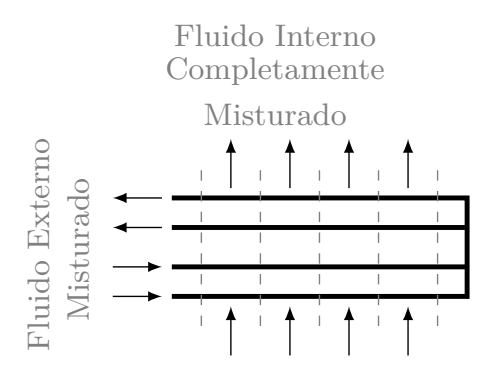

(a) Caso $1 \mathrm{~A}$

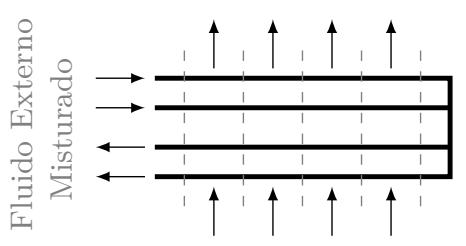

(d) Caso $2 \mathrm{~A}$

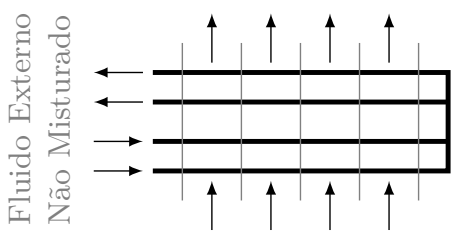

(g) Caso 3A

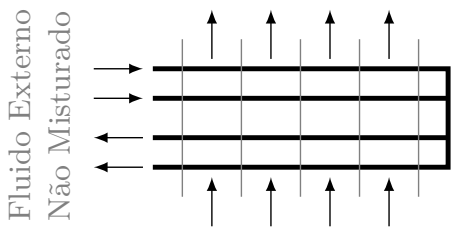

(j) Caso 4A
Fluido Interno Não Misturado com uma Ordem Idêntica

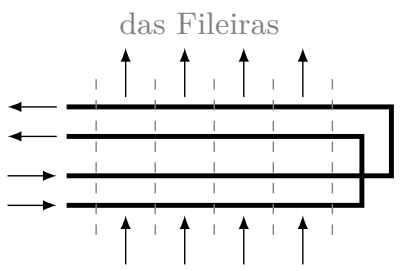

(b) Caso 1B

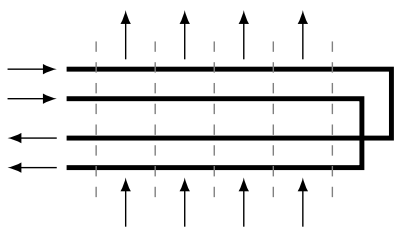

(e) Caso 2B

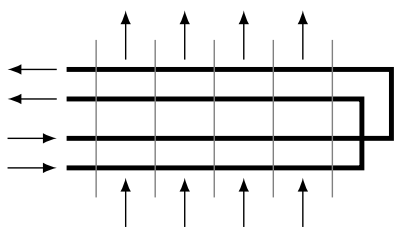

(h) Caso 3B

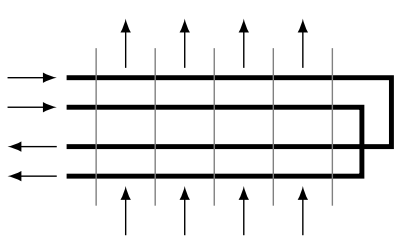

(k) Caso 4B
Fluido Interno

Não Misturado com uma Ordem Inversa

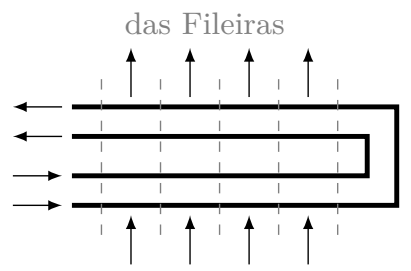

(c) Caso 1C

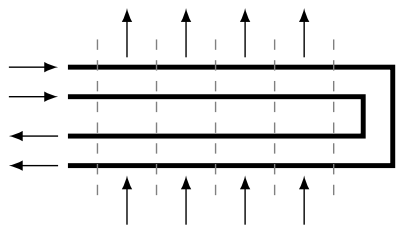

(f) Caso 2C

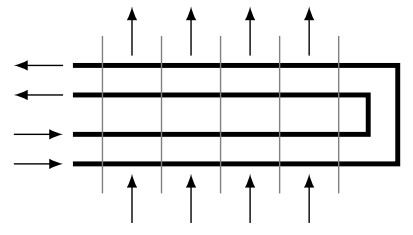

(i) Caso $3 \mathrm{C}$

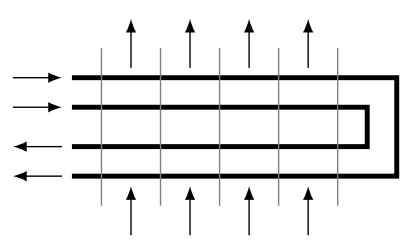

(l) Caso 4C

Figura 10 - Configurações de trocadores de calor de fluxo cruzado de acordo com Pignotti e Cordero (1983a)

Entre cada passe se assumem três condições de mistura: completamente misturado, não misturado com uma ordem idêntica das fileiras e não misturado com uma ordem inversa das fileiras (casos A, B e C, respectivamente). Em relação à mistura do ar se consideram duas alternativas: ar misturado (casos 1 e 2) e ar não misturado (casos 3 e 4 ) quando passa pela fileira de tubos. A primeira consiste na mistura total do ar entre duas fileiras consecutivas, e a segunda onde o ar não é misturado. Além disso, quando há mais 
de um passe de tubos, dois tipos de arranjos são propostos: arranjo contracorrente-cruzado (casos 1 e 3) e paralelo-cruzado (casos 2 e 4). Desta forma, um total de doze configurações diferentes podem ser geradas.

O balanço de energia de um trocador de calor é calculado nos fluidos frio e quente como,

$$
\dot{Q}=\dot{m}_{f} c p_{f}\left(T_{f, e n t}-T_{f, s a i}\right)=\dot{m}_{q} c p_{q}\left(T_{q, \text { ent }}-T_{q, s a i}\right)
$$

onde $\dot{Q}$ é a taxa de transferência de calor, $\dot{m}$ é a vazão mássica, $c p$ é o calor específico e $T_{q}$ e $T_{f}$ são respectivamente as temperaturas do fluido quente e frio.

Realizando um balanço de energia local no fluido quente em um ângulo $d \omega$ (Figura 11), o balanço de energia é dado por $\dot{m}_{f} c p_{f} d T_{f}$. Da mesma maneira, para o fluido quente, o balanço de energia é calculado como $\dot{m}_{q} c p_{q} d T_{q}$. Assim, o balanço de energia local pode ser expresso como,

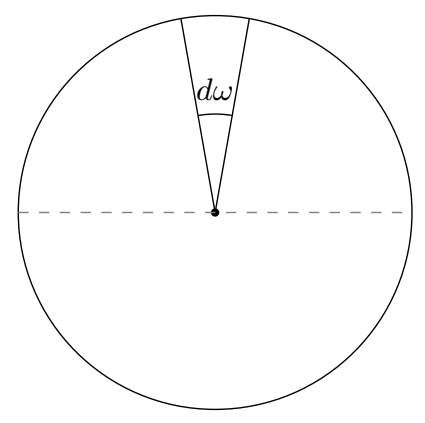

Figura 11 - Superfície de controle para balanço de energia local no fluido quente

$$
\dot{m}_{f} c p_{f} d T_{f}=\dot{m}_{q} c p_{q} d T_{q}=\dot{q} d A=\dot{q}\left(\frac{D L N_{t}}{2}\right) d \omega
$$

onde $\dot{q}$ é taxa de transferência de calor por área, $A$ é a área, $L$ é o comprimento de cada tubo, $N_{t}$ é o número de linhas de tubo, $\omega$ é o ângulo do tubo em relação ao seu centro e $D$ é o diâmetro do tubo.

Rearranjando a Equação 4.7 e utilizando o conceito de coeficiente global de transferência de calor, a variação da temperatura do ar em cada fileira é obtida conforme a seguinte equação de transferência de calor (PIGNOTTI; CORDERO, 1983a),

$$
\left(\frac{2 \dot{m}_{f} c p_{f}}{L N_{t}}\right) \frac{\partial T_{f,(x, \omega)}}{\partial \omega}=U D\left[T_{q,(x)}-T_{f,(x, \omega)}\right], 0 \leq \omega \leq 2 \pi
$$

onde $U$ é o coeficiente global de transferência de calor.

Integrando a expressão anterior em função de $\omega$ e fixando $x$, obtém-se,

$$
T_{f, s a i,(x)}=\rho T_{f, e n t,(x)}+(1-\rho) T_{q,(x)}
$$


onde,

$$
\begin{gathered}
T_{f, s a i,(x)}=T_{f,(x, \pi)} \\
T_{f, e n t,(x)}=T_{f,(x, 0)} \\
\rho=\exp \left(-\frac{N U T}{N}\right) \\
N=N_{r} N_{p}
\end{gathered}
$$

Segundo Pignotti e Cordero (1983a), a variação da temperatura do fluido interno se obtém da seguinte relação,

$$
\begin{array}{r}
-\left(\frac{\dot{m}_{q} c p_{q}}{N_{r}}\right) d T=\dot{m}_{f} c p_{f}\left[T_{f, s a i,(x)}-T_{f, e n t,(x)}\right] d x= \\
(1-\rho)\left[T_{q,(x)}-T_{f, e n t,(x)}\right] \dot{m}_{f} c p_{f} d x
\end{array}
$$

Resultando na seguinte expressão,

$$
\frac{d T_{q}}{d x}=-\lambda\left[T_{q,(x)}-T_{f, e n t,(x)}\right]
$$

onde o parâmetro $\lambda$ é calculado segundo a equação a seguir,

$$
\lambda=R N_{r}(1-\rho)
$$

Uma solução particular de primeira ordem da equação diferencial 4.15 é,

$$
T_{q,(x)}=\exp (-\lambda x)\left\{T_{q,(0)}+\lambda \int_{0}^{x}\left[\exp (\lambda y) T_{f, e n t,(y)} d y\right]\right\}
$$

As Equações 4.9 e 4.17 definem completamente as variações da temperatura dos fluidos externo e interno em uma fileira de tubo. Utilizando as definições de temperatura adimensional, $\theta$ e $\tau$, as seguintes expressões podem ser obtidas,

$$
\begin{gathered}
\theta_{F}(x)=\rho \theta_{I}(x)+(1-\rho) \tau(x) \\
\tau(x)=\exp (-\lambda x)\left\{\tau(0)+\lambda \int_{0}^{x}\left[\exp (\lambda y) \theta_{I}(y) d y\right]\right\}
\end{gathered}
$$


Segundo Pignotti e Cordero (1983a), a aplicação dessas equações em fileiras sucessivas permite a solução para qualquer arranjo de trocador de calor em diferentes tipos de escoamento. Esse método tem sido aplicado em diversos trabalhos (NICOLE, 1972, SCHEDWILL, 1968; BRAUN, 1975). De fato, integrando a Equação 4.17 para o caso de um trocador de calor com apenas uma fileira e assumindo que o ar misture entre os tubos se obtém,

$$
T_{(p, q, x)}=\left[T_{q,(p, q, 0)}-T_{f, e n t,(p, q)}\right] \exp (-\lambda x)+T_{f, e n t, p, q}
$$

Usando as Equações 4.9 e 4.20 encontra-se a temperatura média do ar na saída,

$$
T_{f, s a i,(p, q)}=\int_{0}^{1}\left[T_{f, s a i,(p, q, x)} d x\right]=T_{f, e n t,(p, q)}+\frac{1-\exp (-\lambda)}{R_{r}}\left[T_{q, i n,(p, q)}-T_{f, e n t,(p, q)}\right]
$$

Empregando a definição de efetividade de temperatura da Equação 4.5. calcula-se a efetividade de um único tubo do trocador de calor,

$$
P_{r}=\frac{T_{f, s a i,(p, q)}-T_{f, e n t,(p, q)}}{T_{q, i n,(p, q)}-T_{f, e n t,(p, q)}}=\frac{1-\exp (-\lambda)}{R_{r}}
$$

A Equação 4.22 é válida para qualquer fileira no caso do ar ser completamente misturado entre elas. Também é valida para um trocador de calor em fluxo cruzado com apenas uma fileira de tubos. Em alguns casos especiais como o descrito pela Equação 4.22, o fator de correção é calculado diretamente através dos parâmetros $R$ e $P$, porém na maioria dos casos a efetividade $P$ é calculada inicialmente em função de $R$ e $N U T$, e $F$ é calculado posteriormente pela Equação 4.1 .

Nas subseções posteriores são apresentados os algoritmos matemáticos das configurações de trocadores de calor de fluxo cruzado: escoamento contracorrente (casos 2 e 4) e escoamento paralelo (casos 1 e 3 ).

\subsubsection{Caso 1A}

O caso 1A do procedimento de Pignotti e Cordero (1983a) se refere ao trocador de calor de fluxo cruzado em escoamento paralelo com os fluidos quente e frio completamente misturados entre os passes. Na Figura 12 é apresentado um exemplo deste tipo de arranjo com dois passes e dois tubos (2-2).

Inicialmente, calcula-se a efetividade de temperatura para um único tubo do trocador de calor de fluxo cruzado, $P_{r}$, através da Equação 4.22 .

A efetividade de temperatura de um único passe $P_{p}$ é dada por, 


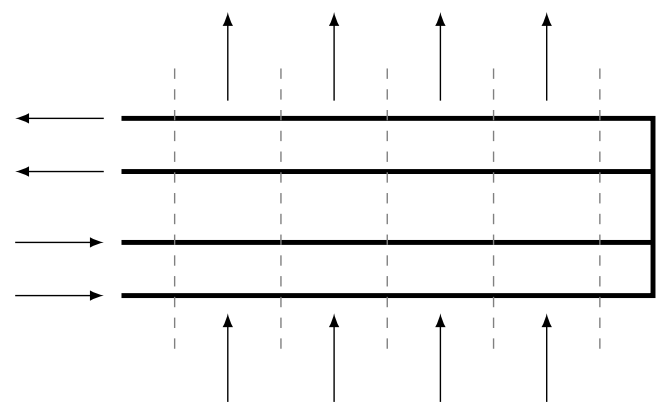

Figura 12 - Caso 1A: Trocador de calor de fluxo cruzado em escoamento paralelo com dois passes e dois tubos (2-2) com os fluidos quente e frio completamente misturados entre os passes

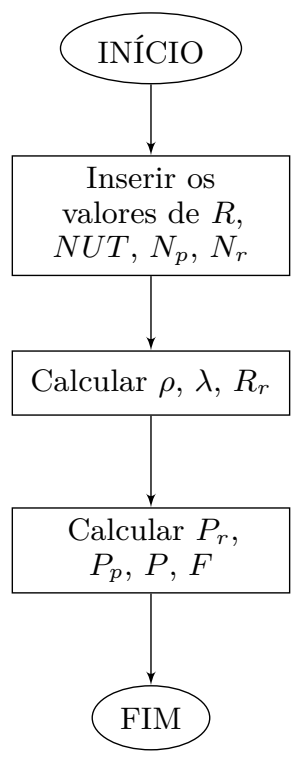

Figura 13 - Fluxograma para calcular a efetividade de temperatura e o fator de correção para o caso $1 \mathrm{~A}$

$$
P_{p}=1-\left(1-P_{r}\right)^{N_{r}}
$$

Portanto, a efetividade de temperatura $P$ para este arranjo de trocador de calor em função da efetividade $P_{p}$ e da razão de temperatura $R$ é calculada como,

$$
P=\frac{1-\left[1-P_{p}(1+R)\right]^{N_{p}}}{1+R}
$$

O fator de correção é então obtido em função do número de unidades de transferência $N U T$, da razão de capacidade $R$ e da efetividade de temperatura $P$ pelas Equações 4.1 e 4.2. O fluxograma do algoritmo é apresentado na Figura 13 , que se destaca pelo fato do algoritmo não ser iterativo e não apresentar nenhum loop condicional. 


\subsubsection{Casos 1B e 1C}

Os casos 1B e 1C provenientes dos trabalhos de Pignotti e Cordero (1983a) se referem aos trocadores de calor de fluxo cruzado em escoamento paralelo com fluido frio completamente misturado entre os passes e com fluido quente não misturado com uma ordem idêntica das fileiras e não misturado com uma ordem inversa das fileiras, respectivamente. Na Figura 14 são apresentados um exemplo destes arranjos de trocador de calor com dois passes e dois tubos (2-2).

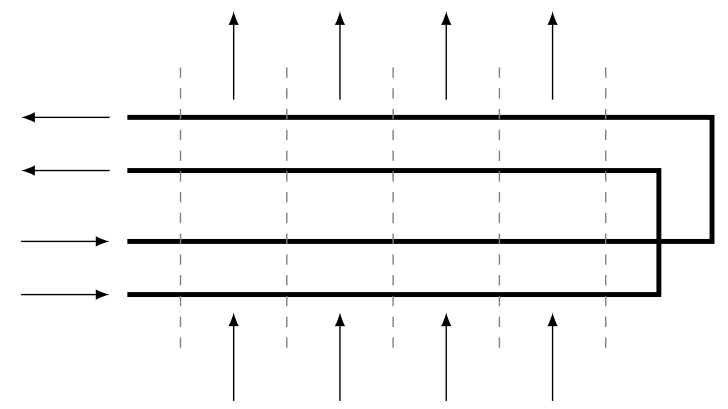

(a) Caso 1B

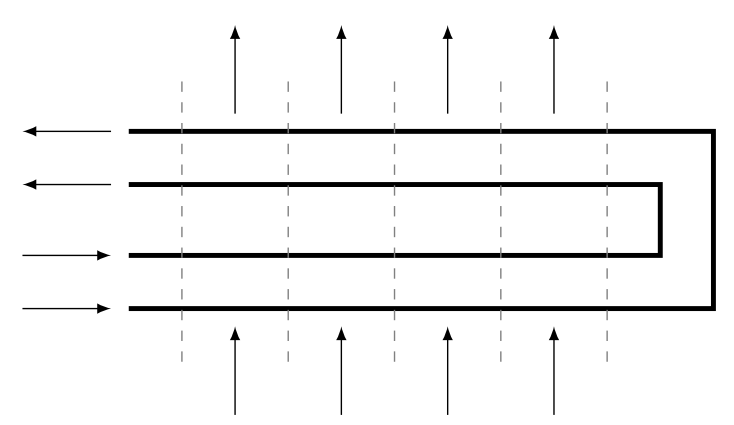

(b) Caso $1 \mathrm{C}$

Figura 14 - Casos 1B e 1C: Trocador de calor de fluxo cruzado em escoamento paralelo com fluido frio completamente misturado entre os passes e com fluido quente não misturado com uma ordem idêntica das fileiras (caso 1B) e não misturado com uma ordem inversa das fileiras (caso 1C)

Calcula-se a efetividade de temperatura para um único tubo do trocador de calor de fluxo cruzado, $P_{r}$, através da Equação 4.22. A efetividade de temperatura de um único passe $P_{p}$ é dada pela Equação 4.23 .

Definem-se as variáveis adimensionais de temperatura dos fluidos quente e frio,

$$
\begin{gathered}
\theta_{\text {ent },(p, q)}=\frac{T_{f, e n t,(p, q)}-T_{f, e n t}}{T_{q, e n t}-T_{f, e n t}} \\
\theta_{\text {sai },(p, q)}=\frac{T_{f, s a i,(p, q)}-T_{f, e n t}}{T_{q, e n t}-T_{f, e n t}} \\
\tau_{\text {ent },(p, q)}=\frac{T_{q, e n t,(p, q)}-T_{f, e n t}}{T_{q, e n t}-T_{f, e n t}} \\
\tau_{\text {sai },(p, q)}=\frac{T_{q, s a i,(p, q)}-T_{f, e n t}}{T_{q, e n t}-T_{f, e n t}}
\end{gathered}
$$

Para este caso, as condições iniciais de temperatura adimensional são,

$$
\tau_{\text {ent },(1,1)}=0, \quad \theta_{\text {ent },(1, q)}=1
$$




$$
\begin{gathered}
\theta_{\text {ent },(p, q+1)}=\theta_{\text {sai },(p, q)} \\
\theta_{\text {ent },(p+1, q)}=\theta_{\text {sai },\left(p, N_{r}\right)} \\
\tau_{\text {ent },(p+1, q)}=\left\{\begin{array}{lc}
\tau_{\text {sai },(p, q)}, & \text { caso } 1 \mathrm{~B} \\
\tau_{\text {sai },\left(p, N_{r}+1-q\right)}, & \text { caso } 1 \mathrm{C}
\end{array}\right.
\end{gathered}
$$

Das Equações 4.20 e 4.21, encontram-se expressões da temperatura adimensional dos fluidos quente e frio na saída do tubo,

$$
\begin{gathered}
\tau_{s a i,(p, q)}=P_{r} R_{r} \theta_{e n t,(p, q)}+\left(1-P_{r} R_{r}\right) \tau_{e n t,(p, q)} \\
\theta_{s a i,(p, q)}=\left(1-P_{r}\right) \theta_{\text {ent },(p, q)}+P_{r} \tau_{e n t,(p, q)}
\end{gathered}
$$

Assim, é possível calcular a efetividade de temperatura do trocador de calor através da expressão abaixo e o fator de correção utilizando as Equações 4.1 e 4.2.

$$
P=\theta_{\text {sai },\left(N_{p}, N_{r}\right)}
$$

O fluxograma de algoritmo dos trocadores de calor discutidos nesta seção está apresentado na Figura 15. No algoritmo apresentado se mostra a necessidade de empregar três laços condicionais, dois na variável $q$ relacionados com o número de fileiras em cada passe, $N_{r}$, e um na variável $p$ relacionado com o número de passes, $N_{p}$.

\subsubsection{Caso 2A}

O caso 2A de Pignotti e Cordero (1983a) se refere ao trocador de calor de fluxo cruzado em escoamento contracorrente com os fluidos quente e frio completamente misturados entre os passes, conforme apresentado na Figura 16.

Calcula-se a efetividade de temperatura para um único tubo do trocador de calor de fluxo cruzado, $P_{r}$, através da Equação 4.22. A efetividade de temperatura de um único passe $P_{p}$ é dada pela Equação 4.23 .

Assim, a efetividade de temperatura para este arranjo de trocador de calor é calculada como, 


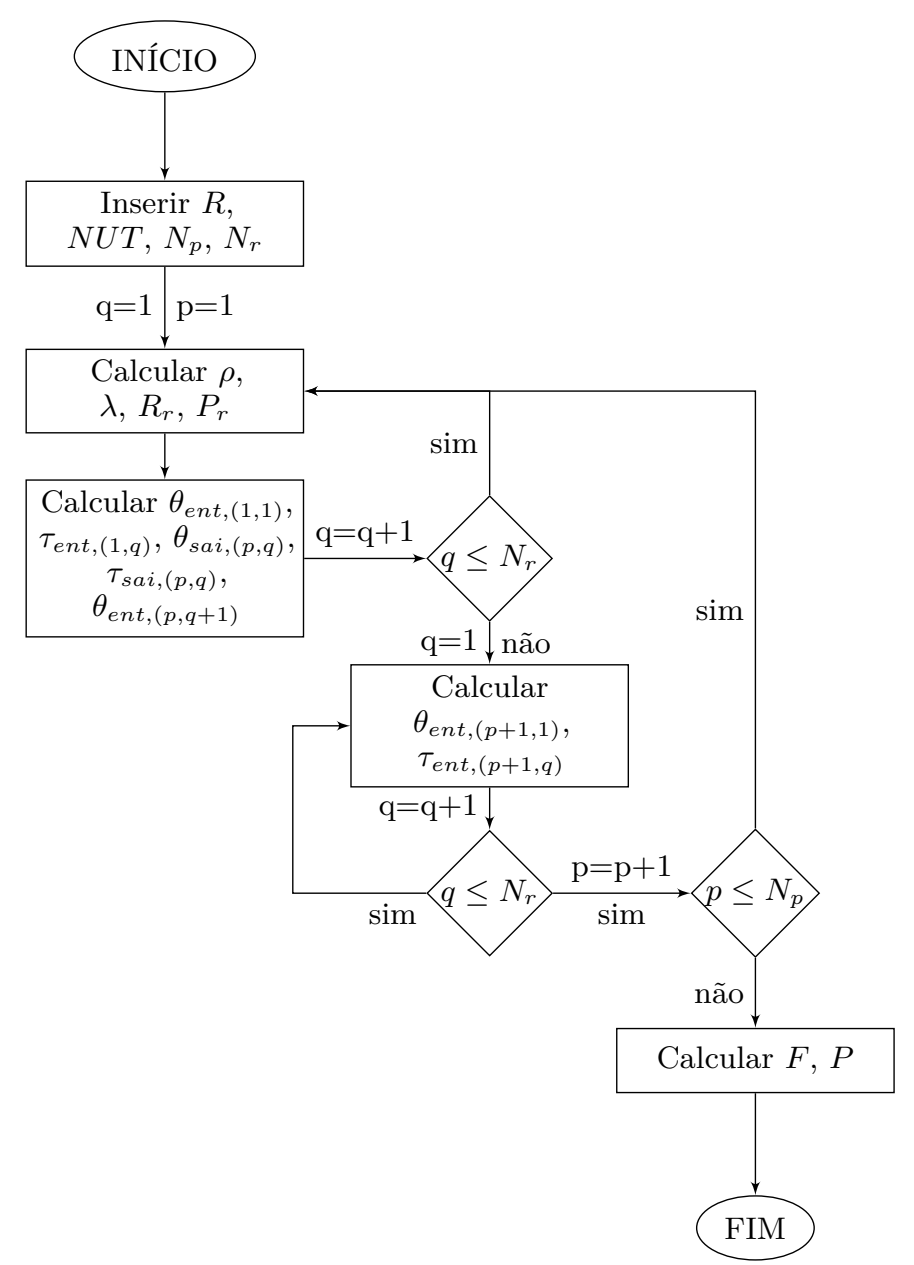

Figura 15 - Fluxograma para calcular a efetividade de temperatura e o fator de correção para os casos $1 \mathrm{~B}$ e $1 \mathrm{C}$

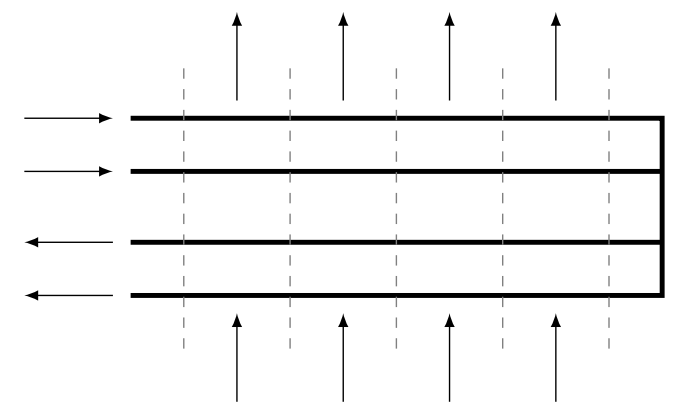

Figura 16 - Caso 2A: Trocador de calor de fluxo cruzado em escoamento contracorrente com dois passes e dois tubos (2-2) com os fluidos quente e frio completamente misturados entre os passes 


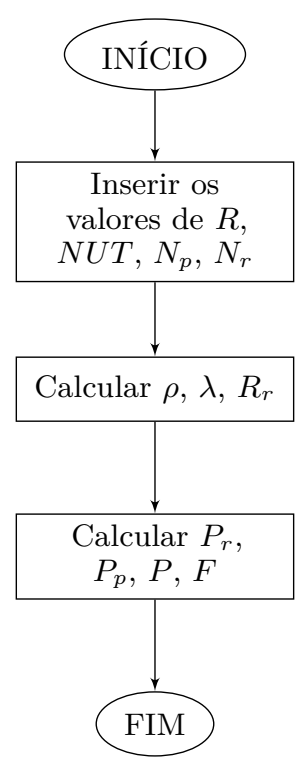

Figura 17 - Fluxograma para calcular a efetividade de temperatura e o fator de correção para o caso $2 \mathrm{~A}$

$$
P= \begin{cases}\frac{1-\left(\frac{1-P_{p}}{1-R P_{p}}\right)^{N_{p}}}{1-R\left(\frac{1-P_{p}}{1-R P_{p}}\right)^{N_{p}}}, & R \neq 1 \\ \frac{P_{p}}{P_{p}+\frac{1-P_{p}}{N_{p}}}, & R=1\end{cases}
$$

O fator de correção é então calculado a partir de $R, N U T$ e $P$ através das Equações $4.1 \mathrm{e} 4.2$.

O fluxograma do algoritmo é apresentado na Figura 17, que se destaca pelo fato do algoritmo não ser iterativo e não precisar de nenhum loop condicional.

\subsubsection{Casos 2B e 2C}

Os casos 2B e 2C do trabalho de Pignotti e Cordero (1983a) se referem aos trocadores de calor de fluxo cruzado em escoamento contracorrente com fluido frio completamente misturado entre os passes e com fluido quente não misturado com uma ordem idêntica das fileiras e não misturado com uma ordem inversa das fileiras. Na Figura 18 são apresentados um exemplo destes arranjos de trocador de calor com dois passes e dois tubos (2-2).

Calcula-se a efetividade de temperatura para um único tubo do trocador de calor de fluxo cruzado, $P_{r}$, através da Equação 4.22. A efetividade de temperatura de um único passe $P_{p}$ é dada pela Equação 4.23 . 


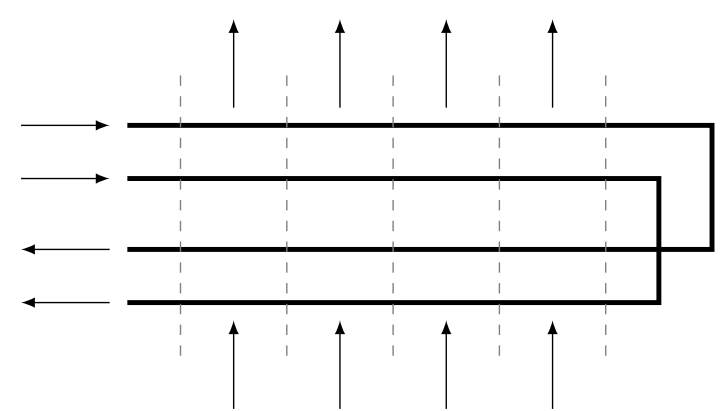

(a) Caso 2B

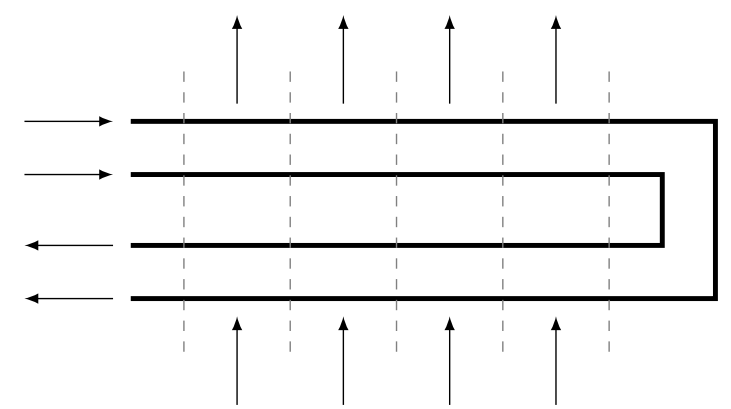

(b) Caso 2C

Figura 18 - Casos 2B e 2C: Trocador de calor de fluxo cruzado em escoamento contracorrente com fluido frio não misturado entre os passes e com fluido quente não misturado com uma ordem idêntica das fileiras (caso 2B) e não misturado com uma ordem inversa das fileiras (caso $2 \mathrm{C}$ )

Definem-se as variáveis adimensionais de temperatura dos fluidos quente e frio,

$$
\begin{aligned}
& \theta_{\text {ent },(p, q)}=\frac{T_{f, e n t,(p, q)}-T_{f, e n t}}{T_{q, e n t}-T_{f, s a i}} \\
& \theta_{s a i,(p, q)}=\frac{T_{f, s a i,(p, q)}-T_{f, e n t}}{T_{q, e n t}-T_{f, s a i}} \\
& \tau_{\text {ent },(p, q)}=\frac{T_{q, e n t,(p, q)}-T_{f, e n t}}{T_{q, e n t}-T_{f, s a i}} \\
& \tau_{s a i,(p, q)}=\frac{T_{q, s a i,(p, q)}-T_{f, e n t}}{T_{q, e n t}-T_{f, s a i}}
\end{aligned}
$$

Para este caso, as condições iniciais de temperatura adimensional são,

$$
\begin{gathered}
\tau_{\text {ent },\left(N_{p}, q\right)}=1 \\
\theta_{\text {sai },\left(N_{p}, N_{r}\right)}=0 \\
\theta_{\text {sai },(p, q-1)}=\theta_{\text {ent },(p, q)} \\
\theta_{\text {sai },\left(p-1, N_{r}\right)}=\theta_{\text {ent },(p, 1)} \\
\tau_{\text {ent },(p-1, q)}=\left\{\begin{array}{l}
\tau_{\text {sai },(p, q)}, \\
\text { caso } 2 \mathrm{~B} \\
\tau_{\text {sai },\left(p, N_{r}+1-q\right),}
\end{array}\right.
\end{gathered}
$$


Das Equações 4.20 e 4.21, encontram-se expressões da temperatura adimensional dos fluidos quente e frio na saída do tubo,

$$
\begin{gathered}
\theta_{e n t,(p, q)}=\frac{\theta_{\text {sai },(p, q)}}{1-P_{r}}-\frac{\tau_{e n t,(p, q)} P_{r}}{1-P_{r}} \\
\tau_{s a i,(p, q)}=P_{r} R_{r} \theta_{e n t,(p, q)}+\left(1-P_{r} R_{r}\right) \tau_{e n t,(p, q)}
\end{gathered}
$$

Assim, é possível calcular a efetividade de temperatura do trocador de calor através da expressão abaixo e o fator de correção utilizando as Equações 4.1 e 4.2 ,

$$
P=\frac{\theta_{\text {ent },(1,1)}}{\theta_{\text {ent },(1,1)}-1}
$$

O fluxograma de algoritmo dos trocadores de calor discutidos nesta seção está apresentado na Figura 19. No algoritmo apresentado também é necessário empregar três laços condicionais, dois na variável $q$ relacionada com o número de fileiras em cada passe, $N_{r}$, e um na variável $p$ relacionada com o número de passes, $N_{p}$.

\subsubsection{Casos 3A, 3B e 3C}

Para o ar não misturado também se consideram duas configurações globais, a paralelo-cruzada (casos 3A, 3B e 3C) e a contracorrente-cruzada (casos 4A, 4B e 4C). As três variantes do caso 3 foram implementadas em um mesmo algoritmo.

Nesta seção são apresentados os casos 3A, 3B e 3C de Pignotti e Cordero (1983a), que são trocadores de calor de fluxo cruzado em escoamento paralelo com fluido frio não misturado entre os passes e com fluido quente misturado, não misturado com uma ordem idêntica das fileiras e não misturado com uma ordem inversa das fileiras. Isto é mostrado no exemplo de um trocador de calor com dois passes e dois tubos (2-2) na Figura 20.

A consideração do ar não misturado entre as fileiras complica o procedimento de cálculo. De forma geral aplicam-se novamente as expressões desenvolvidas na Seção 4.1 derivadas para uma fileira simples, para calcular os perfis de temperatura em termos das temperaturas adimensionais. Pignotti e Cordero (1983a) apresentam esses perfis de temperatura como produtos de polinômios em $x$ e exponenciais $\exp ( \pm \lambda x)$, considerando os perfis da temperatura de entrada e de saída do ar (fluido externo) da fileira e do perfil da temperatura do fluido interno,

$$
\theta_{\text {ent },(p, q, x)}=\exp (-\lambda x) \sum_{k=0}^{N_{a}}\left[a_{k,(p, q)} x^{k}\right]+\exp (\lambda x) \sum_{k=0}^{N_{\alpha}}\left[\alpha_{k,(p, q)} x^{k}\right]
$$




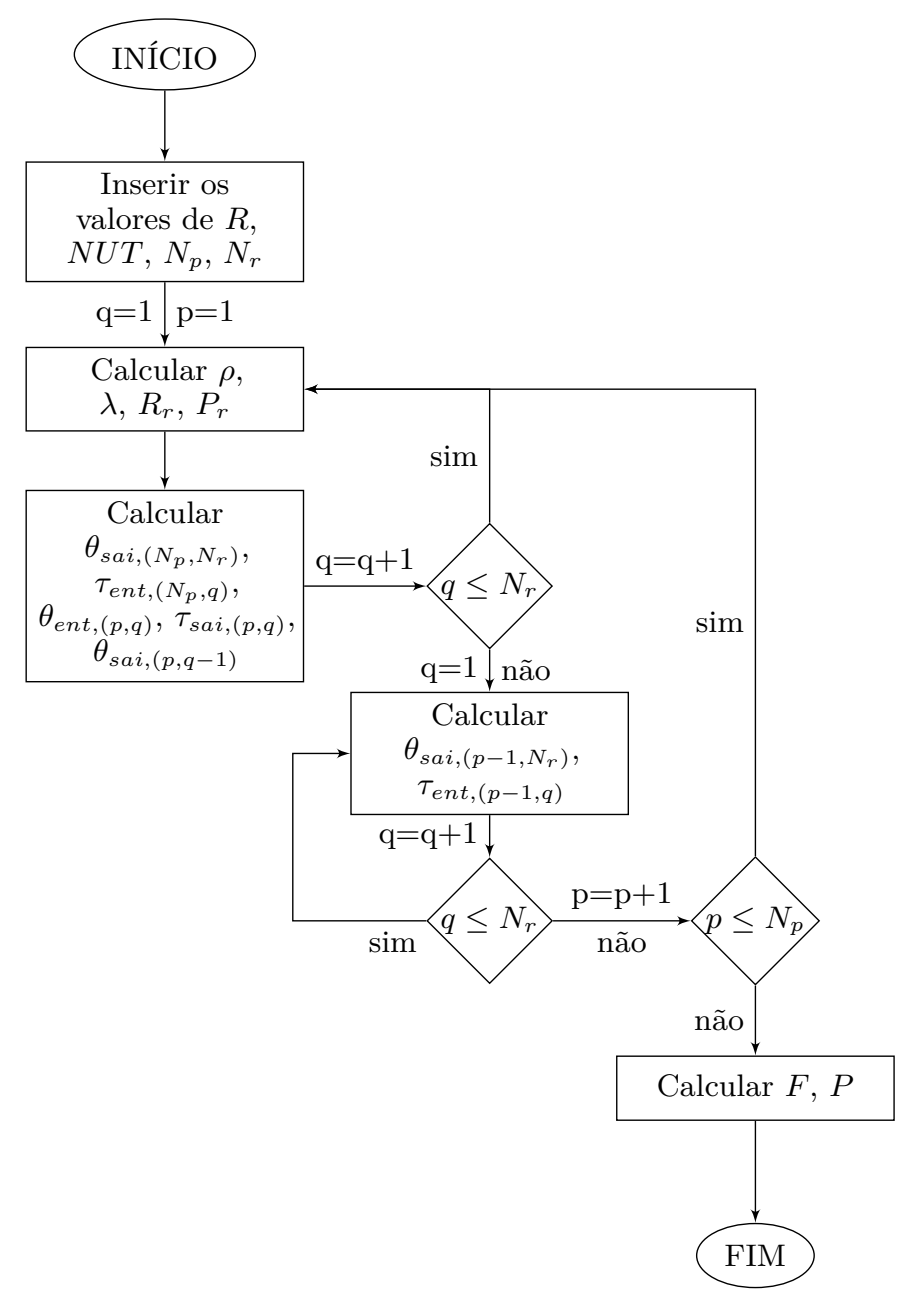

Figura 19 - Fluxograma para calcular a efetividade de temperatura e o fator de correção para os casos $2 \mathrm{~B}$ e $2 \mathrm{C}$

$$
\begin{gathered}
\tau_{(p, q, x)}=\exp (-\lambda x) \sum_{k=0}^{N_{b}}\left[b_{k,(p, q)} x^{k}\right]+\exp (\lambda x) \sum_{k=0}^{N_{\beta}}\left[\beta_{k,(p, q)} x^{k}\right] \\
\theta_{s a i,(p, q, x)}=\exp (-\lambda x) \sum_{k=0}^{N_{c}}\left[c_{k,(p, q)} x^{k}\right]+\exp (\lambda x) \sum_{k=0}^{N_{\gamma}}\left[\gamma_{k,(p, q)} x^{k}\right]
\end{gathered}
$$

Nas expressões apresentadas acima, $N_{a}, N_{b}, N_{c}, N_{\alpha}, N_{\beta}$ e $N_{\gamma}$ representam os limites superiores das somatórias.

Para número de passes ímpares, tem-se,

$$
\begin{gathered}
i=\frac{N_{p}+1}{2} \\
N_{a}+1=N_{b}=N_{c}=(i-1) N_{r}-1+q
\end{gathered}
$$




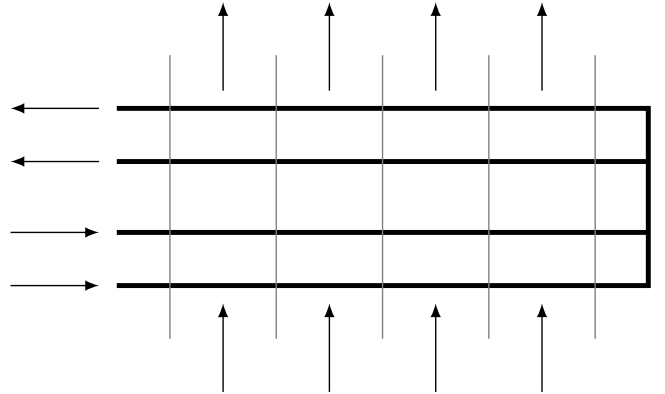

(a) Caso $3 \mathrm{~A}$

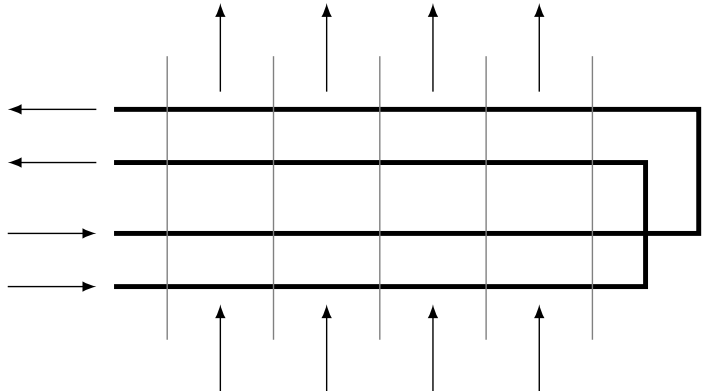

(b) Caso 3B

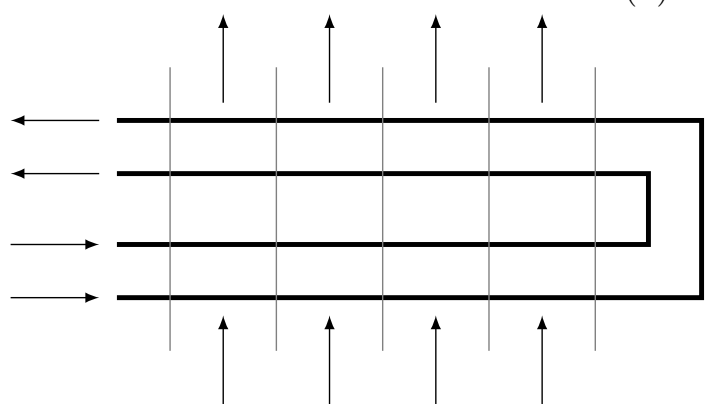

(c) Caso 3C

Figura 20 - Casos 3A, 3B e 3C: Trocador de calor de fluxo cruzado em escoamento paralelo com fluido frio não misturado entre os passes e com fluido quente misturado (caso 3A), não misturado com uma ordem idêntica das fileiras (caso 3B) e não misturado com uma ordem inversa das fileiras (caso 3C)

$$
N_{\alpha}=N_{\beta}=N_{\gamma}=(i-1) N_{r}-1
$$

Para número de passes pares, tem-se,

$$
\begin{gathered}
i=\frac{N_{p}}{2} \\
N_{a}+1=N_{b}=N_{c}=(i-1) N_{r}-1+q \\
N_{\alpha}=N_{\beta}=N_{\gamma}=i N_{r}-1
\end{gathered}
$$

Nas Equações 4.52,4.57, um valor negativo dos limites superiores indica que a somatória se reduz a zero.

Pignotti e Cordero (1983a) apresentaram expressões matemáticas para calcular os coeficiente das Equações 4.49, 4.50 e 4.51. Em um mesmo passe de tubos, estabelece-se,

$$
\theta_{\text {ent },(p, q+1, x)}=\theta_{\text {sai },(p, q, x)}
$$

Substituindo e simplificando esta expressão nas Equações 4.49 e 4.51, obtém-se, 


$$
\begin{gathered}
a_{k,(p, q+1)}=c_{k,(p, q)} \\
\alpha_{k,(p, q+1)}=\gamma_{k,(p, q)}
\end{gathered}
$$

Das Equações 4.18, 4.19, 4.49 e 4.51,

$$
\begin{gathered}
\beta_{k+1,(p, q)}=\frac{1}{2 k !} \sum_{j=k}^{N_{\beta}}\left[\alpha_{j+1,(p, q)} j !\left(-\frac{1}{2 \lambda}\right)^{j-k}\right] \\
\gamma_{k+1,(p, q)}=\rho \alpha_{k+1,(p, q)}+(1-\rho) \beta_{k+1,(p, q)} \\
b_{1,(p, q)}=\tau_{p, q, 1}-\beta_{1,(p, q)} \\
b_{k+1,(p, q)}=\frac{\lambda a_{k,(p, q)}}{k}, k \geq 1 \\
c_{k+1,(p, q)}=\rho a_{k+1,(p, q)}+(1-\rho) b_{k+1,(p, q)}
\end{gathered}
$$

Quando há uma mudança no passe do trocador de calor, tem-se,

$$
\begin{gathered}
\theta_{\text {ent }, p+1,1, x}=\theta_{\text {sai },\left(p, N_{r}, 1-x\right)} \\
a_{k+1,(p+1,1)}=(-1)^{k} \frac{\exp (\lambda)}{k !} \sum_{j=k}^{N_{a}}\left[\gamma_{j+1,\left(p, N_{r}\right)} \frac{j !}{(j-k) !}\right] \\
\alpha_{k+1,(p+1,1)}=(-1)^{k} \frac{\exp (-\lambda)}{k !} \sum_{j=k}^{N_{\alpha}}\left[c_{j+1,\left(p, N_{r}\right)} \frac{j !}{(j-k) !}\right]
\end{gathered}
$$

Definem-se as variáveis de entrada a partir de $\theta_{\text {ent },(1,1)}=0$,

$$
a_{k+1,(1,1)}=\alpha_{k+1,(1,1)}=0
$$

As expressões descritas acima são utilizadas para os casos 3 e 4 de Pignotti e Cordero (1983a). As relações matemáticas para cada caso são apresentadas mais detalhadamente nas próximas seções.

Definem-se as temperaturas adimensionais dos fluidos quente e frio, 


$$
\begin{gathered}
\theta_{(p, q, x)}=\frac{T_{q,(p, q, x)}-T_{f, e n t}}{T_{q, e n t}-T_{f, e n t}} \\
\tau_{e n t,(p, q, x)}=\frac{T_{f, e n t,(p, q, x)}-T_{f, e n t}}{T_{q, e n t}-T_{f, e n t}} \\
\tau_{s a i,(p, q, x)}=\frac{T_{f, s a i,(p, q, x)}-T_{f, e n t}}{T_{q, \text { ent }}-T_{f, \text { ent }}}
\end{gathered}
$$

Os valores iniciais dos tubos do primeiro passe são,

$$
\tau_{1, q, 1}=1
$$

Para os outros passes, dependendo do arranjo de mistura do fluido quente entre os passes, pode-se definir,

$$
\tau_{p+1, q, 1}= \begin{cases}\tau_{s a i,(p)}, & \text { caso } 3 \mathrm{~A} \\ \tau_{(p, q, 2)}, & \text { caso 3B } \\ \tau_{\left(p, N_{r}+1-q, 2\right)}, & \text { caso 3C }\end{cases}
$$

onde a temperatura adimensional do último passe $\theta_{s a i,(p)}$ é obtida através da média aritmética da temperatura adimensional na saída dos tubos,

$$
\begin{aligned}
\theta_{\text {sai },(p)} & =\frac{1}{N_{r}} \sum_{q=1}^{N_{r}}\left[\tau_{(p, q, 2)}\right] \\
& =\frac{1}{N_{r}} \sum_{q=1}^{N_{r}}\left\{\exp (-\lambda) \sum_{k=0}^{N_{b}}\left[b_{k+1,(p, q)}\right]+\exp (\lambda) \sum_{k=0}^{N_{\beta}}\left[\beta_{k+1,(p, q)}\right]\right\}
\end{aligned}
$$

A efetividade é então obtida através da Equação 4.75 para o último passe $\left(p=N_{p}\right)$,

$$
P=\frac{1-\theta_{\text {sai, }\left(N_{p}\right)}}{R}
$$

O fator de correção é então obtido em função do número de unidades de transferência $N U T$, da razão de capacidade $R$ e da efetividade de temperatura $P$ pelas Equações $4.1 \mathrm{e} 4.2$.

O fluxograma do algoritmo é apresentado na Figura 21. Os parâmetros são então calculados nesta ordem: todos os coeficientes de cada passe são calculados com as Equações 
4.594 .65 a partir da condição inicial. As Equações 4.69 e 4.73 fornecem as condições iniciais para o primeiro passe e as Equações 4.67, 4.68 e 4.74 fornecem as condições iniciais para todos os outros passes. A única diferença entre os casos 3A, 3B e 3C reside no cálculo das condições de entrada da cada passe dada pela Equação 4.74 .

No algoritmo mostrado na Figura 21 é necessário empregar seis laços condicionais, um na variável $q$ relacionada com o número de fileiras em cada passe, $N_{r}$, um com a variável $p$ relacionada com o número de passes, $N_{p}$, e quatro com a variável $k$ relacionada com o número de fileiras ou passes para calcular os coeficientes $a_{k}, b_{k}, c_{k}, \alpha_{k}, \beta_{K}$ e $\gamma_{k}$. O cálculo desses coeficientes define o cálculo das condições de entrada nas respectivas fileiras e passes, assim como os perfis de temperatura desejados.

\subsubsection{Caso 4A}

O cálculo das relações e obtenção das soluções para os casos 4A, 4B, e 4C são mais complexos. As três variantes foram implementadas em dois programas separados no Matlab 2015a, um para o caso 4A, e outro para os casos 4B e 4C. A seguir se explicam os procedimentos adotados.

O caso 4A de Pignotti e Cordero (1983a) é apresentado nesta seção, que é referente aos trocadores de calor de fluxo cruzado em escoamento contracorrente com fluido frio não misturado entre os passes e fluido quente misturado. Na Figura 22 é apresentado um exemplo de um trocador de calor com dois passes e dois tubos (2-2).

As temperaturas adimensionais para este caso são definidas como,

$$
\begin{aligned}
& \theta_{\text {ent },(p, q, x)}=\frac{T_{f, e n t,(p, q, x)}-T_{f, e n t}}{T_{q, s a i}-T_{f, e n t}} \\
& \theta_{\text {ent },(p, q, x)}=\frac{T_{f, s a i,(p, q, x)}-T_{f, e n t}}{T_{q, s a i}-T_{f, e n t}}
\end{aligned}
$$

Sendo que a temperatura adimensional na saída do trocador de calor $\tau_{\text {sai }}$ é conhecida,

$$
\tau_{\text {sai }}=\tau_{\text {sai }, 1}=\frac{1}{N_{r}} \sum_{q=1}^{N_{r}}\left[\tau_{(1, q, 2)}\right]=1
$$

Assim, pode-se separar os coeficientes $a, b$ e $c$,

$$
\begin{aligned}
& a_{k+1,(p, q)}=a_{k+1,(p, q)}^{\prime} \tau_{(p, 1)}+a_{k+1,(p, q)}^{\prime \prime} \\
& b_{k+1,(p, q)}=b_{k+1,(p, q)}^{\prime} \tau_{(p, 1)}+b_{k+1,(p, q)}^{\prime \prime}
\end{aligned}
$$




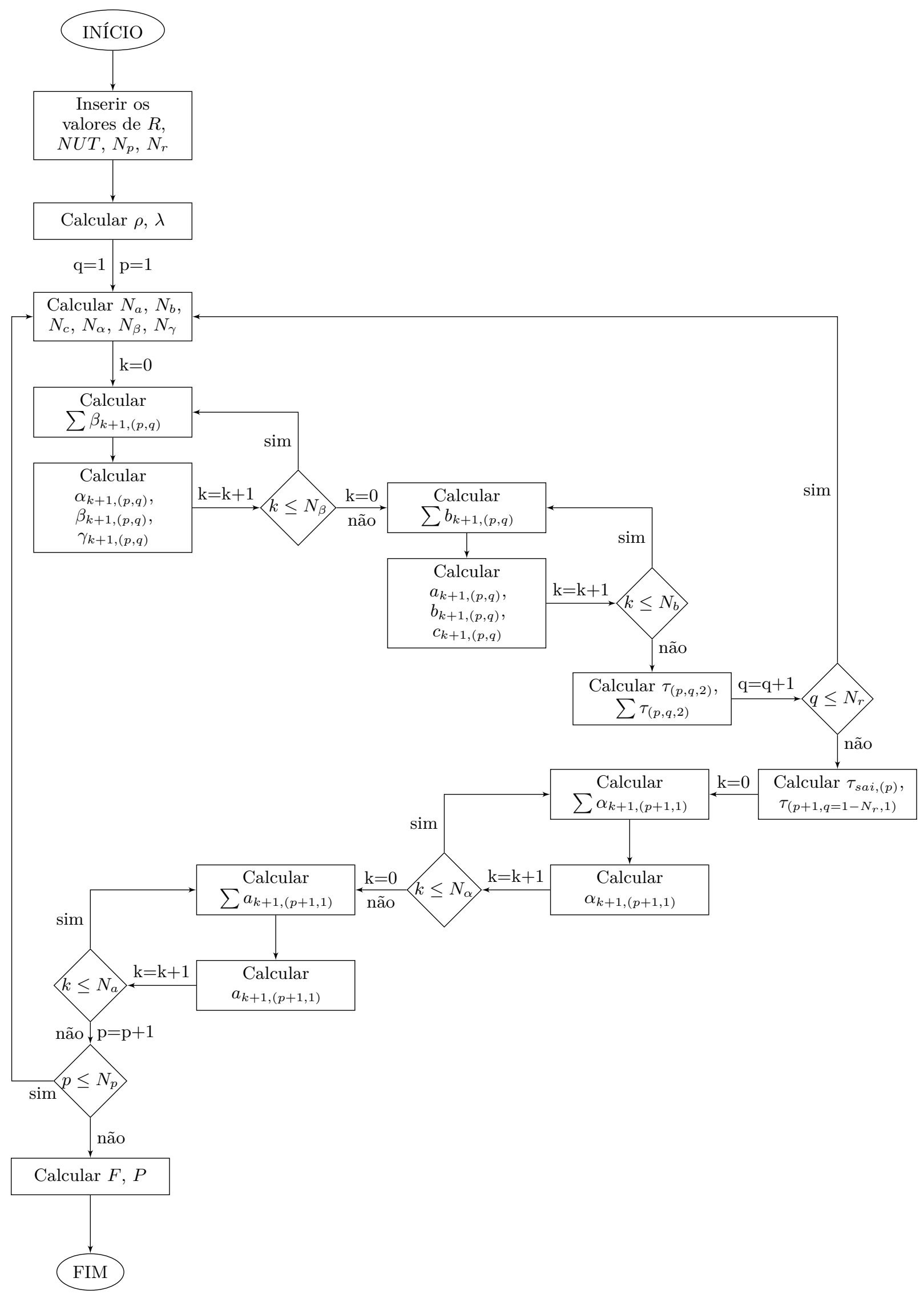

Figura 21 - Fluxograma para calcular a efetividade de temperatura e o fator de correção para os casos $3 \mathrm{~A}, 3 \mathrm{~B}$ e $3 \mathrm{C}$ 


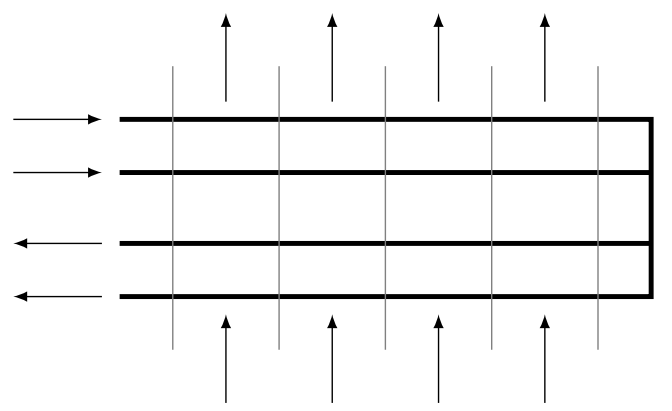

Figura 22 - Caso 4A: Trocador de calor de fluxo cruzado em escoamento contracorrente com dois passes e dois tubos (2-2) com os fluidos quente e frio completamente misturados entre os passes

$$
c_{k+1,(p, q)}=c_{k+1,(p, q)}^{\prime} \tau_{(p, 1)}+c_{k+1,(p, q)}^{\prime \prime}
$$

Os coeficientes $a^{\prime}, a^{\prime \prime}, b^{\prime}, b^{\prime \prime}, c^{\prime}$ e $c^{\prime \prime}$ são calculados de acordo com as Equações 4.59, 4.64 e 4.65 e os coeficientes $b_{1,(p, q)}^{\prime}$ e $b_{1,(p, q)}^{\prime \prime}$ são calculados conforme a expressão abaixo,

$$
\begin{gathered}
b_{1,(p, q)}^{\prime}=1 \\
b_{1,(p, q)}^{\prime \prime}=-\beta_{1,(p, 1)}
\end{gathered}
$$

Os valores iniciais dos coeficientes $a^{\prime}$ e $a^{\prime \prime}$ para cada passe são definidos como,

$$
\begin{gathered}
a_{k+1,(p, 1)}^{\prime}=0 \\
a_{k+1,(p, 1)}^{\prime \prime}=a_{k+1,(p, 1)}
\end{gathered}
$$

Utilizando as Equações 4.83 e 4.85 e as Equações 4.59, 4.64 e 4.65 , é fácil observar que os coeficientes $a_{k+1,(p, q)}^{\prime}, b_{k+1,(p, q)}^{\prime}$ e $c_{k+1,(p, q)}^{\prime}$ são iguais para cada passe do trocador de calor. Logo, pode-se definir este coeficientes sem o índice referente ao passe, $a_{k+1,(p, q)}^{\prime}=$ $a_{k+1,(q)}^{\prime}, b_{k+1,(p, q)}^{\prime}=b_{k+1,(q)}^{\prime}$ e $c_{k+1,(p, q)}^{\prime}=c_{k+1,(q)}^{\prime}$.

A condição na qual o fluido quente é completamento misturado entre os passes implica que,

$$
\begin{gathered}
\tau_{s a i,(p)}=\frac{1}{N_{r}} \sum_{q=1}^{N_{r}}\left[\tau_{(p, q, 2)}\right] \\
\tau_{s a i,(p)}=f \tau_{p, 1}+g
\end{gathered}
$$


onde os parâmetros $f$ e $g$ são definidos como,

$$
\begin{gathered}
f=\frac{\exp (-\lambda)}{N_{r}} \sum_{q=1}^{N_{r}}\left\{\sum_{k=0}^{q-1}\left[b_{k+1,(q)}^{\prime}\right]\right\} \\
g=\frac{1}{N_{r}} \sum_{q=1}^{N_{r}}\left\{\exp (-\lambda) \sum_{k=0}^{N_{b}}\left[b_{k+1,(p, q)}^{\prime \prime}\right]+\exp (\lambda) \sum_{k=0}^{N_{\beta}}\left[\beta_{k+1,(p, q)}\right]\right\}
\end{gathered}
$$

A efetividade de temperatura do trocador de calor pode então ser calculada usando a expressão abaixo,

$$
P=\frac{\tau_{N_{p}, 1}-1}{R \tau_{N_{p}, 1}}
$$

O fator de correção é então obtido em função do número de unidades de transferência $N U T$, da razão de capacidade $R$ e da efetividade de temperatura $P$ pelas Equações 4.1 e 4.2 ,

O fluxograma do algoritmo é apresentado na Figura 23. A efetividade e o fator de correção são calculados na seguinte ordem: todos os coeficientes de cada passe são calculados usando as Equações 4.59, 4.62, 4.64, 4.65, 4.83 e 4.84 e os valores iniciais fornecidos pelas Equações 4.67,4.69, 4.85 e 4.86.

No algoritmo mostrado na Figura 23 é necessário empregar sete laços condicionais. Seis são similares aos mostrados na Figura 21 um na variável $q$ relacionada com o número de fileiras em cada passe, $N_{r}$; um com a variável $p$ relacionada com o número de passes, $N_{p}$; e quatro com a variável $k$ relacionada com o número de fileiras ou passes para calcular os coeficientes $a_{k}, a_{k}^{\prime}, a_{k}^{\prime \prime}, b_{k}, b_{k}^{\prime}, b_{k}^{\prime \prime}, c_{k}, c_{k}^{\prime}, c_{k}^{\prime \prime}, \alpha_{k}, \beta_{k}$ e $\gamma_{k}$. Um sétimo está relacionado com o cálculo da variável $l$ para atualização de alguns parâmetros no início do algoritmo, este laço condicional é de extrema importância para o cálculo correto da efetividade e do fator de correção e não está apresentado no artigo de Pignotti e Cordero (1983a).

\subsubsection{Casos 4B e 4C}

Nesta seção são apresentados os casos 4B e 4C de Pignotti e Cordero (1983a), que são trocadores de calor de fluxo cruzado em escoamento contracorrente com fluido frio não misturado entre os passes e com fluido quente não misturado com uma ordem idêntica das fileiras e não misturado com uma ordem inversa das fileiras. Isto é mostrado no exemplo de um trocador de calor com dois passes e dois tubos (2-2) na Figura 24.

As temperaturas adimensionais escolhidas para estes tipos de trocadores de calor são os mesmos do caso 4A, Equações 4.77 e 4.78 . 


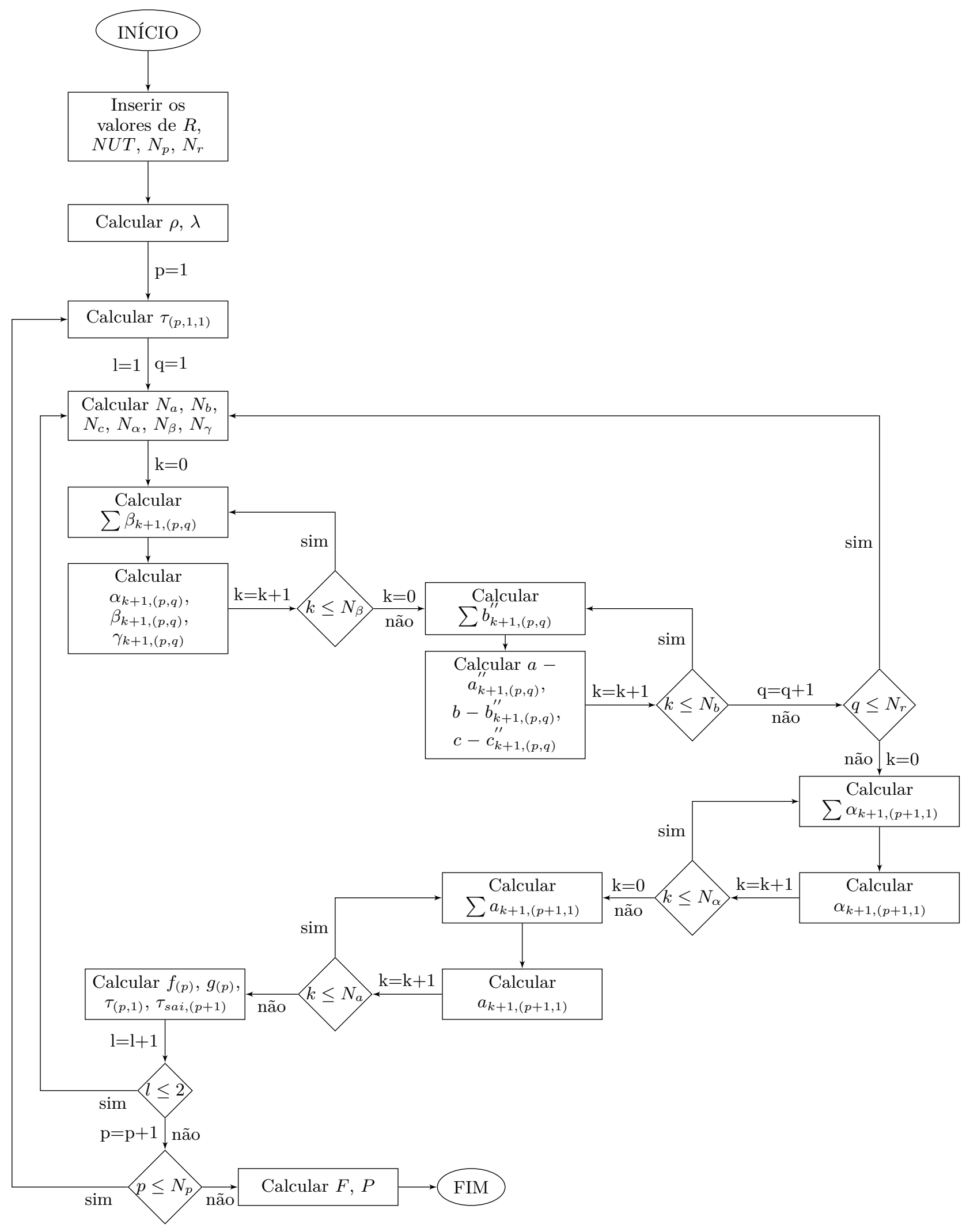

Figura 23 - Fluxograma para calcular a efetividade de temperatura e o fator de correção para o caso $4 \mathrm{~A}$ 


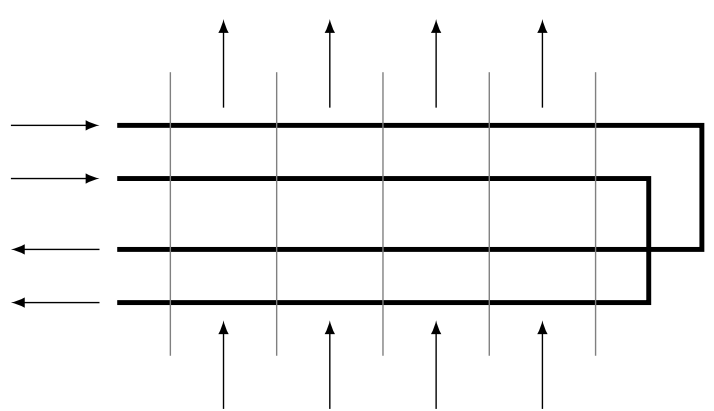

(a) Caso 4B

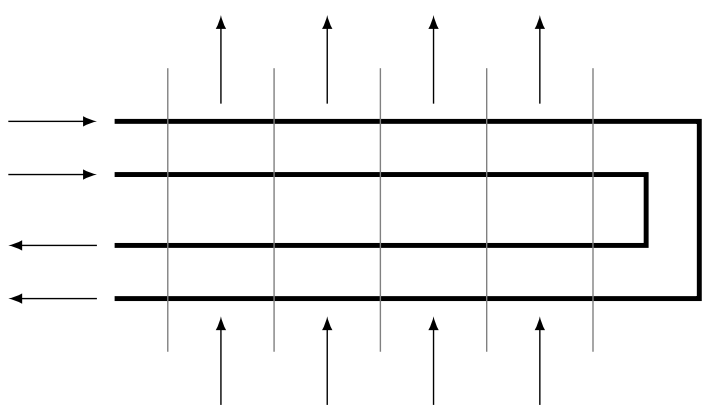

(b) Caso 4C

Figura 24 - Casos 4B e 4C: Trocador de calor de fluxo cruzado em escoamento contracorrente com dois passes e dois tubos (2-2) com os fluidos frio não misturado entre os passes e fluido quente não misturado com uma ordem idêntica das fileiras (caso 4B) e não misturado com uma ordem inversa das fileiras (caso 4C)

Para este algoritmo, define-se um sistema de equações lineares dado pela expressão matemática abaixo,

$$
\sum_{j=1}^{N_{r}}\left[C_{i, j}^{\prime} \tau_{(1, j, 1)}\right]=1
$$

Para o cálculo da variável $C_{i, j}^{\prime}$, o procedimento abaixo deve ser seguido,

1. Define-se as seguintes variáveis,

$$
\begin{gathered}
\tau_{(1, j, 1)}=1, q=j \\
\tau_{(1, q, 1)}=0, q \neq j
\end{gathered}
$$

As Equações 4.59 4.65 e valor inicial da Equação 4.69 definem todos os coeficientes do primeiro passe.

2. Os valores iniciais para os próximos passes são dados pelas Equações 4.67 e 4.68 , e pela condição abaixo, que depende do tipo de mistura do fluido quente,

$$
\tau_{(p+1, q, 2)}= \begin{cases}\tau_{(p, q, 1)}, & \text { caso } 4 \mathrm{~B} \\ \tau_{\left(p, N_{r}+1-q, 1\right)}, & \text { caso } 4 \mathrm{C}\end{cases}
$$

o que permite o cálculo de $\tau_{(p+1, q, 1)}$ como,

$$
\tau_{(p+1, q, 1)}=\exp (\lambda) \tau_{(p, q, 1)}-\exp (2 \lambda) \sum_{k=0}^{N_{\beta}}\left[\beta_{k+1,(p+1, q)}\right]+\beta_{1,(p+1, q)}-\sum_{k=1}^{N_{b}}\left[b_{k+1,(p+1, q)}\right]
$$


3. Novamente utilizam-se as Equações 4.59,4.65 para fornecer os coeficientes necessários para a expansão de $\theta_{\text {ent,(x) }}, \tau_{(x)}$ e $\theta_{\text {sai, }(x)}$.

4. Quando chegar ao último passe, como $\tau_{\left(N_{p}, q, 1\right)}=1$, simplica-se a Equação 4.96 e a expressão abaixo é obtida para $i=1, \ldots, N_{r}$,

$$
\begin{gathered}
B_{i, 1}=1 \\
C_{i, j}^{\prime}=\exp (\lambda) \tau_{\left(N_{p}-1, i, 1\right)}-\exp (2 \lambda) \sum_{k=0}^{N_{\beta}}\left[\beta_{k+1,\left(N_{p}, i\right)}\right]+\beta_{1,\left(N_{p}, i\right)}-\sum_{k=1}^{N_{b}}\left[b_{k+1,\left(N_{p}, i\right)}\right]
\end{gathered}
$$

5. Os passo 1 a 4 são repetidos para toda variável $j$ entre 1 e $N_{r}$.

6. O sistema linear apresentado pela Equação 4.92 fornecem as temperaturas adimensionais $\tau_{(1, q, 1)}$.

$$
\tau_{1, j, 1}=\left(C_{i, j}^{\prime}\right)^{-1} B_{i, 1}
$$

A temperatura na saída do fluido quente é calculada como,

$$
\tau_{\text {sai }}=\frac{1}{N_{r}} \sum_{q=1}^{N_{r}}\left[\tau_{(1, q, 2)}\right]=\frac{1}{N_{r}} \sum_{q=1}^{N_{r}}\left\{\exp (-\lambda) \sum_{k=0}^{q-1}\left[b_{k+1,(1, q)}\right]\right\}
$$

Finalmente, calcula-se a efetividade de temperatura do trocador de calor como,

$$
P=\frac{1-\tau_{\text {sai }}}{R}
$$

O fator de correção é então obtido em função do número de unidades de transferência $N U T$, da razão de capacidade $R$ e da efetividade de temperatura $P$ pelas Equações 4.1 e 4.2 ,

O algoritmo de cálculo empregado para o cálculo de $F$ para os casos $4 \mathrm{~B}$ e $4 \mathrm{C}$ se mostra na Figura 25, enquanto na Figura 26 se apresentam dois procedimentos numéricos chamados pelo algoritmo principal. Esses procedimentos são empregados para calcular o sistema de equações antes comentado. Nota-se que os casos 4B e 4C são os mais complexos do ponto de vista computacional. De fato no algoritmo principal (Figura 25) se empregam onze laços computacionais, enquanto se utilizam seis laços computacionais adicionais nos procedimentos numéricos mostrados na Figura 26. O significado das variáveis empregadas nos laços $q, p, k$ e $l$ é similar ao comentado nos algoritmos anteriores. 


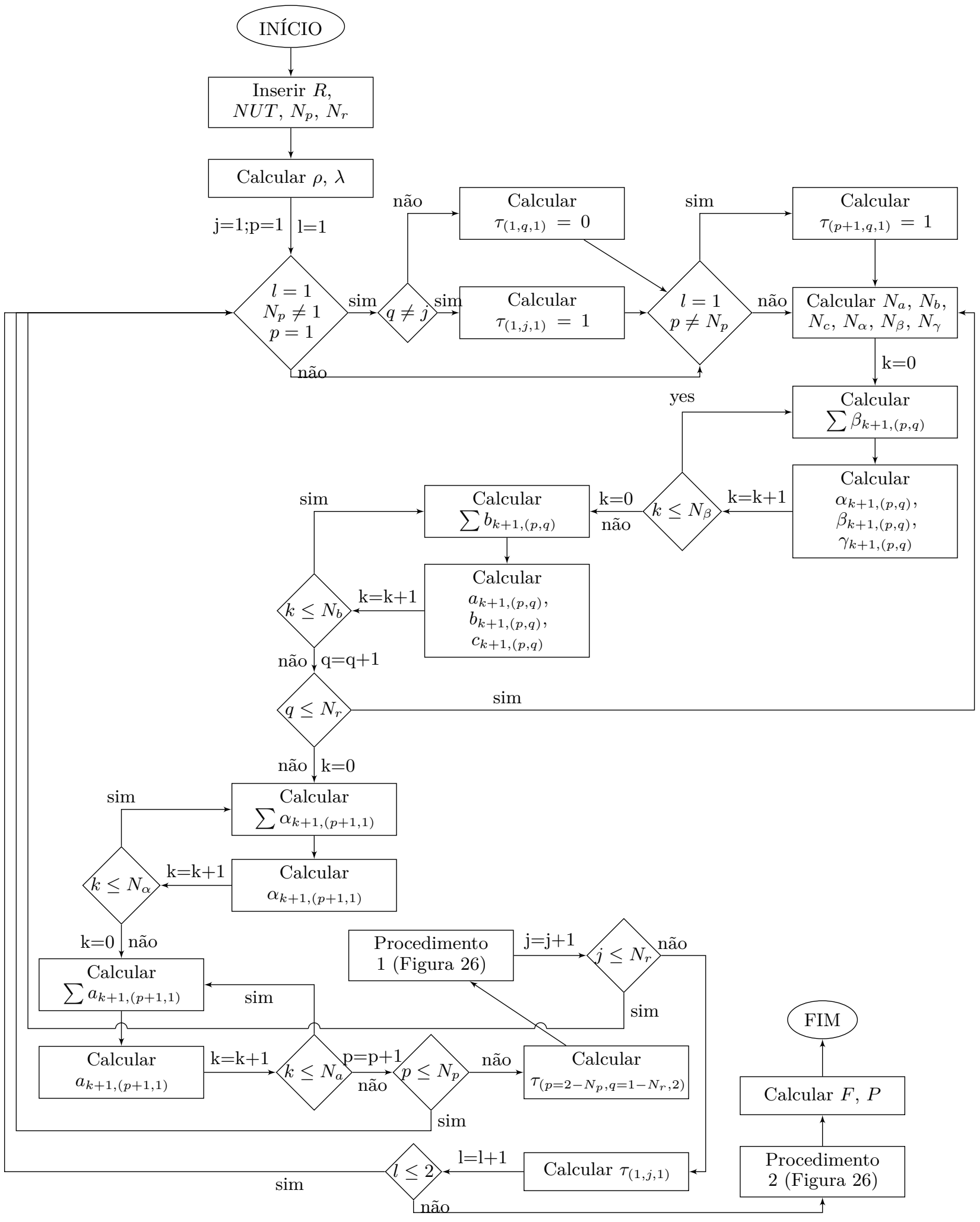

Figura 25 - Fluxograma para calcular a efetividade de temperatura e o fator de correção para os casos $4 \mathrm{~B}$ e $4 \mathrm{C}$ 

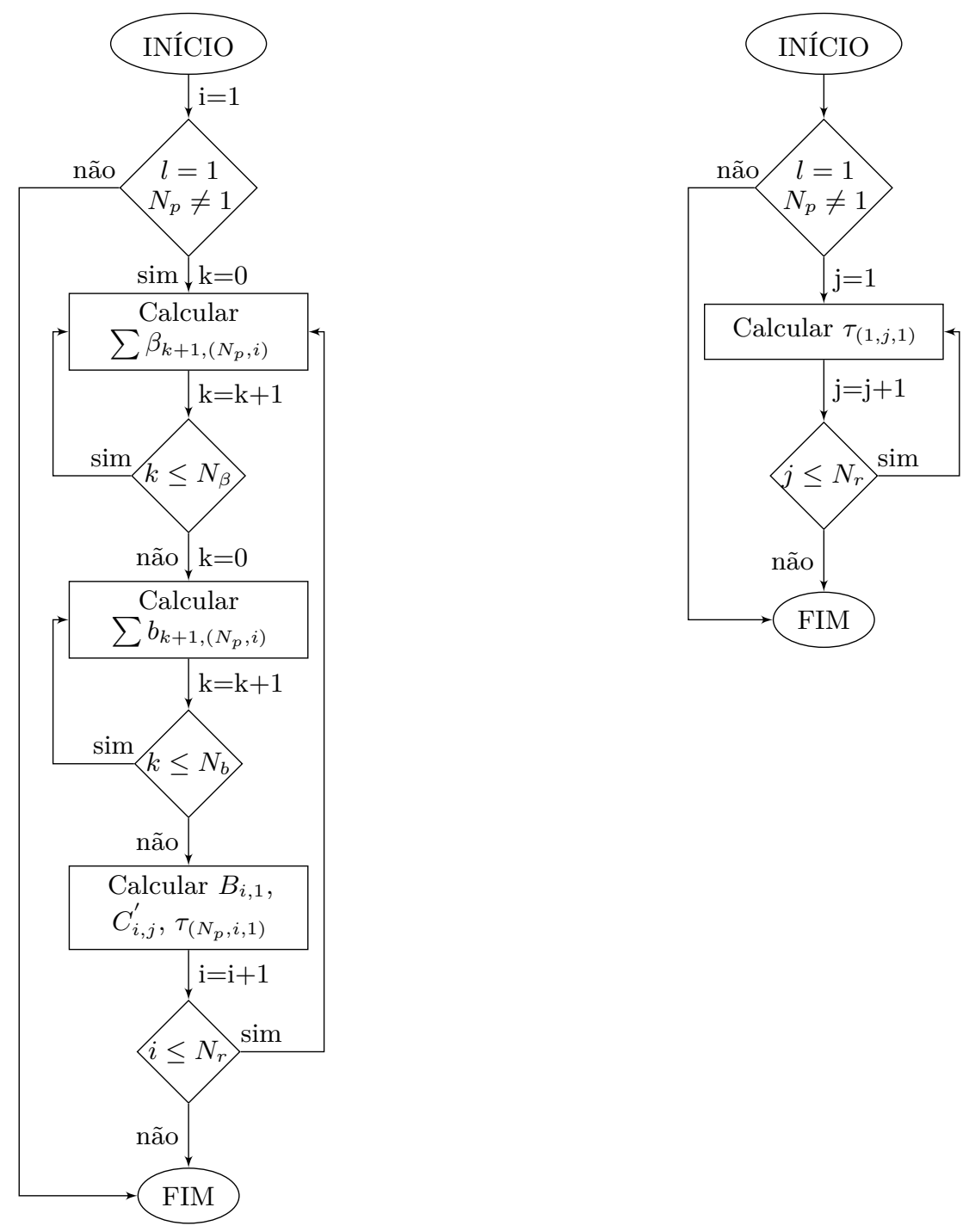

Figura 26 - Procedimento complementar 1 e 2 dos casos 4B e 4C 


\section{Resultados e Discussões}

Neste capítulo se apresentam os resultados fundamentais obtidos com o código desenvolvido por Pignotti e Cordero (1983a), detalhado por Magazoni e Cabezas-Gómez (2016) e apresentado na Seção 4.1. Um dos objetivos é demonstrar a capacidade do algoritmo para simular diferentes configurações de trocadores de calor de fluxo cruzado e de casco e tubo.

Na Seção 5.1 se apresentam os resultados para trocadores de calor de fluxo cruzado. São apresentados diversos resultados e comparações do modelo proposto com relações teóricas e aproximadas bem conhecidas na literatura aberta, assim como os resultados desenvolvidos utilizando o código HETE (explicado na Seção 3.4).

A metodologia desenvolvida para trocadores de calor de fluxo cruzado é aplicada no cálculo da efetividade de temperatura e do fator de correção para trocadores de calor de casco e tubo tipo TEMA E com um passe no casco e um no tubo (1-1) em escoamentos contracorrente e paralelo. Os resultados para trocadores de calor de casco e tubo são apresentados na Seção 5.2 .

Nas comparações dos resultados numéricos com aqueles fornecidos com relações teóricas ou aproximadas, os erros relativo, $\delta$, e o relativo médio, $\delta_{m}$, são calculados pelas seguintes definições,

$$
\begin{gathered}
\delta=100\left|\frac{F_{t h}-F}{F_{t h}}\right| \\
\delta_{m}=100\left(\frac{1}{N_{d}} \sum_{1}^{N_{d}}\left|\frac{F_{t h}-F}{F_{t h}}\right|\right)
\end{gathered}
$$

onde $F_{\text {th }}$ e $F$ são respectivamente os fatores de correção calculados pelo código desenvolvido no presente trabalho e avaliados através das expressões teóricas ou aproximadas disponíveis na literatura, $N_{d}$ representa o número de dados considerados na avaliação de um arranjo em particular.

\subsection{Trocador de Calor de Fluxo Cruzado}

Dados da efetividade de temperatura e do fator de correção de trocadores de calor com um tubo por passe e dois, cinco e dez passes são determinados pelo algoritmo da Seção 4.1 e apresentados a seguir. Os resultados podem ser observados respectivamente nas Tabelas 6, 7] e 8 para configurações de trocadores de calor em contracorrente com 
o fluido frio não misturado e o fluido quente misturado, caso 4A de Pignotti e Cordero (1983a). Os resultados são sumarizados na Figura 27, onde o comportamento do fator de correção, $F$, em função da efetividade de temperatura, $P$, e da razão de temperatura, $R$, pode ser visto graficamente para os três tipos de trocadores de calor de fluxo cruzado considerados.

Tabela 6 - Efetividade de temperatura e fator de correção para trocador de calor de fluxo cruzado em escoamento contracorrente com dois passes e um tubo por passe (2-1) com o fluido frio não misturado e o fluido quente misturado - Caso $4 \mathrm{~A}$

\begin{tabular}{|c|c|c|c|c|c|c|c|c|c|c|}
\hline & \multicolumn{5}{|c|}{$P$} & \multicolumn{5}{|c|}{$F$} \\
\hline NUT ${ }^{R}$ & 0,1 & 0,5 & 1,0 & 2,0 & 4,0 & 0,1 & 0,5 & 1,0 & 2,0 & 4,0 \\
\hline 0,1 & 0,095 & 0,093 & 0,091 & 0,087 & 0,079 & 1,000 & 1,000 & 1,000 & 0,999 & 0,998 \\
\hline 0,2 & 0,180 & 0,174 & 0,166 & 0,153 & 0,130 & 0,999 & 0,997 & 0,995 & 0,990 & 0,981 \\
\hline 0,4 & 0,325 & 0,306 & 0,284 & 0,246 & 0,187 & 0,998 & 0,993 & 0,985 & 0,972 & 0,951 \\
\hline 0,6 & 0,443 & 0,410 & 0,372 & 0,307 & 0,215 & 0,998 & 0,993 & 0,985 & 0,972 & 0,951 \\
\hline 0,8 & 0,539 & 0,492 & 0,438 & 0,348 & 0,229 & 0,997 & 0,987 & 0,975 & 0,953 & 0,921 \\
\hline 1,0 & 0,617 & 0,558 & 0,490 & 0,377 & 0,237 & 0,996 & 0,980 & 0,961 & 0,931 & 0,890 \\
\hline 1,2 & 0,681 & 0,613 & 0,532 & 0,399 & 0,241 & 0,994 & 0,971 & 0,946 & 0,906 & 0,857 \\
\hline 1,4 & 0,734 & 0,657 & 0,565 & 0,415 & 0,244 & 0,992 & 0,961 & 0,928 & 0,880 & 0,825 \\
\hline 1,6 & 0,778 & 0,695 & 0,593 & 0,427 & 0,246 & 0,989 & 0,950 & 0,910 & 0,853 & 0,793 \\
\hline 1,8 & 0,814 & 0,726 & 0,616 & 0,436 & 0,247 & 0,986 & 0,937 & 0,890 & 0,826 & 0,762 \\
\hline 2,0 & 0,844 & 0,752 & 0,635 & 0,444 & 0,248 & 0,983 & 0,924 & 0,869 & 0,799 & 0,733 \\
\hline 3,0 & 0,932 & 0,836 & 0,695 & 0,464 & 0,249 & 0,960 & 0,845 & 0,760 & 0,673 & 0,604 \\
\hline 4,0 & 0,968 & 0,876 & 0,725 & 0,473 & 0,250 & 0,927 & 0,757 & 0,658 & 0,569 & 0,505 \\
\hline 5,0 & 0,983 & 0,897 & 0,740 & 0,477 & 0,250 & 0,884 & 0,672 & 0,570 & 0,486 & 0,429 \\
\hline 6,0 & 0,990 & 0,909 & 0,749 & 0,479 & 0,250 & 0,831 & 0,596 & 0,498 & 0,421 & 0,371 \\
\hline 7,0 & 0,993 & 0,915 & 0,754 & 0,480 & 0,250 & 0,773 & 0,530 & 0,438 & 0,369 & 0,324 \\
\hline 8,0 & 0,995 & 0,919 & 0,757 & 0,481 & 0,250 & 0,713 & 0,474 & 0,390 & 0,327 & 0,287 \\
\hline 9,0 & 0,996 & 0,921 & 0,759 & 0,481 & 0,250 & 0,655 & 0,427 & 0,350 & 0,293 & 0,257 \\
\hline 10,0 & 0,996 & 0,922 & 0,760 & 0,482 & 0,250 & 0,602 & 0,387 & 0,317 & 0,265 & 0,232 \\
\hline
\end{tabular}

Trocador de calor de fluxo cruzado ilustrado na Figura 90 do Anexo A

Na Tabela 9 são apresentados os resultados da efetividade de temperatura e do fator de correção para trocadores de calor de fluxo cruzado em escoamentos paralelo (casos $1 \mathrm{~A}$ e $3 \mathrm{~A}$ ) e contracorrente (casos $2 \mathrm{~A}$ e $4 \mathrm{~A}$ ) com dois passes e um tubo por passe (2-1) e cinco passes e um tubo por passe (5-1) para $R=1,0$, onde o fluido frio entre os tubos é considerado misturado (casos $1 \mathrm{~A}$ e $2 \mathrm{~A}$ ) e não misturado (casos $3 \mathrm{~A}$ e $4 \mathrm{~A}$ ). Observa-se que a efetividade de temperatura das configurações de trocador de calor em escoamento contracorrente é maior em comparação com as configurações em escoamento paralelo. Outra conclusão é que a efetividade de trocadores de calor em escoamento contracorrente com o fluido frio misturado é levemente maior em comparação com o fluido frio não misturado, por causa do fato que a temperatura do fluido frio misturado é igual entre os tubos e consequentemente a diferença de temperatura entre os dois fluidos é uniformemente distribuída. Isto é melhor evidenciado nas Figuras 27 e 28, onde é possível notar graficamente a diferença entre os fluidos frio misturado (caso $2 \mathrm{~A}$ ) e o não misturado (caso 4A) para trocadores de calor de fluxo cruzado em escoamento contracorrente com um tubo por passe e dois, cinco e dez passes. Na Figura 28 é apresentado o comportamento da 
Tabela 7 - Efetividade de temperatura e fator de correção para trocador de calor de fluxo cruzado em escoamento contracorrente com cinco passes e um tubo (5-1) com o fluido frio não misturado e o fluido quente misturado - Caso 4A

\begin{tabular}{|c|c|c|c|c|c|c|c|c|c|c|}
\hline & \multicolumn{5}{|c|}{$P$} & \multicolumn{5}{|c|}{$F$} \\
\hline$\overbrace{N U T}^{R}$ & 0,1 & 0,5 & 1,0 & 2,0 & 4,0 & 0,1 & 0,5 & 1,0 & 2,0 & 4,0 \\
\hline 0,1 & 0,095 & 0,093 & 0,091 & 0,001 & 0,080 & 1,000 & 1,000 & 1,000 & 1,000 & 1,000 \\
\hline 0,2 & 0,180 & 0,174 & 0,167 & 0,153 & 0,131 & 1,000 & 1,000 & 0,999 & 0,998 & 0,997 \\
\hline 0,4 & 0,325 & 0,307 & 0,285 & 0,248 & 0,189 & 1,000 & 0,999 & 0,998 & 0,995 & 0,991 \\
\hline 0,6 & 0,443 & 0,411 & 0,374 & 0,310 & 0,217 & 1,000 & 0,999 & 0,998 & 0,995 & 0,991 \\
\hline 0,8 & 0,539 & 0,495 & 0,443 & 0,354 & 0,232 & 1,000 & 0,998 & 0,996 & 0,992 & 0,984 \\
\hline 1,0 & 0,618 & 0,564 & 0,498 & 0,386 & 0,240 & 0,999 & 0,997 & 0,993 & 0,987 & 0,976 \\
\hline 1,2 & 0,683 & 0,620 & 0,543 & 0,409 & 0,244 & 0,999 & 0,995 & 0,991 & 0,982 & 0,966 \\
\hline 1,4 & 0,737 & 0,668 & 0,580 & 0,427 & 0,247 & 0,999 & 0,994 & 0,987 & 0,975 & 0,955 \\
\hline 1,6 & 0,781 & 0,708 & 0,611 & 0,441 & 0,248 & 0,998 & 0,992 & 0,983 & 0,968 & 0,943 \\
\hline 1,8 & 0,818 & 0,742 & 0,638 & 0,451 & 0,249 & 0,998 & 0,989 & 0,979 & 0,961 & 0,931 \\
\hline 2,0 & 0,848 & 0,771 & 0,661 & 0,460 & 0,249 & 0,997 & 0,9 & 0,975 & 0,952 & 0,918 \\
\hline 3,0 & 0,938 & 0,868 & 0,739 & 0,483 & 0,250 & 0,994 & 0,971 & 0,945 & 0,903 & 0,850 \\
\hline 4,0 & 0,974 & 0,919 & 0,784 & 0,491 & 0,250 & 0,989 & 0,950 & 0,908 & 0,848 & 0,782 \\
\hline 5,0 & 0,989 & 0,948 & 0,812 & 0,495 & 0,250 & 0,983 & 0,923 & 0,866 & 0,791 & 0,720 \\
\hline 6,0 & 0,995 & 0,964 & 0,831 & 0,497 & 0,250 & 0,975 & 0,893 & 0,821 & 0,736 & 0,663 \\
\hline 7,0 & 0,998 & 0,975 & 0,844 & 0,498 & 0,250 & 0,966 & 0,860 & 0,775 & 0,684 & 0,613 \\
\hline 8,0 & 0,999 & 0,981 & 0,854 & 0,498 & 0,250 & 0,955 & 0,824 & 0,730 & 0,636 & 0,568 \\
\hline 9,0 & 1,000 & 0,985 & 0,861 & 0,499 & 0,250 & 0,942 & 0,788 & 0,687 & 0,593 & 0,527 \\
\hline 10,0 & 1,000 & 0,988 & 0,866 & 0,499 & 0,250 & 0,927 & 0,752 & 0,647 & 0,553 & 0,491 \\
\hline
\end{tabular}

Trocador de calor de fluxo cruzado ilustrado na Figura 93 do Anexo A

Tabela 8 - Efetividade de temperatura e fator de correção para trocador de calor de fluxo cruzado em escoamento contracorrente com dez passes e um tubo (10-1) com o fluido frio não misturado e o fluido quente misturado - Caso 4A

\begin{tabular}{|c|c|c|c|c|c|c|c|c|c|c|}
\hline & \multicolumn{5}{|c|}{$P$} & \multicolumn{5}{|c|}{$F$} \\
\hline $\mathrm{NUT}^{R}$ & 0,1 & 0,5 & 1,0 & 2,0 & 4,0 & 0,1 & 0,5 & 1,0 & 2,0 & 4,0 \\
\hline 0,1 & 0,095 & 0,093 & 0,091 & 0,087 & 0,080 & 1,000 & 1,000 & 1,000 & 1,000 & 1,000 \\
\hline 0,2 & 0,180 & 0,174 & 0,167 & 0,153 & 0,131 & 1,000 & 1,000 & 1,000 & 1,000 & 0,999 \\
\hline 0,4 & 0,325 & 0,307 & 0,286 & 0,248 & 0,189 & 1,000 & 1,000 & 0,999 & 0,999 & 0,998 \\
\hline 0,6 & 0,443 & 0,412 & 0,375 & 0,311 & 0,218 & 1,000 & 1,000 & 0,999 & 0,999 & 0,998 \\
\hline 0,8 & 0,539 & 0,496 & 0,444 & 0,355 & 0,232 & 1,000 & 0,999 & 0,999 & 0,998 & 0,996 \\
\hline 1,0 & 0,619 & 0,564 & 0,500 & 0,387 & 0,240 & 1,000 & 0,999 & 0,998 & 0,997 & 0,993 \\
\hline 1,2 & 0,684 & 0,621 & 0,545 & 0,411 & 0,245 & 1,000 & 0,999 & 0,998 & 0,995 & 0,991 \\
\hline 1,4 & 0,737 & 0,669 & 0,583 & 0,429 & 0,247 & 1,000 & 0,998 & 0,997 & 0,994 & 0,987 \\
\hline 1,6 & 0,781 & 0,710 & 0,614 & 0,443 & 0,248 & 1,000 & 0,998 & 0,996 & 0,992 & 0,984 \\
\hline 1,8 & 0,818 & 0,744 & 0,642 & 0,454 & 0,249 & 0,999 & 0,997 & 0,995 & 0,989 & 0,980 \\
\hline 2,0 & 0,849 & 0,774 & 0,665 & 0,463 & 0,249 & 0,999 & 0,997 & 0,993 & 0,987 & 0,975 \\
\hline 3,0 & 0,939 & 0,873 & 0,747 & 0,486 & 0,250 & 0,998 & 0,993 & 0,9 & 0,972 & 0,949 \\
\hline 4,0 & 0,975 & 0,925 & 0,796 & 0,494 & 0,250 & 0,997 & 0,987 & 0,974 & 0,952 & 0,917 \\
\hline 5,0 & 0,990 & 0,955 & 0,828 & 0,498 & 0,250 & 0,996 & 0,980 & 0,961 & 0,928 & 0,882 \\
\hline 6,0 & 0,996 & 0,972 & 0,850 & 0,499 & 0,250 & 0,994 & 0,971 & 0,945 & 0,902 & 0,847 \\
\hline 7,0 & 0,998 & 0,982 & 0,866 & 0,499 & 0,250 & 0,992 & 0,961 & 0,927 & 0,874 & 0,813 \\
\hline 8,0 & 0,999 & 0,989 & 0,879 & 0,500 & 0,250 & 0,989 & 0,949 & 0,907 & 0,846 & 0,779 \\
\hline 9,0 & 1,000 & 0,993 & 0,889 & 0,500 & 0,250 & 0,986 & 0,936 & 0,886 & 0,817 & 0,747 \\
\hline 10,0 & 1,000 & 0,995 & 0,896 & 0,500 & 0,250 & 0,983 & 0,923 & 0,864 & 0,788 & 0,716 \\
\hline
\end{tabular}

Trocador de calor de fluxo cruzado ilustrado na Figura 98 do Anexo A 
razão entre a efetividade de temperatura do trocador de calor e a de um contracorrente, $P / P_{c c}$, em função de $N U T$ e $R$. Observa-se que à medida que o número de passes aumenta, a efetividade do trocador de calor de fluxo cruzado se aproxima mais dos resultados de um contracorrente.

Tabela 9 - Efetividade de temperatura e fator de correção para trocadores de calor de fluxo cruzado em escoamentos paralelo e cruzado com o fluido frio misturado (casos $1 \mathrm{~A}$ e $2 \mathrm{~A}$ ) e não misturado (casos $3 \mathrm{~A}$ e $4 \mathrm{~A}$ ) entre os tubos para $R=1,0$

\begin{tabular}{|c|c|c|c|c|c|c|c|c|c|}
\hline \multirow{2}{*}{$N_{p^{-}} N_{r}$} & \multirow{2}{*}{$N U T$} & \multicolumn{4}{|c|}{$P$} & \multicolumn{4}{|c|}{$F$} \\
\hline & & $1 \mathrm{~A}$ & $3 \mathrm{~A}$ & $2 \mathrm{~A}$ & $4 \mathrm{~A}$ & $1 \mathrm{~A}$ & $3 \mathrm{~A}$ & $2 \mathrm{~A}$ & $4 \mathrm{~A}$ \\
\hline \multirow{19}{*}{$2-1$} & 0,1 & 0,091 & 0,091 & 0,091 & 0,091 & 0,997 & 1,000 & 0,997 & 1,000 \\
\hline & 0,2 & 0,165 & 0,166 & 0,165 & 0,166 & 0,989 & 0,998 & 0,988 & 0,998 \\
\hline & 0,4 & 0,277 & 0,284 & 0,277 & 0,284 & 0,956 & 0,994 & 0,956 & 0,993 \\
\hline & 0,6 & 0,352 & 0,372 & 0,352 & 0,372 & 0,907 & 0,986 & 0,906 & 0,985 \\
\hline & 0,8 & 0,404 & 0,439 & 0,403 & 0,438 & 0,847 & 0,976 & 0,845 & 0,975 \\
\hline & 1,0 & 0,439 & 0,491 & 0,438 & 0,490 & 0,782 & 0,964 & 0,778 & 0,961 \\
\hline & 1,2 & 0,463 & 0,533 & 0,460 & 0,532 & 0,717 & 0,950 & 0,711 & 0,946 \\
\hline & 1,4 & 0,478 & 0,567 & 0,475 & 0,565 & 0,655 & 0,935 & 0,646 & 0,928 \\
\hline & 1,6 & 0,488 & 0,595 & 0,484 & 0,593 & 0,596 & 0,918 & 0,586 & 0,910 \\
\hline & 1,8 & 0,494 & 0,618 & 0,489 & 0,616 & 0,543 & 0,900 & 0,531 & 0,890 \\
\hline & 2,0 & 0,498 & 0,638 & 0,491 & 0,635 & 0,496 & 0,882 & 0,482 & 0,869 \\
\hline & 3,0 & 0,497 & 0,701 & 0,482 & 0,695 & 0,329 & 0,783 & 0,310 & 0,760 \\
\hline & 4,0 & 0,488 & 0,733 & 0,467 & 0,725 & 0,238 & 0,687 & 0,219 & 0,658 \\
\hline & 5,0 & 0,480 & 0,750 & 0,455 & 0,740 & 0,184 & 0,602 & 0,167 & 0,570 \\
\hline & 6,0 & 0,474 & 0,760 & 0,446 & 0,749 & 0,150 & 0,529 & 0,134 & 0,498 \\
\hline & 7,0 & 0,471 & 0,766 & 0,441 & 0,754 & 0,127 & 0,468 & 0,113 & 0,438 \\
\hline & 8,0 & 0,469 & 0,769 & 0,438 & 0,757 & 0,110 & 0,417 & 0,097 & 0,390 \\
\hline & 9,0 & 0,467 & 0,771 & 0,436 & 0,759 & 0,097 & 0,375 & 0,086 & 0,350 \\
\hline & 10,0 & 0,466 & 0,773 & 0,434 & 0,760 & 0,087 & 0,340 & 0,077 & 0,317 \\
\hline \multirow{19}{*}{$5-1$} & 0,1 & 0,091 & 0,091 & 0,091 & 0,091 & 0,997 & 0,997 & 1,000 & 1,000 \\
\hline & 0,2 & 0,165 & 0,165 & 0,167 & 0,167 & 0,987 & 0,987 & 1,000 & 0,999 \\
\hline & 0,4 & 0,276 & 0,276 & 0,286 & 0,285 & 0,951 & 0,951 & 0,999 & 0,998 \\
\hline & 0,6 & 0,350 & 0,350 & 0,374 & 0,374 & 0,897 & 0,897 & 0,998 & 0,998 \\
\hline & 0,8 & 0,400 & 0,400 & 0,443 & 0,443 & 0,833 & 0,832 & 0,996 & 0,996 \\
\hline & 1,0 & 0,433 & 0,433 & 0,498 & 0,498 & 0,765 & 0,764 & 0,994 & 0,993 \\
\hline & 1,2 & 0,456 & 0,456 & 0,543 & 0,543 & 0,698 & 0,698 & 0,991 & 0,991 \\
\hline & 1,4 & 0,471 & 0,471 & 0,580 & 0,580 & 0,635 & 0,635 & 0,988 & 0,987 \\
\hline & 1,6 & 0,481 & 0,481 & 0,612 & 0,611 & 0,579 & 0,579 & 0,984 & 0,983 \\
\hline & 1,8 & 0,487 & 0,487 & 0,638 & 0,638 & 0,528 & 0,528 & 0,981 & 0,979 \\
\hline & 2,0 & 0,492 & 0,492 & 0,661 & 0,661 & 0,484 & 0,484 & 0,976 & 0,975 \\
\hline & 3,0 & 0,499 & 0,499 & 0,740 & 0,739 & 0,332 & 0,332 & 0,950 & 0,945 \\
\hline & 4,0 & 0,500 & 0,500 & 0,786 & 0,784 & 0,250 & 0,250 & 0,918 & 0,908 \\
\hline & 5,0 & 0,500 & 0,500 & 0,815 & 0,812 & 0,200 & 0,200 & 0,882 & 0,866 \\
\hline & 6,0 & 0,500 & 0,500 & 0,835 & 0,831 & 0,167 & 0,167 & 0,843 & 0,821 \\
\hline & 7,0 & 0,500 & 0,501 & 0,849 & 0,844 & 0,143 & 0,143 & 0,803 & 0,775 \\
\hline & 8,0 & 0,500 & 0,501 & 0,859 & 0,854 & 0,125 & 0,125 & 0,763 & 0,730 \\
\hline & 9,0 & 0,500 & 0,501 & 0,867 & 0,861 & 0,111 & 0,112 & 0,725 & 0,687 \\
\hline & 10,0 & 0,500 & 0,502 & 0,873 & 0,866 & 0,100 & 0,101 & 0,687 & 0,647 \\
\hline
\end{tabular}

Trocadores de calor de fluxo cruzado ilustrados no Anexo A

Da mesma maneira, na Figura 29 é analisado o comportamento do fator de correção em função da efetividade de temperatura e da razão de temperatura para trocadores de calor de fluxo cruzado em escoamento paralelo com fluido quente misturado e fluido frio misturado entre os tubos, caso 1A (linha sólida), e fluido frio não misturado, caso 3A 


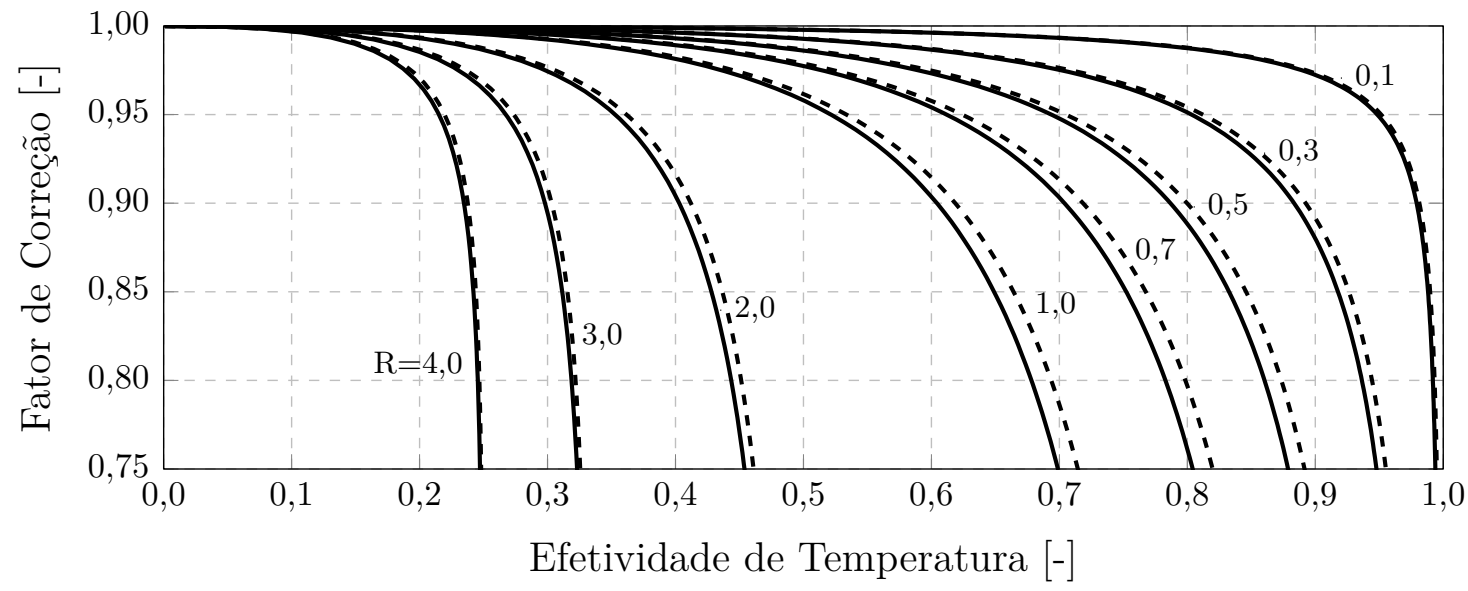

(a) Dois passes e um tubo por passe (2-1) - trocador de calor ilustrado na Figura 90

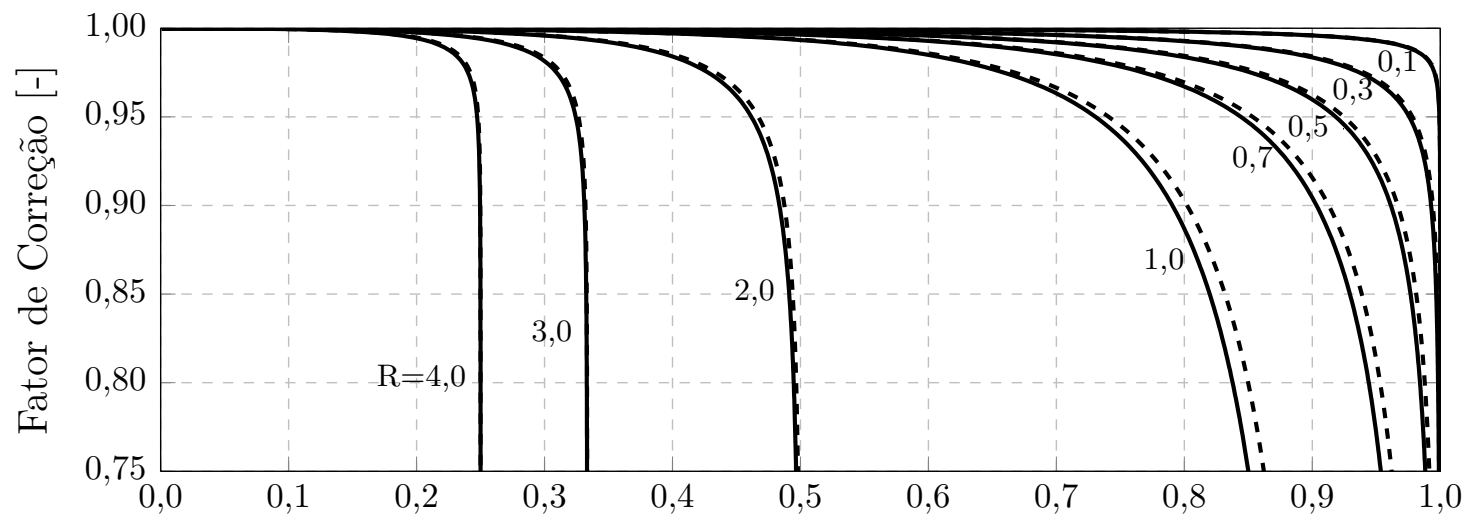

Efetividade de Temperatura [-]

(b) Cinco passes e um tubo por passe (5-1) - trocador de calor ilustrado na Figura 93

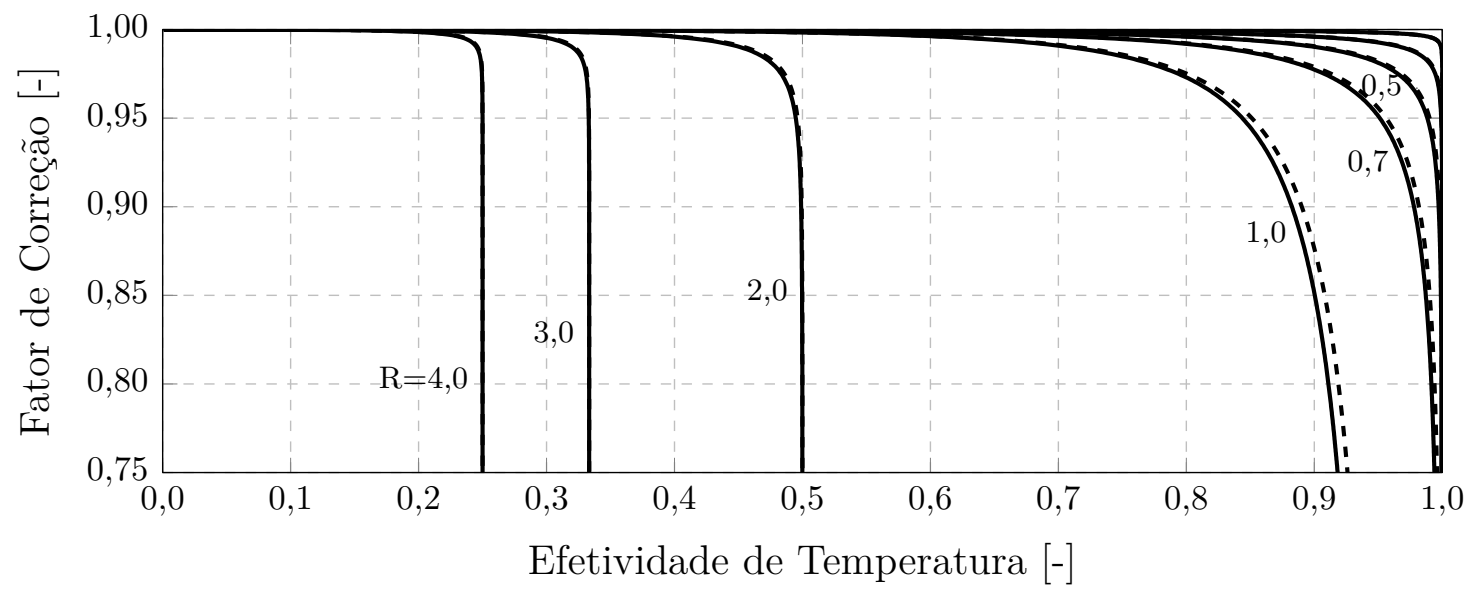

(c) Dez passes e um tubo por passe (10-1) - trocador de calor ilustrado na Figura 98

Figura 27 - Fator de correção para trocadores de calor de fluxo cruzado em escoamento contracorrente com fluido quente misturado e fluido frio misturado entre os tubos, caso 2A (---), e fluido frio não misturado, caso $4 \mathrm{~A}(-)$ 


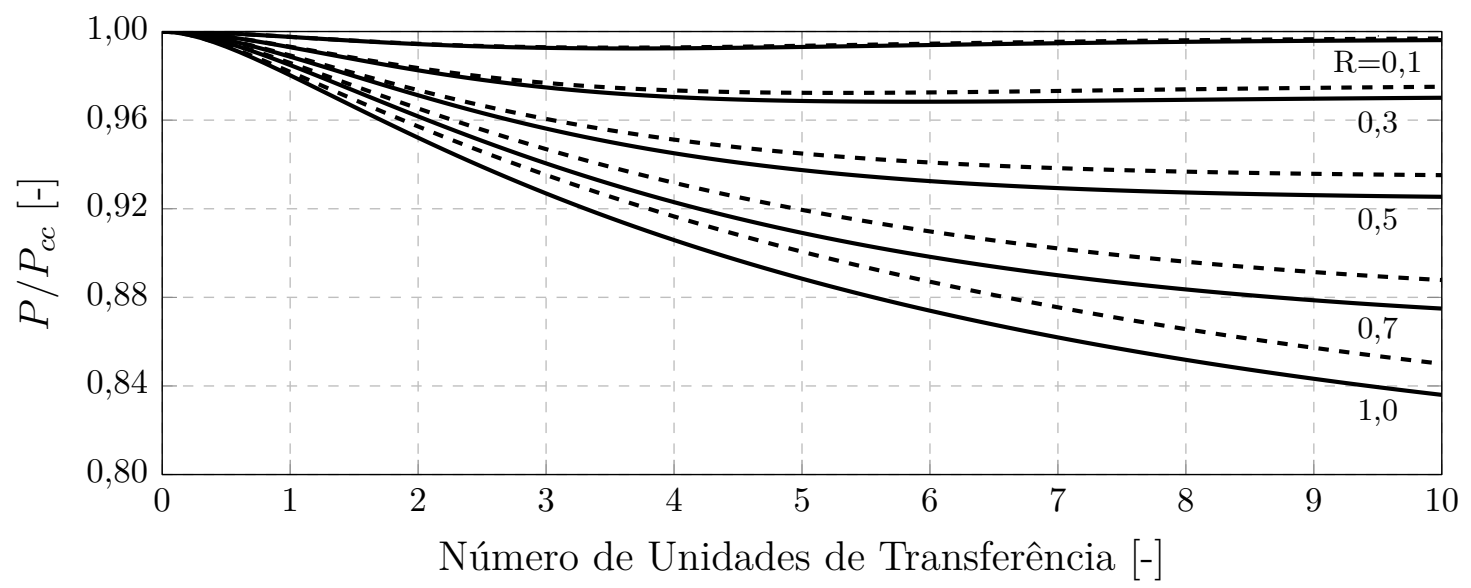

(a) Dois passes e um tubo por passe (2-1) - trocador de calor ilustrado na Figura 90

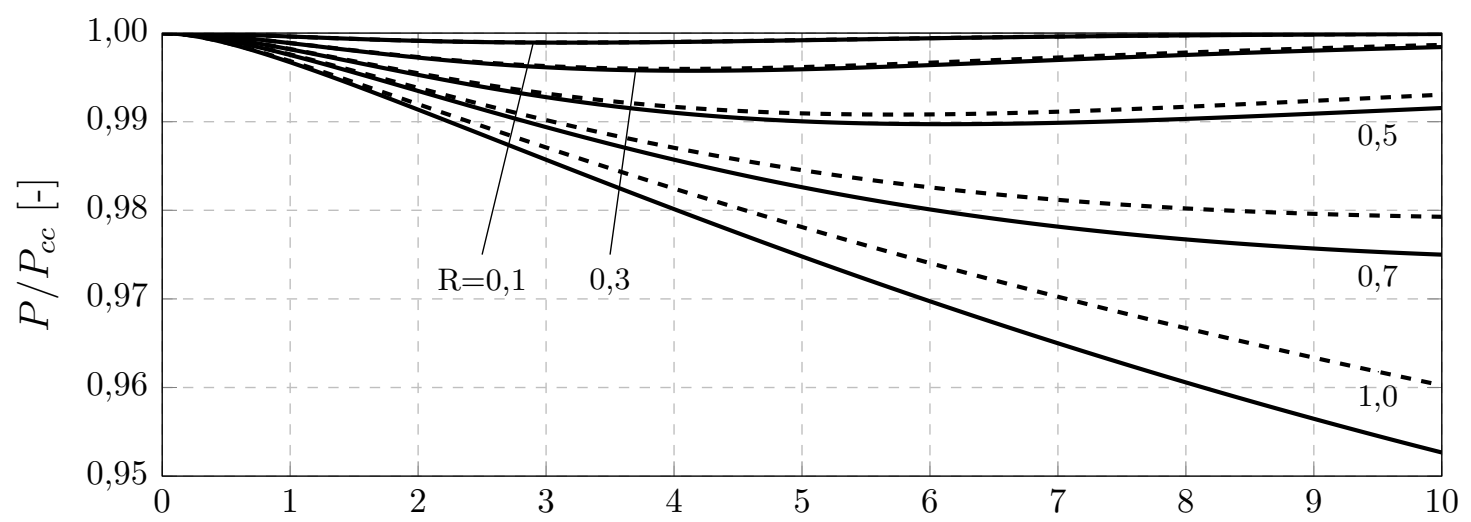

Número de Unidades de Transferência [-]

(b) Cinco passes e um tubo por passe (5-1) - trocador de calor ilustrado na Figura 93

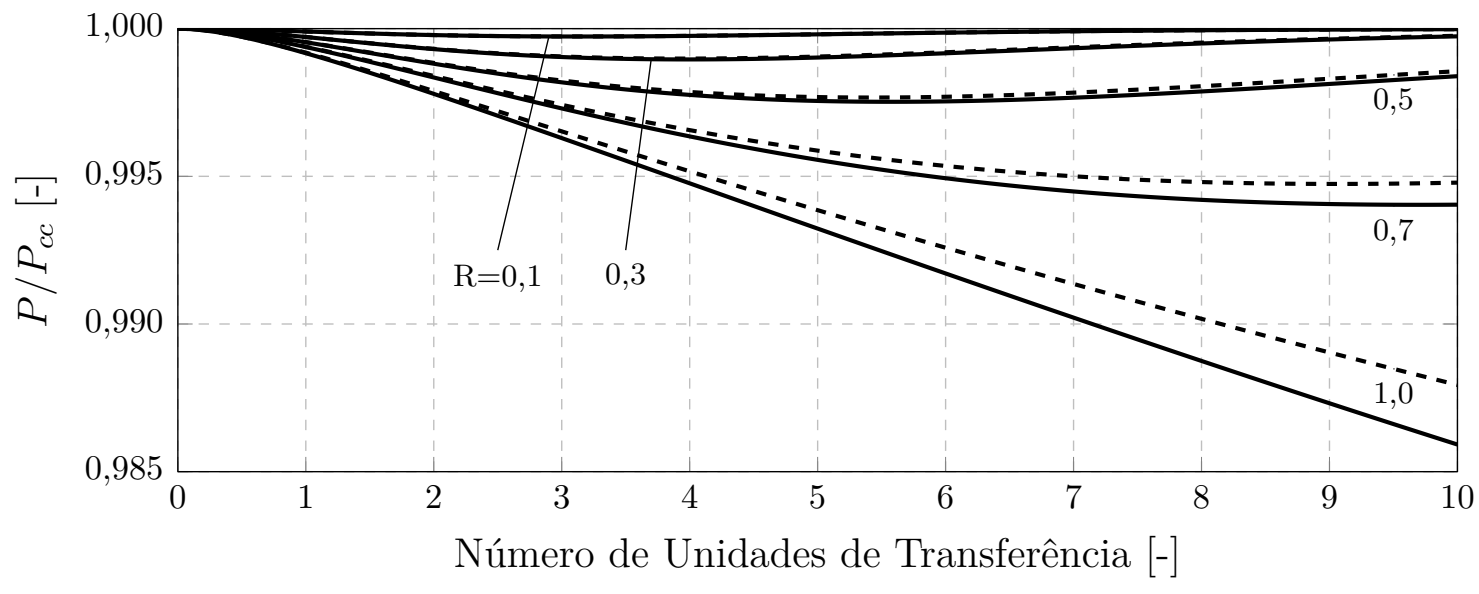

(c) Dez passes e um tubo por passe (10-1) - trocador de calor ilustrado na Figura 98

Figura 28 - Comportamento da razão $P / P_{c c}$ em função de $N U T$ para um trocador de calor de fluxo cruzado em escoamento contracorrente com fluido quente misturado e fluido frio misturado entre os tubos, caso $2 \mathrm{~A}(---)$, e fluido frio não misturado, caso $4 \mathrm{~A}$ $(\longrightarrow)$ 
(linha tracejada). Observa-se que a efetividade de temperatura é muito similar para os dois casos de trocador de calor. Por exemplo, considerando $R=0,3$ e $P=0,55$ e um trocador de calor de fluxo cruzado com cinco passes e um tubo por passe, a diferença do fator de correção é de 0,00215\%.
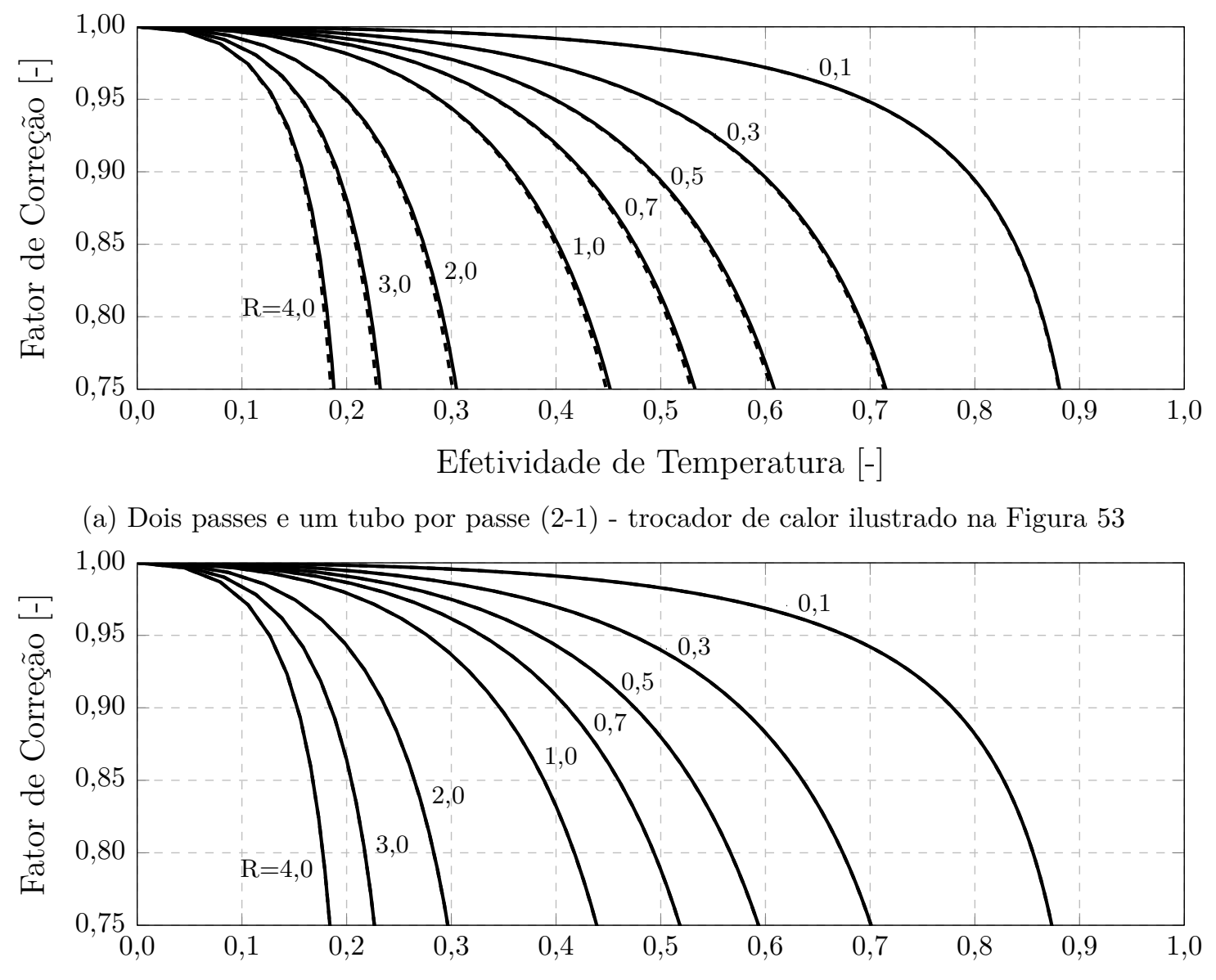

Efetividade de Temperatura [-]

(b) Cinco passes e um tubo por passe (5-1) - trocador de calor ilustrado na Figura 56

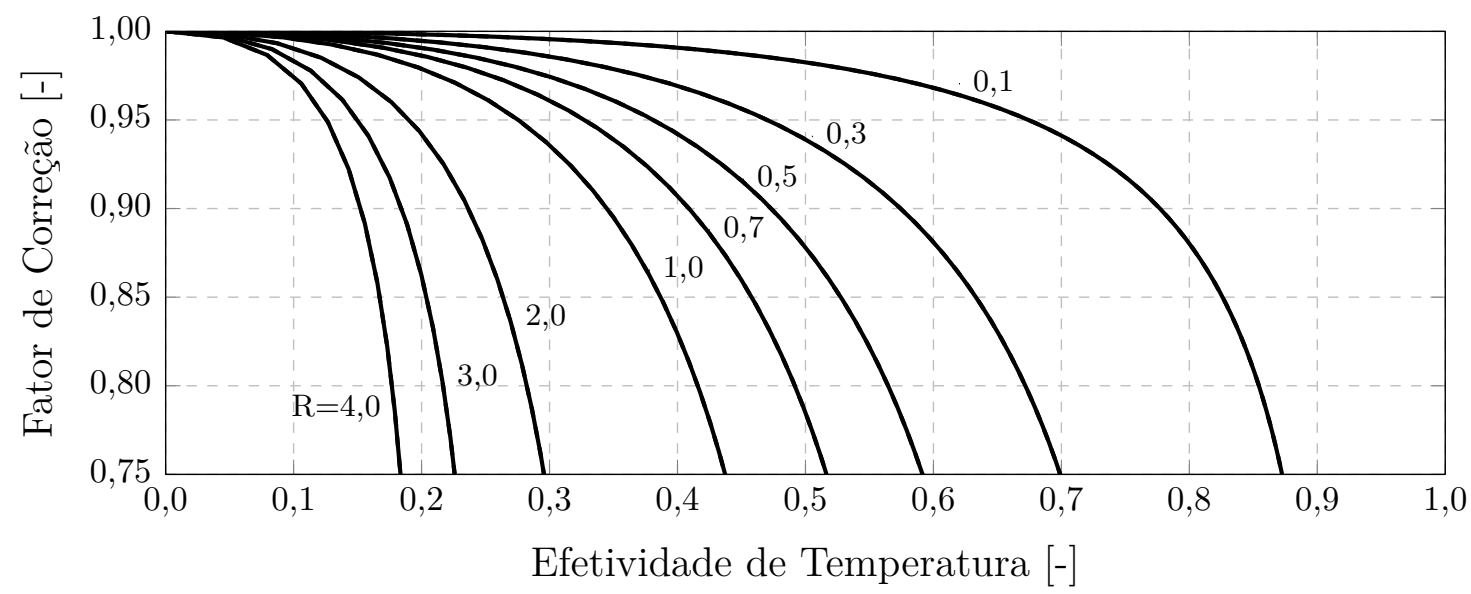

(c) Dez passes e um tubo por passe (10-1) - trocador de calor ilustrado na Figura 61

Figura 29 - Fator de correção para trocadores de calor de fluxo cruzado em escoamento paralelo com fluido quente misturado e fluido frio misturado entre os tubos, caso 1A (-), e fluido frio não misturado, caso 3A (----) 
O comportamento do fator de correção em função da efetividade de temperatura e da razão de temperatura está apresentado na Figura 30 para um trocador de calor de fluxo cruzado com o fluido quente misturado e o fluido frio misturado entre os tubos, casos 1 e 2 (linha tracejada), e fluido frio não misturado, casos 3 e 4 (linha sólida). O valor do fator de correção é maior para o caso do trocador de calor com fluido frio não misturado. Por exemplo, o fator de correção para um trocador de calor de fluxo cruzado com um passe e cinco tubos por passe considerando $R=1,0$ e $P=0,55$ é 0,854 para a condição de fluido frio não misturado (casos 3 e 4), e igual a 0,784 para a de fluido frio misturado ( $\operatorname{casos} 1$ e 2$)$.

Nas Tabelas 10 e 11 são apresentados respectivamente os valores da efetividade de temperatura e do fator de correção para um trocador de calor com um tubo por passe e diversos passes, considerando $R=1,0$ e o fluido frio não misturado e o quente misturado, caso 4A de Pignotti e Cordero (1983a). O número de passes, onde a influência do número na efetividade de temperatura não é significativamente maior que $1,0 \%$, é 12, o que significa que número de passes maior que 12 não é tecnicamente aceitável em função da uniformidade do valor da efetividade de temperatura. Isto representa o caso de infinitos passes e um tubo por passe ( $\infty-1)$, onde o número de passes não influencia os valores da efetividade. Entretanto, à medida que o número de passes aumenta, o fator de correção se aproxima de um, que é o caso do fator de correção de trocadores de calor de fluxo contracorrente. A mesma análise é feita para trocadores de calor do caso 4B de Pignotti e Cordero (1983a), onde o fluido quente não misturado possui a mesma ordem de tubos depois de cada passe. Neste caso, o número de passes, onde a influência do número na efetividade de temperatura não é significativamente maior que 1,0\%, é também igual a 12.

Da mesma maneira, o estudo é realizado para trocadores de calor de fluxo cruzado com um passe e diversos número de tubos por passe para $R=1,0$. Nas Tabelas 12 e 13 são mostrados respectivamente a efetividade de temperatura e o fator de correção para este tipo de trocador de calor (caso 4A) com fluido frio não misturado e o quente misturado. Assim, a partir de nove tubos por passe, a influência na efetividade de temperatura não é significantemente maior que $1,0 \%$. Isto representa o caso de um passe e infinitos tubos por passe $(1-\infty)$, onde o número de passe não influencia os valores de efetividade. Entretanto, à medida que o número de passes aumenta, a efetividade se aproxima da efetividade de trocadores de calor de fluxo paralelo. Considerando dois passes, o número de tubos por passe para o caso de infinitos tubos é 5 , o que significa que um trocador de calor com dois passes e cinco tubos por passe (2-5) representa o caso de um trocador de calor com dois passes e infinitos tubos $(2-\infty)$, considerando um erro relativo da efetividade de temperatura não maior que $1,0 \%$.

Desta maneira, a Tabela 14 são sumarizados os resultados de trocadores de calor 


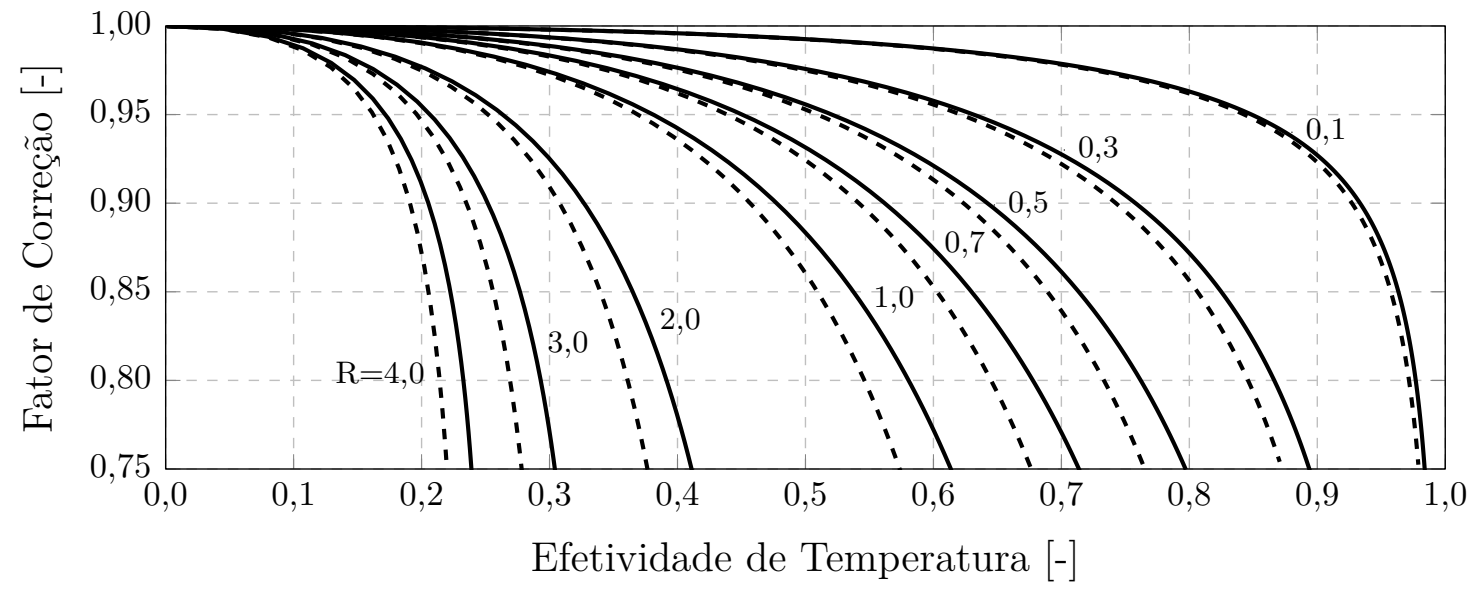

(a) Um passe e dois tubos por passe (1-2) - trocador de calor ilustrado na Figura 72

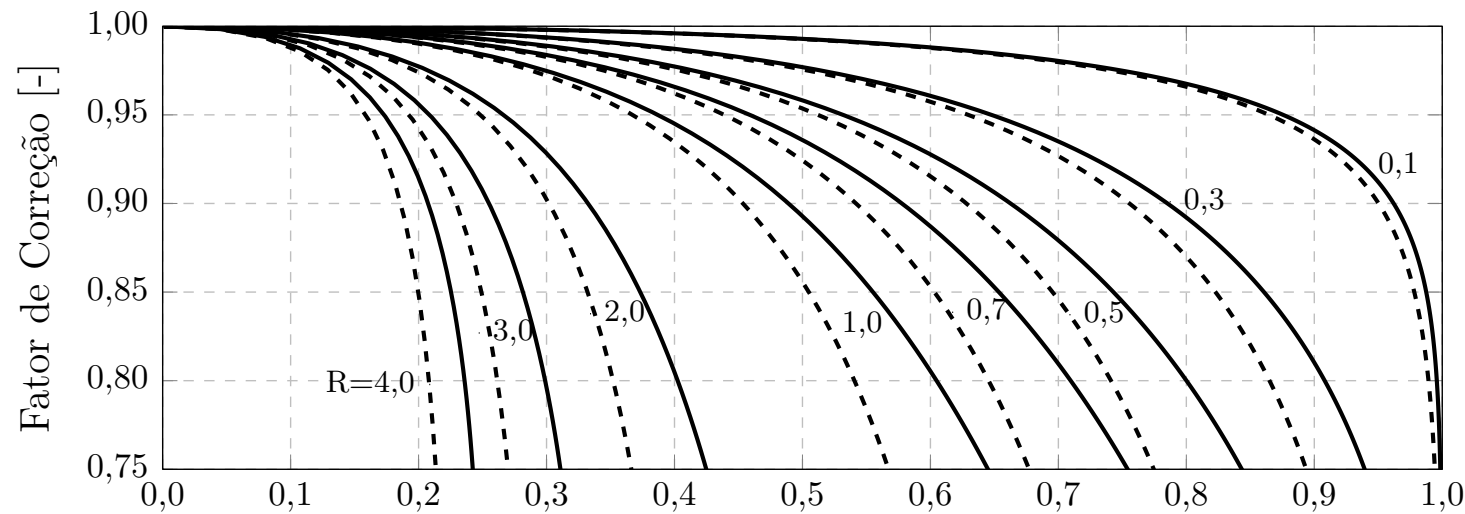

Efetividade de Temperatura [-]

(b) Um passe e cinco tubos por passe (1-5) - trocador de calor ilustrado na Figura 75

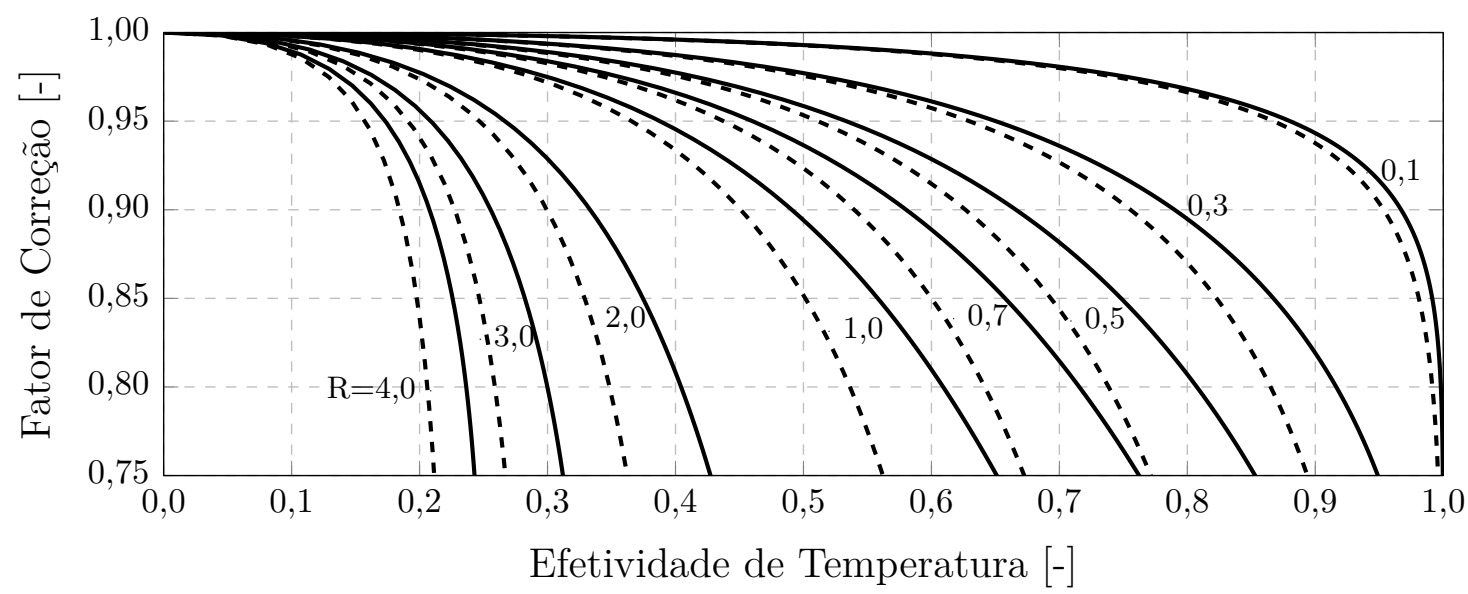

(c) Um passe e dez tubos por passe (1-10) - trocador de calor ilustrado na Figura 80

Figura 30 - Fator de correção para trocadores de calor de fluxo cruzado em escoamento contracorrente com o fluido quente misturado e o fluido frio misturado entre os tubos, casos 1 e 2 (--- -), e fluido frio não misturado, casos 3 e 4 (-) 
Tabela 10 - Efetividade de temperatura para trocadores de calor de fluxo cruzado em escoamento contracorrente com um tubo, considerando fluido frio não misturado e fluido quente misturado, em função do número de passes para $R=1,0$ - Caso $4 \mathrm{~A}$

\begin{tabular}{|c|ccccccccc|}
\hline NUT & 1 & 2 & 5 & 10 & 20 & 30 & 50 & 100 & cc \\
\hline 0,1 & 0,091 & 0,091 & 0,091 & 0,091 & 0,091 & 0,091 & 0,091 & 0,091 & 0,091 \\
0,2 & 0,256 & 0,258 & 0,259 & 0,259 & 0,259 & 0,259 & 0,259 & 0,167 & 0,167 \\
0,4 & 0,363 & 0,372 & 0,374 & 0,375 & 0,375 & 0,375 & 0,375 & 0,286 & 0,286 \\
0,6 & 0,363 & 0,372 & 0,374 & 0,375 & 0,375 & 0,375 & 0,375 & 0,375 & 0,375 \\
0,8 & 0,423 & 0,438 & 0,443 & 0,444 & 0,444 & 0,444 & 0,444 & 0,444 & 0,444 \\
1,0 & 0,469 & 0,490 & 0,498 & 0,500 & 0,500 & 0,500 & 0,500 & 0,500 & 0,500 \\
1,2 & 0,503 & 0,532 & 0,543 & 0,545 & 0,545 & 0,545 & 0,545 & 0,545 & 0,545 \\
1,4 & 0,529 & 0,565 & 0,580 & 0,583 & 0,583 & 0,583 & 0,583 & 0,583 & 0,583 \\
1,6 & 0,550 & 0,593 & 0,611 & 0,614 & 0,615 & 0,615 & 0,615 & 0,615 & 0,615 \\
1,8 & 0,566 & 0,616 & 0,638 & 0,642 & 0,643 & 0,643 & 0,643 & 0,643 & 0,643 \\
2,0 & 0,579 & 0,635 & 0,661 & 0,665 & 0,666 & 0,667 & 0,667 & 0,667 & 0,667 \\
3,0 & 0,613 & 0,695 & 0,739 & 0,747 & 0,749 & 0,750 & 0,750 & 0,750 & 0,750 \\
4,0 & 0,625 & 0,725 & 0,784 & 0,796 & 0,799 & 0,800 & 0,800 & 0,800 & 0,800 \\
5,0 & 0,630 & 0,740 & 0,812 & 0,828 & 0,832 & 0,833 & 0,833 & 0,833 & 0,833 \\
6,0 & 0,631 & 0,749 & 0,831 & 0,850 & 0,855 & 0,856 & 0,857 & 0,857 & 0,857 \\
7,0 & 0,632 & 0,754 & 0,844 & 0,866 & 0,873 & 0,874 & 0,875 & 0,875 & 0,875 \\
8,0 & 0,632 & 0,757 & 0,854 & 0,879 & 0,886 & 0,888 & 0,888 & 0,889 & 0,889 \\
9,0 & 0,632 & 0,759 & 0,861 & 0,889 & 0,897 & 0,899 & 0,900 & 0,900 & 0,900 \\
10,0 & 0,632 & 0,760 & 0,866 & 0,896 & 0,906 & 0,908 & 0,909 & 0,909 & 0,909 \\
\hline
\end{tabular}

Trocadores de calor de fluxo cruzado ilustrados no Anexo A

cc: contracorrente

Tabela 11 - Fator de correção para trocadores de calor de fluxo cruzado em escoamento contracorrente com um tubo, considerando fluido frio não misturado e fluido quente misturado, em função do número de passes para $R=1,0$ - Caso $4 \mathrm{~A}$

\begin{tabular}{|c|c|c|c|c|c|c|c|c|c|}
\hline $\mathrm{NUT}^{N_{p}}$ & 1 & 2 & 5 & 10 & 20 & 30 & 50 & 100 & $\mathrm{cc}$ \\
\hline 0,1 & 0,998 & 1,000 & 1,000 & 1,000 & 1,000 & 1,000 & 1,000 & 1,000 & 1,000 \\
\hline 0,2 & 0,994 & 0,995 & 0,999 & 1,000 & 1,000 & 1,000 & 1,000 & 1,000 & 1,000 \\
\hline 0,4 & 0,976 & 0,985 & 0,998 & 0,999 & 1,000 & 1,000 & 1,000 & 1,000 & 1,000 \\
\hline 0,6 & 0,950 & 0,985 & 0,998 & 0,999 & 1,000 & 1,000 & 1,000 & 1,000 & 1,000 \\
\hline 0,8 & 0,918 & 0,975 & 0,996 & 0,999 & 1,000 & 1,000 & 1,000 & 1,000 & 1,000 \\
\hline 1,0 & 0,882 & 0,961 & 0,993 & 0,998 & 1,000 & 1,000 & 1,000 & 1,000 & 1,000 \\
\hline 1,2 & 0,843 & 0,946 & 0,991 & 0,998 & 0,999 & 1,000 & 1,000 & 1,000 & 1,000 \\
\hline 1,4 & 0,803 & 0,928 & 0,987 & 0,997 & 0,999 & 1,000 & 1,000 & 1,000 & 1,000 \\
\hline 1,6 & 0,763 & 0,910 & 0,983 & 0,996 & 0,999 & 1,000 & 1,000 & 1,000 & 1,000 \\
\hline 1,8 & 0,725 & 0,890 & 0,979 & 0,995 & 0,999 & 0,999 & 1,000 & 1,000 & 1,000 \\
\hline 2,0 & 0,687 & 0,869 & 0,975 & 0,993 & 0,998 & 0,999 & 1,000 & 1,000 & 1,000 \\
\hline 3,0 & 0,529 & 0,760 & 0,945 & 0,985 & 0,996 & 0,998 & 0,999 & 1,000 & 1,000 \\
\hline 4,0 & 0,417 & 0,658 & 0,908 & 0,974 & 0,993 & 0,997 & 0,999 & 1,000 & 1,000 \\
\hline 5,0 & 0,340 & 0,570 & 0,866 & 0,961 & 0,990 & 0,995 & 0,998 & 1,000 & 1,000 \\
\hline 6,0 & 0,285 & 0,498 & 0,821 & 0,945 & 0,985 & 0,993 & 0,998 & 0,999 & 1,000 \\
\hline 7,0 & 0,245 & 0,438 & 0,775 & 0,927 & 0,980 & 0,991 & 0,997 & 0,999 & 1,000 \\
\hline 8,0 & 0,215 & 0,390 & 0,730 & 0,907 & 0,974 & 0,988 & 0,996 & 0,999 & 1,000 \\
\hline 9,0 & 0,191 & 0,350 & 0,687 & 0,886 & 0,968 & 0,985 & 0,995 & 0,999 & 1,000 \\
\hline 10,0 & 0,172 & 0,317 & 0,647 & 0,864 & 0,961 & 0,982 & 0,993 & 0,998 & 1,000 \\
\hline
\end{tabular}

Trocadores de calor de fluxo cruzado ilustrados no Anexo A

cc: contracorrente 
Tabela 12 - Efetividade de temperatura para trocadores de calor de fluxo cruzado em escoamento contracorrente com um tubo, considerando fluido frio não misturado e fluido quente misturado, em função do número de tubos por passe para $R=1,0$ - Caso $4 \mathrm{~A}$

\begin{tabular}{|c|c|c|c|c|c|c|c|c|}
\hline $\mathrm{NUT}^{N_{r}}$ & 1 & 2 & 5 & 10 & 20 & 30 & 50 & 100 \\
\hline 0,1 & 0,091 & 0,091 & 0,091 & 0,091 & 0,091 & 0,091 & 0,091 & 0,091 \\
\hline 0,2 & 0,256 & 0,166 & 0,166 & 0,166 & 0,166 & 0,166 & 0,166 & 0,166 \\
\hline 0,4 & 0,363 & 0,281 & 0,281 & 0,281 & 0,281 & 0,281 & 0,281 & 0,281 \\
\hline 0,6 & 0,363 & 0,365 & 0,365 & 0,365 & 0,365 & 0,365 & 0,365 & 0,365 \\
\hline 0,8 & 0,423 & 0,427 & 0,427 & 0,428 & 0,428 & 0,428 & 0,428 & 0,428 \\
\hline 1,0 & 0,469 & 0,474 & 0,476 & 0,476 & 0,476 & 0,476 & 0,476 & 0,476 \\
\hline 1,2 & 0,503 & 0,512 & 0,514 & 0,515 & 0,515 & 0,515 & 0,515 & 0,515 \\
\hline 1,4 & 0,529 & 0,542 & 0,546 & 0,546 & 0,546 & 0,546 & 0,546 & 0,546 \\
\hline 1,6 & 0,550 & 0,567 & 0,572 & 0,573 & 0,573 & 0,573 & 0,573 & 0,573 \\
\hline 1,8 & 0,566 & 0,587 & 0,594 & 0,595 & 0,595 & 0,595 & 0,595 & 0,595 \\
\hline 2,0 & 0,579 & 0,605 & 0,613 & 0,614 & 0,614 & 0,614 & 0,614 & 0,614 \\
\hline 3,0 & 0,613 & 0,661 & 0,678 & 0,680 & 0,681 & 0,681 & 0,681 & 0,681 \\
\hline 4,0 & 0,625 & 0,690 & 0,717 & 0,721 & 0,722 & 0,722 & 0,722 & 0,722 \\
\hline 5,0 & 0,630 & 0,706 & 0,743 & 0,749 & 0,750 & 0,751 & 0,751 & 0,751 \\
\hline 6,0 & 0,631 & 0,716 & 0,761 & 0,769 & 0,771 & 0,772 & 0,772 & 0,772 \\
\hline 7,0 & 0,632 & 0,721 & 0,774 & 0,785 & 0,788 & 0,788 & 0,789 & 0,789 \\
\hline 8,0 & 0,632 & 0,724 & 0,785 & 0,797 & 0,801 & 0,802 & 0,802 & 0,802 \\
\hline 9,0 & 0,632 & 0,726 & 0,793 & 0,808 & 0,812 & 0,813 & 0,813 & 0,813 \\
\hline 10,0 & 0,632 & 0,727 & 0,799 & 0,816 & 0,821 & 0,822 & 0,822 & 0,823 \\
\hline
\end{tabular}

Trocadores de calor de fluxo cruzado ilustrados no Anexo A

Tabela 13 - Fator de correção para trocadores de calor de fluxo cruzado em escoamento contracorrente com um tubo, considerando fluido frio não misturado e fluido quente misturado, em função do número de tubos por passe para $R=1,0$ - Caso $4 \mathrm{~A}$

\begin{tabular}{|c|c|c|c|c|c|c|c|c|}
\hline${ }_{N U T}{ }^{N r}$ & 1 & 2 & 5 & 10 & 20 & 30 & 50 & 100 \\
\hline 0,1 & 0,998 & 0,998 & 0,998 & 0,998 & 0,998 & 0,998 & 0,998 & 0,998 \\
\hline 0,2 & 0,982 & 0,994 & 0,994 & 0,994 & 0,994 & 0,994 & 0,994 & 0,994 \\
\hline 0,4 & 0,950 & 0,978 & 0,979 & 0,979 & 0,979 & 0,979 & 0,979 & 0,979 \\
\hline 0,6 & 0,950 & 0,956 & 0,958 & 0,958 & 0,958 & 0,958 & 0,958 & 0,958 \\
\hline 0,8 & 0,918 & 0,930 & 0,933 & 0,934 & 0,934 & 0,934 & 0,934 & 0,934 \\
\hline 1,0 & 0,882 & 0,902 & 0,908 & 0,909 & 0,909 & 0,909 & 0,909 & 0,909 \\
\hline 1,2 & 0,843 & 0,874 & 0,883 & 0,884 & 0,884 & 0,884 & 0,884 & 0,885 \\
\hline 1,4 & 0,803 & 0,845 & 0,858 & 0,860 & 0,860 & 0,861 & 0,861 & 0,861 \\
\hline 1,6 & 0,763 & 0,818 & 0,835 & 0,837 & 0,838 & 0,838 & 0,838 & 0,838 \\
\hline 1,8 & 0,725 & 0,791 & 0,812 & 0,815 & 0,816 & 0,816 & 0,816 & 0,816 \\
\hline 2,0 & 0,687 & 0,765 & 0,791 & 0,795 & 0,796 & 0,796 & 0,796 & 0,796 \\
\hline 3,0 & 0,529 & 0,650 & 0,701 & 0,710 & 0,712 & 0,712 & 0,712 & 0,713 \\
\hline 4,0 & 0,417 & 0,556 & 0,632 & 0,646 & 0,649 & 0,650 & 0,650 & 0,651 \\
\hline 5,0 & 0,340 & 0,481 & 0,577 & 0,596 & 0,601 & 0,602 & 0,603 & 0,603 \\
\hline 6,0 & 0,285 & 0,419 & 0,530 & 0,555 & 0,562 & 0,564 & 0,564 & 0,565 \\
\hline 7,0 & 0,245 & 0,369 & 0,491 & 0,521 & 0,530 & 0,532 & 0,533 & 0,533 \\
\hline 8,0 & 0,215 & 0,328 & 0,456 & 0,492 & 0,503 & 0,505 & 0,506 & 0,507 \\
\hline 9,0 & 0,191 & 0,295 & 0,425 & 0,467 & 0,479 & 0,482 & 0,483 & 0,484 \\
\hline 10,0 & 0,172 & 0,267 & 0,397 & 0,444 & 0,459 & 0,462 & 0,463 & 0,464 \\
\hline
\end{tabular}

Trocadores de calor de fluxo cruzado ilustrados no Anexo A 
de fluxo cruzado com diversos passes e tubos por passe para um fluido frio não misturado e o quente misturado (caso $4 \mathrm{~A}$ ), considerando $R=1,0$ e $N U T=5,0$.

Tabela 14 - Efetividade de temperatura e fator de correção para trocadores de calor de fluxo cruzado em escoamento contracorrente com diversos passes e tubos por passe considerando fluido frio não misturado e fluido quente misturado para $R=1,0$ e $N U T=5,0$

- Caso 4A

\begin{tabular}{|c|c|c|c|c|c|}
\hline & $N_{r} N_{p}$ & 1 & 2 & 5 & 10 \\
\hline \multirow{5}{*}{$P$} & 1 & 0,630 & 0,740 & 0,812 & 0,828 \\
\hline & 2 & 0,706 & 0,770 & 0,816 & 0,828 \\
\hline & 5 & 0,743 & 0,779 & 0,817 & 0,828 \\
\hline & 10 & 0,749 & 0,781 & 0,817 & 0,828 \\
\hline & 20 & 0,750 & 0,781 & 0,817 & 0,828 \\
\hline \multirow{5}{*}{$F$} & 1 & 0,340 & 0,570 & 0,866 & 0,961 \\
\hline & 2 & 0,481 & 0,669 & 0,887 & 0,964 \\
\hline & 5 & 0,577 & 0,706 & 0,893 & 0,965 \\
\hline & 10 & 0,596 & 0,712 & 0,894 & 0,965 \\
\hline & 20 & 0,601 & 0,713 & 0,894 & 0,965 \\
\hline
\end{tabular}

ilustrados no Anexo A

As condições de mistura do fluido quente depois de cada passe, caracterizadas por três tipos de configuração: (i) misturado (caso 3A); (ii) não misturado mantendo uma ordem idêntica dos tubos (caso 3B); e (iii) não misturado com ordem inversa dos tubos (caso 3C), são analisadas na Tabela 15 para trocadores de calor de fluxo cruzado em escoamento paralelo com dois passes e quatro tubos por passe (2-4) para $R=0,2$ e $R=1,0$. O comportamento da efetividade de temperatura em função do fator de correção e da razão de temperatura está apresentado na Figura 31. O valor do fator de correção é maior para o trocador de calor com a condição de fluido quente não misturado com uma ordem idêntica das fileiras (caso 3B) e menor para a condição de fluido quente não misturado com uma ordem inversa das fileiras (caso 3C). Por exemplo, para um trocador de calor com dois passes e quatro tubos por passes, o fator de correção é 0,905 para $P=0,80$ e $R=0,1$, considerando o caso 3B. Já para o caso 3C, o fator de correção é 0,888 , uma diferença de aproximadamente $2,0 \%$. Isto é por causa que o caso B tem uma diferença de temperatura uniformemente mais distribuída entre os fluidos quente e frio, provocando assim uma efetividade de temperatura mais alta.

Os resultados da efetividade de temperatura e do fator de correção para configurações mais complexas de trocadores de calor de fluxo cruzado também podem ser feitas utilizando o presente algoritmo. Na Tabela 16 são apresentados a efetividade de temperatura e do fator de correção para um trocador de calor de fluxo cruzado em escoamento contracorrente com dois passes e quatro tubos por passe (2-4), considerando o fluido frio não misturado e o quente misturado dentro dos tubos e não misturado entre os passes mantendo uma ordem idêntica dos tubos (caso 4B). O mesmo resultados é apresentado na Tabela 17 para um trocador de calor de fluxo cruzado em escoamento contracorrente 
Tabela 15 - Efetividade de temperatura e fator de correção para trocador de calor de fluxo cruzado em escoamento paralelo com dois passes e quatro tubos por passe (2-4) considerando três tipos de configuração de mistura do fluido quente

\begin{tabular}{|c|c|ccc|ccc|}
\hline \multirow{2}{*}{$R$} & \multirow{2}{*}{$N U T$} & \multicolumn{3}{|c|}{$P$} & \multicolumn{3}{|c|}{$F$} \\
\cline { 3 - 8 } & & $3 \mathrm{~A}$ & $3 \mathrm{~B}$ & $3 \mathrm{C}$ & $3 \mathrm{~A}$ & $3 \mathrm{~B}$ & $3 \mathrm{C}$ \\
\hline 0,2 & 0,1 & 0,094 & 0,094 & 0,094 & 0,999 & 0,999 & 0,999 \\
0,2 & 0,2 & 0,178 & 0,178 & 0,178 & 0,998 & 0,998 & 0,998 \\
0,2 & 0,4 & 0,318 & 0,318 & 0,318 & 0,991 & 0,991 & 0,991 \\
0,2 & 0,6 & 0,429 & 0,429 & 0,429 & 0,979 & 0,980 & 0,979 \\
0,2 & 0,8 & 0,516 & 0,516 & 0,516 & 0,964 & 0,965 & 0,963 \\
0,2 & 1,0 & 0,585 & 0,586 & 0,585 & 0,944 & 0,946 & 0,943 \\
0,2 & 1,2 & 0,640 & 0,641 & 0,639 & 0,921 & 0,924 & 0,919 \\
0,2 & 1,4 & 0,683 & 0,685 & 0,682 & 0,895 & 0,899 & 0,891 \\
0,2 & 1,6 & 0,717 & 0,720 & 0,715 & 0,866 & 0,872 & 0,860 \\
0,2 & 1,8 & 0,744 & 0,748 & 0,741 & 0,835 & 0,843 & 0,827 \\
0,2 & 2,0 & 0,766 & 0,770 & 0,761 & 0,803 & 0,814 & 0,792 \\
0,2 & 3,0 & 0,819 & 0,832 & 0,806 & 0,638 & 0,667 & 0,610 \\
0,2 & 4,0 & 0,832 & 0,856 & 0,806 & 0,500 & 0,547 & 0,457 \\
0,2 & 5,0 & 0,831 & 0,869 & 0,790 & 0,399 & 0,460 & 0,348 \\
0,2 & 6,0 & 0,827 & 0,878 & 0,771 & 0,328 & 0,398 & 0,272 \\
0,2 & 7,0 & 0,823 & 0,886 & 0,750 & 0,277 & 0,353 & 0,219 \\
0,2 & 8,0 & 0,818 & 0,894 & 0,731 & 0,239 & 0,320 & 0,180 \\
0,2 & 9,0 & 0,815 & 0,901 & 0,713 & 0,210 & 0,294 & 0,152 \\
0,2 & 10,0 & 0,812 & 0,908 & 0,697 & 0,187 & 0,273 & 0,130 \\
\hline 1,0 & 0,1 & 0,091 & 0,091 & 0,091 & 0,997 & 0,997 & 0,997 \\
1,0 & 0,2 & 0,165 & 0,165 & 0,165 & 0,989 & 0,989 & 0,988 \\
1,0 & 0,4 & 0,277 & 0,277 & 0,277 & 0,956 & 0,956 & 0,956 \\
1,0 & 0,6 & 0,352 & 0,353 & 0,352 & 0,906 & 0,908 & 0,905 \\
1,0 & 0,8 & 0,404 & 0,404 & 0,403 & 0,846 & 0,848 & 0,844 \\
1,0 & 1,0 & 0,438 & 0,440 & 0,437 & 0,780 & 0,784 & 0,776 \\
1,0 & 1,2 & 0,461 & 0,463 & 0,459 & 0,714 & 0,719 & 0,708 \\
1,0 & 1,4 & 0,476 & 0,479 & 0,473 & 0,649 & 0,657 & 0,642 \\
1,0 & 1,6 & 0,485 & 0,489 & 0,481 & 0,589 & 0,598 & 0,580 \\
1,0 & 1,8 & 0,490 & 0,495 & 0,485 & 0,534 & 0,545 & 0,523 \\
1,0 & 2,0 & 0,492 & 0,498 & 0,486 & 0,484 & 0,497 & 0,472 \\
1,0 & 3,0 & 0,480 & 0,492 & 0,467 & 0,307 & 0,323 & 0,293 \\
1,0 & 4,0 & 0,456 & 0,473 & 0,439 & 0,210 & 0,225 & 0,196 \\
1,0 & 5,0 & 0,433 & 0,453 & 0,413 & 0,153 & 0,166 & 0,140 \\
1,0 & 6,0 & 0,412 & 0,435 & 0,390 & 0,117 & 0,128 & 0,106 \\
1,0 & 7,0 & 0,395 & 0,419 & 0,371 & 0,093 & 0,103 & 0,084 \\
1,0 & 8,0 & 0,380 & 0,405 & 0,355 & 0,077 & 0,085 & 0,069 \\
1,0 & 9,0 & 0,367 & 0,392 & 0,341 & 0,064 & 0,072 & 0,058 \\
1,0 & 10,0 & 0,356 & 0,382 & 0,330 & 0,055 & 0,062 & 0,049 \\
\hline
\end{tabular}

Trocadores de calor de fluxo cruzado ilustrados nas Figuras 100101 e 102 do Anexo A 


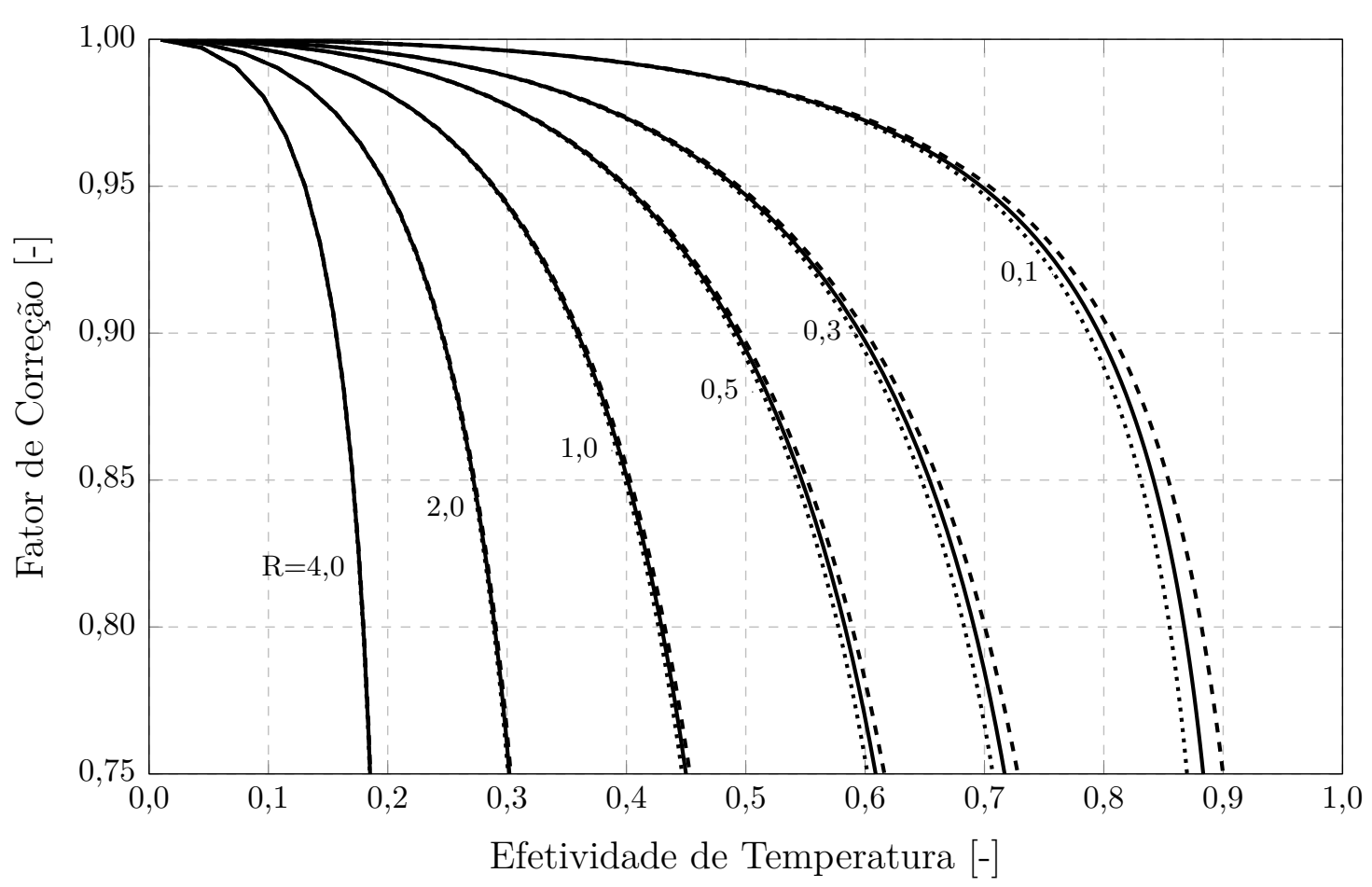

Figura 31 - Comportamento da efetividade de temperatura em função do fator de correção e da razão de temperatura para trocador de calor de fluxo cruzado em escoamento paralelo com dois passes e quatro tubos por passe (2-4) considerando três condições de mistura do fluido quente: caso 3A (-), caso 3B (-.-) e caso 3C (.........) trocadores de calor ilustrados nas Figuras 100, 101 e 102

com três passes e dois tubos por passe (3-2), considerando o caso 4B. Na Figura 32 está apresentado o comportamento da efetividade de temperatura para estes dois trocadores de calor de fluxo cruzado.

Os resultados do presente algoritmo são comparados com dados de diversas literaturas. Primeiramente, realiza-se uma comparação entre os resultados simulados da efetividade de temperatura e os resultados publicados por Baclic e Heggs (1985), assumindo o caso 3A para um arranjo cruzado com ambos os fluidos não misturados. Nesse caso, considera-se $N_{p}=1$ e $N_{r}=\infty$. Para modelar infinitas fileiras de tubos no algoritmo desenvolvido se emprega um número de fileiras fixo, nesta caso utiliza-se $N_{r}=200$. Como se trata de um arranjo simétrico, os valores de $P$ se igualam aos valores de $\varepsilon$. Na Tabela 18 se apresentam os valores da efetividade de temperatura e do erro relativo considerando os valores publicados por Baclic e Heggs (1985) para diversos valores de número de unidades de transferência, NUT, e da razão de temperatura, $R$. O valor máximo do erro relativo apresentado na tabela é de $-0,002 \%$, sendo o erro relativo médio de $-0,00031 \%$. A partir dos resultados apresentados na Tabela 18 se pode concluir que o procedimento computacional implementado produz resultados corretos e exatos para esta configuração de trocador de calor.

Na Tabela 19 são apresentados os valores da efetividade de temperatura e do erro 
Tabela 16 - Efetividade de temperatura e fator de correção para trocador de calor de fluxo cruzado em escoamento contracorrente com dois passes e quatro tubos por passe (2-4) com o fluido frio não misturado e o quente misturado - Caso 4B

\begin{tabular}{|c|c|c|c|c|c|c|c|c|c|c|}
\hline & \multicolumn{5}{|c|}{$P$} & \multicolumn{5}{|c|}{$F$} \\
\hline NUT & 0,1 & 0,5 & 1,0 & 2,0 & 4,0 & 0,1 & 0,5 & 1,0 & 2,0 & 4,0 \\
\hline 0,1 & 0,095 & 0,093 & 0,091 & 0,087 & 0,079 & 1,000 & 1,000 & 1,000 & 0,999 & 0,998 \\
\hline 0,2 & 0,180 & 0,174 & 0,166 & 0,153 & 0,130 & 1,000 & 0,999 & 0,998 & 0,997 &, 994 \\
\hline 0,4 & 0,325 & 0,306 & 0,284 & 0,246 & 0,187 & 0,999 & 0,997 & 0,994 & 0,988 & 0,978 \\
\hline 0,6 & 0,443 & 0,410 & 0,372 & 0,307 & 0,215 & 0,999 & 0,993 & 0,987 & 0,976 & 0,957 \\
\hline 0,8 & 0,539 & 0,492 & 0,439 & 0,349 & 0,230 & 0,998 & 0,989 & 0,978 & 0,960 & 0,934 \\
\hline 1,0 & 0,617 & 0,560 & 0,492 & 0,379 & 0,238 & 0,997 & 0,983 & 0,968 & 0,943 & 0,910 \\
\hline 1,2 & 0,682 & 0,615 & 0,535 & 0,401 & 0,242 & 0,995 & 0,977 & 0,957 & 0,925 & 0,887 \\
\hline 1,4 & 0,735 & 0,660 & 0,569 & 0,418 & 0,245 & 0,994 & 0,970 & 0,945 & 0,907 & 0,866 \\
\hline 1,6 & 0,779 & 0,699 & 0,599 & 0,431 & 0,247 & 0,992 & 0,962 & 0,932 & 0, & 0,845 \\
\hline 1,8 & 0,815 & 0,731 & 0,623 & 0,442 & 0,248 & 0,990 & 0,954 & 0,919 & 0,870 & 0,825 \\
\hline 2,0 & 0,845 & & 0,6 & & & 0,9 & 0,946 & & & 0,806 \\
\hline 3,0 & 0,935 & 0,851 & 0,715 & 0,474 & 0,250 & 0,976 & 0,900 & 0,837 & 0,772 & 0,727 \\
\hline 4,0 & 0,972 & 0,900 & 0,756 & 0,485 & 0,250 & 0,9 & & 0,775 & 0,704 & 0,665 \\
\hline 5,0 & 0,987 & 0,928 & 0,782 & 0,490 & 0,250 & 0,945 & 0,805 & 0,719 & 0,647 & 0,614 \\
\hline 6,0 & 0,994 & 0,946 & 0,801 & 0,493 & 0,250 & 0,927 & 0,762 & 0,671 & 0,600 & 0,573 \\
\hline 7,0 & 0,997 & 0,959 & 0,815 & 0,495 & 0,250 & 0,908 & 0,723 & 0,628 & 0,559 & 0,538 \\
\hline 8,0 & 0,999 & 0,967 & 0,825 & 0,496 & 0,250 & 0,889 & 0,687 & 0,591 & 0,524 & 0,507 \\
\hline 9,0 & 0,999 & 0,973 & 0,834 & 0,497 & 0,250 & 0,870 & 0,655 & 0,557 & 0,493 & 0,480 \\
\hline 10,0 & 1,000 & 0,978 & 0,841 & 0,498 & 0,250 & 0,851 & 0,626 & 0,527 & 0,466 & 0,455 \\
\hline
\end{tabular}

Trocador de calor de fluxo cruzado ilustrados na Figura 104 do Anexo A

Tabela 17 - Efetividade de temperatura e fator de correção para trocador de calor de fluxo cruzado em escoamento contracorrente com três passes e dois tubos por passe (3-2) com o fluido frio não misturado e o quente misturado - Caso 4B

\begin{tabular}{|c|c|c|c|c|c|c|c|c|c|c|}
\hline & \multicolumn{5}{|c|}{$P$} & \multicolumn{5}{|c|}{$F$} \\
\hline $\mathrm{NUT}^{R}$ & 0,1 & 0,5 & 1,0 & 2,0 & 4,0 & 0,1 & 0,5 & 1,0 & 2,0 & 4,0 \\
\hline 0,1 & 0,095 & 0,093 & 0,091 & 0,087 & 0,079 & 1,000 & 1,000 & 1,000 & 1,000 & 0,999 \\
\hline 0,2 & 0,180 & 0,174 & 0,167 & 0,153 & 0,131 & 1,000 & 1,000 & 0,999 & 0,999 & 0,997 \\
\hline 0,4 & 0,325 & 0,307 & 0,285 & 0,247 & 0,188 & 1,000 & 0,999 & 0,997 & 0,995 & 0,990 \\
\hline 0,6 & 0,443 & 0,411 & 0,374 & 0,309 & 0,216 & 0,999 & 0,997 & 0,994 & 0,988 & 0,978 \\
\hline 0,8 & 0,539 & 0,494 & 0,442 & 0,352 & 0,231 & 0,999 & 0,995 & 0,990 & 0,981 & 0,964 \\
\hline 1,0 & 0,618 & 0,562 & 0,496 & 0,383 & 0,239 & 0,998 & 0,992 & 0,985 & 0,971 & 0,949 \\
\hline 1,2 & 0,683 & 0,618 & 0,540 & 0,406 & 0,243 & 0,998 & 0,989 & 0,979 & 0,961 & 0,933 \\
\hline 1,4 & 0,736 & 0,665 & 0,576 & 0,424 & 0,246 & 0,997 & 0,986 & 0,972 & 0,949 & 0,916 \\
\hline 1,6 & 0,780 & 0,705 & 0,607 & 0,437 & 0,247 & 0,996 & 0,982 & 0,965 & 0,937 & 0,899 \\
\hline 1,8 & 0,817 & 0,738 & 0,633 & 0,448 & 0,248 & 0,995 & 0,977 & 0,957 & 0,924 & 0,883 \\
\hline 2,0 & 0,847 & 0,767 & 0,655 & 0,456 & 0,249 & 0,994 & 0,973 & 0,949 & 0,911 & 0,866 \\
\hline 3,0 & 0,937 & 0,862 & 0,730 & 0,479 & 0,250 & 0,9 & 0,945 & 0,902 & 0,843 & 0,789 \\
\hline 4,0 & 0,973 & 0,912 & 0,773 & 0,489 & 0,250 & 0,980 & 0,911 & 0,850 & 0,778 & 0,722 \\
\hline 5,0 & 0,989 & 0,940 & 0,800 & 0,493 & 0,250 & 0,969 & 0,874 & 0,798 & 0,718 & 0,664 \\
\hline 6,0 & 0,995 & 0,957 & 0,818 & 0,495 & 0,250 & 0,957 & 0,835 & 0,748 & 0,664 & 0,614 \\
\hline 7,0 & 0,998 & 0,968 & 0,831 & 0,497 & 0,250 & 0,943 & 0,795 & 0,701 & 0,616 & 0,569 \\
\hline 8,0 & 0,999 & 0,975 & 0,840 & 0,497 & 0,250 & 0,928 & 0,757 & 0,657 & 0,574 & 0,531 \\
\hline 9,0 & 0,999 & 0,980 & 0,848 & 0,498 & 0,250 & 0,911 & 0,720 & 0,618 & 0,536 & 0,496 \\
\hline 10,0 & 1,000 & 0,983 & 0,853 & 0,498 & 0,250 & 0,893 & 0,685 & 0,581 & 0,502 & 0,465 \\
\hline
\end{tabular}

Trocador de calor de fluxo cruzado ilustrados na Figura 104 do Anexo A 


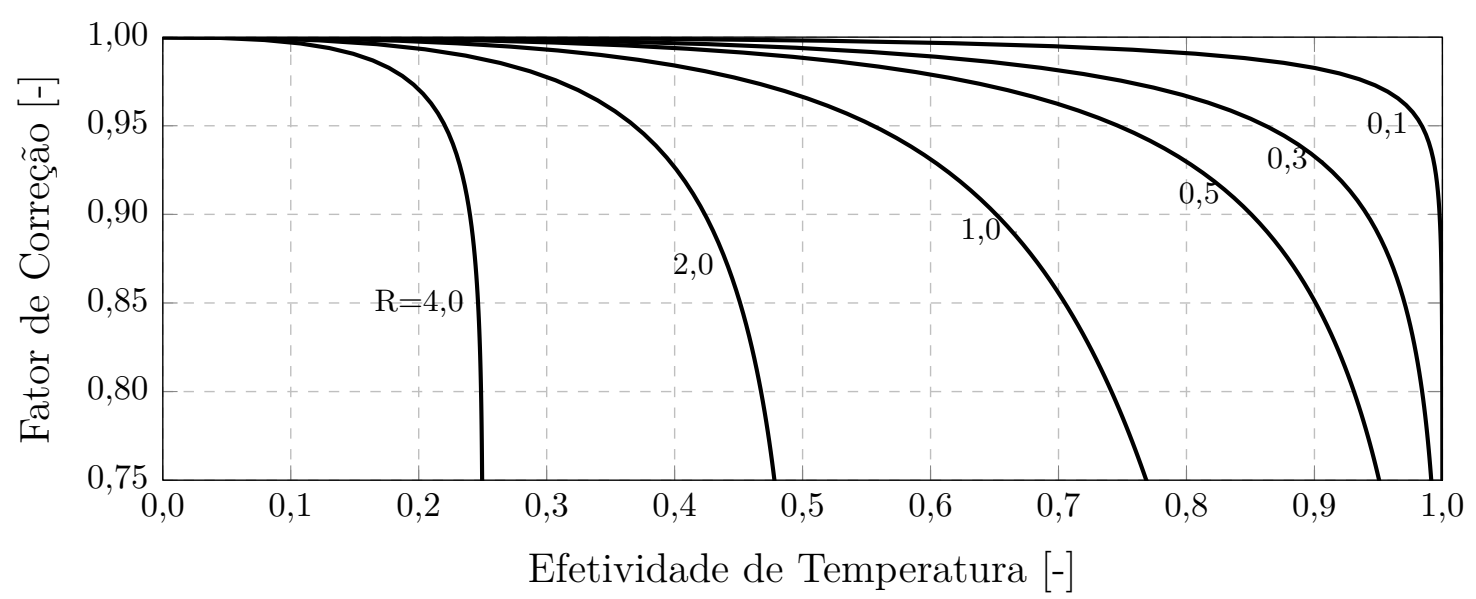

(a) Dois passes e quatro tubos por passe (2-4) - trocador de calor ilustrado na Figura 104

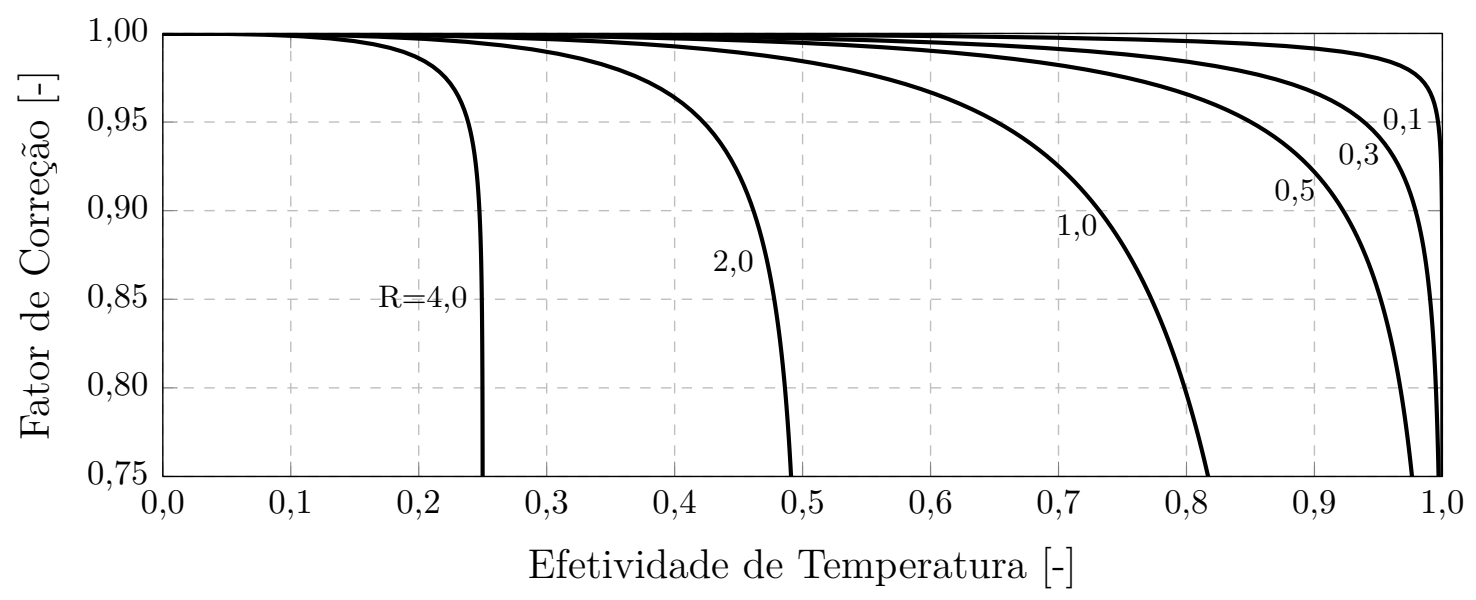

(b) Três passes e dois tubos por passe (3-2) - trocador de calor ilustrado na Figura 106

Figura 32 - Comportamento da efetividade de temperatura em função do fator de correção e da razão de temperatura para trocador de calor de fluxo cruzado em escoamento contracorrente - Caso 4B

relativo considerando os valores da efetividade calculados e tabelados por Gvozdenac (1986) como referência. O arranjo simulado é um trocador de calor de fluxo cruzado em escoamento contracorrente de dois passes do fluido interno, $N_{p}=2$, com infinitas fileiras de tubos em cada passo, $N_{r}=\infty$, e com ambos os fluidos não misturados. Para modelar a condição de infinitas fileiras se empregam 25 fileiras de tubos nas simulações com o algoritmo mostrado no fluxograma da Figura 23, considerando o caso 4B. A solução analítica desenvolvida por Gvozdenac (1986) é complexa e se baseia na solução de uma equação integral de Fredholm de segunda ordem, utilizando o método da colocação que resolve a equação integral por meio de séries de potência. As relações para a efetividade se obtém através de uma integração simples das séries de potências obtidas. Como se pode observar na Tabela 19, o erro relativo oscila bastante sendo o seu valor médio igual a $0,01724 \%$ e seu valor máximo de $0,14598 \%$ para $N U T=4,0$ e $R=1,0$. Devido à dificuldade de aplicação das soluções apresentadas por Gvozdenac (1986) e aos pequenos erros obtidos, se conclui que o procedimento computacional implementado produz resultados 
Tabela 18 - Efetividade de temperatura e erro relativo $\left(\times 10^{4}\right)$ do presente algoritmo em relação ao trabalho de Baclic e Heggs (1985) para trocador de calor de fluxo cruzado com um passe e infinitos tubos (1- $\infty)$ com o fluido quente não misturado - Caso 3A

\begin{tabular}{|c|c|c|c|c|c|c|c|c|c|c|}
\hline & \multicolumn{5}{|c|}{$P$} & \multicolumn{5}{|c|}{$\delta\left[\times 10^{4} \%\right]$} \\
\hline NUT ${ }^{R}$ & 0,1 & 0,3 & 0,5 & 0,7 & 1,0 & 0,1 & 0,3 & 0,5 & 0,7 & 1,0 \\
\hline 0,1 & 0,095 & 0,094 & 0,093 & 0,092 & 0,091 & $-4,3$ & 1,4 & $-1,2$ & $-3,3$ & 3,6 \\
\hline 0,2 & 0,180 & 0,176 & 0,173 & 0,170 & 0,166 & $-2,4$ & 0,6 & 0,9 & $-1,8$ & $-2,4$ \\
\hline 0,4 & 0,324 & 0,314 & 0,304 & 0,295 & 0,281 & 0,5 & 0,6 & $-0,6$ & $-1,7$ & 1,3 \\
\hline 0,6 & 0,441 & 0,423 & 0,405 & 0,388 & 0,365 & $-0,7$ & 0,4 & 0,7 & $-1,1$ & 0,0 \\
\hline 0,8 & 0,537 & 0,510 & 0,484 & 0,461 & 0,428 & 0,4 & $-1,1$ & $-1,0$ & 0,8 & $-1,4$ \\
\hline 1,0 & 0,614 & 0,580 & 0,547 & 0,517 & 0,476 & $-0,7$ & $-0,3$ & $-0,6$ & $-1,3$ & 0,4 \\
\hline 1,2 & 0,677 & 0,637 & 0,599 & 0,563 & 0,515 & $-0,6$ & $-1,0$ & $-0,2$ & $-1,0$ & $-1,4$ \\
\hline 1,4 & 0,730 & 0,684 & 0,641 & 0,601 & 0,546 & $-0,8$ & 0,0 & 0,2 & $-0,3$ & $-0,7$ \\
\hline 1,6 & 0,773 & 0,723 & 0,677 & 0,633 & 0,573 & $-0,9$ & $-1,1$ & $-1,3$ & $-0,5$ & $-1,9$ \\
\hline 1,8 & 0,808 & 0,756 & 0,707 & 0,660 & 0,595 & 0,2 & $-0,8$ & $-0,7$ & $-1,9$ & $-2,1$ \\
\hline 2,0 & 0,838 & 0,784 & 0,732 & 0,683 & 0,614 & $-0,8$ & $-0,9$ & $-0,7$ & $-1,7$ & $-1,2$ \\
\hline 3,0 & 0,927 & 0,875 & 0,820 & 0,763 & 0,681 & $-0,2$ & $-1,9$ & $-1,7$ & $-3,2$ & $-3,0$ \\
\hline 4,0 & 0,965 & 0,922 & 0,870 & 0,812 & 0,722 & $-0,5$ & $-2,2$ & $-3,6$ & $-4,6$ & $-5,5$ \\
\hline 5,0 & 0,983 & 0,949 & 0,902 & 0,844 & 0,751 & $-0,5$ & $-2,1$ & $-4,5$ & $-5,7$ & $-7,2$ \\
\hline 6,0 & 0,991 & 0,966 & 0,924 & 0,868 & 0,772 & $-0,3$ & $-3,0$ & $-5,7$ & $-7,8$ & $-8,9$ \\
\hline 7,0 & 0,995 & 0,976 & 0,939 & 0,886 & 0,789 & $-0,7$ & $-2,3$ & $-6,0$ & $-9,5$ & $-11,9$ \\
\hline 8,0 & 0,998 & 0,983 & 0,951 & 0,901 & 0,802 & $-0,5$ & $-3,0$ & $-6,9$ & $-11,8$ & $-14,4$ \\
\hline 9,0 & 0,999 & 0,988 & 0,960 & 0,912 & 0,813 & $-0,6$ & $-3,1$ & $-8,2$ & $-13,2$ & $-17,6$ \\
\hline 10,0 & 0,999 & 0,991 & 0,967 & 0,922 & 0,823 & 0,0 & $-2,8$ & $-8,5$ & $-14,5$ & $-20,0$ \\
\hline
\end{tabular}

corretos. De fato, Gvozdenac (1986) apenas comentou que os seus resultados concordaram bem com os obtidos por Stevens, Fernandez e Woolf (1957), mas não apresentou uma comparação formal. Já Stevens, Fernandez e Woolf (1957) apresentaram suas soluções numéricas apenas graficamente. Os mesmos discretizaram o trocador de calor em cada passe considerando apenas vinte células computacionais, produzindo resultados razoáveis no sentido da simulação da condição de não mistura de cada fluido. A solução obtida pelo algoritmo desenvolvido no presente trabalho se apresenta graficamente na Figura 33 a modo de comparação. Nota-se que os resultados apresentam um comportamento similar aos mostrados por Stevens, Fernandez e Woolf (1957), corroborando a exatidão do método computacional implementado. Note que na Figura 33 se mostra o comportamento da razão $P / P_{c c}$ em função de $N U T$ para um trocador de calor com dois passes e vinte e cinco tubos por passe (2-25), considerando o caso 4B de Pignotti e Cordero (1983a). O mesmo parâmetro foi empregado por Stevens, Fernandez e Woolf (1957).

Algumas relações apresentadas em Bowman, Mueller e Nagle (1940) também foram empregadas com o iNUTito de avaliar os resultados de simulação produzidos pelo procedimento de Pignotti e Cordero (1983a) e detalhados por Magazoni e Cabezas-Gómez (2016). Dois arranjos foram considerados para comparar os valores obtidos do fator de correção, F. O primeiro arranjo corresponde a um trocador de calor de fluxo cruzado de um passe e um tubo (1-1) com o fluido frio misturado e o quente não misturado. Para este arranjo de trocador de calor, os valores do fator de correção e do erro relativo estão apresentados 
Tabela 19 - Efetividade de temperatura e erro relativo $\left(\times 10^{2}\right)$ do presente algoritmo em relação ao trabalho de Gvozdenac (1986) para trocadores de calor de fluxo cruzado com dois passes e infinitos tubos $(2-\infty)$ com o fluido quente não misturado - Caso 4B

\begin{tabular}{|c|ccccc|ccccc|}
\hline & \multicolumn{5}{|c|}{$P$} & & \multicolumn{5}{c|}{$\delta\left[\times 10^{2} \%\right]$} \\
\hline NUT & 0,1 & 0,3 & 0,5 & 0,7 & 1,0 & 0,1 & 0,3 & 0,5 & 0,7 & 1,0 \\
\hline 0,1 & 0,095 & 0,094 & 0,093 & 0,092 & 0,091 & 0,1 & 0,0 & 0,1 & 0,0 & $-0,1$ \\
0,2 & 0,180 & 0,177 & 0,174 & 0,171 & 0,166 & 0,0 & 0,1 & 0,1 & 0,1 & 0,0 \\
0,4 & 0,325 & 0,315 & 0,306 & 0,297 & 0,284 & 0,4 & 0,8 & 0,9 & 0,7 & 0,0 \\
0,6 & 0,443 & 0,426 & 0,410 & 0,394 & 0,372 & 1,1 & 2,2 & 2,4 & 1,8 & 0,0 \\
0,8 & 0,539 & 0,515 & 0,493 & 0,471 & 0,439 & 2,0 & 4,1 & 4,3 & 3,1 & 0,0 \\
1,0 & 0,617 & 0,588 & 0,560 & 0,532 & 0,492 & 3,1 & 6,2 & 6,3 & 4,5 & $-0,1$ \\
1,2 & 0,682 & 0,648 & 0,615 & 0,582 & 0,535 & 4,3 & 8,4 & 8,4 & 5,8 & $-0,1$ \\
1,4 & 0,735 & 0,698 & 0,661 & 0,623 & 0,570 & 5,5 & 10,5 & 10,1 & 6,8 & $-0,1$ \\
1,6 & 0,779 & 0,740 & 0,699 & 0,658 & 0,599 & 6,5 & 12,2 & 11,5 & 7,5 & $-0,2$ \\
1,8 & 0,815 & 0,775 & 0,732 & 0,688 & 0,624 & 7,4 & 13,6 & 12,5 & 7,9 & $-0,2$ \\
2,0 & 0,846 & 0,804 & 0,760 & 0,714 & 0,645 & 8,1 & 14,6 & 13,1 & 8,0 & $-0,3$ \\
3,0 & 0,935 & 0,898 & 0,852 & 0,800 & 0,717 & 8,5 & 13,8 & 10,6 & 5,1 & $-0,5$ \\
4,0 & 0,972 & 0,943 & 0,901 & 0,849 & 0,758 & 6,0 & 8,1 & 4,2 & 0,3 & $-0,8$ \\
5,0 & 0,987 & 0,966 & 0,930 & 0,880 & 0,786 & 3,2 & 2,4 & $-1,5$ & $-3,4$ & $-1,1$ \\
6,0 & 0,994 & 0,979 & 0,949 & 0,901 & 0,805 & 1,3 & $-1,3$ & $-5,0$ & $-5,4$ & $-1,4$ \\
7,0 & 0,997 & 0,987 & 0,961 & 0,917 & 0,820 & 0,3 & $-3,2$ & $-6,6$ & $-6,0$ & $-1,7$ \\
8,0 & 0,999 & 0,991 & 0,970 & 0,929 & 0,832 & $-0,1$ & $-3,8$ & $-6,8$ & $-5,8$ & $-2,1$ \\
9,0 & 0,999 & 0,994 & 0,976 & 0,938 & 0,841 & $-0,2$ & $-3,7$ & $-6,4$ & $-5,2$ & $-2,4$ \\
10,0 & 1,000 & 0,996 & 0,981 & 0,946 & 0,849 & $-0,2$ & $-3,2$ & $-5,5$ & $-4,4$ & $-2,8$ \\
\hline
\end{tabular}

$\delta=100\left(P_{t h}-P\right) / P_{t h} \times 10^{-2}$

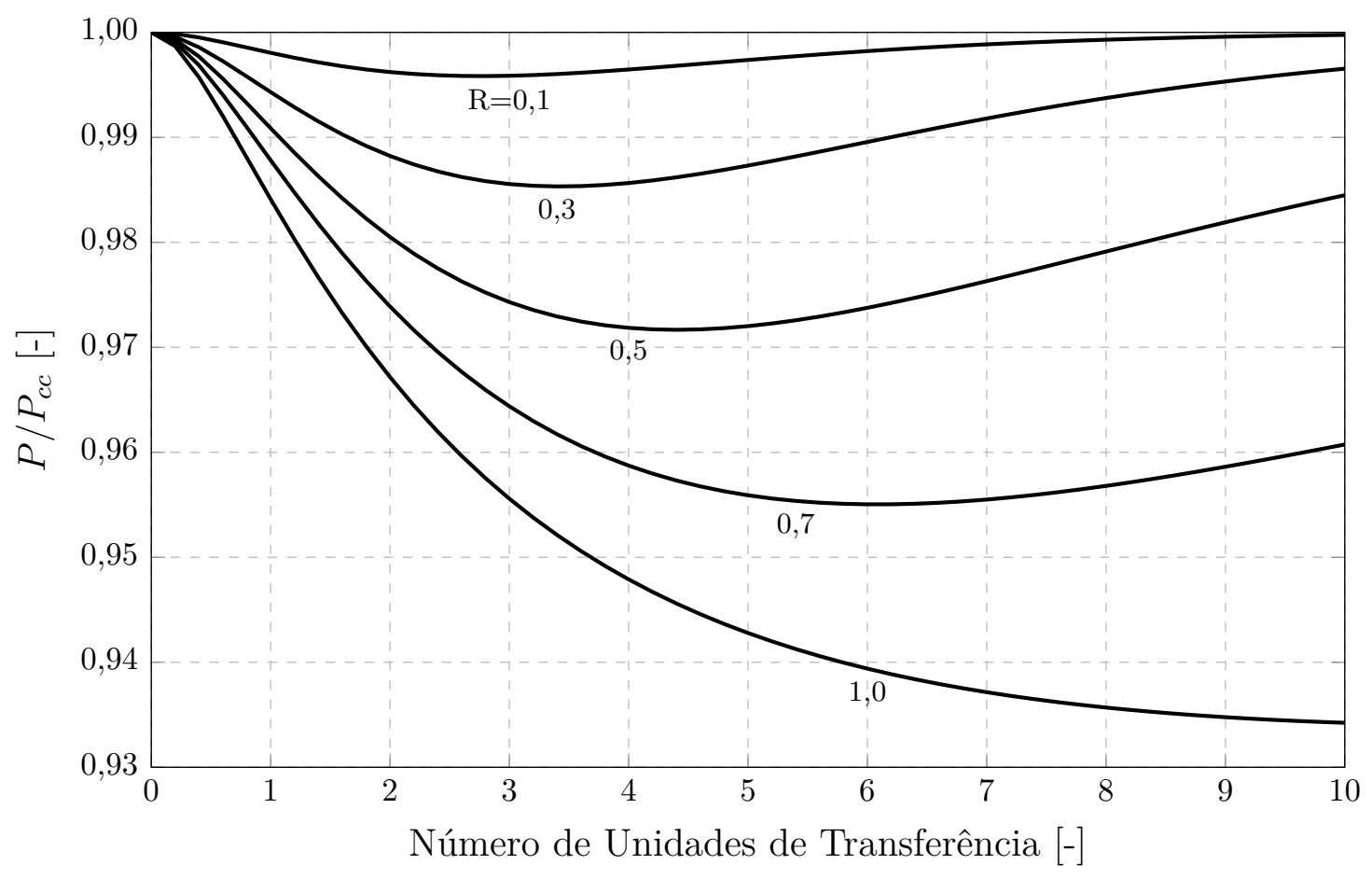

Figura 33 - Comportamento da razão $P / P_{c c}$ em função de $N U T$ para o caso $4 \mathrm{~B}$ considerando um trocador de fluxo cruzado com dois passes e vinte cinco tubos por passe (2-25) e ambos os fluidos não misturados 
na Tabela 20 e o erro relativo médio obtido é igual a $-1,0 \times 10^{-9} \%$. Na comparação se empregou o algoritmo do caso 3A de Pignotti e Cordero (1983a).

Tabela 20 - Fator de correção e erro relativo $\left(\times 10^{7}\right)$ do presente algoritmo em relação ao trabalho de Bowman, Mueller e Nagle (1940) para trocador de calor de fluxo cruzado com um passe e um tubo (1-1) com o fluido quente não misturado - Caso 3A

\begin{tabular}{|c|c|c|c|c|c|c|c|c|c|c|}
\hline & \multicolumn{5}{|c|}{$F$} & \multicolumn{5}{|c|}{$\delta\left[\times 10^{7} \%\right]$} \\
\hline${ }_{N U T}^{R}$ & 0,1 & 0,3 & 0,5 & 0,7 & 1,0 & 0,1 & 0,3 & 0,5 & 0,7 & 1,0 \\
\hline 0,1 & 1,000 & 0,999 & 0,998 & 0,997 & 0,994 & 0,0 & 0,0 & $-12,3$ & 0,0 & 0,0 \\
\hline 0,2 & 0,999 & 0,997 & 0,994 & 0,988 & 0,978 & 0,0 & 0,0 & $-71,9$ & 0,0 & 0,0 \\
\hline 0,4 & 0,997 & 0,987 & 0,976 & 0,958 & 0,930 & 0,0 & 0,0 & $-21,2$ & 0,0 & 0,0 \\
\hline 0,6 & 0,994 & 0,973 & 0,950 & 0,916 & 0,872 & 0,0 & 0,0 & 37,6 & 0,0 & 0,0 \\
\hline 0,8 & 0,989 & 0,953 & 0,918 & 0,869 & 0,813 & 0,0 & 0,0 & $-48,1$ & 0,0 & 0,0 \\
\hline 1,0 & 0,983 & 0,930 & 0,882 & 0,820 & 0,756 & 0,0 & 0,0 & 57,4 & 0,0 & 0,0 \\
\hline 1,2 & 0,976 & 0,903 & 0,843 & 0,771 & 0,702 & 0,0 & 0,0 & $-80,7$ & 0,0 & 0,0 \\
\hline 1,4 & 0,967 & 0,874 & 0,803 & 0,724 & 0,653 & 0,0 & 0,0 & $-70,0$ & 0,0 & 0,0 \\
\hline 1,6 & 0,956 & 0,843 & 0,763 & 0,680 & 0,608 & 0,0 & 0,0 & 63,3 & 0,0 & 0,0 \\
\hline 1,8 & 0,944 & 0,811 & 0,725 & 0,638 & 0,567 & 0,0 & 0,0 & 9,3 & 0,0 & 0,0 \\
\hline 2,0 & 0,931 & 0,778 & 0,687 & 0,600 & 0,530 & 0,0 & 0,0 & 3,4 & 0,0 & 0,0 \\
\hline 3,0 & 0,842 & 0,625 & 0,529 & 0,449 & 0,391 & 0,0 & 0,0 & $-60,1$ & 0,0 & 0,0 \\
\hline 4,0 & 0,732 & 0,502 & 0,417 & 0,350 & 0,304 & 0,0 & 0,0 & $-10,6$ & 0,0 & 0,0 \\
\hline 5,0 & 0,625 & 0,412 & 0,340 & 0,284 & 0,246 & 0,0 & 0,0 & 38,2 & 0,0 & 0,0 \\
\hline 6,0 & 0,534 & 0,347 & 0,285 & 0,238 & 0,206 & 0,0 & 0,0 & 33,9 & 0,0 & 0,0 \\
\hline 7,0 & 0,462 & 0,298 & 0,245 & 0,205 & 0,177 & 0,0 & 0,0 & $-84,5$ & 0,0 & 0,0 \\
\hline 8,0 & 0,406 & 0,261 & 0,215 & 0,179 & 0,155 & 0,0 & 0,0 & $-23,7$ & 0,0 & 0,0 \\
\hline 9,0 & 0,361 & 0,232 & 0,191 & 0,159 & 0,138 & $-0,1$ & 0,0 & 5,2 & 0,0 & 0,1 \\
\hline 10,0 & 0,325 & 0,209 & 0,172 & 0,143 & 0,124 & $-0,1$ & 0,0 & 48,4 & 0,0 & $-0,1$ \\
\hline
\end{tabular}

Trocador de calor de fluxo cruzado ilustrados na Figura 71 do Anexo A $\delta=100\left(F_{t h}-F\right) / F_{t h} \times 10^{-7}$

Já o segundo arranjo corresponde a um trocador de calor de fluxo cruzado com um passe e infinitos tubos $(1-\infty)$ com o fluido frio misturado e o fluido quente não misturado. Novamente, para modelar infinitas fileiras de tubos no algoritmo desenvolvido se emprega um número de fileiras fixo, nesta caso utiliza-se $N_{r}=200$ e o algoritmo desenvolvido para o caso 3A apresentado na Figura 21. Na Tabela 21, são apresentados os valores de efetividade de temperatura e do erro relativo, sendo o erro relativo médio de -0,02567 \% . As expressões apresentadas por Bowman, Mueller e Nagle (1940) e obtidas por Nusselt (1930) devem ser utilizadas com cuidado, pois à medida que os valores de $N U T$ e $R$ aumentam, o valores do erro relativo aumentam também. Isto é evidenciado para $N U T=10$ e $R=1,0$, onde o erro relativo é de $-2,02 \%$. Nesta região o fator de correção atinge valores menores que 0,65 que não são interessantes para o projeto de trocadores de calor. Porém, os problemas de convergência dessa solução teórica são comentados na literatura (BACLIC; HEGGS, $1985)$.

O gráfico para o fator de correção $F$ desse arranjo obtido por Bowman, Mueller e Nagle (1940) e mostrado na Figura 34 também foi criticado por Tucker (1996). Segundo esse autor, o gráfico do fator de correção, amplamente utilizado em livros de texto da área, tais como Incropera e DeWitt (2014) e Kays e London (1998), apresenta imprecisões devido à 
Tabela 21 - Fator de correção e erro relativo $\left(\times 10^{1}\right)$ do presente algoritmo em relação ao trabalho de Bowman, Mueller e Nagle (1940) para trocador de calor de fluxo cruzado com um passe e infinitos tubos (1- $\infty$ ) com o fluido quente não misturado - Caso 3A

\begin{tabular}{|c|c|c|c|c|c|c|c|c|c|c|}
\hline & \multicolumn{5}{|c|}{$F$} & \multicolumn{5}{|c|}{$\delta\left[\times 10^{1} \%\right]$} \\
\hline NUT ${ }^{R}$ & 0,1 & 0,3 & 0,5 & 0,7 & 1,0 & 0,1 & 0,3 & 0,5 & 0,7 & 1,0 \\
\hline 0,1 & 1,000 & 1,000 & 0,999 & 0,999 & 0,998 & 0,0 & 0,0 & 0,0 & 0,0 & 0,0 \\
\hline 0,2 & 0,999 & 0,998 & 0,997 & 0,996 & 0,994 & 0,0 & 0,0 & 0,0 & 0,0 & 0,0 \\
\hline 0,4 & 0,998 & 0,993 & 0,989 & 0,985 & 0,979 & 0,0 & 0,0 & 0,0 & 0,0 & 0,0 \\
\hline 0,6 & 0,995 & 0,985 & 0,977 & 0,969 & 0,958 & 0,0 & 0,0 & 0,0 & 0,0 & 0,0 \\
\hline 0,8 & 0,991 & 0,976 & 0,962 & 0,950 & 0,934 & 0,0 & 0,0 & 0,0 & 0,0 & 0,0 \\
\hline 1,0 & 0,987 & 0,965 & 0,946 & 0,930 & 0,909 & 0,0 & 0,0 & 0,0 & 0,0 & 0,0 \\
\hline 1,2 & 0,983 & 0,953 & 0,929 & 0,909 & 0,885 & 0,0 & 0,0 & 0,0 & 0,0 & 0,0 \\
\hline 1,4 & 0,978 & 0,941 & 0,912 & 0,889 & 0,861 & 0,0 & 0,0 & 0,0 & 0,0 & 0,0 \\
\hline 1,6 & 0,973 & 0,929 & 0,895 & 0,869 & 0,838 & 0,0 & 0,0 & 0,0 & 0,0 & 0,0 \\
\hline 1,8 & 0,967 & 0,916 & 0,878 & 0,849 & 0,816 & 0,0 & 0,0 & 0,0 & 0,0 & 0,0 \\
\hline 2,0 & 0,961 & 0,904 & 0,862 & 0,831 & 0,796 & 0,0 & 0,0 & 0,0 & 0,0 & 0,0 \\
\hline 3,0 & 0,932 & 0,845 & 0,791 & 0,752 & 0,713 & 0,0 & 0,0 & 0,0 & 0,0 & 0,0 \\
\hline 4,0 & 0,904 & 0,796 & 0,734 & 0,692 & 0,651 & 0,0 & 0,0 & 0,0 & 0,0 & 0,0 \\
\hline 5,0 & 0,879 & 0,756 & 0,688 & 0,644 & 0,603 & 0,0 & 0,0 & 0,0 & 0,0 & 0,0 \\
\hline 6,0 & 0,856 & 0,722 & 0,651 & 0,606 & 0,565 & 0,0 & 0,0 & 0,0 & $-0,1$ & $-0,1$ \\
\hline 7,0 & 0,836 & 0,693 & 0,620 & 0,574 & 0,533 & 0,0 & 0,0 & $-0,1$ & $-0,1$ & $-0,1$ \\
\hline 8,0 & 0,819 & 0,669 & 0,593 & 0,547 & 0,507 & 0,0 & $-0,1$ & $-0,1$ & $-0,1$ & $-0,1$ \\
\hline 9,0 & 0,803 & 0,648 & 0,571 & 0,524 & 0,484 & 0,0 & $-0,1$ & $-0,1$ & $-0,1$ & $-1,4$ \\
\hline 10,0 & 0,789 & 0,629 & 0,551 & 0,504 & 0,464 & $-0,1$ & $-0,1$ & $-0,1$ & $-0,3$ & $-20,2$ \\
\hline
\end{tabular}

consideração de poucos termos na solução da série obtida por Nusselt (1930) e reproduzida por Bowman, Mueller e Nagle (1940). Os resultados da efetividade de temperatura e do fator de correção obtidos no procedimento numérico do caso 3A (Figura 21) apresentam resultados idênticos aos resultados obtidos por Tucker (1996). Nas Figuras 35 e 36 são apresentados respectivamente os comportamentos da efetividade de temperatura e da razão $P / P_{c c}$ em função do número de unidades de transferência, $N U T$, e da razão de temperatura, $R$.

Nas Tabelas 22 e 23 são apresentados os valores da efetividade de temperatura e do erro relativo provenientes da comparação dos resultados calculados para o fator de correção $F$ entre as expressões matemáticas aproximadas de Roetzel e Spang (2010) e Roetzel e Nicole (1975) com os resultados produzidos pelo algoritmo, considerando o caso $3 \mathrm{~A}$ para um trocador de calor de fluxo cruzado de um passe e um tubo por passe $\left(N_{r}=1\right.$ e $N_{p}=1$ ). O erro médio relativo entre as relações teóricas de Pignotti e Cordero (1983a) e a relação desenvolvida por Roetzel e Spang (2010) é de 0,24004 \%, e o erro médio relativo em relação as relações aproximadas desenvolvidas por Roetzel e Nicole (1975) é igual a $-0,02163 \%$. Entretanto, as expressões aproximadas apresentam incertezas no seu cálculo para valores elevados de $N U T$, que não permitem um cálculo correto do fator de correção.

As expressões fornecidas em Roetzel e Spang (2010) são válidas para valores de $F$ maiores que 0,25 e possuem erro relativo máximo de $5 \%$ segundo o próprio autor. 


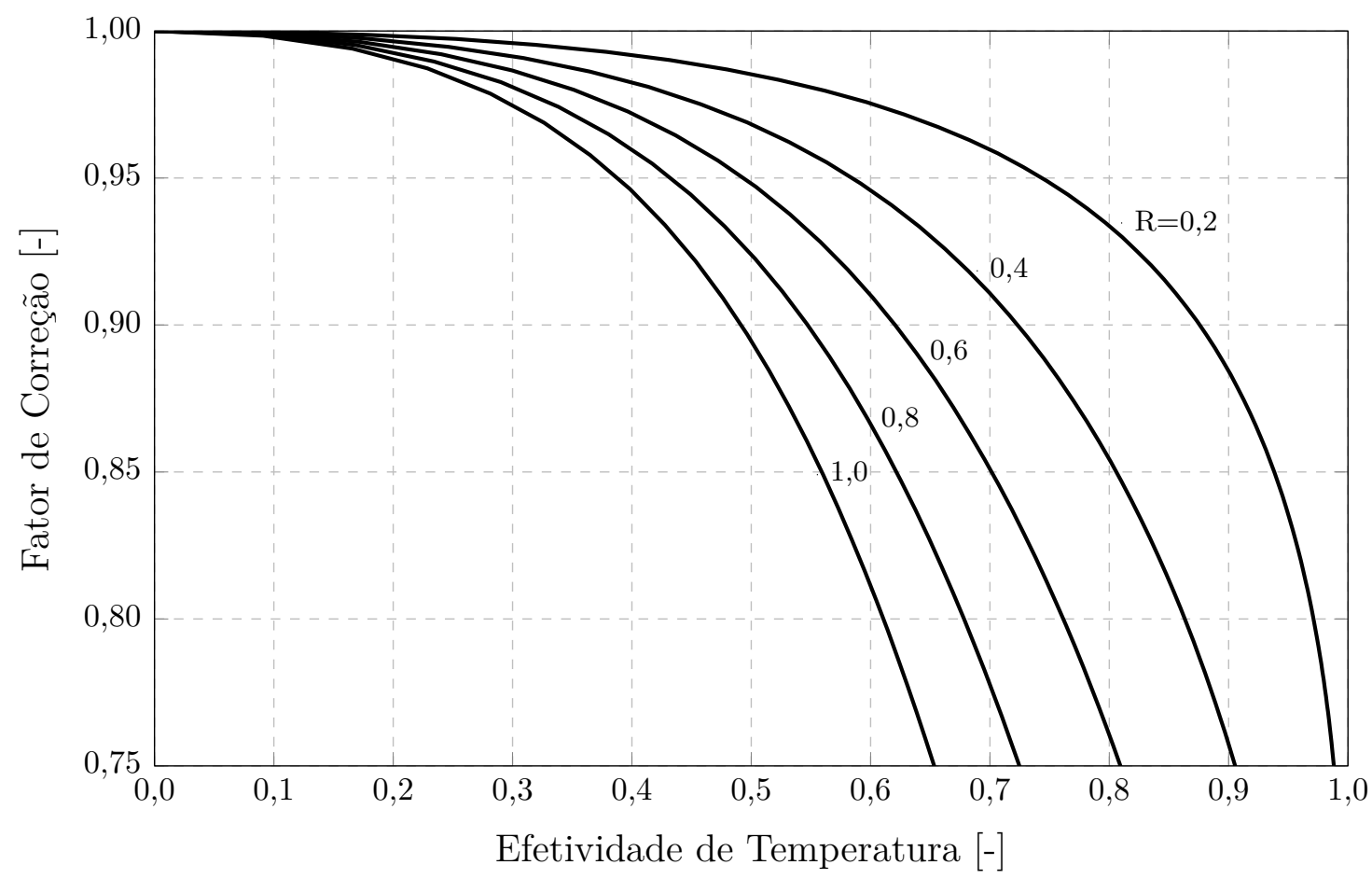

Figura 34 - Fator de correção em função de $P$ e $R$ de um trocador de calor de fluxo cruzado com um passe e infinitos tubos (1- $\infty$ ) com o fluido frio misturado e o quente não misturado - Caso $3 \mathrm{~A}$

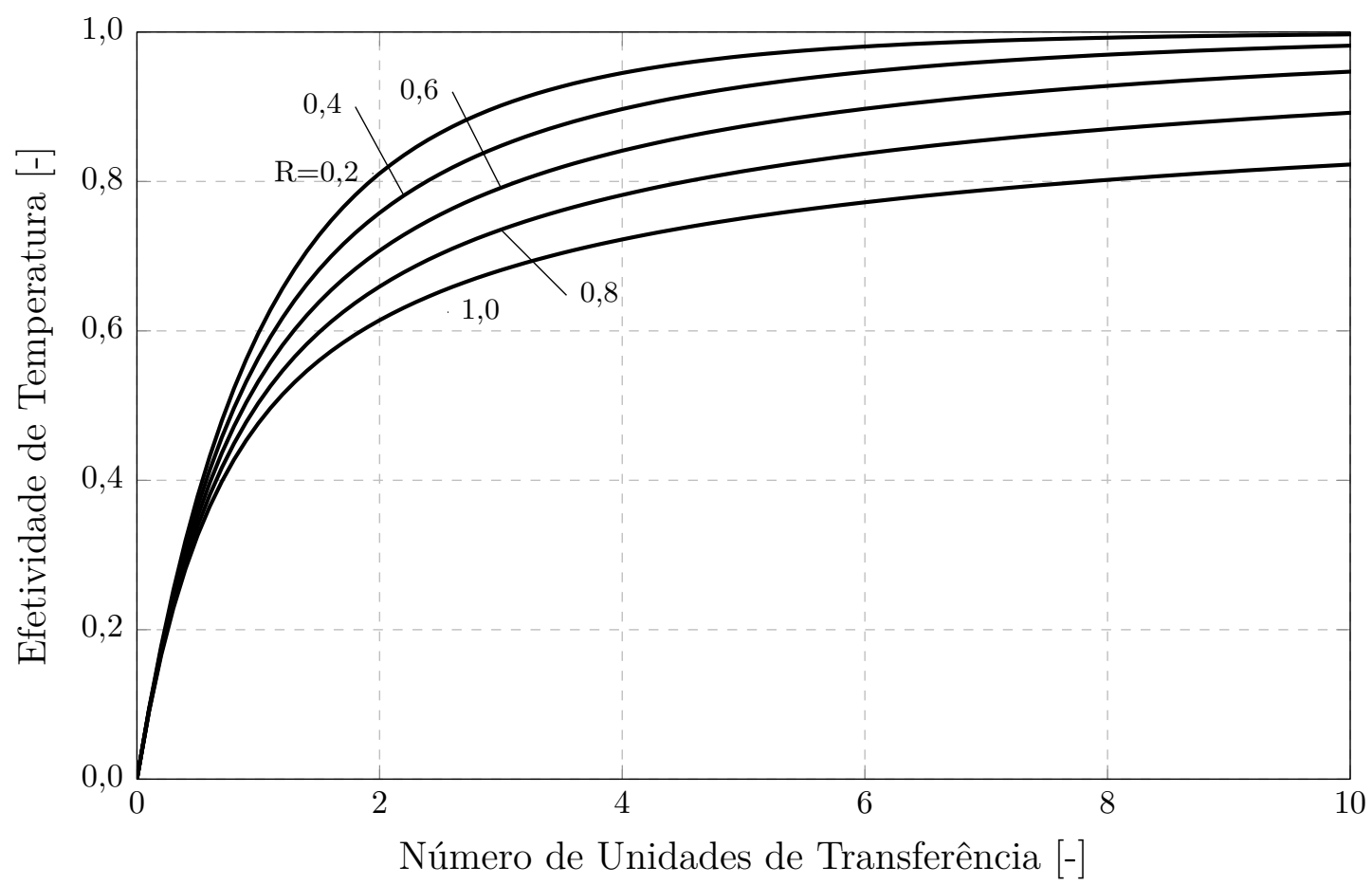

Figura 35 - Efetividade de temperatura em função de $N U T$ e $R$ de um trocador de calor de fluxo cruzado com um passe e infinitos tubos $(1-\infty)$ com o fluido frio misturado e o quente não misturado - Caso 3A 


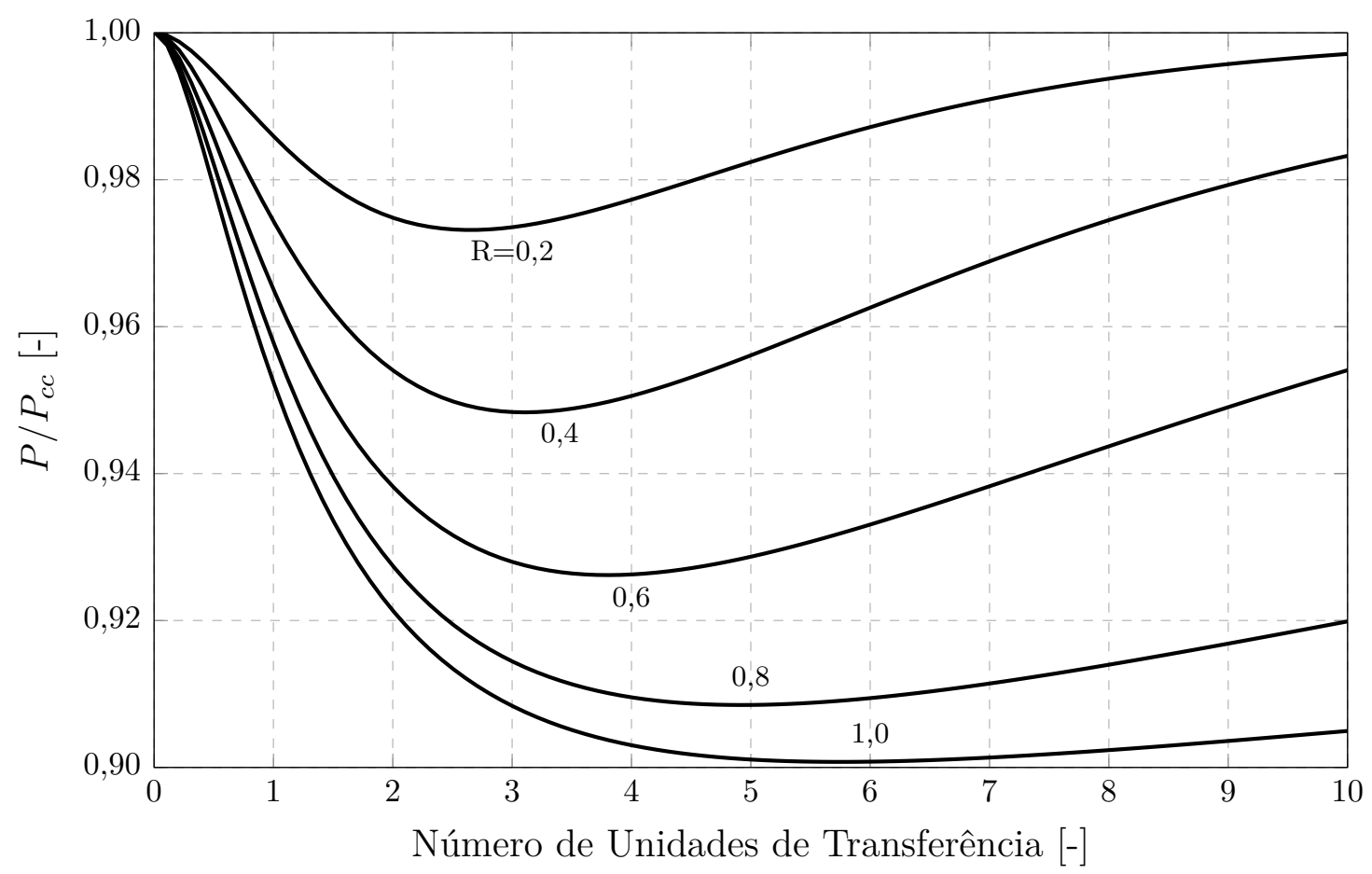

Figura 36 - Comportamento da razão $P / P_{c c}$ em função de $N U T$ para o caso $3 \mathrm{~A}$ considerando um trocador de calor de fluxo cruzado com um passe e infinitos tubos $(1-\infty)$ com o fluido frio misturado e o quente não misturado

Entretanto, isto não foi comprovado no presente trabalho, onde o erro máximo é de 10,8 \% para um trocador de calor de fluxo cruzado com um passe e um tubo por passe (1-1) apresentado na Tabela 22. Da mesma maneira, as relações apresentadas por Roetzel e Nicole (1975) são válidas para valores de $F$ maiores que 0,50 e para razões entre a efetividade do trocador e a diferença média de temperatura, $P / r_{l m}$, no intervalo de 0,25 a 2,50. Por essas razões alguns valores de fator de correção das Tabelas 22 e 23 não são calculados e apresentados.

O fator de correção e o erro relativo entre o fator de correção teórico dado pelo procedimento de Pignotti e Cordero (1983a) e o fator de correção aproximado estimado por Roetzel e Spang (2010) para um trocador de fluxo cruzado de um passe e dez fileiras de tubos por passe $\left(N_{r}=10\right.$ e $\left.N_{p}=1\right)$ com o fluido externo não misturado é apresentado na Tabela 24. O erro médio relativo neste caso é de 1,63525\%. Novamente a correlação aproximada apresenta um comportamento similar aos resultados mostrados anteriormente para valores elevados de $N U T$, para os quais o erro relativo é relativamente grande. Essa região está destacada na Tabela 24, assim como nas Tabelas 22 e 23. Note que os erros relativos máximos apresentados nas Tabelas 22 e 24 são iguais a 10,8 \% e 12,2 \%, respectivamente. Esse fato indica a necessidade de tomar cuidado na aplicação das relações aproximadas publicadas na literatura. Nesses casos, recomenda-se o emprego do procedimento apresentado neste trabalho. Entretanto, a decisão sobre o uso de um ou outro tipo de solução deve ser baseada em comparações dos procedimentos na faixa operacional de 
Tabela 22 - Fator de correção e erro relativo do presente algoritmo em relação ao trabalho de Roetzel e Spang (2010) para trocador de calor de fluxo cruzado com um passe e um tubo por passe (1-1) com o fluido quente não misturado

\begin{tabular}{|c|c|c|c|c|c|c|c|c|c|c|}
\hline & \multicolumn{5}{|c|}{$F$} & \multicolumn{5}{|c|}{$\delta[\%]$} \\
\hline $\mathrm{VUT}^{R}$ & 0,1 & 0,3 & 0,5 & 0,7 & 1,0 & 0,1 & 0,3 & 0,5 & 0,7 & 1,0 \\
\hline 0,1 & 1,000 & 1,000 & 0,999 & 0,999 & 0,998 & 0,0 & 0,0 & 0,0 & 0,0 & 0,0 \\
\hline 0,2 & 0,999 & 0,998 & 0,997 & 0,996 & 0,994 & $-0,1$ & $-0,1$ & $-0,1$ & $-0,1$ & 0,0 \\
\hline 0,4 & 0,997 & 0,992 & 0,987 & 0,983 & 0,976 & $-0,3$ & $-0,3$ & $-0,3$ & $-0,2$ & 0,0 \\
\hline 0,6 & 0,994 & 0,983 & 0,973 & 0,963 & 0,950 & $-0,6$ & $-0,7$ & $-0,5$ & $-0,3$ & 0,1 \\
\hline 0,8 & 0,989 & 0,970 & 0,953 & 0,938 & 0,918 & $-1,0$ & $-1,1$ & $-0,8$ & -0 & 0,1 \\
\hline 1,0 & 0,983 & 0,954 & 0,930 & 0,908 & 0,882 & $-1,5$ & $-1,5$ & $-1,1$ & $-0,6$ & 0,0 \\
\hline 1,2 & 0,976 & 0,9 & 0,903 & 0,876 & 0,843 & $-2,0$ & $-1,9$ & $-1,3$ & $-0,7$ & 0,0 \\
\hline 1,4 & 0,967 & 0,914 & 0,874 & 0,841 & 0,803 & $-2,5$ & $-2,3$ & $-1,5$ & $-0,8$ & 0,0 \\
\hline 1,6 & 0,956 & 0,891 & 0,843 & 0,806 & 0,763 & $-3,1$ & $-2,6$ & $-1,7$ & $-0,9$ & $-0,1$ \\
\hline 1,8 & 0,944 & 0,865 & 0,811 & 0,770 & 0,725 & $-3,6$ & $-2,8$ & $-1,8$ & $-0,9$ & $-0,1$ \\
\hline 2,0 & 0,931 & 0,839 & 0,778 & 0,735 & 0,687 & $-4,0$ & $-3,0$ & $-1,8$ & $-0,9$ & $-0,1$ \\
\hline 3,0 & 0,842 & 0,699 & 0,625 & 0,577 & 0,529 & $-4,9$ & $-2,2$ & $-0,8$ & $-0,2$ & 0,0 \\
\hline 4,0 & 0,732 & 0,573 & 0,502 & 0,459 & 0,417 & $-2,9$ & 0,0 & 0,8 & 0,8 & 0,3 \\
\hline 5,0 & 0,625 & 0,474 & 0,412 & 0,375 & 0,340 & 0,7 & 2,2 & 2,1 & 1,5 & 0,3 \\
\hline 6,0 & 0,534 & 0,400 & 0,347 & 0,315 & 0,285 & 4,1 & 3,8 & 2,8 & 1,7 & 0,0 \\
\hline 7,0 & 0,462 & 0,345 & 0,298 & 0,271 & 0,245 & 6,8 & 4,7 & 3,1 & 1,6 & - \\
\hline 8,0 & 0,406 & 0,302 & 0,261 & 0,237 & 0,215 & 8,8 & 5,2 & 3,0 & - & - \\
\hline 9,0 & 0,361 & 0,269 & 0,232 & 0,211 & 0,191 & 10,0 & 5,2 & - & - & - \\
\hline 10,0 & 0,325 & 0,242 & 0,209 & 0,190 & 0,172 & 10,8 & 5,1 & - & - & - \\
\hline
\end{tabular}

Trocador de calor de fluxo cruzado ilustrado na Figura 71 do Anexo A

$\delta=100\left(F_{t h}-F\right) / F_{t h}$

Tabela 23 - Fator de correção e erro relativo do presente algoritmo em relação ao trabalho de Roetzel e Nicole (1975) para trocador de calor de fluxo cruzado com um passe e um tubo por passe (1-1) com o fluido quente não misturado

\begin{tabular}{|c|c|c|c|c|c|c|c|c|c|c|}
\hline & \multicolumn{5}{|c|}{$F$} & \multicolumn{5}{|c|}{$\delta[\%]$} \\
\hline $\mathrm{NUT}^{R}$ & 0,1 & 0,3 & 0,5 & 0,7 & 1,0 & 0,1 & 0,3 & 0,5 & 0,7 & 1,0 \\
\hline 0,1 & 1,000 & 1,000 & 0,999 & 0,999 & 0,998 & - & - & - & - & - \\
\hline 0,2 & 0,999 & 0,998 & 0,997 & 0,996 & 0,994 & - & 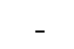 & - & - & - \\
\hline 0,4 & 0,997 & 0,992 & 0,987 & 0,983 & 0,976 & 0,2 & 0,0 & $-0,4$ & $-0,5$ & $-0,4$ \\
\hline 0,6 & 0,994 & 0,983 & 0,973 & 0,963 & 0,950 & $-0,1$ & $-0,3$ & $-0,2$ & 0,2 & 0,6 \\
\hline 0,8 & 0,989 & 0,970 & 0,953 & 0,938 & 0,918 & 0,0 & 0,0 & 0,5 & 0,9 & 1,1 \\
\hline 1,0 & 0,983 & 0,954 & 0,930 & 0,908 & 0,88 & 0,2 & 0,5 & 0,9 & 1,1 & 0,9 \\
\hline 1,2 & 0,976 & 0,935 & 0,903 & 0,876 & 0,843 & 0,5 & 0,8 & 0,9 & 0,7 & 0,3 \\
\hline 1,4 & 0,967 & 0,914 & 0,874 & 0,8 & 0,8 & 0,6 & 0,8 & 0,5 & 0,0 & $-0,5$ \\
\hline 1,6 & 0,956 & 0,891 & 0,843 & 0,806 & 0,763 & 0,6 & 0,6 & $-0,1$ & $-0,8$ & $-1,2$ \\
\hline 1,8 & 0,944 & 0,865 & 0,811 & 0,770 & 0,725 & 0,5 & 0,3 & $-0,7$ & $-1,5$ & $-1,6$ \\
\hline 2,0 & 0,931 & 0,839 & 0,778 & 0,735 & 0,687 & 0,4 & $-0,1$ & $-1,2$ & $-1,9$ & $-1,6$ \\
\hline 3,0 & 0,842 & 0,699 & 0,625 & 0,577 & 0,529 & 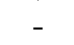 & - & - & - & - \\
\hline 4,0 & 0,732 & 0,573 & 0,502 & 0,459 & 0,4 & - & 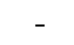 & - & - & - \\
\hline 5,0 & 0,625 & 0,4 & 0,4 & 0,3 & & - & - & - & - & - \\
\hline 6,0 & 0,534 & 0,400 & 0,347 & 0,315 & 0,285 & - & - & - & - & - \\
\hline 7,0 & 0,462 & 0,345 & 0,298 & 0,271 & 0,245 & - & - & - & - & - \\
\hline 8,0 & 0,406 & 0,302 & 0,261 & 0,237 & 0,215 & - & - & - & - & - \\
\hline 9,0 & 0,361 & 0,269 & 0,232 & 0,211 & 0,191 & - & - & - & 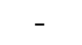 & - \\
\hline 10,0 & 0,325 & 0,242 & 0,209 & 0,190 & 0,172 & - & - & - & - & \\
\hline
\end{tabular}

Trocador de calor de fluxo cruzado ilustrado na Figura 71 do Anexo A.

$\delta=100\left(F_{t h}-F\right) / F_{t h}$ 
projeto de um determinado trocador de calor e na disponibilidade do procedimento de cálculo.

Tabela 24 - Fator de correção e erro relativo do presente algoritmo em relação ao trabalho de Roetzel e Spang (2010) para trocador de calor de fluxo cruzado com um passe e dez tubos por passe (1-10) com o fluido quente não misturado - Caso 3A

\begin{tabular}{|c|ccccc|cccccc|}
\hline & \multicolumn{9}{|c|}{$F$} & & \multicolumn{5}{c|}{$\delta[\%]$} \\
NUT & 0,1 & 0,3 & 0,5 & 0,7 & 1,0 & 0,1 & 0,3 & 0,5 & 0,7 & 1,0 \\
\hline 0,1 & 1,000 & 1,000 & 0,999 & 0,999 & 0,998 & 0,1 & 0,1 & 0,1 & 0,2 & 0,2 \\
0,2 & 0,999 & 0,998 & 0,997 & 0,996 & 0,994 & 0,1 & 0,2 & 0,3 & 0,3 & 0,4 \\
0,4 & 0,998 & 0,993 & 0,989 & 0,985 & 0,979 & 0,3 & 0,5 & 0,6 & 0,6 & 0,6 \\
0,6 & 0,995 & 0,985 & 0,977 & 0,969 & 0,958 & 0,5 & 0,7 & 0,7 & 0,7 & 0,5 \\
0,8 & 0,991 & 0,976 & 0,962 & 0,950 & 0,934 & 0,7 & 0,9 & 0,8 & 0,6 & 0,4 \\
1,0 & 0,987 & 0,965 & 0,946 & 0,930 & 0,909 & 0,9 & 1,0 & 0,8 & 0,5 & 0,2 \\
1,2 & 0,983 & 0,953 & 0,929 & 0,909 & 0,884 & 1,1 & 1,1 & 0,7 & 0,4 & 0,0 \\
1,4 & 0,978 & 0,941 & 0,912 & 0,888 & 0,860 & 1,3 & 1,1 & 0,7 & 0,2 & $-0,2$ \\
1,6 & 0,972 & 0,928 & 0,895 & 0,868 & 0,837 & 1,5 & 1,2 & 0,6 & 0,1 & $-0,4$ \\
1,8 & 0,967 & 0,916 & 0,878 & 0,849 & 0,815 & 1,7 & 1,3 & 0,6 & 0,0 & $-0,5$ \\
2,0 & 0,961 & 0,903 & 0,861 & 0,830 & 0,795 & 1,9 & 1,3 & 0,6 & 0,0 & $-0,5$ \\
3,0 & 0,931 & 0,844 & 0,788 & 0,750 & 0,710 & 2,9 & 1,9 & 0,8 & 0,1 & $-0,3$ \\
4,0 & 0,902 & 0,793 & 0,730 & 0,688 & 0,646 & 4,1 & 2,7 & 1,3 & 0,5 & 0,2 \\
5,0 & 0,876 & 0,751 & 0,682 & 0,638 & 0,596 & 5,5 & 3,7 & 2,1 & 1,1 & 0,7 \\
6,0 & 0,852 & 0,715 & 0,643 & 0,598 & 0,555 & 6,8 & 4,8 & 2,8 & 1,6 & 1,2 \\
7,0 & 0,830 & 0,684 & 0,610 & 0,563 & 0,521 & 8,2 & 5,8 & 3,5 & 2,1 & 1,4 \\
8,0 & 0,810 & 0,657 & 0,581 & 0,534 & 0,492 & 9,6 & 6,8 & 4,1 & 2,4 & 1,6 \\
9,0 & 0,792 & 0,633 & 0,555 & 0,508 & 0,467 & 10,9 & 7,6 & 4,5 & 2,6 & 1,6 \\
10,0 & 0,776 & 0,612 & 0,532 & 0,485 & 0,444 & 12,2 & 8,4 & 4,9 & 2,6 & 1,4 \\
\hline
\end{tabular}

Trocador de calor de fluxo cruzado ilustrado na Figura 80 do Anexo A

$\delta=100\left(F_{t h}-F\right) / F_{t h}$

Para finalizar a análise comparativa, nas Tabelas 25 e 26 são apresentados os valores do fator de correção e do erro relativo para um arranjo contracorrente-cruzado de dois passes e um tubo por passe $\left(N_{r}=1\right.$ e $\left.N_{p}=2\right)$, considerando ambos os fluidos não misturados. Novamente comparam-se os resultados produzidos pelo procedimento de cálculo de Pignotti e Cordero (1983a) e as relações aproximadas desenvolvidas por Roetzel e Spang (2010) e Roetzel e Nicole (1975). Observam-se as mesmas tendências comentadas nas Tabelas 22 e 23. Porém os erros relativos máximos são menores em ambos os casos. Esse fenômeno está associado com a qualidade do polinômio de ajuste desenvolvido, que pode ser influenciada pelo tipo de arranjo modelado.

Desta forma, na Tabela 27 é sumarizado o erro relativo médio da comparação entre os resultados do presente algoritmo e dos trabalhos provenientes da literatura para vários tipos de trocadores de calor de fluxo cruzado. Além disso, o intervalo de confiança de $95 \%$ para cada configuração de trocadores de calor de fluxo cruzado também é apresentado na mesma tabela. O intervalo de confiança descreve a incerteza associada com o método, o que significa que dentro deste intervalo contém o valor real da média. Os resultados apresentados nesta tabela demonstram que as expressões matemáticas desenvolvidas e apresentadas pela literatura externa devem ser utilizadas com cautela. As expressões 
Tabela 25 - Fator de correção e erro relativo do presente algoritmo em relação ao trabalho de Roetzel e Spang (2010) para trocador de calor de fluxo cruzado em escoamento contracorrente com dois passes e um tubo por passe (2-1) com o fluido quente não misturado - Caso $4 \mathrm{~A}$

\begin{tabular}{|c|c|c|c|c|c|c|c|c|c|c|}
\hline & \multicolumn{5}{|c|}{$F$} & \multicolumn{5}{|c|}{$\delta[\%]$} \\
\hline $\mathrm{NUT}^{R}$ & 0,1 & 0,3 & 0,5 & 0,7 & 1,0 & 0,1 & 0,3 & 0,5 & 0,7 & 1,0 \\
\hline 0,1 & 1,000 & 1,000 & 1,000 & 1,000 & 1,000 & 0,0 & 0,0 & 0,0 & 0,0 & 0,0 \\
\hline 0,2 & 1,000 & 1,000 & 0,999 & 0,999 & 0,998 & 0,0 & 0,0 & 0,0 & 0,0 & 0,0 \\
\hline 0,4 & 0,999 & 0,998 & 0,997 & 0,995 & 0,993 & 0,1 & 0,1 & 0,1 & 0,1 & 0,0 \\
\hline 0,6 & 0,998 & 0,996 & 0,993 & 0,990 & 0,985 & 0,1 & 0,2 & 0,2 & 0,1 & 0,0 \\
\hline 0,8 & 0,997 & 0,992 & 0,987 & 0,982 & 0,975 & 0,2 & 0,3 & 0,3 & 0,2 & 0,0 \\
\hline 1,0 & 0,996 & 0,988 & 0,980 & 0,972 & 0,961 & 0,4 & 0,5 & 0,4 & 0,2 & 0,0 \\
\hline 1,2 & 0,994 & 0,982 & 0,971 & 0,960 & 0,946 & 0,5 & 0,6 & 0,5 & 0,3 & 0,0 \\
\hline 1,4 & 0,992 & 0,976 & 0,961 & 0,947 & 0,928 & 0,7 & 0,8 & 0,7 & 0,4 & 0,0 \\
\hline 1,6 & 0,989 & 0,969 & 0,950 & 0,932 & 0,910 & 0,9 & 1,0 & 0,8 & 0,5 & 0,0 \\
\hline 1,8 & 0,986 & 0,960 & 0,937 & 0,916 & 0,890 & 1,1 & 1,2 & 0,9 & 0,5 & 0,0 \\
\hline 2,0 & 0,983 & 0,951 & 0,924 & 0,900 & 0,869 & 1,3 & 1,4 & 1,1 & 0,6 & 0,0 \\
\hline 3,0 & 0,960 & 0,895 & 0,845 & 0,805 & 0,760 & 2,5 & 2,2 & 1,4 & 0,7 & 0,0 \\
\hline 4,0 & 0,927 & 0,825 & 0,757 & 0,709 & 0,658 & 3,4 & 2,5 & 1,3 & 0,5 & 0,0 \\
\hline 5,0 & 0,884 & 0,749 & 0,672 & 0,622 & 0,570 & 3,9 & 2,0 & 0,6 & 0,0 & $-0,1$ \\
\hline 6,0 & 0,831 & 0,675 & 0,596 & 0,546 & 0,498 & 3,5 & 0,9 & $-0,3$ & $-0,6$ & $-0,3$ \\
\hline 7,0 & 0,773 & 0,606 & 0,530 & 0,483 & 0,438 & 2,4 & $-0,5$ & $-1,3$ & $-1,2$ & $-0,5$ \\
\hline 8,0 & 0,713 & 0,546 & 0,474 & 0,431 & 0,390 & 0,6 & $-1,9$ & $-2,2$ & $-1,8$ & $-0,7$ \\
\hline 9,0 & 0,655 & 0,494 & 0,427 & 0,387 & 0,350 & $-1,5$ & $-3,2$ & $-3,0$ & $-2,3$ & $-0,8$ \\
\hline 10,0 & 0,602 & 0,449 & 0,387 & 0,351 & 0,317 & $-3,7$ & $-4,4$ & $-3,7$ & $-2,7$ & $-0,9$ \\
\hline
\end{tabular}

aproximadas desenvolvidas por Spang e Roetzel (1995), Roetzel e Spang (2010) possuem erros consideráveis, como exemplo, o erro relativo médio é de 1,64 \% para um trocador de calor de fluxo cruzado em escoamento paralelo com um passe e dez tubos por passe $(1-10)$. 
Tabela 26 - Fator de correção e erro relativo do presente algoritmo em relação ao trabalho de Roetzel e Nicole (1975) para trocador de calor de fluxo cruzado em escoamento contracorrente com dois passes e um tubo por passe (2-1) com o fluido quente não misturado - Caso $4 \mathrm{~A}$

\begin{tabular}{|c|c|c|c|c|c|c|c|c|c|c|}
\hline & \multicolumn{5}{|c|}{$F$} & \multicolumn{5}{|c|}{$\delta[\%]$} \\
\hline $\mathrm{NUT}^{R}$ & 0,1 & 0,3 & 0,5 & 0,7 & 1,0 & 0,1 & 0,3 & 0,5 & 0,7 & 1,0 \\
\hline 0,1 & 1,000 & 1,000 & 1,000 & 1,000 & 1,000 & - & - & - & - & - \\
\hline 0,2 & 1,000 & 1,000 & 0,999 & 0,999 & 0,998 & - & - & - & - & - \\
\hline 0,4 & 0,999 & 0,998 & 0,997 & 0,995 & 0,993 & $-0,2$ & $-0,2$ & 0,0 & 0,3 & 0,4 \\
\hline 0,6 & 0,998 & 0,996 & 0,993 & 0,990 & 0,985 & 0,0 & 0,2 & 0,3 & 0,2 & 0,0 \\
\hline 0,8 & 0,997 & 0,992 & 0,987 & 0,982 & 0,975 & 0,1 & 0,2 & 0,1 & $-0,2$ & $-0,5$ \\
\hline 1,0 & 0,996 & 0,988 & 0,980 & 0,972 & 0,961 & 0,1 & 0,1 & $-0,2$ & $-0,5$ & $-0,7$ \\
\hline 1,2 & 0,994 & 0,982 & 0,971 & 0,960 & 0,946 & 0,0 & $-0,2$ & $-0,4$ & $-0,6$ & $-0,5$ \\
\hline 1,4 & 0,992 & 0,976 & 0,961 & 0,947 & 0,928 & $-0,1$ & $-0,4$ & $-0,5$ & $-0,5$ & $-0,2$ \\
\hline 1,6 & 0,989 & 0,969 & 0,950 & 0,932 & 0,910 & $-0,2$ & $-0,4$ & $-0,5$ & $-0,3$ & 0,2 \\
\hline 1,8 & 0,986 & 0,960 & 0,937 & 0,916 & 0,890 & $-0,2$ & $-0,4$ & $-0,3$ & 0,0 & 0,6 \\
\hline 2,0 & 0,983 & 0,951 & 0,924 & 0,900 & 0,869 & $-0,2$ & $-0,3$ & $-0,1$ & 0,4 & 1,0 \\
\hline 3,0 & 0,960 & 0,895 & 0,845 & 0,805 & 0,760 & - & - & - & - & - \\
\hline 4,0 & 0,927 & 0,825 & 0,757 & 0,709 & 0,658 & - & - & - & - & - \\
\hline 5,0 & 0,884 & 0,749 & 0,672 & 0,622 & 0,570 & - & - & - & - & - \\
\hline 6,0 & 0,831 & 0,675 & 0,596 & 0,546 & 0,498 & - & - & - & - & - \\
\hline 7,0 & 0,773 & 0,606 & 0,530 & 0,483 & 0,438 & - & - & - & - & - \\
\hline 8,0 & 0,713 & 0,546 & 0,474 & 0,431 & 0,390 & - & - & - & - & - \\
\hline 9,0 & 0,655 & 0,494 & 0,427 & 0,387 & 0,350 & - & - & - & - & - \\
\hline 10,0 & 0,602 & 0,449 & 0,387 & 0,351 & 0,317 & - & - & - & - & - \\
\hline
\end{tabular}

Trocador de calor de fluxo cruzado ilustrado na Figura 90 do Anexo A. $\delta=100\left(F_{t h}-F\right) / F_{t h}$ 


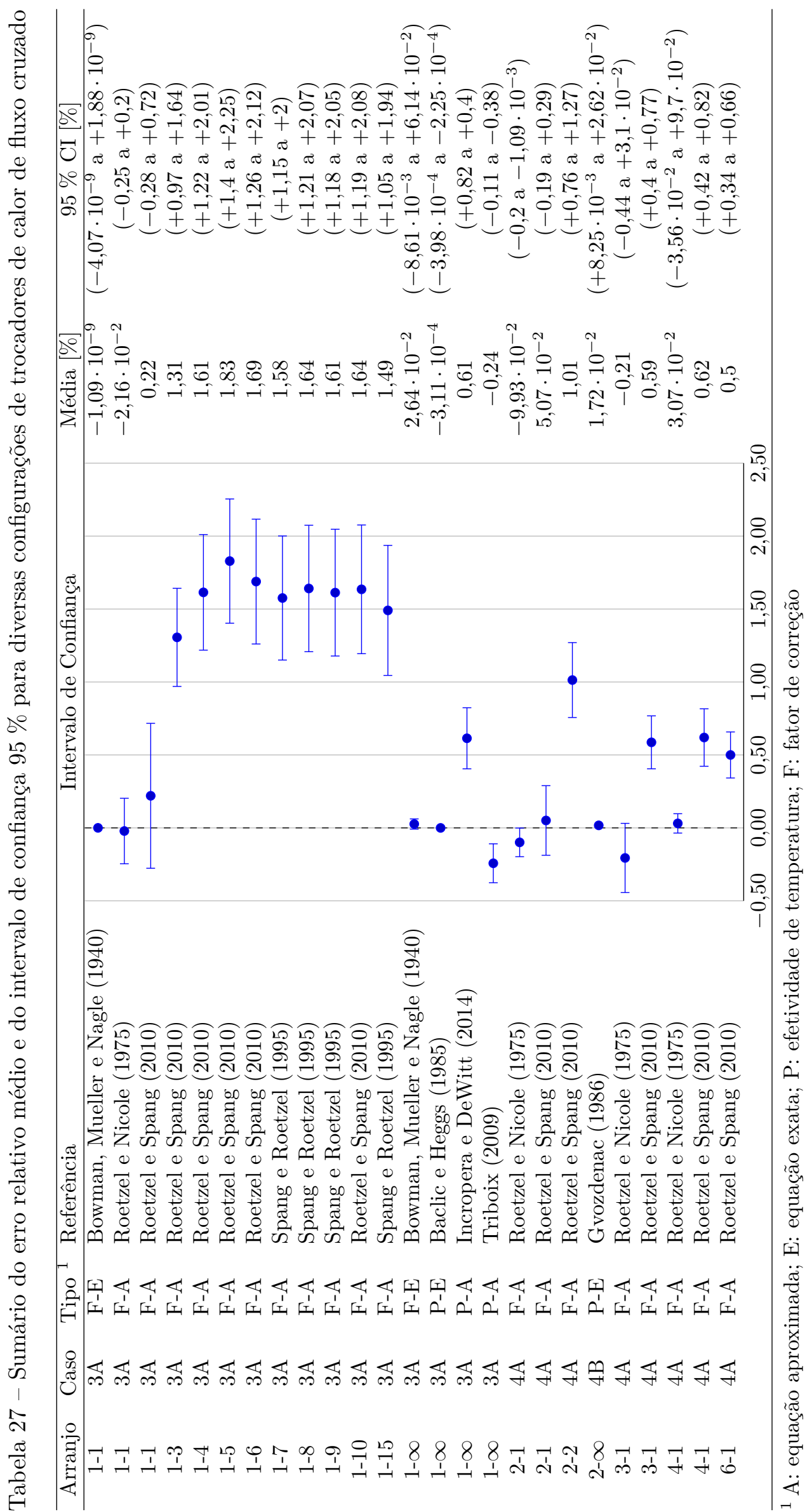


A mesma comparação é realizada entre os resultados desenvolvidos no presente trabalho e o programa de trocadores de calor HETE. Na Tabela 28 são apresentados o erro relativo médio e o intervalo de confiança de $95 \%$ para diversas configurações de trocadores de calor de fluxo cruzado. Observa-se que o erro relativo médio é pequeno para a maioria dos trocadores de calor, porém para as configurações de diversos passes e um tubo $\left(N_{p^{-}}-1\right)$ em escoamento contracorrente com fluido frio não misturado entre os passes, o erro relativo médio aumenta. Entretanto, o erro relativo médio ainda é pequeno, como exemplo, para um trocador de calor de fluxo cruzado em escoamento contracorrente com dez passes e um tubo por passe (10-1), o erro relativo médio é de $-0,00467 \%$. Os resultados calculados com o programa HETE podem ser utilizados de forma segura na simulação dos trocadores de calor. 


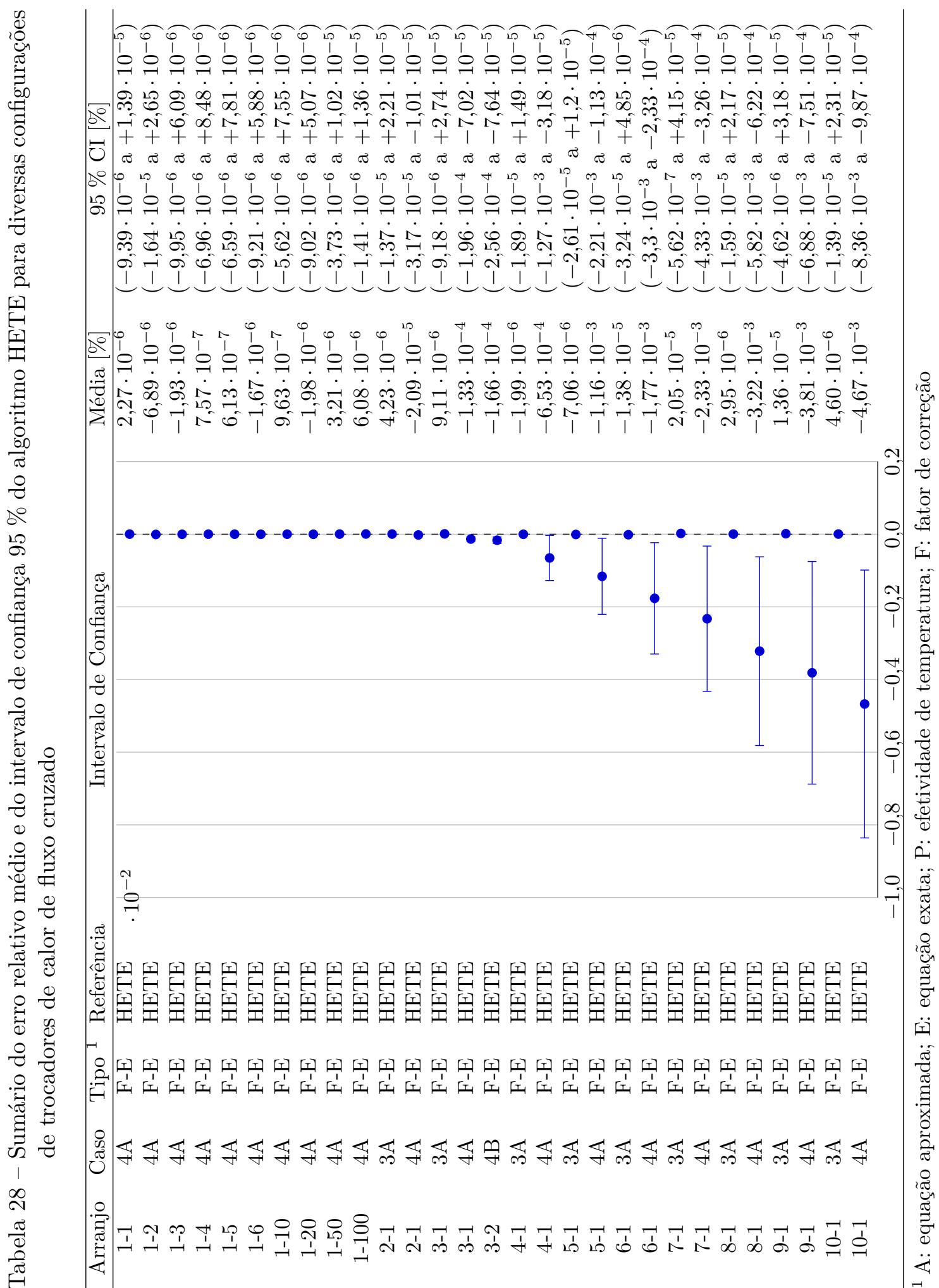


Com o objetivo de diminuir os erros de cálculo da taxa de transferência de calor e aumentar a confiabilidade do desenvolvimento de trocadores de calor, desenvolvem-se expressões matemáticas teóricas a partir do algoritmo apresentado por Pignotti e Cordero (1983a) e detalhado por Magazoni e Cabezas-Gómez (2016). Estas relações teóricas obtidas com os algoritmos explicados na Seção 4.1 e programados no Maple 18 para trocadores de calor de fluxo cruzado são apresentadas nas Tabelas 29.34. Foram consideradas três configurações básicas: cruzada, paralelo-cruzada e contracorrente-cruzada, considerando os fluidos quente (externo) e frio (interno) misturados e não misturados em todo o trocador de calor. O principal propósito da obtenção dessas relações e de sua apresentação nas tabelas citadas é a validação do procedimento de cálculo explicado na Seção 4.1 pela comparação simples com as relações explicitadas nas Tabelas 1,2 e 3 , e a apresentação de relações teóricas que não tinham sido publicadas anteriormente na literatura aberta.

Nas Tabelas 29, 30 e 31 são apresentadas as relações teóricas para trocadores de calor de fluxo cruzado com ambos os fluidos misturados em configuração cruzada, paralelocruzada e contracorrente-cruzada. A mesma análise é realizada para os trocadores de calor de fluxo cruzado com o fluido quente não misturado, onde as relações teóricas são apresentadas nas Tabelas 32, 33 e 34. Algumas expressões analíticas estão disponíveis na literatura aberta para estes últimos arranjos de trocadores de calor.

Na Tabela 29 são apresentadas relações teóricas para trocadores de calor com uma configuração de fluxo cruzado com um passe do fluido interno e até dez tubos por passe, considerando o fluido quente misturado em todo o trocador de calor. Esta configuração pode ser modelada utilizando quaisquer dos algoritmos desenvolvidos para os casos 1 e 2 e com um número de passes igual a um, $N_{r}=1$. Note-se que não se apresentam relações teóricas para mais de dez fileiras por questão de espaço e complexidade e também pela disponibilidade dos códigos computacionais mencionados. Entretanto, o algoritmo apresentado é capaz de reproduzir resultados satisfatórios para inúmeros tubos.

Tabela 29 - Relação matemática teórica da efetividade de trocadores de calor de fluxo cruzado com um passe e o fluido quente misturado - Casos 1A, 1B, 1C, 2A, 2B, 2C - trocadores de calor ilustrados nas Figuras 43,52 do Anexo A

\begin{tabular}{|llr|}
\hline$N_{p^{-} N_{r}}$ & Relação teórica & Equação \\
\hline $1-2$ & $P$ & $=\frac{1}{R}\left[\sum_{i=0}^{2}\left(a_{i} e^{-2 i R K}\right)\right], K=1-e^{-N U T / 2}$ \\
& $a_{0}=1-0,25 R^{-1}$ \\
$a_{1}$ & $=-1+0,5 R^{-1}$ \\
$a_{2}$ & $=-0,25 R^{-1}$ \\
$1-3$ & $P$ & $=\frac{1}{R}\left[\sum_{i=0}^{3}\left(a_{i} e^{-3 i R K}\right)\right], K=1-e^{-N U T / 3}$
\end{tabular}


Tabela 29 - continuação da página anterior

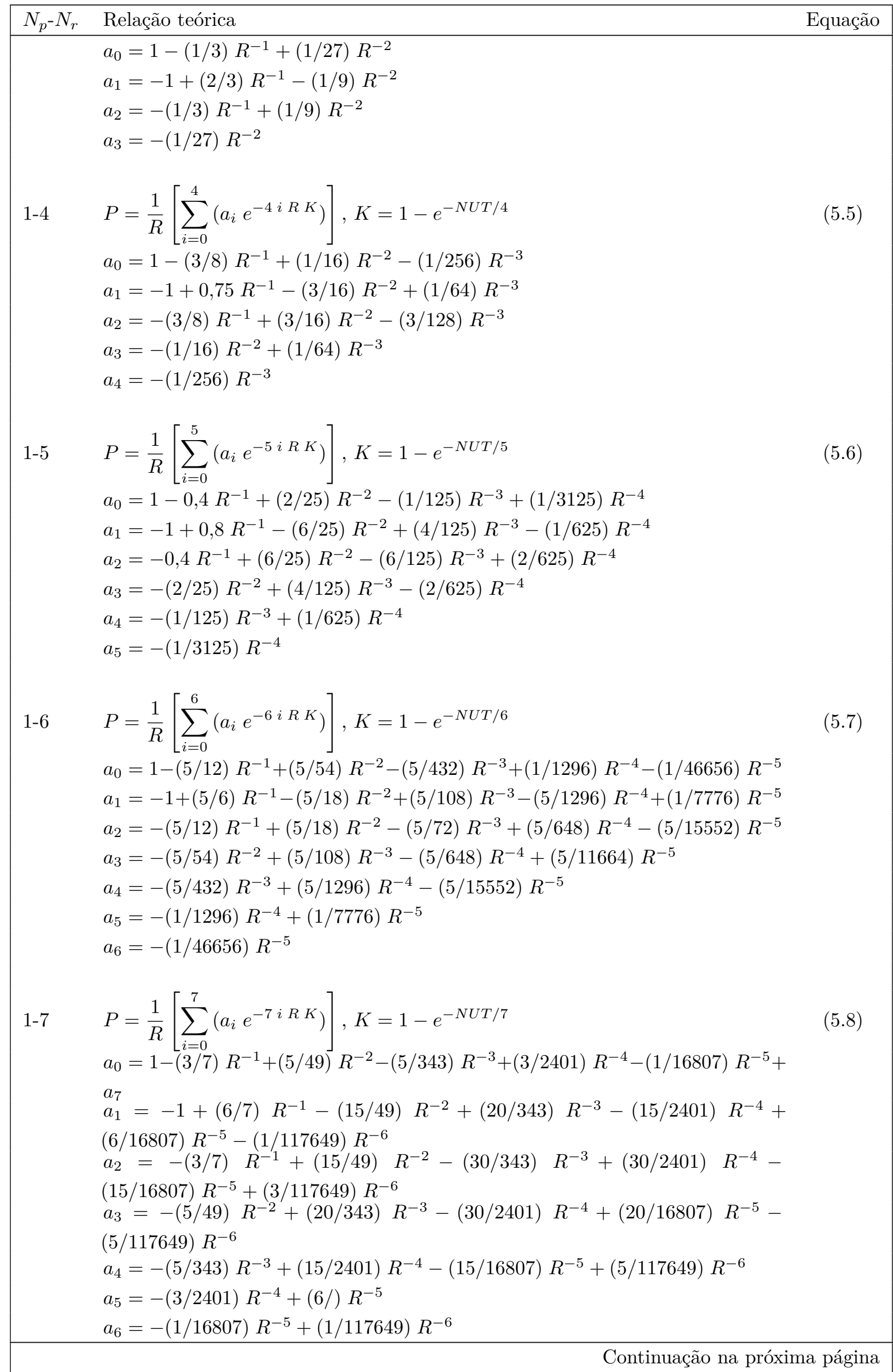


Tabela 29 - continuação da página anterior

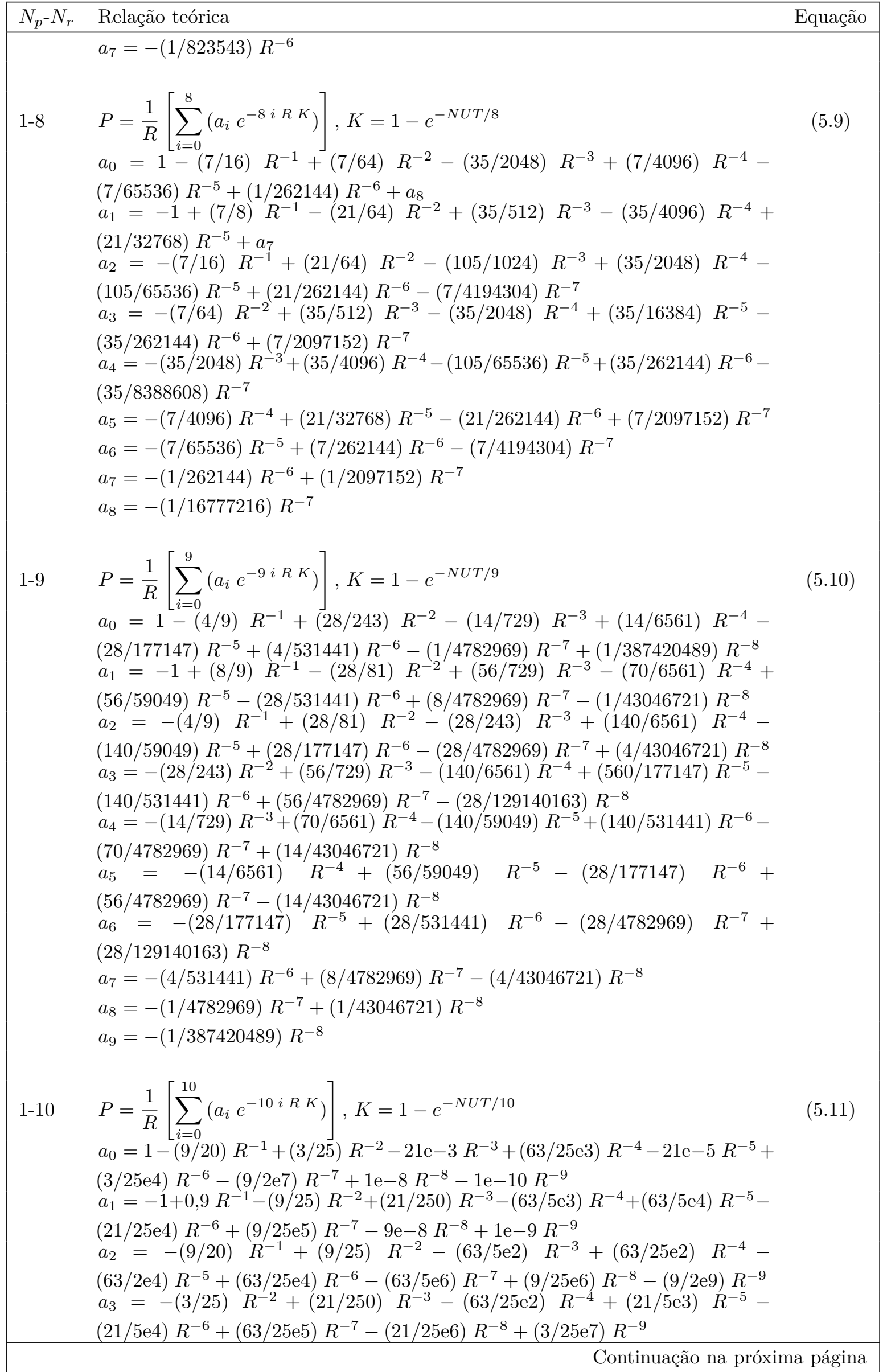


Tabela 29 - continuação da página anterior

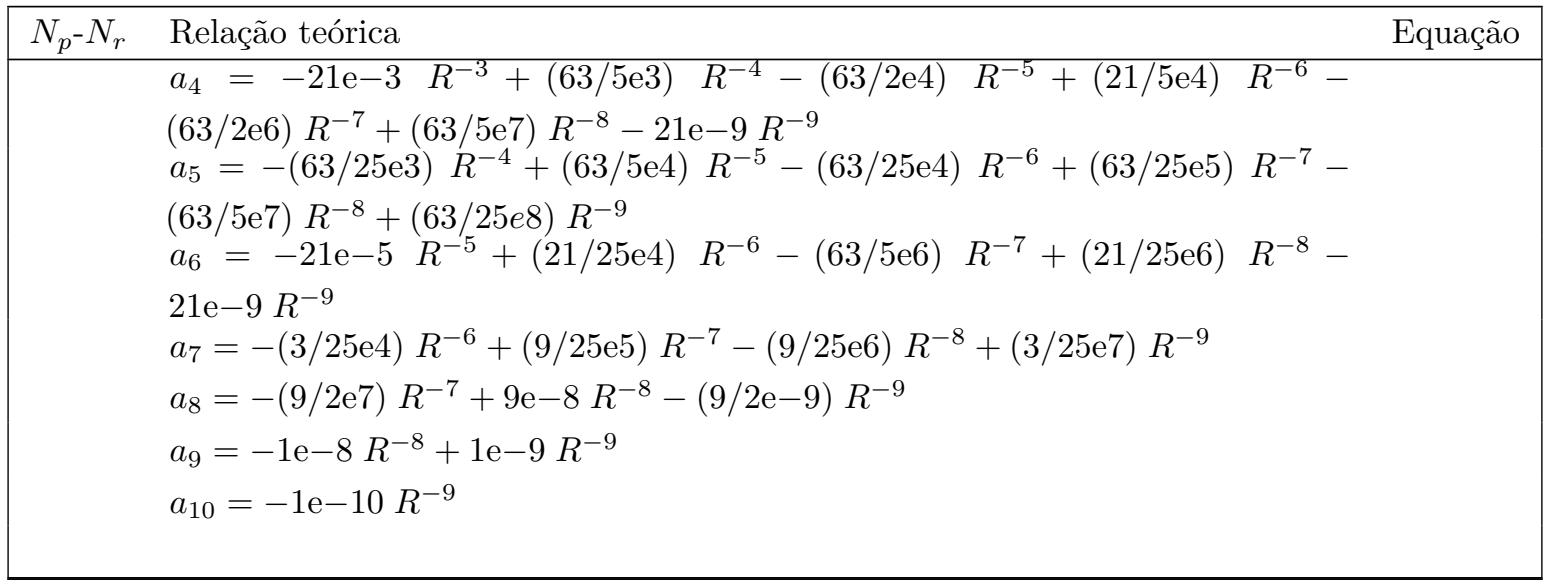

As relações teóricas dos trocadores de calor com configuração de fluxo cruzado em escoamento paralelo com múltiplos passes e o fluido quente misturado são apresentadas na Tabela 30. As expressões matemáticas teóricas são apresentadas para trocadores de calor de até dez passes. Estas relações são encontradas utilizando quaisquer dos algoritmos desenvolvidos no caso 1 de Pignotti e Cordero (1983a).

Tabela 30 - Relação matemática teórica da efetividade de trocadores de calor de fluxo cruzado em escoamento paralelo com múltiplos passes com o fluido quente misturado - Casos 1A, 1B, 1C - trocadores de calor ilustrados nas Figuras 53 61 do Anexo A

\begin{tabular}{|c|c|c|}
\hline$N_{p}-N_{r}$ & Relação teórica & Equação \\
\hline $2-1$ & $\begin{array}{l}P=\frac{1}{R}\left[\sum_{i=0}^{2}\left(a_{i} e^{-i R K}\right)\right], K=1-e^{-N U T / 2} \\
a_{0}=1-R^{-1} \\
a_{1}=2 R^{-1} \\
a_{2}=-\left(1+R^{-1}\right)\end{array}$ & $(5.12)$ \\
\hline 3-1 & $\begin{array}{l}P=\frac{1}{R}\left[\sum_{i=0}^{3}\left(a_{i} e^{-i R K}\right)\right], K=1-e^{-N U T / 3} \\
a_{0}=1-R^{-1}+R^{-2} \\
a_{1}=3 R^{-2} \\
a_{2}=3 R^{-1}+3 R^{-2} \\
a_{3}=-\left(1+2 R^{-1}+R^{-2}\right)\end{array}$ & $(5.13)$ \\
\hline $4-1$ & $\begin{array}{l}P=\frac{1}{R}\left[\sum_{i=0}^{4}\left(a_{i} e^{-i R K}\right)\right], K=1-e^{-N U T / 4} \\
a_{0}=1-R^{-1}+R^{-2}-R^{-3} \\
a_{1}=4 R^{-3} \\
a_{2}=-6\left(R^{-2}+R^{-3}\right) \\
a_{3}=4 R^{-1}+8 R^{-2}+4 R^{-3} \\
a_{4}=-\left(1+3 R^{-1}+3 R^{-2}+R^{-3}\right)\end{array}$ & (5.14) \\
\hline & & la página \\
\hline
\end{tabular}


Tabela 30 - continuação da página anterior

$$
\begin{aligned}
& \begin{array}{lll}
N_{p^{-}} N_{r} & \text { Relação teórica } & \text { Equação }
\end{array} \\
& \text { 5-1 } \quad P=\frac{1}{R}\left[\sum_{i=0}^{5}\left(a_{i} e^{-i R K}\right)\right], K=1-e^{-N U T / 5} \\
& a_{0}=1-R^{-1}+R^{-2}-R^{-3}+R^{-4} \\
& a_{1}=-5 R^{-4} \\
& a_{2}=10\left(R^{-3}+R^{-4}\right) \\
& a_{3}=-10\left(10 R^{-2}+20 R^{-2}+10 R^{-4}\right) \\
& a_{4}=\left(5 R^{-1}+15 R^{-2}+15 R^{-3}+5 R^{-4}\right) \\
& a_{5}=-\left(1+4 R^{-1}+6 R^{-2}+4 R^{-3}+R^{-4}\right) \\
& \text { 6-1 } \quad P=\frac{1}{R}\left[\sum_{i=0}^{6}\left(a_{i} e^{-i R K}\right)\right], K=1-e^{-N U T / 6} \\
& a_{0}=1-R^{-1}+R^{-2}-R^{-3}+R^{-4}-R^{-5} \\
& a_{1}=6 R^{-5} \\
& a_{2}=-15\left(R^{-4}+R^{-5}\right) \\
& a_{3}=\left(20 R^{-3}+40 R^{-4}+20 R^{-5}\right) \\
& a_{4}=-\left(15 R^{-2}+45 R^{-3}+45 R^{-4}+15 R^{-5}\right) \\
& a_{5}=\left(6 R^{-1}+24 R^{-2}+36 R^{-3}+24 R^{-4}+6 R^{-5}\right) \\
& a_{6}=-\left(1+5 R^{-1}+10 R^{-2}+10 R^{-3}+5 R^{-4}+R^{-5}\right) \\
& \text { 7-1 } \quad P=\frac{1}{R}\left[\sum_{i=0}^{7}\left(a_{i} e^{-i R K}\right)\right], K=1-e^{-N U T / 7} \\
& a_{0}=1-R^{-1}+R^{-2}-R^{-3}+R^{-4}-R^{-5}+R^{-6} \\
& a_{1}=-7 R^{-6} \\
& a_{2}=21\left(R^{-5}+R^{-6}\right) \\
& a_{3}=-\left(35 R^{-4}+70 R^{-5}+35 R^{-6}\right) \\
& a_{4}=\left(35 R^{-3}+105 R^{-4}+105 R^{-5}+35 R^{-6}\right) \\
& a_{5}=-\left(21 R^{-2}+84 R^{-3}+126 R^{-4}+84 R^{-5}+21 R^{-6}\right) \\
& a_{6}=\left(7 R^{-1}+35 R^{-2}+70 R^{-3}+70 R^{-4}+35 R^{-5}+7 R^{-6}\right) \\
& a_{7}=\left(1+6 R^{-1}+15 R^{-2}+20 R^{-3}+15 R^{-4}+6 R^{-5}+R^{-6}\right) \\
& \text { 8-1 } \quad P=\frac{1}{R}\left[\sum_{i=0}^{8}\left(a_{i} e^{-i R K}\right)\right], K=1-e^{-N U T / 8} \\
& a_{0}=1-R^{-1}+R^{-2}-R^{-3}+R^{-4}-R^{-5}+R^{-6}-R^{-7} \\
& a_{1}=8 R^{-7} \\
& a_{2}=-28\left(R^{-6}+R^{-7}\right) \\
& a_{3}=\left(56 R^{-5}+112 R^{-6}+56 R^{-7}\right) \\
& a_{4}=-\left(70 R^{-4}+210 R^{-5}+210 R^{-6}+70 R^{-7}\right) \\
& a_{5}=\left(56 R^{-3}+224 R^{-4}+336 R^{-5}+224 R^{-6}+56 R^{-7}\right) \\
& a_{6}=-\left(28 R^{-2}+140 R^{-3}+280 R^{-4}+280 R^{-5}+140 R^{-6}+28 R^{-7}\right) \\
& a_{7}=\left(8 R^{-1}+48 R^{-2}+120 R^{-3}+160 R^{-4}+120 R^{-5}+48 R^{-6}+8 R^{-7}\right) \\
& a_{8}=-\left(1+7 R^{-1}+21 R^{-2}+35 R^{-3}+35 R^{-4}+21 R^{-5}+7 R^{-6}+R^{-7}\right)
\end{aligned}
$$


Tabela 30 - continuação da página anterior

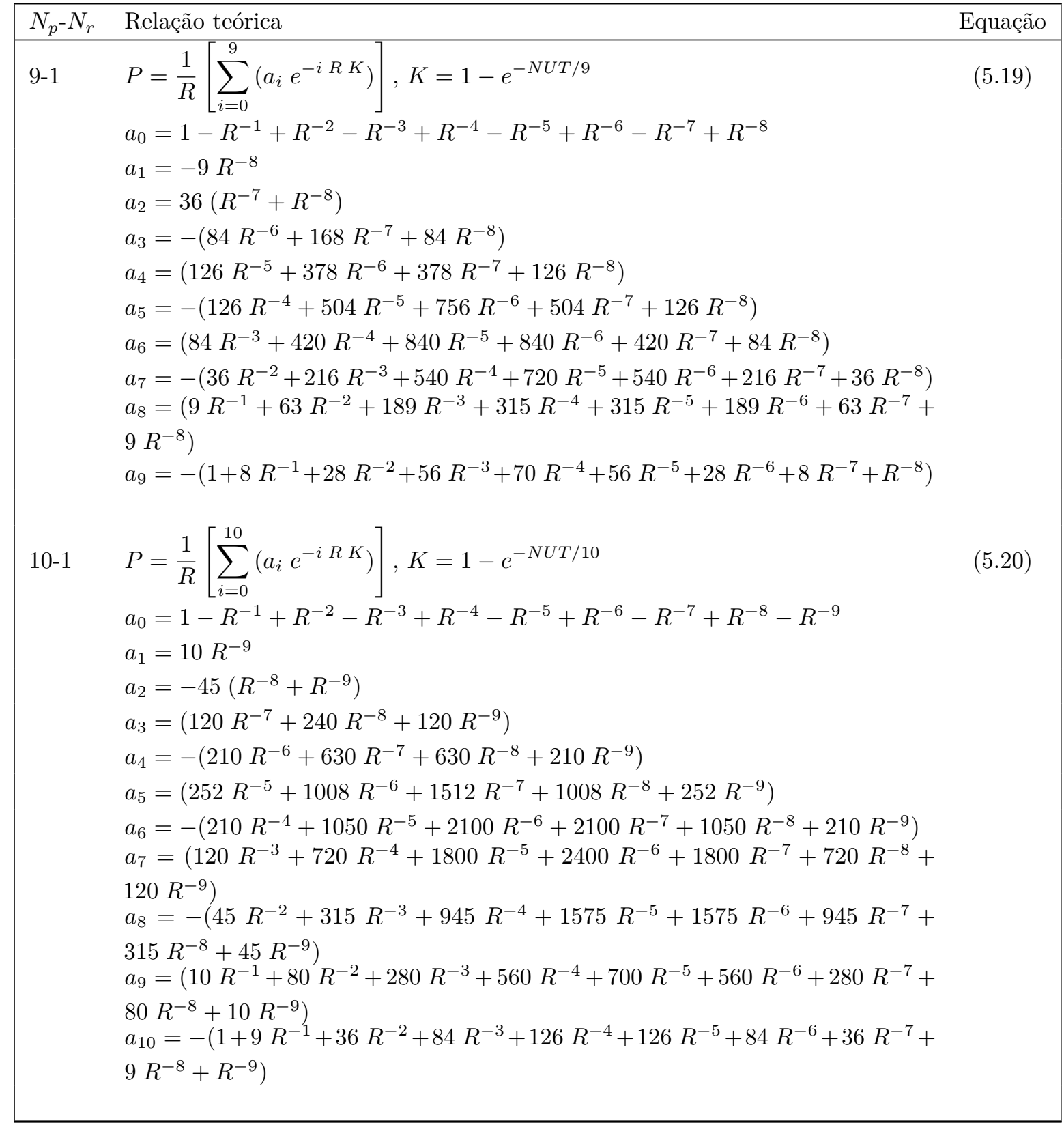

As relações matemáticas teóricas da efetividade de temperatura de trocadores de calor de fluxo cruzado em escoamento paralelo com múltiplos passes com os fluidos frio e quente completamente misturados são apresentadas na Tabela 31. As expressões foram obtidas utilizando o algoritmo do caso 2 de Pignotti e Cordero (1983a).

Tabela 31 - Relação matemática teórica da efetividade de trocadores de calor de fluxo cruzado em escoamento contracorrente com múltiplos passes com o fluido quente misturado - Casos 2A, 2B, 2C - trocadores de calor ilustrados nas Figuras 62 70 do Anexo A

\begin{tabular}{|rrr|}
\hline$N_{p}-N_{r}$ & Relação teórica & Equação \\
\hline & & \\
\hline & Continuação na próxima página \\
\hline
\end{tabular}


Tabela 31 - continuação da página anterior

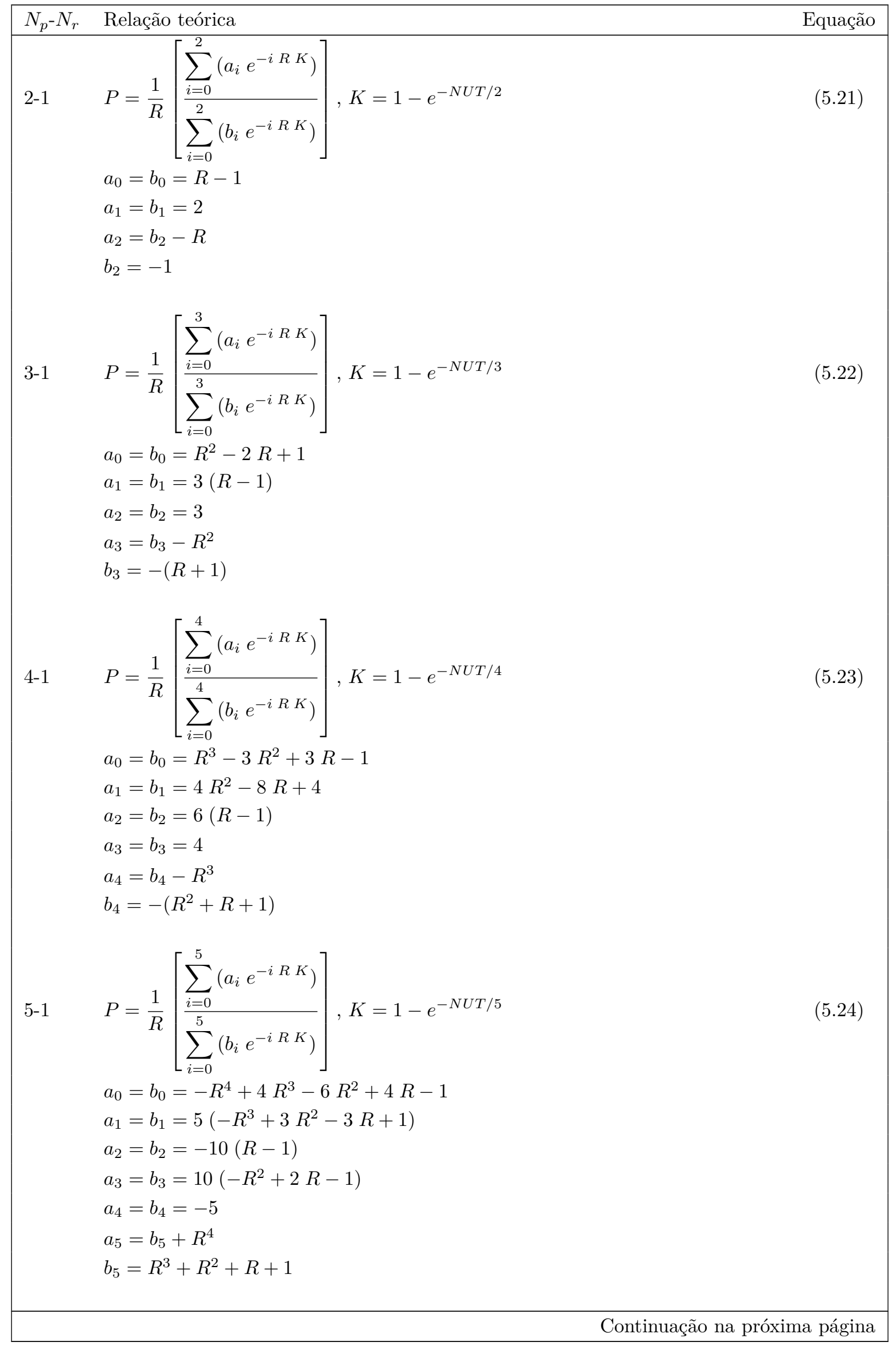


Tabela 31 - continuação da página anterior

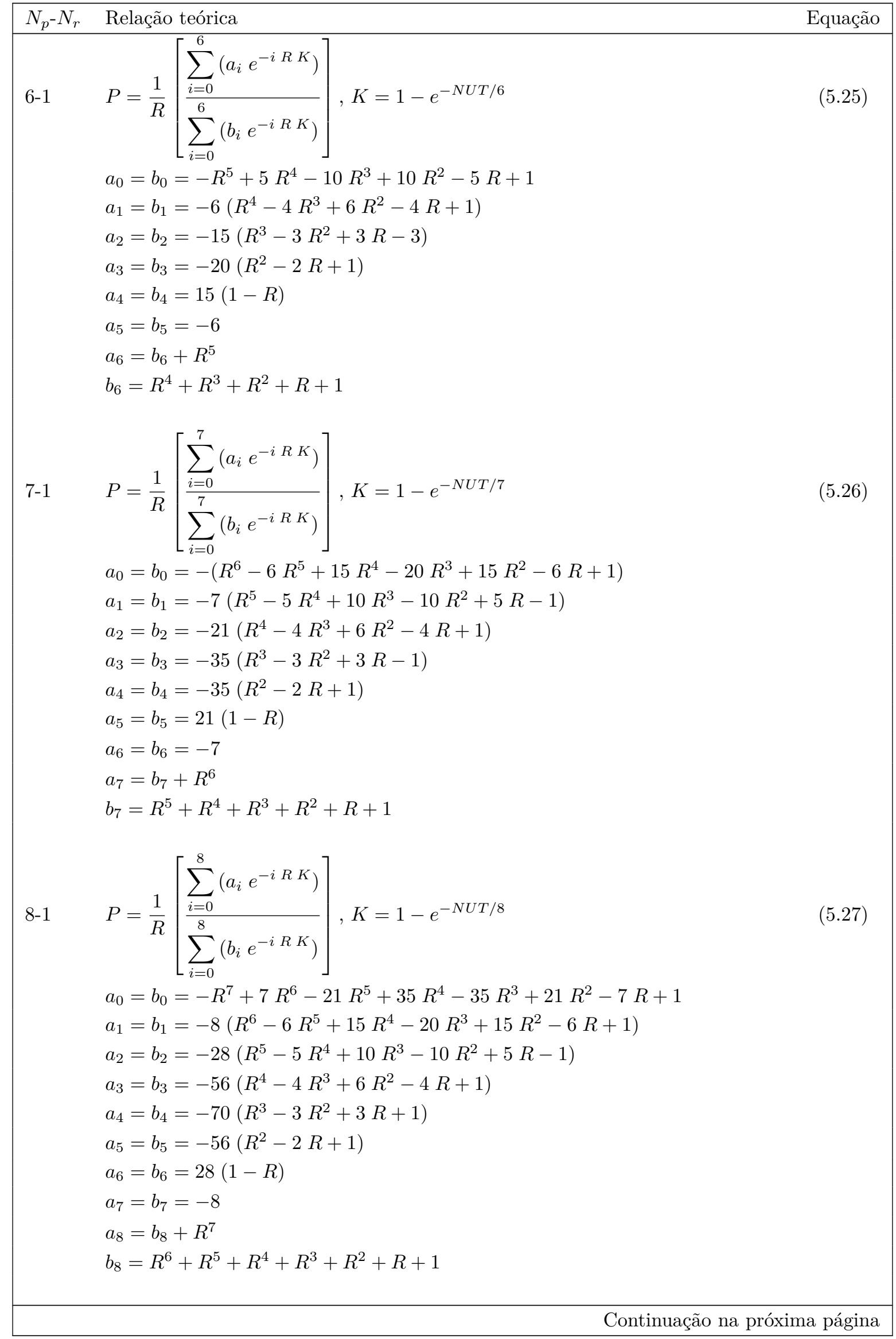


Tabela 31 - continuação da página anterior

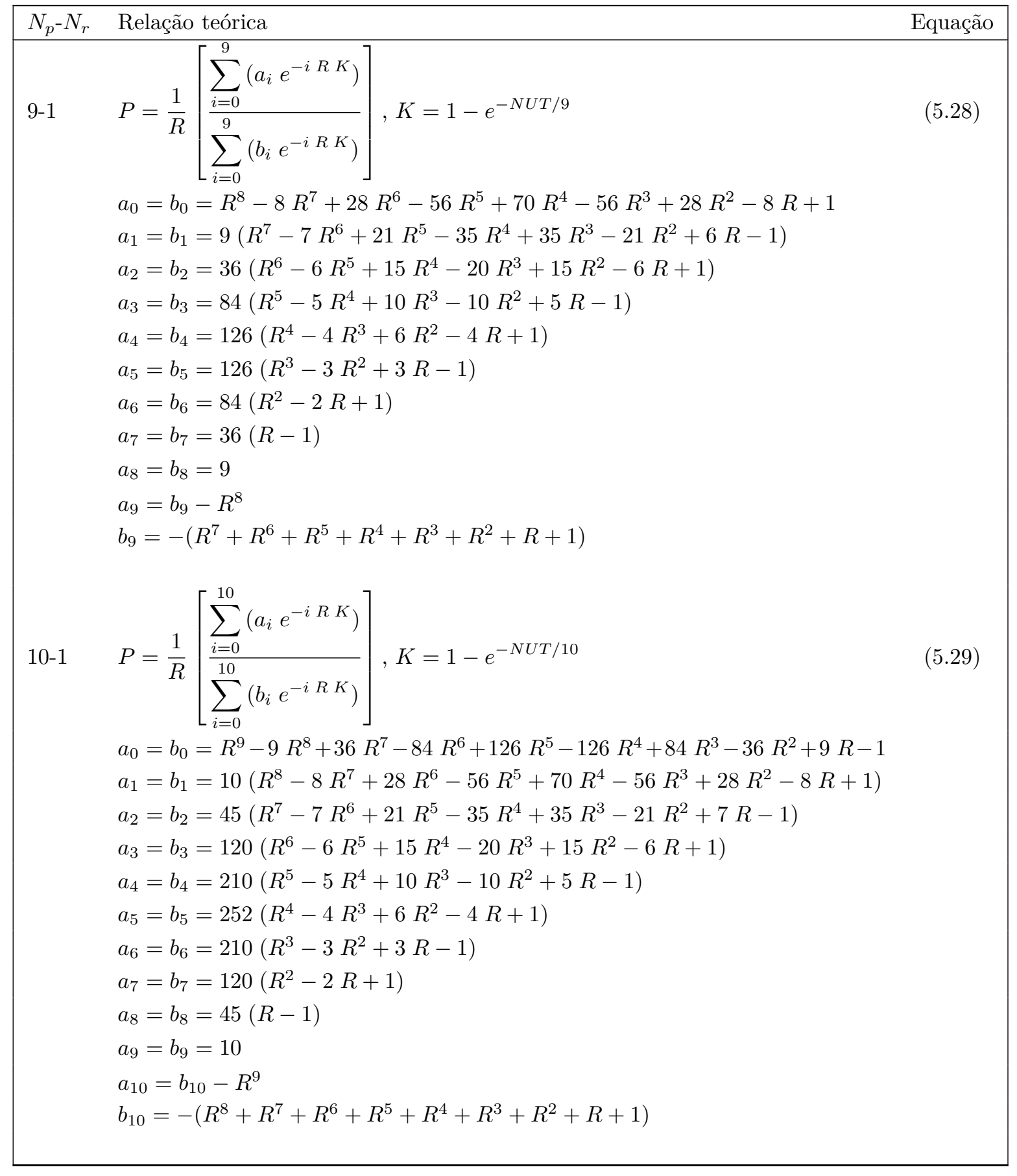

Na Tabela 32 são apresentadas as relações teóricas da efetividade de temperatura do trocador de calor de fluxo cruzado de um passe com o fluido frio completamente mistura e o quente não misturado. Estas relações podem ser obtidas através dos algoritmos desenvolvidos para os casos 3 e 4 de Pignotti e Cordero (1983a) com $N_{p}=1$. As relações da Tabela 32 podem ser comparadas com as relações apresentadas na Tabela 1 (Equações 3.30 3.37, considerando de um a quatro tubos por passe. Note que neste caso a efetividade de temperatura $P$ corresponde à efetividade $\varepsilon$ para o fluido externo não misturado (fluido $\mathrm{B}$ da Tabela 11. As relações denotadas pelas Equações 5.30 5.33 são idênticas às mostradas 
na Tabela 1 para o mesmo número de tubos por passe, $N_{r}$. As relações matemáticas teóricas para mais de quatro fileiras não se encontram disponíveis na literatura aberta. Com a disponibilidade das relações da Tabela 32 e dos procedimentos de cálculo apresentados na Seção 4.1 se elimina a necessidade do uso de relações aproximadas. Note-se que não se apresentam relações teóricas para mais de dez fileiras por questão de espaço e pela disponibilidade dos códigos computacionais mencionados.

Tabela 32 - Relação matemática teórica da efetividade de trocadores de calor de fluxo cruzado com um passe e o fluido quente não misturado - Casos 3A, 3B, 3C, 4A, 4B, 4C trocadores de calor ilustrados nas Figuras 71,80 do Anexo A

\begin{tabular}{|c|c|c|}
\hline$N_{p}-N_{r}$ & Relação teórica & Equação \\
\hline $1-1$ & $P=\frac{1}{R}\left(1-e^{-R K}\right), K=1-e^{-N U T}$ & $(5.30)$ \\
\hline $1-2$ & $\begin{array}{l}P=\frac{1}{R}\left(1-a_{1} R e^{-2 R K}\right), K=1-e^{-N U T / 2} \\
a_{1}=K^{2}\end{array}$ & $(5.31)$ \\
\hline $1-3$ & $\begin{array}{l}P=\frac{1}{R}\left[1-e^{-3 R K} \sum_{i=0}^{2}\left(a_{i} R^{i}\right)\right], K=1-e^{-N U T / 3} \\
a_{1}=K^{2}(3-K) \\
a_{2}=1,5 K^{4}\end{array}$ & $(5.32)$ \\
\hline $1-4$ & $\begin{array}{l}P=\frac{1}{R}\left[1-e^{-4 R K} \sum_{i=0}^{3}\left(a_{i} R^{i}\right)\right], K=1-e^{-N U T / 4} \\
a_{1}=K^{2}\left(K^{2}-4 K+6\right) \\
a_{2}=4 K^{4}(2-K) \\
a_{3}=(8 / 3) K^{6}\end{array}$ & $(5.33)$ \\
\hline $1-5$ & $\begin{array}{l}P=\frac{1}{R}\left[1-e^{-5 R K} \sum_{i=0}^{4}\left(a_{i} R^{i}\right)\right], K=1-e^{-N U T / 5} \\
a_{0}=1 \\
a_{1}=K^{2}\left(-K^{3}+5 K^{2}-10 K+10\right) \\
a_{2}=2,5 K^{4}\left(3 K^{2}-10 K+10\right) \\
a_{3}=(25 / 6) K^{6}(5-3 K) \\
a_{4}=(125 / 24) K^{8}\end{array}$ & $(5.34)$ \\
\hline $1-6$ & $\begin{array}{l}P=\frac{1}{R}\left[1-e^{(-6 R K)} \sum_{i=0}^{5}\left(a_{i} R^{i}\right)\right], K=1-e^{-N U T / 6} \\
a_{0}=1 \\
a_{1}=K^{2}\left(K^{4}-6 K^{3}+15 K^{2}-20 K+15\right) \\
a_{2}=6 K^{4}(2-K)\left(2 K^{2}-5 K+5\right) \\
a_{3}=18 K^{6}\left(2 K^{2}-6 K+5\right) \\
a_{4}=18 K^{8}(3-2 K) \\
a_{5}=10,8 K^{10}\end{array}$ & $(5.35)$ \\
\hline
\end{tabular}


Tabela 32 - continuação da página anterior

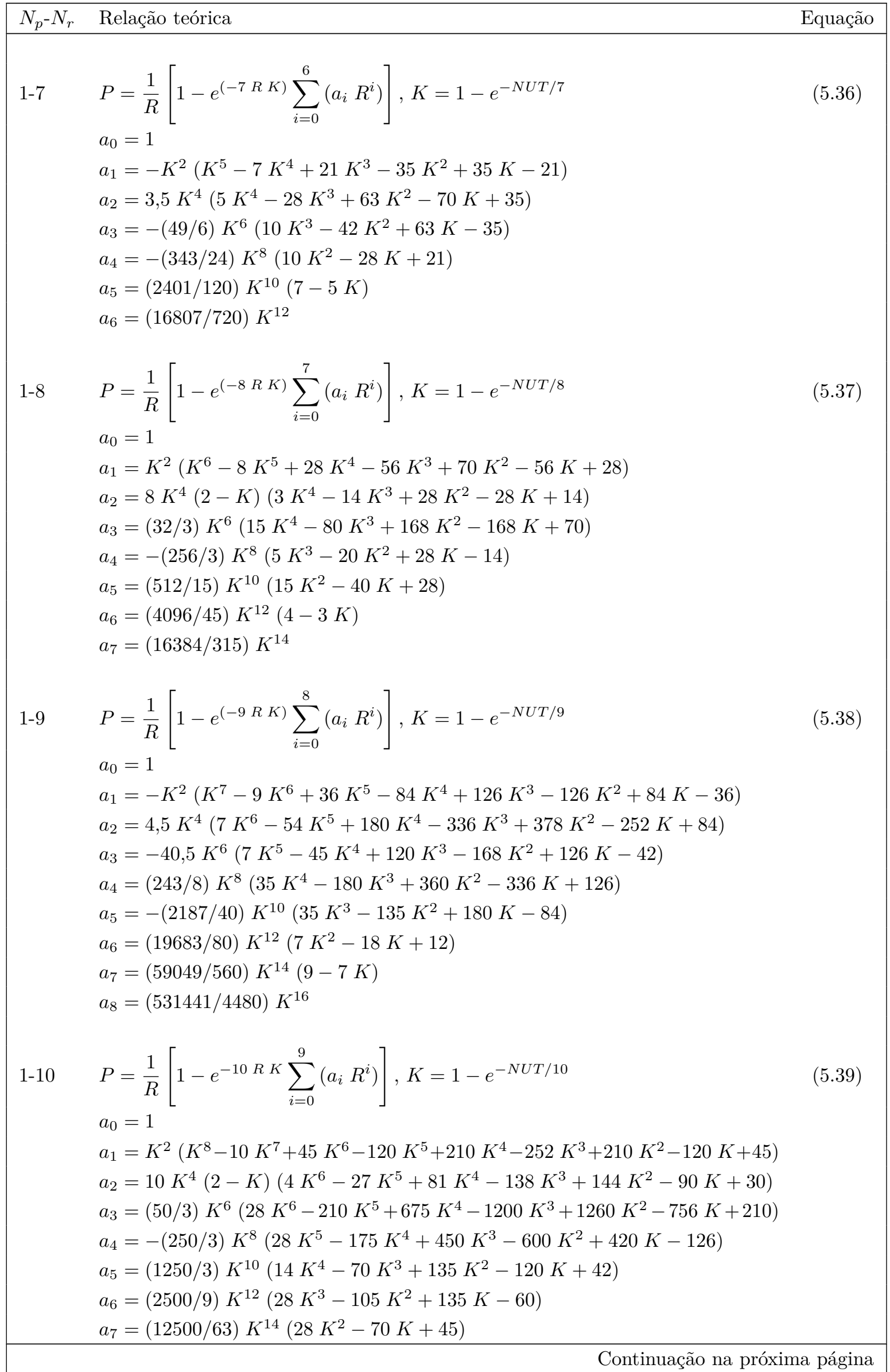


Tabela 32 - continuação da página anterior

\begin{tabular}{|llr|}
\hline$N_{p}-N_{r}$ & Relação teórica & Equação \\
\hline & $a_{8}=(31250 / 63) K^{16}(5-4 K)$ & \\
& $a_{9}=(156250 / 567) K^{18}$ & \\
&
\end{tabular}

Nas Tabelas 33 e 34 são apresentadas respectivamente as relações teóricas para trocadores de calor de fluxo cruzado com múltiplos passes em escoamentos paralelo (caso 3 ) e contracorrente (caso 4) com o fluido frio misturado e o quente não misturado.

Tabela 33 - Relação matemática teórica da efetividade de trocadores de calor de fluxo cruzado em escoamento paralelo com múltiplos passes com o fluido quente não misturado Casos 3A, 3B, 3C - trocadores de calor ilustrados nas Figuras 81,89 do Anexo A

\begin{tabular}{|c|c|c|}
\hline$N_{p^{-}} N_{r}$ & Relação teórica & Equação \\
\hline $2-1$ & $\begin{array}{l}P=\frac{1}{R}\left(b_{0}+a_{0} e^{-2 R K}\right), K=1-e^{-N U T / 2} \\
a_{0}=-b_{0} \\
b_{0}=1-0,5 K\end{array}$ & $(5.40)$ \\
\hline $3-1$ & $\begin{array}{l}P=\frac{1}{R}\left\{b_{0}+\sum_{i=1}^{2}\left[a_{i-1} e^{(1-2 i) R K}\right]\right\}, K=1-e^{-N U T / 3} \\
a_{0}=b_{1}+b_{2} R \\
a_{1}=b_{3} \\
b_{0}=1 \\
b_{1}=0,25 K(K-4) \\
b_{2}=0,5 K^{2}(K-2) \\
b_{3}=-0,25(K-2)^{2}\end{array}$ & $(5.41)$ \\
\hline $4-1$ & $\begin{array}{l}P=\frac{1}{R}\left[b_{0}+\sum_{i=1}^{2}\left(a_{i-1} e^{-2 i R K}\right)\right], K=1-e^{-N U T / 4} \\
a_{0}=b_{1}+b_{2} R \\
a_{1}=b_{3} \\
b_{0}=-0,125(K-2)\left(K^{2}+4\right) \\
b_{1}=0,5 K(K-2) \\
b_{2}=-0,5 K^{2}(K-2)^{2} \\
b_{3}=0,125(K-2)^{3}\end{array}$ & $(5.42)$ \\
\hline $5-1$ & $\begin{array}{l}P=\frac{1}{R}\left\{b_{0}+\sum_{i=1}^{3}\left[a_{i-1} e^{(1-2 i) R K}\right]\right\}, K=1-e^{-N U T / 5} \\
a_{0}=b_{1}+b_{2} R+b_{3} R^{2} \\
a_{1}=b_{4}+b_{5} R \\
a_{2}=b_{6} \\
b_{0}=1 \\
b_{1}=0,125 K\left(K^{3}-4 K^{2}+6 K-8\right)\end{array}$ & $(5.43)$ \\
\hline
\end{tabular}


Tabela 33 - continuação da página anterior

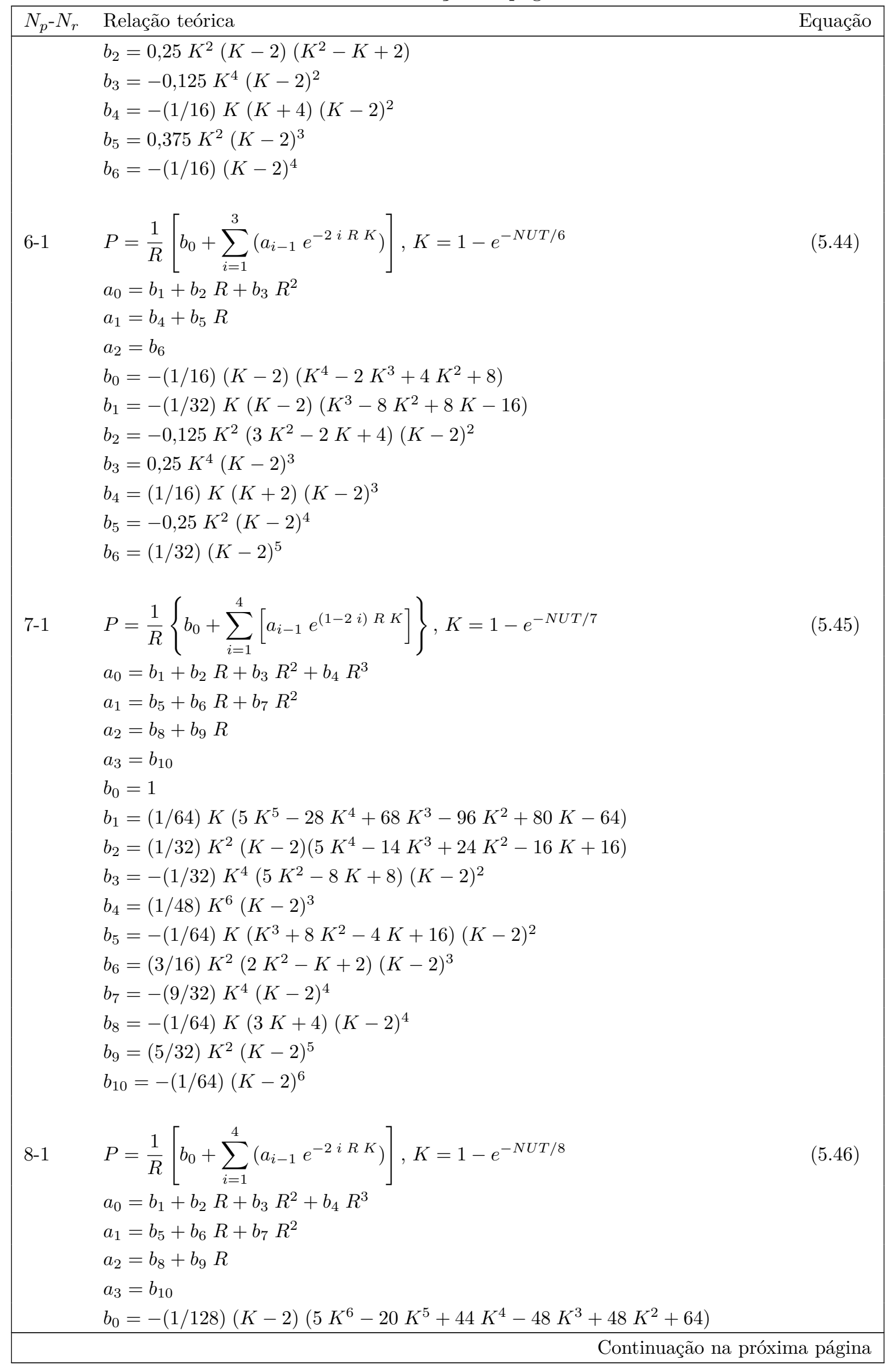


Tabela 33 - continuação da página anterior

\begin{tabular}{|c|c|c|}
\hline$N_{p^{-}} N_{r}$ & Relação teórica & Equação \\
\hline & $\begin{array}{l}b_{1}=-(1 / 32) K(K-2)\left(K^{5}-7 K^{4}+16 K^{3}-24 K^{2}+16 K-16\right) \\
b_{2}=-(1 / 32) K^{2}\left(9 K^{4}-20 K^{3}+32 K^{2}-16 K+16\right)(K-2)^{2} \\
b_{3}=0,125 K^{4}\left(3 K^{2}-4 K+4\right)(K-2)^{3} \\
b_{4}=-(1 / 12) K^{6}(K-2)^{4} \\
b_{5}=(1 / 32) K\left(K^{3}+2 K^{2}+4\right)(K-2)^{3} \\
b_{6}=-(1 / 16) K^{2}\left(5 K^{2}-2 K+4\right)(K-2)^{4} \\
b_{7}=0,25 K^{4}(K-2)^{5} \\
b_{8}=-(3 / 32) K^{2}(K-2)^{6} \\
b_{9}=-(3 / 32) K^{2}(K-2)^{6} \\
b_{10}=(1 / 128)(K-2)^{7}\end{array}$ & \\
\hline $9-1$ & $\begin{array}{l}P=\frac{1}{R}\left\{b_{0}+\sum_{i=1}^{5}\left[a_{i-1} e^{(1-2 i) R K}\right]\right\}, K=1-e^{-N U T / 9} \\
a_{0}=b_{1}+b_{2} R+b_{3} R^{2}+b_{4} R^{3}+b_{5} R^{4} \\
a_{1}=b_{6}+b_{7} R+b_{8} R^{2}+b_{9} R^{3} \\
a_{2}=b_{10}+b_{11} R+b_{12} R^{2} \\
a_{3}=b_{13}+b_{14} R \\
a_{4}=b_{15} \\
b_{0}=1 \\
b_{1}=(1 / 128) K\left(7 K^{7}-52 K^{6}+174 K^{5}-344 K^{4}+440 K^{3}-384 K^{2}+224 K-\right. \\
128) \\
b_{2}=(1 / 64) K^{2}(K-2)\left(7 K^{6}-33 K^{5}+78 K^{4}-104 K^{3}+96 K^{2}-48 K+32\right) \\
b_{3}=-(3 / 128) K^{4}\left(7 K^{4}-24 K^{3}+40 K^{2}-32 K+16\right)(K-2)^{2} \\
b_{4}=(1 / 96) K^{6}\left(4 K^{2}-7 K+6\right)(K-2)^{3} \\
b_{5}=-(1 / 384) K^{8}(K-2)^{4} \\
b_{6}=-(1 / 64) K\left(6 K^{4}-13 K^{3}+24 K^{2}-12 K+16\right)(K-2)^{2} \\
b_{7}=(3 / 64) K^{2}\left(7 K^{4}-13 K^{3}+20 K^{2}-8 K+8\right)(K-2)^{3} \\
b_{8}=-(9 / 128) K^{4}\left(7 K^{2}-8 K+8\right)(K-2)^{4} \\
b_{9}=(9 / 64) K^{6}(K-2)^{5} \\
b_{10}=-(1 / 64) K\left(2 K^{3}+2 K^{2}+K+4\right)(K-2)^{4} \\
b_{11}=(5 / 64) K^{2}\left(3 K^{2}-K+2\right)(K-2)^{5} \\
b_{12}=-(25 / 128) K^{4}(K-2)^{6} \\
b_{13}=-(1 / 256) K(5 K+4)(K-2)^{6} \\
b_{14}=(7 / 128) K^{2}(K-2)^{7} \\
b_{15}=-(1 / 256)(K-2)^{8}\end{array}$ & $(5.47)$ \\
\hline $10-1$ & $\begin{array}{l}P=\frac{1}{R}\left[b_{0}+\sum_{i=1}^{5}\left(a_{i-1} e^{-2 i R K}\right)\right], K=1-e^{-N U T / 10} \\
a_{0}=b_{1}+b_{2} R+b_{3} R^{2}+b_{4} R^{3}+b_{5} R^{4} \\
a_{1}=b_{6}+b_{7} R+b_{8} R^{2}+b_{9} R^{3} \\
a_{2}=b_{10}+b_{11} R+b_{12} R^{2} \\
a_{3}=b_{13}+b_{14} R \\
a_{4}=b_{15} \\
b_{0}=-(1 / 256)(K-2)\left(7 K^{8}-42 K^{7}+124 K^{6}-216 K^{5}+256 K^{4}-192 K^{3}+\right. \\
\left.128 K^{2}+128\right)\end{array}$ & $(5.48)$ \\
\hline
\end{tabular}


Tabela 33 - continuação da página anterior

\begin{tabular}{|c|c|c|}
\hline$N_{p^{-}} N_{r}$ & Relação teórica & Equação \\
\hline & $\begin{array}{l}b_{1}=-(1 / 256) K(K-2)\left(7 K^{7}-56 K^{6}+184 K^{5}-360 K^{4}+440 K^{3}-\right. \\
\left.384 K^{2}+192 K-128\right) \\
b_{2}=-(1 / 32) K^{2}\left(7 K^{6}-28 K^{5}+60 K^{4}-70 K^{3}+60 K^{2}-24 K+16\right)(K-2)^{2} \\
b_{3}=(1 / 16) K^{4}\left(7 K^{4}-21 K^{3}+33 K^{2}-24 K+12\right)(K-2)^{3} \\
b_{4}=-(1 / 48) K^{6}\left(9 K^{2}-14 K+12\right)(K-2)^{4} \\
b_{5}=(1 / 48) K^{8}(K-2)^{5} \\
b_{6}=(1 / 64) K\left(K^{5}+2 K^{4}-4 K^{3}+12 K^{2}-4 K+8\right)(K-2)^{3} \\
b_{7}=-(1 / 16) K^{2}\left(5 K^{4}-8 K^{3}+12 K^{2}-4 K+4\right)(K-2)^{4} \\
b_{8}=0,5 K^{4}\left(K^{2}-K+1\right)(K-2)^{5} \\
b_{9}=-(1 / 6) K^{6}(K-2)^{6} \\
b_{10}=(1 / 512) K\left(13 K^{3}+8 K^{2}+8 K+16\right)(K-2)^{5} \\
b_{11}=-(3 / 128) K^{2}\left(7 K^{2}-2 K+4\right)(K-2)^{6} \\
b_{12}=(9 / 64) K^{4}(K-2)^{7} \\
b_{13}=(1 / 256) K(3 K+2)(K-2)^{7} \\
b_{14}=-(1 / 32) K^{2}(K-2)^{8} \\
b_{15}=(1 / 512)(K-2)^{9}\end{array}$ & \\
\hline
\end{tabular}

Tabela 34 - Relação matemática teórica da efetividade de trocadores de calor de fluxo cruzado em escoamento contracorrente com múltiplos passes com o fluido quente não misturado - Casos 4A, 4B, 4C - trocadores de calor ilustrados nas Figuras 90 98 do Anexo A

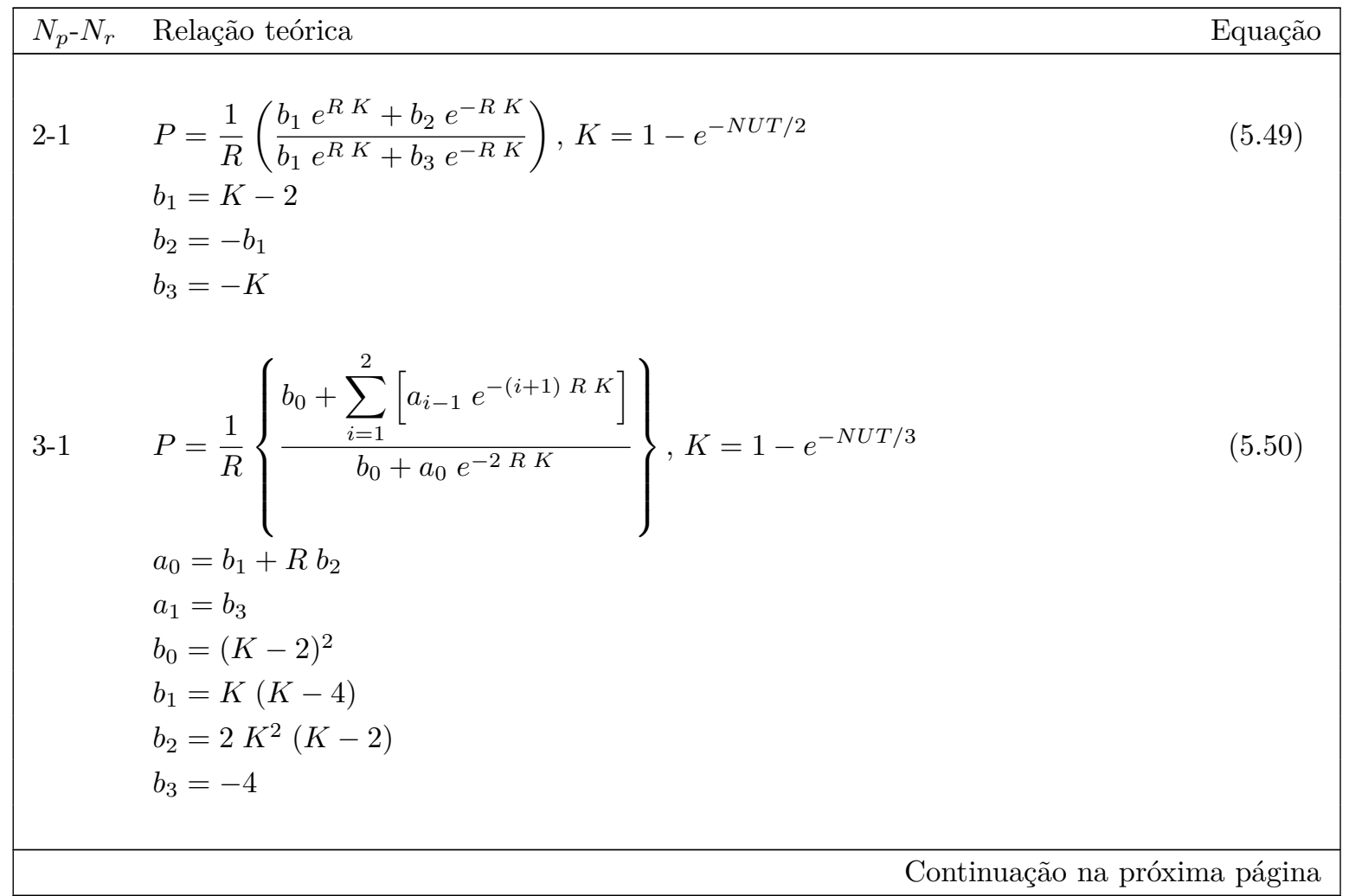


Tabela 34 - continuação da página anterior

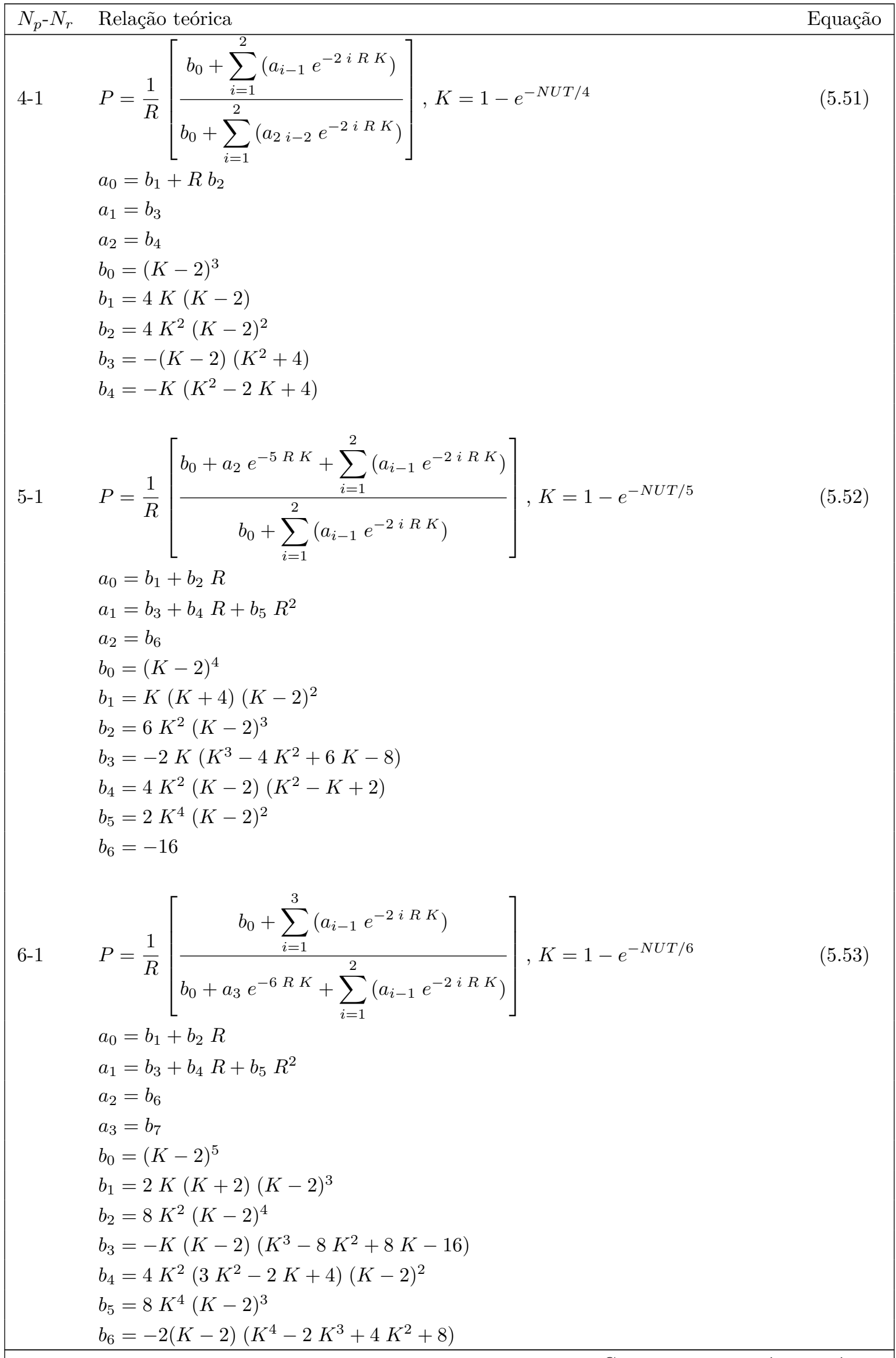


Tabela 34 - continuação da página anterior

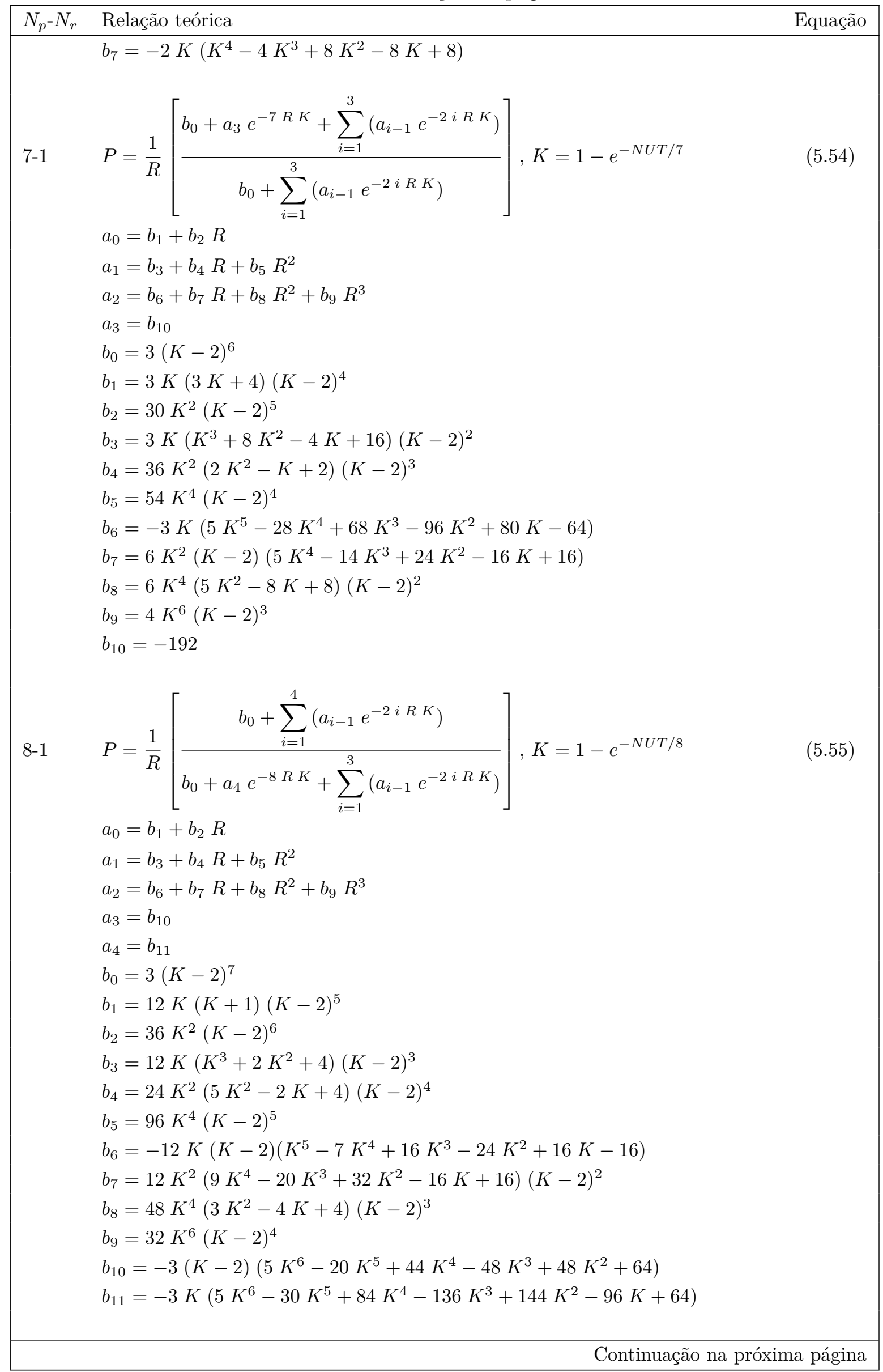


Tabela 34 - continuação da página anterior

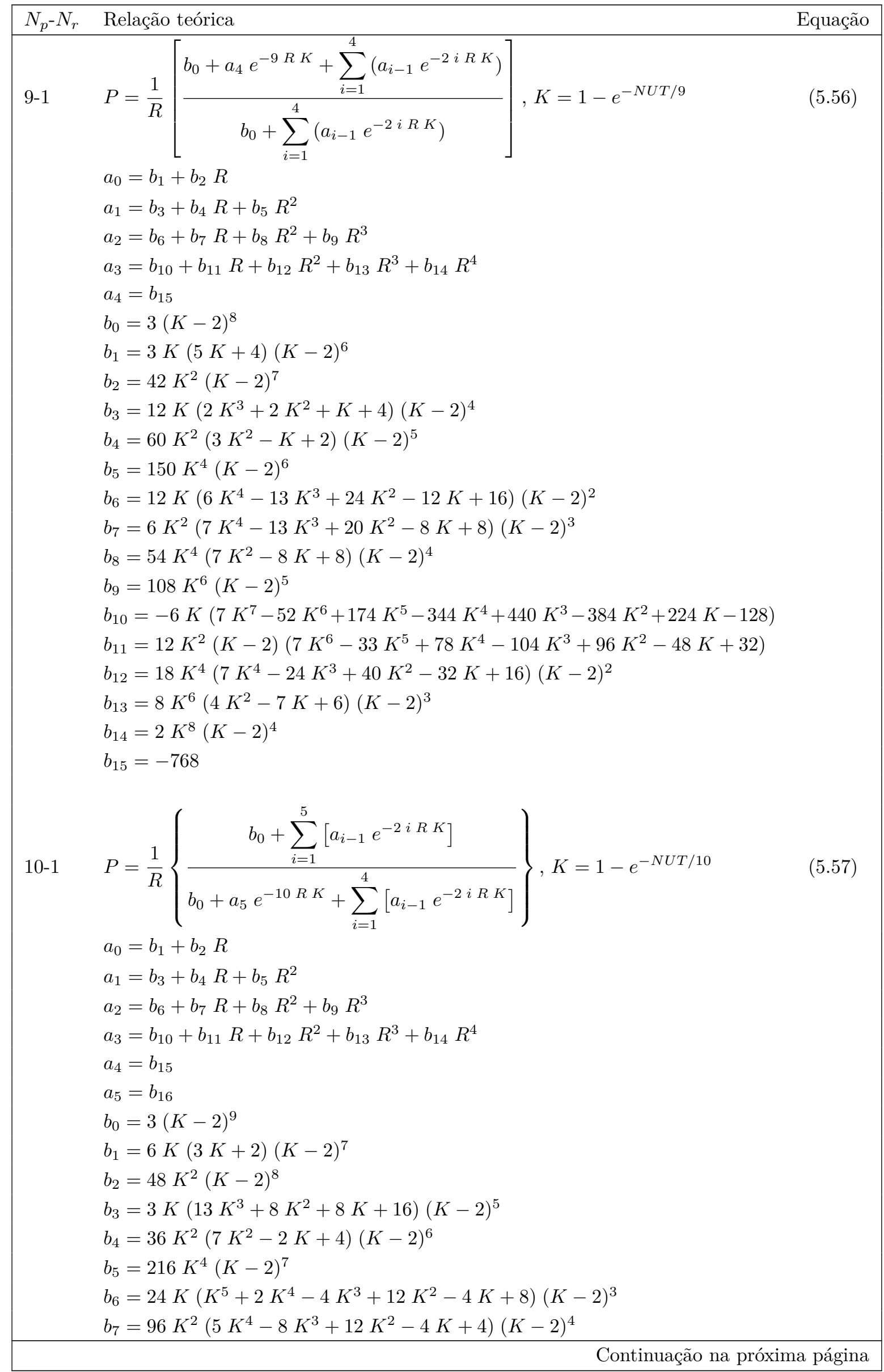


Tabela 34 - continuação da página anterior

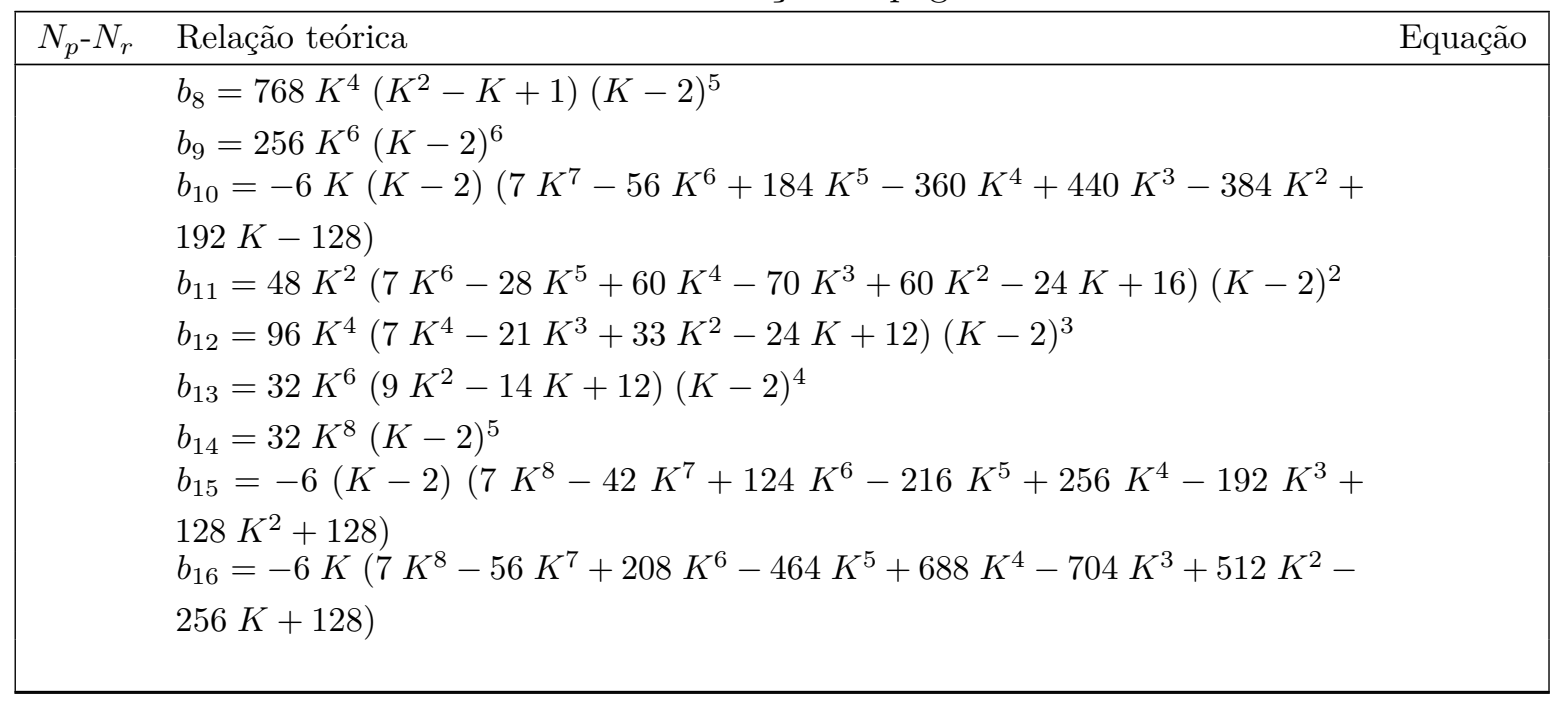

No melhor conhecimento do presente autor, as relações válidas para mais de quatro passes (fileiras de tubos) no caso dos arranjos paralelo-cruzados e para mais de seis passes no caso dos arranjos contracorrente-cruzados não se encontram na literatura aberta. Assim, com a disponibilidade dessas relações (Tabelas 29.34) e dos procedimentos de cálculo da Seção 4.1 se elimina a necessidade do uso de relações aproximadas, sem incorrer nos erros comentados anteriormente. No Anexo B são apresentados dados de efetividade de temperatura e de fator de correção para diversas configurações de trocadores de calor de fluxo cruzado.

Com isto tudo, podem-ser aplicar as expressões teóricas encontradas no presente trabalho no cálculo de trocadores de calor de fluxo cruzado, como exemplo em trocadores de calor tipo PFHE, plate fin heat exchanger (BABAELAHI; SADRI; SAYYAADI, 2014; YOON; SABHARWALL; KIM, 2014). PFHE consiste de um pequeno trocador muito utilizado em indústrias aeronáuticas com camadas alternadas de placas de fluidos quente e frio, onde a transferência de calor é realizada. Na Figura 37 um esquema ilustrativo deste tipo de trocador de calor é apresentado.

Os dados físicos e termodinâmicos do trocador de calor simulado neste trabalho são apresentados na Tabela 35, onde as propriedades termodinâmicas são calculadas iterativamente utilizando a média das temperaturas de entrada e de saída do trocador de calor.

A taxa de transferência de calor é calculada utilizando um balanço de energia nos fluidos frio e quente, e usando os conceitos de diferença de temperatura média logarítmica e de fator de correção. As equações abaixo para um trocador de calor em escoamento contracorrente podem ser escritas,

$$
\dot{Q}=F U A \Delta T_{L M T D}
$$




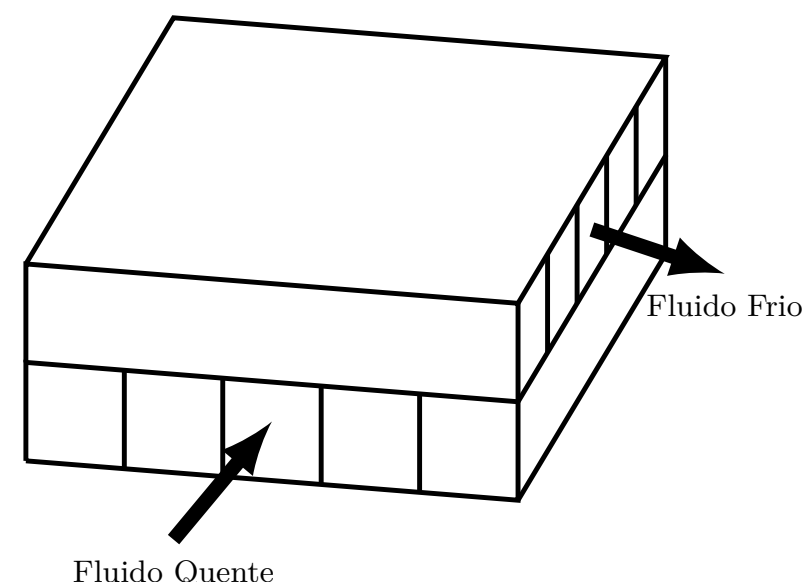

Figura 37 - Esquema de um trocador de calor tipo Plate Fin Heat Exchanger

Tabela 35 - Dados físicos e termodinâmicos dos fluidos frio e quente

\begin{tabular}{|l|cc|}
\hline Parâmetro & Fluido Frio & Fluido Quente \\
\hline Fluido & $\mathrm{Ar}$ & $\mathrm{Ar}$ \\
Vazão mássica $\left[\mathrm{kg} \mathrm{s}^{-1}\right]$ & 0,005 & 1,0 \\
Temperatura de entrada $\left[{ }^{\circ} \mathrm{C}\right]$ & 30 & 100 \\
Pressão de entrada $[\mathrm{kPa}]$ & 101,325 & 101,325 \\
Número de tubos & 10 & 100 \\
Largura do tubo $[\mathrm{mm}]$ & 10 & 10 \\
Altura do tubo $[\mathrm{mm}]$ & 10 & 10 \\
Calor específico $\left[\mathrm{J} \mathrm{kg}{ }^{-1} \mathrm{~K}^{-1}\right]$ & 1006,4 & 1011,2 \\
Massa específica $\left[\mathrm{kg} \mathrm{m}^{-3}\right]$ & 1,138 & 0,947 \\
Viscosidade dinâmica $\left[\mathrm{kg} \mathrm{m}^{-1} \mathrm{~s}^{-1}\right]$ & $2,003 \mathrm{e}-5$ & $2,168 \mathrm{e}-5$ \\
Condutividade térmica $\left[\mathrm{W} \mathrm{m}^{-1} \mathrm{~K}^{-1}\right]$ & 0,0271 & 0,0316 \\
Número de Prandtl & 0,706 & 0,694 \\
\hline
\end{tabular}

$$
\Delta T_{L M T D}=\frac{\left(T_{q, \text { ent }}-T_{f, s a i}\right)-\left(T_{q, \text { sai }}-T_{f, \text { ent }}\right)}{\ln \left(\frac{T_{q, \text { ent }}-T_{f, s a i}}{T_{q, s a i}-T_{f, \text { ent }}}\right)}
$$

onde o fator de correção $F$ é calculado através das expressões teóricas apresentadas nas Tabelas 29, 34 de acordo com o arranjo do trocador de calor e do escoamento dos fluidos frio e quente. Neste exemplo, utiliza-se a Equação 5.39 utilizando a razão de temperatura igual a $R=0,149$ e a a efetividade de temperatura igual a $P=0,225$. O fator de correção calculado deste trocador de calor é igual a 0,998 .

O coeficiente global de transferência de calor $U A$ e o coeficiente de transferência de calor por convecção $h$ dado pela correlação de Gnielinski são calculados segundo as expressões a seguir,

$$
\frac{1}{U A}=\frac{1}{(h A)_{f}}+\frac{1}{(h A)_{q}}
$$




$$
\begin{gathered}
h=\left[\frac{\left(\frac{f}{8}\right)(R e-1000) \operatorname{Pr}}{1+12,7\left(\frac{f}{8}\right)^{1 / 2}\left(\operatorname{Pr}^{2 / 3}-1\right)}\right]\left(\frac{k}{D_{h}}\right) \\
f=[0,79 \ln (R e)-1,64]^{-2} \\
\operatorname{Re}=\frac{\rho V D_{h}}{\mu}
\end{gathered}
$$

onde $f$ é o fator de atrito de Darcy-Weisbach para tubos lisos (INCROPERA; DEWITT, 2014), Re é o número de Reynolds, Pr é o número de Prandtl, $k$ é a condutividade térmica do fluido e $D_{h}$ é o diâmetro hidráulico do duto.

Assim, pode-ser calcular a taxa de transferência de calor do trocador de calor e as temperaturas de saída dos fluidos frio e quente, que para este caso são iguais a $23,8 \mathrm{~W}$, $45,7^{\circ} \mathrm{C}$ e $97,6^{\circ} \mathrm{C}$, respectivamente. Este exemplo mostra a versatilidade do algoritmo desenvolvido no presente trabalho, que pode ser utilizado para o cálculo da efetividade de temperatura e da taxa de transferência de calor de trocadores de calor de fluxo cruzado.

\subsection{Trocador de Calor de Casco e Tubo}

A metodologia desenvolvida neste trabalho é utilizada para calcular a efetividade de temperatura e o fator de correção de trocadores de calor de casco e tubo tipo TEMA E com um passe no casco e um no tubo (1-1) em escoamentos contracorrente e paralelo. Este trabalho é baseado em diversos trabalhos de trocadores de calor de fluxo cruzado, onde os algoritmos desenvolvidos na Seção 5.1 são utilizados.

Na Figura 38 é apresentado um exemplo de um trocador de calor de casco e tubo 1-1 tipo TEMA E com uma chicana. O trocador de calor de casco e tubo é idealizado como sendo uma série de trocadores de calor de fluxo cruzado. Os trocadores de calor são então conectados em série em escoamentos contracorrente e paralelo. Cada seção de chicana é idealizada como um trocador de calor de fluxo cruzado considerando os fluidos quente e frio não misturados (SHAH; PIGNOTTI, 1997). Na saída de cada seção da chicana, o fluido do casco é misturado e este fluido vai para a próxima seção da chicana. O fluido do tubo é considerado não misturado. Assim, para este exemplo, o trocador de calor de casco e tubo é idealizado como um trocador de fluxo cruzado com infinitos tubos e dois passes $(2-\infty)$. Esta configuração pode então ser modelada utilizando o algoritmo desenvolvido para o caso 4A de Pignotti e Cordero (1983a) e Magazoni e Cabezas-Gómez (2016) e apresentado no fluxograma da Figura 23. 


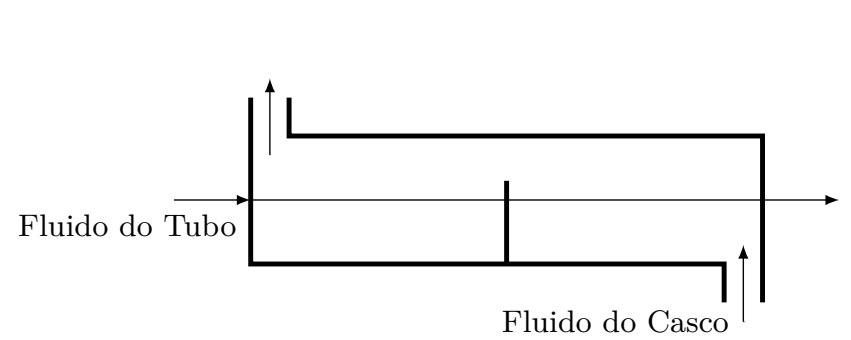

(a) Trocador de calor

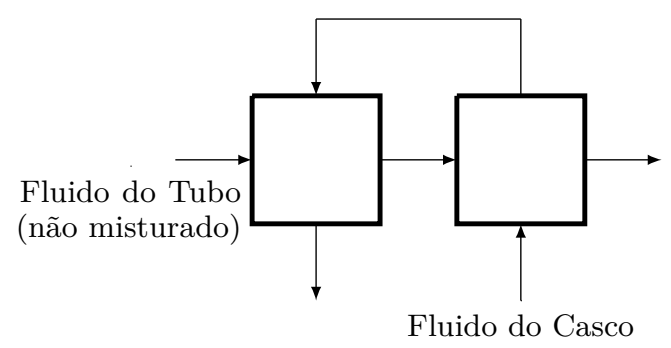

(b) Esquema do trocador de calor de casco e tubo

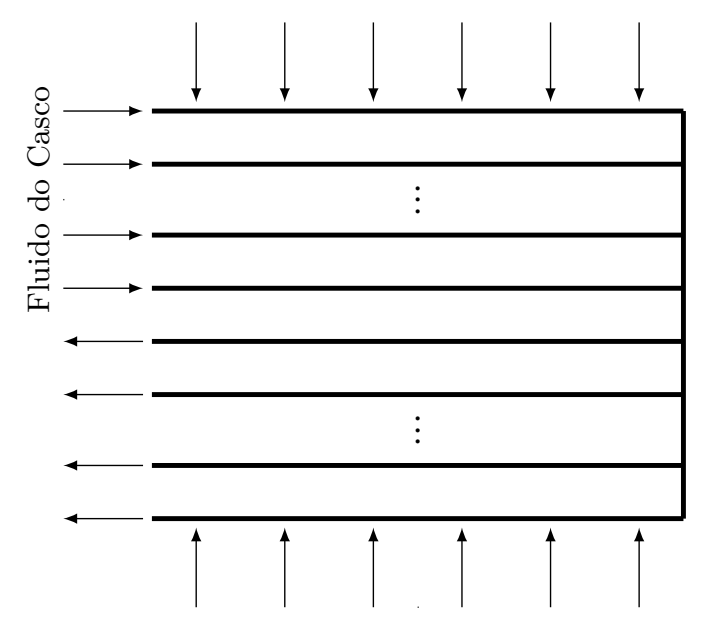

Fluido do Tubo

(c) Trocador de calor de casco e tubo modelado como um de fluxo cruzado

Figura 38 - Trocador de calor de casco e tubo tipo TEMA E com uma chicana

Nas Tabelas 36, 37] e 38 são apresentados os valores do fator de correção e da efetividade de temperatura de um trocador de calor de casco e tubos 1-1 tipo TEMA E em escoamento contracorrente com um, cinco e dez chicanas, respectivamente. As simulações foram realizadas utilizando o algoritmo de trocador de calor de fluxo cruzado com uma grande quantidade de tubos, onde em teoria, o número de tubos é infinito. Entretanto, na prática, o número de tubos precisa ser definido. Assim, os resultados apresentados nas Tabelas 36, 37 e 38 são obtidos através de um processo iterativo variando o número de tubos a partir de um até um número de tubos onde o valor máximo do fator de correção não muda em $0,01 \%$. Por exemplo, o número de tubos é igual a trinta para um trocador de calor de casco e tubo com uma chicana, que representa para este caso a teoria de número de tubos infinito. Para cada configuração de trocador de calor, o número de tubos infinito varia de acordo com o número de chicanas, o que é representado graficamente na Figura 39. Para dez chicanas, o número de tubos que representa a configuração de fluido do casco não misturado é nove. Note que os valores das Tabelas 36, 37] e 38 são obtidos considerando o fluido do lado do casco não misturado no interior das chicanas, e misturado entre as chicanas quando o fluido do casco escoa de uma chicana para outra. Os resultados encontrados nestas tabelas demonstram claramente que para valores médios e altos de $N U T$ (> 5), o fator de correção é menor que um. Portanto, para estes casos, 
mesmo que o número de chicanas seja maior, o trocador de calor não se comporta como um contracorrente. Observe que para alguns valores de $N U T(>9)$ e $R$ (2 e 4), o fator de correção assume valores menores que 0,75 , que é o mínimo valor que deveria ser considerado para projeto e desenvolvimento de trocadores de calor de casco e tubo.

Tabela 36 - Efetividade de temperatura e fator de correção do trocador de calor de casco e tubo 1-1 tipo TEMA E em escoamento contracorrente com uma chicana

\begin{tabular}{|c|c|c|c|c|c|c|c|c|c|c|}
\hline & \multicolumn{5}{|c|}{$P$} & \multicolumn{5}{|c|}{$F$} \\
\hline NUT ${ }^{R}$ & 0,1 & 0,5 & 1,0 & 2,0 & 4,0 & 0,1 & 0,5 & 1,0 & 2,0 & 4,0 \\
\hline 0,1 & 0,095 & 0,093 & 0,091 & 0,087 & 0,079 & 1,000 & 1,000 & 1,000 & 0,999 & 0,998 \\
\hline 0,2 & 0,180 & 0,174 & 0,166 & 0,153 & 0,130 & 1,000 & 0,999 & 0,998 & 0,997 & 0,994 \\
\hline 0,4 & 0,325 & 0,306 & 0,284 & 0,246 & 0,187 & 0,999 & 0,997 & 0,994 & 0,988 & 0,977 \\
\hline 0,6 & 0,443 & 0,410 & 0,372 & 0,307 & 0,215 & 0,999 & 0,993 & 0,986 & 0,974 & 0,955 \\
\hline 0,8 & 0,539 & 0,492 & 0,439 & 0,349 & 0,229 & 0,998 & 0,988 & 0,977 & 0,958 & 0,930 \\
\hline 1,0 & 0,617 & 0,559 & 0,491 & 0,378 & 0,237 & 0,996 & 0,982 & 0,966 & 0,939 & 0,904 \\
\hline 1,2 & 0,682 & 0,614 & 0,534 & 0,401 & 0,242 & 0,995 & 0,975 & 0,953 & 0,919 & 0,879 \\
\hline 1,4 & 0,735 & 0,659 & 0,568 & 0,417 & 0,245 & 0,993 & 0,967 & 0,940 & 0,899 & 0,855 \\
\hline 1,6 & 0,779 & 0,698 & 0,597 & 0,430 & 0,247 & 0,991 & 0,959 & 0,926 & 0,879 & 0,833 \\
\hline 1,8 & 0,815 & 0,730 & 0,621 & 0,440 & 0,248 & 0,989 & 0,950 & 0,911 & 0,860 & 0,812 \\
\hline 2,0 & 0,845 & 0,758 & 0,642 & 0,449 & 0,248 & 0,987 & 0,941 & 0,897 & 0,841 & 0,793 \\
\hline 3,0 & 0,935 & 0,849 & 0,713 & 0,473 & 0,250 & 0,974 & 0,891 & 0,826 & 0,759 & 0,718 \\
\hline 4,0 & 0,971 & 0,898 & 0,754 & 0,484 & 0,250 & 0,959 & 0,843 & 0,765 & 0,696 & 0,665 \\
\hline 5,0 & 0,987 & 0,927 & 0,781 & 0,490 & 0,250 & 0,943 & 0,799 & 0,714 & 0,647 & 0,627 \\
\hline 6,0 & 0,994 & 0,946 & 0,801 & 0,493 & 0,250 & 0,926 & 0,760 & 0,671 & 0,608 & 0,598 \\
\hline 7,0 & 0,997 & 0,959 & 0,816 & 0,496 & 0,250 & 0,910 & 0,725 & 0,635 & 0,576 & 0,574 \\
\hline 8,0 & 0,999 & 0,968 & 0,829 & 0,497 & 0,250 & 0,894 & 0,696 & 0,604 & 0,550 & 0,555 \\
\hline 9,0 & 0,999 & 0,975 & 0,839 & 0,498 & 0,250 & 0,879 & 0,669 & 0,578 & 0,527 & 0,539 \\
\hline 10,0 & 1,000 & 0,980 & 0,847 & 0,498 & 0,250 & 0,864 & 0,646 & 0,554 & 0,507 & 0,526 \\
\hline
\end{tabular}

Nas Tabelas 39, 40 e 41, são apresentados os valores de efetividade de temperatura do trocador de calor para $R=0,7, R=1,0$ e $R=4,0$, respectivamente, em função do número de chicanas, $N_{c h}$. À medida que o número de chicana aumenta, a efetividade também aumenta e se aproxima do valor da efetividade de trocadores de calor em contracorrente. Para baixos valores do número de unidades de transferência $(N U T<0,6)$, o número de chicanas não influencia diretamente a efetividade do trocador de calor. Entretanto na região de valores médios e altos de $N U T$, o número de chicanas exerce uma maior influência sobre os valores do fator de correção. A razão para este comportamento está no fato que a efetividade de temperatura assume valores maiores para configuração de trocadores de calor em contracorrente. Assim, para estes casos, somente os trocadores de calor com um considerável número de chicanas apresentam o valor de efetividade de temperatura próximo de um. Isto é evidenciado nas Figuras 40 e 41, onde são apresentados respectivamente os comportamentos do fator de correção e da razão $P / P_{c c}$ em função da efetividade de temperatura e do número de chicanas para $R=1,0$. À medida que o número de chicanas aumenta, a solução obtida se torna mais complicada, e rapidamente se aproxima do limite assintótico. Como observado nestas figuras, o fator de correção para altos números de chicanas se aproxima de um para uma grande faixa de valores da 
Tabela 37 - Efetividade de temperatura e fator de correção do trocador de calor de casco e tubo 1-1 tipo TEMA E em escoamento contracorrente com cinco chicanas

\begin{tabular}{|c|c|c|c|c|c|c|c|c|c|c|}
\hline & \multicolumn{5}{|c|}{$P$} & \multicolumn{5}{|c|}{$F$} \\
\hline $\mathrm{NUT}^{R}$ & 0,1 & 0,5 & 1,0 & 2,0 & 4,0 & 0,1 & 0,5 & 1,0 & 2,0 & 4,0 \\
\hline 0,1 & 0,095 & 0,093 & 0,091 & 0,087 & 0,080 & 1,000 & 1,000 & 1,000 & 1,000 & 1,000 \\
\hline 0,2 & 0,180 & 0,174 & 0,167 & 0,153 & 0,131 & 1,000 & 1,000 & 1,000 & 1,000 & 0,999 \\
\hline 0,4 & 0,325 & 0,307 & 0,286 & 0,248 & 0,189 & 1,000 & 1,000 & 0,999 & 0,999 & 0,997 \\
\hline 0,6 & 0,443 & 0,411 & 0,375 & 0,310 & 0,217 & 1,000 & 0,999 & 0,998 & 0,997 & 0,994 \\
\hline 0,8 & 0,539 & 0,495 & 0,444 & 0,354 & 0,232 & 1,000 & 0,999 & 0,997 & 0,994 & 0,989 \\
\hline 1,0 & 0,618 & 0,564 & 0,499 & 0,386 & 0,240 & 1,000 & 0,998 & 0,996 & 0,991 & 0,983 \\
\hline 1,2 & 0,683 & 0,621 & 0,544 & 0,410 & 0,244 & 0,999 & 0,997 & 0,994 & 0,988 & 0,977 \\
\hline 1,4 & 0,737 & 0,668 & 0,581 & 0,428 & 0,247 & 0,999 & 0,996 & 0,992 & 0,984 & 0,969 \\
\hline 1,6 & 0,781 & 0,709 & 0,613 & 0,442 & 0,248 & 0,999 & 0,994 & 0,989 & 0,979 & 0,961 \\
\hline 1,8 & 0,818 & 0,743 & 0,640 & 0,453 & 0,249 & 0,999 & 0,993 & 0,986 & 0,974 & 0,953 \\
\hline 2,0 & 0,848 & 0,772 & 0,663 & 0,461 & 0,249 & 0,998 & 0,992 & 0,983 & 0,969 & 0,944 \\
\hline 3,0 & 0,938 & 0,871 & 0,743 & 0,484 & 0,250 & 0,996 & 0,982 & 0,965 & 0,937 & 0,898 \\
\hline 4,0 & 0,975 & 0,923 & 0,791 & 0,493 & 0,250 & 0,994 & 0,970 & 0,943 & 0,902 & 0,853 \\
\hline 5,0 & 0,990 & 0,952 & 0,821 & 0,497 & 0,250 & 0,991 & 0,956 & 0,919 & 0,866 & 0,813 \\
\hline 6,0 & 0,996 & 0,969 & 0,843 & 0,498 & 0,250 & 0,987 & 0,940 & 0,893 & 0,831 & 0,778 \\
\hline 7,0 & 0,998 & 0,980 & 0,859 & 0,499 & 0,250 & 0,983 & 0,923 & 0,867 & 0,799 & 0,747 \\
\hline 8,0 & 0,999 & 0,986 & 0,871 & 0,499 & 0,250 & 0,979 & 0,906 & 0,842 & 0,769 & 0,721 \\
\hline 9,0 & 1,000 & 0,991 & 0,880 & 0,500 & 0,250 & 0,974 & 0,889 & 0,817 & 0,742 & 0,698 \\
\hline 10,0 & 1,000 & 0,994 & 0,888 & 0,500 & 0,250 & 0,969 & 0,871 & 0,794 & 0,717 & 0,678 \\
\hline
\end{tabular}

Tabela 38 - Efetividade de temperatura e fator de correção do trocador de calor de casco e tubo 1-1 tipo TEMA E em escoamento contracorrente com dez chicanas

\begin{tabular}{|c|c|c|c|c|c|c|c|c|c|c|}
\hline & \multicolumn{5}{|c|}{$P$} & \multicolumn{5}{|c|}{$F$} \\
\hline NUT ${ }^{R}$ & 0,1 & 0,5 & 1,0 & 2,0 & 4,0 & 0,1 & 0,5 & 1,0 & 2,0 & 4,0 \\
\hline 0,1 & 0,095 & 0,093 & 0,091 & 0,087 & 0,080 & 1,000 & 1,000 & 1,000 & 1,000 & 1,000 \\
\hline 0,2 & 0,180 & 0,174 & 0,167 & 0,153 & 0,131 & 1,000 & 1,000 & 1,000 & 1,000 & 1,000 \\
\hline 0,4 & 0,325 & 0,307 & 0,286 & 0,248 & 0,189 & 1,000 & 1,000 & 1,000 & 1,000 & 0,999 \\
\hline 0,6 & 0,443 & 0,412 & 0,375 & 0,311 & 0,218 & 1,000 & 1,000 & 1,000 & 0,999 & 0,998 \\
\hline 0,8 & 0,539 & 0,496 & 0,444 & 0,355 & 0,232 & 1,000 & 1,000 & 0,999 & 0,998 & 0,997 \\
\hline 1,0 & 0,619 & 0,565 & 0,500 & 0,387 & 0,240 & 1,000 & 0,999 & 0,999 & 0,997 & 0,995 \\
\hline 1,2 & 0,684 & 0,622 & 0,545 & 0,411 & 0,245 & 1,000 & 0,999 & 0,998 & 0,996 & 0,992 \\
\hline 1,4 & 0,737 & 0,669 & 0,583 & 0,429 & 0,247 & 1,000 & 0,999 & 0,997 & 0,995 & 0,990 \\
\hline 1,6 & 0,781 & 0,710 & 0,615 & 0,443 & 0,248 & 1,000 & 0,998 & 0,997 & 0,993 & 0,987 \\
\hline 1,8 & 0,818 & 0,744 & 0,642 & 0,454 & 0,249 & 1,000 & 0,998 & 0,996 & 0,992 & 0,984 \\
\hline 2,0 & 0,849 & 0,774 & 0,666 & 0,463 & 0,249 & 0,999 & 0,997 & 0,995 & 0,990 & 0,980 \\
\hline 3,0 & 0,939 & 0,873 & 0,748 & 0,486 & 0,250 & 0,999 & 0,994 & 0,989 & 0,978 & 0,959 \\
\hline 4,0 & 0,975 & 0,926 & 0,797 & 0,495 & 0,250 & 0,998 & 0,990 & 0,981 & 0,963 & 0,935 \\
\hline 5,0 & 0,990 & 0,955 & 0,829 & 0,498 & 0,250 & 0,997 & 0,985 & 0,971 & 0,946 & 0,909 \\
\hline 6,0 & 0,996 & 0,973 & 0,852 & 0,499 & 0,250 & 0,996 & 0,979 & 0,960 & 0,927 & 0,883 \\
\hline 7,0 & 0,998 & 0,983 & 0,869 & 0,500 & 0,250 & 0,994 & 0,972 & 0,947 & 0,907 & 0,858 \\
\hline 8,0 & 0,999 & 0,989 & 0,882 & 0,500 & 0,250 & 0,993 & 0,965 & 0,934 & 0,887 & 0,835 \\
\hline 9,0 & 1,000 & 0,993 & 0,892 & 0,500 & 0,250 & 0,991 & 0,957 & 0,920 & 0,867 & 0,813 \\
\hline 10,0 & 1,000 & 0,996 & 0,901 & 0,500 & 0,250 & 0,989 & 0,948 & 0,906 & 0,848 & 0,793 \\
\hline
\end{tabular}




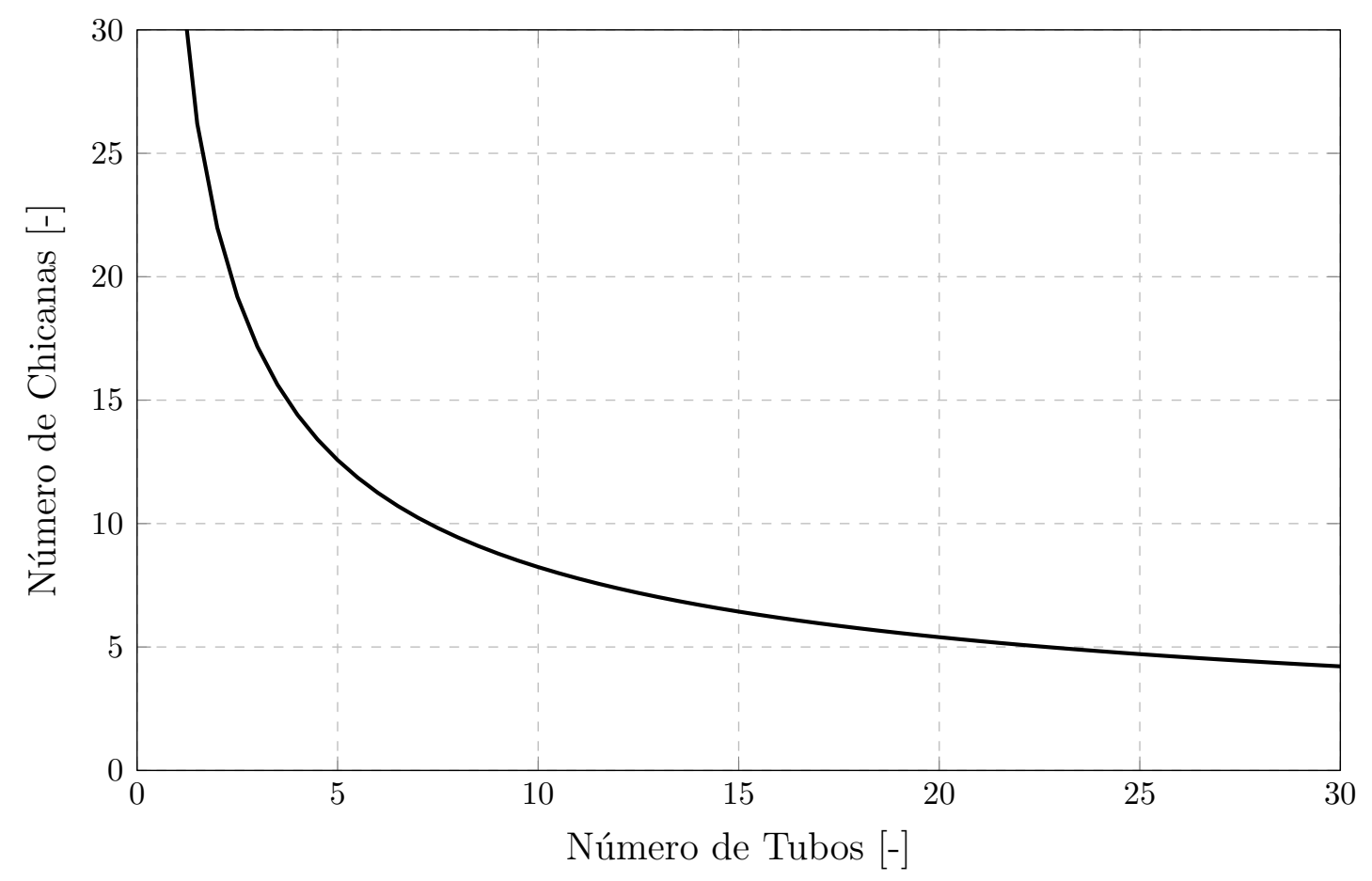

Figura 39 - Número de tubos em função do número de chicanas para trocadores de calor de casco e tubo 1-1 tipo TEMA E

efetividade de temperatura, $P$, e do número de unidades de transferência, $N U T$.

Análises similares são realizadas para trocadores de calor de casco e tubo 1-1 tipo TEMA E em escoamento paralelo. Nas Tabelas 42,43 e 44 são apresentados os valores do fator de correção em função de $N U T$ e $R$. Observa-se que a partir de um determinado número de chicanas, o fator de correção não altera significativamente.

Caglayan e Buthod (1976) analisaram numericamente pelo método de diferenças finitas um trocador de calor de casco e tubo 1-1 tipo TEMA E em escoamento contracorrente. Os resultados do fator de correção são apresentados em função do número de chicanas, $N_{c h}$, da efetividade de temperatura, $P$, e da razão de temperatura, $R$. Estes valores são então comparados com os valores encontrados no presente trabalho e são apresentados na Tabela 45. Observa-se que à medida que o número de chicanas aumenta, o fator de correção aumenta também. Quanto maior o número de chicanas, mais próximo de um se aproxima o valor do fator de correção, que é o caso de trocadores de calor contracorrente. Conclui-se que o procedimento computacional implementado produz resultados coerentes. Os resultados calculados neste trabalho são então comparados com os valores apresentados por Caglayan e Buthod (1976) e o erro relativo máximo encontrado é de $1,0 \%$ para $N_{c h}=6$ e $R=1,0$. Entretanto, a razão mais provável para esta diferença pode ser o arredondamento dos resultados realizados por Caglayan e Buthod (1976), que utilizaram somente duas casas decimais. Por esta razão, os resultados do presente trabalho são apresentados com as mesmas casas decimais. Para um trocador de calor de casco 
Tabela 39 - Efetividade de temperatura do trocador de calor de casco e tubo 1-1 tipo TEMA E em escoamento contracorrente em função do número de chicanas e $R=0,7$

\begin{tabular}{|cc|ccccccc|}
\hline & & \multicolumn{7}{|c|}{$N_{c h}$} \\
\hline$R$ & $N U T$ & 1 & 2 & 5 & 10 & 20 & 30 & $\begin{array}{c}\text { Contra- } \\
\text { corrente }\end{array}$ \\
\hline 0,7 & 0,1 & 0,092 & 0,092 & 0,092 & 0,092 & 0,092 & 0,092 & 0,092 \\
0,7 & 0,2 & 0,171 & 0,171 & 0,171 & 0,171 & 0,171 & 0,171 & 0,171 \\
0,7 & 0,4 & 0,297 & 0,298 & 0,298 & 0,298 & 0,298 & 0,298 & 0,298 \\
0,7 & 0,6 & 0,394 & 0,395 & 0,396 & 0,397 & 0,397 & 0,397 & 0,397 \\
0,7 & 0,8 & 0,470 & 0,473 & 0,474 & 0,475 & 0,475 & 0,475 & 0,475 \\
0,7 & 1,0 & 0,531 & 0,535 & 0,537 & 0,538 & 0,538 & 0,538 & 0,538 \\
0,7 & 1,2 & 0,581 & 0,586 & 0,590 & 0,591 & 0,591 & 0,591 & 0,591 \\
0,7 & 1,4 & 0,622 & 0,629 & 0,633 & 0,635 & 0,635 & 0,635 & 0,635 \\
0,7 & 1,6 & 0,657 & 0,665 & 0,670 & 0,672 & 0,672 & 0,672 & 0,673 \\
0,7 & 1,8 & 0,686 & 0,695 & 0,702 & 0,704 & 0,705 & 0,705 & 0,705 \\
0,7 & 2,0 & 0,711 & 0,722 & 0,730 & 0,732 & 0,732 & 0,733 & 0,733 \\
0,7 & 3,0 & 0,796 & 0,812 & 0,824 & 0,828 & 0,829 & 0,829 & 0,830 \\
0,7 & 4,0 & 0,844 & 0,862 & 0,878 & 0,883 & 0,885 & 0,885 & 0,886 \\
0,7 & 5,0 & 0,876 & 0,894 & 0,912 & 0,918 & 0,920 & 0,920 & 0,921 \\
0,7 & 6,0 & 0,897 & 0,915 & 0,934 & 0,940 & 0,943 & 0,943 & 0,944 \\
0,7 & 7,0 & 0,913 & 0,930 & 0,949 & 0,956 & 0,959 & 0,959 & 0,960 \\
0,7 & 8,0 & 0,926 & 0,942 & 0,960 & 0,967 & 0,970 & 0,970 & 0,971 \\
0,7 & 9,0 & 0,936 & 0,950 & 0,968 & 0,975 & 0,978 & 0,978 & 0,979 \\
0,7 & 10,0 & 0,944 & 0,957 & 0,974 & 0,981 & 0,983 & 0,984 & 0,985 \\
\hline
\end{tabular}

Tabela 40 - Efetividade de temperatura do trocador de calor de casco e tubo 1-1 tipo TEMA E em escoamento contracorrente em função do número de chicanas e $R=1,0$

\begin{tabular}{|cc|ccccccc|}
\hline & & \multicolumn{7}{|c|}{$N_{c h}$} \\
\hline$R$ & NUT & 1 & 2 & 5 & 10 & 20 & 30 & $\begin{array}{c}\text { Contra- } \\
\text { corrente }\end{array}$ \\
\hline 1,0 & 0,1 & 0,091 & 0,091 & 0,091 & 0,091 & 0,091 & 0,091 & 0,091 \\
1,0 & 0,2 & 0,166 & 0,167 & 0,167 & 0,167 & 0,167 & 0,167 & 0,167 \\
1,0 & 0,4 & 0,284 & 0,285 & 0,286 & 0,286 & 0,286 & 0,286 & 0,286 \\
1,0 & 0,6 & 0,372 & 0,374 & 0,375 & 0,375 & 0,375 & 0,375 & 0,375 \\
1,0 & 0,8 & 0,439 & 0,442 & 0,444 & 0,444 & 0,444 & 0,444 & 0,444 \\
1,0 & 1,0 & 0,491 & 0,496 & 0,499 & 0,500 & 0,500 & 0,500 & 0,500 \\
1,0 & 1,2 & 0,534 & 0,540 & 0,544 & 0,545 & 0,545 & 0,545 & 0,545 \\
1,0 & 1,4 & 0,568 & 0,576 & 0,581 & 0,583 & 0,583 & 0,583 & 0,583 \\
1,0 & 1,6 & 0,597 & 0,606 & 0,613 & 0,615 & 0,615 & 0,615 & 0,615 \\
1,0 & 1,8 & 0,621 & 0,632 & 0,640 & 0,642 & 0,643 & 0,643 & 0,643 \\
1,0 & 2,0 & 0,642 & 0,654 & 0,663 & 0,666 & 0,666 & 0,667 & 0,667 \\
1,0 & 3,0 & 0,713 & 0,729 & 0,743 & 0,748 & 0,749 & 0,750 & 0,750 \\
1,0 & 4,0 & 0,754 & 0,772 & 0,791 & 0,797 & 0,799 & 0,800 & 0,800 \\
1,0 & 5,0 & 0,781 & 0,800 & 0,821 & 0,829 & 0,832 & 0,833 & 0,833 \\
1,0 & 6,0 & 0,801 & 0,820 & 0,843 & 0,852 & 0,856 & 0,856 & 0,857 \\
1,0 & 7,0 & 0,816 & 0,835 & 0,859 & 0,869 & 0,873 & 0,874 & 0,875 \\
1,0 & 8,0 & 0,829 & 0,846 & 0,871 & 0,882 & 0,887 & 0,888 & 0,889 \\
1,0 & 9,0 & 0,839 & 0,856 & 0,880 & 0,892 & 0,898 & 0,899 & 0,900 \\
1,0 & 10,0 & 0,847 & 0,864 & 0,888 & 0,901 & 0,906 & 0,908 & 0,909 \\
\hline
\end{tabular}


Tabela 41 - Efetividade de temperatura do trocador de calor de casco e tubo 1-1 tipo TEMA E em escoamento contracorrente em função do número de chicanas e $R=4,0$

\begin{tabular}{|cc|ccccccc|}
\hline & & \multicolumn{7}{|c|}{$N_{c h}$} \\
\hline$R$ & NUT & 1 & 2 & 5 & 10 & 20 & 30 & $\begin{array}{c}\text { Contra- } \\
\text { corrente }\end{array}$ \\
\hline 4,0 & 0,1 & 0,079 & 0,079 & 0,080 & 0,080 & 0,080 & 0,080 & 0,080 \\
4,0 & 0,2 & 0,130 & 0,130 & 0,131 & 0,131 & 0,131 & 0,131 & 0,131 \\
4,0 & 0,4 & 0,187 & 0,188 & 0,189 & 0,189 & 0,189 & 0,189 & 0,189 \\
4,0 & 0,6 & 0,215 & 0,216 & 0,217 & 0,218 & 0,218 & 0,218 & 0,218 \\
4,0 & 0,8 & 0,229 & 0,231 & 0,232 & 0,232 & 0,233 & 0,233 & 0,233 \\
4,0 & 1,0 & 0,237 & 0,239 & 0,240 & 0,240 & 0,240 & 0,241 & 0,241 \\
4,0 & 1,2 & 0,242 & 0,243 & 0,244 & 0,245 & 0,245 & 0,245 & 0,245 \\
4,0 & 1,4 & 0,245 & 0,246 & 0,247 & 0,247 & 0,247 & 0,247 & 0,247 \\
4,0 & 1,6 & 0,247 & 0,247 & 0,248 & 0,248 & 0,248 & 0,248 & 0,248 \\
4,0 & 1,8 & 0,248 & 0,248 & 0,249 & 0,249 & 0,249 & 0,249 & 0,249 \\
4,0 & 2,0 & 0,248 & 0,249 & 0,249 & 0,249 & 0,250 & 0,250 & 0,250 \\
4,0 & 3,0 & 0,250 & 0,250 & 0,250 & 0,250 & 0,250 & 0,250 & 0,250 \\
4,0 & 4,0 & 0,250 & 0,250 & 0,250 & 0,250 & 0,250 & 0,250 & 0,250 \\
4,0 & 5,0 & 0,250 & 0,250 & 0,250 & 0,250 & 0,250 & 0,250 & 0,250 \\
4,0 & 6,0 & 0,250 & 0,250 & 0,250 & 0,250 & 0,250 & 0,250 & 0,250 \\
4,0 & 7,0 & 0,250 & 0,250 & 0,250 & 0,250 & 0,250 & 0,250 & 0,250 \\
4,0 & 8,0 & 0,250 & 0,250 & 0,250 & 0,250 & 0,250 & 0,250 & 0,250 \\
4,0 & 9,0 & 0,250 & 0,250 & 0,250 & 0,250 & 0,250 & 0,250 & 0,250 \\
4,0 & 10,0 & 0,250 & 0,250 & 0,250 & 0,250 & 0,250 & 0,250 & 0,250 \\
\hline
\end{tabular}

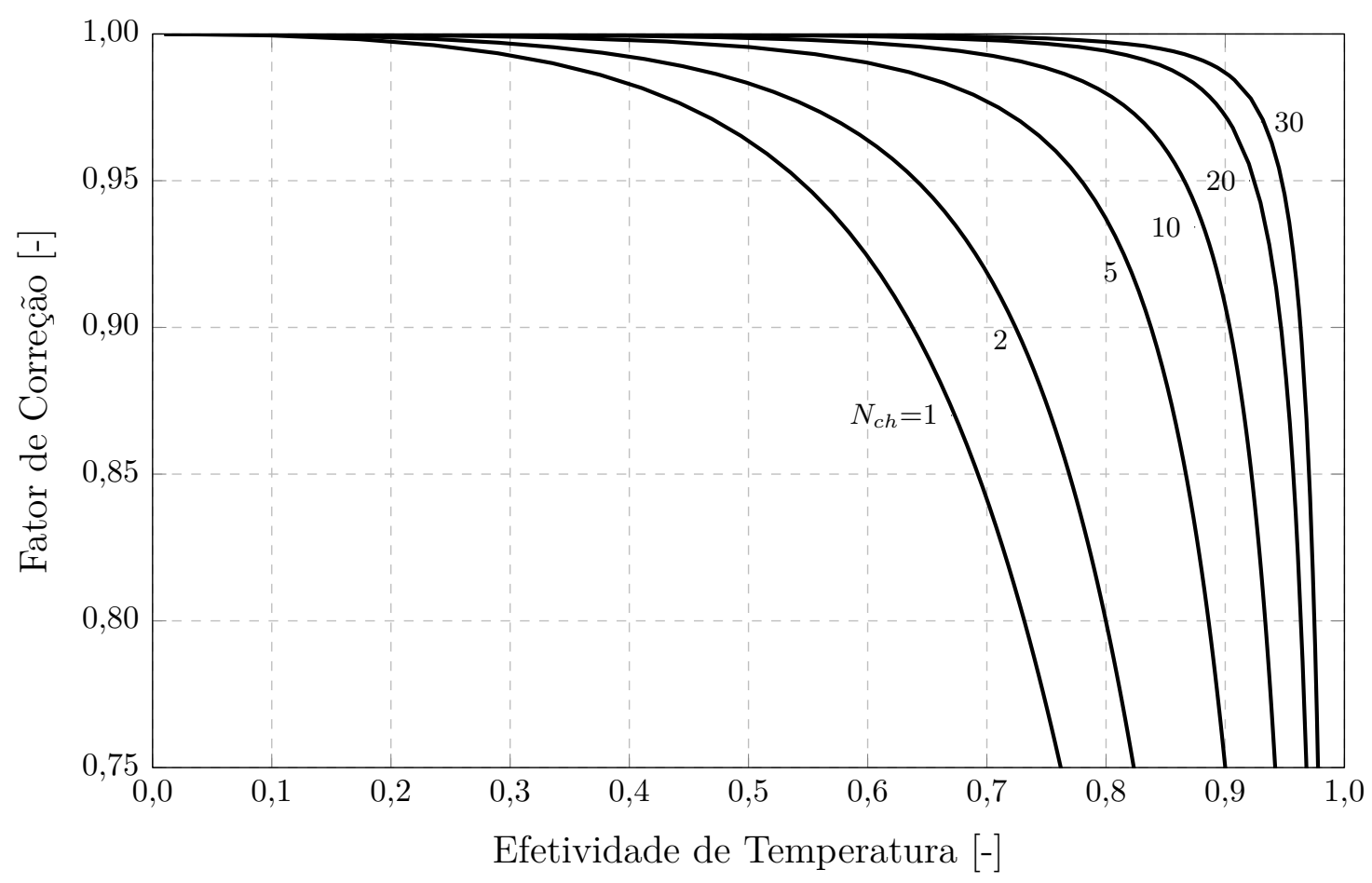

Figura 40 - Comportamento do fator de correção de trocador de calor de casco e tubo 1-1 tipo TEMA E em escoamento contracorrente em função da efetividade de temperatura e do número de chicanas para $R=1,0$ 


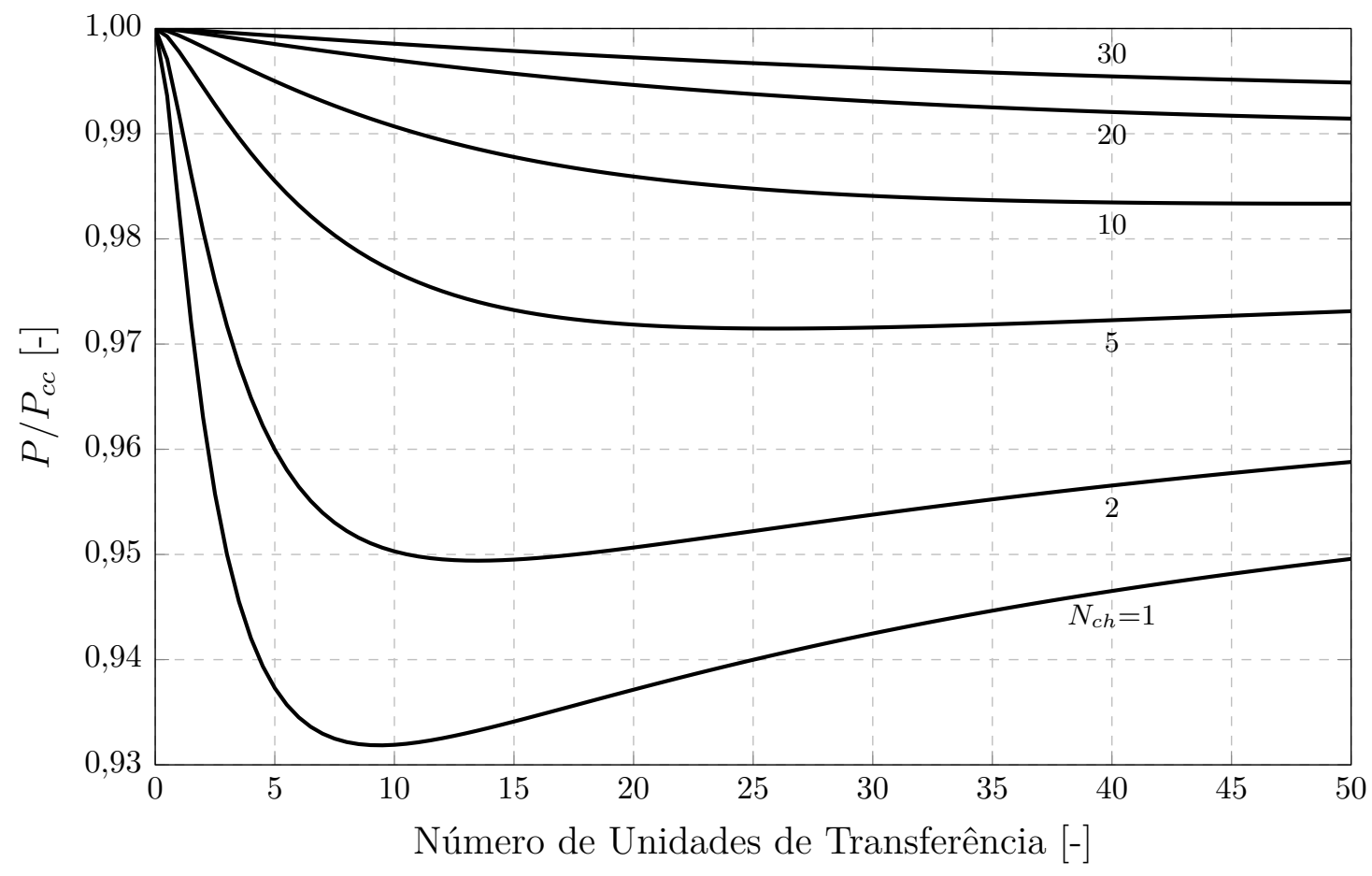

Figura 41 - Comportamento da razão $P / P_{c c}$ em função de $N U T$ e do número de chicanas para $R=1,0$ de um trocador de calor de casco e tubo 1-1 tipo TEMA E em escoamento contracorrente

Tabela 42 - Efetividade de temperatura e fator de correção do trocador de calor de casco e tubo 1-1 tipo TEMA E em escoamento paralelo com uma chicana

\begin{tabular}{|c|c|c|c|c|c|c|c|c|c|c|}
\hline & \multicolumn{5}{|c|}{$P$} & \multicolumn{5}{|c|}{$F$} \\
\hline $\mathrm{NUT}^{R}$ & 0,1 & 0,5 & 1,0 & 2,0 & 4,0 & 0,1 & 0,5 & 1,0 & 2,0 & 4,0 \\
\hline 0,1 & 0,095 & 0,093 & 0,091 & 0,086 & 0,079 & 1,000 & 0,999 & 0,997 & 0,994 & 0,988 \\
\hline 0,2 & 0,180 & 0,173 & 0,165 & 0,151 & 0,127 & 0,999 & 0,994 & 0,989 & 0,977 & 0,955 \\
\hline 0,4 & 0,324 & 0,302 & 0,277 & 0,235 & 0,174 & 0,995 & 0,977 & 0,956 & 0,915 & 0,834 \\
\hline 0,6 & 0,440 & 0,398 & 0,352 & 0,281 & 0,190 & 0,990 & 0,951 & 0,907 & 0,827 & 0,679 \\
\hline 0,8 & 0,533 & 0,469 & 0,404 & 0,306 & 0,194 & 0,981 & 0,916 & 0,846 & 0,728 & 0,533 \\
\hline 1,0 & 0,608 & 0,523 & 0,438 & 0,319 & 0,192 & 0,971 & 0,875 & 0,780 & 0,632 & 0,417 \\
\hline 1,2 & 0,668 & 0,563 & 0,461 & 0,324 & 0,188 & 0,958 & 0,830 & 0,714 & 0,544 & 0,330 \\
\hline 1,4 & 0,717 & 0,593 & 0,476 & 0,325 & 0,183 & 0,943 & 0,782 & 0,649 & 0,468 & 0,266 \\
\hline 1,6 & 0,756 & 0,615 & 0,485 & 0,322 & 0,178 & 0,926 & 0,735 & 0,589 & 0,404 & 0,218 \\
\hline 1,8 & 0,788 & 0,632 & 0,490 & 0,318 & 0,173 & 0,906 & 0,688 & 0,534 & 0,350 & 0,182 \\
\hline 2,0 & 0,813 & 0,643 & 0,492 & 0,313 & 0,168 & 0,885 & 0,642 & 0,484 & 0,305 & 0,155 \\
\hline 3,0 & 0,882 & 0,662 & 0,479 & 0,285 & 0,147 & 0,757 & 0,456 & 0,307 & 0,169 & 0,080 \\
\hline 4,0 & 0,903 & 0,655 & 0,455 & 0,258 & 0,131 & 0,622 & 0,333 & 0,209 & 0,107 & 0,050 \\
\hline 5,0 & 0,909 & 0,640 & 0,431 & 0,237 & 0,119 & 0,510 & 0,255 & 0,152 & 0,074 & 0,035 \\
\hline 6,0 & 0,909 & 0,625 & 0,409 & 0,219 & 0,110 & 0,425 & 0,202 & 0,115 & 0,055 & 0,026 \\
\hline 7,0 & 0,907 & 0,612 & 0,390 & 0,205 & 0,103 & 0,362 & 0,166 & 0,091 & 0,043 & 0,020 \\
\hline 8,0 & 0,906 & 0,599 & 0,373 & 0,193 & 0,096 & 0,315 & 0,140 & 0,074 & 0,034 & 0,016 \\
\hline 9,0 & 0,904 & 0,589 & 0,358 & 0,183 & 0,091 & 0,278 & 0,120 & 0,062 & 0,028 & 0,013 \\
\hline 10,0 & 0,903 & 0,579 & 0,345 & 0,174 & 0,087 & 0,249 & 0,105 & 0,053 & 0,024 & 0,011 \\
\hline
\end{tabular}


Tabela 43 - Efetividade de temperatura e fator de correção do trocador de calor de casco e tubo 1-1 tipo TEMA E em escoamento paralelo com cinco chicanas

\begin{tabular}{|c|c|c|c|c|c|c|c|c|c|c|}
\hline & \multicolumn{5}{|c|}{$P$} & \multicolumn{5}{|c|}{$F$} \\
\hline$U T T$ & 0,1 & 0,5 & 1,0 & 2,0 & 4,0 & 0,1 & 0,5 & 1,0 & 2,0 & 4,0 \\
\hline 0,1 & 0,095 & 0,093 & 0,091 & 0,086 & 0,079 & 1,000 & 0,998 & 0,997 & 0,993 & 0,987 \\
\hline 0,2 & 0,180 & 0,173 & 0,165 & 0,150 & 0,126 & 0,999 & 0,993 & 0,987 & 0,974 & 0,950 \\
\hline 0,4 & 0,324 & 0,301 & 0,275 & 0,233 & 0,173 & 0,995 & 0,974 & 0,951 & 0,906 & 0,824 \\
\hline 0,6 & 0,439 & 0,396 & 0,350 & 0,279 & 0,190 & 0,988 & 0,945 & 0,896 & 0,813 & 0,678 \\
\hline 0,8 & 0,532 & 0,466 & 0,400 & 0,304 & 0,196 & 0,979 & 0,906 & 0,832 & 0,715 & 0,551 \\
\hline 1,0 & 0,607 & 0,518 & 0,433 & 0,317 & 0,199 & 0,967 & 0,861 & 0,764 & 0,625 & 0,454 \\
\hline 1,2 & 0,666 & 0,557 & 0,455 & 0,325 & 0,199 & 0,953 & 0,813 & 0,697 & 0,546 & 0,382 \\
\hline 1,4 & 0,714 & 0,586 & 0,470 & 0,329 & 0,200 & 0,936 & 0,764 & 0,634 & 0,480 & 0,328 \\
\hline 1,6 & 0,753 & 0,607 & 0,480 & 0,331 & 0,200 & 0,9 & 0,716 & 0,578 & 0,426 & 0,287 \\
\hline 1,8 & 0,784 & 0,623 & 0,487 & 0,332 & 0,199 & 0,896 & 0,669 & 0,528 & 0,382 & 0,255 \\
\hline 2,0 & 0,809 & 0,634 & 0,492 & & 0,199 & & & & 45 & 0,229 \\
\hline 3,0 & 0,876 & 0,660 & 0,499 & 0,333 & 0,198 & 0,739 & 0,452 & 0,332 & 0,230 & 0,150 \\
\hline 4,0 & 0,898 & 0,665 & 0,500 & 0,333 & 0,196 & 0,609 & 0,3 & 0,250 & 0,173 & 0,110 \\
\hline 5,0 & 0,906 & 0,666 & 0,500 & 0,332 & 0,194 & 0,504 & 0,277 & 0,200 & 0,138 & 0,085 \\
\hline 6,0 & 0,908 & 0,667 & 0,500 & 0,332 & 0,191 & 0,424 & 0,231 & 0,167 & 0,114 & 0,069 \\
\hline 7,0 & 0,909 & 0,667 & 0,500 & 0,331 & 0,188 & 0,365 & 0,198 & 0,143 & 0,097 & 0,057 \\
\hline 8,0 & 0,909 & 0,667 & 0,500 & 0,330 & 0,185 & 0,320 & 0,173 & 0,125 & 0,085 & 0,048 \\
\hline 9,0 & 0,909 & 0,667 & 0,500 & 0,328 & 0,182 & 0,284 & 0,154 & 0,111 & 0,075 & 0,041 \\
\hline 10,0 & 0,909 & 0,667 & 0,500 & 0,327 & 0,179 & 0,256 & 0,139 & 0,100 & 0,066 & 0,035 \\
\hline
\end{tabular}

Tabela 44 - Efetividade de temperatura e fator de correção do trocador de calor de casco e tubo 1-1 tipo TEMA E em escoamento paralelo com dez chicanas

\begin{tabular}{|c|c|c|c|c|c|c|c|c|c|c|}
\hline & \multicolumn{5}{|c|}{$P$} & \multicolumn{5}{|c|}{$F$} \\
\hline $\mathrm{NUT}^{R}$ & 0,1 & 0,5 & 1,0 & 2,0 & 4,0 & 0,1 & 0,5 & 1,0 & 2,0 & 4,0 \\
\hline 0,1 & 0,095 & 0,093 & 0,091 & 0,086 & 0,079 & 1,000 & 0,998 & 0,997 & 0,993 & 0,987 \\
\hline 0,2 & 0,180 & 0,173 & 0,165 & 0,150 & 0,126 & 0,999 & 0,993 & 0,987 & 0,974 & 0,949 \\
\hline 0,4 & 0,324 & 0,301 & 0,275 & 0,233 & 0,173 & 0,995 & 0,974 & 0,950 & 0,905 & 0,823 \\
\hline 0,6 & 0,439 & 0,396 & 0,349 & 0,278 & 0,190 & 0,988 & 0,944 & 0,895 & 0,812 & 0,677 \\
\hline 0,8 & 0,532 & 0,466 & 0,399 & 0,303 & 0,196 & 0,979 & 0,905 & 0,831 & 0,714 & 0,550 \\
\hline 1,0 & 0,607 & 0,518 & 0,433 & 0,317 & 0,199 & 0,967 & 0,860 & 0,762 & 0,623 & 0,454 \\
\hline 1,2 & 0,666 & 0,557 & 0,455 & 0,324 & 0,200 & 0,952 & 0,812 & 0,695 & 0,545 & 0,383 \\
\hline 1,4 & 0,714 & 0,585 & 0,470 & 0,328 & 0,200 & 0,935 & 0,763 & 0,633 & 0,480 & 0,329 \\
\hline 1,6 & 0,753 & 0,606 & 0,480 & 0,331 & 0,200 & 0,916 & 0,714 & 0,577 & 0,426 & 0,289 \\
\hline 1,8 & 0,784 & 0,622 & 0,487 & 0,332 & 0,200 & 0,895 & 0,667 & 0,526 & 0,382 & 0,257 \\
\hline 2,0 & 0,808 & 0,634 & 0,491 & 0,333 & 0,200 & 0,871 & 0,623 & 0,482 & 0,345 & 0,231 \\
\hline 3,0 & 0,876 & 0,659 & 0,499 & 0,333 & 0,200 & 0,738 & 0,451 & 0,332 & 0,231 & 0,154 \\
\hline 4,0 & 0,898 & 0,665 & 0,500 & 0,333 & 0,200 & 0,608 & 0,345 & 0,250 & 0,173 & 0,116 \\
\hline 5,0 & 0,905 & 0,666 & 0,500 & 0,333 & 0,200 & 0,503 & 0,277 & 0,200 & 0,139 & 0,093 \\
\hline 6,0 & 0,908 & 0,667 & 0,500 & 0,333 & 0,200 & 0,424 & 0,231 & 0,167 & 0,116 & 0,077 \\
\hline 7,0 & 0,909 & 0,667 & 0,500 & 0,333 & 0,201 & 0,365 & 0,198 & 0,143 & 0,099 & 0,066 \\
\hline 8,0 & 0,909 & 0,667 & 0,500 & 0,333 & 0,201 & 0,320 & 0,173 & 0,125 & 0,087 & 0,058 \\
\hline 9,0 & 0,909 & 0,667 & 0,500 & 0,333 & 0,201 & 0,284 & 0,154 & 0,111 & 0,077 & 0,052 \\
\hline 10,0 & 0,909 & 0,667 & 0,500 & 0,333 & 0,201 & 0,256 & 0,139 & 0,100 & 0,069 & 0,047 \\
\hline
\end{tabular}


e tubo com quatro chicanas, $R=1,0$ e $P=0,75$, o fator de correção de acordo com Caglayan e Buthod (1976) é 0,95, que é uma diferença de 0,00169 \% em comparação com os resultados do presente algoritmo. Assim, a partir dos resultados apresentados na Tabela 45. conclui-se que o procedimento computacional implementado neste trabalho produz resultados satisfatórios.

Tabela 45 - Comparação do fator de correção de um trocador de calor de casco e tubo 1-1 tipo TEMA E em escoamento contracorrente com diversas chicanas

\begin{tabular}{|c|c|c|c|c|c|c|c|}
\hline & & & \multicolumn{5}{|c|}{$N_{c h}$} \\
\hline & $P$ & $R$ & 1 & 2 & 3 & 4 & 6 \\
\hline Caglayan e Buthod (1976) & 0,70 & 0,6 & 0,94 & 0,97 & 0,99 & 0,99 & 1,00 \\
\hline Presente trabalho: algoritmo & 0,70 & 0,6 & 0,94 & 0,97 & 0,99 & 0,99 & 1,00 \\
\hline Presente trabalho: equações aproximadas & 0,70 & 0,6 & 0,94 & 0,97 & 0,98 & 0,99 & 0,99 \\
\hline Caglayan e Buthod (1976) & 0,70 & 1,0 & 0,84 & 0,92 & 0,95 & 0,97 & 0,99 \\
\hline Presente trabalho: algoritmo & 0,70 & 1,0 & 0,84 & 0,92 & 0,95 & 0,97 & 0,98 \\
\hline Presente trabalho: equações aproximadas & 0,70 & 1,0 & 0,84 & 0,92 & 0,94 & 0,96 & 0,98 \\
\hline Caglayan e Buthod (1976) & 0,35 & 2,0 & 0,955 & 0,99 & - & - & - \\
\hline Presente trabalho: algoritmo & 0,35 & 2,0 & 0,957 & 0,98 & - & - & - \\
\hline Presente trabalho: equações aproximadas & 0,35 & 2,0 & 0,957 & 0,98 & - & - & - \\
\hline
\end{tabular}

Para muitas configurações de trocadores de calor de casco e tubo, diagramas estão disponíveis na literatura e são muito efetivos para o cálculo manual. Entretanto, estas soluções possuem muitos erros que podem influenciar o cálculo e o desenvolvimento do trocador de calor. Alguns deste estudos foram realizados por Nagle (1933) e Shah e Pignotti (1997), que obtiveram diagramas para o rápido cálculo da diferença de temperatura média.

O desenvolvimento de expressões matemáticas analíticas de trocador de calor de casco e tubo 1-1 tipo TEMA E é muito difícil de ser obtido, por causa de sua complexidade. Assim, relações aproximadas de um trocador de calor de casco e tubo em escoamento contracorrente e considerando o fluido do casco misturado na saída de cada chicana são obtidos usando o Matlab 2015a e o algoritmo desenvolvido no presente trabalho. São geradas expressões matemáticas similares às desenvolvidas por Spang e Roetzel (1995) e apresentadas na Equação 5.64 , onde cada configuração de escoamento possui três coeficientes individuais $(a, b, c)$, considerando uma razão de temperatura constante. Na Tabela 46 são apresentados os coeficientes para trocadores de calor de casco e tubo em escoamento contracorrente e na Tabela 47 são mostrados os coeficientes para trocadores em escoamento paralelo. Os coeficiente são determinados utilizando uma ferramenta do Matlab 2015a, baseado nos resultados encontrados com o desenvolvimento do algoritmo deste trabalho. As expressões são calculadas variando o número de tubos e utilizando um erro relativo máximo de 0,40\%. Na Tabela 48 são apresentados os valores de erro relativo médio e de intervalo de confiança $95 \%$ destas expressões matemáticas aproximadas. Observam-se os baixos valores do erro relativo médio para trocadores de calor em escoamento contracorrente. Para os trocadores de calor em escoamento paralelo, o erro relativo médio é um pouco maior, por exemplo, para equipamentos com duas chicanas, o erro relativo médio é 
de $-0,0443 \%$. Os coeficientes são válidos para $F \geq 0,75$ e $0,1 \leq R \leq 4,0$.

$$
F=\frac{1}{\left(1+a N U T^{b}\right)^{c}}
$$

Tabela 46 - Coeficientes da expressão matemática aproximada em função da razão de temperatura e do número de chicanas para um trocador de calor de casco e tubo 1-1 tipo TEMA E em escoamento contracorrente

\begin{tabular}{|c|c|ccc|c|}
\hline Tipo- $N_{c h}$ & $R$ & $a$ & $b$ & $c$ & $\delta_{\max }[\%]$ \\
\hline \multirow{5}{*}{$1-1-1$} & 0,10 & 0,03042 & 1,965 & 0,1092 & 0,14 \\
& 0,50 & 0,09232 & 1,912 & 0,2045 & 0,01 \\
& 1,00 & 0,16710 & 1,875 & 0,2277 & 0,06 \\
& 2,00 & 0,37600 & 1,908 & 0,1967 & 0,02 \\
& 4,00 & 0,92140 & 1,911 & 0,1550 & 0,01 \\
\hline \multirow{5}{*}{$1-1-2$} & 0,10 & 0,01250 & 1,927 & 0,1236 & 0,17 \\
& 0,50 & 0,03799 & 1,906 & 0,2256 & 0,02 \\
& 1,00 & 0,07394 & 1,924 & 0,2305 & 0,01 \\
& 2,00 & 0,16550 & 1,937 & 0,2049 & 0,01 \\
& 4,00 & 0,43020 & 1,954 & 0,1563 & 0,02 \\
\hline \multirow{5}{*}{$1-1-5$} & 0,15 & 0,004102 & 1,869 & 0,1747 & 0,08 \\
& 0,50 & 0,00957 & 1,903 & 0,2428 & 0,02 \\
& 1,00 & 0,01845 & 1,927 & 0,2460 & 0,01 \\
& 2,00 & 0,04132 & 1,946 & 0,2164 & 0,01 \\
& 4,00 & 0,10930 & 1,974 & 0,1611 & 0,02 \\
\hline \multirow{5}{*}{$1-1-10$} & 0,25 & 0,001712 & 1,874 & 0,2258 & 0,08 \\
& 0,50 & 0,00288 & 1,904 & 0,2548 & 0,01 \\
& 1,00 & 0,00552 & 1,930 & 0,2557 & 0,01 \\
& 2,00 & 0,01231 & 1,951 & 0,2232 & 0,01 \\
& 4,00 & 0,03235 & 1,979 & 0,1651 & 0,02 \\
\hline \multirow{3}{*}{$1-1-30$} & 0,50 & 0,0003546 & 1,893 & 0,2993 & 0,40 \\
& 1,00 & 0,00069 & 1,928 & 0,2811 & 0,04 \\
& 2,00 & 0,00153 & 1,946 & 0,2417 & 0,02 \\
\hline$\delta=100$ & $\left(F_{t h}-F\right) / F_{t h}$ & & &
\end{tabular}

Os resultados encontrados utilizando estas expressões aproximadas são comparados com os dados de Caglayan e Buthod (1976) e apresentados na Tabela 45. Para este comparação, o maior valor do erro relativo é 1,0 \% . Note que são utilizadas uma interpolação linear para a razão de temperatura, $R$, e uma interpolação logarítmica para o número de chicanas, $N_{c h}$, para encontrar o fator de correção de algumas configurações de trocadores de calor que não são apresentadas na Tabela 46. Como pode ser observado, as relações aproximadas podem ser muito úteis para o projeto e desenvolvimento de trocadores de calor. O procedimento computacional proposto também pode ser utilizado para obter expressões para outros arranjos de trocadores de calor.

Na Figura 42 é apresentado o comportamento do fator de correção em função da razão de temperatura e da efetividade de temperatura para um trocador de calor de casco e tubo 1-1 tipo TEMA E em escoamento contracorrente para uma, três e cinco chicanas. Nesta análise, a saída de cada chicana do fluido do lado do casco é considerada misturada e não misturada. O grau de condição de mistura entre as chicanas de um trocador de calor 
Tabela 47 - Coeficientes da expressão matemática aproximada em função da razão de temperatura e do número de chicanas para um trocador de calor de casco e tubo 1-1 tipo TEMA E em escoamento paralelo

\begin{tabular}{|c|c|c|c|c|c|}
\hline Tipo- $N_{c h}$ & $R$ & $a$ & $b$ & $c$ & $\delta_{\max }[\%]$ \\
\hline \multirow{5}{*}{$1-1-1$} & 0,10 & 0,0237 & 2,168 & 1,2190 & $-0,11$ \\
\hline & 0,50 & 0,1659 & 1,998 & 0,8719 & 0,00 \\
\hline & 1,00 & 0,3495 & 1,997 & 0,8264 & $-0,02$ \\
\hline & 2,00 & 0,7288 & 2,031 & 0,8296 & 0,02 \\
\hline & 4,00 & 0,8208 & 2,039 & 1,5230 & $-0,02$ \\
\hline \multirow{5}{*}{$1-1-2$} & 0,10 & 0,0154 & 2,086 & 2,0790 & $-0,04$ \\
\hline & 0,50 & 0,2144 & 2,011 & 0,7383 & $-0,03$ \\
\hline & 1,00 & 0,4799 & 2,015 & 0,6649 & $-0,01$ \\
\hline & 2,00 & 0,7824 & 1,995 & 0,8007 & $-0,02$ \\
\hline & 4,00 & 0,9875 & 1,981 & 1,2490 & $-0,05$ \\
\hline \multirow{5}{*}{$1-1-5$} & 0,10 & 0,0207 & 2,088 & 1,6250 & $-0,04$ \\
\hline & 0,50 & 0,2298 & 2,009 & 0,7212 & $-0,01$ \\
\hline & 1,00 & 0,4847 & 2,005 & 0,6825 & 0,00 \\
\hline & 2,00 & 0,7704 & 1,982 & 0,8366 & 0,02 \\
\hline & 4,00 & 1,0020 & 1,972 & 1,2680 & $-0,05$ \\
\hline \multirow{5}{*}{$1-1-10$} & 0,10 & 0,0226 & 2,092 & 1,4960 & $-0,07$ \\
\hline & 0,50 & 0,2350 & 2,010 & 0,7129 & 0,00 \\
\hline & 1,00 & 0,4942 & 2,005 & 0,6763 & 0,00 \\
\hline & 2,00 & 0,7736 & 1,980 & 0,8385 & $-0,03$ \\
\hline & 4,00 & 1,0030 & 1,970 & 1,2730 & $-0,05$ \\
\hline \multirow{5}{*}{$1-1-30$} & 0,10 & 0,0229 & 2,091 & 1,4880 & $-0,04$ \\
\hline & 0,50 & 0,2364 & 2,010 & 0,7111 & $-0,01$ \\
\hline & 1,00 & 0,4983 & 2,005 & 0,6733 & 0,00 \\
\hline & 2,00 & 0,7747 & 1,979 & 0,8393 & $-0,03$ \\
\hline & 4,00 & 1,0040 & 1,968 & 1,2740 & 0,05 \\
\hline
\end{tabular}

Tabela 48 - Sumário do erro relativo médio e do intervalo de confiança $95 \%$ das expressões aproximadas apresentadas na Equação 5.64 e Tabelas 46 e 47 para trocadores de calor de casco e tubo em escoamentos contracorrente e paralelo

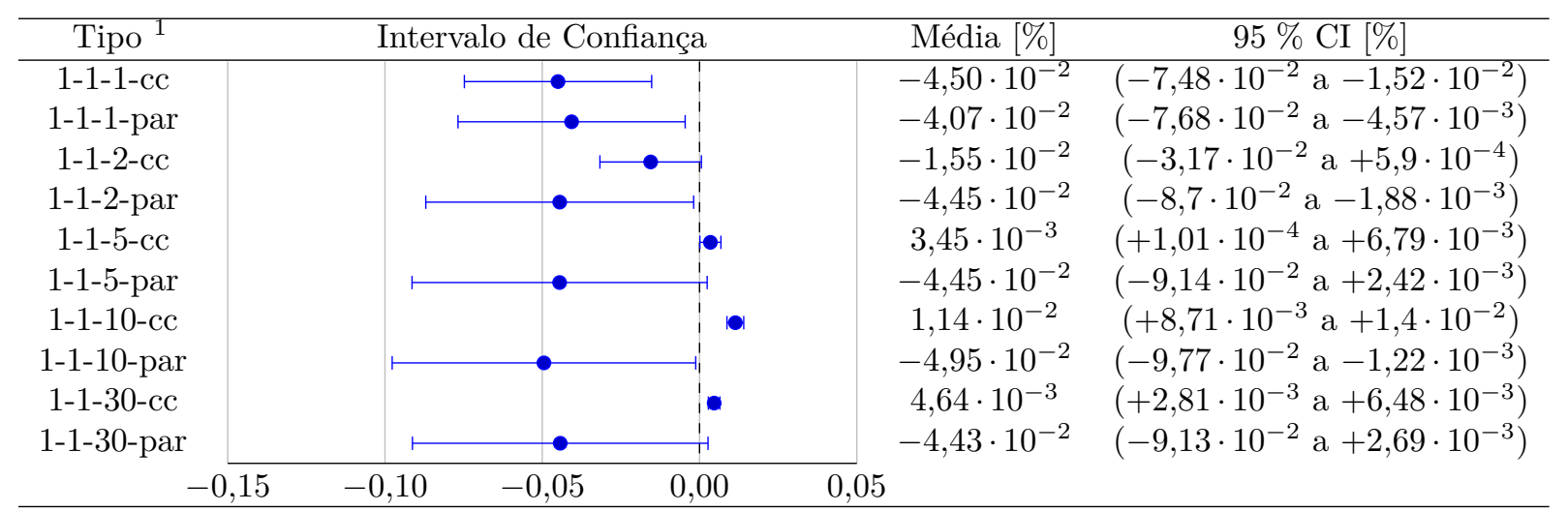

${ }^{1}$ cc: contracorrente; par: paralelo 
real pode ser definido utilizando uma interpolação linear entre as condições de fluidos misturado e não misturado. Este estudo não é objetivo do presente trabalho, porém é considerado de extrema importância para o cálculo de um trocador de calor em condições reais. Nota-se que a condição de fluido não misturada possui um maior valor de efetividade de temperatura e fator de correção. Esta condição implica que o fluido do lado do casco permanece não misturado quando escoa entre as chicanas. A outra condição de mistura pode ser simulada considerando um trocador de calor de fluxo cruzado com apenas um tubo. Este caso corresponde a um fluido do casco completamente misturado. Como observado na Figura 42, esta condição produz valores menores de efetividade de temperatura e fator de correção. Entre estes dois limites de condições de mistura é encontrada a condição de mistura mencionada anteriormente e simulada por Caglayan e Buthod (1976) e outros autores. Como esperado, os resultados para este tipo de mistura assume valores intermediários do fator de correção, $F$, e da efetividade de temperatura, $P$, em comparação com as outras condições. Como observado na Figura 42 , para grandes valores de $R$, a diferença causada pelo grau de mistura do fluido é muito pequena para qualquer número de chicana. A hipótese do efeito de mistura pode ser realizada devido à disponibilidade do presente procedimento computacional, que permite a realização deste tipo de análise.

Nas Tabelas 49, 50 e 51 são apresentados como referência os dados de fator de correção para diversos valores de $P$ e $R$ em função do número de chicanas considerando trocadores de calor de casco e tubo 1-1 tipo TEMA E em escoamento contracorrente com as três condições de grau mistura do fluido do casco: misturado entre as chicanas, não misturado entre as chicanas e completamente misturado. A determinação do fator de correção é um processo iterativo, no qual o número de unidades de transferência, NUT, é estimado inicialmente e ajustado através de uma correção baseada na efetividade de temperatura. Com isso, pode-se determinar os valores do fator de correção apresentados nas Tabelas 49, 50 e 51. Para a configuração de grau de mistura considerando o fluido do casco misturado entre as chicanas, o caso 4A de Pignotti e Cordero (1983a) é utilizado. Já para a condição de grau de mistura com o fluido do casco não misturado, o caso 4B de Pignotti e Cordero (1983a) é considerado. Conforme já citado anteriormente, a condição de fluido do casco completamente misturado pode ser simulada considerando um trocador de calor de fluxo cruzado com apenas um tubo. Este é o caso mais simples, onde expressões analíticas de trocadores de calor de fluxo cruzado estão disponíveis na literatura e podem ser utilizadas em trocadores de casco e tubo considerando o fluido do casco completamente misturado em todo o trocador de calor (linha pontilhada da Figura 42). Cabezas-Gómez, Navarro e Saiz-Jabardo (2007), Cabezas-Gómez, Navarro e Saiz-Jabardo (2015) e os outros trabalhos citados anteriormente apresentaram algumas relações analíticas para o cálculo da efetividade, que podem ser utilizadas em trocadores de calor de casco e tubo com uma a três chicanas. Novas equações são obtidas com o presente algoritmo para os casos com número de chicanas superiores a quatro. Estas 


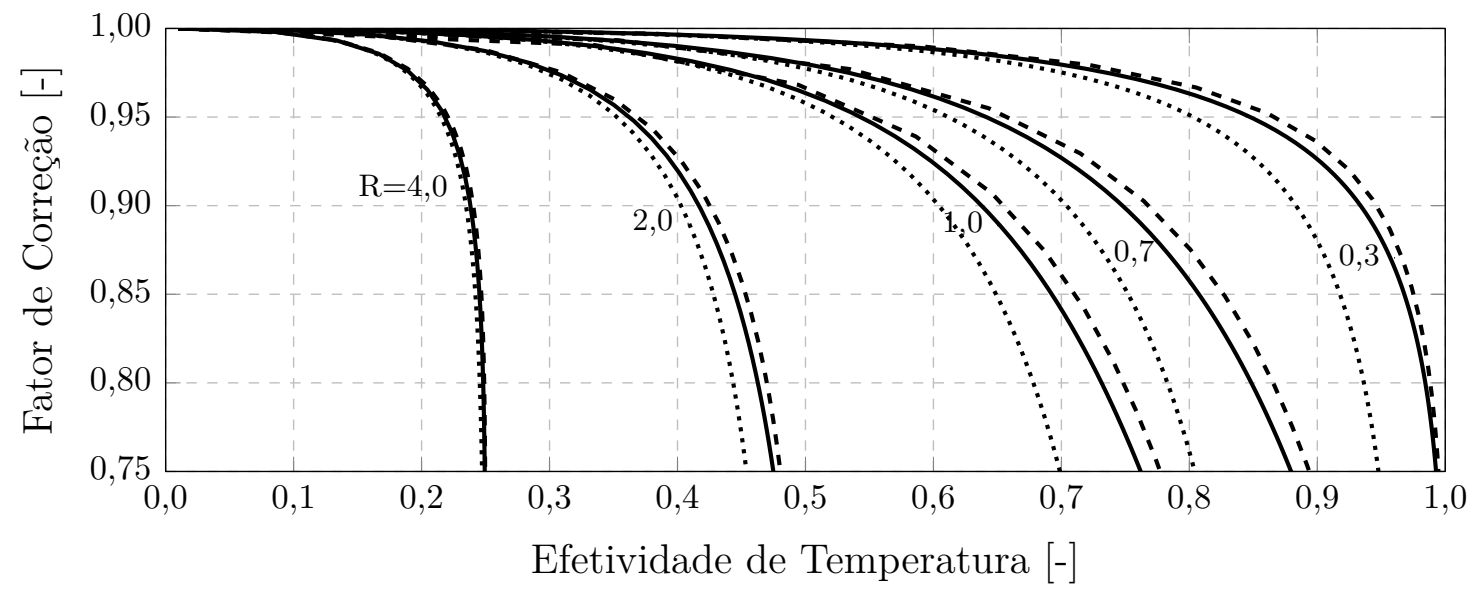

(a) Trocador de calor de casco e tubo com uma chicana

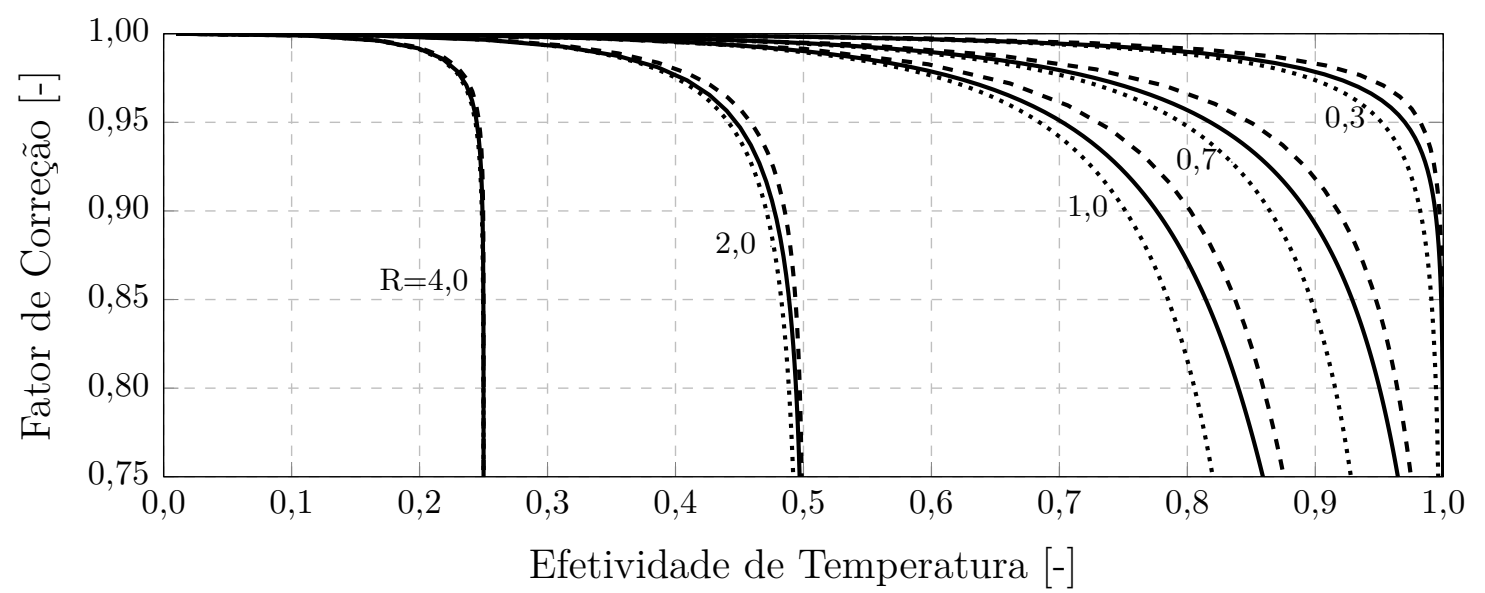

(b) Trocador de calor de casco e tubo com três chicanas

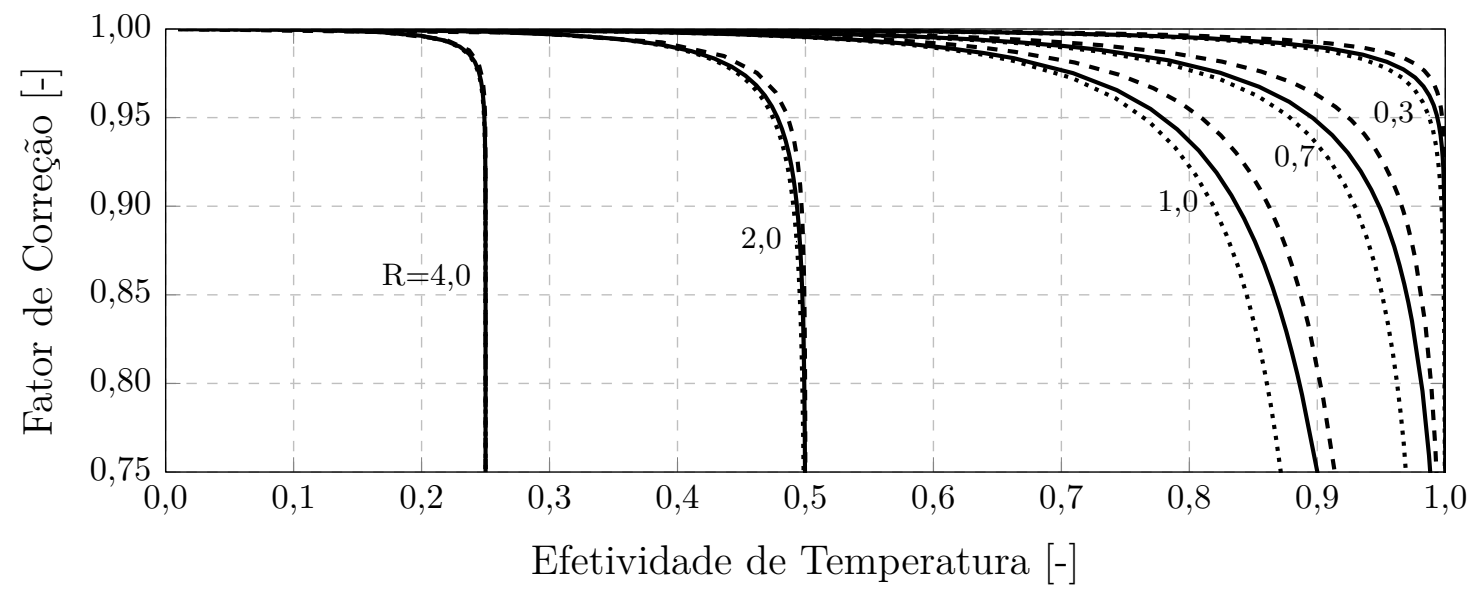

(c) Trocador de calor de casco e tubo com cinco chicanas

Figura 42 - Fator de correção de um trocador de calor de casco e tubo 1-1 tipo TEMA E em escoamento contracorrente considerando três condições de grau de mistura do fluido do casco: misturado entre as chicanas (-), não misturado entre as chicanas (----) e completamente misturado (.........) 
expressões matemáticas, que são apresentadas na Tabela 32 em função da efetividade de temperatura, podem ser utilizadas para o cálculo inicial de trocadores de calor de casco e tubo com poucas chicanas, considerando o caso mais conservativo, chamado de fluido do casco completamente misturado.

Tabela 49 - Fator de correção de um trocador de calor de casco e tubo 1-1 tipo TEMA E em escoamento contracorrente em função do número de chicanas, efetividade de temperatura e razão de temperatura considerando fluido do casco misturado entre as chicanas

\begin{tabular}{|c|c|c|c|c|c|c|c|c|c|c|}
\hline \multirow{2}{*}{$P$} & \multirow{2}{*}{$R$} & \multicolumn{9}{|c|}{$N_{c h}$} \\
\hline & & 1 & 2 & 3 & 4 & 5 & 6 & 10 & 20 & 30 \\
\hline \multirow{6}{*}{0,4} & 0,1 & 0,999 & 1,000 & 1,000 & 1,000 & 1,000 & 1,000 & 1,000 & 1,000 & 1,000 \\
\hline & 0,3 & 0,996 & 0,998 & 0,999 & 0,999 & 1,000 & 1,000 & 1,000 & 1,000 & 1,000 \\
\hline & 0,5 & 0,994 & 0,997 & 0,998 & 0,999 & 0,999 & 0,999 & 1,000 & 1,000 & 1,000 \\
\hline & 0,7 & 0,990 & 0,995 & 0,997 & 0,998 & 0,999 & 0,999 & 1,000 & 1,000 & 1,000 \\
\hline & 1,0 & 0,983 & 0,992 & 0,996 & 0,997 & 0,998 & 0,999 & 0,999 & 1,000 & 1,000 \\
\hline & 2,0 & 0,920 & 0,961 & 0,977 & 0,985 & 0,989 & 0,992 & 0,997 & 0,999 & 1,000 \\
\hline \multirow{6}{*}{0,5} & 0,1 & 0,998 & 0,999 & 0,999 & 1,000 & 1,000 & 1,000 & 1,000 & 1,000 & 1,000 \\
\hline & 0,3 & 0,993 & 0,997 & 0,998 & 0,999 & 0,999 & 0,999 & 1,000 & 1,000 & 1,000 \\
\hline & 0,5 & 0,988 & 0,994 & 0,997 & 0,998 & 0,999 & 0,999 & 1,000 & 1,000 & 1,000 \\
\hline & 0,7 & 0,980 & 0,991 & 0,995 & 0,997 & 0,998 & 0,998 & 0,999 & 1,000 & 1,000 \\
\hline & 1,0 & 0,964 & 0,983 & 0,990 & 0,994 & 0,996 & 0,997 & 0,999 & 1,000 & 1,000 \\
\hline & 2,0 & - & - & - & - & - & - & - & - & - \\
\hline \multirow{6}{*}{0,6} & 0,1 & 0,997 & 0,998 & 0,999 & 0,999 & 1,000 & 1,000 & 1,000 & 1,000 & 1,000 \\
\hline & 0,3 & 0,988 & 0,995 & 0,997 & 0,998 & 0,999 & 0,999 & 1,000 & 1,000 & 1,000 \\
\hline & 0,5 & 0,977 & 0,989 & 0,994 & 0,996 & 0,997 & 0,998 & 0,999 & 1,000 & 1,000 \\
\hline & 0,7 & 0,962 & 0,982 & 0,990 & 0,993 & 0,995 & 0,997 & 0,999 & 1,000 & 1,000 \\
\hline & 1,0 & 0,924 & 0,964 & 0,979 & 0,986 & 0,990 & 0,993 & 0,997 & 0,999 & 1,000 \\
\hline & 2,0 & - & - & - & - & - & - & - & - & - \\
\hline \multirow{6}{*}{0,7} & 0,1 & 0,994 & 0,997 & 0,998 & 0,999 & 0,999 & 0,999 & 1,000 & 1,000 & 1,000 \\
\hline & 0,3 & 0,980 & 0,991 & 0,994 & 0,996 & 0,997 & 0,998 & 0,999 & 1,000 & 1,000 \\
\hline & 0,5 & 0,958 & 0,981 & 0,989 & 0,993 & 0,995 & 0,996 & 0,998 & 1,000 & 1,000 \\
\hline & 0,7 & 0,927 & 0,965 & 0,979 & 0,987 & 0,991 & 0,993 & 0,997 & 0,999 & 1,000 \\
\hline & 1,0 & 0,842 & 0,919 & 0,951 & 0,968 & 0,977 & 0,983 & 0,993 & 0,998 & 0,999 \\
\hline & 2,0 & - & - & - & - & - & - & - & - & - \\
\hline \multirow{6}{*}{0,8} & 0,1 & 0,990 & 0,995 & 0,997 & 0,998 & 0,999 & 0,999 & 1,000 & 1,000 & 1,000 \\
\hline & 0,3 & 0,963 & 0,983 & 0,990 & 0,993 & 0,995 & 0,997 & 0,999 & 1,000 & 1,000 \\
\hline & 0,5 & 0,922 & 0,963 & 0,978 & 0,986 & 0,990 & 0,992 & 0,997 & 0,999 & 1,000 \\
\hline & 0,7 & 0,858 & 0,928 & 0,957 & 0,972 & 0,980 & 0,985 & 0,994 & 0,998 & 0,999 \\
\hline & 1,0 & 0,673 & 0,800 & 0,872 & 0,913 & 0,937 & 0,953 & 0,980 & 0,994 & 0,997 \\
\hline & 2,0 & - & - & - & - & - & - & - & - & - \\
\hline \multirow{6}{*}{0,9} & 0,1 & 0,981 & 0,991 & 0,995 & 0,996 & 0,997 & 0,998 & 0,999 & 1,000 & 1,000 \\
\hline & 0,3 & 0,926 & 0,964 & 0,979 & 0,986 & 0,990 & 0,993 & 0,997 & 0,999 & 1,000 \\
\hline & 0,5 & 0,840 & 0,918 & 0,950 & 0,967 & 0,976 & 0,982 & 0,993 & 0,998 & 0,999 \\
\hline & 0,7 & 0,710 & 0,830 & 0,893 & 0,928 & 0,948 & 0,961 & 0,983 & 0,995 & 0,998 \\
\hline & 1,0 & 0,390 & 0,501 & 0,601 & 0,684 & 0,750 & 0,802 & 0,908 & 0,972 & 0,987 \\
\hline & 2,0 & - & - & - & - & - & - & - & - & - \\
\hline
\end{tabular}


Tabela 50 - Fator de correção de um trocador de calor de casco e tubo 1-1 tipo TEMA E em escoamento contracorrente em função do número de chicanas, efetividade de temperatura e razão de temperatura considerando fluido do casco não misturado entre as chicanas

\begin{tabular}{|c|c|c|c|c|c|c|c|c|c|c|}
\hline \multirow{2}{*}{$P$} & \multirow{2}{*}{$R$} & \multicolumn{9}{|c|}{$N_{c h}$} \\
\hline & & 1 & 2 & 3 & 4 & 5 & 6 & 10 & 20 & 30 \\
\hline \multirow{6}{*}{0,4} & 0,1 & 0,999 & 1,000 & 1,000 & 1,000 & 1,000 & 1,000 & 1,000 & 1,000 & 1,000 \\
\hline & 0,3 & 0,997 & 0,999 & 0,999 & 0,999 & 1,000 & 1,000 & 1,000 & 1,000 & 1,000 \\
\hline & 0,5 & 0,994 & 0,997 & 0,998 & 0,999 & 0,999 & 1,000 & 1,000 & 1,000 & 1,000 \\
\hline & 0,7 & 0,991 & 0,996 & 0,998 & 0,998 & 0,999 & 0,999 & 1,000 & 1,000 & 1,000 \\
\hline & 1,0 & 0,984 & 0,993 & 0,996 & 0,997 & 0,998 & 0,999 & 0,999 & 1,000 & 1,000 \\
\hline & 2,0 & 0,928 & 0,966 & 0,980 & 0,987 & 0,991 & 0,993 & 0,997 & 0,999 & 1,000 \\
\hline \multirow{6}{*}{0,5} & 0,1 & 0,998 & 0,999 & 1,000 & 1,000 & 1,000 & 1,000 & 1,000 & 1,000 & 1,000 \\
\hline & 0,3 & 0,994 & 0,997 & 0,998 & 0,999 & 0,999 & 1,000 & 1,000 & 1,000 & 1,000 \\
\hline & 0,5 & 0,989 & 0,995 & 0,997 & 0,998 & 0,999 & 0,999 & 1,000 & 1,000 & 1,000 \\
\hline & 0,7 & 0,982 & 0,992 & 0,995 & 0,997 & 0,998 & 0,998 & 0,999 & 1,000 & 1,000 \\
\hline & 1,0 & 0,967 & 0,985 & 0,992 & 0,995 & 0,996 & 0,997 & 0,999 & 1,000 & 1,000 \\
\hline & 2,0 & - & - & - & - & - & - & - & - & - \\
\hline \multirow{6}{*}{0,6} & 0,1 & 0,997 & 0,999 & 0,999 & 1,000 & 1,000 & 1,000 & 1,000 & 1,000 & 1,000 \\
\hline & 0,3 & 0,989 & 0,995 & 0,997 & 0,998 & 0,999 & 0,999 & 1,000 & 1,000 & 1,000 \\
\hline & 0,5 & 0,979 & 0,991 & 0,995 & 0,997 & 0,998 & 0,998 & 0,999 & 1,000 & 1,000 \\
\hline & 0,7 & 0,966 & 0,985 & 0,991 & 0,994 & 0,996 & 0,997 & 0,999 & 1,000 & 1,000 \\
\hline & 1,0 & 0,933 & 0,970 & 0,982 & 0,989 & 0,992 & 0,994 & 0,998 & 0,999 & 1,000 \\
\hline & 2,0 & - & - & - & - & - & - & - & - & - \\
\hline \multirow{6}{*}{0,7} & 0,1 & 0,995 & 0,998 & 0,999 & 0,999 & 0,999 & 1,000 & 1,000 & 1,000 & 1,000 \\
\hline & 0,3 & 0,982 & 0,992 & 0,995 & 0,997 & 0,998 & 0,998 & 0,999 & 1,000 & 1,000 \\
\hline & 0,5 & 0,963 & 0,984 & 0,991 & 0,994 & 0,996 & 0,997 & 0,999 & 1,000 & 1,000 \\
\hline & 0,7 & 0,936 & 0,971 & 0,983 & 0,989 & 0,993 & 0,995 & 0,998 & 0,999 & 1,000 \\
\hline & 1,0 & 0,862 & 0,934 & 0,962 & 0,975 & 0,983 & 0,987 & 0,995 & 0,999 & 0,999 \\
\hline & 2,0 & - & - & - & - & - & - & - & - & - \\
\hline \multirow{6}{*}{0,8} & 0,1 & 0,991 & 0,996 & 0,998 & 0,999 & 0,999 & 0,999 & 1,000 & 1,000 & 1,000 \\
\hline & 0,3 & 0,968 & 0,986 & 0,992 & 0,995 & 0,996 & 0,997 & 0,999 & 1,000 & 1,000 \\
\hline & 0,5 & 0,932 & 0,970 & 0,982 & 0,989 & 0,992 & 0,994 & 0,999 & 0,999 & 1,000 \\
\hline & 0,7 & 0,876 & 0,942 & 0,967 & 0,979 & 0,985 & 0,989 & 0,997 & 0,999 & 0,999 \\
\hline & 1,0 & 0,702 & 0,838 & 0,903 & 0,936 & 0,955 & 0,967 & 0,983 & 0,996 & 0,998 \\
\hline & 2,0 & - & - & - & - & - & - & - & - & - \\
\hline \multirow{6}{*}{0,9} & 0,1 & 0,983 & 0,993 & 0,996 & 0,997 & 0,998 & 0,999 & 0,999 & 1,000 & 1,000 \\
\hline & 0,3 & 0,936 & 0,971 & 0,983 & 0,989 & 0,993 & 0,995 & 0,998 & 0,999 & 1,000 \\
\hline & 0,5 & 0,860 & 0,934 & 0,962 & 0,976 & 0,983 & 0,987 & 0,995 & 0,999 & 0,999 \\
\hline & 0,7 & 0,737 & 0,863 & 0,919 & 0,947 & 0,963 & 0,973 & 0,989 & 0,997 & 0,999 \\
\hline & 1,0 & 0,383 & 0,517 & 0,644 & 0,742 & 0,810 & 0,856 & 0,939 & 0,983 & 0,992 \\
\hline & 2,0 & - & - & - & - & - & - & - & - & - \\
\hline
\end{tabular}


Tabela 51 - Fator de correção de um trocador de calor de casco e tubo 1-1 tipo TEMA E em escoamento contracorrente em função do número de chicanas, efetividade de temperatura e razão de temperatura considerando fluido do casco completamente misturado nos compartimentos

\begin{tabular}{|c|c|c|c|c|c|c|c|c|c|c|}
\hline \multirow{2}{*}{$P$} & \multirow{2}{*}{$R$} & \multicolumn{9}{|c|}{$N_{c h}$} \\
\hline & & 1 & 2 & 3 & 4 & 5 & 6 & 10 & 20 & 30 \\
\hline \multirow{6}{*}{0,4} & 0,1 & 0,999 & 0,999 & 1,000 & 1,000 & 1,000 & 1,000 & 1,000 & 1,000 & 1,000 \\
\hline & 0,3 & 0,996 & 0,998 & 0,999 & 0,999 & 1,000 & 1,000 & 1,000 & 1,000 & 1,000 \\
\hline & 0,5 & 0,993 & 0,997 & 0,998 & 0,999 & 0,999 & 0,999 & 1,000 & 1,000 & 1,000 \\
\hline & 0,7 & 0,989 & 0,995 & 0,997 & 0,998 & 0,999 & 0,999 & 1,000 & 1,000 & 1,000 \\
\hline & 1,0 & 0,981 & 0,992 & 0,995 & 0,997 & 0,998 & 0,998 & 0,999 & 1,000 & 1,000 \\
\hline & 2,0 & 0,904 & 0,957 & 0,975 & 0,984 & 0,989 & 0,992 & 0,997 & 0,999 & 1,000 \\
\hline \multirow{6}{*}{0,5} & 0,1 & 0,998 & 0,999 & 0,999 & 1,000 & 1,000 & 1,000 & 1,000 & 1,000 & 1,000 \\
\hline & 0,3 & 0,993 & 0,997 & 0,998 & 0,999 & 0,999 & 0,999 & 1,000 & 1,000 & 1,000 \\
\hline & 0,5 & 0,986 & 0,994 & 0,997 & 0,998 & 0,998 & 0,999 & 1,000 & 1,000 & 1,000 \\
\hline & 0,7 & 0,977 & 0,990 & 0,994 & 0,996 & 0,998 & 0,998 & 0,999 & 1,000 & 1,000 \\
\hline & 1,0 & 0,958 & 0,982 & 0,990 & 0,993 & 0,995 & 0,997 & 0,999 & 1,000 & 1,000 \\
\hline & 2,0 & - & - & - & - & - & - & - & - & - \\
\hline \multirow{6}{*}{0,6} & 0,1 & 0,996 & 0,998 & 0,999 & 0,999 & 1,000 & 1,000 & 1,000 & 1,000 & 1,000 \\
\hline & 0,3 & 0,987 & 0,994 & 0,997 & 0,998 & 0,999 & 0,999 & 1,000 & 1,000 & 1,000 \\
\hline & 0,5 & 0,973 & 0,988 & 0,993 & 0,996 & 0,997 & 0,998 & 0,999 & 1,000 & 1,000 \\
\hline & 0,7 & 0,954 & 0,980 & 0,989 & 0,993 & 0,995 & 0,996 & 0,999 & 1,000 & 1,000 \\
\hline & 1,0 & 0,904 & 0,958 & 0,976 & 0,985 & 0,990 & 0,992 & 0,997 & 0,999 & 1,000 \\
\hline & 2,0 & - & - & - & - & - & - & - & - & - \\
\hline \multirow{6}{*}{0,7} & 0,1 & 0,993 & 0,997 & 0,998 & 0,999 & 0,999 & 0,999 & 1,000 & 1,000 & 1,000 \\
\hline & 0,3 & 0,975 & 0,989 & 0,994 & 0,996 & 0,997 & 0,998 & 0,999 & 1,000 & 1,000 \\
\hline & 0,5 & 0,948 & 0,978 & 0,987 & 0,992 & 0,994 & 0,996 & 0,998 & 1,000 & 1,000 \\
\hline & 0,7 & 0,903 & 0,959 & 0,977 & 0,985 & 0,990 & 0,993 & 0,997 & 0,999 & 1,000 \\
\hline & 1,0 & 0,747 & 0,896 & 0,942 & 0,963 & 0,975 & 0,981 & 0,992 & 0,998 & 0,999 \\
\hline & 2,0 & - & - & - & - & - & - & - & - & - \\
\hline \multirow{6}{*}{0,8} & 0,1 & 0,987 & 0,995 & 0,997 & 0,998 & 0,999 & 0,999 & 1,000 & 1,000 & 1,000 \\
\hline & 0,3 & 0,951 & 0,979 & 0,988 & 0,993 & 0,995 & 0,996 & 0,998 & 1,000 & 1,000 \\
\hline & 0,5 & 0,888 & 0,954 & 0,974 & 0,984 & 0,989 & 0,992 & 0,997 & 0,999 & 1,000 \\
\hline & 0,7 & 0,761 & 0,905 & 0,948 & 0,967 & 0,977 & 0,983 & 0,993 & 0,998 & 0,999 \\
\hline & 1,0 & - & 0,631 & 0,816 & 0,887 & 0,923 & 0,944 & 0,978 & 0,994 & 0,997 \\
\hline & 2,0 & - & - & - & - & - & - & - & - & - \\
\hline \multirow{6}{*}{0,9} & 0,1 & 0,972 & 0,988 & 0,994 & 0,996 & 0,997 & 0,998 & 0,999 & 1,000 & 1,000 \\
\hline & 0,3 & 0,880 & 0,952 & 0,974 & 0,984 & 0,989 & 0,992 & 0,997 & 0,999 & 1,000 \\
\hline & 0,5 & 0,658 & 0,880 & 0,935 & 0,960 & 0,972 & 0,980 & 0,992 & 0,998 & 0,999 \\
\hline & 0,7 & - & 0,679 & 0,843 & 0,905 & 0,935 & 0,953 & 0,981 & 0,995 & 0,998 \\
\hline & 1,0 & - & - & - & - & 0,382 & 0,647 & 0,880 & 0,969 & 0,986 \\
\hline & 2,0 & - & - & - & - & - & - & - & - & - \\
\hline
\end{tabular}




\section{Conclusão}

O presente trabalho descreve e introduz uma metodologia numérica de simulação térmica de trocadores de calor de fluxo cruzado e de casco e tubo 1-1 tipo TEMA E. A metodologia computacional é utilizada para simular doze configurações de arranjos de escoamento de trocadores de calor de fluxo cruzado com número de passes e tubos por passe arbitrários, assim como diversas condições de mistura de ambos os fluidos. O procedimento computacional é desenvolvido, baseado no trabalho realizado por Pignotti e Cordero (1983a) e detalhado por Magazoni e Cabezas-Gómez (2016), para calcular a efetividade de temperatura e o fator de correção da diferença média logarítmica de temperatura para trocadores de calor de fluxo cruzado em escoamentos contracorrente e paralelo.

Dados da efetividade de temperatura e do fator de correção para trocadores de calor de fluxo cruzado com diversas arranjos de montagem são determinados utilizando a metodologia computacional desenvolvida.

Os algoritmos desenvolvidos no presente trabalho são utilizados no desdobramento de expressões analíticas da efetividade de temperatura para trocadores de calor de fluxo cruzado considerando diferentes arranjos de escoamento, onde não tinham sido publicadas anteriormente na literatura. As relações da efetividade foram obtidas levando em conta as considerações básicas, comumente empregadas na literatura, Kays e London (1998), Shah e Sekulic (2003) e Cabezas-Gómez, Navarro e Saiz-Jabardo (2015): (i) o trocador de calor opera em regime permanente; (ii) as transferências de calor com o meio externo são desprezadas, ou seja, o trocador de calor é modelado como adiabático em relação ao meio externo; (iii) não há fontes ou sumidouros de energia térmica nas paredes do trocador de calor e/ou nos fluidos; (iv) o fluido que escoa por dentro dos tubos está perfeitamente misturado em toda a sua seção transversal, acontecendo uma variação linear de sua temperatura ao longo do eixo axial dos tubos; (v) os coeficientes de transferência de calor e as propriedades de transporte dos fluidos e das paredes do trocador de calor são uniformes e constantes; (vi) os efeitos da transferência de calor axial nas paredes sólidas e nos fluidos são desprezíveis; e (vii) não há mudança de fase em ambas as correntes ou fluidos.

Os resultados das expressões analíticas são comparados com diversos trabalhos de diferentes autores e mostram a capacidade dos algoritmos desenvolvidos. As expressões aproximadas desenvolvidas por Spang e Roetzel (1995) e Roetzel e Spang (2010) possuem erros consideráveis, como exemplo, os erros relativos médio e máximo são respectivamente de $1,64 \%$ e $12,2 \%$ para um trocador de calor de fluxo cruzado com um passe e dez 
tubos por passe (1-10). A mesma comparação é realizada com os resultados do programa computacional de trocadores de calor HETE. O erro relativo médio é pequeno para a maioria dos arranjos, porém para os trocadores de calor de diversos passes e um tubo $\left(N_{p^{-}}-1\right)$ em escoamento contracorrente com fluido frio não misturado entre os passes, o erro relativo médio aumenta. Entretanto, o erro relativo médio ainda é pequeno, como exemplo, para um trocador de calor de fluxo cruzado em escoamento contracorrente com dez passes e um tubo por passe (10-1), os erros relativos médio e máximo são respectivamente de $-0,00467 \%$ e $0,17641 \%$. Os resultados calculados com o programa HETE podem ser utilizados de forma segura na simulação dos trocadores de calor.

Uma importante conclusão para trocadores de calor de fluxo cruzado é o máximo número de passes e de tubos por passe onde a influência na efetividade de temperatura não é significativamente maior que 1,0\%, o que não é tecnicamente aceitável em função da uniformidade do valor da efetividade. O caso de infinitos passes e um tubo ( $\infty-1)$ é representado por um trocador de calor com doze passes e um tubo por passe (12-1). Já os casos de um passe e infinitos tubos $(1-\infty)$ e dois passes e infinitos tubos $(2-\infty)$ são representados respectivamente por um trocador com nove (1-9) e cinco tubos (1-5).

As condições de mistura do fluido interno depois de cada passe, que são caracterizadas por três configurações: misturado, não misturado com uma ordem idêntica das fileiras e não misturado com uma ordem inversa das fileiras, são também analisadas. O fator de correção é maior para trocadores de calor com a condição de fluido quente não misturado com uma ordem idêntica das fileiras (caso 3B) e menor para a condição de fluido quente não misturado com uma ordem inversa das fileiras (caso 3C). Por exemplo, para um trocador de calor com dois passes e quatro tubos por passes, o fator de correção é 0,905 para $P=0,80$ e $R=0,1$, considerando o caso 3B. Já para o caso 3C, o fator de correção é 0,888 , uma diferença de aproximadamente $2,0 \%$. Isto é por causa que o caso de fluido não misturado com uma ordem idêntica das fileiras tem uma diferença de temperatura uniformemente mais distribuída entre os fluidos quente e frio, provocando assim uma efetividade de temperatura mais alta.

A metodologia desenvolvida neste trabalho também é utilizada para calcular a efetividade de temperatura e o fator de correção de trocadores de calor de casco e tubo tipo TEMA E com um passe no casco e um no tubo (1-1) em escoamentos contracorrente e paralelo. O trocador de calor de casco e tubo é idealizado como sendo uma série de trocadores de calor de fluxo cruzado. Os trocadores de calor são então conectados em série em escoamentos contracorrente e paralelo. Cada seção de chicana é idealizada como um trocador de calor de fluxo cruzado considerando os fluidos quente e frio não misturados (SHAH; PIGNOTTI, 1997). Na saída de cada seção da chicana, o fluido do casco é misturado e este fluido vai para a próxima seção da chicana. O fluido do tubo é considerado não misturado. 
Assim, para trocadores de calor de casco e tubo 1-1 tipo TEMA E em escoamentos contracorrente e paralelo são apresentadas relações matemáticas aproximadas, que reproduzem de forma satisfatória os resultados teóricos dos algoritmos desenvolvidos no presente trabalho. As expressões e coeficientes são calculados com um erro relativo máximo de $0,40 \%$ e os coeficientes são válidos para $F \geq 0,75$ e $0,1 \leq R \leq 4,0$. Estas expressões são apropriadas no cálculo e desenvolvimento computacionais, e facilita o cálculo da efetividade de temperatura e do fator de correção. Os resultados encontrados utilizando estas expressões aproximadas são comparados com os dados de Caglayan e Buthod (1976), onde o maior valor do erro relativo encontrado é de 1,0 \%. Note que são utilizadas uma interpolação linear para a razão de temperatura e uma interpolação logarítmica para o número de chicanas para encontrar o fator de correção de algumas configurações de trocadores de calor que não são apresentadas nas expressões aproximadas.

O grau de condição de mistura entre as chicanas de trocadores de calor casco e tubo 1-1 tipo TEMA E em escoamento contracorrente também é analisado no presente trabalho. Três condições de mistura são analisadas: misturada, não misturada e fluido do casco completamente misturado nos compartimentos. O grau de condição de mistura entre as chicanas pode ser definido utilizando uma interpolação linear entre as condições de fluidos misturado e não misturado. A condição de fluido não misturada, que implica que o fluido do lado do casco permanece não misturado quando escoa entre as chicanas, possui um maior valor de efetividade de temperatura e fator de correção. Já a condição de fluido do casco completamente misturado produz valores menores de efetividade de temperatura e fator de correção. Dados que devem ser utilizados como referência do fator de correção em função da efetividade de temperatura, da razão de temperatura e do número de chicanas são apresentados para as três configurações de grau de mistura do fluido do casco.

\subsection{Recomendações para trabalhos futuros}

Com os resultados obtidos no presente trabalho e os algoritmos desenvolvidos, podem-se sugerir os seguintes trabalhos de continuidade:

- Extensão do presente procedimento computacional para o cálculo de efetividade de temperatura para trocadores de calor de casco e tubo com mais de um passe de tubos;

- Extensão do presente procedimento computacional para o cálculo de efetividade de temperatura para trocadores de calor de fluxo cruzado com configuração das fileiras dos tubos tipo Z, conforme apresentado por Cabezas-Gómez et al. (2014);

- Simular trocadores de calor de casco e tubos com o código HETE e com os códigos em MATLAB desenvolvidos em Magazoni e Cabezas-Gómez (2016) e apresentados neste 
presente trabalho. Esta proposta já foi desenvolvida parcialmente em Guimaraes (2015) e também está sendo desenvolvida atualmente por Magazoni e Cabezas-Gómez (2016). A ideia principal é modelar trocadores de calor do tipo E (norma TEMA da ASME) com um e dois passes no casco com um número finito e reduzido de chicanas. O objetivo é propor correlações para cálculo do fator de correção, $F$, e da efetividade de temperatura, $P$, em função do número de chicanas e apresentar dados novos de efetividade de temperatura;

- Desenvolvimento de expressões matemáticas analíticas para trocadores de calor de fluxo cruzado com número elevado de passes e de tubos por passe utilizando séries de Bessel ou Taylor;

- Desenvolvimento de expressões matemáticas analíticas para trocadores de calor casco tubo 1-1 e 1-2 tipo TEMA E utilizando séries de Bessel ou Taylor;

- Estender as ferramentas computacionais desenvolvidas para possibilitar o projeto de trocadores de calor de fluxo cruzado considerando o cálculo dos coeficientes convectivos e das diversas resistências térmicas presentes nesses equipamentos;

- Utilizar essas ferramentas computacionais para o estudo experimental em bancada (túnel de vento) de superfícies de transferência de calor existentes ou novas. Neste contexto, também se propõe realizar estudos relacionados com a modelagem da mistura do fluido externo;

- Desenvolver simulações computacionais de volumes finitos (CAE) para possibilitar entender o comportamento do escoamento dos fluidos frio e quente no trocador de calor e possibilitar assim o desenvolvimento de ferramentas de otimizações;

- Empregar as técnicas matriciais descritas em Pignotti e Tamborenea (1988) e outros trabalhos desse autor e co-autores para sofisticar as ferramentas desenvolvidas, e obter soluções numéricas considerando perfis no uniformes das temperaturas de entrada e diversos tipos de hipóteses de mistura dos fluidos. Por exemplo, isto permitiria a simulação de trocadores de calor de casco e tubos do tipo J (norma TEMA), além de diversos trocadores de calor de fluxo cruzado (PIGNOTTI; SHAW, 1992). 


\section{Referências}

BABAELAHI, M.; SADRI, S.; SAYYAADI, H. Multi-objective optimization of a cross-flow plate heat exchanger using entropy generation minimization. Chemical Engineering Technology, v. 37, n. 1, p. 87-94, 2014.

BACLIC, B. S. . $\varepsilon$-ntu analysis of complicated flow arrangements. In: SHAH, R. K.; KRAUS, A. D.; METZGER, D. (Ed.). Compact heat exchangers - A Festschrift for AL London. New York, United States of America: Hemisphere Publishing Corporation, 1990. p. 31-90.

BACLIC, B. S. A simplified formula for cross-flow heat exchanger effectiveness. Journal of Heat Transfer, v. 100, n. 4, p. 746-747, 1978.

BACLIC, B. S.; HEGGS, P. J. On the search for new solutions of the single-pass crossflow heat exchanger problem. International Journal of Heat and Mass Transfer, v. 28, n. 10, p. 1965-1976, 1985.

BINNIE, A. M.; POOLE, E. G. C. The theory of single-pass cross-flow heat exchanger. Proceedings of the Cambridge Philosophical Society, v. 33, n. 3, p. 403-411, 1937.

BOWMAN, R. A.; MUELLER, A. C.; NAGLE, W. M. Mean temperature difference in design. Transactions ASME, v. 62, p. 283, 1940.

BRAUN, B. Wärmeübergang und temperaturverlauf in quetstrom-rohrbündeln bei beliebiger schaltung der rohrreihen. Forsch. Ing., v. 41, n. 6, p. 181-191, 1975.

CABEZAS-GÓMEZ, L. .; NAVARRO, H. A.; SAIZ-JABARDO, J. M. Thermal performance of multipass parallel and counter-cross-flow heat exchangers. Journal of Heat Transfer, v. 129, n. 3, p. 282-290, 2007.

CABEZAS-GÓMEZ, L. . et al. Analysis of a new cross flow heat exchanger flow arrangement - Extension to several rows. International Journal of Thermal Sciences, v. 55, n. 4 , p. $122-132,2012$.

CABEZAS-GÓMEZ, L. et al. Thermal characterization of a cross-flow heat exchanger with a new flow arrangement. International Journal of Thermal Sciences, v. 48, n. 11, p. 2165-2170, 2009.

CABEZAS-GÓMEZ, L.; NAVARRO, H. A.; SAIZ-JABARDO, J. . M. Thermal Performance Modeling of Cross-Flow Heat Exchangers. London, England: Springer, 2015.

CABEZAS-GÓMEZ, L.; NAVARRO, H. A.; SAIZ-JABARDO, J. M. Thermal performance of multipass parallel and counter-cross-flow heat exchangers. Journal of Heat Transfer, v. 129, n. 3, p. 282-290, 2006.

CABEZAS-GÓMEZ, L. et al. New thermal effectiveness data and formulae for some cross-flow arrangements of practical interest. International Journal of Heat and Mass Transfer, v. 69, p. 237-246, 2014. 
CAGLAYAN, A. N.; BUTHOD, P. Factors correct air-cooler and S and T exchangers LMTD. Oil and Gas Journal, v. 6, p. 91-94, 1976.

CENGEL, Y. A. Introduction to Thermodynamics and Heat Transfer. 2nd. ed. New York, Unites States of America: McGraw-Hill, 2008.

CHEN, T. D.; CONKLIN, J. C.; BAXTER, V. D. Comparison of analytical and experimental effectiveness of four-row plate-fin-tube heat exchangers with water, R-22 and R-410A. ASME Winter Annual Meeting, 1998.

COLBURN, A. P.; PONT, E. I. Mean temperature difference and heat transfer coefficient in liquid heat exchangers. Industrial \& Engineering Chemistry, v. 25, n. 8, p. 873-875, 1933.

DIGIOVANNI, M. A.; WEBB, R. L. Uncertainty in effectiveness-N T U calculation for cross flow heat exchangers. Heat Transfer Engineering, v. 10, n. 3, p. 61-70, 1989.

DOMINGOS, J. D. Analysis of complex assemblies of heat exchangers. International Journal of Heat and Mass Transfer, v. 12, n. 5, p. 537-548, 1969.

ECKERT, E. R. G. Heat Transfer. New York, United States of America: McGraw-Hill, 1959.

ESDU. Effectiveness-N T U relations for the design and performance evaluation of two-stream heat exchangers. Engineering Science Data Unit 86018 with amendment, London ESDU International plc, p. 92-107, 1991.

FERNANDEZ, J. Mean Temperature Difference in Co-Cross-Flow Heat Exchangers. Dissertação (Mestrado) — Southern Methodist University, 1956.

FISCHER, F. K. Mean temperature difference correction in multipass exchangers. Industrial \& Engineering Chemistry, v. 30, n. 4, p. 377-383, 1938.

GARDNER, K. A.; TABOREK, J. Mean temperature difference: A reappraisal. American Institute of Chemical Engineers Journal, v. 23, n. 6, p. 777-786, 1977.

GUIMARAES, L. G. M. Determinação numérica do fator de correção F para trocadores de calor casco e tubos. Tese (Doutorado) - Pontifícia Universidade Católica de Minas Gerais, Belo Horizonte, Brasil, 2015.

GVOZDENAC, D. D. Two-pass countercrossflow heat exchangers with both bluids unmixed throughout. Wärme- und Stoffübertragung, v. 20, p. 151-161, 1986.

HAUSEN, H. Heat transfer in counterflow, parallel flow, and cross flow. New York, United States of America: McGraw Hill, 1983.

HEWITT, G.; SHIRES, G.; BOTT, T. Process heat transfer. Florida, United States of America: CRC Press, 1994.

INCROPERA, F.; DEWITT, D. Fundamentos de Transferência de Calor e Massa. 4. ed. Rio de Janeiro, Brasil: LTC Editora, 2014.

KAYS, W. M.; LONDON, A. L. Compact Heat Exchangers. 3rd. ed. New York, United States of America: McGraw Hill, 1998. 
LI, C. H. A. New simplified formula for crossflow heat exchanger effectiveness. ASME Journal Heat Transf, v. 109, n. 2, p. 521-522, 1987.

LONDON, A. L.; SEBAN, R. A. A generalization of the methods of heat exchangers analysis. International Journal of Heat and Mass Transfer, v. 23, n. 1, p. 5-16, 1980.

MAGAZONI, F.; CABEZAS-GÓMEZ, L. Numerical methodologies for computing effectiveness of crossflow heat exchangers with multiple pass and mixture conditions of both fluids. In: COOPER, J. K. (Ed.). Heat Exchangers: Characteristics, Types and Emerging Applications. New York, United States of America: Nova Science Publishers, 2016, (Energy Science, Engineering and Technology). cap. 4, p. 81-126.

MARTIN, H. Heat exchangers. Washington, United States of America: Hemisphere Publishing Corporation, 1990.

MASON, J. L. Heat transfer in cross flow. Proceedings of 2nd US National Congress of Applied Mechanics, p. 801-803, 1955.

NAGLE, W. M. Mean temperature differences in multipass heat exchangers. Industrial $\mathscr{E}$ Engineering Chemistry, v. 25, n. 6, p. 604-609, 1933.

NAVARRO, H. A.; CABEZAS-GÓMEZ, L. . Effectiveness-N T U computation with a mathematical model for cross-flow heat exchangers. Brazilian Journal of Chemical Engineering, v. 24, n. 4, p. 509-521, 2007.

NAVARRO, H. A.; CABEZAS-GÓMEZ, L. A new approach for thermal performance calculation of cross-flow heat exchangers. International Journal of Heat and Mass Transfer, v. 48, p. 3880-3888, 2005.

NAVARRO, H. A. et al. Effectiveness-NT U data and analysis for air conditioning and refrigeration air coils. Journal of the Brazilian Society of Mechanical Sciences and Engineering, v. 32, n. 3, p. 218-226, 2010.

NELLIS, G.; KLEIN, S. Heat Transfer. New York, United States of America: Cambridge University Press, 2009.

NICOLE, F. J. L. Mean Temperature Difference in Cross-Flow Heat Exchange, Applied to Multipass Air-Cooled Fin-Tube Units with a Finite Number of Rows. Dissertação (CSIR Special Report CHEM 223) — University of Pretoria, 1972.

NUSSELT, W. . Eine neue formel für den wärmedurchgang im kreuzstrom. Technische Mechanik und Thermodynamik, v. 1, n. 12, p. 417-422, 1930.

NUSSELT, W. Der wärmeübertragung in kreuztrom. VDI-Zeitschr, v. 55, p. 2021-2024, 1911.

PERUSSI, R. Análise do desempenho de trocadores de calor de fluxo cruzado por simulação numérica. Tese (Doutorado) - Universidade de São Paulo, São Paulo, Brasil, 2010.

PIGNOTTI, A. Relation between the thermal effectiveness of overall parallel and counterflow heat exchanger geometries. Journal of Heat Transfer, v. 111, n. 2, p. 294-299, 1989. 
PIGNOTTI, A. .; CORDERO, G. O. Mean temperature difference in multipass crossflow. Journal of Heat Transfer, v. 105, n. 3, p. 584-591, 1983.

PIGNOTTI, A.; CORDERO, G. O. Mean temperature difference charts for air coolers. Journal of Heat Transfer, v. 105, n. 3, p. 592-597, 1983.

PIGNOTTI, A.; SHAW, R. K. Effectiveness-number of transfer units relationships for heat exchanger complex flow arrangements. International Journal of Heat and Mass Transfer, v. 35, n. 5, p. 1275-1291, 1992.

PIGNOTTI, A.; TAMBORENEA, P. I. Thermal effectiveness of multiple shell and tube pass TEMA E heat exchangers. Journal of Heat Transfer, v. 110, n. 1, p. 54-59, 1988.

ROETZEL, W.; NEUBERT, J. Calculation of mean temperature difference in air-cooled cross-flow heat exchangers. Journal of Heat Transfer, v. 101, n. 3, p. 511-513, 1979.

ROETZEL, W.; NICOLE, F. J. L. Mean temperature difference for heat exchanger design - a general approximate explicit equation. Journal of Heat Transfer, v. 97, n. 1, p. 5-8, 1975 .

ROETZEL, W.; SPANG, B. Fundamentals of heat exchanger design - Thermal design of heat exchangers - Chapter C 1. In: VDI-GVC (Ed.). VDI Heat Atlas. 2nd. ed. Düsseldorf, Germany: Springer-Verlag Berlin Heidelberg, 2010. p. 33-66.

SCHEDWILL, H. Thermische auslegung von kreuzstromwarmeaustauschern. Fortschritt-Ber VDI-Z. Reihe 6, n. 19, 1968.

SEKULIC, D. P.; SHAH, R. K.; PIGNOTTI, A. A review of solution methods for determining effectiveness-ntu relationships for heat exchangers with complex flow arrangements. Applied Mechanics Reviews, v. 52, n. 3, 1999.

SHAH, R. . K.; PIGNOTTI, A. Influence of a finite number of baffles on shell-and-tube heat exchanger performance. Heat Transfer Engineering, v. 18, n. 1, p. 82-94, 1997.

SHAH, R. K.; MUELLER, A. C. Heat exchanger basic thermal design methods. In: ROSHENOW, W. M.; HARTNETT, J. P.; GANIC, E. N. (Ed.). Handbook of Heat Transfer. 2nd. ed. New York, United States of America: McGraw Hill, 1985.

SHAH, R. K.; PIGNOTTI, A. Thermal analysis of complex cross-flow exchangers in terms of standard configuration. Journal of Heat Transfer, v. 115, n. 2, p. 353-359, 1993.

SHAH, R. K.; SEKULIC, D. P. Fundamentals of Heat Exchanger Design. New Jersey, United States of America: John Wiley \& Sons, Inc., 2003.

SMITH, D. M. Mean temperature-difference in cross flow. Engineering, v. 138, p. 479-481 and 606-607, 1934.

SPANG, B.; ROETZEL, W. Neue näherungsgleichung zur einheitlichen berechnung von wärmeübertragern. Heat and Mass Transfer, v. 30, n. 6, p. 417-422, 1995.

STEVENS, R. S.; FERNANDEZ, J.; WOOLF, J. R. Mean-temperature difference in one-, two- and three-pass crossflow heat exchangers. Transactions of the ASME, v. 79, p. 287-297, 1957. 
TABOREK, J. Charts for mean temperature difference in industrial heat exchanger configuration. New York, United States of America: Hemisphere Publishing Corporation, 1983.

THULUKKANAM, K. Heat exchanger design handbook. 2nd. ed. New York, United States of America: CRC Press, 2013.

TRIBOIX, A. Exact and approximative formulas for cross flow heat exchangers with unmixed fluids. International Communications in Heat and Mass Transfer, v. 36, n. 2, p. 121-124, 2009.

TUCKER, A. S. The LM T D correction factor for single-pass crossflow heat exchangers with both fluids unmixed. Journal of Heat Transfer, v. 118, n. 2, p. 488-490, 1996.

UNDERWOOD, A. J. V. The calculation of the mean temperature difference in multipass heat exchangers. Institute of Petroleum Technologists, v. 20, p. 145-158, 1934.

VDI. VDI Heat Atlas. 2nd. ed. Düsseldorf, Germany: Springer-Verlag Berlin Heidelberg, 2010 .

WEBB, R. L.; KIM, N. H. Principles of Enhanced Heat Transfer. 2nd. ed. New York, United States of America: Taylor \& Francis, 2005.

YOON, S. J.; SABHARWALL, P.; KIM, E. S. Numerical study on crossflow printed circuit heat exchanger for advanced small modular reactors. International Journal of Heat and Mass Transfer, v. 70, p. 250-263, 2014. 



\section{A Esquema dos Trocadores de Calor}

Tabela 52 - Desenhos esquemáticos dos trocadores de calor de fluxo cruzado

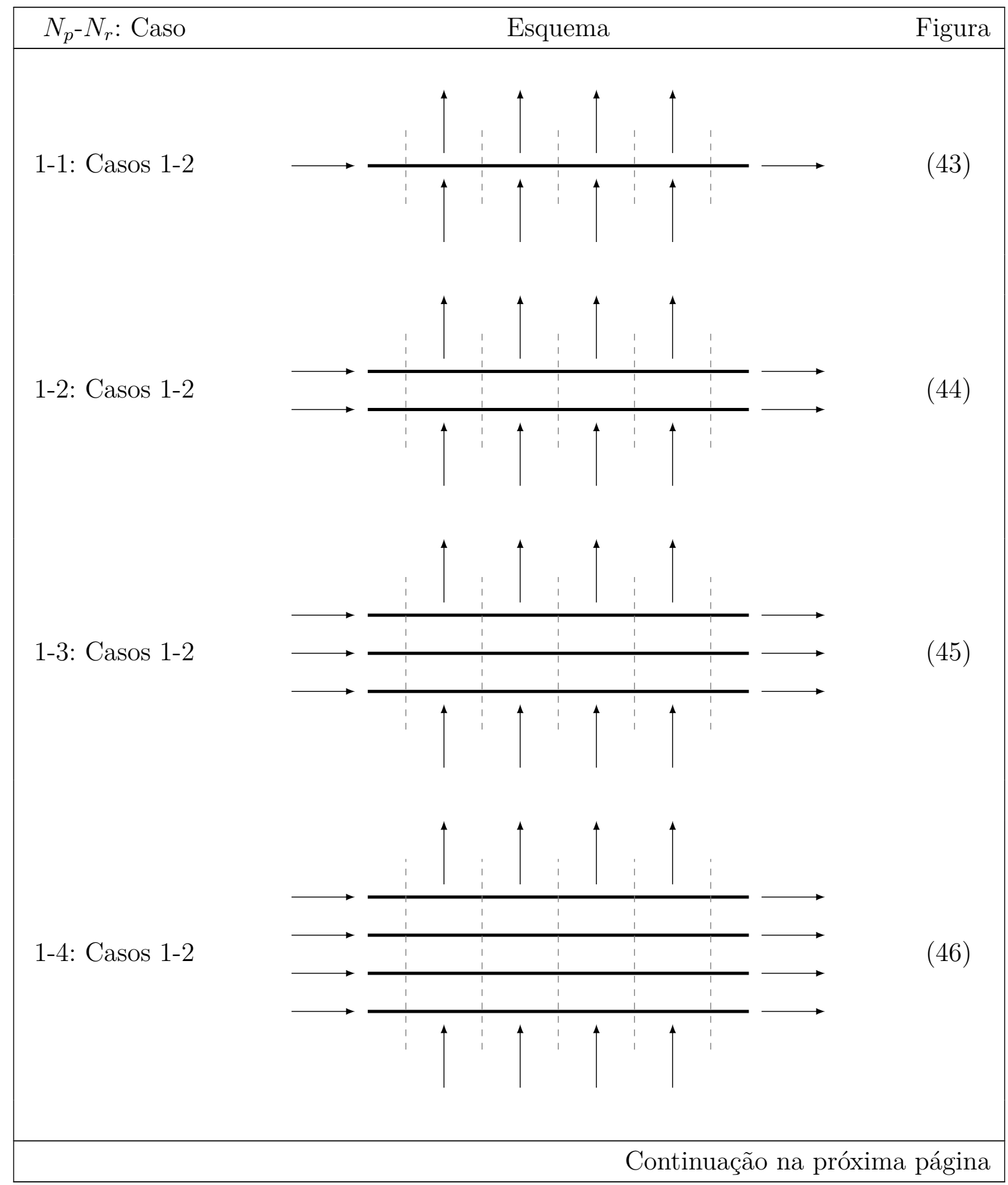


Tabela 52 - continuação da página anterior

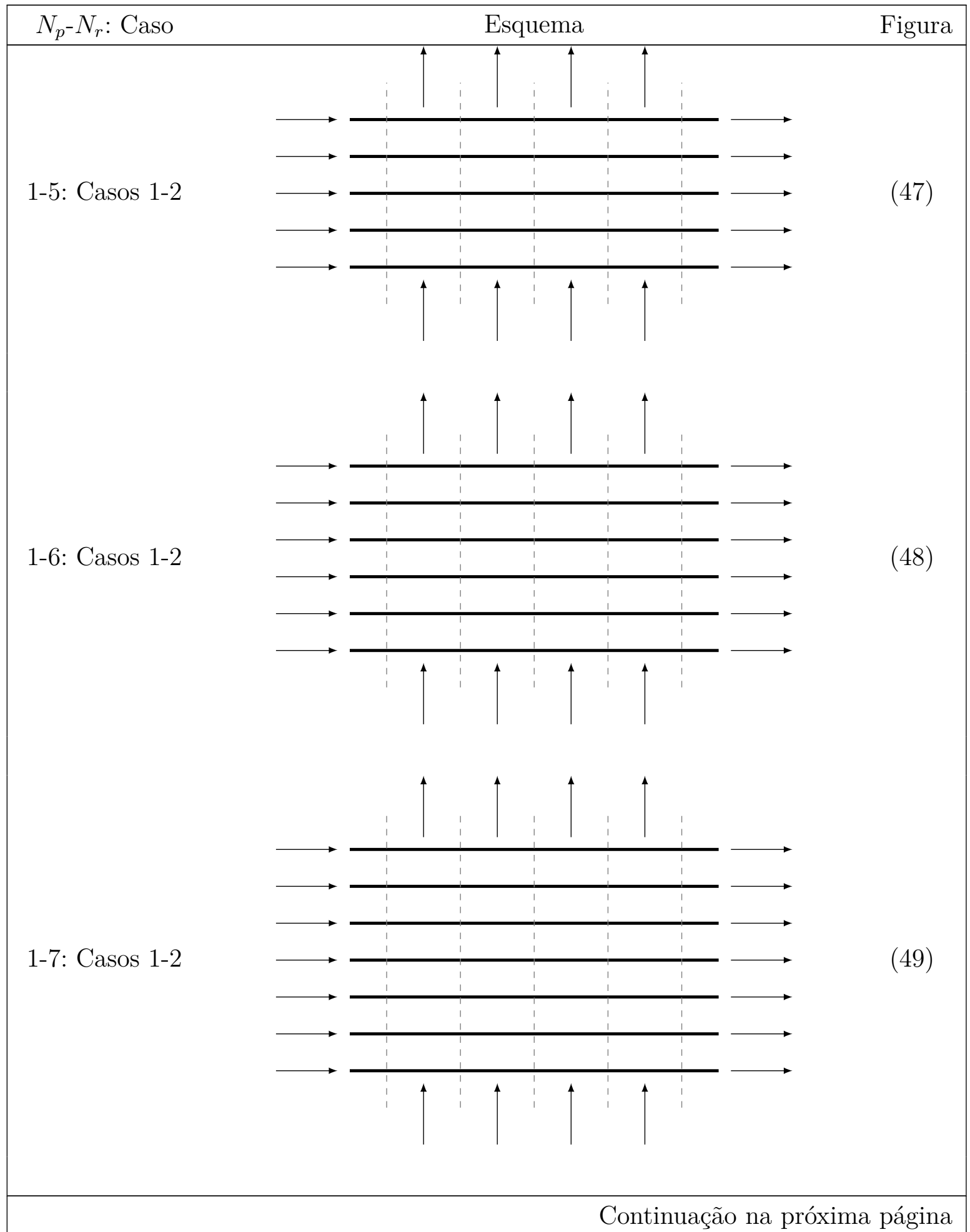


Tabela 52 - continuação da página anterior

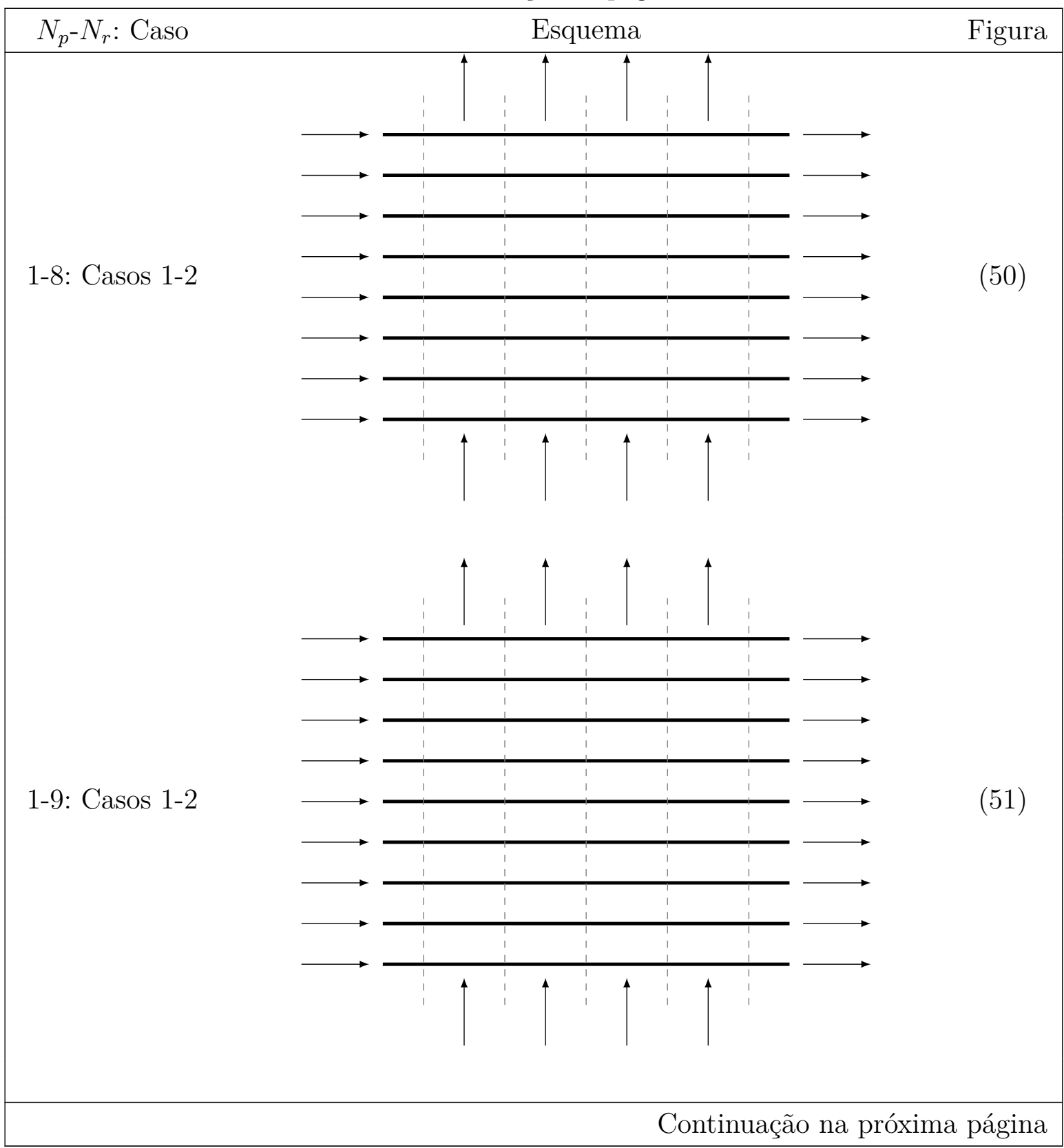


Tabela 52 - continuação da página anterior

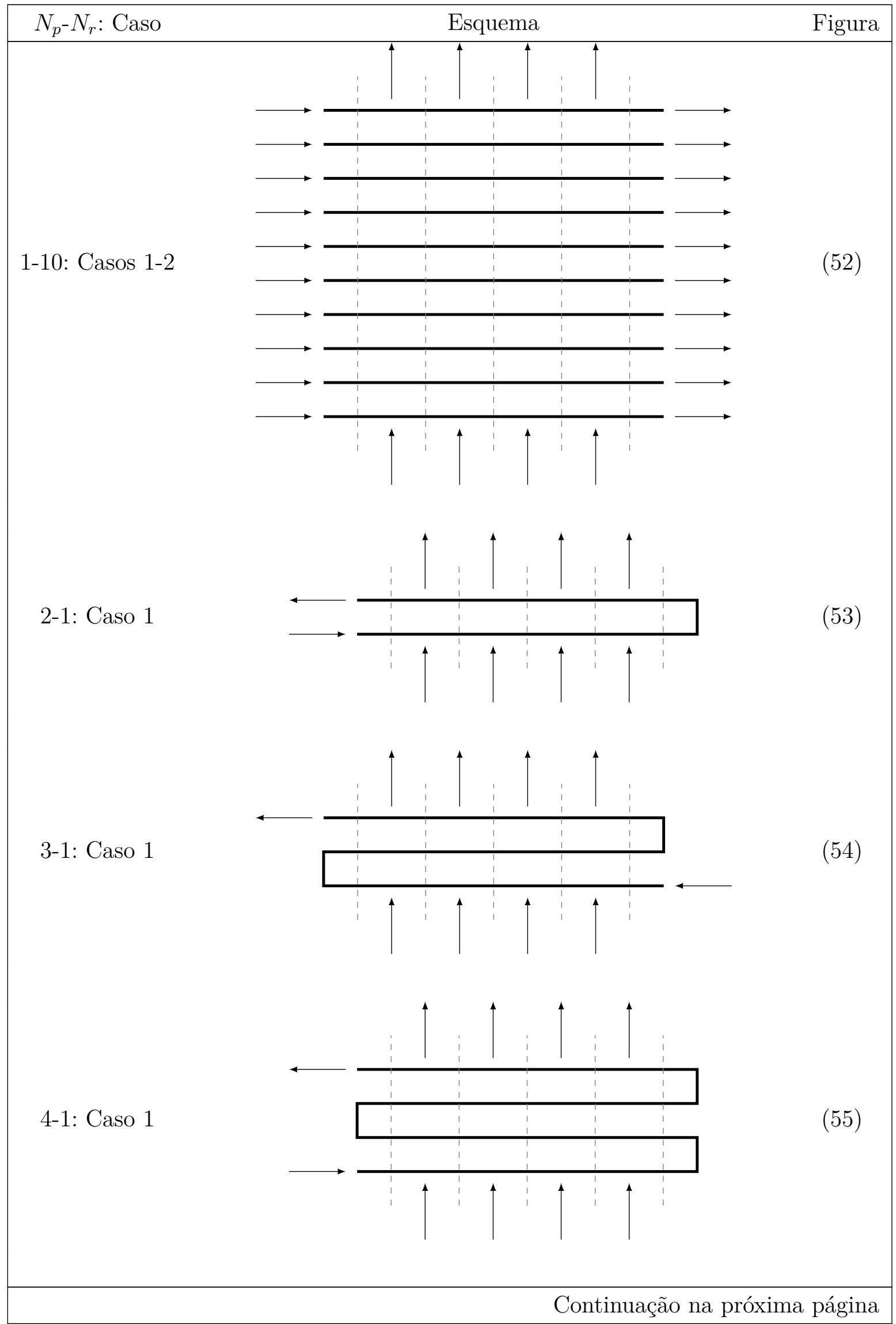


Tabela 52 - continuação da página anterior

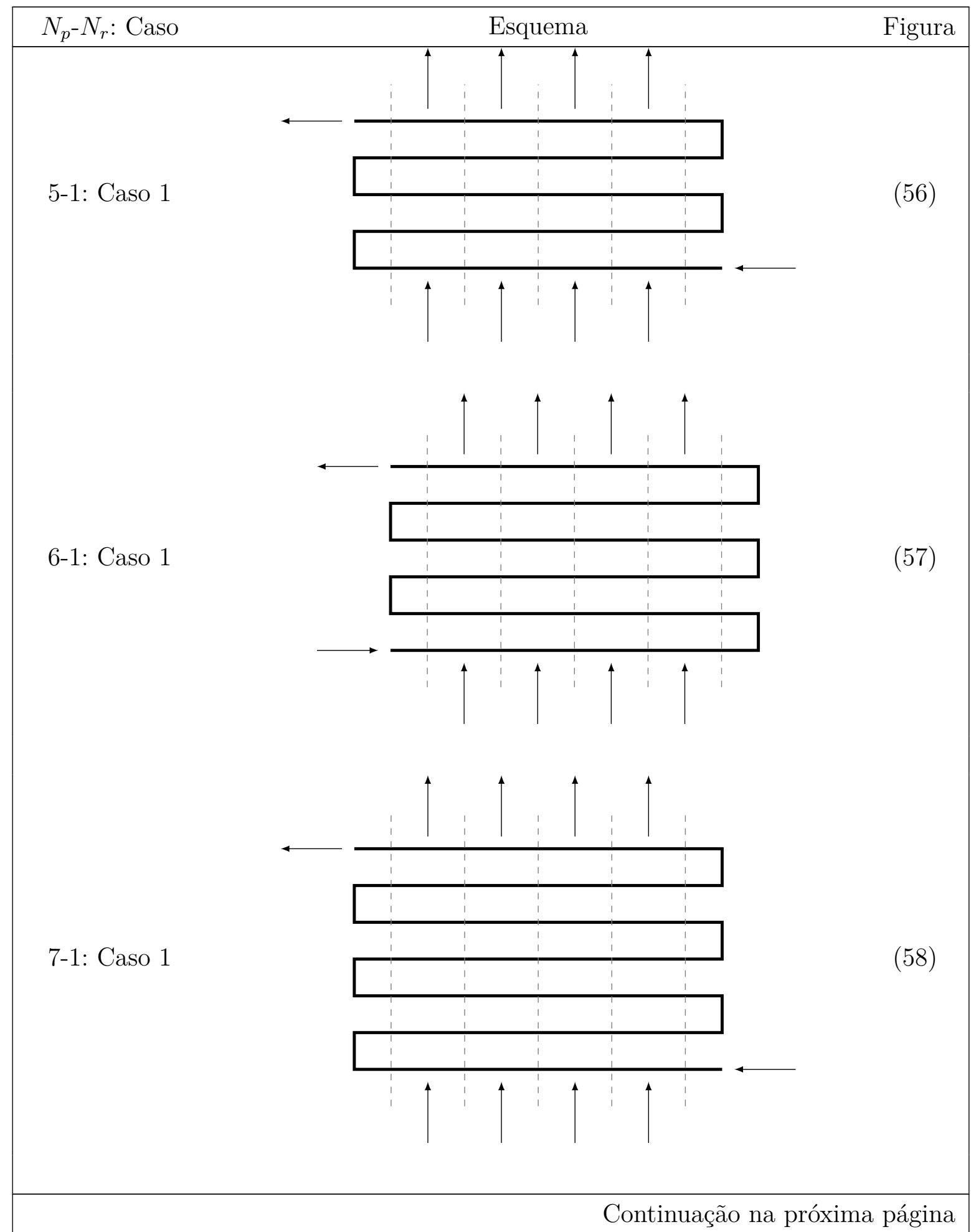


Tabela 52 - continuação da página anterior

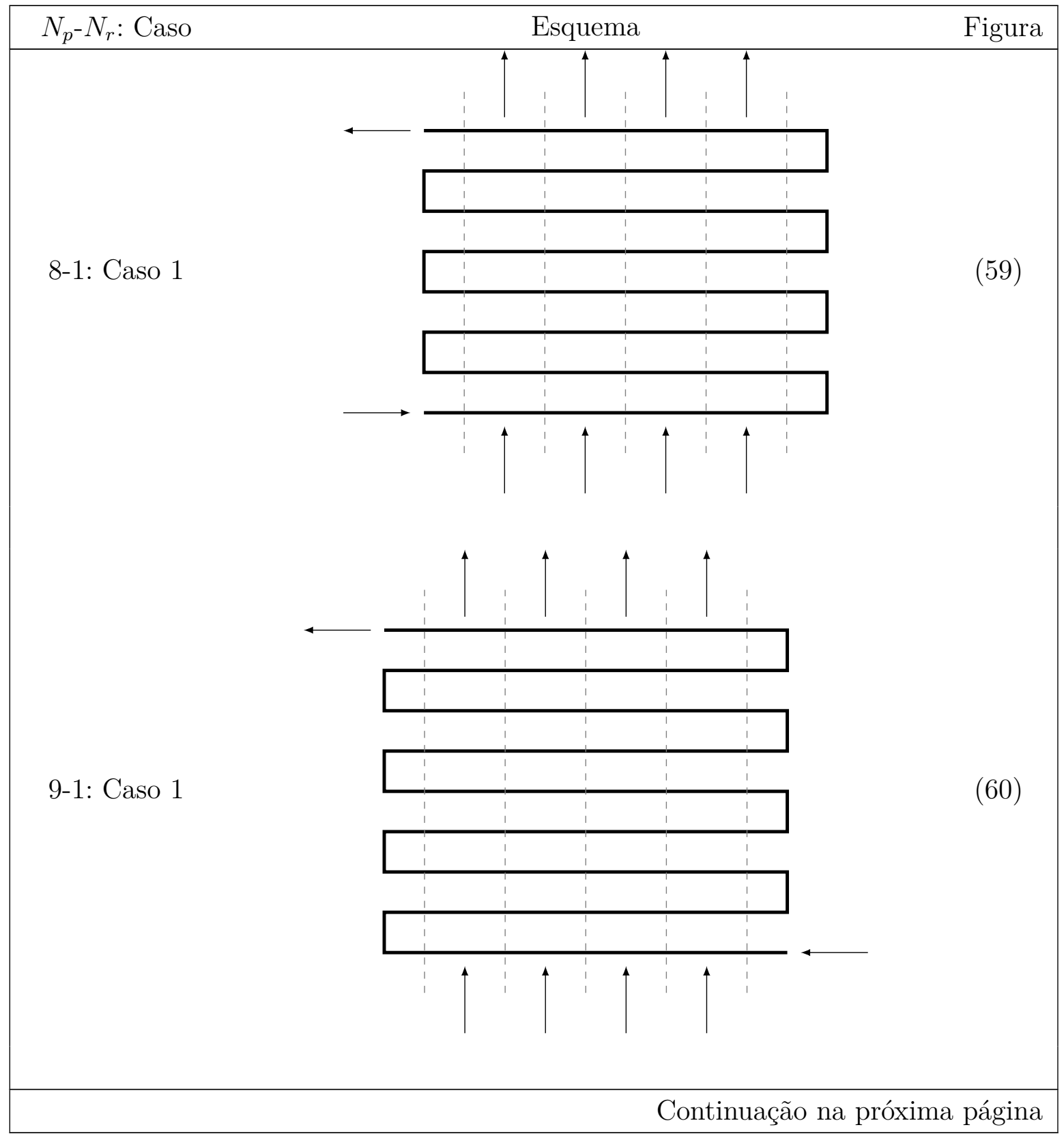


Tabela 52 - continuação da página anterior

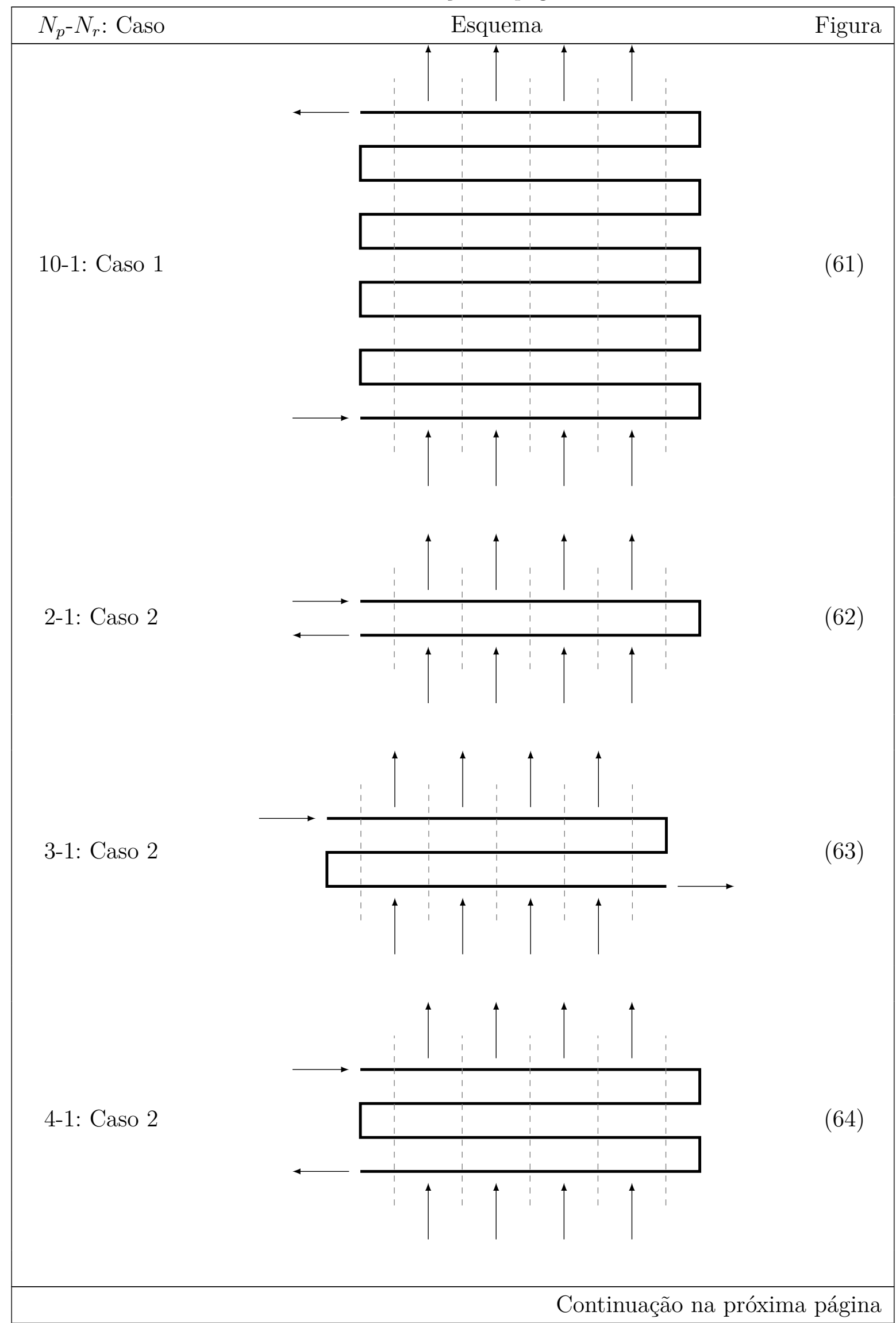


Tabela 52 - continuação da página anterior

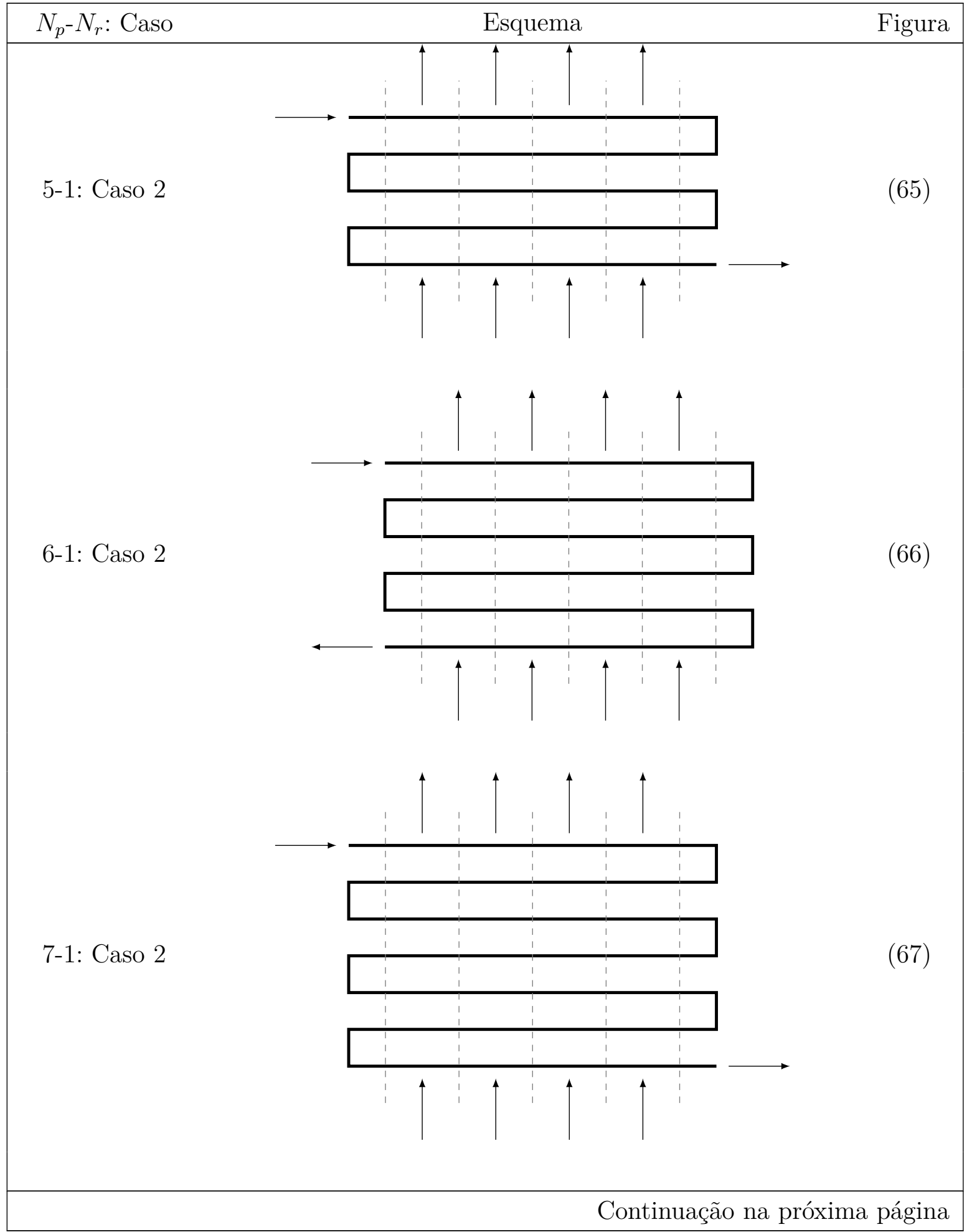


Tabela 52 - continuação da página anterior

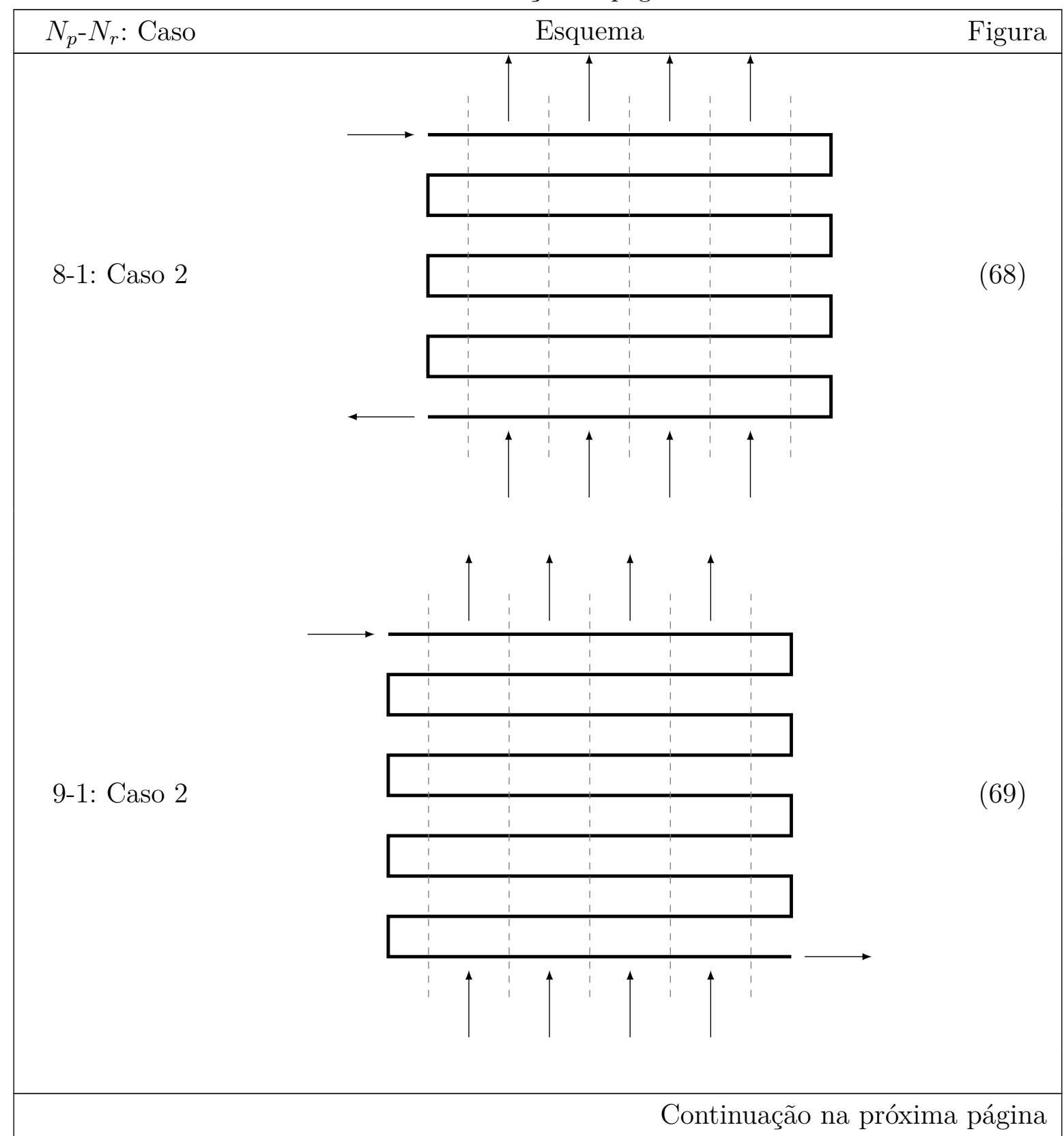


Tabela 52 - continuação da página anterior

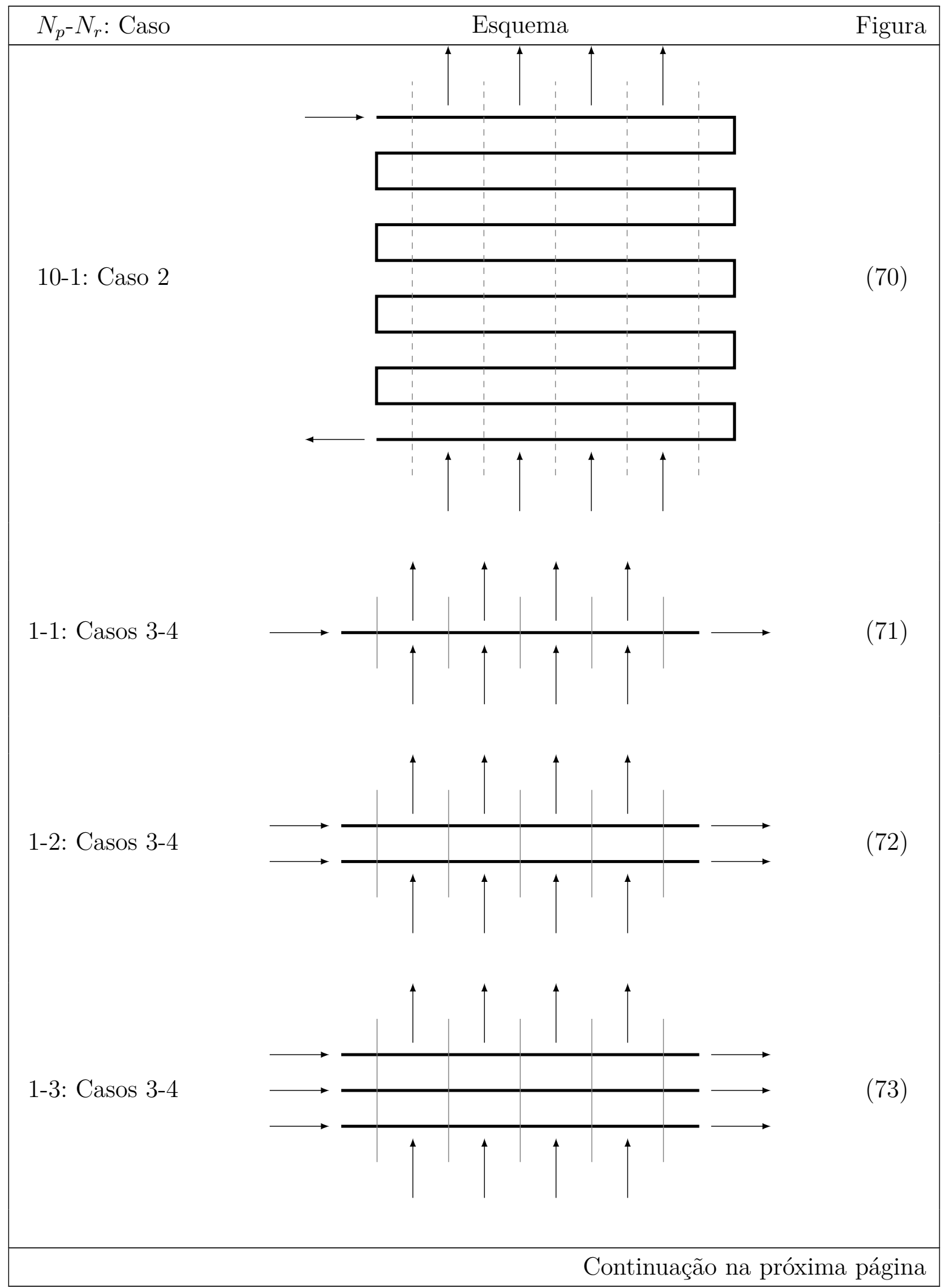


Tabela 52 - continuação da página anterior

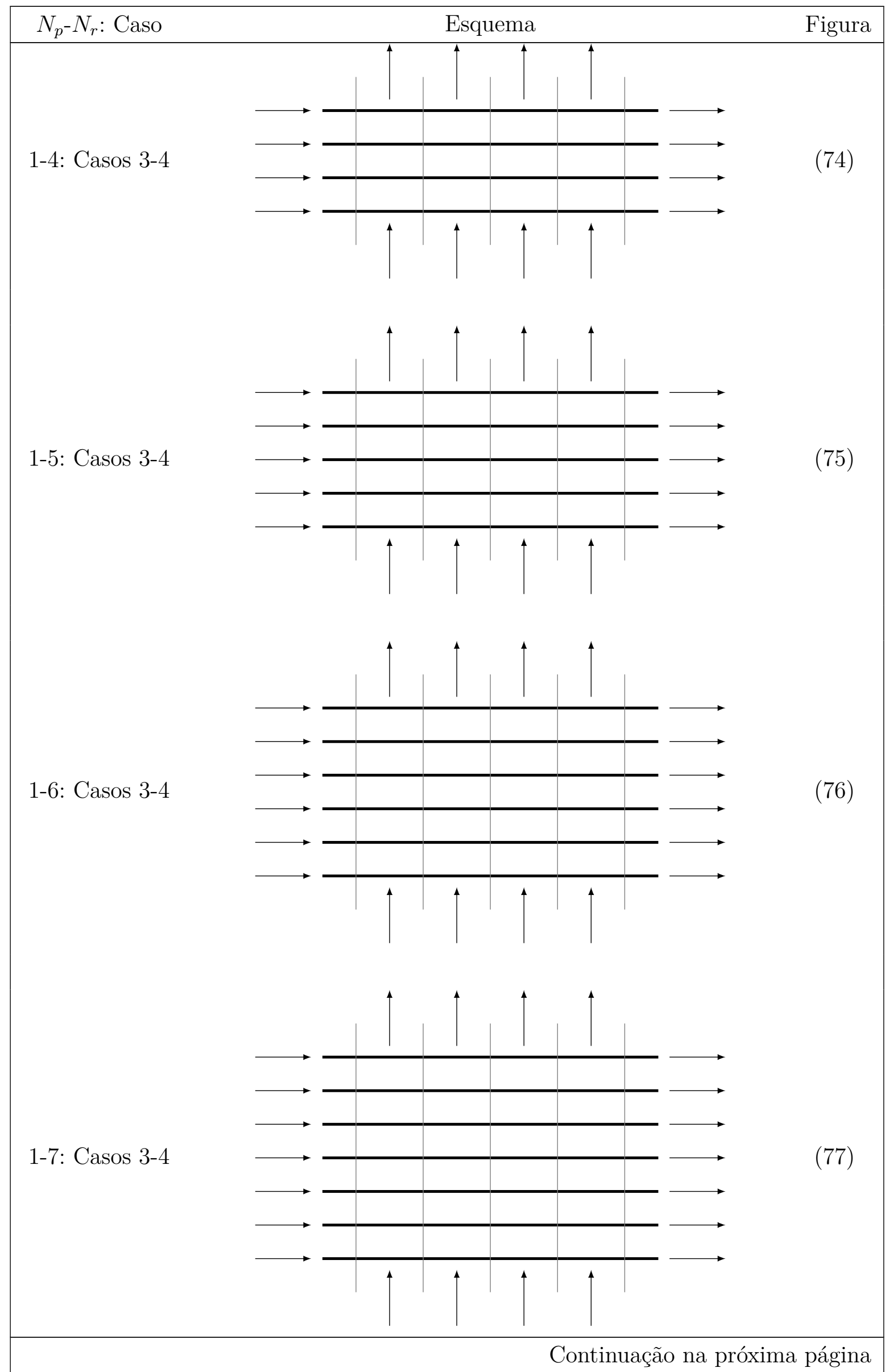


Tabela 52 - continuação da página anterior

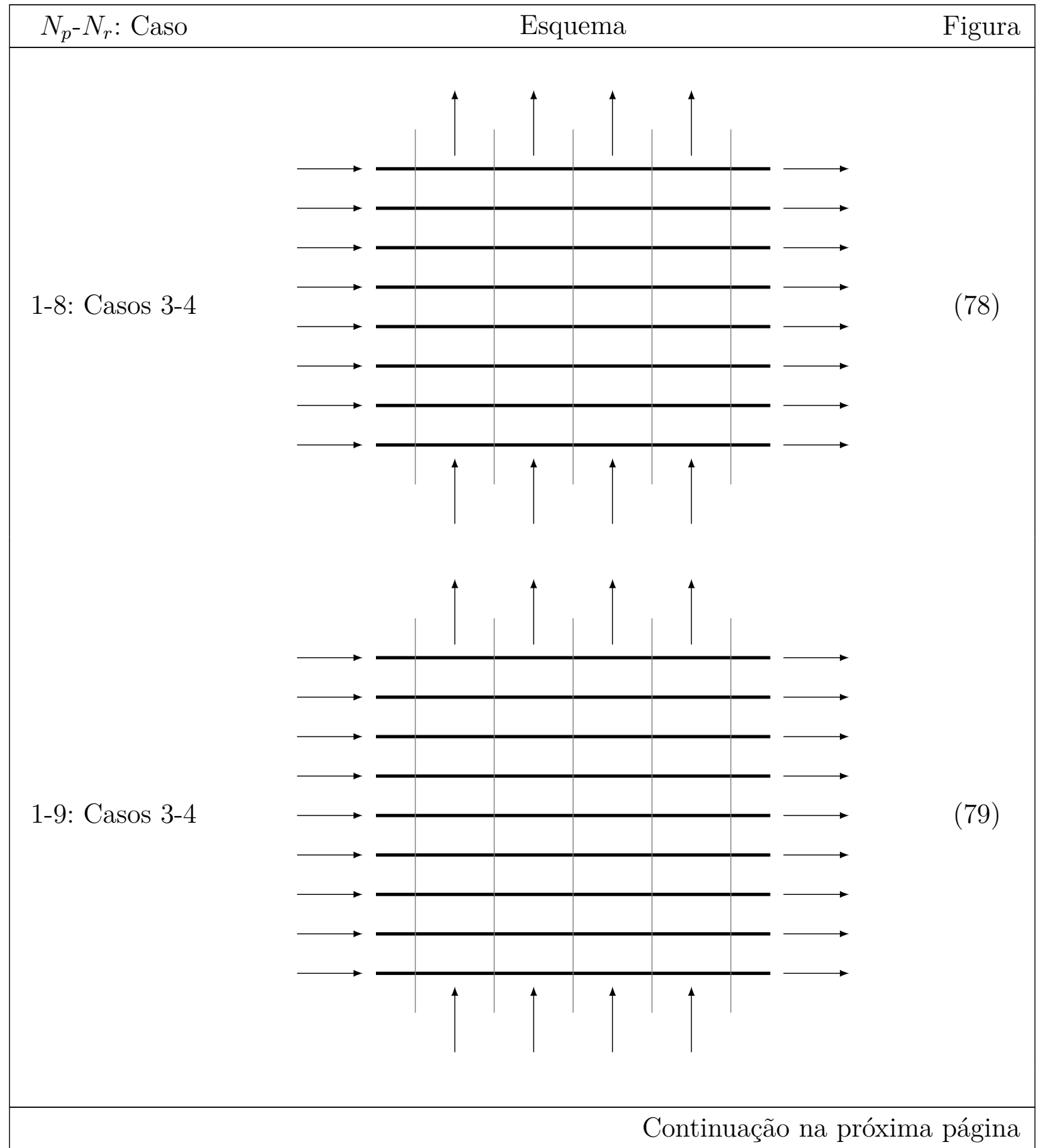


Tabela 52 - continuação da página anterior

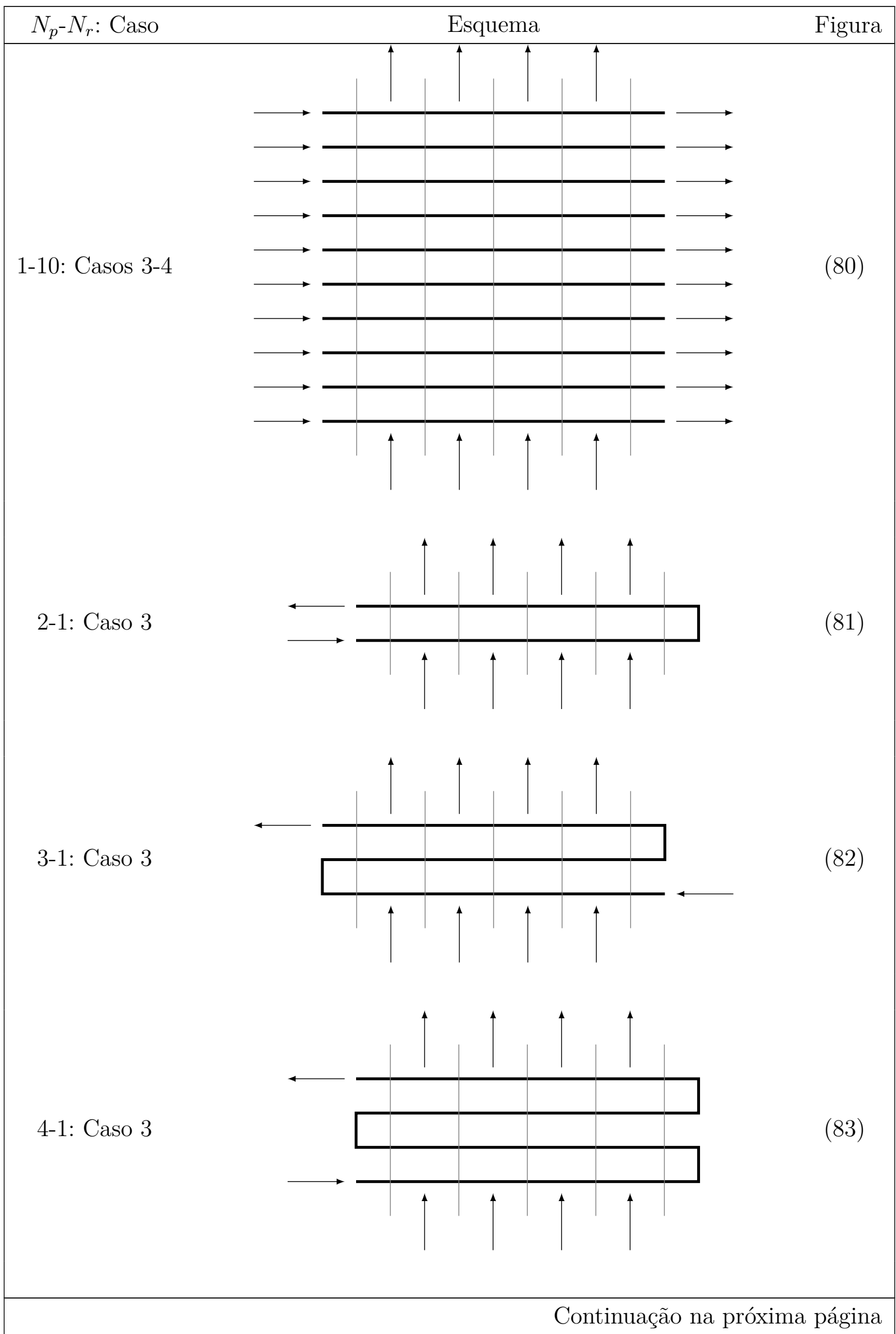


Tabela 52 - continuação da página anterior

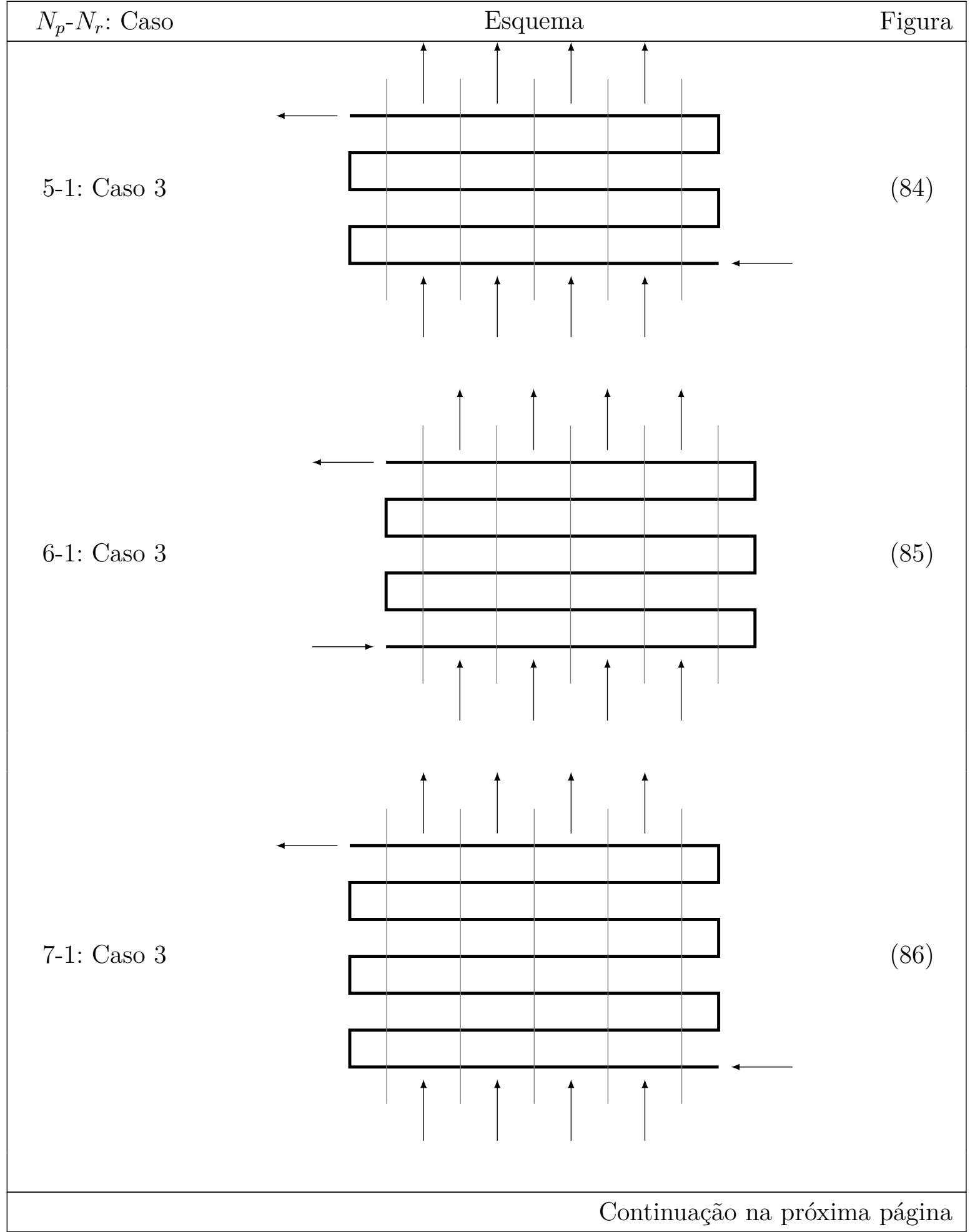


Tabela 52 - continuação da página anterior

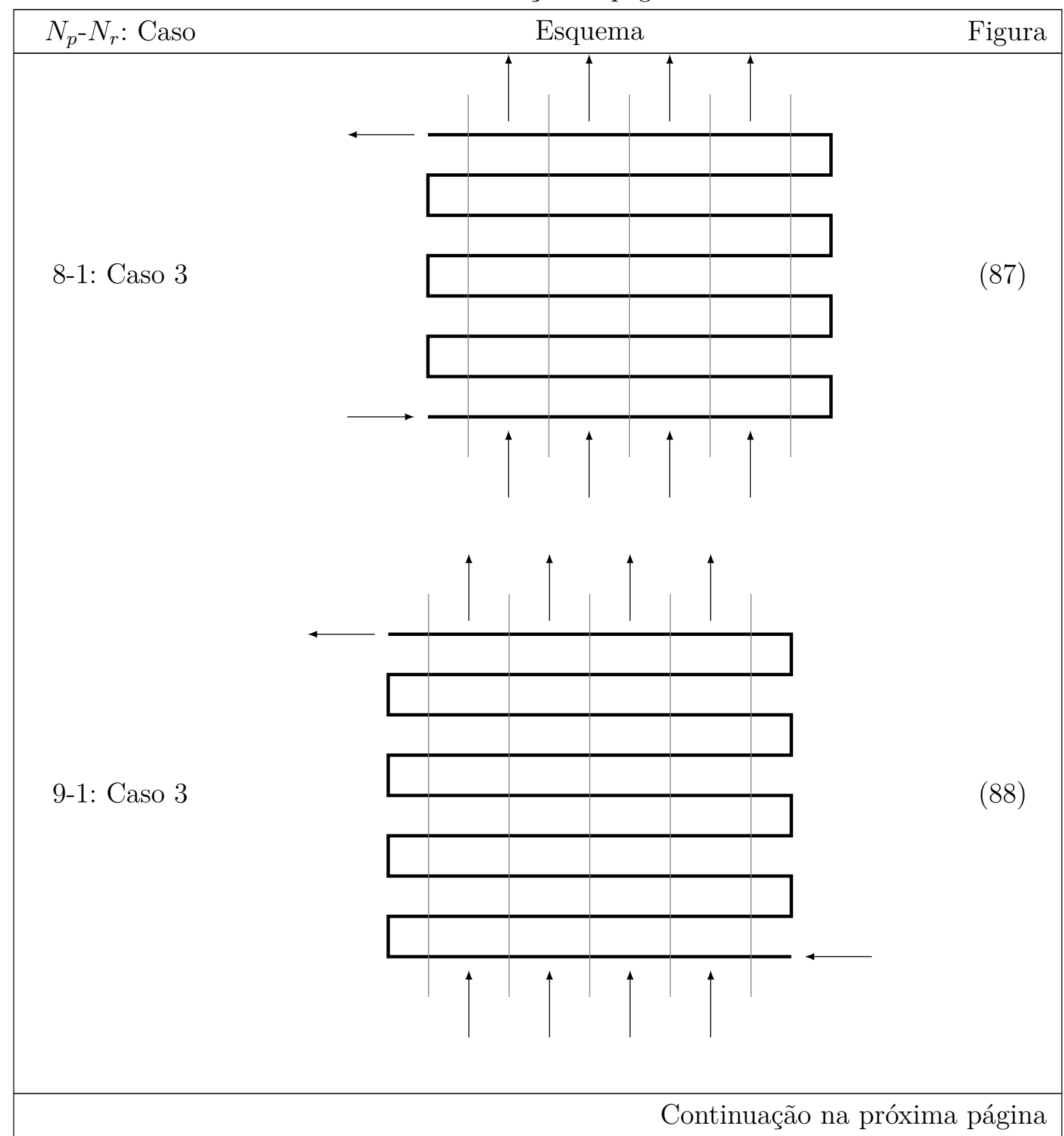


Tabela 52 - continuação da página anterior

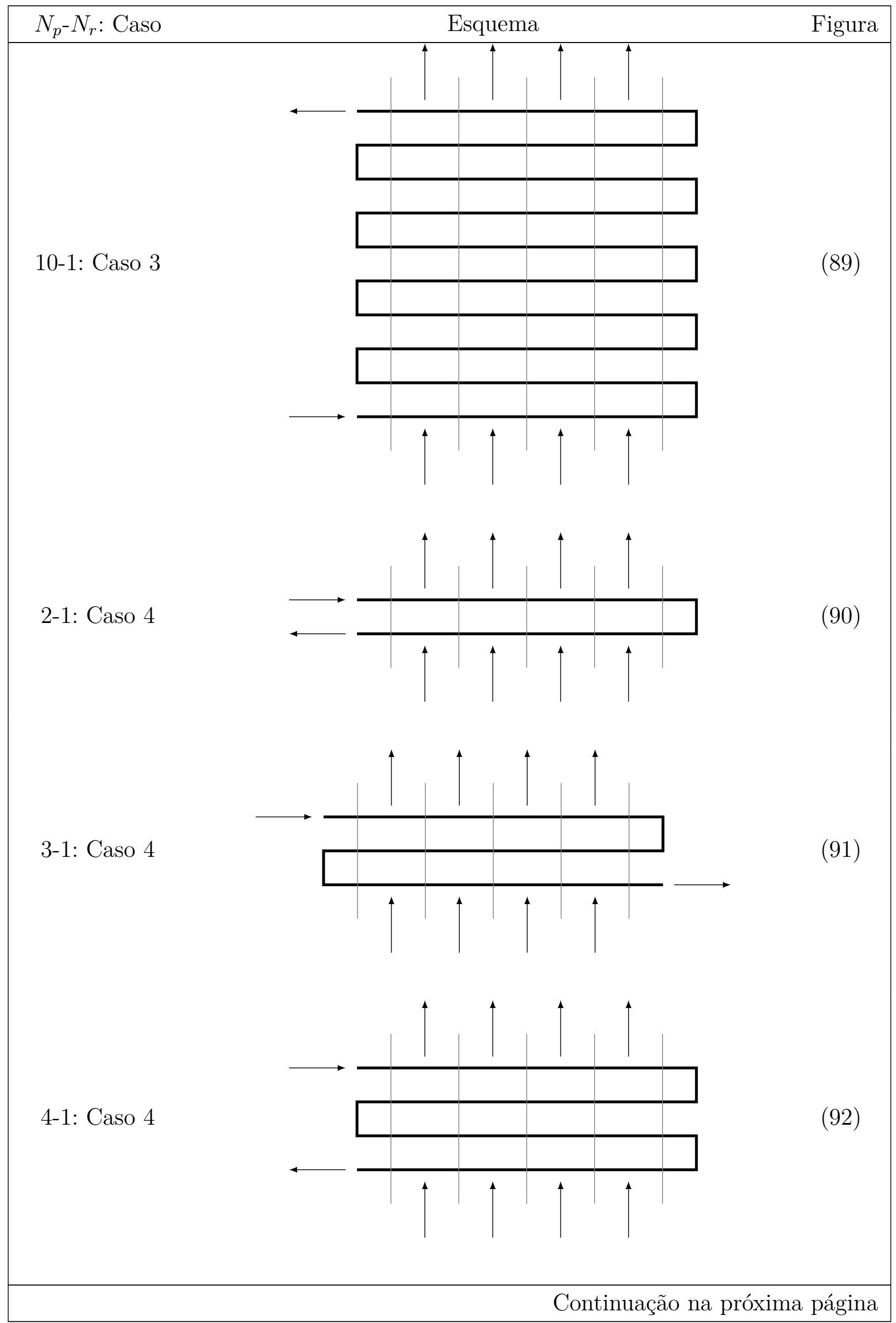


Tabela 52 - continuação da página anterior

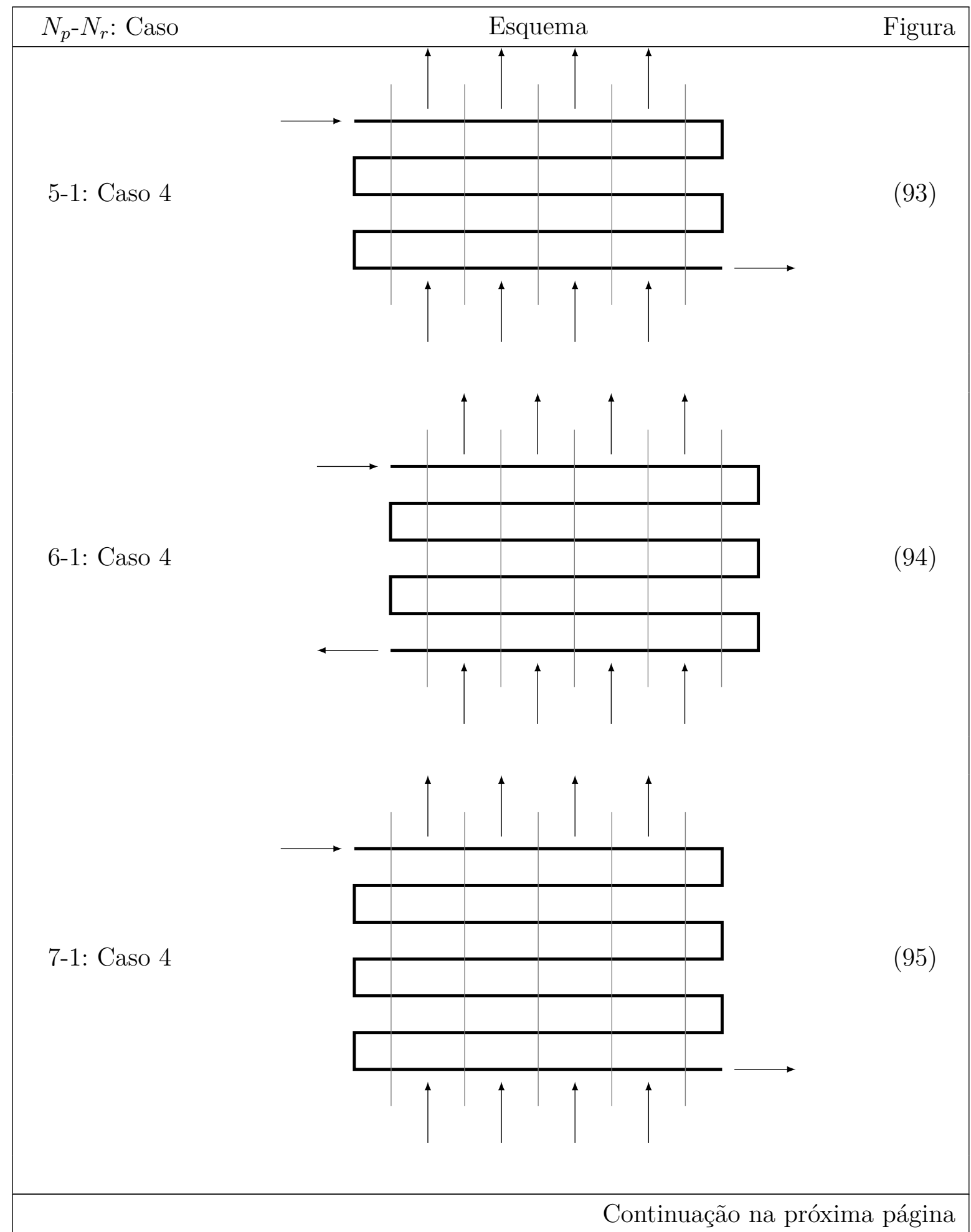


Tabela 52 - continuação da página anterior

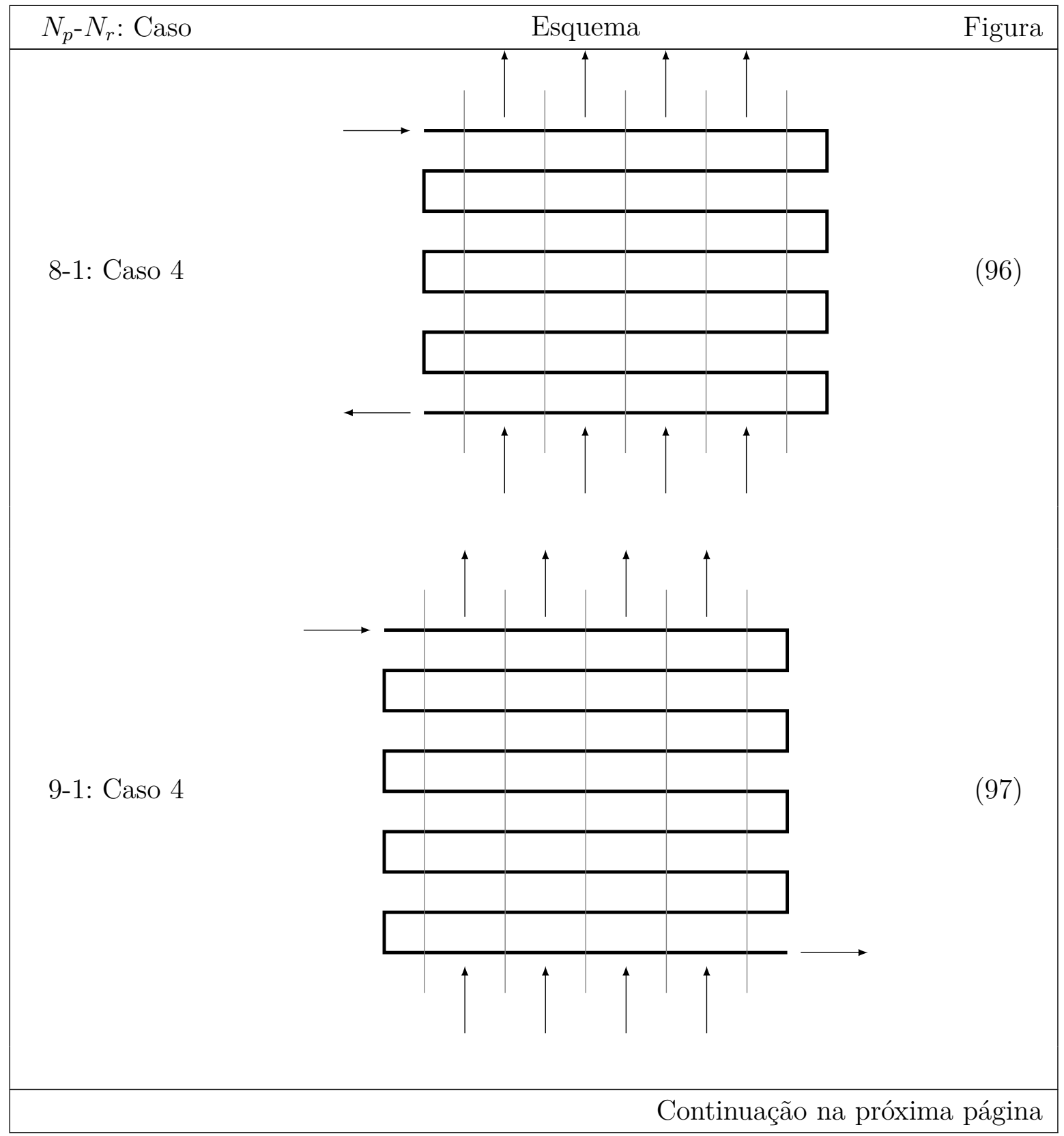


Tabela 52 - continuação da página anterior

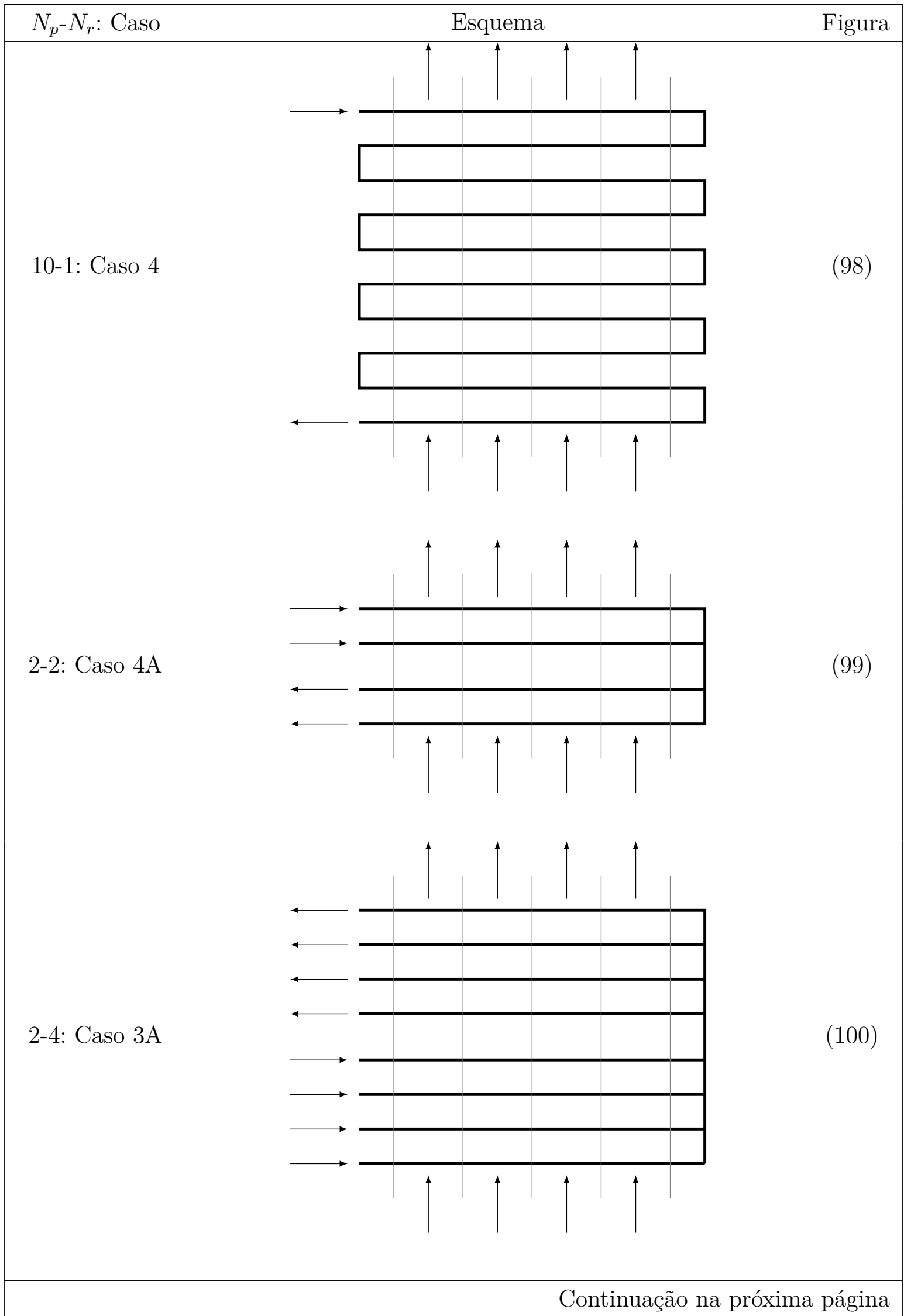


Tabela 52 - continuação da página anterior

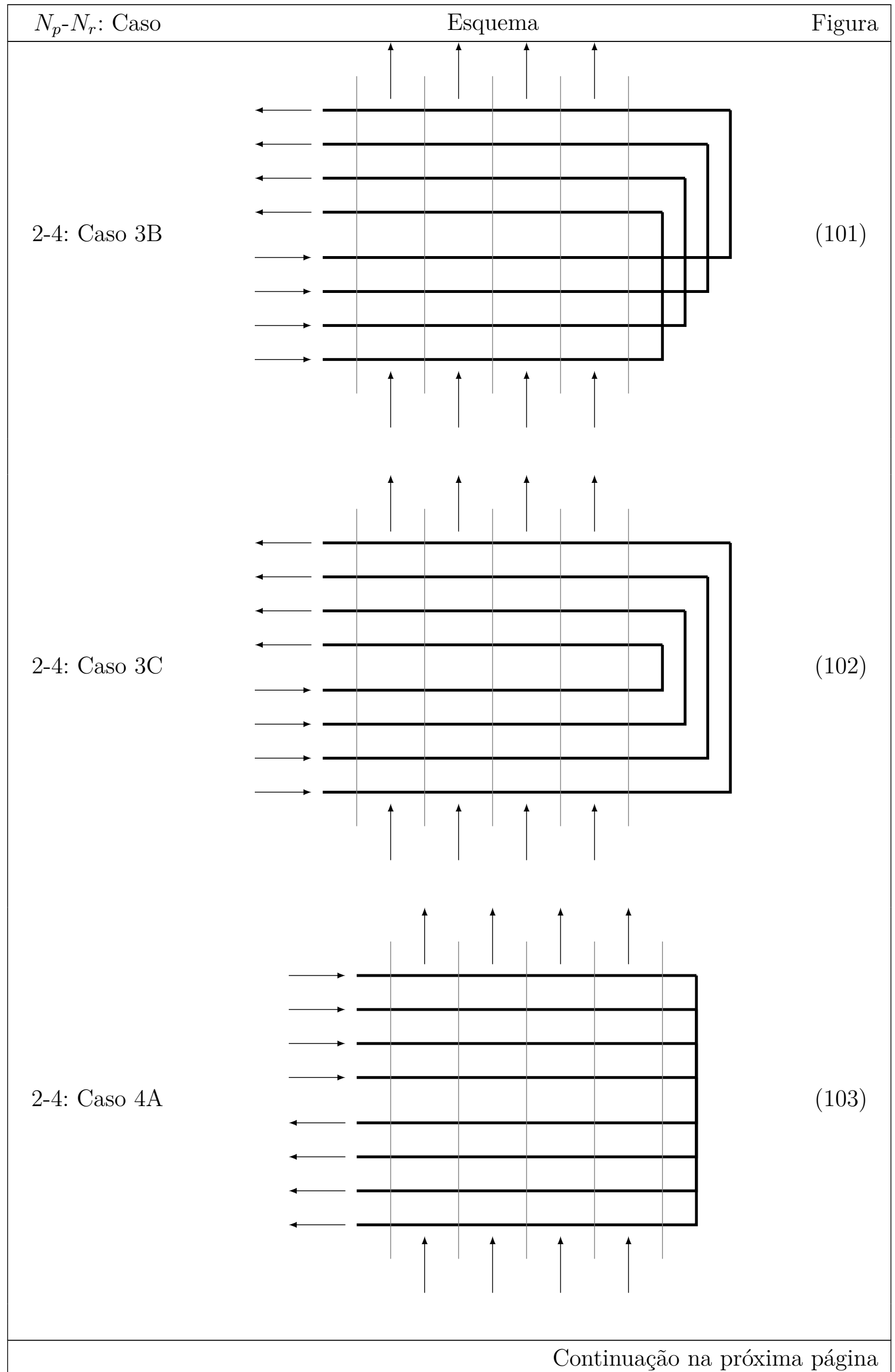


Tabela 52 - continuação da página anterior

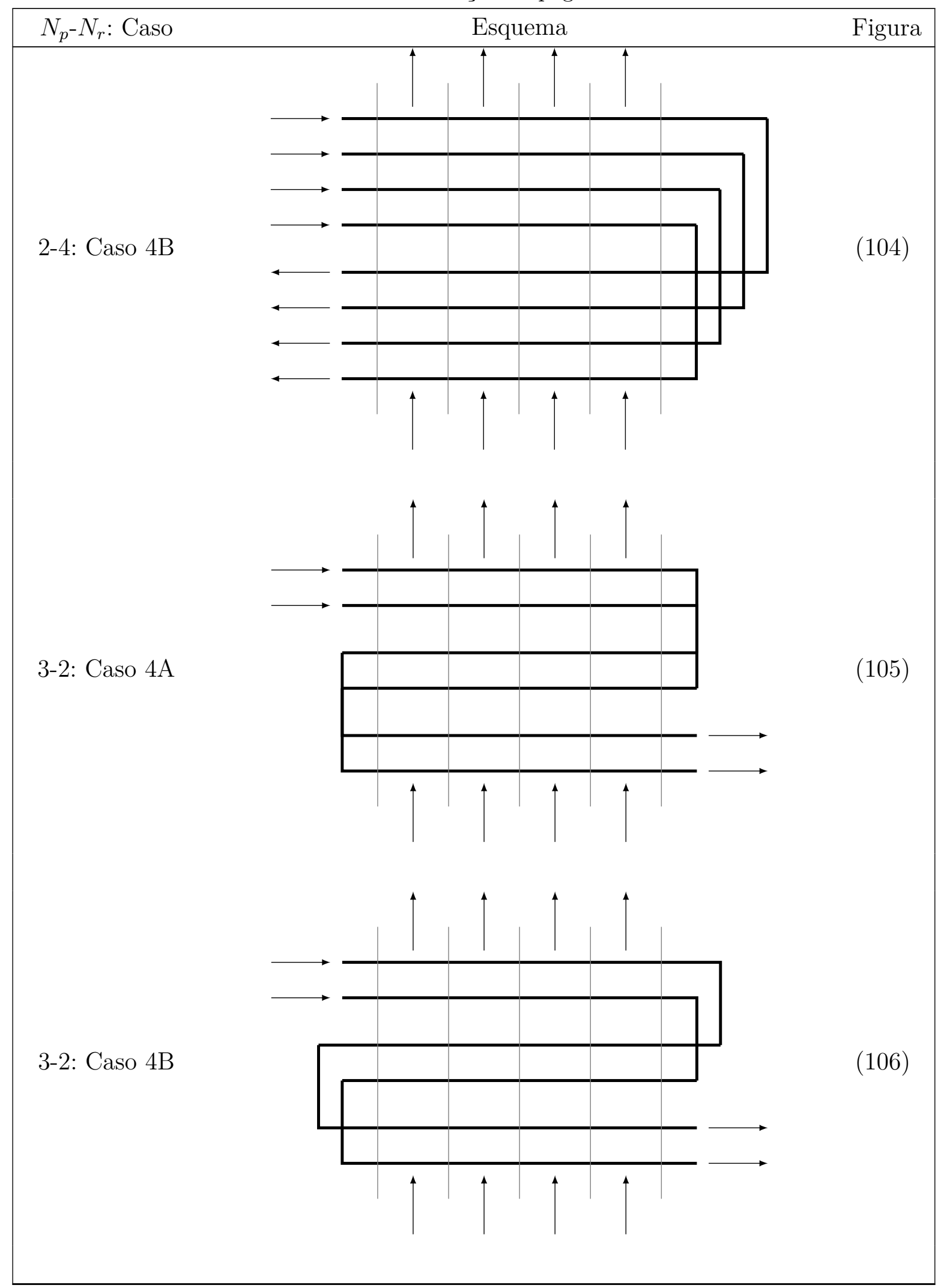





\section{B Dados de Efetividade de Temperatura e Fa- tor de Correção}

Dados de efetividade de temperatura e fator de correção são apresentados para diversas configuração de trocadores de calor de fluxo cruzado.

Tabela 53 - Efetividade de temperatura para trocador de calor de fluxo cruzado com um passe e um tubo por passe (1-1) - Caso 3 ou 4 - trocador de calor ilustrado na Figura 71 do Anexo A

\begin{tabular}{|c|c|c|c|c|c|c|c|c|c|c|c|c|}
\hline${ }^{R}$ & 0,0 & 0,2 & 0,4 & 0,6 & 0,8 & 1,0 & 1,5 & 2,0 & 2,5 & 3,0 & 3,5 & 4,0 \\
\hline 0,0 & 0,000 & 0,000 & 0,000 & 0,000 & 0,000 & 0,000 & 0,000 & 0,000 & 0,000 & 0,000 & 0,000 & 0,000 \\
\hline 0,1 & 0,095 & 0,094 & 0,093 & 0,092 & 0,092 & 0,091 & 0,089 & 0,087 & 0,085 & 0,083 & 0,081 & 0,079 \\
\hline 0,2 & 0,181 & 0,178 & 0,175 & 0,172 & 0,169 & 0,166 & 0,159 & 0,152 & 0,146 & 0,140 & 0,134 & 0,129 \\
\hline 0,3 & 0,259 & 0,253 & 0,246 & 0,240 & 0,234 & 0,228 & 0,215 & 0,202 & 0,191 & 0,180 & 0,170 & 0,161 \\
\hline 0,4 & 0,330 & 0,319 & 0,309 & 0,299 & 0,290 & 0,281 & 0,260 & 0,241 & 0,225 & 0,209 & 0,196 & 0,183 \\
\hline 0,5 & 0,393 & 0,378 & 0,364 & 0,350 & 0,338 & 0,325 & 0,297 & 0,272 & 0,250 & 0,231 & 0,214 & 0,198 \\
\hline 0,6 & 0,451 & 0,431 & 0,413 & 0,395 & 0,379 & 0,363 & 0,328 & 0,297 & 0,271 & 0,247 & 0,227 & 0,209 \\
\hline 0,7 & 0,503 & 0,479 & 0,456 & 0,434 & 0,414 & 0,396 & 0,353 & 0,317 & 0,286 & 0,260 & 0,237 & 0,217 \\
\hline 0,8 & 0,551 & 0,521 & 0,494 & 0,469 & 0,445 & 0,423 & 0,375 & 0,334 & 0,299 & 0,269 & 0,244 & 0,222 \\
\hline 0,9 & 0,593 & 0,560 & 0,528 & 0,499 & 0,472 & 0,448 & 0,393 & 0,347 & 0,309 & 0,277 & 0,250 & 0,227 \\
\hline 1,0 & 0,632 & 0,594 & 0,559 & 0,526 & 0,496 & 0,469 & 0,408 & 0,359 & 0,318 & 0,283 & 0,254 & 0,230 \\
\hline 1,1 & 0,667 & 0,625 & 0,586 & 0,550 & 0,517 & 0,487 & 0,422 & 0,368 & 0,325 & 0,288 & 0,258 & 0,233 \\
\hline 1,2 & 0,699 & 0,652 & 0,610 & 0,571 & 0,535 & 0,503 & 0,433 & 0,376 & 0,330 & 0,292 & 0,261 & 0,235 \\
\hline 1,3 & 0,727 & 0,677 & 0,631 & 0,589 & 0,552 & 0,517 & 0,443 & 0,383 & 0,335 & 0,296 & 0,263 & 0,236 \\
\hline 1,4 & 0,753 & 0,699 & 0,650 & 0,606 & 0,566 & 0,529 & 0,451 & 0,389 & 0,339 & 0,299 & 0,265 & 0,238 \\
\hline 1,5 & 0,777 & 0,720 & 0,668 & 0,621 & 0,579 & 0,540 & 0,459 & 0,394 & 0,343 & 0,301 & 0,267 & 0,239 \\
\hline 1,6 & 0,798 & 0,738 & 0,683 & 0,634 & 0,590 & 0,550 & 0,465 & 0,399 & 0,346 & 0,303 & 68 & 0,240 \\
\hline 1,7 & 0,817 & 0,754 & 0,697 & 0,646 & 0,600 & 0,558 & 0,471 & 0,402 & 0,348 & 0,305 & 0,269 & 0,240 \\
\hline 1,8 & 0,835 & 0,769 & 0,710 & 0,657 & 0,609 & 0,566 & 0,476 & 0,406 & 0,350 & 0,306 & 0,270 & 0,241 \\
\hline 1,9 & 0,850 & 0,782 & & & & & & & & & & 0,242 \\
\hline 2,0 & 0,865 & 0,794 & 0,731 & 0,675 & 0,624 & 0,579 & 0,484 & 0,411 & 0,354 & 0,308 & 0,272 & 0,242 \\
\hline 2,1 & 0,878 & 0,805 & 0,740 & 0,682 & 0,631 & 0,584 & 0,488 & 0,414 & 0,355 & 0,309 & 0,272 & 0,243 \\
\hline 2,2 & 0,889 & 0,815 & 0,748 & 0,689 & 0,636 & 0,589 & 0,491 & 0,416 & & 0,310 & 0,273 & 0,243 \\
\hline 2,3 & 0,900 & 0,823 & 0,756 & 0,695 & 0,641 & 0,593 & 0,494 & 0,417 & 0,358 & 0,311 & 0,273 & 0,243 \\
\hline 2,4 & 0,909 & 0,831 & 0,762 & 0,701 & 0,646 & 0,597 & 0,496 & 0,419 & 0,359 & 0,312 & 0,274 & 0,243 \\
\hline 2,5 & 0,918 & 0,839 & 0,768 & 0,706 & 0,650 & 0,601 & 0,498 & 0,420 & 0,360 & 0,312 & 0,274 & 0,244 \\
\hline 2,6 & 0,926 & 0,845 & 0,774 & 0,710 & 0,654 & 0,604 & 0,500 & 0,421 & 0,360 & 0,313 & 0,275 & 0,244 \\
\hline 2,7 & 0,933 & 0,851 & 0,779 & 0,714 & 0,657 & 0,607 & 0,502 & 0,423 & 0,361 & 0,313 & 0,275 & 0,244 \\
\hline 2,8 & 0,939 & 0,856 & 0,783 & 0,718 & 0,660 & 0,609 & 0,504 & 0,424 & 0,362 & 0,313 & 0,275 & 0,244 \\
\hline 2,9 & 0,945 & 0,861 & 0,787 & 0,721 & 0,663 & 0,611 & 0,505 & 0,424 & 0,362 & 0,314 & 0,275 & 0,244 \\
\hline 3,0 & 0,950 & 0,865 & 0,790 & 0,724 & 0,666 & 0,613 & 0,506 & 0,425 & 0,363 & 0,314 & 0,275 & 0,244 \\
\hline 3,1 & 0,955 & 0,869 & 0,794 & 0,727 & 0,668 & 0,615 & 0,508 & 0,426 & 0,363 & 0,314 & 0,276 & 0,245 \\
\hline 3,2 & 0,959 & 0,873 & 0,797 & 0,729 & 0,670 & 0,617 & 0,509 & 0,427 & 0,364 & 0,315 & 0,276 & 0,245 \\
\hline 3,3 & 0,963 & 0,876 & 0,799 & 0,732 & 0,672 & 0,618 & 0,509 & 0,427 & 0,364 & 0,315 & 0,276 & 0,245 \\
\hline 3,4 & 0,967 & 0,879 & 0,802 & 0,733 & 0,673 & 0,620 & 0,510 & 0,428 & 0,364 & 0,315 & 0,276 & 0,245 \\
\hline 3,5 & 0,970 & 0,882 & 0,804 & 0,735 & 0,675 & 0,621 & 0,511 & 0,428 & 0,365 & 0,315 & 0,276 & 0,245 \\
\hline 3,6 & 0,973 & 0,884 & 0,806 & 0,737 & 0,676 & 0,622 & 0,512 & 0,429 & 0,365 & 0,315 & 0,276 & 0,245 \\
\hline 3,7 & 0,975 & 0,886 & 0,808 & 0,738 & 0,677 & 0,623 & 0,512 & 0,429 & 0,365 & 0,315 & 0,276 & 0,245 \\
\hline
\end{tabular}


Tabela 53 - continuação da página anterior

\begin{tabular}{|c|c|c|c|c|c|c|c|c|c|c|c|c|}
\hline NTU ${ }^{R}$ & 0,0 & 0,2 & 0,4 & 0,6 & 0,8 & 1,0 & 1,5 & 2,0 & 2,5 & 3,0 & 3,5 & 4,0 \\
\hline 3,8 & 0,978 & 0,888 & 0,809 & 0,740 & 0,678 & 0,624 & 0,513 & 0,429 & 0,365 & 0,316 & 0,276 & 0,245 \\
\hline 3,9 & 0,980 & 0,890 & 0,811 & 0,741 & 0,679 & 0,625 & 0,513 & 0,430 & 0,365 & 0,316 & 0,276 & 0,245 \\
\hline 4,0 & 0,982 & 0,891 & 0,812 & 0,742 & 0,680 & 0,625 & 0,514 & 0,430 & 0,366 & 0,316 & 0,277 & 0,245 \\
\hline 4,1 & 0,983 & 0,893 & 0,813 & 0,743 & 0,681 & 0,626 & 0,514 & 0,430 & 0,366 & 0,316 & 0,277 & 0,245 \\
\hline 4,2 & 0,985 & 0,894 & 0,814 & 0,744 & 0,682 & 0,627 & 0,515 & 0,430 & 0,366 & 0,316 & 0,277 & 0,245 \\
\hline 4,3 & 0,986 & 0,895 & 0,815 & 0,745 & 0,682 & 0,627 & 0,515 & 0,430 & 0,366 & 0,316 & 0,277 & 0,245 \\
\hline 4,4 & 0,988 & 0,896 & 0,816 & 0,745 & 0,683 & 0,628 & 0,515 & 0,431 & 0,366 & 0,316 & 0,277 & 0,245 \\
\hline 4,5 & 0,989 & 0,897 & 0,817 & 0,746 & 0,683 & 0,628 & 0,515 & 0,431 & 0,366 & 0,316 & 0,277 & 0,245 \\
\hline 4,6 & 0,990 & 0,898 & 0,817 & 0,746 & 0,684 & 0,628 & 0,516 & 0,431 & 0,366 & 0,316 & 0,277 & 0,245 \\
\hline 4,7 & 0,991 & 0,899 & 0,818 & 0,747 & 0,684 & 0,629 & 0,516 & 0,431 & 0,366 & 0,316 & 0,277 & 0,245 \\
\hline 4,8 & 0,992 & 0,900 & 0,819 & 0,747 & 0,685 & 0,629 & 0,516 & 0,431 & 0,366 & 0,316 & 0,277 & 0,245 \\
\hline 4,9 & 0,993 & 0,900 & 0,819 & 0,748 & 0,685 & 0,629 & 0,516 & 0,431 & 0,367 & 0,316 & 0,277 & 0,245 \\
\hline 5,0 & 0,993 & 0,901 & 0,820 & 0,748 & 0,685 & 0,630 & 0,516 & 0,431 & 0,367 & 0,316 & 0,277 & 0,245 \\
\hline 5,1 & 0,994 & 0,901 & 0,820 & 0,749 & 0,686 & 0,630 & 0,517 & 0,432 & 0,367 & 0,316 & 0,277 & 0,245 \\
\hline 5,2 & 0,994 & 0,902 & 0,820 & 0,749 & 0,686 & 0,630 & 0,517 & 0,432 & 0,367 & 0,316 & 0,277 & 0,245 \\
\hline 5,3 & 0,995 & 0,902 & 0,821 & 0,749 & 0,686 & 0,630 & 0,517 & 0,432 & 0,367 & 0,316 & 0,277 & 0,245 \\
\hline 5,4 & 0,995 & 0,903 & 0,821 & 0,749 & 0,686 & 0,630 & 0,517 & 0,432 & 0,367 & 0,317 & 0,277 & 0,245 \\
\hline 5,5 & 0,996 & 0,903 & 0,821 & 0,750 & 0,686 & 0,631 & 0,517 & 0,432 & 0,367 & 0,317 & 0,277 & 0,245 \\
\hline 5,6 & 0,996 & 0,903 & 0,822 & 0,750 & 0,687 & 0,631 & 0,517 & 0,432 & 0,367 & 0,317 & 0,277 & 0,245 \\
\hline 5,7 & 0,997 & 0,904 & 0,822 & 0,750 & 0,687 & 0,631 & 0,517 & 0,432 & 0,367 & 0,317 & 0,277 & 0,245 \\
\hline 5,8 & 0,997 & 0,904 & 0,822 & 0,750 & 0,687 & 0,631 & 0,517 & 0,432 & 0,367 & 0,317 & 0,277 & 0,245 \\
\hline 5,9 & 0,997 & 0,904 & 0,822 & 0,750 & 0,687 & 0,631 & 0,517 & 0,432 & 0,367 & 0,317 & 0,277 & 0,245 \\
\hline 6,0 & 0,997 & 0,904 & 0,823 & 0,751 & 0,687 & 0,631 & 0,517 & 0,432 & 0,367 & 0,317 & 0,277 & 0,245 \\
\hline 6,1 & 0,998 & 0,905 & 0,823 & 0,751 & 0,687 & 0,631 & 0,517 & 0,432 & 0,367 & 0,317 & 0,277 & 0,245 \\
\hline 6,2 & 0,998 & 0,905 & 0,823 & 0,751 & 0,687 & 0,631 & 0,517 & 0,432 & 0,367 & 0,317 & 0,277 & 0,245 \\
\hline 6,3 & 0,998 & 0,905 & 0,823 & 0,751 & 0,688 & 0,631 & 0,518 & 0,432 & 0,367 & 0,317 & 0,277 & 0,245 \\
\hline 6,4 & 0,998 & 0,905 & 0,823 & 0,751 & 0,688 & 0,631 & 0,518 & 0,432 & 0,367 & 0,317 & 0,277 & 0,245 \\
\hline 6,5 & 0,998 & 0,905 & 0,823 & 0,751 & 0,688 & 0,632 & 0,518 & 0,432 & 0,367 & 0,317 & 0,277 & 0,245 \\
\hline 6,6 & 0,999 & 0,905 & 0,823 & 0,751 & 0,688 & 0,632 & 0,518 & 0,432 & 0,367 & 0,317 & 0,277 & 0,245 \\
\hline 6,7 & 0,999 & 0,905 & 0,823 & 0,751 & 0,688 & 0,632 & 0,518 & 0,432 & 0,367 & 0,317 & 0,277 & 0,245 \\
\hline 6,8 & 0,999 & 0,905 & 0,823 & 0,751 & 0,688 & 0,632 & 0,518 & 0,432 & 0,367 & 0,317 & 0,277 & 0,245 \\
\hline 6,9 & 0,999 & 0,906 & 0,824 & 0,751 & 0,688 & 0,632 & 0,518 & 0,432 & 0,367 & 0,317 & 0,277 & 0,245 \\
\hline 7,0 & 0,999 & 0,906 & 0,824 & 0,751 & 0,688 & 0,632 & 0,518 & 0,432 & 0,367 & 0,317 & 0,277 &, 245 \\
\hline 7,1 & 0,999 & 0,906 & 0,824 & 0,752 & 0,688 & 0,632 & 0,518 & 0,432 & 0,367 & 0,317 & 0,277 & 45 \\
\hline 7,2 & 999 & 0,906 & & 0,752 & 0,688 & 0,632 & 0 & 0,432 & 0,367 & 0,317 & 0,277 & 0,245 \\
\hline 7,3 & 0,999 & 0,906 & & 0,752 & 0,688 & 0,632 & 0, & 0 , & 0,367 & 0,317 & 0,277 & 0,245 \\
\hline 7,4 & 0,999 & 0,906 & 0,824 & 0,752 & 0,688 & 0,632 & 0,518 & 0,432 & 0,367 & 0,317 & 0,277 & 0,245 \\
\hline 7,5 & 0,999 & 0,906 & 0,824 & 0,752 & 0,688 & 0,632 & 0,518 & 0,432 & 0,367 & 0,317 & 0,277 & 0,245 \\
\hline 7,6 & 0,999 & 0,9 & 0,8 & 0,752 & 0,688 & 0,632 & 0 & 0,432 & 0,367 & 0,317 & 0,277 & 0,245 \\
\hline 7,7 & 0,999 & 0,906 & 0,8 & 0,752 & 0,688 & 0,632 & 0,518 & 0,432 & 0,367 & 0,317 & 0,277 & 0,245 \\
\hline 7,8 & 1,000 & 0,906 & 0,824 & 0,752 & 0,688 & 0,632 & 0,518 & 0,432 & 0,367 & 0,317 & 0,277 & 0,245 \\
\hline 7,9 & 1,000 & 0,906 & 0,824 & 0,752 & 0,688 & 0,632 & 0,518 & 0,432 & 0,367 & 0,317 & 0,277 & 0,245 \\
\hline 8,0 & 1,000 & 0,906 & 0,824 & 0,752 & 0,688 & 0,632 & 0,518 & 0,432 & 0,367 & 0,317 & 0,277 & 0,245 \\
\hline 8,1 & 1,000 & 0,906 & 0,824 & 0,752 & 0,688 & 0,632 & 0,518 & 0,432 & 0,367 & 0,317 & 0,277 & 0,245 \\
\hline 8,2 & 1,000 & 0,906 & 0,824 & 0,752 & 0,688 & 0,632 & 0,518 & 0,432 & 0,367 & 0,317 & 0,277 & 0,245 \\
\hline 8,3 & 1,000 & 0,906 & 0,824 & 0,752 & 0,688 & 0,632 & 0,518 & 0,432 & 0,367 & 0,317 & 0,277 & 0,245 \\
\hline 8,4 & 1,000 & 0,906 & 0,824 & 0,752 & 0,688 & 0,632 & 0,518 & 0,432 & 0,367 & 0,317 & 0,277 & 0,245 \\
\hline 8,5 & 1,000 & 0,906 & 0,824 & 0,752 & 0,688 & 0,632 & 0,518 & 0,432 & 0,367 & 0,317 & 0,277 & 0,245 \\
\hline 8,6 & 1,000 & 0,906 & 0,824 & 0,752 & 0,688 & 0,632 & 0,518 & 0,432 & 0,367 & 0,317 & 0,277 & 0,245 \\
\hline 8,7 & 1,000 & 0,906 & 0,824 & 0,752 & 0,688 & 0,632 & 0,518 & 0,432 & 0,367 & 0,317 & 0,277 & 0,245 \\
\hline 8,8 & 1,000 & 0,906 & 0,824 & 0,752 & 0,688 & 0,632 & 0,518 & 0,432 & 0,367 & 0,317 & 0,277 & 0,245 \\
\hline 8,9 & 1,000 & 0,906 & 0,824 & 0,752 & 0,688 & 0,632 & 0,518 & 0,432 & 0,367 & 0,317 & 0,277 & 0,245 \\
\hline 9,0 & 1,000 & 0,906 & 0,824 & 0,752 & 0,688 & 0,632 & 0,518 & 0,432 & 0,367 & 0,317 & 0,277 & 0,245 \\
\hline
\end{tabular}


Tabela 53 - continuação da página anterior

\begin{tabular}{|c|cccccccccccc|}
\hline NTU & \multirow{2}{*}{0,0} & 0,2 & 0,4 & 0,6 & 0,8 & 1,0 & 1,5 & 2,0 & 2,5 & 3,0 & 3,5 & 4,0 \\
\hline 9,1 & 1,000 & 0,906 & 0,824 & 0,752 & 0,688 & 0,632 & 0,518 & 0,432 & 0,367 & 0,317 & 0,277 & 0,245 \\
9,2 & 1,000 & 0,906 & 0,824 & 0,752 & 0,688 & 0,632 & 0,518 & 0,432 & 0,367 & 0,317 & 0,277 & 0,245 \\
9,3 & 1,000 & 0,906 & 0,824 & 0,752 & 0,688 & 0,632 & 0,518 & 0,432 & 0,367 & 0,317 & 0,277 & 0,245 \\
9,4 & 1,000 & 0,906 & 0,824 & 0,752 & 0,688 & 0,632 & 0,518 & 0,432 & 0,367 & 0,317 & 0,277 & 0,245 \\
9,5 & 1,000 & 0,906 & 0,824 & 0,752 & 0,688 & 0,632 & 0,518 & 0,432 & 0,367 & 0,317 & 0,277 & 0,245 \\
9,6 & 1,000 & 0,906 & 0,824 & 0,752 & 0,688 & 0,632 & 0,518 & 0,432 & 0,367 & 0,317 & 0,277 & 0,245 \\
9,7 & 1,000 & 0,906 & 0,824 & 0,752 & 0,688 & 0,632 & 0,518 & 0,432 & 0,367 & 0,317 & 0,277 & 0,245 \\
9,8 & 1,000 & 0,906 & 0,824 & 0,752 & 0,688 & 0,632 & 0,518 & 0,432 & 0,367 & 0,317 & 0,277 & 0,245 \\
9,9 & 1,000 & 0,906 & 0,824 & 0,752 & 0,688 & 0,632 & 0,518 & 0,432 & 0,367 & 0,317 & 0,277 & 0,245 \\
10,0 & 1,000 & 0,906 & 0,824 & 0,752 & 0,688 & 0,632 & 0,518 & 0,432 & 0,367 & 0,317 & 0,277 & 0,245 \\
\hline
\end{tabular}

Tabela 54 - Fator de correção para trocador de calor de fluxo cruzado com um passe e um tubo por passe (1-1) - Caso 3 ou 4 - trocador de calor ilustrado na Figura 71 do Anexo A

\begin{tabular}{|c|c|c|c|c|c|c|c|c|c|c|c|c|}
\hline $\mathrm{NTU}^{R}$ & 0,0 & 0,2 & 0,4 & 0,6 & 0,8 & 1,0 & 1,5 & 2,0 & 2,5 & 3,0 & 3,5 & 4,0 \\
\hline 0,0 & 1,000 & 1,000 & 1,000 & 1,000 & 1,000 & 1,000 & 1,000 & 1,000 & 1,000 & 1,000 & 1,000 & 1,000 \\
\hline 0,1 & 1,000 & 1,000 & 0,999 & 0,999 & 0,999 & 0,998 & 0,998 & 0,997 & 0,996 & 0,995 & 0,995 & 0,994 \\
\hline 0,2 & 1,000 & 0,999 & 0,997 & 0,996 & 0,995 & 0,994 & 0,991 & 0,988 & 0,985 & 0,983 & 0,981 & 0,978 \\
\hline 0,3 & 1,000 & 0,997 & 0,994 & 0,991 & 0,989 & 0,986 & 0,980 & 0,975 & 0,970 & 0,965 & 0,960 & 0,956 \\
\hline 0,4 & 1,000 & 0,995 & 0,990 & 0,985 & 0,981 & 0,976 & 0,966 & 0,958 & 0,950 & 0,943 & 0,936 & 0,930 \\
\hline 0,5 & 1,000 & 0,992 & 0,984 & 0,977 & 0,970 & 0,964 & 0,950 & 0,938 & 0,927 & 0,918 & 0,909 & 0,902 \\
\hline 0,6 & 1,000 & 0,988 & 0,978 & 0,968 & 0,959 & 0,950 & 0,932 & 0,916 & 0,903 & 0,891 & 0,881 & 0,872 \\
\hline 0,7 & 1,000 & 0,984 & 0,970 & 0,957 & 0,945 & 0,935 & 0,912 & 0,893 & 0,877 & 0,864 & 0,853 & 0,843 \\
\hline 0,8 & 1,000 & 0,979 & 0,961 & 0,945 & 0,931 & 0,918 & 0,891 & 0,869 & 0,851 & 0,836 & 0,824 & 0,813 \\
\hline 0,9 & 1,000 & 0,974 & 0,952 & 0,932 & 0,915 & 0,900 & 0,869 & 0,845 & 0,825 & 0,809 & 0,795 & 0,784 \\
\hline 1,0 & 1,000 & 0,968 & 0,941 & 0,919 & 0,899 & 0,882 & 0,847 & 0,820 & 0,799 & 0,782 & 0,768 & 0,756 \\
\hline 1,1 & 1,000 & 0,962 & 0,930 & 0,904 & 0,882 & 0,862 & 0,824 & 0,795 & 0,773 & 0,755 & 0,741 & 0,728 \\
\hline 1,2 & 1,000 & 0,954 & 0,918 & 0,889 & 0,864 & 0,843 & 0,801 & 0,771 & 0,748 & 0,729 & 0,714 & 0,702 \\
\hline 1,3 & 1,000 & 0,947 & 0,906 & 0,873 & 0,846 & 0,823 & 0,779 & 0,747 & 0,723 & 0,705 & 0,689 & 0,677 \\
\hline 1,4 & 1,000 & 0,939 & 0,893 & 0,857 & 0,827 & 0,803 & 0,757 & 0,724 & 0,700 & 0,681 & 0,665 & 0,653 \\
\hline 1,5 & 1,000 & 0,930 & 0,879 & 0,840 & 0,809 & 0,783 & 0,735 & 0,702 & 0,677 & 0,658 & 0,642 & 0,630 \\
\hline 1,6 & 1,000 & 0,921 & 0,865 & 0,823 & 0,790 & 0,763 & 0,714 & 0,680 & 0,655 & 0,635 & 0,620 & 0,608 \\
\hline 1,7 & 1,000 & 0,911 & 0,851 & 0,806 & 0,772 & 0,744 & 0,693 & 0,659 & 0,633 & 0,614 & 0,599 & 0,587 \\
\hline 1,8 & 1,000 & 0,901 & 0,836 & 0,789 & 0,753 & 0,725 & 0,673 & 0,638 & 0,613 & 0,594 & 0,579 & 0,567 \\
\hline 1,9 & 1,000 & 0,890 & 0,821 & 0,772 & 0,735 & 0,706 & 0,653 & 0,619 & 0,594 & 0,575 & 0,560 & 0,548 \\
\hline 2,0 & 1,000 & 0,879 & 0,806 & 0,755 & 0,717 & 0,687 & 0,635 & 0,600 & 0,575 & 0,556 & 0,542 & 0,530 \\
\hline 2,1 & 1,000 & 0,868 & 0,791 & 0,738 & 0,699 & 0,669 & 0,616 & 0,582 & 0,557 & 0,539 & 0,524 & 0,513 \\
\hline 2,2 & 1,000 & 0,857 & 0,776 & 0,721 & 0,682 & 0,651 & 0,599 & 0,564 & 0,540 & 0,522 & 0,508 & 0,497 \\
\hline 2,3 & 1,000 & 0,845 & 0,760 & 0,705 & 0,665 & 0,634 & 0,582 & 0,548 & 0,524 & 0,506 & 0,492 & 0,481 \\
\hline 2,4 & 1,000 & 0,832 & 0,745 & 0,689 & 0,648 & 0,618 & 0,565 & 0,532 & 0,508 & 0,491 & 0,477 & 0,466 \\
\hline 2,5 & 1,000 & 0,820 & 0,730 & 0,673 & 0,632 & 0,602 & 0,550 & 0,516 & 0,493 & 0,476 & 0,463 & 0,452 \\
\hline 2,6 & 1,000 & 0,808 & 0,715 & 0,657 & 0,617 & 0,586 & 0,534 & 0,502 & 0,479 & 0,462 & 0,449 & 0,439 \\
\hline 2,7 & 1,000 & 0,795 & 0,700 & 0,642 & 0,601 & 0,571 & 0,520 & 0,488 & 0,465 & 0,449 & 0,436 & 0,426 \\
\hline 2,8 & 1,000 & 0,782 & 0,686 & 0,627 & 0,587 & 0,556 & 0,506 & 0,474 & 0,452 & 0,436 & 0,424 & 0,414 \\
\hline 2,9 & 1,000 & 0,769 & 0,671 & 0,613 & 0,572 & 0,542 & 0,492 & 0,461 & 0,440 & 0,424 & 0,412 & 0,402 \\
\hline 3,0 & 1,000 & 0,756 & 0,657 & 0,598 & 0,558 & 0,529 & 0,480 & 0,449 & 0,428 & 0,412 & 0,400 & 0,391 \\
\hline 3,1 & 1,000 & 0,743 & 0,643 & 0,585 & 0,545 & 0,516 & 0,467 & 0,437 & 0,416 & 0,401 & 0,390 & 0,381 \\
\hline 3,2 & 1,000 & 0,731 & 0,630 & 0,571 & 0,532 & 0,503 & 0,455 & 0,426 & 0,405 & 0,391 & 0,379 & 0,370 \\
\hline 3,3 & 1,000 & 0,718 & 0,616 & 0,558 & 0,519 & 0,491 & 0,444 & 0,415 & 0,395 & 0,381 & 0,369 & 0,361 \\
\hline 3,4 & 1,000 & 0,705 & 0,604 & 0,546 & 0,507 & 0,479 & 0,433 & 0,404 & 0,385 & 0,371 & 0,360 & 0,352 \\
\hline 3,5 & 1,000 & 0,693 & 0,591 & 0,534 & 0,496 & 0,468 & 0,422 & 0,395 & 0,375 & 0,362 & 0,351 & 0,343 \\
\hline
\end{tabular}


Tabela 54 - continuação da página anterior

\begin{tabular}{|c|c|c|c|c|c|c|c|c|c|c|c|c|}
\hline NTU ${ }^{R}$ & 0,0 & 0,2 & 0,4 & 0,6 & 0,8 & 1,0 & 1,5 & 2,0 & 2,5 & 3,0 & 3,5 & 4,0 \\
\hline 3,6 & 1,000 & 0,680 & 0,579 & 0,522 & 0,484 & 0,457 & 0,412 & 0,385 & 0,366 & 0,353 & 0,342 & 0,334 \\
\hline 3,7 & 1,000 & 0,668 & 0,567 & 0,510 & 0,473 & 0,446 & 0,403 & 0,376 & 0,357 & 0,344 & 0,334 & 0,326 \\
\hline 3,8 & 1,000 & 0,656 & 0,555 & 0,499 & 0,463 & 0,436 & 0,393 & 0,367 & 0,349 & 0,336 & 0,326 & 0,318 \\
\hline 3,9 & 0,999 & 0,644 & 0,544 & 0,489 & 0,453 & 0,427 & 0,384 & 0,359 & 0,341 & 0,328 & 0,319 & 0,311 \\
\hline 4,0 & 0,999 & 0,632 & 0,532 & 0,478 & 0,443 & 0,417 & 0,376 & 0,350 & 0,333 & 0,321 & 0,311 & 0,304 \\
\hline 4,1 & 0,999 & 0,621 & 0,522 & 0,468 & 0,433 & 0,408 & 0,367 & 0,343 & 0,326 & 0,313 & 0,304 & 0,297 \\
\hline 4,2 & 0,999 & 0,609 & 0,511 & 0,459 & 0,424 & 0,399 & 0,359 & 0,335 & 0,319 & 0,307 & 0,297 & 0,290 \\
\hline 4,3 & 0,999 & 0,598 & 0,501 & 0,449 & 0,415 & 0,391 & 0,352 & 0,328 & 0,312 & 0,300 & 0,291 & 0,284 \\
\hline 4,4 & 0,999 & 0,588 & 0,491 & 0,440 & 0,407 & 0,383 & 0,344 & 0,321 & 0,305 & 0,294 & 0,285 & 0,278 \\
\hline 4,5 & 0,999 & 0,577 & 0,482 & 0,431 & 0,399 & 0,375 & 0,337 & 0,314 & 0,299 & 0,287 & 0,279 & 0,272 \\
\hline 4,6 & 0,999 & 0,567 & 0,473 & 0,423 & 0,391 & 0,368 & 0,330 & 0,308 & 0,293 & 0,281 & 0,273 & 0,267 \\
\hline 4,7 & 0,999 & 0,557 & 0,464 & 0,415 & 0,383 & 0,360 & 0,324 & 0,302 & 0,287 & 0,276 & 0,268 & 0,261 \\
\hline 4,8 & 0,999 & 0,547 & 0,455 & 0,407 & 0,376 & 0,353 & 0,317 & 0,296 & 0,281 & 0,270 & 0,262 & 0,256 \\
\hline 4,9 & 0,999 & 0,537 & 0,447 & 0,399 & 0,368 & 0,347 & 0,311 & 0,290 & 0,275 & 0,265 & 0,257 & 0,251 \\
\hline 5,0 & 0,999 & 0,528 & 0,439 & 0,392 & 0,362 & 0,340 & 0,305 & 0,284 & 0,270 & 0,260 & 0,252 & 0,246 \\
\hline 5,1 & 0,998 & 0,519 & 0,431 & 0,385 & 0,355 & 0,334 & 0,300 & 0,279 & 0,265 & 0,255 & 0,247 & 0,241 \\
\hline 5,2 & 0,998 & 0,510 & 0,423 & 0,378 & 0,348 & 0,328 & 0,294 & 0,274 & 0,260 & 0,250 & 0,243 & 0,237 \\
\hline 5,3 & 0,998 & 0,502 & 0,416 & 0,371 & 0,342 & 0,322 & 0,289 & 0,269 & 0,255 & 0,246 & 0,238 & 0,233 \\
\hline 5,4 & 0,998 & 0,493 & 0,408 & 0,364 & 0,336 & 0,316 & 0,284 & 0,264 & 0,251 & 0,241 & 0,234 & 0,228 \\
\hline 5,5 & 0,998 & 0,485 & 0,401 & 0,358 & 0,330 & 0,310 & 0,279 & 0,259 & 0,246 & 0,237 & 0,230 & 0,224 \\
\hline 5,6 & 0,998 & 0,477 & 0,395 & 0,352 & 0,325 & 0,305 & 0,274 & 0,255 & 0,242 & 0,233 & 0,226 & 0,220 \\
\hline 5,7 & 0,997 & 0,469 & 0,388 & 0,346 & 0,319 & 0,300 & 0,269 & 0,251 & 0,238 & 0,229 & 0,222 & 0,217 \\
\hline 5,8 & 0,997 & 0,462 & 0,3 & 0,340 & 0,314 & 0,295 & 0,265 & 0,246 & 0,234 & 0,225 & 0,218 & 0,213 \\
\hline 5,9 & 0,997 & 0,454 & 0,3 & 0,335 & 0,309 & 0,290 & 0,260 & 0,242 & 0,230 & 0,221 & 0,215 & 0,209 \\
\hline 6,0 & 0,997 & 0,447 & 0,369 & 0,329 & 0,304 & 0,285 & 0,256 & 0,238 & 0,226 & 0,218 & 0,211 & 0,206 \\
\hline 6,1 & 0,996 & 0,440 & 0,364 & 0,324 & 0,299 & 0,281 & 0,252 & 0,234 & 0,223 & 0,214 & 0,208 & 0,203 \\
\hline 6,2 & 0,996 & 0,434 & 0,358 & 0,319 & 0,294 & 0,276 & 0,248 & 0,231 & 0,219 & 0,211 & 0,204 & 0,199 \\
\hline 6,3 & 0,996 & 0,427 & 0,352 & 0,314 & 0,289 & 0,272 & 0,244 & 0,227 & 0,216 & 0,207 & 0,201 & 0,196 \\
\hline 6,4 & 0,995 & 0,421 & 0,347 & 0,309 & 0,285 & 0,268 & 0,240 & 0,224 & 0,212 & 0,204 & 0,198 & 0,193 \\
\hline 6,5 & 0,995 & 0,414 & 0,342 & 0,305 & 0,281 & 0,264 & 0,237 & 0,220 & 0,209 & 0,201 & 0,195 & 0,190 \\
\hline 6,6 & 0,995 & 0,408 & 0,337 & 0,300 & 0,276 & 0,260 & 0,233 & 0,217 & 0,206 & 0,198 & 0,192 & 0,188 \\
\hline 6,7 & 0,994 & 0,403 & 0,332 & 0,296 & 0,272 & 0,256 & 0,230 & 0,214 & 0,203 & 0,195 & 0,189 & 0,185 \\
\hline 6,8 & 0,994 & 0,397 & 0,327 & 0,291 & 0,268 & 0,252 & 0,226 & 0,211 & 0,200 & 0,192 & 0,187 & 82 \\
\hline 6,9 & 0,993 & 0,391 & 0,322 & 0,287 & 0,265 & 0,249 & 0,223 & 0,208 & 97 & 0,190 & 0,184 & 0,179 \\
\hline 7,0 & 992 & 0,386 & & 0,283 & 0,261 & 0,245 & 0 & 0 , & 0,194 & 0,187 & 0,181 & 0,177 \\
\hline 7,1 & 0,992 & 0,380 & 0 & 0 & 0,257 & 0,242 & 0 , & 0,202 & 0,192 & 0,184 & 0,179 & 0,174 \\
\hline 7,2 & 0,991 & 0,375 & 0,309 & 0,275 & 0,254 & 0,238 & 0,214 & 0,199 & 0,189 & 0,182 & 0,176 & 0,172 \\
\hline 7,3 & 0,990 & 0,370 & 0, & 0,272 & 0,250 & 0,235 & 0 & 0,196 & 0,186 & 0,179 & 0,174 & 0,170 \\
\hline 7,4 & 0,989 & 0,365 & 0,3 & 0,268 & 0,247 & 0,232 & 0 , & 0,194 & 0,184 & 0,177 & 0,172 & 0,167 \\
\hline 7,5 & 0,989 & 0,361 & 0,2 & 0,264 & 0 & 0,229 & 0 & 0 & 0,181 & 0,175 & 0,169 & 0,165 \\
\hline 7,6 & 0,988 & 0,356 & 0,293 & 0,261 & 0,240 & 0,226 & 0,203 & 0,189 & 0,179 & 0,172 & 0,167 & 0,163 \\
\hline 7,7 & 0,986 & 0,351 & 0,289 & 0,258 & 0,237 & 0,223 & 0,200 & 0,186 & 0,177 & 0,170 & 0,165 & 0,161 \\
\hline 7,8 & 0,985 & 0,347 & 0,286 & 0,254 & 0,234 & 0,220 & 0,197 & 0,184 & 0,174 & 0,168 & 0,163 & 0,159 \\
\hline 7,9 & 0,984 & 0,343 & 0,282 & 0,251 & 0,231 & 0,217 & 0,195 & 0,181 & 0,172 & 0,166 & 0,161 & 0,157 \\
\hline 8,0 & 0,983 & 0,338 & 0,279 & 0,248 & 0,229 & 0,215 & 0,193 & 0,179 & 0,170 & 0,164 & 0,159 & 0,155 \\
\hline 8,1 & 0,981 & 0,334 & 0,275 & 0,245 & 0,226 & 0,212 & 0,190 & 0,177 & 0,168 & 0,162 & 0,157 & 0,153 \\
\hline 8,2 & 0,980 & 0,330 & 0,272 & 0,242 & 0,223 & 0,209 & 0,188 & 0,175 & 0,166 & 0,160 & 0,155 & 0,151 \\
\hline 8,3 & 0,978 & 0,326 & 0,269 & 0,239 & 0,220 & 0,207 & 0,186 & 0,173 & 0,164 & 0,158 & 0,153 & 0,149 \\
\hline 8,4 & 976 & 0,322 & 0,265 & 0,236 & 0,218 & 0,204 & 0,183 & 0,171 & 0,162 & 0,156 & 0,151 & 0,148 \\
\hline 8,5 & 0,974 & 0,319 & 0,262 & 0,234 & 0,215 & 0,202 & 0,181 & 0,169 & 0,160 & 0,154 & 0,149 & 0,146 \\
\hline 8,6 & 0,972 & 0,315 & 0,259 & 0,231 & 0,213 & 0,200 & 0,179 & 0,167 & 0,158 & 0,152 & 0,148 & 0,144 \\
\hline 8,7 & 0,970 & 0,311 & 0,256 & 0,228 & 0,210 & 0,197 & 0,177 & 0,165 & 0,156 & 0,150 & 0,146 & 0,142 \\
\hline 8,8 & 0,968 & 0,308 & 0,253 & 0,226 & 0,208 & 0,195 & 0,175 & 0,163 & 0,155 & 0,149 & 0,144 & 0,141 \\
\hline
\end{tabular}


Tabela 54 - continuação da página anterior

\begin{tabular}{|c|ccccccccccccc|}
\hline NTU $^{R}$ & 0,0 & 0,2 & 0,4 & 0,6 & 0,8 & 1,0 & 1,5 & 2,0 & 2,5 & 3,0 & 3,5 & 4,0 \\
\hline 8,9 & 0,965 & 0,304 & 0,251 & 0,223 & 0,205 & 0,193 & 0,173 & 0,161 & 0,153 & 0,147 & 0,143 & 0,139 \\
9,0 & 0,962 & 0,301 & 0,248 & 0,221 & 0,203 & 0,191 & 0,171 & 0,159 & 0,151 & 0,145 & 0,141 & 0,138 \\
9,1 & 0,959 & 0,298 & 0,245 & 0,218 & 0,201 & 0,189 & 0,169 & 0,158 & 0,150 & 0,144 & 0,140 & 0,136 \\
9,2 & 0,956 & 0,294 & 0,242 & 0,216 & 0,199 & 0,187 & 0,167 & 0,156 & 0,148 & 0,142 & 0,138 & 0,135 \\
9,3 & 0,953 & 0,291 & 0,240 & 0,213 & 0,197 & 0,185 & 0,166 & 0,154 & 0,146 & 0,141 & 0,137 & 0,133 \\
9,4 & 0,950 & 0,288 & 0,237 & 0,211 & 0,195 & 0,183 & 0,164 & 0,153 & 0,145 & 0,139 & 0,135 & 0,132 \\
9,5 & 0,946 & 0,285 & 0,235 & 0,209 & 0,193 & 0,181 & 0,162 & 0,151 & 0,143 & 0,138 & 0,134 & 0,130 \\
9,6 & 0,943 & 0,282 & 0,232 & 0,207 & 0,191 & 0,179 & 0,160 & 0,149 & 0,142 & 0,136 & 0,132 & 0,129 \\
9,7 & 0,939 & 0,279 & 0,230 & 0,205 & 0,189 & 0,177 & 0,159 & 0,148 & 0,140 & 0,135 & 0,131 & 0,128 \\
9,8 & 0,935 & 0,276 & 0,228 & 0,203 & 0,187 & 0,175 & 0,157 & 0,146 & 0,139 & 0,134 & 0,130 & 0,126 \\
9,9 & 0,930 & 0,274 & 0,225 & 0,201 & 0,185 & 0,174 & 0,156 & 0,145 & 0,138 & 0,132 & 0,128 & 0,125 \\
10,0 & 0,926 & 0,271 & 0,223 & 0,199 & 0,183 & 0,172 & 0,154 & 0,143 & 0,136 & 0,131 & 0,127 & 0,124 \\
\hline
\end{tabular}

Tabela 55 - Efetividade de temperatura para trocador de calor de fluxo cruzado com um passe e dois tubos por passe (1-2) - Caso 3 ou 4 - trocador de calor ilustrado na Figura 72 do Anexo A

\begin{tabular}{|c|c|c|c|c|c|c|c|c|c|c|c|c|}
\hline TU & 0,0 & 0,2 & 0,4 & 0,6 & 0,8 & 1,0 & 1,5 & 2,0 & 2,5 & 3,0 & 3,5 & 4,0 \\
\hline 0,0 & ,000 & 0,000 & 0,000 & 0,000 & 0,000 & 0,000 & 0,000 & 0,000 & 0,000 & 0,000 & 0,000 & 0,000 \\
\hline 0,1 & 095 & 0,094 & 0,093 & 0,092 & 0,092 & 0,091 & 089 & 087 & 085 & 33 & 0,081 & 0,079 \\
\hline 0,2 & 0,181 & 0,178 & 0,175 & 0,172 & 0,169 & 0,166 & 0,159 & 152 & 46 & 0,140 & 0,134 & 0,129 \\
\hline 0,3 & 0,259 & 0,253 & 0,246 & 0,240 & 0,234 & 0,228 & 0,215 & 0,202 & 0,191 & 0,180 & 0,171 & 0,162 \\
\hline 0,4 & 0,330 & 0,319 & 0,309 & 0,299 & 0,290 & 0,281 & 0,261 & 0,242 & 0,225 & 0,210 & 0,196 & 0,184 \\
\hline 0,5 & 0,393 & 0,379 & 0,364 & 0,351 & 0,338 & 0,326 & 0,298 & 0,273 & 0,251 & 0,232 & 0,215 & 0,199 \\
\hline 0,6 & 0,451 & 0,432 & 0,414 & 0,396 & 0,380 & 0,364 & 0,329 & 0,299 & 0,272 & 0,249 & 0,228 & 0,210 \\
\hline 0,7 & 0,503 & 0,480 & 0,457 & 0,436 & 0,416 & 0,398 & 0,356 & ,320 & 0,289 & 0,262 & 0,239 & 0,218 \\
\hline 0,8 & 551 & 0,522 & 0,496 & 0,471 & 0,448 & 0,427 & 0,378 & ,337, & 302 & 0,272 & 0,246 & 0,224 \\
\hline 0,9 & 593 & 0,561 & 0,531 & 0,503 & 76 & 0,452 & 0,398 & ,352 & 13 & 0,281 & 0,253 & 0,229 \\
\hline 1,0 & 0,632 & 0,596 & 0,562 & 0,531 & 0,501 & 0,474 & 0,414 & 0,364 & 322 & 0,287 & 0,258 & 0,233 \\
\hline 1,1 & 0,667 & 0,627 & 0,590 & 0,556 & 4 & 0,4 & 0,429 & 0,375 & , 330 & 0,293 & 0,262 & 0,235 \\
\hline 1,2 & 0,699 & 0,6 & 0,6 & 0 & & & 0,4 & 4 & 7 & 0 , & 0 , & 0,238 \\
\hline 1,3 & 0,727 & 0,681 & 0,639 & 0,5 & 0 & 0,5 & 0,453 & 2 & 0,3 & 1 & 0,268 & 0,240 \\
\hline 1,4 & 0,753 & 0,705 & 0,659 & 0,6 & 0,578 & 0,542 & 0,463 & 0,399 & 0,347 & 0,305 & 0,270 & 0,241 \\
\hline 1,5 & 0,777 & 0,726 & 0,678 & 0,63 & 0,593 & 0,555 & 0,473 & 0,406 & 0,351 & 0,308 & 0,272 & 0,242 \\
\hline 1,6 & 0,798 & 0,745 & 0,696 & 0,6 & 0,6 & 0,567 & 0,481 & 0,411 & 0,355 & 0,310 & 0,273 & 0,243 \\
\hline 1,7 & 0,817 & 0,763 & 0,711 & 0,66 & 0,6 & 0,577 & 0,488 & 0,416 & 0,3 & 0,312 & 0,275 & 0,244 \\
\hline 1,8 & 0,835 & 0,779 & 0,726 & 0,676 & 0,630 & 0,587 & 0,495 & 0,421 & 0,361 & 0,314 & 0,276 & 0,245 \\
\hline 1,9 & 0,850 & 0,793 & 0,739 & 0,688 & 0,640 & 0,596 & 0,501 & 0,425 & 0,364 & 0,315 & 0,277 & 0,245 \\
\hline 2,0 & 0,865 & 0,807 & 0,751 & 0,699 & 0,650 & 0,605 & 0,507 & 0,428 & 0,366 & 0,317 & 0,278 & 0,246 \\
\hline 2,1 & 0,878 & 0,819 & 0,763 & 0,709 & 0,659 & 0,612 & 0,512 & 0,431 & 0,368 & 0,318 & 0,278 & 0,246 \\
\hline 2,2 & 0,889 & 0,830 & 0,773 & 0,718 & 0,667 & 0,619 & 0,516 & 0,434 & 0,370 & 0,319 & 0,279 & 0,247 \\
\hline 2,3 & 0,900 & 0,841 & 0,783 & 0,727 & 0,675 & 0,626 & 0,521 & 0,437 & 0,372 & 0,320 & 0,279 & 0,247 \\
\hline 2,4 & 0,909 & 0,850 & 0,791 & 0,735 & 0,682 & 0,632 & 0,525 & 0,440 & 0,373 & 0,321 & 0,280 & 0,247 \\
\hline 2,5 & 0,918 & 0,859 & 0,800 & 0,742 & 0,688 & 0,638 & 0,528 & 0,442 & , 374 & 0,322 & 0,280 & 0,247 \\
\hline 2,6 & 926 & 0,867 & 80 & 49 & 4 & 0 & 2 & 4 & 76 & 22 & 31 & 0,248 \\
\hline 2,7 & & & & 0,756 & 0,700 & 0,648 & 0,535 & 0,446 & 0,377 & ,323 & 0,281 & 0,248 \\
\hline 2,8 & 0,939 & 0,881 & 0,821 & 0,762 & 0,706 & 0,653 & 0,538 & 0,448 & 378 & 324 & 0,281 & 0,248 \\
\hline 2,9 & 0,945 & 0,887 & 0,827 & 0,768 & 0,711 & 0,657 & 0,541 & 0,449 & 369 & 324 & 0,282 & 0,248 \\
\hline 3,0 & & 0,893 & 000 & 0,7 & 0, & 0,6 & 3 & 51 & 9 & 24 & 0,282 & 0,248 \\
\hline 3, & & 0,8 & & 0,7 & 0,720 & 0,665 & 0,546 & 452 & 0,380 &, 325 & 0,282 & 0,248 \\
\hline 3,2 & 0,959 & 0,904 & 0,843 & 0,783 & 0,724 & 0,668 & 0,548 & 0,453 & 0,381 & 0,325 & 0,282 & 0,249 \\
\hline
\end{tabular}


Tabela 55 - continuação da página anterior

\begin{tabular}{|c|c|c|c|c|c|c|c|c|c|c|c|c|}
\hline $\mathrm{VTU}^{R}$ & 0,0 & 0,2 & 0,4 & 0,6 & 0,8 & 1,0 & 1,5 & 2,0 & 2,5 & 3,0 & 3,5 & 4,0 \\
\hline 3,3 & 0,963 & 0,908 & 0,848 & 0,787 & 0,728 & 0,672 & 0,550 & 0,454 & 0,381 & 0,326 & 0,282 & 0,249 \\
\hline 3,4 & 0,967 & 0,913 & 0,853 & 0,791 & 0,731 & 0,675 & 0,552 & 0,456 & 0,382 & 0,326 & 0,283 & 0,249 \\
\hline 3,5 & 0,970 & 0,917 & 0,857 & 0,795 & 0,735 & 0,678 & 0,554 & 0,457 & 0,383 & 0,326 & 0,283 & 0,249 \\
\hline 3,6 & 0,973 & 0,920 & 0,861 & 0,799 & 0,738 & 0,680 & 0,555 & 0,458 & 0,383 & 0,326 & 0,283 & 0,249 \\
\hline 3,7 & 0,975 & 0,924 & 0,864 & 0,802 & 0,741 & 0,683 & 0,557 & 0,458 & 0,384 & 0,327 & 0,283 &, 249 \\
\hline 3,8 & 0,978 & 0,927 & 0,868 & 0,805 & 0,744 & 0,685 & 0,558 & 0,459 & 0,384 & 0,327 & 0,283 & 0,249 \\
\hline 3,9 & 0,980 & 0,930 & 0,871 & 0,808 & 0,747 & 0,688 & 0,560 & 0,460 & 0,384 & 0,327 & 0,283 & 0,249 \\
\hline 4,0 & 0,982 & 0,933 & 0,874 & 0,811 & 0,749 & 0,690 & 0,561 & 0,461 & 0,385 & 0,327 & 0,283 & 0,249 \\
\hline 4,1 & 0,983 & 0,936 & 0,877 & 0,814 & 0,752 & 0,692 & 0,562 & 0,461 & 0,385 & 0,327 & 0,283 & 0,249 \\
\hline 4,2 & 0,985 & 0,938 & 0,879 & 0,817 & 0,754 & 0,694 & 0,563 & 0,462 & 0,385 & 0,328 & 0,283 & 0,249 \\
\hline 4,3 & 0,986 & 0,940 & 0,882 & 0,819 & 0,756 & 0,696 & 0,564 & 0,463 & 0,386 & 0,328 & 0,284 & 0,249 \\
\hline 4,4 & 0,988 & 0,942 & 0,884 & 0,821 & 0,758 & 0,698 & 0,565 & 0,463 & 0,386 & 0,328 & 0,284 & 0,249 \\
\hline 4,5 & 0,989 & 0,945 & 0,887 & 0,823 & 0,760 & 0,699 & 0,566 & 0,464 & 0,386 & 0,328 & 0,284 & 0,249 \\
\hline 4,6 & 0,990 & 0,946 & 0,889 & 0,825 & 0,762 & 0,701 & 0,567 & 0,464 & 0,387 & 0,328 & 0,284 & 0,249 \\
\hline 4,7 & 0,991 & 0,948 & 0,891 & 0,827 & 0,764 & 0,702 & 0,568 & 0,465 & 0,387 & 0,328 & 0,284 & 0,249 \\
\hline 4,8 & 0,992 & 0,950 & 0,893 & 0,829 & 0,765 & 0,704 & 0,569 & 0,465 & 0,387 & 0,328 & 0,284 & 0,249 \\
\hline 4,9 & 0,993 & 0,951 & 0,894 & 0,831 & 0,767 & 0,705 & 0,570 & 0,465 & 0,387 & 0,328 & 0,284 & 0,249 \\
\hline 5,0 & 0,993 & 0,953 & 0,896 & 0,833 & 0,768 & 0,706 & 0,571 & 0,466 & 0,387 & 0,329 & 0,284 & 0,249 \\
\hline 5,1 & 0,994 & 0,954 & 0,898 & 0,834 & 0,770 & 0,707 & 0,571 & 0,466 & 0,388 & 0,329 & 0 & 0,249 \\
\hline 5,2 & 0,994 & 0,956 & 0,899 & 0,836 & 0,771 & 0,708 & 0,572 & 0,467 & 0,388 & 0,329 & 0,284 & 0,249 \\
\hline 5,3 & 0,995 & 0,957 & 0,9 & 0,837 & 0,772 & 0,709 & 0,572 & 0,467 & 0,388 & 0,329 & 0,284 & 0,249 \\
\hline 5,4 & 0,995 & 0,958 & 0,902 & 0,838 & 0,773 & 0,710 & 0,573 & 0,467 & 0,388 & 0,329 & 0,284 & 0,249 \\
\hline 5,5 & 0,996 & 0,959 & 0,903 & 0,840 & 0,774 & 0,711 & 0,574 & 0,467 & 0,388 & 0,329 & 0,284 & 0,249 \\
\hline 5,6 & 0,996 & 0,960 & 0,9 & 0,841 & 0,776 & 0,712 & 0,574 & 0,468 & 0,388 & 0,329 & 0,284 & 0,249 \\
\hline 5,7 & 0,997 & 0,961 & 0,906 & 0,842 & 0,777 & 0,713 & 0,575 & 0,468 & 0,388 & 0,329 & 0,284 & 0,249 \\
\hline 5,8 & 0,997 & 0,962 & 0,907 & 0,843 & 0,778 & 0,714 & 0,575 & 0,468 & 0,389 & 0,329 & 0,284 & 0,249 \\
\hline 5,9 & 0,997 & 0,963 & 0,908 & 0,844 & 0,778 & 0,715 & 0,576 & 0,468 & 0,389 & 0,329 & 0,284 & 0,249 \\
\hline 6,0 & 0,998 & 0,964 & 0,909 & 0,845 & 0,779 & 0,715 & 0,576 & 0,469 & 0,389 & 0,329 & 0,284 & 0,249 \\
\hline 6,1 & 0,998 & 0,964 & 0,910 & 0,846 & 0,780 & 0,716 & 0,576 & 0,469 & 0,389 & 0,329 & 0,284 & 0,249 \\
\hline 6,2 & 0,998 & 0,965 & 0,911 & 0,847 & 0,781 & 0,717 & 0,577 & 0,469 & 0,389 & 0,329 & 0,284 & 0,249 \\
\hline 6,3 & 0,998 & 0,966 & 0,911 & 0,848 & 0,782 & 0,717 & 0,577 & 0,469 & 0,389 & 0,329 & 0,284 & 0,249 \\
\hline 6,4 & 0,998 & 0,966 & 0,912 & 0,848 & 0,782 & 0,718 & 0,577 & 0,469 & 0,389 & 0,329 & 0,284 & 0,249 \\
\hline 6,5 & 0,998 & 0,967 & 0,913 & 0,849 & 0,783 & 0,719 & 0,578 & 0,470 & 0,389 & 0,329 & 0,284 & 49 \\
\hline 6,6 & 999 & 0,968 & & 0,850 & 0,784 & 0,719 & 0 , & 70 & 0 , & 0,329 & 4 & 0,249 \\
\hline 6,7 & 99 & 0,968 & & 0,851 & 0,784 & 0,720 & 0 & 0 , & 0 & 0,329 & 0,284 & 0,249 \\
\hline 6,8 & 99 & 0,969 & 0 & 0,851 & 0,785 & 0,720 & 0,579 & 0,470 & 0,389 & 0,329 & 0,284 & 0,249 \\
\hline 6,9 & 99 & 0,969 & 0,9 & 0,852 & 0,785 & 0,721 & 0,579 & 0,470 & 0,389 & 0,330 & 0,284 & 0,249 \\
\hline 7,0 & 99 & 0,970 & 0, & 0,852 & 0,786 & 0,721 & 0,579 & 0,470 & 0,389 & 0,330 & 0,284 & 0,249 \\
\hline 7,1 & 99 & 0,9 & $0, \mathrm{~s}$ & 0,853 & 0,786 & 0,721 & 0 & 0,470 & 0,390 & 0,330 & 0,284 & 0,249 \\
\hline 7,2 & 0,999 & 0,970 & 0,9 & 0,853 & 0,787 & 0,722 & 0,580 & 0,470 & 0,390 & 0,330 & 0,284 & 0,250 \\
\hline 7,3 & 0,999 & 0,971 & 0,918 & 0,854 & 0,787 & 0,722 & 0,580 & 0,471 & 0,390 & 0,330 & 0,284 & 0,250 \\
\hline 7,4 & 0,999 & 0,971 & 0,918 & 0,854 & 0,788 & 0,723 & 0,580 & 0,471 & 0,390 & 0,330 & 0,284 & 0,250 \\
\hline 7,5 & 0,999 & 0,972 & 0,919 & 0,855 & 0,788 & 0,723 & 0,580 & 0,471 & 0,390 & 0,330 & 0,284 & 0,250 \\
\hline 7,6 & 0,999 & 0,972 & 0,919 & 0,855 & 0,788 & 0,723 & 0,580 & 0,471 & 0,390 & 0,330 & 0,284 & 0,250 \\
\hline 7,7 & 1,000 & 0,972 & 0,920 & 0,856 & 0,789 & 0,723 & 0,580 & 0,471 & 0,390 & 0,330 & 0,284 & 0,250 \\
\hline 7,8 & 1,000 & 0,972 & 0,920 & 0,856 & 0,789 & 0,724 & 0,581 & 0,471 & 0,390 & 0,330 & 0,284 & 0,250 \\
\hline 7,9 & 1,000 & 0,973 & 0,920 & 0,856 & 0,789 & 0,724 & 0,581 & 0,471 & 0,390 & 0,330 & 0,284 & 0,250 \\
\hline 8,0 & 000 & 0,973 & 0,921 & 857 & 0,790 &, 724 & 0,581 & 471 &, 390 & 0,330 & 0,284 & 0,250 \\
\hline 8,1 & 1,000 & 0,973 & 0,921 & 0,857 & 0,790 & 0,725 & 0,581 & 0,471 & 0,390 & 0,330 & 0,284 & 0,250 \\
\hline 8,2 & 1,000 & 0,974 & 0,921 & 0,857 & 0,790 & 0,725 & 0,581 & 0,471 & 0,390 & 0,330 & 0,284 & 0,250 \\
\hline 8,3 & 1,000 & 0,974 & 0,922 & 0,858 & 0,791 & 0,725 & 0,581 & 0,471 & 0,390 & 0,330 & 0,284 & 0,250 \\
\hline 8,4 & 000 & 0,974 & 0,922 & 0,858 & 0,791 & 0,725 & 0,581 & 0,471 & 0,390 & 0,330 & 0,284 & 0,250 \\
\hline 8,5 & 1,000 & 0,974 & 0,922 & 0,858 & 0,791 & 0,725 & 0,582 & 0,471 & 0,390 & 0,330 & 0,284 & 0,250 \\
\hline
\end{tabular}


Tabela 55 - continuação da página anterior

\begin{tabular}{|c|cccccccccccc|}
\hline NTU & \multicolumn{1}{c|}{0,0} & 0,2 & 0,4 & 0,6 & 0,8 & 1,0 & 1,5 & 2,0 & 2,5 & 3,0 & 3,5 & 4,0 \\
\hline 8,6 & 1,000 & 0,974 & 0,922 & 0,859 & 0,791 & 0,726 & 0,582 & 0,472 & 0,390 & 0,330 & 0,284 & 0,250 \\
8,7 & 1,000 & 0,975 & 0,923 & 0,859 & 0,792 & 0,726 & 0,582 & 0,472 & 0,390 & 0,330 & 0,284 & 0,250 \\
8,8 & 1,000 & 0,975 & 0,923 & 0,859 & 0,792 & 0,726 & 0,582 & 0,472 & 0,390 & 0,330 & 0,284 & 0,250 \\
8,9 & 1,000 & 0,975 & 0,923 & 0,859 & 0,792 & 0,726 & 0,582 & 0,472 & 0,390 & 0,330 & 0,284 & 0,250 \\
9,0 & 1,000 & 0,975 & 0,923 & 0,859 & 0,792 & 0,726 & 0,582 & 0,472 & 0,390 & 0,330 & 0,284 & 0,250 \\
9,1 & 1,000 & 0,975 & 0,924 & 0,860 & 0,792 & 0,726 & 0,582 & 0,472 & 0,390 & 0,330 & 0,284 & 0,250 \\
9,2 & 1,000 & 0,975 & 0,924 & 0,860 & 0,792 & 0,727 & 0,582 & 0,472 & 0,390 & 0,330 & 0,284 & 0,250 \\
9,3 & 1,000 & 0,975 & 0,924 & 0,860 & 0,793 & 0,727 & 0,582 & 0,472 & 0,390 & 0,330 & 0,284 & 0,250 \\
9,4 & 1,000 & 0,976 & 0,924 & 0,860 & 0,793 & 0,727 & 0,582 & 0,472 & 0,390 & 0,330 & 0,284 & 0,250 \\
9,5 & 1,000 & 0,976 & 0,924 & 0,860 & 0,793 & 0,727 & 0,582 & 0,472 & 0,390 & 0,330 & 0,284 & 0,250 \\
9,6 & 1,000 & 0,976 & 0,924 & 0,860 & 0,793 & 0,727 & 0,582 & 0,472 & 0,390 & 0,330 & 0,284 & 0,250 \\
9,7 & 1,000 & 0,976 & 0,925 & 0,861 & 0,793 & 0,727 & 0,583 & 0,472 & 0,390 & 0,330 & 0,284 & 0,250 \\
9,8 & 1,000 & 0,976 & 0,925 & 0,861 & 0,793 & 0,727 & 0,583 & 0,472 & 0,390 & 0,330 & 0,284 & 0,250 \\
9,9 & 1,000 & 0,976 & 0,925 & 0,861 & 0,793 & 0,727 & 0,583 & 0,472 & 0,390 & 0,330 & 0,284 & 0,250 \\
10,0 & 1,000 & 0,976 & 0,925 & 0,861 & 0,794 & 0,727 & 0,583 & 0,472 & 0,390 & 0,330 & 0,284 & 0,250 \\
\hline
\end{tabular}

Tabela 56 - Fator de correção para trocador de calor de fluxo cruzado com um passe e dois tubos por passe (1-2) - Caso 3 ou 4 - trocador de calor ilustrado na Figura 72 do Anexo A

\begin{tabular}{|c|c|c|c|c|c|c|c|c|c|c|c|c|}
\hline $\mathrm{NTU}^{R}$ & 0,0 & 0,2 & 0,4 & 0,6 & 0,8 & 1,0 & 1,5 & 2,0 & 2,5 & 3,0 & 3,5 & 4,0 \\
\hline 0,0 & 1,000 & 1,000 & 1,000 & 1,000 & 1,000 & 1,000 & 1,000 & 1,000 & 1,000 & 1,000 & 1,000 & 1,000 \\
\hline 0,1 & 1,000 & 1,000 & 0,999 & 0,999 & 0,999 & 0,998 & 0,998 & 0,997 & 0,996 & 0,995 & 0,995 & 0,994 \\
\hline 0,2 & 1,000 & 0,999 & 0,997 & 0,996 & 0,995 & 0,994 & 0,991 & 0,989 & 0,986 & 0,984 & 0,981 & 0,979 \\
\hline 0,3 & 1,000 & 0,997 & 0,995 & 0,992 & 0,989 & 0,987 & 0,981 & 0,976 & 0,971 & 0,967 & 0,963 & 0,959 \\
\hline 0,4 & 1,000 & 0,995 & 0,991 & 0,986 & 0,982 & 0,978 & 0,969 & 0,961 & 0,954 & 0,947 & 0,942 & 0,936 \\
\hline 0,5 & 1,000 & 0,993 & 0,986 & 0,979 & 0,973 & 0,968 & 0,955 & 0,944 & 0,935 & 0,926 & 0,919 & 0,913 \\
\hline 0,6 & 1,000 & 0,990 & 0,980 & 0,971 & 0,963 & 0,956 & 0,940 & 0,926 & 0,914 & 0,905 & 0,896 & 0,889 \\
\hline 0,7 & 1,000 & 0,986 & 0,974 & 0,963 & 0,953 & 0,943 & 0,923 & 0,907 & 0,894 & 0,883 & 0,873 & 0,865 \\
\hline 0,8 & 1,000 & 0,982 & 0,967 & 0,953 & 0,941 & 0,930 & 0,907 & 0,888 & 0,874 & 0,861 & 0,851 & 0,843 \\
\hline 0,9 & 1,000 & 0,978 & 0,960 & 0,943 & 0,929 & 0,916 & 0,890 & 0,870 & 0,854 & 0,840 & 0,830 & 0,821 \\
\hline 1,0 & 1,000 & 0,974 & 0,952 & 0,933 & 0,917 & 0,902 & 0,873 & 0,851 & 0,834 & 0,820 & 0,809 & 0,800 \\
\hline 1,1 & 1,000 & 0,969 & 0,944 & 0,922 & 0,904 & 0,888 & 0,856 & 0,833 & 0,815 & 0,801 & 0,790 & 0,781 \\
\hline 1,2 & 1,000 & 0,964 & 0,935 & 0,911 & 0,891 & 0,874 & 0,840 & 0,815 & 0,797 & 0,782 & 0,771 & 0,762 \\
\hline 1,3 & 1,000 & 0,959 & 0,926 & 0,900 & 0,878 & 0,859 & 0,824 & 0,798 & 0,779 & 0,764 & 0,753 & 0,744 \\
\hline 1,4 & 1,000 & 0,954 & 0,918 & 0,889 & 0,865 & 0,845 & 0,808 & 0,781 & 0,762 & 0,747 & 0,736 & 0,727 \\
\hline 1,5 & 1,000 & 0,948 & 0,908 & 0,877 & 0,852 & 0,831 & 0,792 & 0,765 & 0,745 & 0,730 & 0,719 & 0,710 \\
\hline 1,6 & 1,000 & 0,942 & 0,899 & 0,866 & 0,839 & 0,818 & 0,777 & 0,749 & 0,729 & 0,714 & 0,703 & 0,694 \\
\hline 1,7 & 1,000 & 0,936 & 0,890 & 0,855 & 0,827 & 0,804 & 0,762 & 0,734 & 0,714 & 0,699 & 0,688 & 0,679 \\
\hline 1,8 & 1,000 & 0,930 & 0,881 & 0,843 & 0,814 & 0,791 & 0,748 & 0,719 & 0,699 & 0,684 & 0,673 & 0,664 \\
\hline 1,9 & 1,000 & 0,924 & 0,871 & 0,832 & 0,802 & 0,778 & 0,734 & 0,705 & 0,685 & 0,670 & 0,659 & 0,650 \\
\hline 2,0 & 1,000 & 0,917 & 0,862 & 0,821 & 0,790 & 0,765 & 0,720 & 0,691 & 0,671 & 0,656 & 0,645 & 0,637 \\
\hline 2,1 & 1,000 & 0,911 & 0,852 & 0,810 & 0,778 & 0,752 & 0,707 & 0,678 & 0,657 & 0,643 & 0,632 & 0,624 \\
\hline 2,2 & 1,000 & 0,904 & 0,843 & 0,799 & 0,766 & 0,740 & 0,694 & 0,665 & 0,644 & 0,630 & 0,619 & 0,611 \\
\hline 2,3 & 1,000 & 0,898 & 0,834 & 0,788 & 0,754 &, 728 & 0,681 & 0,652 & 0,632 & 0,617 & 0,606 & 0,599 \\
\hline 2,4 & 1,000 & 0,891 & 0,824 & 0,778 & 0,743 & 0,716 & 0,669 & 0,639 & 0,619 & 0,605 & 0,594 & 0,587 \\
\hline 2,5 & 1,000 & 0,884 & 0,815 & 0,767 & 0,732 & 0,704 & 0,657 & 0,627 & 0,607 & 0,593 & 0,583 & 0,575 \\
\hline 2,6 & 1,000 & 0,878 & 0,806 & 0,757 & 0,721 & 0,693 & 0,646 & 0,616 & 0,596 & 0,582 & 0,571 & 0,564 \\
\hline 2,7 & 1,000 & 0,871 & 0,796 & 0,746 & 0,710 & 0,682 & 0,634 & 0,604 & 0,585 & 0,571 & 0,561 & 0,553 \\
\hline 2,8 & 1,000 & 0,864 & 0,787 & 0,736 & 0,699 & 0,671 & 0,623 & 0,593 & 0,574 & 0,560 & 0,550 & 0,543 \\
\hline $2, \mathrm{~s}$ & 1,000 & 0,857 & 0,778 & 0,726 & 0,689 & 0,660 & 0,612 & 0,583 & 0,563 & 0,549 & 0,540 & 0,532 \\
\hline 3,0 & 1,000 & 0,850 & 0,769 & 0,716 & 0,678 & 0,650 & 0,602 & 0,572 & 0,553 & 0,539 & 0,530 & 0,522 \\
\hline
\end{tabular}


Tabela 56 - continuação da página anterior

\begin{tabular}{|c|c|c|c|c|c|c|c|c|c|c|c|c|}
\hline $\mathrm{VTU}^{R}$ & 0,0 & 0,2 & 0,4 & 0,6 & 0,8 & 1,0 & 1,5 & 2,0 & 2,5 & 3,0 & 3,5 & 4,0 \\
\hline 3,1 & 1,000 & 0,843 & 0,760 & 0,706 & 0,668 & 0,639 & 0,591 & 0,562 & 0,543 & 0,529 & 0,520 & 0,513 \\
\hline 3,2 & 1,000 & 0,836 & 0,751 & 0,697 & 0,658 & 0,629 & 0,581 & 0,552 & 0,533 & 0,520 & 0,510 & 0,503 \\
\hline 3,3 & 1,000 & 0,829 & 0,743 & 0,687 & 0,649 & 0,620 & 0,572 & 0,543 & 0,524 & 0,510 & 0,501 & 0,494 \\
\hline 3,4 & 1,000 & 0,822 & 0,734 & 0,678 & 0,639 & 0,610 & 0,562 & 0,533 & 0,514 & 0,501 & 0,492 & 0,485 \\
\hline 3,5 & 1,000 & 0,815 & 0,725 & 0,669 & 0,630 & 0,601 & 0,553 & 0,524 & 0,505 & 0,493 & 0,484 & ,477 \\
\hline 3,6 & 1,000 & 0,808 & 0,717 & 0,660 & 0,621 & 0,591 & 0,544 & 0,515 & 0,497 & 0,484 & 0,475 & 0,469 \\
\hline 3,7 & 1,000 & 0,801 & 0,708 & 0,651 & 0,612 & 0,582 & 0,535 & 0,506 & 0,488 & 0,476 & 0,467 & 0,460 \\
\hline 3,8 & 1,000 & 0,794 & 0,700 & 0,642 & 0,603 & 0,573 & 0,526 & 0,498 & 0,480 & 0,468 & 0,459 & 0,452 \\
\hline 3,9 & 1,000 & 0,787 & 0,692 & 0,634 & 0,594 & 0,565 & 0,518 & 0,490 & 0,472 & 0,460 & 0,451 & 0,445 \\
\hline 4,0 & 1,000 & 0,780 & 0,684 & 0,625 & 0,585 & 0,556 & 0,509 & 0,482 & 0,464 & 0,452 & 0,443 & 0,437 \\
\hline 4,1 & 1,000 & 0,773 & 0,675 & 0,617 & 0,577 & 0,548 & 0,501 & 0,474 & 0,456 & 0,444 & 0,436 & 0,430 \\
\hline 4,2 & 1,000 & 0,766 & 0,667 & 0,609 & 0,569 & 0,540 & 0,493 & 0,466 & 0,449 & 0,437 & 0,429 & 0,423 \\
\hline 4,3 & 1,000 & 0,759 & 0,660 & 0,601 & 0,561 & 0,532 & 0,486 & 0,459 & 0,442 & 0,430 & 0,422 & 0,416 \\
\hline 4,4 & 1,000 & 0,752 & 0,652 & 0,593 & 0,553 & 0,524 & 0,478 & 0,451 & 0,434 & 0,423 & 0,415 & 0,409 \\
\hline 4,5 & 1,000 & 0,745 & 0,644 & 0,585 & 0,545 & 0,516 & 0,471 & 0,444 & 0,428 & 0,416 & 0,408 & 0,403 \\
\hline 4,6 & 1,000 & 0,738 & 0,636 & 0,577 & 0,538 & 0,509 & 0,464 & 0,437 & 0,421 & 0,410 & 0,402 & 0,396 \\
\hline 4,7 & 1,000 & 0,731 & 0,629 & 0,570 & 0,530 & 0,502 & 0,457 & 0,431 & 0,414 & 0,403 & 0,395 & 0,390 \\
\hline 4,8 & 1,000 & 0,724 & 0,622 & 0,562 & 0,523 & 0,495 & 0,450 & 0,424 & 0,408 & 0,397 & 0,389 & 0,384 \\
\hline 4,9 & 1,000 & 0,718 & 0,614 & 0,555 & 0,516 & 0,487 & 0,443 & 0,418 & 0,402 & 0,391 & 0,383 & 0,378 \\
\hline 5,0 & 1,000 & 0,711 & 0,607 & 0,548 & 0,509 & 0,481 & 0,437 & 0,411 & 0,395 & 0,385 & 0,377 & 0,372 \\
\hline 5,1 & 1,000 & 0,704 & 0,600 & 0,541 & 0,502 & 0,474 & 0,430 & & 0,390 & 0,379 & 0,372 & 0,366 \\
\hline 5,2 & 1,000 & 0,698 & 0,593 & 0,534 & 0,495 & 0,467 & 0,424 & 0,399 & 0,384 & 0,373 & 0,366 & 0,361 \\
\hline 5,3 & 1,000 & 0,691 & 0,586 & 0,527 & 0,488 & 0,461 & 0,418 & 0,393 & 0,378 & 0,368 & 0,361 & 0,356 \\
\hline 5,4 & 1,000 & 0,684 & 0,579 & 0,520 & 0,482 & 0,454 & 0,412 & 0,388 & 0,373 & 0,362 & 0,355 & 0,350 \\
\hline 5,5 & 1,000 & 0,678 & 0,572 & 0,514 & 0,475 & 0,448 & 0,406 & 0,382 & 0,367 & 0,357 & 0,350 & 0,345 \\
\hline 5,6 & 1,000 & 0,671 & 0,566 & 0,507 & 0,469 & 0,442 & 0,400 & 0,377 & 0,362 & 0,352 & 0,345 & 0,340 \\
\hline 5,7 & 1,000 & 0,665 & 0,559 & 0,501 & 0,463 & 0,436 & 0,395 & 0,371 & 0,357 & 0,347 & 0,340 & 0,335 \\
\hline 5,8 & 1,000 & 0,658 & 0,553 & 0,494 & 0,457 & 0,430 & 0,389 & 0,366 & 0,352 & 0,342 & 0,335 & 0,331 \\
\hline 5,9 & 1,000 & 0,652 & 0,546 & 0,488 & 0,451 & 0,425 & 0,384 & 0,361 & 0,347 & 0,337 & 0,331 & 0,326 \\
\hline 6,0 & 0,999 & 0,646 & 0,540 & 0,482 & 0,445 & 0,419 & 0,379 & 0,356 & 0,342 & 0,333 & 0,326 & 0,321 \\
\hline 6,1 & 0,999 & 0,639 & 0,534 & 0,476 & 0,440 & 0,414 & 0,374 & 0,351 & 0,337 & 0,328 & 0,322 & 0,317 \\
\hline 6,2 & 0,999 & 0,633 & 0,528 & 0,471 & 0,434 & 0,408 & 0,369 & 0,347 & 0,333 & 0,324 & 0,317 & 0,313 \\
\hline 6,3 & 0,999 & 0,627 & 0,521 & 0,465 & 0,429 & 0,403 & 0,364 & 0,342 & 0,328 & 0,319 & 0,313 & ,308 \\
\hline 6,4 & 0,999 & 0,621 & & 0,459 & 3 & 0,398 & 9 & & 0,324 & 15 & 0,309 & 0,304 \\
\hline 6,5 & 0,999 & 0,6 & & 0, & 0 , & 0 & 0 , & & 0,320 & 0 , & 0,305 & 0,300 \\
\hline 6,6 & 0,999 & 0,609 & 0,504 & 0,448 & 0 & 0,388 & 0 , & & 0,315 & 0,307 & 0,301 & 0,296 \\
\hline 6,7 & 0,999 & 0,603 & 0,498 & 0,443 & 0,408 & 0,383 & 0,345 & 24 & 0,311 & 0,303 & 0,297 & 0,293 \\
\hline 6,8 & 0,999 & 0,597 & 0,493 & 0,4 & 0,403 & 0,378 & 0 , & 0 , & 0,307 & 0,299 & 0,293 & 0,289 \\
\hline 6,9 & 0,999 & 0,5 & 0,4 & 0,433 & 0,398 & 0,374 & 0 & 0 , & 0,303 & 0,295 & 0,289 & 0,285 \\
\hline 7,0 & 0,999 & 0,585 & 0,482 & 0,428 & 0,393 & 0,369 & 0,333 & 0 , & 0,300 & 0,291 & 0,286 & 0,281 \\
\hline 7,1 & 0,999 & 0,579 & 0,477 & 0,423 & 0,388 & 0,365 & 0,329 & 0,308 & 0,296 & 0,288 & 0,282 & 0,278 \\
\hline 7,2 & 0,999 & 0,574 & 0,471 & 0,418 & 0,384 & 0,360 & 0,325 & 0,305 & 0,292 & 0,284 & 0,278 & 0,274 \\
\hline 7,3 & 0,999 & 0,568 & 0,466 & 0,413 & 0,379 & 0,356 & 0,321 & 0,301 & 0,289 & 0,281 & 0,275 & 0,271 \\
\hline 7,4 & 0,999 & 0,563 & 0,461 & 0,408 & 0,375 & 0,352 & 0,317 & 0,297 & 0,285 & 0,277 & 0,272 & 0,268 \\
\hline 7,5 & 0,999 & 0,557 & 0,456 & 0,404 & 0,371 & 0,348 & 0,313 & 0,294 & 0,282 & 0,274 & 0,268 & 0,265 \\
\hline 7,6 & 0,999 & 0,552 & 0,451 & 0,399 & 0,366 & 0,344 & 0,309 & 0,290 & 0,278 & 0,271 & 0,265 & 0,261 \\
\hline 7,7 & 0,999 & 0,546 & 0,446 & 0,395 & 0,362 & 0,340 & 0,306 & 0,287 & 0,275 & 0,267 & 0,262 & 0,258 \\
\hline 7,8 & 999 & 0,541 & 0,442 & 0,390 & 0,358 &, 336 & 302 & 283 & 0,272 & 0,264 & 0,259 & 0,255 \\
\hline 7,9 & 0,999 & 0,536 & 0,437 & 0,386 & 0,354 & 0,332 & 0,299 & 0,280 & 0,269 & 0,261 & 0,256 & 0,252 \\
\hline 8,0 & 0,999 & 0,531 & 0,432 & 0,382 & 0,350 & 0,328 & 0,295 & 0,277 & 0,266 & 0,258 & 0,253 & 0,249 \\
\hline 8,1 & 0,999 & 0,526 & 0,428 & 0,378 & 0,346 & 0,325 & 0,292 & 0,274 & 0,263 & 0,255 & 0,250 & 0,247 \\
\hline 8,2 & 0,999 & 0,520 & 0,423 & 0,374 & 0,343 & 0,321 & 0,289 & 0,271 & 0,260 & 0,252 & 0,247 & 0,244 \\
\hline 8,3 & 0,999 & 0,516 & 0,419 & 0,370 & 0,339 & 0,318 & 0,285 & 0,268 & 0,257 & 0,250 & 0,245 & 0,241 \\
\hline \multicolumn{13}{|c|}{ o na próxima página } \\
\hline
\end{tabular}


Tabela 56 - continuação da página anterior

\begin{tabular}{|c|ccccccccccccc|}
\hline NTU & \multicolumn{1}{c}{$0.0,0$} & 0,2 & 0,4 & 0,6 & 0,8 & 1,0 & 1,5 & 2,0 & 2,5 & 3,0 & 3,5 & 4,0 \\
\hline 8,4 & 0,999 & 0,511 & 0,415 & 0,366 & 0,335 & 0,314 & 0,282 & 0,265 & 0,254 & 0,247 & 0,242 & 0,238 \\
8,5 & 0,998 & 0,506 & 0,410 & 0,362 & 0,332 & 0,311 & 0,279 & 0,262 & 0,251 & 0,244 & 0,239 & 0,236 \\
8,6 & 0,998 & 0,501 & 0,406 & 0,358 & 0,328 & 0,308 & 0,276 & 0,259 & 0,248 & 0,241 & 0,237 & 0,233 \\
8,7 & 0,998 & 0,496 & 0,402 & 0,354 & 0,325 & 0,304 & 0,273 & 0,256 & 0,246 & 0,239 & 0,234 & 0,231 \\
8,8 & 0,998 & 0,492 & 0,398 & 0,351 & 0,321 & 0,301 & 0,270 & 0,253 & 0,243 & 0,236 & 0,232 & 0,228 \\
8,9 & 0,998 & 0,487 & 0,394 & 0,347 & 0,318 & 0,298 & 0,268 & 0,251 & 0,241 & 0,234 & 0,229 & 0,226 \\
9,0 & 0,998 & 0,482 & 0,390 & 0,344 & 0,315 & 0,295 & 0,265 & 0,248 & 0,238 & 0,231 & 0,227 & 0,223 \\
9,1 & 0,998 & 0,478 & 0,386 & 0,340 & 0,312 & 0,292 & 0,262 & 0,246 & 0,236 & 0,229 & 0,224 & 0,221 \\
9,2 & 0,998 & 0,474 & 0,383 & 0,337 & 0,308 & 0,289 & 0,259 & 0,243 & 0,233 & 0,227 & 0,222 & 0,219 \\
9,3 & 0,998 & 0,469 & 0,379 & 0,333 & 0,305 & 0,286 & 0,257 & 0,241 & 0,231 & 0,224 & 0,220 & 0,217 \\
9,4 & 0,998 & 0,465 & 0,375 & 0,330 & 0,302 & 0,283 & 0,254 & 0,238 & 0,228 & 0,222 & 0,218 & 0,214 \\
9,5 & 0,998 & 0,461 & 0,372 & 0,327 & 0,299 & 0,280 & 0,252 & 0,236 & 0,226 & 0,220 & 0,215 & 0,212 \\
9,6 & 0,998 & 0,457 & 0,368 & 0,324 & 0,296 & 0,278 & 0,249 & 0,233 & 0,224 & 0,218 & 0,213 & 0,210 \\
9,7 & 0,998 & 0,452 & 0,365 & 0,321 & 0,293 & 0,275 & 0,247 & 0,231 & 0,222 & 0,215 & 0,211 & 0,208 \\
9,8 & 0,997 & 0,448 & 0,361 & 0,318 & 0,291 & 0,272 & 0,244 & 0,229 & 0,219 & 0,213 & 0,209 & 0,206 \\
9,9 & 0,997 & 0,444 & 0,358 & 0,315 & 0,288 & 0,270 & 0,242 & 0,227 & 0,217 & 0,211 & 0,207 & 0,204 \\
10,0 & 0,997 & 0,440 & 0,355 & 0,312 & 0,285 & 0,267 & 0,240 & 0,224 & 0,215 & 0,209 & 0,205 & 0,202 \\
\hline
\end{tabular}

Tabela 57 - Efetividade de temperatura para trocador de calor de fluxo cruzado com um passe e três tubos por passe (1-3) - Caso 3 ou 4 - trocador de calor ilustrado na Figura 73 do Anexo A

\begin{tabular}{|c|c|c|c|c|c|c|c|c|c|c|c|c|}
\hline NTU ${ }^{R}$ & 0,0 & 0,2 & 0,4 & 0,6 & 0,8 & 1,0 & 1,5 & 2,0 & 2,5 & 3,0 & 3,5 & 4,0 \\
\hline 0,0 & 0,000 & 0,000 & 0,000 & 0,000 & 0,000 & 0,000 & 0,000 & 0,000 & 0,000 & 0,000 & 0,000 & 0,000 \\
\hline 0,1 & 0,095 & 0,094 & 0,093 & 0,092 & 0,092 & 0,091 & 0,089 & 0,087 & 0,085 & 0,083 & 0,081 & 0,079 \\
\hline 0,2 & 0,181 & 0,178 & 0,175 & 0,172 & 0,169 & 0,166 & 0,159 & 0,152 & 0,146 & 0,140 & 0,134 & 0,129 \\
\hline 0,3 & 0,259 & 0,253 & 0,246 & 0,240 & 0,234 & 0,228 & 0,215 & 0,203 & 0,191 & 0,180 & 0,171 & 0,162 \\
\hline 0,4 & 0,330 & 0,319 & 0,309 & 0,299 & 0,290 & 0,281 & 0,261 & 0,242 & 0,225 & 0,210 & 0,196 & 0,184 \\
\hline 0,5 & 0,393 & 0,379 & 0,365 & 0,351 & 0,338 & 0,326 & 0,298 & 0,274 & 0,252 & 0,232 & 0,215 & 0,199 \\
\hline 0,6 & 0,451 & 0,432 & 0,414 & 0,396 & 0,380 & 0,365 & 0,330 & 0,299 & 0,272 & 0,249 & 0,228 & 0,210 \\
\hline 0,7 & 0,503 & 0,480 & 0,457 & 0,436 & 0,417 & 0,398 & 0,356 & 0,320 & 0,289 & 0,262 & 0,239 & 0,219 \\
\hline 0,8 & 0,551 & 0,523 & 0,496 & 0,472 & 0,449 & 0,427 & 0,379 & 0,338 & 0,303 & 0,273 & 0,247 & 0,225 \\
\hline 0,9 & 0,593 & 0,561 & 0,531 & 0,503 & 0,477 & 0,453 & 0,398 & 0,353 & 0,314 & 0,281 & 0,253 & 0,229 \\
\hline 1,0 & 0,632 & 0,596 & 0,563 & 0,532 & 0,502 & 0,475 & 0,415 & 0,365 & 0,323 & 0,288 & 0,258 & 0,233 \\
\hline 1,1 & 0,667 & 0,628 & 0,591 & 0,557 & 0,525 & 0,495 & 0,430 & 0,376 & 0,331 & 0,294 & 0,262 & 0,236 \\
\hline 1,2 & 0,699 & 0,656 & 0,617 & 0,580 & 0,545 & 0,514 & 0,444 & 0,386 & 0,338 & 0,299 & 0,266 & 0,238 \\
\hline 1,3 & 0,727 & 0,682 & 0,640 & 0,600 & 0,564 & 0,530 & 0,455 & 0,394 & 0,344 & 0,303 & 0,268 & 0,240 \\
\hline 1,4 & 0,753 & 0,706 & 0,661 & 0,619 & 0,580 & 0,544 & 0,466 & 0,401 & 0,349 & 0,306 & 0,271 & 0,242 \\
\hline 1,5 & 0,777 & 0,727 & 0,680 & 0,636 & 0,596 & 0,558 & 0,475 & 0,408 & 0,353 & 0,309 & 0,273 & 0,243 \\
\hline 1,6 & 0,798 & 0,747 & 0,698 & 0,652 & 0,610 & 0,570 & 0,484 & 0,414 & 0,357 & 0,311 & 0,274 & 0,244 \\
\hline 1,7 & 0,817 & 0,764 & 0,714 & 0,667 & 0,622 & 0,581 & 0,492 & 0,419 & 0,361 & 0,314 & 0,276 & 0,245 \\
\hline 1,8 & 0,835 & 0,781 & 0,729 & 0,680 & 0,634 & 0,592 & 0,499 & 0,424 & 0,364 & 0,315 & 0,277 & 0,245 \\
\hline 1,9 & 0,850 & 0,795 & 0,742 & 0,692 & 0,645 & 0,601 & 0,505 & 0,428 & 0,366 & 0,317 & 0,278 & 0,246 \\
\hline 2,0 & 0,865 & 0,809 & 0,755 & 0,704 & 0,655 & 0,610 & 0,511 & 0,432 & 0,369 & 0,319 & 0,279 & 0,247 \\
\hline 2,1 & 0,878 & 0,821 & 0,767 & 0,714 & 0,665 & 0,618 & 0,517 & 0,435 & 0,371 & 0,320 & 0,279 & 0,247 \\
\hline 2,2 & 0,889 & 0,833 & 0,778 & 0,724 & 0,673 & 0,626 & 0,522 & 0,439 & 0,373 & 0,321 & 0,280 & 0,247 \\
\hline 2,3 & 0,900 & 0,844 & 0,788 & 0,733 & 0,681 & 0,633 & 0,527 & 0,442 & 0,374 & 0,322 & 0,281 & 0,248 \\
\hline 2,4 & 0,909 & 0,853 & 0,797 & 0,742 & 0,689 & 0,640 & 0,531 & 0,444 & 0,376 & 0,323 & 0,281 & 0,248 \\
\hline 2,5 & 0,918 & 0,862 & 0,806 & 0,750 & 0,696 & 0,646 & 0,535 & 0,447 & 0,378 & 0,324 & 0,281 & 0,248 \\
\hline 2,6 & 0,926 & 0,871 & 0,814 & 0,757 &, 703 & 0,652 & 0,539 & 0,449 & 0,379 & 0,324 & 0,282 & 0,248 \\
\hline 2,7 & 0,933 & 0,878 & 321 & 104 & 00 & 0,657 & 0,543 & 0,451 & 0,380 & 0,325 & 0,282 & 0,249 \\
\hline
\end{tabular}


Tabela 57 - continuação da página anterior

\begin{tabular}{|c|c|c|c|c|c|c|c|c|c|c|c|c|}
\hline${ }_{N T U^{R}}$ & 0,0 & 0,2 & 0,4 & 0,6 & 0,8 & 1,0 & 1,5 & 2,0 & 2,5 & 3,0 & 3,5 & 4,0 \\
\hline 2,8 & 0,939 & 0,885 & 0,828 & 0,771 & 0,715 & 0,662 & 0,546 & 0,453 & 0,381 & 0,326 & 0,283 & 0,249 \\
\hline 2,9 & 0,945 & 0,892 & 0,835 & 0,777 & 0,721 & 0,667 & 0,549 & 0,455 & 0,382 & 0,326 & 0,283 & 0,249 \\
\hline 3,0 & 0,950 & 0,898 & 0,841 & 0,783 & 0,726 & 0,672 & 0,552 & 0,457 & 0,383 & 0,327 & 0,283 & 0,249 \\
\hline 3,1 & 0,955 & 0,904 & 0,847 & 0,789 & 0,731 & 0,676 & 0,555 & 0,458 & 0,384 & 0,327 & 0,283 & 0,249 \\
\hline 3,2 & 0,959 & 0,909 & 0,852 & 0,794 & 0,736 & 0,680 & 0,557 & 0,460 & 0,385 & 0,327 & 0,283 & 0,249 \\
\hline 3,3 & 0,963 & 0,914 & 0,858 & 0,799 & 0,741 & 0,684 & 0,560 & 0,461 & 0,385 & 0,328 & 0,284 & 0,249 \\
\hline 3,4 & 0,967 & 0,918 & 0,863 & 0,804 & 0,745 & 0,688 & 0,562 & 0,462 & 0,386 & 0,328 & 0,284 & 0,249 \\
\hline 3,5 & 0,970 & 0,923 & 0,867 & 0,808 & 0,749 & 0,692 & 0,564 & 0,464 & 0,387 & 0,328 & 0,284 & 0,249 \\
\hline 3,6 & 0,973 & 0,926 & 0,871 & 0,812 & 0,753 & 0,695 & 0,566 & 0,465 & 0,387 & 0,329 & 0,284 & 0,249 \\
\hline 3,7 & 0,975 & 0,930 & 0,876 & 0,816 & 0,757 & 0,698 & 0,568 & 0,466 & 0,388 & 0,329 & 0,284 & 0,249 \\
\hline 3,8 & 0,978 & 0,934 & 0,879 & 0,820 & 0,760 & 0,701 & 0,570 & 0,467 & 0,388 & 0,329 & 0,284 & 0,249 \\
\hline 3,9 & 0,980 & 0,937 & 0,883 & 0,824 & 0,763 & 0,704 & 0,572 & 0,468 & 0,389 & 0,329 & 0,284 & 0,249 \\
\hline 4,0 & 0,982 & 0,940 & 0,887 & 0,827 & 0,767 & 0,707 & 0,574 & 0,469 & 0,389 & 0,330 & 0,284 & 0,250 \\
\hline 4,1 & 0,983 & 0,943 & 0,890 & 0,831 & 0,770 & 0,710 & 0,575 & 0,469 & 0,389 & 0,330 & 0,284 & 0,250 \\
\hline 4,2 & 0,985 & 0,945 & 0,893 & 0,834 & 0,773 & 0,712 & 0,577 & 0,470 & 0,390 & 0,330 & 0,285 & 0,250 \\
\hline 4,3 & 0,986 & 0,948 & 0,896 & 0,837 & 0,775 & 0,715 & 0,578 & 0,471 & 0,390 & 0,330 & 0,285 & 0,250 \\
\hline 4,4 & 0,988 & 0,950 & 0,899 & 0,840 & 0,778 & 0,717 & 0,580 & 0,472 & 0,391 & 0,330 & 0,285 & 0,250 \\
\hline 4,5 & 0,989 & 0,952 & 0,902 & 0,843 & 0,781 & 0,719 & 0,581 & 0,472 & 0,391 & 0,330 & 0,285 & 0,250 \\
\hline 4,6 & 0,990 & 0,955 & 0,904 & 0,845 & 0,783 & 0,721 & 0,582 & 0,473 & 0,391 & 0,330 & 0,285 & 0,250 \\
\hline 4,7 & 0,991 & 0,956 & 0,907 & 0,848 & 0,785 & 0,723 & 0,583 & 0,473 & 0,391 & 0,331 & 0,285 & 0,250 \\
\hline 4,8 & 0,992 & 0,958 & 0,909 & 0,850 & 0,788 & 0,725 & 0,584 & 0,474 & 0,392 & 0,331 & 0,285 & 0,250 \\
\hline 4,9 & 0,993 & 0,960 & 0,911 & 0,852 & 0,790 & 0,727 & 0,586 & 0,475 & 0,392 & 0,331 & 0,285 & 0,250 \\
\hline 5,0 & 0,993 & 0,962 & 0,913 & 0,855 & 0,792 & 0,729 & 0,587 & 0,475 & 0,392 & 0,331 & 0,285 & 0,250 \\
\hline 5,1 & 0,994 & 0,963 & 0,915 & 0,857 & 0,794 & 0,731 & 0,588 & 0,476 & 0,392 & 0,331 & 0,285 & 0,250 \\
\hline 5,2 & 0,994 & 0,965 & 0,917 & 0,859 & 0,796 & 0,732 & 0,589 & 0,476 & 0,393 & 0,331 & 0,285 & 0,250 \\
\hline 5,3 & 0,995 & 0,966 & 0,919 & 0,861 & 0,798 & 0,734 & 0,589 & 0,476 & 0,393 & 0,331 & 0,285 & 0,250 \\
\hline 5,4 & 0,995 & 0,967 & 0,921 & 0,863 & 0,799 & 0,735 & 0,590 & 0,477 & 0,393 & 0,331 & 0,285 & 0,250 \\
\hline 5,5 & 0,996 & 0,969 & 0,922 & 0,864 & 0,801 & 0,737 & 0,591 & 0,477 & 0,393 & 0,331 & 0,285 & 0,250 \\
\hline 5,6 & 0,996 & 0,970 & 0,924 & 0,866 & 0,803 & 0,738 & 0,592 & 0,478 & 0,393 & 0,331 & 0,285 & 0,250 \\
\hline 5,7 & 0,997 & 0,971 & 0,926 & 0,868 & 0,804 & 0,740 & 0,593 & 0,478 & 0,393 & 0,331 & 0,285 & 0,250 \\
\hline 5,8 & 0,997 & 0,972 & 0,927 & 0,869 & 0,806 & 0,741 & 0,593 & 0,478 & 0,393 & 0,331 & 0,285 & 0,250 \\
\hline 5,9 & 0,997 & 0,973 & 0,928 & 0,871 & 0,807 & 0,742 & 0,594 & 0,479 & 0,394 & 0,331 & 0,285 & 0,250 \\
\hline 6,0 & 0,998 & 0,974 & 0,930 & 0,872 & 0,808 & 0,743 & 0,595 & 0,479 & 0,394 & 0,331 & 0,285 & 0,250 \\
\hline 6,1 & 0,998 & 0,975 & 0,931 & 0,874 & 0,810 & 0,744 & 0,595 & 0,479 & 0,394 & 0,332 & 0,285 & 0,250 \\
\hline 6,2 & 0,998 & 0,975 & 0,932 & 0,875 & 0,811 & 0,746 & 0,596 & 0,480 & 0,394 & 0,332 & 0,285 & 0,250 \\
\hline 6,3 & 0,998 & 0,976 & 0,933 & 0,876 & 0,812 & 0,747 & 0,597 & 0,480 & 0,394 & 0,332 & 0,285 & 0,250 \\
\hline 6,4 & 0,998 & 0,977 & 0,935 & 0,878 & 0,814 & 0,748 & 0,597 & 0,480 & 0,394 & 0,332 & 0,285 & 0,250 \\
\hline 6,5 & 0,998 & 0,978 & 0,936 & 0,879 & 0,815 & 0,749 & 0,598 & 0,480 & 0,394 & 0,332 & 0,285 & 0,250 \\
\hline 6,6 & 0,999 & 0,978 & 0,937 & 0,880 & 0,816 & 0,750 & 0,598 & 0,481 & 0,394 & 0,332 & 0,285 & 0,250 \\
\hline 6,7 & 0,999 & 0,979 & 0,938 & 0,881 & 0,817 & 0,751 & 0,599 & 0,481 & 0,394 & 0,332 & 0,285 & 0,250 \\
\hline 6,8 & 0,999 & 0,980 & 0,939 & 0,882 & 0,818 & 0,751 & 0,599 & 0,481 & 0,395 & 0,332 & 0,285 & 0,250 \\
\hline 6,9 & 0,999 & 0,980 & 0,940 & 0,883 & 0,819 & 0,752 & 0,600 & 0,481 & 0,395 & 0,332 & 0,285 & 0,250 \\
\hline 7,0 & 0,999 & 0,981 & 0,940 & 0,884 & 0,820 & 0,753 & 0,600 & 0,481 & 0,395 & 0,332 & 0,285 & 0,250 \\
\hline 7,1 & 0,999 & 0,981 & 0,941 & 0,885 & 0,821 & 0,754 & 0,601 & 0,482 & 0,395 & 0,332 & 0,285 & 0,250 \\
\hline 7,2 & 0,999 & 0,982 & 0,942 & 0,886 & 0,822 & 0,755 & 0,601 & 0,482 & 0,395 & 0,332 & 0,285 & 0,250 \\
\hline 7,3 & 0,999 & 0,982 & 0,943 & 0,887 & 0,822 & 0,755 & 0,601 & 0,482 & 0,395 & 0,332 & 0,285 & 0,250 \\
\hline 7,4 & 0,999 & 0,983 & 0,944 & 0,888 & 0,823 & 0,756 & 0,602 & 0,482 & 0,395 & 0,332 & 0,285 & 0,250 \\
\hline 7,5 & 0,999 & 0,983 & 0,944 & 0,889 & 0,824 & 0,757 & 0,602 & 0,482 & 0,395 & 0,332 & 0,285 & 0,250 \\
\hline 7,6 & 0,999 & 0,984 & 0,945 & 0,890 & 0,825 & 0,757 & 0,602 & 0,482 & 0,395 & 0,332 & 0,285 & 0,250 \\
\hline 7,7 & 1,000 & 0,984 & 0,946 & 0,890 & 0,825 & 0,758 & 0,603 & 0,483 & 0,395 & 0,332 & 0,285 & 0,250 \\
\hline 7,8 & 1,000 & 0,984 & 0,946 & 0,891 & 0,826 & 0,759 & 0,603 & 0,483 & 0,395 & 0,332 & 0,285 & 0,250 \\
\hline 7,9 & 1,000 & 0,985 & 0,947 & 0,892 & 0,827 & 0,759 & 0,603 & 0,483 & 0,395 & 0,332 & 0,285 & 0,250 \\
\hline 8,0 & 1,000 & 0,985 & 0,948 & 0,892 & 0,828 & 0,760 & 0,604 & 0,483 & 0,395 & 0,332 & 0,285 & 0,250 \\
\hline \multicolumn{13}{|c|}{ Continuação na próxima página } \\
\hline
\end{tabular}


Tabela 57 - continuação da página anterior

\begin{tabular}{|c|ccccccccccccc|}
\hline NTU & $R$ & 0,0 & 0,2 & 0,4 & 0,6 & 0,8 & 1,0 & 1,5 & 2,0 & 2,5 & 3,0 & 3,5 & 4,0 \\
\hline 8,1 & 1,000 & 0,985 & 0,948 & 0,893 & 0,828 & 0,760 & 0,604 & 0,483 & 0,395 & 0,332 & 0,285 & 0,250 \\
8,2 & 1,000 & 0,986 & 0,949 & 0,894 & 0,829 & 0,761 & 0,604 & 0,483 & 0,395 & 0,332 & 0,285 & 0,250 \\
8,3 & 1,000 & 0,986 & 0,949 & 0,894 & 0,829 & 0,761 & 0,605 & 0,483 & 0,395 & 0,332 & 0,285 & 0,250 \\
8,4 & 1,000 & 0,986 & 0,950 & 0,895 & 0,830 & 0,762 & 0,605 & 0,483 & 0,396 & 0,332 & 0,285 & 0,250 \\
8,5 & 1,000 & 0,987 & 0,950 & 0,895 & 0,831 & 0,762 & 0,605 & 0,483 & 0,396 & 0,332 & 0,285 & 0,250 \\
8,6 & 1,000 & 0,987 & 0,951 & 0,896 & 0,831 & 0,763 & 0,605 & 0,484 & 0,396 & 0,332 & 0,285 & 0,250 \\
8,7 & 1,000 & 0,987 & 0,951 & 0,897 & 0,832 & 0,763 & 0,606 & 0,484 & 0,396 & 0,332 & 0,285 & 0,250 \\
8,8 & 1,000 & 0,987 & 0,952 & 0,897 & 0,832 & 0,764 & 0,606 & 0,484 & 0,396 & 0,332 & 0,285 & 0,250 \\
8,9 & 1,000 & 0,988 & 0,952 & 0,898 & 0,833 & 0,764 & 0,606 & 0,484 & 0,396 & 0,332 & 0,285 & 0,250 \\
9,0 & 1,000 & 0,988 & 0,953 & 0,898 & 0,833 & 0,764 & 0,606 & 0,484 & 0,396 & 0,332 & 0,285 & 0,250 \\
9,1 & 1,000 & 0,988 & 0,953 & 0,899 & 0,833 & 0,765 & 0,606 & 0,484 & 0,396 & 0,332 & 0,285 & 0,250 \\
9,2 & 1,000 & 0,988 & 0,953 & 0,899 & 0,834 & 0,765 & 0,607 & 0,484 & 0,396 & 0,332 & 0,285 & 0,250 \\
9,3 & 1,000 & 0,989 & 0,954 & 0,899 & 0,834 & 0,766 & 0,607 & 0,484 & 0,396 & 0,332 & 0,285 & 0,250 \\
9,4 & 1,000 & 0,989 & 0,954 & 0,900 & 0,835 & 0,766 & 0,607 & 0,484 & 0,396 & 0,332 & 0,285 & 0,250 \\
9,5 & 1,000 & 0,989 & 0,954 & 0,900 & 0,835 & 0,766 & 0,607 & 0,484 & 0,396 & 0,332 & 0,285 & 0,250 \\
9,6 & 1,000 & 0,989 & 0,955 & 0,901 & 0,835 & 0,767 & 0,607 & 0,484 & 0,396 & 0,332 & 0,285 & 0,250 \\
9,7 & 1,000 & 0,989 & 0,955 & 0,901 & 0,836 & 0,767 & 0,607 & 0,484 & 0,396 & 0,332 & 0,285 & 0,250 \\
9,8 & 1,000 & 0,989 & 0,955 & 0,901 & 0,836 & 0,767 & 0,608 & 0,485 & 0,396 & 0,332 & 0,285 & 0,250 \\
9,9 & 1,000 & 0,990 & 0,956 & 0,902 & 0,837 & 0,768 & 0,608 & 0,485 & 0,396 & 0,332 & 0,285 & 0,250 \\
10,0 & 1,000 & 0,990 & 0,956 & 0,902 & 0,837 & 0,768 & 0,608 & 0,485 & 0,396 & 0,332 & 0,285 & 0,250 \\
\hline
\end{tabular}

Tabela 58 - Fator de correção para trocador de calor de fluxo cruzado com um passe e três tubos por passe (1-3) - Caso 3 ou 4 - trocador de calor ilustrado na Figura 73 do Anexo A

\begin{tabular}{|c|c|c|c|c|c|c|c|c|c|c|c|c|}
\hline $\mathrm{NTU}^{R}$ & 0,0 & 0,2 & 0,4 & 0,6 & 0,8 & 1,0 & 1,5 & 2,0 & 2,5 & 3,0 & 3,5 & 4,0 \\
\hline 0,0 & 1,000 & 1,000 & 1,000 & 1,000 & 1,000 & 1,000 & 1,000 & 1,000 & 1,000 & 1,000 & 1,000 & 1,000 \\
\hline 0,1 & 1,000 & 1,000 & 0,999 & 0,999 & 0,999 & 0,998 & 0,998 & 0,997 & 0,996 & 0,995 & 0,995 & 0,994 \\
\hline 0,2 & 1,000 & 0,999 & 0,998 & 0,996 & 0,995 & 0,994 & 0,991 & 0,989 & 0,986 & 0,984 & 0,982 & 0,979 \\
\hline 0,3 & 1,000 & 0,997 & 0,995 & 0,992 & 0,990 & 0,987 & 0,982 & 0,976 & 0,972 & 0,967 & 0,963 & 0,960 \\
\hline 0,4 & 1,000 & 0,995 & 0,991 & 0,986 & 0,982 & 0,978 & 0,970 & 0,962 & 0,955 & 0,948 & 0,943 & 0,938 \\
\hline 0,5 & 1,000 & 0,993 & 0,986 & 0,980 & 0,974 & 0,968 & 0,956 & 0,945 & 0,936 & 0,928 & 0,921 & 0,915 \\
\hline 0,6 & 1,000 & 0,990 & 0,981 & 0,972 & 0,964 & 0,957 & 0,941 & 0,928 & 0,917 & 0,907 & 0,899 & 0,892 \\
\hline 0,7 & 1,000 & 0,987 & 0,975 & 0,964 & 0,954 & 0,945 & 0,926 & 0,910 & 0,897 & 0,886 & 0,877 & 0,870 \\
\hline 0,8 & 1,000 & 0,983 & 0,968 & 0,955 & 0,943 & 0,932 & 0,910 & 0,892 & 0,878 & 0,866 & 0,857 & 0,849 \\
\hline 0,9 & 1,000 & 0,979 & 0,961 & 0,945 & 0,932 & 0,919 & 0,894 & 0,875 & 0,859 & 0,847 & 0,837 & 0,829 \\
\hline 1,0 & 1,000 & 0,975 & 0,954 & 0,936 & 0,920 & 0,906 & 0,878 & 0,857 & 0,841 & 0,828 & 0,818 & 0,810 \\
\hline 1,1 & 1,000 & 0,971 & 0,946 & 0,926 & 0,908 & 0,893 & 0,863 & 0,840 & 0,824 & 0,810 & 0,800 & 0,792 \\
\hline 1,2 & 1,000 & 0,966 & 0,938 & 0,915 & 0,896 & 0,880 & 0,848 & 0,824 & 0,807 & 0,794 & 0,783 & 0,775 \\
\hline 1,3 & 1,000 & 0,961 & 0,930 & 0,905 & 0,884 & 0,867 & 0,833 & 0,809 & 0,791 & 0,777 & 0,767 & 0,759 \\
\hline 1,4 & 1,000 & 0,956 & 0,922 & 0,895 & 0,872 & 0,854 & 0,818 & 0,793 & 0,775 & 0,762 & 0,752 & 0,744 \\
\hline 1,5 & 1,000 & 0,951 & 0,914 & 0,885 & 0,861 & 0,841 & 0,804 & 0,779 & 0,761 & 0,747 & 0,737 & 0,730 \\
\hline 1,6 & 1,000 & 0,946 & 0,906 & 0,874 & 0,849 & 0,829 & 0,791 & 0,765 & 0,747 & 0,733 & 0,723 & 0,716 \\
\hline 1,7 & 1,000 & 0,941 & 0,897 & 0,864 & 0,838 & 0,817 & 0,778 & 0,751 & 0,733 & 0,720 & 0,710 & 0,703 \\
\hline 1,8 & 1,000 & 0,935 & 0,889 & 0,854 & 0,827 & 0,805 & 0,765 & 0,738 & 0,720 & 0,707 & 0,698 & 0,691 \\
\hline 1,9 & 1,000 & 0,930 & 0,881 & 0,844 & 0,816 & 0,793 & 0,752 & 0,726 & 0,708 & 0,695 & 0,685 & 0,679 \\
\hline 2,0 & 1,000 & 0,924 & 0,873 & 0,835 & 0,805 & 0,782 & 0,740 & 0,714 & 0,695 & 0,683 & 0,674 & 0,667 \\
\hline 2,1 & 1,000 & 0,919 & 0,864 & 0,825 & 0,795 & 0,771 & 0,729 & 0,702 & 0,684 & 0,671 & 0,662 & 0,656 \\
\hline 2,2 & 1,000 & 0,913 & 0,856 & 0,815 & 0,784 & 0,760 & 0,718 & 0,691 & 0,673 & 0,660 & 0,652 & 0,645 \\
\hline 2,3 & 1,000 & 0,908 & 0,848 & 0,806 & 0,774 & 0,750 & 0,707 & 0,680 & 0,662 & 0,650 & 0,641 & 0,635 \\
\hline 2,4 & 1,000 & 0,902 & 0,840 & 0,797 & 0,764 & 0,739 & 0,696 & 0,669 & 0,651 & 0,639 & 0,631 & 0,625 \\
\hline 2,5 & 1,000 & 0,896 & 0,832 & 0,788 & 0,755 & 0,729 & 0,686 & 0,659 & 0,641 & 0,629 & 0,621 & 0,616 \\
\hline
\end{tabular}


Tabela 58 - continuação da página anterior

\begin{tabular}{|c|c|c|c|c|c|c|c|c|c|c|c|c|}
\hline${ }_{N T U^{R}}$ & 0,0 & 0,2 & 0,4 & 0,6 & 0,8 & 1,0 & 1,5 & 2,0 & 2,5 & 3,0 & 3,5 & 4,0 \\
\hline 2,6 & 1,000 & 0,891 & 0,825 & 0,779 & 0,745 & 0,719 & 0,676 & 0,649 & 0,631 & 0,620 & 0,612 & 0,606 \\
\hline 2,7 & 1,000 & 0,885 & 0,817 & 0,770 & 0,736 & 0,710 & 0,666 & 0,639 & 0,622 & 0,610 & 0,603 & 0,597 \\
\hline 2,8 & 1,000 & 0,880 & 0,809 & 0,762 & 0,727 & 0,701 & 0,656 & 0,630 & 0,613 & 0,601 & 0,594 & 0,589 \\
\hline 2,9 & 1,000 & 0,874 & 0,802 & 0,753 & 0,718 & 0,692 & 0,647 & 0,620 & 0,604 & 0,592 & 0,585 & 0,580 \\
\hline 3,0 & 1,000 & 0,868 & 0,794 & 0,745 & 0,709 & 0,683 & 0,638 & 0,612 & 0,595 & 0,584 & 0,577 & 0,572 \\
\hline 3,1 & 1,000 & 0,863 & 0,787 & 0,737 & 0,701 & 0,674 & 0,629 & 0,603 & 0,586 & 0,575 & 0,568 & 0,564 \\
\hline 3,2 & 1,000 & 0,857 & 0,780 & 0,729 & 0,693 & 0,665 & 0,621 & 0,594 & 0,578 & 0,567 & 0,560 & 0,556 \\
\hline 3,3 & 1,000 & 0,852 & 0,772 & 0,721 & 0,684 & 0,657 & 0,612 & 0,586 & 0,570 & 0,559 & 0,553 & 0,548 \\
\hline 3,4 & 1,000 & 0,846 & 0,765 & 0,713 & 0,676 & 0,649 & 0,604 & 0,578 & 0,562 & 0,552 & 0,545 & 0,541 \\
\hline 3,5 & 1,000 & 0,841 & 0,758 & 0,706 & 0,668 & 0,641 & 0,596 & 0,570 & 0,554 & 0,544 & 0,537 & 0,533 \\
\hline 3,6 & 1,000 & 0,835 & 0,751 & 0,698 & 0,661 & 0,633 & 0,588 & 0,563 & 0,547 & 0,537 & 0,530 & 0,526 \\
\hline 3,7 & 1,000 & 0,830 & 0,745 & 0,691 & 0,653 & 0,625 & 0,581 & 0,555 & 0,539 & 0,529 & 0,523 & 0,519 \\
\hline 3,8 & 1,000 & 0,824 & 0,738 & 0,684 & 0,646 & 0,618 & 0,573 & 0,548 & 0,532 & 0,522 & 0,516 & 0,512 \\
\hline 3,9 & 1,000 & 0,819 & 0,731 & 0,676 & 0,638 & 0,611 & 0,566 & 0,540 & 0,525 & 0,515 & 0,509 & 0,505 \\
\hline 4,0 & 1,000 & 0,814 & 0,725 & 0,669 & 0,631 & 0,603 & 0,559 & 0,533 & 0,518 & 0,509 & 0,503 & 0,499 \\
\hline 4,1 & 1,000 & 0,808 & 0,718 & 0,663 & 0,624 & 0,596 & 0,552 & 0,527 & 0,512 & 0,502 & 0,496 & 0,493 \\
\hline 4,2 & 1,000 & 0,803 & 0,712 & 0,656 & 0,617 & 0,589 & 0,545 & 0,520 & 0,505 & 0,496 & 0,490 & 0,486 \\
\hline 4,3 & 1,000 & 0,798 & 0,706 & 0,649 & 0,610 & 0,582 & 0,538 & 0,513 & 0,499 & 0,489 & 0,484 & 0,480 \\
\hline 4,4 & 1,000 & 0,793 & 0,699 & 0,642 & 0,604 & 0,576 & 0,531 & 0,507 & 0,492 & 0,483 & 0,478 & 0,474 \\
\hline 4,5 & 1,000 & 0,787 & 0,693 & 0,636 & 0,597 & 0,569 & 0,525 & 0,501 & 0,486 & 0,477 & 0,472 & 0,468 \\
\hline 4,6 & 1,000 & 0,782 & 0,687 & 0,630 & 0,591 & 0,563 & 0,519 & 0,494 & 0,480 & 0,471 & 0,466 & 0,462 \\
\hline 4,7 & 1,000 & 0,777 & 0,681 & 0,623 & 0,584 & 0,556 & 0,512 & 0,488 & 0,474 & 0,465 & 0,460 & 0,457 \\
\hline 4,8 & 1,000 & 0,772 & 0,675 & 0,617 & 0,578 & 0,550 & 0,506 & 0,482 & 0,468 & 0,460 & 0,454 & 0,451 \\
\hline 4,9 & 1,000 & 0,767 & 0,669 & 0,611 & 0,572 & 0,544 & 0,500 & 0,477 & 0,463 & 0,454 & 0,449 & 0,446 \\
\hline 5,0 & 1,000 & 0,762 & 0,663 & 0,605 & 0,566 & 0,538 & 0,494 & 0,471 & 0,457 & 0,449 & 0,443 & 0,440 \\
\hline 5,1 & 1,000 & 0,757 & 0,658 & 0,599 & 0,560 & 0,532 & 0,489 & 0,465 & 0,451 & 0,443 & 0,438 & 0,435 \\
\hline 5,2 & 1,000 & 0,752 & 0,652 & 0,593 & 0,554 & 0,526 & 0,483 & 0,460 & 0,446 & 0,438 & 0,433 & 0,430 \\
\hline 5,3 & 1,000 & 0,747 & 0,646 & 0,587 & 0,548 & 0,520 & 0,477 & 0,454 & 0,441 & 0,433 & 0,428 & 0,425 \\
\hline 5,4 & 1,000 & 0,742 & 0,641 & 0,582 & 0,542 & 0,515 & 0,472 & 0,449 & 0,436 & 0,428 & 0,423 & 0,420 \\
\hline 5,5 & 1,000 & 0,737 & 0,635 & 0,576 & 0,537 & 0,509 & 0,467 & 0,444 & 0,431 & 0,423 & 0,418 & 0,415 \\
\hline 5,6 & 1,000 & 0,732 & 0,630 & 0,570 & 0,531 & 0,504 & 0,461 & 0,439 & 0,426 & 0,418 & 0,413 & 0,410 \\
\hline 5,7 & 1,000 & 0,727 & 0,624 & 0,565 & 0,526 & 0,498 & 0,456 & 0,434 & 0,421 & 0,413 & 0,408 & 0,405 \\
\hline 5,8 & 1,000 & 0,723 & 0,619 & 0,560 & 0,521 & 0,493 & 0,451 & 0,429 & 0,416 & 0,408 & 0,404 & 0,401 \\
\hline 5,9 & 1,000 & 0,718 & 0,614 & 0,554 & 0,515 & 0,488 & 0,446 & 0,424 & 0,411 & 0,404 & 0,399 & 0,396 \\
\hline 6,0 & 1,000 & 0,713 & 0,609 & 0,549 & 0,510 & 0,483 & 0,441 & 0,419 & 0,407 & 0,399 & 0,395 & 0,392 \\
\hline 6,1 & 1,000 & 0,708 & 0,603 & 0,544 & 0,505 & 0,478 & 0,436 & 0,415 & 0,402 & 0,395 & 0,390 & 0,387 \\
\hline 6,2 & 1,000 & 0,704 & 0,598 & 0,539 & 0,500 & 0,473 & 0,432 & 0,410 & 0,398 & 0,390 & 0,386 & 0,383 \\
\hline 6,3 & 1,000 & 0,699 & 0,593 & 0,534 & 0,495 & 0,468 & 0,427 & 0,405 & 0,393 & 0,386 & 0,382 & 0,379 \\
\hline 6,4 & 1,000 & 0,694 & 0,588 & 0,529 & 0,490 & 0,463 & 0,422 & 0,401 & 0,389 & 0,382 & 0,377 & 0,375 \\
\hline 6,5 & 1,000 & 0,690 & 0,583 & 0,524 & 0,485 & 0,458 & 0,418 & 0,397 & 0,385 & 0,378 & 0,373 & 0,371 \\
\hline 6,6 & 1,000 & 0,685 & 0,578 & 0,519 & 0,480 & 0,454 & 0,413 & 0,392 & 0,380 & 0,373 & 0,369 & 0,367 \\
\hline 6,7 & 1,000 & 0,681 & 0,574 & 0,514 & 0,476 & 0,449 & 0,409 & 0,388 & 0,376 & 0,369 & 0,365 & 0,363 \\
\hline 6,8 & 1,000 & 0,676 & 0,569 & 0,509 & 0,471 & 0,445 & 0,405 & 0,384 & 0,372 & 0,365 & 0,361 & 0,359 \\
\hline 6,9 & 1,000 & 0,672 & 0,564 & 0,505 & 0,467 & 0,440 & 0,401 & 0,380 & 0,368 & 0,362 & 0,358 & 0,355 \\
\hline 7,0 & 1,000 & 0,667 & 0,559 & 0,500 & 0,462 & 0,436 & 0,396 & 0,376 & 0,365 & 0,358 & 0,354 & 0,351 \\
\hline 7,1 & 1,000 & 0,663 & 0,555 & 0,496 & 0,458 & 0,431 & 0,392 & 0,372 & 0,361 & 0,354 & 0,350 & 0,348 \\
\hline 7,2 & 1,000 & 0,658 & 0,550 & 0,491 & 0,453 & 0,427 & 0,388 & 0,368 & 0,357 & 0,350 & 0,346 & 0,344 \\
\hline 7,3 & 1,000 & 0,654 & 0,546 & 0,487 & 0,449 & 0,423 & 0,384 & 0,364 & 0,353 & 0,347 & 0,343 & 0,341 \\
\hline 7,4 & 0,999 & 0,649 & 0,541 & 0,482 & 0,445 & 0,419 & 0,381 & 0,361 & 0,350 & 0,343 & 0,339 & 0,337 \\
\hline 7,5 & 0,999 & 0,645 & 0,537 & 0,478 & 0,441 & 0,415 & 0,377 & 0,357 & 0,346 & 0,340 & 0,336 & 0,334 \\
\hline 7,6 & 0,999 & 0,641 & 0,532 & 0,474 & 0,436 & 0,411 & 0,373 & 0,353 & 0,343 & 0,336 & 0,332 & 0,330 \\
\hline 7,7 & 0,999 & 0,636 & 0,528 & 0,469 & 0,432 & 0,407 & 0,369 & 0,350 & 0,339 & 0,333 & 0,329 & 0,327 \\
\hline 7,8 & 0,999 & 0,632 & 0,524 & 0,465 & 0,428 & 0,403 & 0,366 & 0,346 & 0,336 & 0,329 & 0,326 & 0,324 \\
\hline \multicolumn{13}{|c|}{ Continuação na próxima página } \\
\hline
\end{tabular}


Tabela 58 - continuação da página anterior

\begin{tabular}{|c|ccccccccccccc|}
\hline NTU & \multicolumn{1}{c}{$\mathrm{N}^{2}$} & 0,0 & 0,2 & 0,4 & 0,6 & 0,8 & 1,0 & 1,5 & 2,0 & 2,5 & 3,0 & 3,5 & 4,0 \\
\hline 7,9 & 0,999 & 0,628 & 0,519 & 0,461 & 0,424 & 0,399 & 0,362 & 0,343 & 0,332 & 0,326 & 0,323 & 0,320 \\
8,0 & 0,999 & 0,624 & 0,515 & 0,457 & 0,420 & 0,395 & 0,359 & 0,340 & 0,329 & 0,323 & 0,319 & 0,317 \\
8,1 & 0,999 & 0,619 & 0,511 & 0,453 & 0,417 & 0,392 & 0,355 & 0,336 & 0,326 & 0,320 & 0,316 & 0,314 \\
8,2 & 0,999 & 0,615 & 0,507 & 0,449 & 0,413 & 0,388 & 0,352 & 0,333 & 0,323 & 0,317 & 0,313 & 0,311 \\
8,3 & 0,999 & 0,611 & 0,503 & 0,445 & 0,409 & 0,384 & 0,348 & 0,330 & 0,320 & 0,314 & 0,310 & 0,308 \\
8,4 & 0,999 & 0,607 & 0,499 & 0,441 & 0,405 & 0,381 & 0,345 & 0,327 & 0,317 & 0,311 & 0,307 & 0,305 \\
8,5 & 0,999 & 0,603 & 0,495 & 0,438 & 0,402 & 0,377 & 0,342 & 0,324 & 0,313 & 0,308 & 0,304 & 0,302 \\
8,6 & 0,999 & 0,599 & 0,491 & 0,434 & 0,398 & 0,374 & 0,339 & 0,321 & 0,311 & 0,305 & 0,301 & 0,299 \\
8,7 & 0,999 & 0,595 & 0,487 & 0,430 & 0,395 & 0,371 & 0,335 & 0,318 & 0,308 & 0,302 & 0,298 & 0,297 \\
8,8 & 0,999 & 0,591 & 0,483 & 0,426 & 0,391 & 0,367 & 0,332 & 0,315 & 0,305 & 0,299 & 0,296 & 0,294 \\
8,9 & 0,999 & 0,587 & 0,479 & 0,423 & 0,388 & 0,364 & 0,329 & 0,312 & 0,302 & 0,296 & 0,293 & 0,291 \\
9,0 & 0,999 & 0,583 & 0,475 & 0,419 & 0,384 & 0,361 & 0,326 & 0,309 & 0,299 & 0,293 & 0,290 & 0,288 \\
9,1 & 0,999 & 0,579 & 0,472 & 0,416 & 0,381 & 0,358 & 0,323 & 0,306 & 0,296 & 0,291 & 0,288 & 0,286 \\
9,2 & 0,999 & 0,575 & 0,468 & 0,412 & 0,378 & 0,354 & 0,320 & 0,303 & 0,294 & 0,288 & 0,285 & 0,283 \\
9,3 & 0,999 & 0,571 & 0,464 & 0,409 & 0,375 & 0,351 & 0,317 & 0,300 & 0,291 & 0,286 & 0,282 & 0,280 \\
9,4 & 0,999 & 0,567 & 0,461 & 0,405 & 0,371 & 0,348 & 0,315 & 0,298 & 0,288 & 0,283 & 0,280 & 0,278 \\
9,5 & 0,999 & 0,563 & 0,457 & 0,402 & 0,368 & 0,345 & 0,312 & 0,295 & 0,286 & 0,280 & 0,277 & 0,275 \\
9,6 & 0,999 & 0,560 & 0,454 & 0,399 & 0,365 & 0,342 & 0,309 & 0,292 & 0,283 & 0,278 & 0,275 & 0,273 \\
9,7 & 0,999 & 0,556 & 0,450 & 0,396 & 0,362 & 0,339 & 0,306 & 0,290 & 0,281 & 0,275 & 0,272 & 0,271 \\
9,8 & 0,999 & 0,552 & 0,447 & 0,392 & 0,359 & 0,336 & 0,304 & 0,287 & 0,278 & 0,273 & 0,270 & 0,268 \\
9,9 & 0,999 & 0,548 & 0,443 & 0,389 & 0,356 & 0,334 & 0,301 & 0,285 & 0,276 & 0,271 & 0,268 & 0,266 \\
10,0 & 0,999 & 0,545 & 0,440 & 0,386 & 0,353 & 0,331 & 0,298 & 0,282 & 0,273 & 0,268 & 0,265 & 0,264 \\
\hline
\end{tabular}

Tabela 59 - Efetividade de temperatura para trocador de calor de fluxo cruzado com um passe e quatro tubos por passe (1-4) - Caso 3 ou 4 - trocador de calor ilustrado na Figura 74 do Anexo A

\begin{tabular}{|c|c|c|c|c|c|c|c|c|c|c|c|c|}
\hline NTU ${ }^{R}$ & 0,0 & 0,2 & 0,4 & 0,6 & 0,8 & 1,0 & 1,5 & 2,0 & 2,5 & 3,0 & 3,5 & 4,0 \\
\hline 0,0 & 0,000 & 0,000 & 0,000 & 0,000 & 0,000 & 0,000 & 0,000 & 0,000 & 0,000 & 0,000 & 0,000 & 0,000 \\
\hline 0,1 & 0,095 & 0,094 & 0,093 & 0,092 & 0,092 & 0,091 & 0,089 & 0,087 & 0,085 & 0,083 & 0,081 & 0,079 \\
\hline 0,2 & 0,181 & 0,178 & 0,175 & 0,172 & 0,169 & 0,166 & 0,159 & 0,152 & 0,146 & 0,140 & 0,134 & 0,129 \\
\hline 0,3 & 0,259 & 0,253 & 0,246 & 0,240 & 0,234 & 0,228 & 0,215 & 0,203 & 0,191 & 0,180 & 0,171 & 0,162 \\
\hline 0,4 & 0,330 & 0,319 & 0,309 & 0,299 & 0,290 & 0,281 & 0,261 & 0,242 & 0,225 & 0,210 & 0,196 & 0,184 \\
\hline 0,5 & 0,393 & 0,379 & 0,365 & 0,351 & 0,338 & 0,326 & 0,298 & 0,274 & 0,252 & 0,232 & 0,215 & 0,199 \\
\hline 0,6 & 0,451 & 0,432 & 0,414 & 0,397 & 0,380 & 0,365 & 0,330 & 0,299 & 0,273 & 0,249 & 0,229 & 0,210 \\
\hline 0,7 & 0,503 & 0,480 & 0,457 & 0,437 & 0,417 & 0,398 & 0,356 & 0,320 & 0,289 & 0,262 & 0,239 & 0,219 \\
\hline 0,8 & 0,551 & 0,523 & 0,497 & 0,472 & 0,449 & 0, & 0,379 & 0,3 & 0,303 & 0,273 & 0,247 & 0,225 \\
\hline 0,9 & 0,593 & 0,561 & 0,532 & 0,504 & 0,477 & 0,453 & 0,399 & 0,353 & 0,314 & 0,281 & 0,253 & 0,230 \\
\hline 1,0 & 0,632 & 0,596 & 0,563 & 0,532 & 0,503 & 0,476 & 0,416 & 0,366 & 0,324 & 0,288 & 0,259 & 0,233 \\
\hline 1,1 & 0,667 & 0,628 & 0,591 & 0,557 & 0,526 & 0,496 & 0,431 & 0,377 & 0,332 & 0,294 & 0,263 & 0,236 \\
\hline 1,2 & 0,699 & 0,657 & 0,617 & 0,580 & 0,546 & 0,514 & 0,444 & 0,386 & 0,338 & 0,299 & 0,266 & 0,239 \\
\hline 1,3 & 0,727 & 0,682 & 0,640 & 0,601 & 0,564 & 0,530 & 0,456 & 0,395 & 0,344 & 0,303 & 0,269 & 0,240 \\
\hline 1,4 & 0,753 & 0,706 & 0,662 & 0,620 & 0,581 & 0,545 & 0,467 & 0,402 & 0,349 & 0,306 & 0,271 & 0,242 \\
\hline 1,5 & 0,777 & 0,727 & 0,681 & 0,637 & 0,597 & 0,559 & 0,476 & 0,409 & 0,354 & 0,309 & 0,273 & 0,243 \\
\hline 1,6 & 0,798 & 0,747 & 0,699 & 0,653 & 0,611 & 0,571 & 0,485 & 0,415 & 0,358 & 0,312 & 0,275 & 0,244 \\
\hline 1,7 & 0,817 & 0,765 & 0,715 & 0,668 & 0,624 & 0,583 & 0,493 & 0,420 & 0,361 & 0,314 & 0,276 & 0,245 \\
\hline 1,8 & 0,835 & 0,781 & 0,730 & 0,681 & 0,636 & 0,593 & 0,500 & 0,425 & 0,364 & 0,316 & 0,277 & 0,246 \\
\hline 1,9 & 0,850 & 0,796 & 0,744 & 0,694 & 0,647 & 0,603 & 0,507 & 0,429 & 0,367 & 0,318 & 0,278 & 0,246 \\
\hline 2,0 & 0,865 & 0,810 & 0,756 & 0,705 & 0,657 & 0,612 & 0,513 & 0,433 & 0,370 & 0,319 & 0,279 & 0,247 \\
\hline 2,1 & 0,878 & 0,822 & 0,768 & 0,716 & 0,667 & 0,620 & 0,519 & 0,437 & 0,372 & 0,320 & 0,280 & 0,247 \\
\hline 2,2 & 0,889 & 0,834 & 0,779 & 0,726 & 0,676 & 0,628 & 0,524 & 0,440 & 0,374 & 0,322 & 0,280 & 0,248 \\
\hline
\end{tabular}


Tabela 59 - continuação da página anterior

\begin{tabular}{|c|c|c|c|c|c|c|c|c|c|c|c|c|}
\hline${ }_{\text {NTU }}{ }^{R}$ & 0,0 & 0,2 & 0,4 & 0,6 & 0,8 & 1,0 & 1,5 & 2,0 & 2,5 & 3,0 & 3,5 & 4,0 \\
\hline 2,3 & 0,900 & 0,845 & 0,789 & 0,735 & 0,684 & 0,635 & 0,529 & 0,443 & 0,376 & 0,323 & 0,281 & 0,248 \\
\hline 2,4 & 0,909 & 0,854 & 0,799 & 0,744 & 0,692 & 0,642 & 0,533 & 0,446 & 0,377 & 0,324 & 0,281 & 0,248 \\
\hline 2,5 & 0,918 & 0,863 & 0,808 & 0,752 & 0,699 & 0,649 & 0,538 & 0,448 & 0,379 & 0,324 & 0,282 & 0,248 \\
\hline 2,6 & 0,926 & 0,872 & 0,816 & 0,760 & 0,706 & 0,655 & 0,542 & 0,451 & 0,380 & 0,325 & 0,282 & 0,249 \\
\hline 2,7 & 0,933 & 0,880 & 0,824 & 0,767 & 0,713 & 0,660 & 0,545 & 0,453 & 0,381 & 0,326 & 0,283 & 0,249 \\
\hline 2,8 & 0,939 & 0,887 & 0,831 & 0,774 & 0,719 & 0,666 & 0,549 & 0,455 & 0,382 & 0,326 & 0,283 & 0,249 \\
\hline 2,9 & 0,945 & 0,893 & 0,838 & 0,781 & 0,725 & 0,671 & 0,552 & 0,457 & 0,383 & 0,327 & 0,283 & 0,249 \\
\hline 3,0 & 0,950 & 0,900 & 0,844 & 0,787 & 0,730 & 0,676 & 0,555 & 0,459 & 0,384 & 0,327 & 0,283 & 0,249 \\
\hline 3,1 & 0,955 & 0,905 & 0,850 & 0,793 & 0,736 & 0,681 & 0,558 & 0,461 & 0,385 & 0,328 & 0,284 & 0,249 \\
\hline 3,2 & 0,959 & 0,911 & 0,856 & 0,798 & 0,741 & 0,685 & 0,561 & 0,462 & 0,386 & 0,328 & 0,284 & 0,249 \\
\hline 3,3 & 0,963 & 0,916 & 0,861 & 0,803 & 0,745 & 0,689 & 0,564 & 0,464 & 0,387 & 0,329 & 0,284 & 0,249 \\
\hline 3,4 & 0,967 & 0,920 & 0,866 & 0,808 & 0,750 & 0,693 & 0,566 & 0,465 & 0,387 & 0,329 & 0,284 & 0,249 \\
\hline 3,5 & 0,970 & 0,925 & 0,871 & 0,813 & 0,754 & 0,697 & 0,568 & 0,466 & 0,388 & 0,329 & 0,284 & 0,249 \\
\hline 3,6 & 0,973 & 0,929 & 0,875 & 0,817 & 0,758 & 0,701 & 0,571 & 0,467 & 0,389 & 0,329 & 0,284 & 0,250 \\
\hline 3,7 & 0,975 & 0,932 & 0,880 & 0,822 & 0,762 & 0,704 & 0,573 & 0,468 & 0,389 & 0,330 & 0,284 & 0,250 \\
\hline 3,8 & 0,978 & 0,936 & 0,884 & 0,826 & 0,766 & 0,707 & 0,575 & 0,470 & 0,390 & 0,330 & 0,285 & 0,250 \\
\hline 3,9 & 0,980 & 0,939 & 0,887 & 0,830 & 0,770 & 0,710 & 0,577 & 0,471 & 0,390 & 0,330 & 0,285 & 0,250 \\
\hline 4,0 & 0,982 & 0,942 & 0,891 & 0,833 & 0,773 & 0,714 & 0,579 & 0,472 & 0,391 & 0,330 & 0,285 & 0,250 \\
\hline 4,1 & 0,983 & 0,945 & 0,895 & 0,837 & 0,776 & 0,716 & 0,580 & 0,472 & 0,391 & 0,330 & 0,285 & 0,250 \\
\hline 4,2 & 0,985 & 0,948 & 0,898 & 0,840 & 0,780 & 0,719 & 0,582 & 0,473 & 0,391 & 0,331 & 0,285 & 0,250 \\
\hline 4,3 & 0,986 & 0,950 & 0,901 & 0,844 & 0,783 & 0,722 & 0,584 & 0,474 & 0,392 & 0,331 & 0,285 & 0,250 \\
\hline 4,4 & 0,988 & 0,953 & 0,904 & 0,847 & 0,786 & 0,724 & 0,585 & 0,475 & 0,392 & 0,331 & 0,285 & 0,250 \\
\hline 4,5 & 0,989 & 0,955 & 0,907 & 0,850 & 0,788 & 0,727 & 0,587 & 0,476 & 0,392 & 0,331 & 0,285 & 0,250 \\
\hline 4,6 & 0,990 & 0,957 & 0,910 & 0,853 & 0,791 & 0,729 & 0,588 & 0,476 & 0,393 & 0,331 & 0,285 & 0,250 \\
\hline 4,7 & 0,991 & 0,959 & 0,912 & 0,855 & 0,794 & 0,732 & 0,589 & 0,477 & 0,393 & 0,331 & 0,285 & 0,250 \\
\hline 4,8 & 0,992 & 0,961 & 0,915 & 0,858 & 0,796 & 0,734 & 0,591 & 0,477 & 0,393 & 0,331 & 0,285 & 0,250 \\
\hline 4,9 & 0,993 & 0,963 & 0,917 & 0,861 & 0,799 & 0,736 & 0,592 & 0,478 & 0,394 & 0,331 & 0,285 & 0,250 \\
\hline 5,0 & 0,993 & 0,965 & 0,919 & 0,863 & 0,801 & 0,738 & 0,593 & 0,479 & 0,394 & 0,332 & 0,285 & 0,250 \\
\hline 5,1 & 0,994 & 0,966 & 0,921 & 0,865 & 0,803 & 0,740 & 0,594 & 0,479 & 0,394 & 0,332 & 0,285 & 0,250 \\
\hline 5,2 & 0,994 & 0,968 & 0,923 & 0,868 & 0,806 & 0,742 & 0,595 & 0,480 & 0,394 & 0,332 & 0,285 & 0,250 \\
\hline 5,3 & 0,995 & 0,969 & 0,925 & 0,870 & 0,808 & 0,744 & 0,596 & 0,480 & 0,394 & 0,332 & 0,285 & 0,250 \\
\hline 5,4 & 0,995 & 0,970 & 0,927 & 0,872 & 0,810 & 0,746 & 0,597 & 0,481 & 0,395 & 0,332 & 0,285 & 0,250 \\
\hline 5,5 & 0,996 & 0,972 & 0,929 & 0,874 & 0,812 & 0,747 & 0,598 & 0,481 & 0,395 & 0,332 & 0,285 & 0,250 \\
\hline 5,6 & 0,996 & 0,973 & 0,931 & 0,876 & 0,813 & 0,749 & 0,599 & 0,481 & 0,395 & 0,332 & 0,285 & 0,250 \\
\hline 5,7 & 0,997 & 0,974 & 0,933 & 0,878 & 0,815 & 0,751 & 0,600 & 0,482 & 0,395 & 0,332 & 0,285 & 0,250 \\
\hline 5,8 & 0,997 & 0,975 & 0,934 & 0,880 & 0,817 & 0,752 & 0,601 & 0,482 & 0,395 & 0,332 & 0,285 & 0,250 \\
\hline 5,9 & 0,997 & 0,976 & 0,936 & 0,881 & 0,819 & 0,754 & 0,602 & 0,483 & 0,395 & 0,332 & 0,285 & 0,250 \\
\hline 6,0 & 0,998 & 0,977 & 0,937 & 0,883 & 0,820 & 0,755 & 0,603 & 0,483 & 0,396 & 0,332 & 0,285 & 0,250 \\
\hline 6,1 & 0,998 & 0,978 & 0,939 & 0,885 & 0,822 & 0,756 & 0,603 & 0,483 & 0,396 & 0,332 & 0,285 & 0,250 \\
\hline 6,2 & 0,998 & 0,979 & 0,940 & 0,886 & 0,824 & 0,758 & 0,604 & 0,484 & 0,396 & 0,332 & 0,285 & 0,250 \\
\hline 6,3 & 0,998 & 0,980 & 0,941 & 0,888 & 0,825 & 0,759 & 0,605 & 0,484 & 0,396 & 0,332 & 0,285 & 0,250 \\
\hline 6,4 & 0,998 & 0,980 & 0,943 & 0,889 & 0,826 & 0,760 & 0,606 & 0,484 & 0,396 & 0,332 & 0,285 & 0,250 \\
\hline 6,5 & 0,998 & 0,981 & 0,944 & 0,891 & 0,828 & 0,762 & 0,606 & 0,485 & 0,396 & 0,332 & 0,285 & 0,250 \\
\hline 6,6 & 0,999 & 0,982 & 0,945 & 0,892 & 0,829 & 0,763 & 0,607 & 0,485 & 0,396 & 0,332 & 0,285 & 0,250 \\
\hline 6,7 & 0,999 & 0,982 & 0,946 & 0,893 & 0,831 & 0,764 & 0,608 & 0,485 & 0,396 & 0,332 & 0,285 & 0,250 \\
\hline 6,8 & 0,999 & 0,983 & 0,947 & 0,895 & 0,832 & 0,765 & 0,608 & 0,485 & 0,396 & 0,332 & 0,286 & 0,250 \\
\hline 6,9 & 0,999 & 0,984 & 0,948 & 0,896 & 0,833 & 0,766 & 0,609 & 0,486 & 0,396 & 0,332 & 0,286 & 0,250 \\
\hline 7,0 & 0,999 & 0,984 & 0,949 & 0,897 & 0,834 & 0,767 & 0,609 & 0,486 & 0,397 & 0,333 & 0,286 & 0,250 \\
\hline 7,1 & 0,999 & 0,985 & 0,950 & 0,898 & 0,835 & 0,768 & 0,610 & 0,486 & 0,397 & 0,333 & 0,286 & 0,250 \\
\hline 7,2 & 0,999 & 0,985 & 0,951 & 0,899 & 0,837 & 0,769 & 0,610 & 0,486 & 0,397 & 0,333 & 0,286 & 0,250 \\
\hline 7,3 & 0,999 & 0,986 & 0,952 & 0,900 & 0,838 & 0,770 & 0,611 & 0,486 & 0,397 & 0,333 & 0,286 & 0,250 \\
\hline 7,4 & 0,999 & 0,986 & 0,953 & 0,901 & 0,839 & 0,771 & 0,611 & 0,487 & 0,397 & 0,333 & 0,286 & 0,250 \\
\hline 7,5 & 0,999 & 0,987 & 0,954 & 0,903 & 0,840 & 0,772 & 0,612 & 0,487 & 0,397 & 0,333 & 0,286 & 0,250 \\
\hline \multicolumn{13}{|c|}{ Continuação na próxima página } \\
\hline
\end{tabular}


Tabela 59 - continuação da página anterior

\begin{tabular}{|c|c|c|c|c|c|c|c|c|c|c|c|c|}
\hline $\mathrm{NTU}^{R}$ & 0,0 & 0,2 & 0,4 & 0,6 & 0,8 & 1,0 & 1,5 & 2,0 & 2,5 & 3,0 & 3,5 & 4,0 \\
\hline 7,6 & 0,999 & 0,987 & 0,955 & 0,904 & 0,841 & 0,773 & 0,612 & 0,487 & 0,397 & 0,333 & 0,286 & 0,250 \\
\hline 7,7 & 1,000 & 0,988 & 0,955 & 0,904 & 0,842 & 0,774 & 0,613 & 0,487 & 0,397 & 0,333 & 0,286 & 0,250 \\
\hline 7,8 & 1,000 & 0,988 & 0,956 & 0,905 & 0,843 & 0,775 & 0,613 & 0,487 & 0,397 & 0,333 & 0,286 & 0,250 \\
\hline 7,9 & 1,000 & 0,988 & 0,957 & 0,906 & 0,844 & 0,775 & 0,614 & 0,487 & 0,397 & 0,333 & 0,286 & 0,250 \\
\hline 8,0 & 1,000 & 0,989 & 0,957 & 0,907 & 0,844 & 0,776 & 0,614 & 0,488 & 0,397 & 0,333 & 0,286 & 0,250 \\
\hline 8,1 & 1,000 & 0,989 & 0,958 & 0,908 & 0,845 & 0,777 & 0,614 & 0,488 & 0,397 & 0,333 & 0,286 & 0,250 \\
\hline 8,2 & 1,000 & 0,989 & 0,959 & 0,909 & 0,846 & 0,778 & 0,615 & 0,488 & 0,397 & 0,333 & 0,286 & 0,250 \\
\hline 8,3 & 1,000 & 0,990 & 0,959 & 0,910 & 0,847 & 0,778 & 0,615 & 0,488 & 0,397 & 0,333 & 0,286 & 0,250 \\
\hline 8,4 & 1,000 & 0,990 & 0,960 & 0,910 & 0,848 & 0,779 & 0,615 & 0,488 & 0,397 & 0,333 & 0,286 & 0,250 \\
\hline 8,5 & 1,000 & 0,990 & 0,961 & 0,911 & 0,848 & 0,780 & 0,616 & 0,488 & 0,397 & 0,333 & 0,286 & 0,250 \\
\hline 8,6 & 1,000 & 0,991 & 0,961 & 0,912 & 0,849 & 0,780 & 0,616 & 0,488 & 0,397 & 0,333 & 0,286 & 0,250 \\
\hline 8,7 & 1,000 & 0,991 & 0,962 & 0,913 & 0,850 & 0,781 & 0,616 & 0,489 & 0,397 & 0,333 & 0,286 & 0,250 \\
\hline 8,8 & 1,000 & 0,991 & 0,962 & 0,913 & 0,851 & 0,782 & 0,617 & 0,489 & 0,398 & 0,333 & 0,286 & 0,250 \\
\hline 8,9 & 1,000 & 0,991 & 0,963 & 0,914 & 0,851 & 0,782 & 0,617 & 0,489 & 0,398 & 0,333 & 0,286 & 0,250 \\
\hline 9,0 & 1,000 & 0,992 & 0,963 & 0,915 & 0,852 & 0,783 & 0,617 & 0,489 & 0,398 & 0,333 & 0,286 & 0,250 \\
\hline 9,1 & 1,000 & 0,992 & 0,964 & 0,915 & 0,853 & 0,783 & 0,618 & 0,489 & 0,398 & 0,333 & 0,286 & 0,250 \\
\hline 9,2 & 1,000 & 0,992 & 0,964 & 0,916 & 0,853 & 0,784 & 0,618 & 0,489 & 0,398 & 0,333 & 0,286 & 0,250 \\
\hline 9,3 & 1,000 & 0,992 & 0,965 & 0,917 & 0,854 & 0,784 & 0,618 & 0,489 & 0,398 & 0,333 & 0,286 & 0,250 \\
\hline 9,4 & 1,000 & 0,992 & 0,965 & 0,917 & 0,854 & 0,785 & 0,618 & 0,489 & 0,398 & 0,333 & 0,286 & 0,250 \\
\hline 9,5 & 1,000 & 0,993 & 0,966 & 0,918 & 0,855 & 0,786 & 0,619 & 0,489 & 0,398 & 0,333 & 0,286 & 0,250 \\
\hline 9,6 & 1,000 & 0,993 & 0,966 & 0,918 & 0,856 & 0,786 & 0,619 & 0,490 & 0,398 & 0,333 & 0,286 & 0,250 \\
\hline 9,7 & 1,000 & 0,993 & 0,966 & 0,919 & 0,856 & 0,786 & 0,619 & 0,490 & 0,398 & 0,333 & 0,286 & 0,250 \\
\hline 9,8 & 1,000 & 0,993 & 0,967 & 0,919 & 0,857 & 0,787 & 0,619 & 0,490 & 0,398 & 0,333 & 0,286 & 0,250 \\
\hline 9,9 & 1,000 & 0,993 & 0,967 & 0,920 & 0,857 & 0,787 & 0,620 & 0,490 & 0,398 & 0,333 & 0,286 & 0,250 \\
\hline 10,0 & 1,000 & 0,993 & 0,968 & 0,920 & 0,858 & 0,788 & 0,620 & 0,490 & 0,398 & 0,333 & 0,286 & 0,250 \\
\hline
\end{tabular}

Tabela 60 - Fator de correção para trocador de calor de fluxo cruzado com um passe e quatro tubos por passe (1-4) - Caso 3 ou 4 - trocador de calor ilustrado na Figura 74 do Anexo A

\begin{tabular}{|c|ccccccccccccc|}
\hline NTU & $R$ & 0,0 & 0,2 & 0,4 & 0,6 & 0,8 & 1,0 & 1,5 & 2,0 & 2,5 & 3,0 & 3,5 & 4,0 \\
\hline 0,0 & 1,000 & 1,000 & 1,000 & 1,000 & 1,000 & 1,000 & 1,000 & 1,000 & 1,000 & 1,000 & 1,000 & 1,000 \\
0,1 & 1,000 & 1,000 & 0,999 & 0,999 & 0,999 & 0,998 & 0,998 & 0,997 & 0,996 & 0,995 & 0,995 & 0,994 \\
0,2 & 1,000 & 0,999 & 0,998 & 0,996 & 0,995 & 0,994 & 0,991 & 0,989 & 0,986 & 0,984 & 0,982 & 0,980 \\
0,3 & 1,000 & 0,997 & 0,995 & 0,992 & 0,990 & 0,987 & 0,982 & 0,977 & 0,972 & 0,968 & 0,964 & 0,960 \\
0,4 & 1,000 & 0,995 & 0,991 & 0,987 & 0,982 & 0,979 & 0,970 & 0,962 & 0,955 & 0,949 & 0,943 & 0,938 \\
0,5 & 1,000 & 0,993 & 0,986 & 0,980 & 0,974 & 0,969 & 0,956 & 0,946 & 0,936 & 0,928 & 0,921 & 0,915 \\
0,6 & 1,000 & 0,990 & 0,981 & 0,972 & 0,965 & 0,957 & 0,942 & 0,928 & 0,917 & 0,908 & 0,900 & 0,893 \\
0,7 & 1,000 & 0,987 & 0,975 & 0,964 & 0,954 & 0,945 & 0,926 & 0,911 & 0,898 & 0,888 & 0,879 & 0,871 \\
0,8 & 1,000 & 0,983 & 0,968 & 0,955 & 0,944 & 0,933 & 0,911 & 0,893 & 0,879 & 0,868 & 0,859 & 0,851 \\
0,9 & 1,000 & 0,979 & 0,962 & 0,946 & 0,932 & 0,920 & 0,895 & 0,876 & 0,861 & 0,849 & 0,839 & 0,831 \\
1,0 & 1,000 & 0,975 & 0,954 & 0,937 & 0,921 & 0,907 & 0,880 & 0,859 & 0,844 & 0,831 & 0,821 & 0,813 \\
1,1 & 1,000 & 0,971 & 0,947 & 0,927 & 0,909 & 0,895 & 0,865 & 0,843 & 0,827 & 0,814 & 0,804 & 0,796 \\
1,2 & 1,000 & 0,967 & 0,939 & 0,917 & 0,898 & 0,882 & 0,850 & 0,827 & 0,810 & 0,798 & 0,788 & 0,780 \\
1,3 & 1,000 & 0,962 & 0,932 & 0,907 & 0,886 & 0,869 & 0,836 & 0,812 & 0,795 & 0,782 & 0,772 & 0,765 \\
1,4 & 1,000 & 0,957 & 0,924 & 0,897 & 0,875 & 0,857 & 0,822 & 0,798 & 0,780 & 0,768 & 0,758 & 0,751 \\
1,5 & 1,000 & 0,952 & 0,916 & 0,887 & 0,864 & 0,845 & 0,809 & 0,784 & 0,766 & 0,754 & 0,744 & 0,737 \\
1,6 & 1,000 & 0,947 & 0,908 & 0,877 & 0,853 & 0,833 & 0,796 & 0,771 & 0,753 & 0,740 & 0,731 & 0,724 \\
1,7 & 1,000 & 0,942 & 0,900 & 0,868 & 0,842 & 0,821 & 0,783 & 0,758 & 0,740 & 0,728 & 0,719 & 0,712 \\
1,8 & 1,000 & 0,937 & 0,892 & 0,858 & 0,831 & 0,810 & 0,771 & 0,745 & 0,728 & 0,716 & 0,707 & 0,701 \\
1,9 & 1,000 & 0,932 & 0,884 & 0,849 & 0,821 & 0,799 & 0,759 & 0,734 & 0,716 & 0,704 & 0,696 & 0,690 \\
\hline & & & & & & & & & Continuação na próxima página \\
\hline
\end{tabular}


Tabela 60 - continuação da página anterior

\begin{tabular}{|c|c|c|c|c|c|c|c|c|c|c|c|c|}
\hline${ }_{N T U^{R}}$ & 0,0 & 0,2 & 0,4 & 0,6 & 0,8 & 1,0 & 1,5 & 2,0 & 2,5 & 3,0 & 3,5 & 4,0 \\
\hline 2,0 & 1,000 & 0,927 & 0,876 & 0,839 & 0,811 & 0,788 & 0,748 & 0,722 & 0,705 & 0,693 & 0,685 & 0,679 \\
\hline 2,1 & 1,000 & 0,922 & 0,869 & 0,830 & 0,801 & 0,778 & 0,737 & 0,711 & 0,694 & 0,683 & 0,675 & 0,669 \\
\hline 2,2 & 1,000 & 0,916 & 0,861 & 0,821 & 0,791 & 0,767 & 0,726 & 0,701 & 0,684 & 0,672 & 0,665 & 0,660 \\
\hline 2,3 & 1,000 & 0,911 & 0,853 & 0,812 & 0,782 & 0,758 & 0,716 & 0,690 & 0,674 & 0,663 & 0,655 & 0,650 \\
\hline 2,4 & 1,000 & 0,906 & 0,846 & 0,804 & 0,772 & 0,748 & 0,706 & 0,681 & 0,664 & 0,653 & 0,646 & 0,641 \\
\hline 2,5 & 1,000 & 0,901 & 0,839 & 0,795 & 0,763 & 0,739 & 0,697 & 0,671 & 0,655 & 0,644 & 0,637 & 0,633 \\
\hline 2,6 & 1,000 & 0,895 & 0,831 & 0,787 & 0,754 & 0,729 & 0,687 & 0,662 & 0,646 & 0,635 & 0,629 & 0,625 \\
\hline 2,7 & 1,000 & 0,890 & 0,824 & 0,779 & 0,746 & 0,721 & 0,678 & 0,653 & 0,637 & 0,627 & 0,621 & 0,617 \\
\hline 2,8 & 1,000 & 0,885 & 0,817 & 0,771 & 0,737 & 0,712 & 0,669 & 0,644 & 0,629 & 0,619 & 0,613 & 0,609 \\
\hline 2,9 & 1,000 & 0,880 & 0,810 & 0,763 & 0,729 & 0,704 & 0,661 & 0,636 & 0,620 & 0,611 & 0,605 & 0,601 \\
\hline 3,0 & 1,000 & 0,875 & 0,803 & 0,756 & 0,721 & 0,695 & 0,653 & 0,628 & 0,612 & 0,603 & 0,597 & 0,594 \\
\hline 3,1 & 1,000 & 0,870 & 0,797 & 0,748 & 0,713 & 0,687 & 0,644 & 0,620 & 0,605 & 0,596 & 0,590 & 0,587 \\
\hline 3,2 & 1,000 & 0,865 & 0,790 & 0,741 & 0,706 & 0,679 & 0,637 & 0,612 & 0,597 & 0,588 & 0,583 & 0,580 \\
\hline 3,3 & 1,000 & 0,860 & 0,783 & 0,734 & 0,698 & 0,672 & 0,629 & 0,605 & 0,590 & 0,581 & 0,576 & 0,573 \\
\hline 3,4 & 1,000 & 0,855 & 0,777 & 0,726 & 0,691 & 0,664 & 0,621 & 0,597 & 0,583 & 0,574 & 0,569 & 0,566 \\
\hline 3,5 & 1,000 & 0,850 & 0,771 & 0,720 & 0,684 & 0,657 & 0,614 & 0,590 & 0,576 & 0,568 & 0,563 & 0,560 \\
\hline 3,6 & 1,000 & 0,845 & 0,764 & 0,713 & 0,677 & 0,650 & 0,607 & 0,583 & 0,569 & 0,561 & 0,556 & 0,554 \\
\hline 3,7 & 1,000 & 0,840 & 0,758 & 0,706 & 0,670 & 0,643 & 0,600 & 0,576 & 0,563 & 0,555 & 0,550 & 0,548 \\
\hline 3,8 & 1,000 & 0,835 & 0,752 & 0,700 & 0,663 & 0,636 & 0,593 & 0,570 & 0,556 & 0,548 & 0,544 & 0,542 \\
\hline 3,9 & 1,000 & 0,831 & 0,746 & 0,693 & 0,656 & 0,629 & 0,587 & 0,563 & 0,550 & 0,542 & 0,538 & 0,536 \\
\hline 4,0 & 1,000 & 0,826 & 0,740 & 0,687 & 0,650 & 0,623 & 0,580 & 0,557 & 0,544 & 0,536 & 0,532 & 0,530 \\
\hline 4,1 & 1,000 & 0,821 & 0,735 & 0,681 & 0,643 & 0,616 & 0,574 & 0,551 & 0,538 & 0,530 & 0,526 & 0,524 \\
\hline 4,2 & 1,000 & 0,817 & 0,729 & 0,674 & 0,637 & 0,610 & 0,568 & 0,545 & 0,532 & 0,524 & 0,521 & 0,519 \\
\hline 4,3 & 1,000 & 0,812 & 0,723 & 0,668 & 0,631 & 0,604 & 0,561 & 0,539 & 0,526 & 0,519 & 0,515 & 0,513 \\
\hline 4,4 & 1,000 & 0,807 & 0,718 & 0,663 & 0,625 & 0,598 & 0,556 & 0,533 & 0,520 & 0,513 & 0,510 & 0,508 \\
\hline 4,5 & 1,000 & 0,803 & 0,712 & 0,657 & 0,619 & 0,592 & 0,550 & 0,527 & 0,515 & 0,508 & 0,504 & 0,503 \\
\hline 4,6 & 1,000 & 0,798 & 0,707 & 0,651 & 0,613 & 0,586 & 0,544 & 0,522 & 0,509 & 0,503 & 0,499 & 0,498 \\
\hline 4,7 & 1,000 & 0,794 & 0,702 & 0,645 & 0,607 & 0,580 & 0,538 & 0,516 & 0,504 & 0,497 & 0,494 & 0,493 \\
\hline 4,8 & 1,000 & 0,790 & 0,696 & 0,640 & 0,602 & 0,575 & 0,533 & 0,511 & 0,499 & 0,492 & 0,489 & 0,488 \\
\hline 4,9 & 1,000 & 0,785 & 0,691 & 0,634 & 0,596 & 0,569 & 0,527 & 0,506 & 0,494 & 0,487 & 0,484 & 0,483 \\
\hline 5,0 & 1,000 & 0,781 & 0,686 & 0,629 & 0,591 & 0,564 & 0,522 & 0,500 & 0,489 & 0,482 & 0,479 & 0,478 \\
\hline 5,1 & 1,000 & 0,777 & 0,681 & 0,624 & 0,585 & 0,558 & 0,517 & 0,495 & 0,484 & 0,478 & 0,475 & 0,473 \\
\hline 5,2 & 1,000 & 0,772 & 0,676 & 0,619 & 0,580 & 0,553 & 0,512 & 0,490 & 0,479 & 0,473 & 0,470 & 0,469 \\
\hline 5,3 & 1,000 & 0,768 & 0,671 & 0,613 & 0,575 & 0,548 & 0,507 & 0,485 & 0,474 & 0,468 & 0,465 & 0,464 \\
\hline 5,4 & 1,000 & 0,764 & 0,666 & 0,608 & 0,570 & 0,543 & 0,502 & 0,481 & 0,469 & 0,464 & 0,461 & 0,460 \\
\hline 5,5 & 1,000 & 0,760 & 0,662 & 0,603 & 0,565 & 0,538 & 0,497 & 0,476 & 0,465 & 0,459 & 0,456 & 0,455 \\
\hline 5,6 & 1,000 & 0,756 & 0,657 & 0,599 & 0,560 & 0,533 & 0,492 & 0,471 & 0,460 & 0,455 & 0,452 & 0,451 \\
\hline 5,7 & 1,000 & 0,752 & 0,652 & 0,594 & 0,555 & 0,528 & 0,487 & 0,467 & 0,456 & 0,450 & 0,448 & 0,447 \\
\hline 5,8 & 1,000 & 0,748 & 0,647 & 0,589 & 0,550 & 0,523 & 0,483 & 0,462 & 0,451 & 0,446 & 0,443 & 0,443 \\
\hline 5,9 & 1,000 & 0,744 & 0,643 & 0,584 & 0,545 & 0,518 & 0,478 & 0,458 & 0,447 & 0,442 & 0,439 & 0,438 \\
\hline 6,0 & 1,000 & 0,740 & 0,638 & 0,579 & 0,541 & 0,514 & 0,473 & 0,453 & 0,443 & 0,438 & 0,435 & 0,434 \\
\hline 6,1 & 1,000 & 0,736 & 0,634 & 0,575 & 0,536 & 0,509 & 0,469 & 0,449 & 0,439 & 0,433 & 0,431 & 0,430 \\
\hline 6,2 & 1,000 & 0,732 & 0,629 & 0,570 & 0,532 & 0,505 & 0,465 & 0,445 & 0,435 & 0,429 & 0,427 & 0,426 \\
\hline 6,3 & 1,000 & 0,728 & 0,625 & 0,566 & 0,527 & 0,500 & 0,460 & 0,441 & 0,430 & 0,425 & 0,423 & 0,423 \\
\hline 6,4 & 1,000 & 0,724 & 0,621 & 0,561 & 0,523 & 0,496 & 0,456 & 0,437 & 0,426 & 0,421 & 0,419 & 0,419 \\
\hline 6,5 & 1,000 & 0,720 & 0,616 & 0,557 & 0,518 & 0,492 & 0,452 & 0,433 & 0,423 & 0,418 & 0,415 & 0,415 \\
\hline 6,6 & 1,000 & 0,717 & 0,612 & 0,553 & 0,514 & 0,487 & 0,448 & 0,429 & 0,419 & 0,414 & 0,412 & 0,411 \\
\hline 6,7 & 1,000 & 0,713 & 0,608 & 0,548 & 0,510 & 0,483 & 0,444 & 0,425 & 0,415 & 0,410 & 0,408 & 0,407 \\
\hline 6,8 & 1,000 & 0,709 & 0,604 & 0,544 & 0,506 & 0,479 & 0,440 & 0,421 & 0,411 & 0,406 & 0,404 & 0,404 \\
\hline 6,9 & 1,000 & 0,705 & 0,600 & 0,540 & 0,502 & 0,475 & 0,436 & 0,417 & 0,407 & 0,403 & 0,401 & 0,400 \\
\hline 7,0 & 1,000 & 0,702 & 0,596 & 0,536 & 0,497 & 0,471 & 0,432 & 0,413 & 0,404 & 0,399 & 0,397 & 0,397 \\
\hline 7,1 & 1,000 & 0,698 & 0,592 & 0,532 & 0,493 & 0,467 & 0,428 & 0,410 & 0,400 & 0,396 & 0,394 & 0,393 \\
\hline 7,2 & 1,000 & 0,694 & 0,588 & 0,528 & 0,489 & 0,463 & 0,425 & 0,406 & 0,397 & 0,392 & 0,390 & 0,390 \\
\hline \multicolumn{13}{|c|}{ Continuação na próxima página } \\
\hline
\end{tabular}


Tabela 60 - continuação da página anterior

\begin{tabular}{|c|c|c|c|c|c|c|c|c|c|c|c|c|}
\hline $\mathrm{NTU}^{R}$ & 0,0 & 0,2 & 0,4 & 0,6 & 0,8 & 1,0 & 1,5 & 2,0 & 2,5 & 3,0 & 3,5 & 4,0 \\
\hline 7,3 & 1,000 & 0,691 & 0,584 & 0,524 & 0,485 & 0,459 & 0,421 & 0,402 & 0,393 & 0,389 & 0,387 & 0,386 \\
\hline 7,4 & 1,000 & 0,687 & 0,580 & 0,520 & 0,482 & 0,455 & 0,417 & 0,399 & 0,390 & 0,385 & 0,383 & 0,383 \\
\hline 7,5 & 1,000 & 0,684 & 0,576 & 0,516 & 0,478 & 0,452 & 0,414 & 0,395 & 0,386 & 0,382 & 0,380 & 0,380 \\
\hline 7,6 & 1,000 & 0,680 & 0,572 & 0,512 & 0,474 & 0,448 & 0,410 & 0,392 & 0,383 & 0,379 & 0,377 & 0,377 \\
\hline 7,7 & 1,000 & 0,676 & 0,568 & 0,508 & 0,470 & 0,444 & 0,407 & 0,389 & 0,380 & 0,375 & 0,374 & 0,373 \\
\hline 7,8 & 1,000 & 0,673 & 0,565 & 0,505 & 0,467 & 0,441 & 0,403 & 0,385 & 0,376 & 0,372 & 0,371 & 0,370 \\
\hline 7,9 & 1,000 & 0,669 & 0,561 & 0,501 &, 463 & 0,437 & 0,400 & 0,382 & 0,373 & 0,369 & 0,367 & 0,367 \\
\hline 8,0 & 1,000 & 0,666 & 0,557 & 0,497 & 0,459 & 0,433 & 0,396 & 0,379 & 0,370 & 0,366 & 0,364 & 0,364 \\
\hline 8,1 & 1,000 & 0,662 & 0,554 & 0,494 & 0,456 & 0,430 & 0,393 & 0,376 & 0,367 & 0,363 & 0,361 & 0,361 \\
\hline 8,2 & 1,000 & 0,659 & 0,550 & 0,490 & 0,452 & 0,427 & 0,390 & 0,372 & 0,364 & 0,360 & 0,358 & 0,358 \\
\hline 8,3 & 1,000 & 0,656 & 0,546 & 0,487 & 0,449 & 0,423 & 0,387 & 0,369 & 0,361 & 0,357 & 0,355 & 0,355 \\
\hline 8,4 & 0,999 & 0,652 & 0,543 & 0,483 & 0,445 & 0,420 & 0,383 & 0,366 & 0,358 & 0,354 & 0,352 & 0,352 \\
\hline 8,5 & 0,999 & 0,649 & 0,539 & 0,480 & 0,442 & 0,416 & 0,380 & 0,363 & 0,355 & 0,351 & 0,349 & 0,349 \\
\hline 8,6 & 0,999 & 0,645 & 0,536 & 0,476 & 0,439 & 0,413 & 0,377 & 0,360 & 0,352 & 0,348 & 0,347 & 0,346 \\
\hline 8,7 & 0,999 & 0,642 & 0,532 & 0,473 & 0,435 & 0,410 & 0,374 & 0,357 & 0,349 & 0,345 & 0,344 & 0,344 \\
\hline 8,8 & 0,999 & 0,639 & 0,529 & 0,469 & 0,432 & 0,407 & 0,371 & 0,354 & 0,346 & 0,342 & 0,341 & 0,341 \\
\hline 8,9 & 0,999 & 0,636 & 0,525 & 0,466 & 0,429 & 0,404 & 0,368 & 0,352 & 0,343 & 0,340 & 0,338 & 0,338 \\
\hline 9,0 & 0,999 & 0,632 & 0,522 & 0,463 & 0,426 & 0,401 & 0,365 & 0,349 & 0,341 & 0,337 & 0,336 & 0,335 \\
\hline 9,1 & 0,999 & 0,629 & 0,519 & 0,459 & 0,422 & 0,397 & 0,362 & 0,346 & 0,338 & 0,334 & 0,333 & 0,333 \\
\hline 9,2 & 0,999 & 0,626 & 0,515 & 0,456 & ,419 & ),394 & 0,359 & 43 & 0,335 & 0,332 & 0,330 & 0,330 \\
\hline 9,3 & ,999 & 0,622 & 0,512 & 0,453 & 0,416 & 0,391 & 0,357 & 0,340 & 0,333 & 0,329 & 0,328 & 0,327 \\
\hline 9,4 & 0,999 & 0,619 & 0,509 & 0,450 & 0,413 & 0,388 & 0,354 & 0,338 & 0,330 & 0,326 & 0,325 & 0,325 \\
\hline 9,5 & 0,999 & 0,616 & 0,506 & 0,447 & 0,410 & 0,386 & 0,351 & 0,335 & 0,327 & 0,324 & 0,323 & 0,322 \\
\hline 9,6 & 0,999 & 0,613 & 0,502 & 0,444 & 0,407 & 0,383 & 0,348 & 0,332 & 0,325 & 0,321 & 0,320 & 0,320 \\
\hline 9,7 & 0,999 & 0,6 & 0,499 & 0,4 & 0,404 & 0,380 & 0,346 & 0,330 & 0,322 & 0,319 & 0,318 & 0,317 \\
\hline 9,8 & 0,999 & 0,6 & 0,496 & 0,437 & 0,401 & 0,377 & 0,343 & 0,327 & 0,320 & 0,316 &, 315 & 0,315 \\
\hline 9, & 999 & 0,6 & & & ,398 & 0,374 & 0,340 & 0,325 & 0,317 & 0,314 & 0,313 & 0,313 \\
\hline 10,0 & 0,999 & 0,600 & 0,490 & 0,432 & 0,395 & 0,371 & 0,338 & 0,322 & 0,315 & 0,312 & 0,310 & 0,310 \\
\hline
\end{tabular}

Tabela 61 - Efetividade de temperatura para trocador de calor de fluxo cruzado com um passe e cinco tubos por passe (1-5) - Caso 3 ou 4 - trocador de calor ilustrado na Figura 75 do Anexo A

\begin{tabular}{|c|c|c|c|c|c|c|c|c|c|c|c|c|}
\hline${ }_{N T U}^{R}$ & 0,0 & 0,2 & 0,4 & 0,6 & 0,8 & 1,0 & 1,5 & 2,0 & 2,5 & 3,0 & 3,5 & 4,0 \\
\hline 0,0 & 0,000 & 0,000 & 0,000 & 0,000 & 0,000 & 0,000 & 0,000 & 0,000 & 0,000 & 0,000 & 0,000 & 0,000 \\
\hline 0,1 & 0,095 & 0,094 & 0,093 & 0,092 & 0,092 & 0,091 & 0,089 & 0,087 & 0,085 & 0,083 & 0,081 & 0,079 \\
\hline 0,2 & 0,181 & 0,178 & 0,175 & 0,172 & 0,169 & 0,166 & 0,159 & 0,152 & 0,146 & 0,140 & 0,134 & 0,129 \\
\hline 0,3 & 0,259 & 0,253 & 0,246 & 0,240 & 0,234 & 0,228 & 0,215 & 0,203 & 0,191 & 0,180 & 0,171 & 0,162 \\
\hline 0,4 & 0,330 & 0,319 & 0,309 & 0,299 & 0,290 & 0,281 & 0,261 & 0,242 & 0,225 & 0,210 & 0,196 & 0,184 \\
\hline 0,5 & 0,393 & 0,379 & 0,365 & 0,351 & 0,338 & 0,326 & 0,298 & 0,274 & 0,252 & 0,232 & 0,215 & 0,199 \\
\hline 0,6 & 0,451 & 0,432 & 0,414 & 0,397 & 0,380 & 0,365 & 0,330 & 0,299 & 0,273 & 0,249 & 0,229 & 0,210 \\
\hline 0,7 & 0,503 & 0,480 & 0,458 & 0,437 & 0,417 & 0,398 & 0,357 & 0,320 & 0,289 & 0,262 & 0,239 & 0,219 \\
\hline 0,8 & 0,551 & 0,523 & 0,497 & 0,472 & 0,449 & 0,427 & 0,379 & 0,338 & 0,303 & 0,273 & 0,247 & 0,225 \\
\hline 0,9 & 0,593 & 0,561 & 0,532 & 0,504 & 0,478 & 0,453 & 0,399 & 0,353 & 0,314 & 0,281 & 0,254 & 0,230 \\
\hline 1,0 & 0,632 & 0,596 & 0,563 & 0,532 & 0,503 & 0,476 & 0,416 & 0,366 & 0,324 & 0,288 & 0,259 & 0,233 \\
\hline 1,1 & 0,667 & 0,628 & 0,592 & 0,557 & 0,526 & 0,496 & 0,431 & 0,377 & 0,332 & 0,294 & 0,263 & 0,236 \\
\hline 1,2 & 0,699 & 0,657 & 0,617 & 0,580 & 0,546 & 0,514 & 0,444 & 0,387 & 0,339 & 0,299 & 0,266 & 0,239 \\
\hline 1,3 & 0,727 & 0,683 & 0,641 & 0,601 & 0,565 & 0,531 & 0,456 & 0,395 & 0,345 & 0,303 & 0,269 & 0,240 \\
\hline 1,4 & 0,753 & 0,706 & 0,662 & 0,620 & 0,582 & 0,546 & 0,467 & 0,403 & 0,350 & 0,307 & 0,271 & 0,242 \\
\hline 1,5 & 0,777 & 0,728 & 0,681 & 0,638 & 0,597 & 0,559 & 0,477 & 0,409 & 0,354 & 0,310 & 0,273 & 0,243 \\
\hline 1,6 & 0,798 & 0,747 & 0,699 & 0,654 & 0,611 & 0,572 & 0,485 & 0,415 & 0,358 & 0,312 & 0,275 & 0,244 \\
\hline
\end{tabular}


Tabela 61 - continuação da página anterior

\begin{tabular}{|c|c|c|c|c|c|c|c|c|c|c|c|c|}
\hline NTU ${ }^{R}$ & 0,0 & 0,2 & 0,4 & 0,6 & 0,8 & 1,0 & 1,5 & 2,0 & 2,5 & 3,0 & 3,5 & 4,0 \\
\hline 1,7 & 0,817 & 0,765 & 0,715 & 0,668 & 0,624 & 0,583 & 0,493 & 0,420 & 0,362 & 0,314 & 0,276 & 0,245 \\
\hline 1,8 & 0,835 & 0,781 & 0,730 & 0,682 & 0,636 & 0,594 & 0,501 & 0,425 & 0,365 & 0,316 & 0,277 & 0,246 \\
\hline 1,9 & 0,850 & 0,796 & 0,744 & 0,694 & 0,647 & 0,604 & 0,508 & 0,430 & 0,368 & 0,318 & 0,278 & 0,246 \\
\hline 2,0 & 0,865 & 0,810 & 0,757 & 0,706 & 0,658 & 0,613 & 0,514 & 0,434 & 0,370 & 0,319 & 0,279 & 0,247 \\
\hline 2,1 & 0,878 & 0,823 & 0,769 & 0,717 & 0,667 & 0,621 & 0,520 & 0,437 & 0,372 & 0,321 & 0,280 & 0,247 \\
\hline 2,2 & 0,889 & 0,834 & 0,780 & 0,727 & 0,677 & 0,629 & 0,525 & 0,441 & 0,374 & 0,322 & 0,281 & 0,248 \\
\hline 2,3 & 0,900 & 0,845 & 0,790 & 0,736 & 0,685 & 0,636 & 0,530 & 0,444 & 0,376 & 0,323 & 0,281 & 0,248 \\
\hline 2,4 & 0,909 & 0,855 & 0,800 & 0,745 & 0,693 & 0,643 & 0,534 & 0,447 & 0,378 & 0,324 & 0,282 & 0,248 \\
\hline 2,5 & 0,918 & 0,864 & 0,809 & 0,754 & 0,700 & 0,650 & 0,539 & 0,449 & 0,379 & 0,325 & 0,282 & 0,248 \\
\hline 2,6 & 0,926 & 0,872 & 0,817 & 0,761 & 0,708 & 0,656 & 0,543 & 0,452 & 0,381 & 0,325 & 0,282 & 0,249 \\
\hline 2,7 & 0,933 & 0,880 & 0,825 & 0,769 & 0,714 & 0,662 & 0,547 & 0,454 & 0,382 & 0,326 & 0,283 & 0,249 \\
\hline 2,8 & 0,939 & 0,887 & 0,832 & 0,776 & 0,720 & 0,668 & 0,550 & 0,456 & 0,383 & 0,327 & 0,283 & 0,249 \\
\hline 2,9 & 0,945 & 0,894 & 0,839 & 0,782 & 0,726 & 0,673 & 0,554 & 0,458 & 0,384 & 0,327 & 0,283 & 0,249 \\
\hline 3,0 & 0,950 & 0,900 & 0,845 & 0,788 & 0,732 & 0,678 & 0,557 & 0,460 & 0,385 & 0,328 & 0,284 & 0,249 \\
\hline 3,1 & 0,955 & 0,906 & 0,851 & 0,794 & 0,738 & 0,683 & 0,560 & 0,462 & 0,386 & 0,328 & 0,284 & 0,249 \\
\hline 3,2 & 0,959 & 0,911 & 0,857 & 0,800 & 0,743 & 0,687 & 0,563 & 0,463 & 0,387 & 0,328 & 0,284 & 0,249 \\
\hline 3,3 & 0,963 & 0,916 & 0,863 & 0,805 & 0,748 & 0,691 & 0,565 & 0,465 & 0,387 & 0,329 & 0,284 & 0,249 \\
\hline 3,4 & 0,967 & 0,921 & 0,868 & 0,810 & 0,752 & 0,695 & 0,568 & 0,466 & 0,388 & 0,329 & 0,284 & 0,249 \\
\hline 3,5 & 0,970 & 0,925 & 0,873 & 0,815 & 0,757 & 0,699 & 0,570 & 0,467 & 0,389 & 0,329 & 0,284 & 0,250 \\
\hline 3,6 & 0,973 & 0,930 & 0,877 & 0,820 & 0,761 & 0,703 & 0,573 & 0,469 & 0,389 & 0,330 & 0,285 & 0,250 \\
\hline 3,7 & 0,975 & 0,933 & 0,881 & 0,824 & 0,765 & 0,707 & 0,575 & 0,470 & 0,390 & 0,330 & 0,285 & 0,250 \\
\hline 3,8 & 0,978 & 0,937 & 0,886 & 0,828 & 0,769 & 0,710 & 0,577 & 0,471 & 0,390 & 0,330 & 0,285 & 0,250 \\
\hline 3,9 & 0,980 & 0,940 & 0,889 & 0,832 & 0,773 & 0,713 & 0,579 & 0,472 & 0,391 & 0,330 & 0,285 & 0,250 \\
\hline 4,0 & 0,982 & 0,943 & 0,893 & 0,836 & 0,776 & 0,717 & 0,581 & 0,473 & 0,391 & 0,331 & 0,285 & 0,250 \\
\hline 4,1 & 0,983 & 0,946 & 0,897 & 0,840 & 0,780 & 0,720 & 0,583 & 0,474 & 0,392 & 0,331 & 0,285 & 0,250 \\
\hline 4,2 & 0,985 & 0,949 & 0,900 & 0,843 & 0,783 & 0,723 & 0,585 & 0,475 & 0,392 & 0,331 & 0,285 & 0,250 \\
\hline 4,3 & 0,986 & 0,952 & 0,903 & 0,847 & 0,786 & 0,725 & 0,586 & 0,476 & 0,393 & 0,331 & 0,285 & 0,250 \\
\hline 4,4 & 0,988 & 0,954 & 0,906 & 0,850 & 0,789 & 0,728 & 0,588 & 0,476 & 0,393 & 0,331 & 0,285 & 0,250 \\
\hline 4,5 & 0,989 & 0,956 & 0,909 & 0,853 & 0,792 & 0,731 & 0,589 & 0,477 & 0,393 & 0,331 & 0,285 & 0,250 \\
\hline 4,6 & 0,990 & 0,958 & 0,912 & 0,856 & 0,795 & 0,733 & 0,591 & 0,478 & 0,394 & 0,331 & 0,285 & 0,250 \\
\hline 4,7 & 0,991 & 0,960 & 0,915 & 0,859 & 0,798 & 0,736 & 0,592 & 0,479 & 0,394 & 0,332 & 0,285 & 0,250 \\
\hline 4,8 & 0,992 & 0,962 & 0,917 & 0,862 & 0,801 & 0,738 & 0,594 & 0,479 & 0,394 & 0,332 & 0,285 & 0,250 \\
\hline 4,9 & 0,993 & 0,964 & 0,920 & 0,864 & 0,803 & 0,740 & 0,595 & 0,480 & 0,394 & 0,332 & 0,285 & 50 \\
\hline 5,0 & 0,993 & 0,966 & 0,922 & 0,867 & 0,806 & 0,743 & 0,596 & 0,480 & 0,395 & 0,332 & 0,285 & 0,250 \\
\hline 5,1 & 0,994 & 0,967 & 0,924 & 0,869 & 0,808 & 0,745 & 0,598 & 0 , & 0,395 & 0,332 & 0,285 & 0,250 \\
\hline 5,2 & 0,994 & 0,969 & 0,926 & 0,872 & 0,810 & 0,747 & 0,599 & 0, & 0,395 & 0,332 & 0,285 & 0,250 \\
\hline 5,3 & 0,995 & 0,970 & 0,928 & 0,874 & 0,812 & 0,749 & 0,600 & 0,482 & 0,395 & 0,332 & 0,285 & 0,250 \\
\hline 5,4 & 0,995 & 0,972 & 0,930 & 0,876 & 0,815 & 0,751 & 0,601 & 0,482 & 0,395 & 0,332 & 0,285 & 0,250 \\
\hline 5,5 & 0,996 & 0,973 & $0, \mathrm{~s}$ & 0,878 & 0,817 & 0,752 & 0,602 & 0,483 & 0,396 & 0,332 & 0,285 & 0,250 \\
\hline 5,6 & 0,996 & 0,974 & 0,9 & 0,880 & 0,819 & 0,754 & 0,603 & 0,483 & 0,396 & 0,332 & 0,285 & 0,250 \\
\hline 5,7 & 0,997 & 0,975 & 0,936 & 0,882 & 0,821 & 0,756 & 0,604 & 0,484 & 0,396 & 0,332 & 0,285 & 0,250 \\
\hline 5,8 & 0,997 & 0,976 & 0,937 & 0,884 & 0,823 & 0,758 & 0,605 & 0,484 & 0,396 & 0,332 & 0,285 & 0,250 \\
\hline 5,9 & 0,997 & 0,977 & 0,939 & 0,886 & 0,824 & 0,759 & 0,606 & 0,485 & 0,396 & 0,332 & 0,285 & 0,250 \\
\hline 6,0 & 0,998 & 0,978 & 0,941 & 0,888 & 0,826 & 0,761 & 0,607 & 0,485 & 0,396 & 0,332 & 0,286 & 0,250 \\
\hline 6,1 & 0,998 & 0,979 & 0,942 & 0,890 & 0,828 & 0,762 & 0,607 & 0,485 & 0,396 & 0,332 & 0,286 & 0,250 \\
\hline 6,2 & 0,998 & 0,980 & 0,944 & 0,891 & 0,830 & 0,764 & 0,608 & 0,486 & 0,397 & 0,333 & 0,286 & 0,250 \\
\hline 6,3 & 0,998 & 0,981 & 0,945 & 0,893 & 0,831 & 0,765 & 0,609 & 0,486 & 0,397 & 0,333 & 0,286 & 0,250 \\
\hline 6,4 & 0,998 & 0,982 & 0,946 & 0,895 & 0,833 & 0,767 & 0,610 & 0,486 & 0,397 & 0,333 & 0,286 & 0,250 \\
\hline 6,5 & 98 & 0,982 & 0,947 & 0,896 & 0,834 & 0,768 & 0,611 & 0,487 & 0,397 & 0,333 & 0,286 & 0,250 \\
\hline 6,6 & 0,999 & 0,983 & 0,949 & 0,898 & 0,836 & 0,769 & 0,611 & 0,487 & 0,397 & 0,333 & 0,286 & 0,250 \\
\hline 6,7 & 0,999 & 0,984 & 0,950 & 0,899 & 0,837 & 0,771 & 0,612 & 0,487 & 0,397 & 0,333 & 0,286 & 0,250 \\
\hline 6,8 & 0,999 & 0,984 & 0,951 & 0,901 & 0,839 & 0,772 & 0,613 & 0,487 & 0,397 & 0,333 & 0,286 & 0,250 \\
\hline 6,9 & 0,999 & 0,985 & 0,952 & 0,902 & 0,840 & 0,773 & 0,613 & 0,488 & 0,397 & 0,333 & 0,286 & 0,250 \\
\hline
\end{tabular}


Tabela 61 - continuação da página anterior

\begin{tabular}{|c|c|c|c|c|c|c|c|c|c|c|c|c|}
\hline VTU ${ }^{R}$ & 0,0 & 0,2 & 0,4 & 0,6 & 0,8 & 1,0 & 1,5 & 2,0 & 2,5 & 3,0 & 3,5 & 4,0 \\
\hline 7,0 & 999 & 0,986 & 0,953 & 0,903 & 0,842 & 0,774 & 0,614 & 0,488 & 0,397 & 0,333 & 0,286 & 0,250 \\
\hline 7,1 & 999 & 0,986 & 0,954 & 0,905 & 0,843 & 0,776 & 0,615 & 0,488 & 0,397 & ,333 &, 286 & 0,250 \\
\hline 7,2 & 999 & 0,987 & 0,955 & 0,906 & 0,844 & 0,777 & 0,615 & 0,488 & 0,397 & ,333 & 0,286 & 0,250 \\
\hline 7,3 & 999 & 0,987 & 0,956 & 0,907 & 0,845 & 0,778 & 0,616 & 0,489 & 0,398 & 0,333 &, 286 & 0,250 \\
\hline 7,4 & 999 & 0,988 & 0,957 & 0,908 & 0,847 & 0,779 & 0,616 & 0,489 & 0,398 & 0,333 & 0,286 & 0,250 \\
\hline 7,5 & 999 & 0,988 & 0,958 & 0,909 & 0,848 & 0,780 & 0,617 & 0,489 & 0,398 & 0,333 & 0,286 & 0,250 \\
\hline 7,6 & 999 & 0,989 & 0,959 & 0,910 & 0,849 & 0,781 & 0,617 & 0,489 & 0,398 & 0,333 & ,286 & 0,250 \\
\hline 7,7 & 000 & 989 & 0,960 & 0,911 & 0,850 & 0,782 & 18 & 0, & 0 & 0,333 & 6 & 0,250 \\
\hline 7,8 & 000 & 0,989 & 0,960 & 0, & 0,851 & 0,783 & 8 & 0 & 0 & 0. & 6 & 0,250 \\
\hline 7,9 & 00 & 0,990 & 0,961 & 0 & 0,852 & 0,784 & 9 & j & & 3 & 6 & 0,250 \\
\hline 8,0 & & 0,9 & 0,9 & 0, & & 0,785 & 0 & & & & & 0,250 \\
\hline 8,1 & 1,000 & 0,9 & 0,9 & 0,9 & 0,854 & 786 & 0,620 & 0 , & & 3 & 6 & 0,250 \\
\hline 8,2 & 000 & 0,9 & 0,9 & 0,9 & 0,855 & 786 & 0,620 & 0 & & 3 & 36 & 0,250 \\
\hline 8,3 & 00 & 0,991 & 0,964 & 0,917 & 0,856 & 0,787 & 0,621 & 0,490 & 0,398 & 0,3 & 0,286 & 0,250 \\
\hline 8,4 & 000 & 0,991 & 0,965 & 0,918 & 0,857 & 0,788 & 0,621 & 0,491 & 0,3 & 0,333 &, 286 & 0,250 \\
\hline 8,5 & 000 & 0,992 & 0,965 & 0,919 & 0,858 & 0,789 & 0,621 & 0,491 & 0,398 & 33 &, 286 & 0,250 \\
\hline 8,6 & 00 & 0,99 & 0,966 & 0,920 & 0,859 & 790 & 0,622 & 0,491 & 0,3 & 3 &, 286 & 0,250 \\
\hline 8,7 & 00 & 0,99 & 0,967 & 0,921 & 0,860 & 0,791 & 0,622 & 0,491 & 0,3 & 0,333 &, 286 & 0,250 \\
\hline 8,8 & 000 & 0,993 & 0,967 & 0,921 & 0,860 & 0,791 & 0,623 & 0,491 & 0,398 & 0,333 &, 286 & 0,250 \\
\hline 8,9 & 000 & 0,993 & 0,968 & 0,922 & 0,861 & 0,792 & 0,623 & 0,491 & 0,398 & 0,333 &, 286 & 0,250 \\
\hline 9,0 & 000 & 0,993 & 0,968 & 0,923 & 0,862 & 0,793 & 0,623 & 0,491 & 0,39 & 0,333 & 0,286 & 0,250 \\
\hline 9,1 & 000 & 0,993 & 0,969 & 0,924 & 0,863 & 0,793 & 0,624 & 0,491 & 0,398 & 0,333 & 0,286 & 0,250 \\
\hline 9,2 & 000 & 0,993 & 0,969 & 0,924 & 0,863 & 0,794 & 624 & 2 & 8 & 33 & 86 & 0,250 \\
\hline 9,3 & & 0 & & 0,9 & 54 & 0,795 & ,624 & 0,4 & & 0,333 & 0,286 & 0,250 \\
\hline 9,4 & & $0,9 !$ & 0,9 & 0,926 & 0,865 & 0,795 & 0,625 & 0,492 & & 0,333 & 0,286 & 0,250 \\
\hline 9,5 & 000 & 0,994 & 0,971 & 0,926 & 0,866 & 0,796 & 625 & 0, & & 0,333 & 0,286 & 0,250 \\
\hline 9,6 & & 0,9 & 0,9 & 0,9 & 0,8 & 0,797 & 0,6 & & & & ,286 & 0,250 \\
\hline 9,7 & & 0,9 & 0,9 & 0,928 & 0,867 & 7 & 625 & & & &, 286 & 0,250 \\
\hline 9,8 & & 0,9 & 0,9 & 0,9 & & 798 & 0,626 & & & & 0,286 & 0,250 \\
\hline 9, & & & & & & & 0,6 & & & & 0,286 & 0,250 \\
\hline 10,0 & 1,000 & 0,995 & 0,973 & 0,930 & 0,869 & 0,799 & 0,626 & 0,492 & 0,399 & 0,333 & 0,286 & 0,250 \\
\hline
\end{tabular}

Tabela 62 - Fator de correção para trocador de calor de fluxo cruzado com um passe e cinco tubos por passe (1-5) - Caso 3 ou 4 - trocador de calor ilustrado na Figura 75 do Anexo A

\begin{tabular}{|c|c|c|c|c|c|c|c|c|c|c|c|c|}
\hline $\mathrm{NTU}{ }^{R}$ & 0,0 & 0,2 & 0,4 & 0,6 & 0,8 & 1,0 & 1,5 & 2,0 & 2,5 & 3,0 & 3,5 & 4,0 \\
\hline 0,0 & 1,000 & 1,000 & 1,000 & 1,000 & 1,000 & 1,000 & 1,000 & 1,000 & 1,000 & 1,000 & 1,000 & 1,000 \\
\hline 0,1 & 1,000 & 1,000 & 0,999 & 0,999 & 0,999 & 0,998 & 0,998 & 0,997 & 0,996 & 0,995 & 0,995 & 0,994 \\
\hline 0,2 & 1,000 & 0,999 & 0,998 & 0,996 & 0,995 & 0,994 & 0,991 & 0,989 & 0,986 & 0,984 & 0,982 & 0,980 \\
\hline 0,3 & 1,000 & 0,997 & 0,995 & 0,992 & 0,990 & 0,987 & 0,982 & 0,977 & 0,972 & 0,968 & 0,964 & 0,960 \\
\hline 0,4 & 1,000 & 0,995 & 0,991 & 0,987 & 0,982 & 0,979 & 0,970 & 0,962 & 0,955 & 0,949 & 0,943 & 0,938 \\
\hline 0,5 & 1,000 & 0,993 & 0,986 & 0,980 & 0,974 & 0,969 & 0,956 & 0,946 & 0,937 & 0,929 & 0,922 & 0,916 \\
\hline 0,6 & 1,000 & 0,990 & 0,981 & 0,972 & 0,965 & 0,958 & 0,942 & 0,929 & 0,918 & 0,908 & 0,900 & 0,893 \\
\hline 0,7 & 1,000 & 0,987 & 0,975 & 0,964 & 0,955 & 0,946 & 0,927 & 0,911 & 0,899 & 0,888 & 0,879 & 0,872 \\
\hline 0,8 & 1,000 & 0,983 & 0,969 & 0,956 & 0,944 & 0,933 & 0,911 & 0,894 & 0,880 & 0,869 & 0,859 & 0,852 \\
\hline 0,9 & 1,000 & 0,980 & 0,962 & 0,946 & 0,933 & 0,921 & 0,896 & 0,877 & 0,862 & 0,850 & 0,840 & 0,833 \\
\hline 1,0 & 1,000 & 0,975 & 0,955 & 0,937 & 0,922 & 0,908 & 0,881 & 0,860 & 0,845 & 0,832 & 0,823 & 0,815 \\
\hline 1,1 & 1,000 & 0,971 & 0,947 & 7 & 0,910 & 0,895 &, 866 & 0,844 & ,828 & 0,815 & 0,806 & 0,798 \\
\hline 1,2 & 1,000 & 0,967 & 0,940 & 0,918 & 0,899 & 0,883 & 0,851 & 0,829 & 0,812 & 0,800 & 0,790 & 0,782 \\
\hline 1,3 & 1,000 & 0,962 & 0,932 & 0,908 & 0,887 & 0,870 & 0,837 & 0,814 & 0,797 & 0,784 & 0,775 & 0,767 \\
\hline
\end{tabular}


Tabela 62 - continuação da página anterior

\begin{tabular}{|c|c|c|c|c|c|c|c|c|c|c|c|c|}
\hline${ }_{N T U^{R}}$ & 0,0 & 0,2 & 0,4 & 0,6 & 0,8 & 1,0 & 1,5 & 2,0 & 2,5 & 3,0 & 3,5 & 4,0 \\
\hline 1,4 & 1,000 & 0,958 & 0,925 & 0,898 & 0,876 & 0,858 & 0,824 & 0,800 & 0,783 & 0,770 & 0,761 & 0,754 \\
\hline 1,5 & 1,000 & 0,953 & 0,917 & 0,888 & 0,865 & 0,846 & 0,811 & 0,786 & 0,769 & 0,757 & 0,747 & 0,741 \\
\hline 1,6 & 1,000 & 0,948 & 0,909 & 0,879 & 0,854 & 0,835 & 0,798 & 0,773 & 0,756 & 0,744 & 0,735 & 0,728 \\
\hline 1,7 & 1,000 & 0,943 & 0,901 & 0,869 & 0,844 & 0,823 & 0,786 & 0,761 & 0,744 & 0,731 & 0,723 & 0,717 \\
\hline 1,8 & 1,000 & 0,938 & 0,894 & 0,860 & 0,833 & 0,812 & 0,774 & 0,749 & 0,732 & 0,720 & 0,711 & 0,706 \\
\hline 1,9 & 1,000 & 0,933 & 0,886 & 0,851 & 0,823 & 0,801 & 0,762 & 0,737 & 0,720 & 0,709 & 0,701 & 0,695 \\
\hline 2,0 & 1,000 & 0,928 & 0,878 & 0,842 & 0,813 & 0,791 & 0,751 & 0,726 & 0,709 & 0,698 & 0,690 & 0,685 \\
\hline 2,1 & 1,000 & 0,923 & 0,871 & 0,833 & 0,804 & 0,781 & 0,741 & 0,716 & 0,699 & 0,688 & 0,681 & 0,676 \\
\hline 2,2 & 1,000 & 0,918 & 0,863 & 0,824 & 0,794 & 0,771 & 0,731 & 0,705 & 0,689 & 0,678 & 0,671 & 0,667 \\
\hline 2,3 & 1,000 & 0,913 & 0,856 & 0,815 & 0,785 & 0,761 & 0,721 & 0,696 & 0,680 & 0,669 & 0,662 & 0,658 \\
\hline 2,4 & 1,000 & 0,908 & 0,849 & 0,807 & 0,776 & 0,752 & 0,711 & 0,686 & 0,670 & 0,660 & 0,654 & 0,649 \\
\hline 2,5 & 1,000 & 0,903 & 0,842 & 0,799 & 0,767 & 0,743 & 0,702 & 0,677 & 0,661 & 0,651 & 0,645 & 0,641 \\
\hline 2,6 & 1,000 & 0,898 & 0,835 & 0,791 & 0,759 & 0,734 & 0,693 & 0,668 & 0,653 & 0,643 & 0,637 & 0,634 \\
\hline 2,7 & 1,000 & 0,893 & 0,828 & 0,783 & 0,751 & 0,726 & 0,684 & 0,660 & 0,645 & 0,635 & 0,630 & 0,626 \\
\hline 2,8 & 1,000 & 0,888 & 0,821 & 0,775 & 0,742 & 0,717 & 0,676 & 0,651 & 0,637 & 0,628 & 0,622 & 0,619 \\
\hline 2,9 & 1,000 & 0,883 & 0,814 & 0,768 & 0,735 & 0,709 & 0,668 & 0,643 & 0,629 & 0,620 & 0,615 & 0,612 \\
\hline 3,0 & 1,000 & 0,878 & 0,808 & 0,761 & 0,727 & 0,701 & 0,660 & 0,636 & 0,621 & 0,613 & 0,608 & 0,605 \\
\hline 3,1 & 1,000 & 0,873 & 0,801 & 0,753 & 0,719 & 0,694 & 0,652 & 0,628 & 0,614 & 0,606 & 0,601 & 0,599 \\
\hline 3,2 & 1,000 & 0,868 & 0,795 & 0,746 & 0,712 & 0,686 & 0,644 & 0,621 & 0,607 & 0,599 & 0,595 & 0,592 \\
\hline 3,3 & 1,000 & 0,863 & 0,789 & 0,740 & 0,705 & 0,679 & 0,637 & 0,614 & 0,600 & 0,592 & 0,588 & 0,586 \\
\hline 3,4 & 1,000 & 0,859 & 0,782 & 0,733 & 0,698 & 0,672 & 0,630 & 0,607 & 0,594 & 0,586 & 0,582 & 0,580 \\
\hline 3,5 & 1,000 & 0,854 & 0,776 & 0,726 & 0,691 & 0,665 & 0,623 & 0,600 & 0,587 & 0,580 & 0,576 & 0,574 \\
\hline 3,6 & 1,000 & 0,850 & 0,771 & 0,720 & 0,684 & 0,658 & 0,616 & 0,594 & 0,581 & 0,574 & 0,570 & 0,569 \\
\hline 3,7 & 1,000 & 0,845 & 0,765 & 0,713 & 0,678 & 0,651 & 0,610 & 0,587 & 0,575 & 0,568 & 0,564 & 0,563 \\
\hline 3,8 & 1,000 & 0,840 & 0,759 & 0,707 & 0,671 & 0,645 & 0,603 & 0,581 & 0,569 & 0,562 & 0,559 & 0,558 \\
\hline 3,9 & 1,000 & 0,836 & 0,753 & 0,701 & 0,665 & 0,639 & 0,597 & 0,575 & 0,563 & 0,556 & 0,553 & 0,552 \\
\hline 4,0 & 1,000 & 0,832 & 0,748 & 0,695 & 0,659 & 0,632 & 0,591 & 0,569 & 0,557 & 0,551 & 0,548 & 0,547 \\
\hline 4,1 & 1,000 & 0,827 & 0,742 & 0,689 & 0,653 & 0,626 & 0,585 & 0,563 & 0,552 & 0,545 & 0,543 & 0,542 \\
\hline 4,2 & 1,000 & 0,823 & 0,737 & 0,684 & 0,647 & 0,620 & 0,579 & 0,558 & 0,546 & 0,540 & 0,538 & 0,537 \\
\hline 4,3 & 1,000 & 0,819 & 0,732 & 0,678 & 0,641 & 0,615 & 0,574 & 0,552 & 0,541 & 0,535 & 0,533 & 0,532 \\
\hline 4,4 & 1,000 & 0,814 & 0,727 & 0,672 & 0,635 & 0,609 & 0,568 & 0,547 & 0,536 & 0,530 & 0,528 & 0,527 \\
\hline 4,5 & 1,000 & 0,810 & 0,722 & 0,667 & 0,630 & 0,603 & 0,562 & 0,541 & 0,530 & 0,525 & 0,523 & 0,523 \\
\hline 4,6 & 1,000 & 0,806 & 0,716 & 0,662 & 0,624 & 0,598 & 0,557 & 0,536 & 0,525 & 0,520 & 0,518 & 0,518 \\
\hline 4,7 & 1,000 & 0,802 & 0,712 & 0,656 & 0,619 & 0,592 & 0,552 & 0,531 & 0,521 & 0,515 & 0,514 & 0,514 \\
\hline 4,8 & 1,000 & 0,798 & 0,707 & 0,651 & 0,614 & 0,587 & 0,547 & 0,526 & 0,516 & 0,511 & 0,509 & 0,509 \\
\hline 4,9 & 1,000 & 0,794 & 0,702 & 0,646 & 0,609 & 0,582 & 0,542 & 0,521 & 0,511 & 0,506 & 0,505 & 0,505 \\
\hline 5,0 & 1,000 & 0,790 & 0,697 & 0,641 & 0,604 & 0,577 & 0,537 & 0,517 & 0,506 & 0,502 & 0,500 & 0,500 \\
\hline 5,1 & 1,000 & 0,786 & 0,693 & 0,636 & 0,599 & 0,572 & 0,532 & 0,512 & 0,502 & 0,497 & 0,496 & 0,496 \\
\hline 5,2 & 1,000 & 0,782 & 0,688 & 0,631 & 0,594 & 0,567 & 0,527 & 0,507 & 0,497 & 0,493 & 0,492 & 0,492 \\
\hline 5,3 & 1,000 & 0,778 & 0,683 & 0,627 & 0,589 & 0,562 & 0,522 & 0,503 & 0,493 & 0,489 & 0,487 & 0,488 \\
\hline 5,4 & 1,000 & 0,775 & 0,679 & 0,622 & 0,584 & 0,557 & 0,518 & 0,498 & 0,489 & 0,485 & 0,483 & 0,484 \\
\hline 5,5 & 1,000 & 0,771 & 0,675 & 0,617 & 0,579 & 0,553 & 0,513 & 0,494 & 0,484 & 0,480 & 0,479 & 0,480 \\
\hline 5,6 & 1,000 & 0,767 & 0,670 & 0,613 & 0,575 & 0,548 & 0,509 & 0,490 & 0,480 & 0,476 & 0,475 & 0,476 \\
\hline 5,7 & 1,000 & 0,764 & 0,666 & 0,608 & 0,570 & 0,544 & 0,504 & 0,485 & 0,476 & 0,472 & 0,471 & 0,472 \\
\hline 5,8 & 1,000 & 0,760 & 0,662 & 0,604 & 0,566 & 0,539 & 0,500 & 0,481 & 0,472 & 0,468 & 0,468 & 0,468 \\
\hline 5,9 & 1,000 & 0,756 & 0,657 & 0,600 & 0,561 & 0,535 & 0,496 & 0,477 & 0,468 & 0,465 & 0,464 & 0,465 \\
\hline 6,0 & 1,000 & 0,753 & 0,653 & 0,595 & 0,557 & 0,530 & 0,492 & 0,473 & 0,464 & 0,461 & 0,460 & 0,461 \\
\hline 6,1 & 1,000 & 0,749 & 0,649 & 0,591 & 0,553 & 0,526 & 0,487 & 0,469 & 0,460 & 0,457 & 0,456 & 0,457 \\
\hline 6,2 & 1,000 & 0,746 & 0,645 & 0,587 & 0,549 & 0,522 & 0,483 & 0,465 & 0,457 & 0,453 & 0,453 & 0,454 \\
\hline 6,3 & 1,000 & 0,742 & 0,641 & 0,583 & 0,544 & 0,518 & 0,479 & 0,461 & 0,453 & 0,450 & 0,449 & 0,450 \\
\hline 6,4 & 1,000 & 0,739 & 0,637 & 0,579 & 0,540 & 0,514 & 0,475 & 0,457 & 0,449 & 0,446 & 0,446 & 0,447 \\
\hline 6,5 & 1,000 & 0,735 & 0,633 & 0,575 & 0,536 & 0,510 & 0,472 & 0,454 & 0,446 & 0,443 & 0,442 & 0,443 \\
\hline 6,6 & 1,000 & 0,732 & 0,630 & 0,571 & 0,532 & 0,506 & 0,468 & 0,450 & 0,442 & 0,439 & 0,439 & 0,440 \\
\hline \multicolumn{13}{|c|}{ Continuação na próxima página } \\
\hline
\end{tabular}


Tabela 62 - continuação da página anterior

\begin{tabular}{|c|c|c|c|c|c|c|c|c|c|c|c|c|}
\hline $\mathrm{NTU}^{R}$ & 0,0 & 0,2 & 0,4 & 0,6 & 0,8 & 1,0 & 1,5 & 2,0 & 2,5 & 3,0 & 3,5 & 4,0 \\
\hline 6,7 & 1,000 & 0,729 & 0,626 & 0,567 & 0,528 & 0,502 & 0,464 & 0,446 & 0,439 & 0,436 & 0,435 & 0,436 \\
\hline 6,8 & 1,000 & 0,725 & 0,622 & 0,563 & 0,524 & 0,498 & 0,460 & 0,443 & 0,435 & 0,432 & 0,432 & 0,433 \\
\hline 6,9 & 1,000 & 0,722 & 0,618 & 0,559 & 0,521 & 0,494 & 0,457 & 0,439 & 0,432 & 0,429 & 0,429 & 0,430 \\
\hline 7,0 & 1,000 & 0,719 & 0,615 & 0,555 & 0,517 & 0,491 & 0,453 & 0,436 & 0,428 & 0,426 & 0,425 & 0,427 \\
\hline 7,1 & 1,000 & 0,716 & 0,611 & 0,551 & 0,513 & 0,487 & 0,449 & 0,432 & 0,425 & 0,422 & 0,422 & 0,423 \\
\hline 7,2 & 1,000 & 0,712 & 0,607 & 0,548 & 0,509 & 0,483 & 0,446 & 0,429 & 0,422 & 0,419 & 0,419 & 0,420 \\
\hline 7,3 & 1,000 & 0,709 & 0,604 & 0,544 & 0,506 & 0,480 & 0,443 & 0,426 & 0,418 & 0,416 & 0,416 & 0,417 \\
\hline 7,4 & 1,000 & 0,706 & 0,600 & 0,541 & 0,502 & 0,476 & 0,439 & 0,422 & 0,415 & 0,413 & 0,413 & 0,414 \\
\hline 7,5 & 1,000 & 0,703 & 0,597 & 0,537 & 0,499 & 0,473 & 0,436 & 0,419 & 0,412 & 0,410 & 0,410 & 0,411 \\
\hline 7,6 & 1,000 & 0,700 & 0,593 & 0,533 & 0,495 & 0,469 & 0,432 & 0,416 & 0,409 & 0,407 & 0,407 & 0,408 \\
\hline 7,7 & 1,000 & 0,697 & 0,590 & 0,530 & 0,492 & 0,466 & 0,429 & 0,413 & 0,406 & 0,403 & 0,404 & 0,405 \\
\hline 7,8 & 1,000 & 0,693 & 0,587 & 0,527 & 0,488 & 0,462 & 0,426 & 0,410 & 0,403 & 0,401 & 0,401 & 0,402 \\
\hline 7,9 & 1,000 & 0,690 & 0,583 & 0,523 & 0,485 & 0,459 & 0,423 & 0,407 & 0,400 & 0,398 & 0,398 & 0,399 \\
\hline 8,0 & 1,000 & 0,687 & 0,580 & 0,520 & 0,482 & 0,456 & 0,420 & 0,404 & 0,397 & 0,395 & 0,395 & 0,396 \\
\hline 8,1 & 1,000 & 0,684 & 0,577 & 0,516 & 0,478 & 0,453 & 0,416 & 0,401 & 0,394 & 0,392 & 0,392 & 0,393 \\
\hline 8,2 & 1,000 & 0,681 & 0,573 & 0,513 & 0,475 & 0,449 & 0,413 & 0,398 & 0,391 & 0,389 & 0,389 & 0,391 \\
\hline 8,3 & 1,000 & 0,678 & 0,570 & 0,510 & 0,472 & 0,446 & 0,410 & 0,395 & 0,388 & 0,386 & 0,386 & 0,388 \\
\hline 8,4 & 1,000 & 0,675 & 0,567 & 0,507 & 0,469 & 0,443 & 0,407 & 0,392 & 0,385 & 0,383 & 0,384 & 0,385 \\
\hline 8,5 & 1,000 & 0,673 & 0,564 & 0,503 & 0,465 & 0,440 & 0,404 & 0,389 & 0,383 & 0,381 & 0,381 & 0,382 \\
\hline 8,6 & 1,000 & 0,670 & 0,561 & 0,500 & 0,462 & 0,437 & 0,402 & 0,386 & 0,380 & 0,378 & 0,378 & 0,380 \\
\hline 8,7 & 1,000 & 0,667 & 0,557 & 0,497 & 0,459 & 0,434 & 0,399 & 0,383 & 0,377 & 0,375 & 0,375 & 0,377 \\
\hline 8,8 & 1,000 & 0,664 & 0,554 & 0,494 & 0,456 & 0,431 & 0,396 & 0,381 & 0,374 & 0,373 & 0,373 & 0,374 \\
\hline 8,9 & 1,000 & 0,661 & 0,551 & 0,491 & 0,453 & 0,428 & 0,393 & 0,378 & 0,372 & 0,370 & 0,370 & 0,372 \\
\hline 9,0 & 1,000 & 0,658 & 0,548 & 0,488 & 0,450 & 0,425 & 0,390 & 0,375 & 0,369 & 0,367 & 0,368 & 0,369 \\
\hline 9,1 & 0,999 & 0,655 & 0,545 & 0,485 & 0,447 & 0,422 & 0,387 & 0,373 & 0,366 & 0,365 & 0,365 & 0,367 \\
\hline 9,2 & 0,999 & 0,653 & 0,542 & 0,482 & 0,444 & 0,419 & 0,385 & 0,370 & 0,364 & 0,362 & 0,363 & 0,364 \\
\hline 9,3 & 0,999 & 0,650 & 0,539 & 0,479 & 0,441 & 0,416 & 0,382 & 0,367 & 0,361 & 0,360 & 0,360 & 0,362 \\
\hline 9,4 & 0,999 & 0,647 & 0,536 & 0,476 & 0,439 & 0,414 & 0,379 & 0,365 & 0,359 & 0,357 & 0,358 & 0,359 \\
\hline 9,5 & 0,999 & 0,644 & 0,533 & 0,473 & 0,436 & 0,411 & 0,377 & 0,362 & 0,356 & 0,355 & 0,355 & 0,357 \\
\hline 9,6 & 0,999 & 0,641 & 0,531 & 0,470 & 0,433 & 0,408 & 0,374 & 0,360 & 0,354 & 0,352 & 0,353 & 0,354 \\
\hline 9,7 & 0,999 & 0,639 & 0,528 & 0,468 & 0,430 & 0,405 & 0,372 & 0,357 & 0,351 & 0,350 & 0,350 & 0,352 \\
\hline 9,8 & 0,999 & 0,636 & 0,525 & 0,465 & 0,427 & 0,403 & 0,369 & 0,355 & 0,349 & 0,348 & 0,348 & 0,350 \\
\hline 9,9 & 0,999 & 0,633 & 0,522 & 0,462 & 0,425 & 0,400 & 0,366 & 0,352 & 0,347 & 0,345 & 0,346 & 0,347 \\
\hline 10,0 & 0,999 & 0,631 & 0,519 & 0,459 & 0,422 & 0,397 & 0,364 & 0,350 & 0,344 & 0,343 & 0,343 & 0,345 \\
\hline
\end{tabular}

Tabela 63 - Efetividade de temperatura para trocador de calor de fluxo cruzado com um passe e dez tubos por passe (1-10) - Caso 3 ou 4 - trocador de calor ilustrado na Figura 80 do Anexo A

\begin{tabular}{|c|c|c|c|c|c|c|c|c|c|c|c|c|}
\hline${ }_{N T U}^{R}$ & 0,0 & 0,2 & 0,4 & 0,6 & 0,8 & 1,0 & 1,5 & 2,0 & 2,5 & 3,0 & 3,5 & 4,0 \\
\hline 0,0 & 0,000 & 0,000 & 0,000 & 0,000 & 0,000 & 0,000 & 0,000 & 0,000 & 0,000 & 0,000 & 0,000 & 0,000 \\
\hline 0,1 & 0,095 & 0,094 & 0,093 & 0,092 & 0,092 & 0,091 & 0,089 & 0,087 & 0,085 & 0,083 & 0,081 & 0,079 \\
\hline 0,2 & 0,181 & 0,178 & 0,175 & 0,172 & 0,169 & 0,166 & 0,159 & 0,152 & 0,146 & 0,140 & 0,134 & 0,129 \\
\hline 0,3 & 0,259 & 0,253 & 0,246 & 0,240 & 0,234 & 0,229 & 0,215 & 0,203 & 0,191 & 0,180 & 0,171 & 0,162 \\
\hline 0,4 & 0,330 & 0,319 & 0,309 & 0,299 & 0,290 & 0,281 & 0,261 & 0,242 & 0,225 & 0,210 & 0,196 & 0,184 \\
\hline 0,5 & 0,393 & 0,379 & 0,365 & 0,351 & 0,338 & 0,326 & 0,298 & 0,274 & 0,252 & 0,232 & 0,215 & 0,199 \\
\hline 0,6 & 0,451 & 0,432 & 0,414 & 0,397 & 0,380 & 0,365 & 0,330 & 0,299 & 0,273 & 0,249 & 0,229 & 0,211 \\
\hline 0,7 & 0,503 & 0,480 & 0,458 & 0,437 & 0,417 & 0,398 & 0,357 & 0,321 & 0,289 & 0,263 & 0,239 & 0,219 \\
\hline 0,8 & 0,551 & 0,523 & 0,497 & 0,472 & 0,449 & 0,428 & 0,379 & 0,338 & 0,303 & 0,273 & 0,247 & 0,225 \\
\hline 0,9 & 0,593 & 0,562 & 0,532 & 0,504 & 0,478 & 0,453 & 0,399 & 0,353 & 0,315 & 0,282 & 0,254 & 0,230 \\
\hline 1,0 & 0,632 & 0,597 & 0,563 & 0,532 & 0,503 & 0,476 & 0,416 & 0,366 & 0,324 & 0,289 & 0,259 & 0,233 \\
\hline \multicolumn{13}{|c|}{ Continuação na próxima página } \\
\hline
\end{tabular}


Tabela 63 - continuação da página anterior

\begin{tabular}{|c|c|c|c|c|c|c|c|c|c|c|c|c|}
\hline${ }_{N T U^{R}}$ & 0,0 & 0,2 & 0,4 & 0,6 & 0,8 & 1,0 & 1,5 & 2,0 & 2,5 & 3,0 & 3,5 & 4,0 \\
\hline 1,1 & 0,667 & 0,628 & 0,592 & 0,558 & 0,526 & 0,496 & 0,431 & 0,377 & 0,332 & 0,294 & 0,263 & 0,236 \\
\hline 1,2 & 0,699 & 0,657 & 0,617 & 0,581 & 0,547 & 0,515 & 0,445 & 0,387 & 0,339 & 0,299 & 0,266 & 0,239 \\
\hline 1,3 & 0,727 & 0,683 & 0,641 & 0,602 & 0,565 & 0,531 & 0,457 & 0,395 & 0,345 & 0,303 & 0,269 & 0,241 \\
\hline 1,4 & 0,753 & 0,706 & 0,662 & 0,621 & 0,582 & 0,546 & 0,468 & 0,403 & 0,350 & 0,307 & 0,271 & 0,242 \\
\hline 1,5 & 0,777 & 0,728 & 0,682 & 0,638 & 0,598 & 0,560 & 0,477 & 0,410 & 0,355 & 0,310 & 0,273 & 0,243 \\
\hline 1,6 & 0,798 & 0,747 & 0,699 & 0,654 & 0,612 & 0,572 & 0,486 & 0,416 & 0,359 & 0,312 & 0,275 & 0,244 \\
\hline 1,7 & 0,817 & 0,765 & 0,716 & 0,669 & 0,625 & 0,584 & 0,494 & 0,421 & 0,362 & 0,315 & 0,276 & 0,245 \\
\hline 1,8 & 0,835 & 0,782 & 0,731 & 0,683 & 0,637 & 0,595 & 0,502 & 0,426 & 0,365 & 0,317 & 0,278 & 0,246 \\
\hline 1,9 & 0,850 & 0,797 & 0,745 & 0,695 & 0,648 & 0,605 & 0,509 & 0,430 & 0,368 & 0,318 & 0,279 & 0,247 \\
\hline 2,0 & 0,865 & 0,811 & 0,758 & 0,707 & 0,659 & 0,614 & 0,515 & 0,435 & 0,371 & 0,320 & 0,279 & 0,247 \\
\hline 2,1 & 0,878 & 0,823 & 0,770 & 0,718 & 0,669 & 0,622 & 0,521 & 0,438 & 0,373 & 0,321 & 0,280 & 0,247 \\
\hline 2,2 & 0,889 & 0,835 & 0,781 & 0,728 & 0,678 & 0,630 & 0,526 & 0,442 & 0,375 & 0,322 & 0,281 & 0,248 \\
\hline 2,3 & 0,900 & 0,846 & 0,791 & 0,738 & 0,687 & 0,638 & 0,531 & 0,445 & 0,377 & 0,323 & 0,281 & 0,248 \\
\hline 2,4 & 0,909 & 0,856 & 0,801 & 0,747 & 0,695 & 0,645 & 0,536 & 0,448 & 0,378 & 0,324 & 0,282 & 0,248 \\
\hline 2,5 & 0,918 & 0,865 & 0,810 & 0,755 & 0,702 & 0,652 & 0,540 & 0,450 & 0,380 & 0,325 & 0,282 & 0,249 \\
\hline 2,6 & 0,926 & 0,873 & 0,818 & 0,763 & 0,709 & 0,658 & 0,545 & 0,453 & 0,381 & 0,326 & 0,283 & 0,249 \\
\hline 2,7 & 0,933 & 0,881 & 0,826 & 0,771 & 0,716 & 0,664 & 0,548 & 0,455 & 0,383 & 0,327 & 0,283 & 0,249 \\
\hline 2,8 & 0,939 & 0,888 & 0,834 & 0,778 & 0,723 & 0,670 & 0,552 & 0,457 & 0,384 & 0,327 & 0,283 & 0,249 \\
\hline 2,9 & 0,945 & 0,895 & 0,841 & 0,784 & 0,729 & 0,675 & 0,556 & 0,459 & 0,385 & 0,328 & 0,284 & 0,249 \\
\hline 3,0 & 0,950 & 0,901 & 0,847 & 0,791 & 0,735 & 0,680 & 0,559 & 0,461 & 0,386 & 0,328 & 0,284 & 0,249 \\
\hline 3,1 & 0,955 & 0,907 & 0,853 & 0,797 & 0,740 & 0,685 & 0,562 & 0,463 & 0,387 & 0,329 & 0,284 & 0,249 \\
\hline 3,2 & 0,959 & 0,912 & 0,859 & 0,803 & 0,746 & 0,690 & 0,565 & 0,465 & 0,388 & 0,329 & 0,284 & 0,249 \\
\hline 3,3 & 0,963 & 0,918 & 0,865 & 0,808 & 0,751 & 0,694 & 0,568 & 0,466 & 0,388 & 0,329 & 0,284 & 0,250 \\
\hline 3,4 & 0,967 & 0,922 & 0,870 & 0,813 & 0,755 & 0,699 & 0,571 & 0,468 & 0,389 & 0,330 & 0,284 & 0,250 \\
\hline 3,5 & 0,970 & 0,927 & 0,875 & 0,818 & 0,760 & 0,703 & 0,573 & 0,469 & 0,390 & 0,330 & 0,285 & 0,250 \\
\hline 3,6 & 0,973 & 0,931 & 0,879 & 0,823 & 0,764 & 0,707 & 0,576 & 0,470 & 0,390 & 0,330 & 0,285 & 0,250 \\
\hline 3,7 & 0,975 & 0,935 & 0,884 & 0,827 & 0,769 & 0,710 & 0,578 & 0,472 & 0,391 & 0,330 & 0,285 & 0,250 \\
\hline 3,8 & 0,978 & 0,938 & 0,888 & 0,832 & 0,773 & 0,714 & 0,580 & 0,473 & 0,391 & 0,331 & 0,285 & 0,250 \\
\hline 3,9 & 0,980 & 0,942 & 0,892 & 0,836 & 0,777 & 0,718 & 0,582 & 0,474 & 0,392 & 0,331 & 0,285 & 0,250 \\
\hline 4,0 & 0,982 & 0,945 & 0,896 & 0,840 & 0,781 & 0,721 & 0,584 & 0,475 & 0,392 & 0,331 & 0,285 & 0,250 \\
\hline 4,1 & 0,983 & 0,948 & 0,900 & 0,844 & 0,784 & 0,724 & 0,586 & 0,476 & 0,393 & 0,331 & 0,285 & 0,250 \\
\hline 4,2 & 0,985 & 0,950 & 0,903 & 0,847 & 0,788 & 0,727 & 0,588 & 0,477 & 0,393 & 0,331 & 0,285 & 0,250 \\
\hline 4,3 & 0,986 & 0,953 & 0,906 & 0,851 & 0,791 & 0,730 & 0,590 & 0,478 & 0,394 & 0,332 & 0,285 & 0,250 \\
\hline 4,4 & 0,988 & 0,955 & 0,910 & 0,854 & 0,794 & 0,733 & 0,592 & 0,479 & 0,394 & 0,332 & 0,285 & 0,250 \\
\hline 4,5 & 0,989 & 0,958 & 0,913 & 0,858 & 0,797 & 0,736 & 0,593 & 0,479 & 0,394 & 0,332 & 0,285 & 0,250 \\
\hline 4,6 & 0,990 & 0,960 & 0,915 & 0,861 & 0,800 & 0,739 & 0,595 & 0,480 & 0,395 & 0,332 & 0,285 & 0,250 \\
\hline 4,7 & 0,991 & 0,962 & 0,918 & 0,864 & 0,803 & 0,741 & 0,596 & 0,481 & 0,395 & 0,332 & 0,285 & 0,250 \\
\hline 4,8 & 0,992 & 0,964 & 0,921 & 0,867 & 0,806 & 0,744 & 0,598 & 0,481 & 0,395 & 0,332 & 0,285 & 0,250 \\
\hline 4,9 & 0,993 & 0,966 & 0,923 & 0,869 & 0,809 & 0,746 & 0,599 & 0,482 & 0,395 & 0,332 & 0,285 & 0,250 \\
\hline 5,0 & 0,993 & 0,967 & 0,926 & 0,872 & 0,812 & 0,749 & 0,601 & 0,483 & 0,396 & 0,332 & 0,285 & 0,250 \\
\hline 5,1 & 0,994 & 0,969 & 0,928 & 0,875 & 0,814 & 0,751 & 0,602 & 0,483 & 0,396 & 0,332 & 0,285 & 0,250 \\
\hline 5,2 & 0,994 & 0,971 & 0,930 & 0,877 & 0,817 & 0,753 & 0,603 & 0,484 & 0,396 & 0,332 & 0,286 & 0,250 \\
\hline 5,3 & 0,995 & 0,972 & 0,932 & 0,880 & 0,819 & 0,755 & 0,605 & 0,484 & 0,396 & 0,332 & 0,286 & 0,250 \\
\hline 5,4 & 0,995 & 0,973 & 0,934 & 0,882 & 0,822 & 0,758 & 0,606 & 0,485 & 0,396 & 0,333 & 0,286 & 0,250 \\
\hline 5,5 & 0,996 & 0,975 & 0,936 & 0,884 & 0,824 & 0,760 & 0,607 & 0,485 & 0,397 & 0,333 & 0,286 & 0,250 \\
\hline 5,6 & 0,996 & 0,976 & 0,938 & 0,887 & 0,826 & 0,762 & 0,608 & 0,486 & 0,397 & 0,333 & 0,286 & 0,250 \\
\hline 5,7 & 0,997 & 0,977 & 0,940 & 0,889 & 0,828 & 0,764 & 0,609 & 0,486 & 0,397 & 0,333 & 0,286 & 0,250 \\
\hline 5,8 & 0,997 & 0,978 & 0,942 & 0,891 & 0,830 & 0,766 & 0,610 & 0,487 & 0,397 & 0,333 & 0,286 & 0,250 \\
\hline 5,9 & 0,997 & 0,979 & 0,944 & 0,893 & 0,832 & 0,767 & 0,611 & 0,487 & 0,397 & 0,333 & 0,286 & 0,250 \\
\hline 6,0 & 0,998 & 0,980 & 0,945 & 0,895 & 0,834 & 0,769 & 0,612 & 0,488 & 0,397 & 0,333 & 0,286 & 0,250 \\
\hline 6,1 & 0,998 & 0,981 & 0,947 & 0,897 & 0,836 & 0,771 & 0,613 & 0,488 & 0,397 & 0,333 & 0,286 & 0,250 \\
\hline 6,2 & 0,998 & 0,982 & 0,948 & 0,899 & 0,838 & 0,773 & 0,614 & 0,488 & 0,398 & 0,333 & 0,286 & 0,250 \\
\hline 6,3 & 0,998 & 0,983 & 0,950 & 0,900 & 0,840 & 0,774 & 0,615 & 0,489 & 0,398 & 0,333 & 0,286 & 0,250 \\
\hline \multicolumn{13}{|c|}{ Continuação na próxima página } \\
\hline
\end{tabular}


Tabela 63 - continuação da página anterior

\begin{tabular}{|c|c|c|c|c|c|c|c|c|c|c|c|c|}
\hline $\mathrm{NTU}^{R}$ & 0,0 & 0,2 & 0,4 & 0,6 & 0,8 & 1,0 & 1,5 & 2,0 & 2,5 & 3,0 & 3,5 & 4,0 \\
\hline 6,4 & 0,998 & 0,983 & 0,951 & 0,902 & 0,842 & 0,776 & 0,616 & 0,489 & 0,398 & 0,333 & 0,286 & 0,250 \\
\hline 6,5 & 0,998 & 0,984 & 0,952 & 0,904 & 0,844 & 0,778 & 0,617 & 0,489 & 0,398 & 0,333 & 0,286 & 0,250 \\
\hline 6,6 & 0,999 & 0,985 & 0,954 & 0,906 & 0,845 & 0,779 & 0,618 & 0,490 & 0,398 & 0,333 & 0,286 & 0,250 \\
\hline 6,7 & 0,999 & 0,986 & 0,955 & 0,907 & 0,847 & 0,781 & 0,618 & 0,490 & 0,398 & 0,333 & 0,286 & 0,250 \\
\hline 6,8 & 0,999 & 0,986 & 0,956 & 0,909 & 0,849 & 0,782 & 0,619 & 0,490 & 0,398 & 0,333 & 0,286 & 0,250 \\
\hline 6,9 & 0,999 & 0,987 & 0,957 & 0,910 & 0,850 & 0,784 & 0,620 & 0,491 & 0,398 & 0,333 & 0,286 & 0,250 \\
\hline 7,0 & 0,999 & 0,987 & 0,958 & 0,912 & 0,852 & 0,785 & 0,621 & 0,491 & 0,398 & 0,333 & 0,286 & 0,250 \\
\hline 7,1 & 0,999 & 0,988 & 0,959 & 0,913 & 0,853 & 0,786 & 0,621 & 0,491 & 0,398 & 0,333 & 0,286 & 0,250 \\
\hline 7,2 & 0,999 & 0,989 & 0,961 & 0,915 & 0,855 & 0,788 & 0,622 & 0,491 & 0,398 & 0,333 & 0,286 & 0,250 \\
\hline 7,3 & 0,999 & 0,989 & 0,962 & 0,916 & 0,856 & 0,789 & 0,623 & 0,492 & 0,399 & 0,333 & 0,286 & 0,250 \\
\hline 7,4 & 0,999 & 0,989 & 0,963 & 0,917 & 0,858 & 0,790 & 0,624 & 0,492 & 0,399 & 0,333 & 0,286 & 0,250 \\
\hline 7,5 & 0,999 & 0,990 & 0,963 & 0,919 & 0,859 & 0,792 & 0,624 & 0,492 & 0,399 & 0,333 & 0,286 & 0,250 \\
\hline 7,6 & 0,999 & 0,990 & 0,964 & 0,920 & 0,860 & 0,793 & 0,625 & 0,492 & 0,399 & 0,333 & 0,286 & 0,250 \\
\hline 7,7 & 1,000 & 0,991 & 0,965 & 0,921 & 0,862 & 0,794 & 0,625 & 0,492 & 0,399 & 0,333 & 0,286 & 0,250 \\
\hline 7,8 & 1,000 & 0,991 & 0,966 & 0,922 & 0,863 & 0,795 & 0,626 & 0,493 & 0,399 & 0,333 & 0,286 & 0,250 \\
\hline 7,9 & 1,000 & 0,992 & 0,967 & 0,923 & 0,864 & 0,796 & 0,627 & 0,493 & 0,399 & 0,333 & 0,286 & 0,250 \\
\hline 8,0 & 1,000 & 0,992 & 0,968 & 0,925 & 0,866 & 0,797 & 0,627 & 0,493 & 0,399 & 0,333 & 0,286 & 0,250 \\
\hline 8,1 & 1,000 & 0,992 & 0,969 & 0,926 & 0,867 & 0,799 & 0,628 & 0,493 & 0,399 & 0,333 & 0,286 & 0,250 \\
\hline 8,2 & 1,000 & 0,993 & 0,969 & 0,927 & 0,868 & 0,800 & 0,628 & 0,493 & 0,399 & 0,333 & 0,286 & 0,250 \\
\hline 8,3 & 1,000 & 0,993 & 0,970 & 0,928 & 0,869 & 0,801 & 0,629 & 0,494 & 0,399 & 0,333 & 0,286 & 0,250 \\
\hline 8,4 & 1,000 & 0,993 & 0,971 & 0,929 & 0,870 & 0,802 & 0,629 & 0,494 & 0,399 & 0,333 & 0,286 & 0,250 \\
\hline 8,5 & 1,000 & 0,993 & 0,971 & 0,930 & 0,871 & 0,803 & 0,630 & 0,494 & 0,399 & 0,333 & 0,286 & 0,250 \\
\hline 8,6 & 1,000 & 0,994 & 0,972 & 0,931 & 0,872 & 0,804 & 0,630 & 0,494 & 0,399 & 0,333 & 0,286 & 0,250 \\
\hline 8,7 & 1,000 & 0,994 & 0,973 & 0,932 & 0,874 & 0,805 & 0,631 & 0,494 & 0,399 & 0,333 & 0,286 & 0,250 \\
\hline 8,8 & 1,000 & 0,994 & 0,973 & 0,933 & 0,875 & 0,806 & 0,631 & 0,494 & 0,399 & 0,333 & 0,286 & 0,250 \\
\hline 8,9 & 1,000 & 0,994 & 0,974 & 0,934 & 0,876 & 0,807 & 0,632 & 0,494 & 0,399 & 0,333 & 0,286 & 0,250 \\
\hline 9,0 & 1,000 & 0,995 & 0,975 & 0,935 & 0,877 & 0,808 & 0,632 & 0,495 & 0,399 & 0,333 & 0,286 & 0,250 \\
\hline 9,1 & 1,000 & 0,995 & 0,975 & 0,935 & 0,878 & 0,809 & 0,633 & 0,495 & 0,399 & 0,333 & 0,286 & 0,250 \\
\hline 9,2 & 1,000 & 0,995 & 0,976 & 0,936 & 0,879 & 0,809 & 0,633 & 0,495 & 0,399 & 0,333 & 0,286 & 0,250 \\
\hline 9,3 & 1,000 & 0,995 & 0,976 & 0,937 & 0,880 & 0,810 & 0,633 & 0,495 & 0,399 & 0,333 & 0,286 & 0,250 \\
\hline 9,4 & 1,000 & 0,995 & 0,977 & 0,938 & 0,881 & 0,811 & 0,634 & 0,495 & 0,399 & 0,333 & 0,286 & 0,250 \\
\hline 9,5 & 1,000 & 0,996 & 0,977 & 0,939 & 0,881 & 0,812 & 0,634 & 0,495 & 0,399 & 0,333 & 0,286 & 0,250 \\
\hline 9,6 & 1,000 & 0,996 & 0,978 & 0,940 & 0,882 & 0,813 & 0,635 & 0,495 & 0,399 & 0,333 & 0,286 & 0,250 \\
\hline 9,7 & 1,000 & 0,996 & 0,978 & 0,940 & 0,883 & 0,814 & 0,635 & 0,495 & 0,399 & 0,333 & 0,286 & 0,250 \\
\hline 9,8 & 1,000 & 0,996 & 0,979 & 0,941 & 0,884 & 0,815 & 0,635 & 0,495 & 0,399 & 0,333 & 0,286 & 0,250 \\
\hline 9,9 & 1,000 & 0,996 & 0,979 & 0,942 & 0,885 & 0,815 & 0,636 & 0,496 & 0,399 & 0,333 & 0,286 & 0,250 \\
\hline 10,0 & 1,000 & 0,996 & 0,980 & 0,943 & 0,886 & 0,816 & 0,636 & 0,496 & 0,399 & 0,333 & 0,286 & 0,250 \\
\hline
\end{tabular}

Tabela 64 - Fator de correção para trocador de calor de fluxo cruzado com um passe e dez tubos por passe (1-10) - Caso 3 ou 4 - trocador de calor ilustrado na Figura 80 do Anexo $\mathrm{A}$

\begin{tabular}{|c|cccccccccccc|}
\hline NTU & 0,0 & 0,2 & 0,4 & 0,6 & 0,8 & 1,0 & 1,5 & 2,0 & 2,5 & 3,0 & 3,5 & 4,0 \\
\hline 0,0 & 1,000 & 1,000 & 1,000 & 1,000 & 1,000 & 1,000 & 1,000 & 1,000 & 1,000 & 1,000 & 1,000 & 1,000 \\
0,1 & 1,000 & 1,000 & 0,999 & 0,999 & 0,999 & 0,998 & 0,998 & 0,997 & 0,996 & 0,995 & 0,995 & 0,994 \\
0,2 & 1,000 & 0,999 & 0,998 & 0,996 & 0,995 & 0,994 & 0,991 & 0,989 & 0,986 & 0,984 & 0,982 & 0,980 \\
0,3 & 1,000 & 0,997 & 0,995 & 0,992 & 0,990 & 0,987 & 0,982 & 0,977 & 0,972 & 0,968 & 0,964 & 0,960 \\
0,4 & 1,000 & 0,995 & 0,991 & 0,987 & 0,983 & 0,979 & 0,970 & 0,962 & 0,955 & 0,949 & 0,943 & 0,938 \\
0,5 & 1,000 & 0,993 & 0,986 & 0,980 & 0,974 & 0,969 & 0,957 & 0,946 & 0,937 & 0,929 & 0,922 & 0,916 \\
0,6 & 1,000 & 0,990 & 0,981 & 0,973 & 0,965 & 0,958 & 0,942 & 0,929 & 0,918 & 0,909 & 0,901 & 0,894 \\
0,7 & 1,000 & 0,987 & 0,975 & 0,964 & 0,955 & 0,946 & 0,927 & 0,912 & 0,899 & 0,889 & 0,880 & 0,873 \\
\hline & & 1 & & & \multicolumn{1}{c}{ Continuação na próxima página } \\
\hline
\end{tabular}


Tabela 64 - continuação da página anterior

\begin{tabular}{|c|c|c|c|c|c|c|c|c|c|c|c|c|}
\hline $\mathrm{NTU}^{R}$ & 0,0 & 0,2 & 0,4 & 0,6 & 0,8 & 1,0 & 1,5 & 2,0 & 2,5 & 3,0 & 3,5 & 4,0 \\
\hline 0,8 & 1,000 & 0,983 & 0,969 & 0,956 & 0,944 & 0,934 & 0,912 & 0,895 & 0,881 & 0,870 & 0,861 & 0,853 \\
\hline 0,9 & 1,000 & 0,980 & 0,962 & 0,947 & 0,933 & 0,921 & 0,897 & 0,878 & 0,863 & 0,852 & 0,842 & 0,834 \\
\hline 1,0 & 1,000 & 0,976 & 0,955 & 0,938 & 0,922 & 0,909 & 0,882 & 0,862 & 0,846 & 0,834 & 0,824 & 0,817 \\
\hline 1,1 & 1,000 & 0,972 & 0,948 & 0,928 & 0,911 & 0,896 & 0,867 & 0,846 & 0,830 & 0,818 & 0,808 & 0,800 \\
\hline 1,2 & 1,000 & 0,967 & 0,941 & 0,919 & 0,900 & 0,884 & 0,853 & 0,831 & 0,815 & 0,802 & 0,793 & 0,785 \\
\hline 1,3 & 1,000 & 0,963 & 0,933 & 0,909 & 0,889 & 0,872 & 0,839 & 0,817 & 0,800 & 0,787 & 0,778 & 0,771 \\
\hline 1,4 & 1,000 & 0,958 & 0,926 & 0,899 & 0,878 & 0,860 & 0,826 & 0,803 & 0,786 & 0,774 & 0,765 & 0,758 \\
\hline 1,5 & 1,000 & 0,953 & 0,918 & 0,890 & 0,867 & 0,848 & 0,813 & 0,789 & 0,773 & 0,761 & 0,752 & 0,745 \\
\hline 1,6 & 1,000 & 0,949 & 0,910 & 0,881 & 0,857 & 0,837 & 0,801 & 0,777 & 0,760 & 0,748 & 0,740 & 0,734 \\
\hline 1,7 & 1,000 & 0,944 & 0,903 & 0,871 & 0,846 & 0,826 & 0,789 & 0,765 & 0,748 & 0,737 & 0,728 & 0,723 \\
\hline 1,8 & 1,000 & 0,939 & 0,895 & 0,862 & 0,836 & 0,815 & 0,778 & 0,753 & 0,737 & 0,725 & 0,718 & 0,712 \\
\hline 1,9 & 1,000 & 0,934 & 0,888 & 0,853 & 0,826 & 0,805 & 0,767 & 0,742 & 0,726 & 0,715 & 0,708 & 0,703 \\
\hline 2,0 & 1,000 & 0,929 & 0,881 & 0,845 & 0,817 & 0,795 & 0,756 & 0,732 & 0,716 & 0,705 & 0,698 & 0,693 \\
\hline 2,1 & 1,000 & 0,924 & 0,873 & 0,836 & 0,808 & 0,785 & 0,746 & 0,722 & 0,706 & 0,696 & 0,689 & 0,685 \\
\hline 2,2 & 1,000 & 0,920 & 0,866 & 0,828 & 0,798 & 0,776 & 0,736 & 0,712 & 0,696 & 0,687 & 0,680 & 0,676 \\
\hline 2,3 & 1,000 & 0,915 & 0,859 & 0,820 & 0,790 & 0,766 & 0,727 & 0,703 & 0,687 & 0,678 & 0,672 & 0,668 \\
\hline 2,4 & 1,000 & 0,910 & 0,852 & 0,812 & 0,781 & 0,758 & 0,718 & 0,694 & 0,679 & 0,670 & 0,664 & 0,661 \\
\hline 2,5 & 1,000 & 0,905 & 0,845 & 0,804 & 0,773 & 0,749 & 0,709 & 0,685 & 0,671 & 0,662 & 0,657 & 0,654 \\
\hline 2,6 & 1,000 & 0,900 & 0,839 & 0,796 & 0,765 & 0,741 & 0,701 & 0,677 & 0,663 & 0,654 & 0,649 & 0,647 \\
\hline 2,7 & 1,000 & 0,896 & 0,832 & 0,789 & 0,757 & 0,733 & 0,692 & 0,669 & 0,655 & 0,647 & 0,642 & 0,640 \\
\hline 2,8 & 1,000 & 0,891 & 0,826 & 0,781 & 0,749 & 0,725 & 0,684 & 0,661 & 0,648 & 0,640 & 0,636 & 0,634 \\
\hline 2,9 & 1,000 & 0,886 & 0,820 & 0,774 & 0,742 & 0,717 & 0,677 & 0,654 & 0,641 & 0,633 & 0,629 & 0,628 \\
\hline 3,0 & 1,000 & 0,882 & 0,813 & 0,767 & 0,734 & 0,710 & 0,669 & 0,647 & 0,634 & 0,627 & 0,623 & 0,622 \\
\hline 3,1 & 1,000 & 0,877 & 0,807 & 0,761 & 0,727 & 0,703 & 0,662 & 0,640 & 0,627 & 0,621 & 0,617 & 0,617 \\
\hline 3,2 & 1,000 & 0,873 & 0,801 & 0,754 & 0,721 & 0,696 & 0,655 & 0,633 & 0,621 & 0,615 & 0,612 & 0,611 \\
\hline 3,3 & 1,000 & 0,868 & 0,796 & 0,748 & 0,714 & 0,689 & 0,649 & 0,627 & 0,615 & 0,609 & 0,606 & 0,606 \\
\hline 3,4 & 1,000 & 0,864 & 0,790 & 0,741 & 0,707 & 0,682 & 0,642 & 0,621 & 0,609 & 0,603 & 0,601 & 0,601 \\
\hline 3,5 & 1,000 & 0,860 & 0,784 & 0,735 & 0,701 & 0,676 & 0,636 & 0,615 & 0,603 & 0,598 & 0,596 & 0,596 \\
\hline 3,6 & 1,000 & 0,856 & 0,779 & 0,729 & 0,695 & 0,669 & 0,630 & 0,609 & 0,598 & 0,593 & 0,591 & 0,591 \\
\hline 3,7 & 1,000 & 0,851 & 0,773 & 0,724 & 0,689 & 0,663 & 0,624 & 0,603 & 0,592 & 0,588 & 0,586 & 0,587 \\
\hline 3,8 & 1,000 & 0,847 & 0,768 & 0,718 & 0,683 & 0,657 & 0,618 & 0,598 & 0,587 & 0,583 & 0,581 & 0,582 \\
\hline 3,9 & 1,000 & 0,843 & 0,763 & 0,712 & 0,677 & 0,652 & 0,612 & 0,592 & 0,582 & 0,578 & 0,577 & 0,578 \\
\hline 4,0 & 1,000 & 0,839 & 0,758 & 0,707 & 0,672 & 0,646 & 0,607 & 0,587 & 0,577 & 0,573 & 0,573 & 0,574 \\
\hline 4,1 & 1,000 & 0,835 & 0,753 & 0,701 & 0,666 & 0,640 & 0,601 & 0,582 & 0,572 & 0,569 & 0,568 & 0,570 \\
\hline 4,2 & 1,000 & 0,831 & 0,748 & 0,696 & 0,661 & 0,635 & 0,596 & 0,577 & 0,568 & 0,564 & 0,564 & 0,566 \\
\hline 4,3 & 1,000 & 0,828 & 0,743 & 0,691 & 0,655 & 0,630 & 0,591 & 0,572 & 0,563 & 0,560 & 0,560 & 0,562 \\
\hline 4,4 & 1,000 & 0,824 & 0,739 & 0,686 & 0,650 & 0,625 & 0,586 & 0,567 & 0,559 & 0,556 & 0,556 & 0,558 \\
\hline 4,5 & 1,000 & 0,820 & 0,734 & 0,681 & 0,645 & 0,620 & 0,581 & 0,563 & 0,554 & 0,552 & 0,552 & 0,555 \\
\hline 4,6 & 1,000 & 0,816 & 0,730 & 0,676 & 0,640 & 0,615 & 0,576 & 0,558 & 0,550 & 0,548 & 0,549 & 0,551 \\
\hline 4,7 & 1,000 & 0,813 & 0,725 & 0,672 & 0,636 & 0,610 & 0,572 & 0,554 & 0,546 & 0,544 & 0,545 & 0,548 \\
\hline 4,8 & 1,000 & 0,809 & 0,721 & 0,667 & 0,631 & 0,605 & 0,567 & 0,550 & 0,542 & 0,540 & 0,541 & 0,544 \\
\hline 4,9 & 1,000 & 0,806 & 0,717 & 0,663 & 0,626 & 0,601 & 0,563 & 0,545 & 0,538 & 0,536 & 0,538 & 0,541 \\
\hline 5,0 & 1,000 & 0,802 & 0,713 & 0,658 & 0,622 & 0,596 & 0,559 & 0,541 & 0,534 & 0,533 & 0,534 & 0,538 \\
\hline 5,1 & 1,000 & 0,799 & 0,708 & 0,654 & 0,617 & 0,592 & 0,554 & 0,537 & 0,531 & 0,529 & 0,531 & 0,535 \\
\hline 5,2 & 1,000 & 0,796 & 0,704 & 0,650 & 0,613 & 0,587 & 0,550 & 0,533 & 0,527 & 0,526 & 0,528 & 0,531 \\
\hline 5,3 & 1,000 & 0,792 & 0,700 & 0,645 & 0,609 & 0,583 & 0,546 & 0,530 & 0,523 & 0,523 & 0,525 & 0,528 \\
\hline 5,4 & 1,000 & 0,789 & 0,697 & 0,641 & 0,605 & 0,579 & 0,542 & 0,526 & 0,520 & 0,519 & 0,522 & 0,525 \\
\hline 5,5 & 1,000 & 0,786 & 0,693 & 0,637 & 0,600 & 0,575 & 0,538 & 0,522 & 0,516 & 0,516 & 0,518 & 0,523 \\
\hline 5,6 & 1,000 & 0,783 & 0,689 & 0,633 & 0,596 & 0,571 & 0,534 & 0,519 & 0,513 & 0,513 & 0,515 & 0,520 \\
\hline 5,7 & 1,000 & 0,779 & 0,685 & 0,629 & 0,592 & 0,567 & 0,531 & 0,515 & 0,510 & 0,510 & 0,513 & 0,517 \\
\hline 5,8 & 1,000 & 0,776 & 0,682 & 0,625 & 0,589 & 0,563 & 0,527 & 0,512 & 0,506 & 0,507 & 0,510 & 0,514 \\
\hline 5,9 & 1,000 & 0,773 & 0,678 & 0,622 & 0,585 & 0,559 & 0,523 & 0,508 & 0,503 & 0,504 & 0,507 & 0,511 \\
\hline 6,0 & 1,000 & 0,770 & 0,674 & 0,618 & 0,581 & 0,555 & 0,520 & 0,505 & 0,500 & 0,501 & 0,504 & 0,509 \\
\hline
\end{tabular}


Tabela 64 - continuação da página anterior

\begin{tabular}{|c|c|c|c|c|c|c|c|c|c|c|c|c|}
\hline $\mathrm{NTU}^{R}$ & 0,0 & 0,2 & 0,4 & 0,6 & 0,8 & 1,0 & 1,5 & 2,0 & 2,5 & 3,0 & 3,5 & 4,0 \\
\hline 6,1 & 1,000 & 0,767 & 0,671 & 0,614 & 0,577 & 0,552 & 0,516 & 0,502 & 0,497 & 0,498 & 0,501 & 0,506 \\
\hline 6,2 & 1,000 & 0,765 & 0,668 & 0,611 & 0,574 & 0,548 & 0,513 & 0,498 & 0,494 & 0,495 & 0,499 & 0,503 \\
\hline 6,3 & 1,000 & 0,762 & 0,664 & 0,607 & 0,570 & 0,545 & 0,509 & 0,495 & 0,491 & 0,492 & 0,496 & 0,501 \\
\hline 6,4 & 1,000 & 0,759 & 0,661 & 0,604 & 0,567 & 0,541 & 0,506 & 0,492 & 0,488 & 0,489 & 0,493 & 0,498 \\
\hline 6,5 & 1,000 & 0,756 & 0,658 & 0,600 & 0,563 & 0,538 & 0,503 & 0,489 & 0,485 & 0,487 & 0,491 & 0,496 \\
\hline 6,6 & 1,000 & 0,753 & 0,654 & 0,597 & 0,560 & 0,534 & 0,500 & 0,486 & 0,483 & 0,484 & 0,488 & 0,493 \\
\hline 6,7 & 1,000 & 0,751 & 0,651 & 0,594 & 0,556 & 0,531 & 0,497 & 0,483 & 0,480 & 0,481 & 0,486 & 0,491 \\
\hline 6,8 & 1,000 & 0,748 & 0,648 & 0,590 & 0,553 & 0,528 & 0,493 & 0,480 & 0,477 & 0,479 & 0,483 & 0,489 \\
\hline 6,9 & 1,000 & 0,745 & 0,645 & 0,587 & 0,550 & 0,525 & 0,490 & 0,477 & 0,474 & 0,476 & 0,481 & 0,486 \\
\hline 7,0 & 1,000 & 0,743 & 0,642 & 0,584 & 0,547 & 0,521 & 0,487 & 0,475 & 0,472 & 0,474 & 0,478 & 0,484 \\
\hline 7,1 & 1,000 & 0,740 & 0,639 & 0,581 & 0,544 & 0,518 & 0,484 & 0,472 & 0,469 & 0,471 & 0,476 & 0,482 \\
\hline 7,2 & 1,000 & 0,737 & 0,636 & 0,578 & 0,540 & 0,515 & 0,482 & 0,469 & 0,467 & 0,469 & 0,474 & 0,479 \\
\hline 7,3 & 1,000 & 0,735 & 0,633 & 0,575 & 0,537 & 0,512 & 0,479 & 0,466 & 0,464 & 0,467 & 0,471 & 0,477 \\
\hline 7,4 & 1,000 & 0,732 & 0,630 & 0,572 & 0,534 & 0,509 & 0,476 & 0,464 & 0,462 & 0,464 & 0,469 & 0,475 \\
\hline 7,5 & 1,000 & 0,730 & 0,627 & 0,569 & 0,531 & 0,506 & 0,473 & 0,461 & 0,459 & 0,462 & 0,467 & 0,473 \\
\hline 7,6 & 1,000 & 0,727 & 0,625 & 0,566 & 0,528 & 0,503 & 0,470 & 0,459 & 0,457 & 0,460 & 0,465 & 0,471 \\
\hline 7,7 & 1,000 & 0,725 & 0,622 & 0,563 & 0,526 & 0,501 & 0,468 & 0,456 & 0,454 & 0,457 & 0,462 & 0,469 \\
\hline 7,8 & 1,000 & 0,723 & 0,619 & 0,560 & 0,523 & 0,498 & 0,465 & 0,454 & 0,452 & 0,455 & 0,460 & 0,467 \\
\hline 7,9 & 1,000 & 0,720 & 0,616 & 0,557 & 0,520 & 0,495 & 0,462 & 0,451 & 0,450 & 0,453 & 0,458 & 0,464 \\
\hline 8,0 & 1,000 & 0,718 & 0,614 & 0,555 & 0,517 & 0,492 & 0,460 & 0,449 & 0,447 & 0,451 & 0,456 & 0,462 \\
\hline 8,1 & 1,000 & 0,716 & 0,611 & 0,552 & 0,514 & 0,490 & 0,457 & 0,446 & 0,445 & 0,448 & 0,454 & 0,460 \\
\hline 8,2 & 1,000 & 0,713 & 0,609 & 0,549 & 0,512 & 0,487 & 0,455 & 0,444 & 0,443 & 0,446 & 0,452 & 0,458 \\
\hline 8,3 & 1,000 & 0,711 & 0,606 & 0,547 & 0,509 & 0,484 & 0,452 & 0,442 & 0,441 & 0,444 & 0,450 & 0,456 \\
\hline 8,4 & 1,000 & 0,709 & 0,603 & 0,544 & 0,506 & 0,482 & 0,450 & 0,439 & 0,438 & 0,442 & 0,448 & 0,454 \\
\hline 8,5 & 1,000 & 0,707 & 0,601 & 0,541 & 0,504 & 0,479 & 0,447 & 0,437 & 0,436 & 0,440 & 0,446 & 0,452 \\
\hline 8,6 & 1,000 & 0,704 & 0,598 & 0,539 & 0,501 & 0,477 & 0,445 & 0,435 & 0,434 & 0,438 & 0,444 & 0,451 \\
\hline 8,7 & 1,000 & 0,702 & 0,596 & 0,536 & 0,499 & 0,474 & 0,442 & 0,432 & 0,432 & 0,436 & 0,442 & 0,449 \\
\hline 8,8 & 1,000 & 0,700 & 0,594 & 0,534 & 0,496 & 0,472 & 0,440 & 0,430 & 0,430 & 0,434 & 0,440 & 0,447 \\
\hline 8,9 & 1,000 & 0,698 & 0,591 & 0,531 & 0,494 & 0,469 & 0,438 & 0,428 & 0,428 & 0,432 & 0,438 & 0,445 \\
\hline 9,0 & 1,000 & 0,696 & 0,589 & 0,529 & 0,491 & 0,467 & 0,436 & 0,426 & 0,426 & 0,430 & 0,436 & 0,443 \\
\hline 9,1 & 1,000 & 0,694 & 0,586 & 0,526 & 0,489 & 0,464 & 0,433 & 0,424 & 0,424 & 0,428 & 0,434 & 0,441 \\
\hline 9,2 & 1,000 & 0,692 & 0,584 & 0,524 & 0,487 & 0,462 & 0,431 & 0,422 & 0,422 & 0,426 & 0,433 & 0,439 \\
\hline 9,3 & 1,000 & 0,690 & 0,582 & 0,522 & 0,484 & 0,460 & 0,429 & 0,420 & 0,420 & 0,424 & 0,431 & 0,438 \\
\hline 9,4 & 1,000 & 0,688 & 0,580 & 0,519 & 0,482 & 0,457 & 0,427 & 0,418 & 0,418 & 0,423 & 0,429 & 0,436 \\
\hline 9,5 & 1,000 & 0,686 & 0,577 & 0,517 & 0,479 & 0,455 & 0,425 & 0,416 & 0,416 & 0,421 & 0,427 & 0,434 \\
\hline 9,6 & 1,000 & 0,684 & 0,575 & 0,515 & 0,477 & 0,453 & 0,422 & 0,414 & 0,414 & 0,419 & 0,425 & 0,432 \\
\hline 9,7 & 1,000 & 0,682 & 0,573 & 0,512 & 0,475 & 0,451 & 0,420 & 0,412 & 0,412 & 0,417 & 0,423 & 0,430 \\
\hline 9,8 & 1,000 & 0,680 & 0,571 & 0,510 & 0,473 & 0,448 & 0,418 & 0,410 & 0,410 & 0,415 & 0,422 & 0,429 \\
\hline 9,9 & 1,000 & 0,678 & 0,569 & 0,508 & 0,471 & 0,446 & 0,416 & 0,408 & 0,409 & 0,413 & 0,420 & 0,427 \\
\hline 10,0 & 1,000 & 0,676 & 0,566 & 0,506 & 0,468 & 0,444 & 0,414 & 0,406 & 0,407 & 0,412 & 0,418 & 0,425 \\
\hline
\end{tabular}

Tabela 65 - Efetividade de temperatura para trocador de calor de fluxo cruzado com um passe e infinitos tubos por passe $(1-\infty)$ - Caso $3 \mathrm{~A}$

\begin{tabular}{|c|cccccccccccc|}
\hline NTU & 0,0 & 0,2 & 0,4 & 0,6 & 0,8 & 1,0 & 1,5 & 2,0 & 2,5 & 3,0 & 3,5 & 4,0 \\
\hline 0,0 & 0,000 & 0,000 & 0,000 & 0,000 & 0,000 & 0,000 & 0,000 & 0,000 & 0,000 & 0,000 & 0,000 & 0,000 \\
0,1 & 0,095 & 0,094 & 0,093 & 0,093 & 0,092 & 0,091 & 0,089 & 0,087 & 0,085 & 0,083 & 0,081 & 0,079 \\
0,2 & 0,181 & 0,178 & 0,175 & 0,172 & 0,169 & 0,166 & 0,159 & 0,152 & 0,146 & 0,140 & 0,134 & 0,129 \\
0,3 & 0,259 & 0,253 & 0,246 & 0,240 & 0,234 & 0,229 & 0,215 & 0,203 & 0,191 & 0,181 & 0,171 & 0,162 \\
0,4 & 0,330 & 0,319 & 0,309 & 0,300 & 0,290 & 0,281 & 0,261 & 0,242 & 0,225 & 0,210 & 0,196 & 0,184 \\
0,5 & 0,394 & 0,379 & 0,365 & 0,351 & 0,339 & 0,326 & 0,298 & 0,274 & 0,252 & 0,232 & 0,215 & 0,199 \\
\hline
\end{tabular}


Tabela 65 - continuação da página anterior

\begin{tabular}{|c|c|c|c|c|c|c|c|c|c|c|c|c|}
\hline${ }_{N T U^{R}}$ & 0,0 & 0,2 & 0,4 & 0,6 & 0,8 & 1,0 & 1,5 & 2,0 & 2,5 & 3,0 & 3,5 & 4,0 \\
\hline 0,6 & 0,451 & 0,432 & 0,414 & 0,397 & 0,380 & 0,365 & 0,330 & 0,299 & 0,273 & 0,249 & 0,229 & 0,211 \\
\hline 0,7 & 0,503 & 0,480 & 0,458 & 0,437 & 0,417 & 0,398 & 0,357 & 0,321 & 0,290 & 0,263 & 0,239 & 0,219 \\
\hline 0,8 & 0,551 & 0,523 & 0,497 & 0,472 & 0,449 & 0,428 & 0,379 & 0,338 & 0,303 & 0,273 & 0,247 & 0,225 \\
\hline 0,9 & 0,593 & 0,562 & 0,532 & 0,504 & 0,478 & 0,453 & 0,399 & 0,353 & 0,315 & 0,282 & 0,254 & 0,230 \\
\hline 1,0 & 0,632 & 0,597 & 0,563 & 0,532 & 0,503 & 0,476 & 0,416 & 0,366 & 0,324 & 0,289 & 0,259 & 0,234 \\
\hline 1,1 & 0,667 & 0,628 & 0,592 & 0,558 & 0,526 & 0,497 & 0,432 & 0,377 & 0,332 & 0,294 & 0,263 & 0,236 \\
\hline 1,2 & 0,699 & 0,657 & 0,618 & 0,581 & 0,547 & 0,515 & 0,445 & 0,387 & 0,339 & 0,299 & 0,266 & 0,239 \\
\hline 1,3 & 0,727 & 0,683 & 0,641 & 0,602 & 0,565 & 0,531 & 0,457 & 0,396 & 0,345 & 0,303 & 0,269 & 0,241 \\
\hline 1,4 & 0,753 & 0,706 & 0,662 & 0,621 & 0,582 & 0,546 & 0,468 & 0,403 & 0,350 & 0,307 & 0,271 & 0,242 \\
\hline 1,5 & 0,777 & 0,728 & 0,682 & 0,638 & 0,598 & 0,560 & 0,478 & 0,410 & 0,355 & 0,310 & 0,273 & 0,243 \\
\hline 1,6 & 0,798 & 0,748 & 0,700 & 0,654 & 0,612 & 0,573 & 0,486 & 0,416 & 0,359 & 0,313 & 0,275 & 0,244 \\
\hline 1,7 & 0,817 & 0,766 & 0,716 & 0,669 & 0,625 & 0,584 & 0,495 & 0,421 & 0,362 & 0,315 & 0,276 & 0,245 \\
\hline 1,8 & 0,835 & 0,782 & 0,731 & 0,683 & 0,638 & 0,595 & 0,502 & 0,426 & 0,365 & 0,317 & 0,278 & 0,246 \\
\hline 1,9 & 0,850 & 0,797 & 0,745 & 0,696 & 0,649 & 0,605 & 0,509 & 0,431 & 0,368 & 0,318 & 0,279 & 0,247 \\
\hline 2,0 & 0,865 & 0,811 & 0,758 & 0,707 & 0,659 & 0,614 & 0,515 & 0,435 & 0,371 & 0,320 & 0,280 & 0,247 \\
\hline 2,1 & 0,878 & 0,823 & 0,770 & 0,718 & 0,669 & 0,623 & 0,521 & 0,439 & 0,373 & 0,321 & 0,280 & 0,248 \\
\hline 2,2 & 0,889 & 0,835 & 0,781 & 0,729 & 0,678 & 0,631 & 0,527 & 0,442 & 0,375 & 0,322 & 0,281 & 0,248 \\
\hline 2,3 & 0,900 & 0,846 & 0,792 & 0,738 & 0,687 & 0,639 & 0,532 & 0,445 & 0,377 & 0,323 & 0,281 & 0,248 \\
\hline 2,4 & 0,909 & 0,856 & 0,801 & 0,747 & 0,695 & 0,646 & 0,536 & 0,448 & 0,379 & 0,324 & 0,282 & 0,248 \\
\hline 2,5 & 0,918 & 0,865 & 0,810 & 0,756 & 0,703 & 0,652 & 0,541 & 0,451 & 0,380 & 0,325 & 0,282 & 0,249 \\
\hline 2,6 & 0,926 & 0,873 & 0,819 & 0,764 & 0,710 & 0,659 & 0,545 & 0,453 & 0,382 & 0,326 & 0,283 & 0,249 \\
\hline 2,7 & 0,933 & 0,881 & 0,827 & 0,771 & 0,717 & 0,665 & 0,549 & 0,456 & 0,383 & 0,327 & 0,283 & 0,249 \\
\hline 2,8 & 0,939 & 0,889 & 0,834 & 0,778 & 0,723 & 0,671 & 0,553 & 0,458 & 0,384 & 0,327 & 0,283 & 0,249 \\
\hline 2,9 & 0,945 & 0,895 & 0,841 & 0,785 & 0,730 & 0,676 & 0,556 & 0,460 & 0,385 & 0,328 & 0,284 & 0,249 \\
\hline 3,0 & 0,950 & 0,902 & 0,848 & 0,792 & 0,736 & 0,681 & 0,560 & 0,462 & 0,386 & 0,328 & 0,284 & 0,249 \\
\hline 3,1 & 0,955 & 0,907 & 0,854 & 0,798 & 0,741 & 0,686 & 0,563 & 0,464 & 0,387 & 0,329 & 0,284 & 0,249 \\
\hline 3,2 & 0,959 & 0,913 & 0,860 & 0,803 & 0,746 & 0,691 & 0,566 & 0,465 & 0,388 & 0,329 & 0,284 & 0,250 \\
\hline 3,3 & 0,963 & 0,918 & 0,865 & 0,809 & 0,752 & 0,695 & 0,569 & 0,467 & 0,389 & 0,329 & 0,284 & 0,250 \\
\hline 3,4 & 0,967 & 0,923 & 0,871 & 0,814 & 0,756 & 0,700 & 0,571 & 0,468 & 0,389 & 0,330 & 0,285 & 0,250 \\
\hline 3,5 & 0,970 & 0,927 & 0,876 & 0,819 & 0,761 & 0,704 & 0,574 & 0,470 & 0,390 & 0,330 & 0,285 & 0,250 \\
\hline 3,6 & 0,973 & 0,931 & 0,880 & 0,824 & 0,766 & 0,708 & 0,577 & 0,471 & 0,391 & 0,330 & 0,285 & 0,250 \\
\hline 3,7 & 0,975 & 0,935 & 0,885 & 0,829 & 0,770 & 0,712 & 0,579 & 0,472 & 0,391 & 0,331 & 0,285 & 0,250 \\
\hline 3,8 & 0,978 & 0,939 & 0,889 & 0,833 & 0,774 & 0,715 & 0,581 & 0,473 & 0,392 & 0,331 & 0,285 & 0,250 \\
\hline 3,9 & 0,980 & 0,942 & 0,893 & 0,837 & 0,778 & 0,719 & 0,583 & 0,475 & 0,392 & 0,331 & 0,285 & 0,250 \\
\hline 4,0 & 0,982 & 0,945 & 0,897 & 0,841 & 0,782 & 0,722 & 0,585 & 0,476 & 0,393 & 0,331 & 0,285 & 0,250 \\
\hline 4,1 & 0,983 & 0,948 & 0,901 & 0,845 & 0,786 & 0,726 & 0,587 & 0,477 & 0,393 & 0,331 & 0,285 & 0,250 \\
\hline 4,2 & 0,985 & 0,951 & 0,904 & 0,849 & 0,789 & 0,729 & 0,589 & 0,478 & 0,394 & 0,332 & 0,285 & 0,250 \\
\hline 4,3 & 0,986 & 0,954 & 0,907 & 0,852 & 0,793 & 0,732 & 0,591 & 0,478 & 0,394 & 0,332 & 0,285 & 0,250 \\
\hline 4,4 & 0,988 & 0,956 & 0,911 & 0,856 & 0,796 & 0,735 & 0,593 & 0,479 & 0,394 & 0,332 & 0,285 & 0,250 \\
\hline 4,5 & 0,989 & 0,958 & 0,914 & 0,859 & 0,799 & 0,738 & 0,595 & 0,480 & 0,395 & 0,332 & 0,285 & 0,250 \\
\hline 4,6 & 0,990 & 0,960 & 0,917 & 0,862 & 0,802 & 0,741 & 0,596 & 0,481 & 0,395 & 0,332 & 0,285 & 0,250 \\
\hline 4,7 & 0,991 & 0,963 & 0,919 & 0,865 & 0,805 & 0,743 & 0,598 & 0,482 & 0,395 & 0,332 & 0,285 & 0,250 \\
\hline 4,8 & 0,992 & 0,964 & 0,922 & 0,868 & 0,808 & 0,746 & 0,599 & 0,482 & 0,395 & 0,332 & 0,285 & 0,250 \\
\hline 4,9 & 0,993 & 0,966 & 0,925 & 0,871 & 0,811 & 0,748 & 0,601 & 0,483 & 0,396 & 0,332 & 0,285 & 0,250 \\
\hline 5,0 & 0,993 & 0,968 & 0,927 & 0,874 & 0,814 & 0,751 & 0,602 & 0,484 & 0,396 & 0,332 & 0,285 & 0,250 \\
\hline 5,1 & 0,994 & 0,970 & 0,929 & 0,877 & 0,816 & 0,753 & 0,604 & 0,484 & 0,396 & 0,332 & 0,286 & 0,250 \\
\hline 5,2 & 0,994 & 0,971 & 0,932 & 0,879 & 0,819 & 0,756 & 0,605 & 0,485 & 0,396 & 0,333 & 0,286 & 0,250 \\
\hline 5,3 & 0,995 & 0,973 & 0,934 & 0,882 & 0,822 & 0,758 & 0,606 & 0,485 & 0,397 & 0,333 & 0,286 & 0,250 \\
\hline 5,4 & 0,995 & 0,974 & 0,936 & 0,884 & 0,824 & 0,760 & 0,608 & 0,486 & 0,397 & 0,333 & 0,286 & 0,250 \\
\hline 5,5 & 0,996 & 0,975 & 0,938 & 0,887 & 0,826 & 0,762 & 0,609 & 0,486 & 0,397 & 0,333 & 0,286 & 0,250 \\
\hline 5,6 & 0,996 & 0,976 & 0,940 & 0,889 & 0,829 & 0,764 & 0,610 & 0,487 & 0,397 & 0,333 & 0,286 & 0,250 \\
\hline 5,7 & 0,997 & 0,978 & 0,942 & 0,891 & 0,831 & 0,766 & 0,611 & 0,487 & 0,397 & 0,333 & 0,286 & 0,250 \\
\hline 5,8 & 0,997 & 0,979 & 0,943 & 0,893 & 0,833 & 0,768 & 0,612 & 0,488 & 0,397 & 0,333 & 0,286 & 0,250 \\
\hline \multicolumn{13}{|c|}{ Continuação na próxima página } \\
\hline
\end{tabular}


Tabela 65 - continuação da página anterior

\begin{tabular}{|c|c|c|c|c|c|c|c|c|c|c|c|c|}
\hline $\mathrm{NTU}^{R}$ & 0,0 & 0,2 & 0,4 & 0,6 & 0,8 & 1,0 & 1,5 & 2,0 & 2,5 & 3,0 & 3,5 & 4,0 \\
\hline 5,9 & 0,997 & 0,980 & 0,945 & 0,895 & 0,835 & 0,770 & 0,613 & 0,488 & 0,398 & 0,333 & 0,286 & 0,250 \\
\hline 6,0 & 0,998 & 0,981 & 0,947 & 0,897 & 0,837 & 0,772 & 0,614 & 0,489 & 0,398 & 0,333 & 0,286 & 0,250 \\
\hline 6,1 & 0,998 & 0,982 & 0,948 & 0,899 & 0,839 & 0,774 & 0,615 & 0,489 & 0,398 & 0,333 & 0,286 & 0,250 \\
\hline 6,2 & 0,998 & 0,982 & 0,950 & 0,901 & 0,841 & 0,776 & 0,616 & 0,489 & 0,398 & 0,333 & 0,286 & 0,250 \\
\hline 6,3 & 0,998 & 0,983 & 0,951 & 0,903 & 0,843 & 0,777 & 0,617 & 0,490 & 0,398 & 0,333 & 0,286 & 0,250 \\
\hline 6,4 & 0,998 & 0,984 & 0,953 & 0,905 & 0,845 & 0,779 & 0,618 & 0,490 & 0,398 & 0,333 & 0,286 & 0,250 \\
\hline 6,5 & 0,998 & 0,985 & 0,954 & 0,907 & 0,847 & 0,781 & 0,619 & 0,490 & 0,398 & 0,333 & 0,286 & 0,250 \\
\hline 6,6 & 0,999 & 0,986 & 0,955 & 0,908 & 0,849 & 0,782 & 0,620 & 0,491 & 0,398 & 0,333 & 0,286 & 0,250 \\
\hline 6,7 & 0,999 & 0,986 & 0,957 & 0,910 & 0,850 & 0,784 & 0,621 & 0,491 & 0,398 & 0,333 & 0,286 & 0,250 \\
\hline 6,8 & 0,999 & 0,987 & 0,958 & 0,911 & 0,852 & 0,786 & 0,622 & 0,491 & 0,398 & 0,333 & 0,286 & 0,250 \\
\hline 6,9 & 0,999 & 0,987 & 0,959 & 0,913 & 0,854 & 0,787 & 0,622 & 0,492 & 0,399 & 0,333 & 0,286 & 0,250 \\
\hline 7,0 & 0,999 & 0,988 & 0,960 & 0,915 & 0,855 & 0,789 & 0,623 & 0,492 & 0,399 & 0,333 & 0,286 & 0,250 \\
\hline 7,1 & 0,999 & 0,989 & 0,961 & 0,916 & 0,857 & 0,790 & 0,624 & 0,492 & 0,399 & 0,333 & 0,286 & 0,250 \\
\hline 7,2 & 0,999 & 0,989 & 0,962 & 0,918 & 0,859 & 0,792 & 0,625 & 0,492 & 0,399 & 0,333 & 0,286 & 0,250 \\
\hline 7,3 & 0,999 & 0,990 & 0,963 & 0,919 & 0,860 & 0,793 & 0,625 & 0,493 & 0,399 & 0,333 & 0,286 & 0,250 \\
\hline 7,4 & 0,999 & 0,990 & 0,964 & 0,920 & 0,862 & 0,794 & 0,626 & 0,493 & 0,399 & 0,333 & 0,286 & 0,250 \\
\hline 7,5 & 0,999 & 0,990 & 0,965 & 0,922 & 0,863 & 0,796 & 0,627 & 0,493 & 0,399 & 0,333 & 0,286 & 0,250 \\
\hline 7,6 & 0,999 & 0,991 & 0,966 & 0,923 & 0,865 & 0,797 & 0,627 & 0,493 & 0,399 & 0,333 & 0,286 & 0,250 \\
\hline 7,7 & 1,000 & 0,991 & 0,967 & 0,924 & 0,866 & 0,798 & 0,628 & 0,493 & 0,399 & 0,333 & 0,286 & 0,250 \\
\hline 7,8 & 1,000 & 0,992 & 0,968 & 0,926 & 0,867 & 0,800 & 0,629 & 0,494 & 0,399 & 0,333 & 0,286 & 0,250 \\
\hline 7,9 & 1,000 & 0,992 & 0,969 & 0,927 & 0,869 & 0,801 & 0,629 & 0,494 & 0,399 & 0,333 & 0,286 & 0,250 \\
\hline 8,0 & 1,000 & 0,992 & 0,970 & 0,928 & 0,870 & 0,802 & 0,630 & 0,494 & 0,399 & 0,333 & 0,286 & 0,250 \\
\hline 8,1 & 1,000 & 0,993 & 0,970 & 0,929 & 0,871 & 0,803 & 0,631 & 0,494 & 0,399 & 0,333 & 0,286 & 0,250 \\
\hline 8,2 & 1,000 & 0,993 & 0,971 & 0,930 & 0,873 & 0,804 & 0,631 & 0,494 & 0,399 & 0,333 & 0,286 & 0,250 \\
\hline 8,3 & 1,000 & 0,993 & 0,972 & 0,931 & 0,874 & 0,806 & 0,632 & 0,495 & 0,399 & 0,333 & 0,286 & 0,250 \\
\hline 8,4 & 1,000 & 0,994 & 0,973 & 0,932 & 0,875 & 0,807 & 0,632 & 0,495 & 0,399 & 0,333 & 0,286 & 0,250 \\
\hline 8,5 & 1,000 & 0,994 & 0,973 & 0,934 & 0,876 & 0,808 & 0,633 & 0,495 & 0,399 & 0,333 & 0,286 & 0,250 \\
\hline 8,6 & 1,000 & 0,994 & 0,974 & 0,935 & 0,877 & 0,809 & 0,633 & 0,495 & 0,399 & 0,333 & 0,286 & 0,250 \\
\hline 8,7 & 1,000 & 0,994 & 0,975 & 0,936 & 0,879 & 0,810 & 0,634 & 0,495 & 0,399 & 0,333 & 0,286 & 0,250 \\
\hline 8,8 & 1,000 & 0,995 & 0,975 & 0,937 & 0,880 & 0,811 & 0,634 & 0,495 & 0,399 & 0,333 & 0,286 & 0,250 \\
\hline 8,9 & 1,000 & 0,995 & 0,976 & 0,938 & 0,881 & 0,812 & 0,635 & 0,495 & 0,399 & 0,333 & 0,286 & 0,250 \\
\hline 9,0 & 1,000 & 0,995 & 0,977 & 0,938 & 0,882 & 0,813 & 0,635 & 0,496 & 0,399 & 0,333 & 0,286 & 0,250 \\
\hline 9,1 & 1,000 & 0,995 & 0,977 & 0,939 & 0,883 & 0,814 & 0,636 & 0,496 & 0,400 & 0,333 & 0,286 & 0,250 \\
\hline 9,2 & 1,000 & 0,996 & 0,978 & 0,940 & 0,884 & 0,815 & 0,636 & 0,496 & 0,400 & 0,333 & 0,286 & 0,250 \\
\hline 9,3 & 1,000 & 0,996 & 0,978 & 0,941 & 0,885 & 0,816 & 0,637 & 0,496 & 0,400 & 0,333 & 0,286 & 0,250 \\
\hline 9,4 & 1,000 & 0,996 & 0,979 & 0,942 & 0,886 & 0,817 & 0,637 & 0,496 & 0,400 & 0,333 & 0,286 & 0,250 \\
\hline 9,5 & 1,000 & 0,996 & 0,979 & 0,943 & 0,887 & 0,818 & 0,638 & 0,496 & 0,400 & 0,333 & 0,286 & 0,250 \\
\hline 9,6 & 1,000 & 0,996 & 0,980 & 0,944 & 0,888 & 0,819 & 0,638 & 0,496 & 0,400 & 0,333 & 0,286 & 0,250 \\
\hline 9,7 & 1,000 & 0,996 & 0,980 & 0,945 & 0,889 & 0,820 & 0,638 & 0,496 & 0,400 & 0,333 & 0,286 & 0,250 \\
\hline 9,8 & 1,000 & 0,997 & 0,981 & 0,945 & 0,890 & 0,821 & 0,639 & 0,497 & 0,400 & 0,333 & 0,286 & 0,250 \\
\hline 9,9 & 1,000 & 0,997 & 0,981 & 0,946 & 0,891 & 0,822 & 0,639 & 0,497 & 0,400 & 0,333 & 0,286 & 0,250 \\
\hline 10,0 & 1,000 & 0,997 & 0,982 & 0,947 & 0,892 & 0,823 & 0,640 & 0,497 & 0,400 & 0,333 & 0,286 & 0,250 \\
\hline
\end{tabular}

Tabela 66 - Fator de correção para trocador de calor de fluxo cruzado com um passe e infinitos tubos por passe $(1-\infty)$ - Caso $3 \mathrm{~A}$

\begin{tabular}{|c|cccccccccccc|}
\hline NTU & \multirow{2}{*}{0,0} & 0,2 & 0,4 & 0,6 & 0,8 & 1,0 & 1,5 & 2,0 & 2,5 & 3,0 & 3,5 & 4,0 \\
\hline 0,0 & 1,000 & 1,000 & 1,000 & 1,000 & 1,000 & 1,000 & 1,000 & 1,000 & 1,000 & 1,000 & 1,000 & 1,000 \\
0,1 & 1,000 & 1,000 & 0,999 & 0,999 & 0,999 & 0,998 & 0,998 & 0,997 & 0,996 & 0,995 & 0,995 & 0,994 \\
0,2 & 1,000 & 0,999 & 0,998 & 0,996 & 0,995 & 0,994 & 0,991 & 0,989 & 0,986 & 0,984 & 0,982 & 0,980 \\
0,3 & 1,000 & 0,997 & 0,995 & 0,992 & 0,990 & 0,987 & 0,982 & 0,977 & 0,972 & 0,968 & 0,964 & 0,960 \\
\hline \multicolumn{1}{c}{} & \multicolumn{1}{c}{ Continuação na próxima página } \\
\hline
\end{tabular}


Tabela 66 - continuação da página anterior

\begin{tabular}{|c|c|c|c|c|c|c|c|c|c|c|c|c|}
\hline${ }_{N T U^{R}}$ & 0,0 & 0,2 & 0,4 & 0,6 & 0,8 & 1,0 & 1,5 & 2,0 & 2,5 & 3,0 & 3,5 & 4,0 \\
\hline 0,4 & 1,000 & 0,995 & 0,991 & 0,987 & 0,983 & 0,979 & 0,970 & 0,962 & 0,955 & 0,949 & 0,944 & 0,938 \\
\hline 0,5 & 1,000 & 0,993 & 0,986 & 0,980 & 0,974 & 0,969 & 0,957 & 0,946 & 0,937 & 0,929 & 0,922 & 0,916 \\
\hline 0,6 & 1,000 & 0,990 & 0,981 & 0,973 & 0,965 & 0,958 & 0,942 & 0,929 & 0,918 & 0,909 & 0,901 & 0,894 \\
\hline 0,7 & 1,000 & 0,987 & 0,975 & 0,965 & 0,955 & 0,946 & 0,927 & 0,912 & 0,900 & 0,889 & 0,881 & 0,873 \\
\hline 0,8 & 1,000 & 0,983 & 0,969 & 0,956 & 0,944 & 0,934 & 0,912 & 0,895 & 0,881 & 0,870 & 0,861 & 0,853 \\
\hline 0,9 & 1,000 & 0,980 & 0,962 & 0,947 & 0,934 & 0,922 & 0,897 & 0,878 & 0,864 & 0,852 & 0,843 & 0,835 \\
\hline 1,0 & 1,000 & 0,976 & 0,955 & 0,938 & 0,922 & 0,909 & 0,882 & 0,862 & 0,847 & 0,835 & 0,825 & 0,817 \\
\hline 1,1 & 1,000 & 0,972 & 0,948 & 0,928 & 0,911 & 0,897 & 0,868 & 0,847 & 0,831 & 0,818 & 0,809 & 0,801 \\
\hline 1,2 & 1,000 & 0,967 & 0,941 & 0,919 & 0,900 & 0,885 & 0,854 & 0,832 & 0,815 & 0,803 & 0,794 & 0,786 \\
\hline 1,3 & 1,000 & 0,963 & 0,933 & 0,909 & 0,889 & 0,872 & 0,840 & 0,817 & 0,801 & 0,788 & 0,779 & 0,772 \\
\hline 1,4 & 1,000 & 0,958 & 0,926 & 0,900 & 0,878 & 0,861 & 0,827 & 0,804 & 0,787 & 0,775 & 0,766 & 0,759 \\
\hline 1,5 & 1,000 & 0,954 & 0,918 & 0,890 & 0,868 & 0,849 & 0,814 & 0,791 & 0,774 & 0,762 & 0,753 & 0,747 \\
\hline 1,6 & 1,000 & 0,949 & 0,911 & 0,881 & 0,857 & 0,838 & 0,802 & 0,778 & 0,761 & 0,750 & 0,741 & 0,736 \\
\hline 1,7 & 1,000 & 0,944 & 0,903 & 0,872 & 0,847 & 0,827 & 0,790 & 0,766 & 0,750 & 0,738 & 0,730 & 0,725 \\
\hline 1,8 & 1,000 & 0,939 & 0,896 & 0,863 & 0,837 & 0,816 & 0,779 & 0,755 & 0,739 & 0,727 & 0,720 & 0,715 \\
\hline 1,9 & 1,000 & 0,935 & 0,889 & 0,854 & 0,827 & 0,806 & 0,768 & 0,744 & 0,728 & 0,717 & 0,710 & 0,705 \\
\hline 2,0 & 1,000 & 0,930 & 0,881 & 0,846 & 0,818 & 0,796 & 0,758 & 0,734 & 0,718 & 0,707 & 0,701 & 0,696 \\
\hline 2,1 & 1,000 & 0,925 & 0,874 & 0,837 & 0,809 & 0,787 & 0,748 & 0,724 & 0,708 & 0,698 & 0,692 & 0,688 \\
\hline 2,2 & 1,000 & 0,920 & 0,867 & 0,829 & 0,800 & 0,777 & 0,738 & 0,714 & 0,699 & 0,689 & 0,683 & 0,680 \\
\hline 2,3 & 1,000 & 0,915 & 0,860 & 0,821 & 0,791 & 0,768 & 0,729 & 0,705 & 0,690 & 0,681 & 0,675 & 0,672 \\
\hline 2,4 & 1,000 & 0,911 & 0,853 & 0,813 & 0,783 & 0,759 & 0,720 & 0,696 & 0,682 & 0,673 & 0,668 & 0,665 \\
\hline 2,5 & 1,000 & 0,906 & 0,847 & 0,805 & 0,775 & 0,751 & 0,711 & 0,688 & 0,674 & 0,665 & 0,660 & 0,658 \\
\hline 2,6 & 1,000 & 0,901 & 0,840 & 0,798 & 0,767 & 0,743 & 0,703 & 0,680 & 0,666 & 0,658 & 0,654 & 0,651 \\
\hline 2,7 & 1,000 & 0,897 & 0,834 & 0,791 & 0,759 & 0,735 & 0,695 & 0,672 & 0,659 & 0,651 & 0,647 & 0,645 \\
\hline 2,8 & 1,000 & 0,892 & 0,828 & 0,783 & 0,751 & 0,727 & 0,687 & 0,665 & 0,652 & 0,644 & 0,641 & 0,639 \\
\hline 2,9 & 1,000 & 0,888 & 0,821 & 0,777 & 0,744 & 0,720 & 0,680 & 0,658 & 0,645 & 0,638 & 0,635 & 0,634 \\
\hline 3,0 & 1,000 & 0,883 & 0,815 & 0,770 & 0,737 & 0,713 & 0,673 & 0,651 & 0,638 & 0,632 & 0,629 & 0,628 \\
\hline 3,1 & 1,000 & 0,879 & 0,809 & 0,763 & 0,730 & 0,706 & 0,666 & 0,644 & 0,632 & 0,626 & 0,623 & 0,623 \\
\hline 3,2 & 1,000 & 0,874 & 0,804 & 0,757 & 0,723 & 0,699 & 0,659 & 0,638 & 0,626 & 0,620 & 0,618 & 0,618 \\
\hline 3,3 & 1,000 & 0,870 & 0,798 & 0,751 & 0,717 & 0,692 & 0,653 & 0,631 & 0,620 & 0,615 & 0,613 & 0,613 \\
\hline 3,4 & 1,000 & 0,866 & 0,792 & 0,744 & 0,711 & 0,686 & 0,646 & 0,626 & 0,615 & 0,609 & 0,608 & 0,608 \\
\hline 3,5 & 1,000 & 0,862 & 0,787 & 0,738 & 0,704 & 0,679 & 0,640 & 0,620 & 0,609 & 0,604 & 0,603 & 0,604 \\
\hline 3,6 & 1,000 & 0,858 & 0,782 & 0,733 & 0,698 & 0,673 & 0,634 & 0,614 & 0,604 & 0,599 & 0,599 & 0,600 \\
\hline 3,7 & 1,000 & 0,854 & 0,776 & 0,727 & 0,693 & 0,667 & 0,629 & 0,609 & 0,599 & 0,595 & 0,594 & 0,596 \\
\hline 3,8 & 1,000 & 0,850 & 0,771 & 0,721 & 0,687 & 0,662 & 0,623 & 0,603 & 0,594 & 0,590 & 0,590 & 0,592 \\
\hline 3,9 & 1,000 & 0,846 & 0,766 & 0,716 & 0,681 & 0,656 & 0,618 & 0,598 & 0,589 & 0,586 & 0,586 & 0,588 \\
\hline 4,0 & 1,000 & 0,842 & 0,761 & 0,711 & 0,676 & 0,651 & 0,612 & 0,593 & 0,584 & 0,581 & 0,582 & 0,584 \\
\hline 4,1 & 1,000 & 0,838 & 0,757 & 0,706 & 0,671 & 0,645 & 0,607 & 0,588 & 0,580 & 0,577 & 0,578 & 0,581 \\
\hline 4,2 & 1,000 & 0,834 & 0,752 & 0,701 & 0,665 & 0,640 & 0,602 & 0,584 & 0,576 & 0,573 & 0,574 & 0,577 \\
\hline 4,3 & 1,000 & 0,831 & 0,747 & 0,696 & 0,660 & 0,635 & 0,597 & 0,579 & 0,571 & 0,569 & 0,571 & 0,574 \\
\hline 4,4 & 1,000 & 0,827 & 0,743 & 0,691 & 0,655 & 0,630 & 0,593 & 0,575 & 0,567 & 0,566 & 0,567 & 0,570 \\
\hline 4,5 & 1,000 & 0,823 & 0,739 & 0,686 & 0,651 & 0,625 & 0,588 & 0,571 & 0,563 & 0,562 & 0,564 & 0,567 \\
\hline 4,6 & 1,000 & 0,820 & 0,734 & 0,682 & 0,646 & 0,621 & 0,583 & 0,566 & 0,560 & 0,558 & 0,560 & 0,564 \\
\hline 4,7 & 1,000 & 0,816 & 0,730 & 0,677 & 0,641 & 0,616 & 0,579 & 0,562 & 0,556 & 0,555 & 0,557 & 0,561 \\
\hline 4,8 & 1,000 & 0,813 & 0,726 & 0,673 & 0,637 & 0,612 & 0,575 & 0,558 & 0,552 & 0,552 & 0,554 & 0,558 \\
\hline 4,9 & 1,000 & 0,810 & 0,722 & 0,668 & 0,632 & 0,607 & 0,571 & 0,554 & 0,549 & 0,548 & 0,551 & 0,556 \\
\hline 5,0 & 1,000 & 0,806 & 0,718 & 0,664 & 0,628 & 0,603 & 0,567 & 0,551 & 0,545 & 0,545 & 0,548 & 0,553 \\
\hline 5,1 & 1,000 & 0,803 & 0,714 & 0,660 & 0,624 & 0,599 & 0,563 & 0,547 & 0,542 & 0,542 & 0,545 & 0,550 \\
\hline 5,2 & 1,000 & 0,800 & 0,710 & 0,656 & 0,620 & 0,595 & 0,559 & 0,543 & 0,538 & 0,539 & 0,543 & 0,548 \\
\hline 5,3 & 1,000 & 0,797 & 0,706 & 0,652 & 0,616 & 0,591 & 0,555 & 0,540 & 0,535 & 0,536 & 0,540 & 0,545 \\
\hline 5,4 & 1,000 & 0,794 & 0,703 & 0,648 & 0,612 & 0,587 & 0,551 & 0,536 & 0,532 & 0,533 & 0,537 & 0,543 \\
\hline 5,5 & 1,000 & 0,791 & 0,699 & 0,644 & 0,608 & 0,583 & 0,547 & 0,533 & 0,529 & 0,530 & 0,535 & 0,541 \\
\hline 5,6 & 1,000 & 0,788 & 0,695 & 0,640 & 0,604 & 0,579 & 0,544 & 0,530 & 0,526 & 0,528 & 0,532 & 0,538 \\
\hline \multicolumn{13}{|c|}{ Continuação na próxima página } \\
\hline
\end{tabular}


Tabela 66 - continuação da página anterior

\begin{tabular}{|c|c|c|c|c|c|c|c|c|c|c|c|c|}
\hline $\mathrm{NTU}^{R}$ & 0,0 & 0,2 & 0,4 & 0,6 & 0,8 & 1,0 & 1,5 & 2,0 & 2,5 & 3,0 & 3,5 & 4,0 \\
\hline 5,7 & 1,000 & 0,785 & 0,692 & 0,637 & 0,600 & 0,575 & 0,540 & 0,527 & 0,523 & 0,525 & 0,530 & 0,536 \\
\hline 5,8 & 1,000 & 0,782 & 0,689 & 0,633 & 0,597 & 0,572 & 0,537 & 0,523 & 0,520 & 0,522 & 0,527 & 0,534 \\
\hline 5,9 & 1,000 & 0,779 & 0,685 & 0,630 & 0,593 & 0,568 & 0,534 & 0,520 & 0,517 & 0,520 & 0,525 & 0,532 \\
\hline 6,0 & 1,000 & 0,776 & 0,682 & 0,626 & 0,590 & 0,565 & 0,530 & 0,517 & 0,515 & 0,517 & 0,523 & 0,530 \\
\hline 6,1 & 1,000 & 0,774 & 0,679 & 0,623 & 0,586 & 0,561 & 0,527 & 0,514 & 0,512 & 0,515 & 0,521 & 0,528 \\
\hline 6,2 & 1,000 & 0,771 & 0,675 & 0,619 & 0,583 & 0,558 & 0,524 & 0,512 & 0,510 & 0,513 & 0,518 & 0,526 \\
\hline 6,3 & 1,000 & 0,768 & 0,672 & 0,616 & 0,579 & 0,555 & 0,521 & 0,509 & 0,507 & 0,510 & 0,516 & 0,524 \\
\hline 6,4 & 1,000 & 0,766 & 0,669 & 0,613 & 0,576 & 0,551 & 0,518 & 0,506 & 0,504 & 0,508 &, 514 & 0,522 \\
\hline 6,5 & 1,000 & 0,763 & 0,666 & 0,610 & 0,573 & 0,548 & 0,515 & 0,503 & 0,502 & 0,506 &, 512 & 0,520 \\
\hline 6,6 & 1,000 & 0,761 & 0,663 & 0,606 & 0,570 & 0,545 & 0,512 & 0,501 & 0,500 & 0,504 & 510 & 0,518 \\
\hline 6,7 & 1,000 & 0,758 & 0,660 & 0,603 & 0,567 & 0,542 & 0,509 & 0,498 & 0,497 & 0,502 & 0,508 & 0,516 \\
\hline 6,8 & 1,000 & 0,756 & 0,657 & 0,600 & 0,564 & 0,539 & 0,506 & 0,496 & 0,495 & 0,500 & 0,507 & 0,515 \\
\hline 6,9 & 1,000 & 0,753 & 0,654 & 0,597 & 0,561 & 0,536 & 0,504 & 0,493 & 0,493 & 0,497 & 0,505 & 0,513 \\
\hline 7,0 & 1,000 & 0,751 & 0,652 & 0,594 & 0,558 & 0,533 & 0,501 & 0,491 & 0,491 & 0,495 & 0,503 & 0,511 \\
\hline 7,1 & 1,000 & 0,748 & 0,649 & 0,592 & 0,555 & 0,530 & 0,498 & 0,488 & 0,488 & 0,494 & 0,501 & 0,510 \\
\hline 7,2 & 1,000 & 0,746 & 0,646 & 0,589 & 0,552 & 0,527 & 0,496 & 0,486 & 0,486 & 0,492 & 0,499 & 0,508 \\
\hline 7,3 & 1,000 & 0,744 & 0,644 & 0,586 & 0,549 & 0,525 & 0,493 & 0,484 & 0,484 & 0,490 & 0,498 & 0,507 \\
\hline 7,4 & 1,000 & 0,741 & 0,641 & 0,583 & 0,546 & 0,522 & 0,491 & 0,481 & 0,482 & 0,488 & 0,496 & 0,505 \\
\hline 7,5 & 1,000 & 0,739 & 0,638 & 0,581 & 0,544 & 0,519 & 0,488 & 0,479 & 0,480 & 0,486 & 0,494 & 0,504 \\
\hline 7,6 & 1,000 & 0,737 & 0,636 & 0,578 & 0,541 & 0,517 & 0,486 & 0,477 & 0,478 & 0,484 & 0,493 & 0,502 \\
\hline 7,7 & 1,000 & 0,735 & 0,633 & 0,575 & 0,538 & 0,514 & 0,483 & 0,475 & 0,476 & 0,483 & 0,491 & 0,501 \\
\hline 7,8 & 1,000 & 0,733 & 0,631 & 0,573 & 0,536 & 0,512 & 0,481 & 0,473 & 0,474 & 0,481 & 0,490 & 0,499 \\
\hline 7,9 & 1,000 & 0,731 & 0,628 & 0,570 & 0,533 & 0,509 & 0,479 & 0,471 & 0,473 & 0,479 & 0,488 & 0,498 \\
\hline 8,0 & 1,000 & 0,729 & 0,626 & 0,568 & 0,531 & 0,507 & 0,476 & 0,468 & 0,471 & 0,478 & ,487 & 0,497 \\
\hline 8,1 & 1,000 & 0,726 & 0,624 & 0,565 & 0,528 & 0,504 & 0,474 & 66 & 0,469 & 0,476 & 0,485 & 0,495 \\
\hline 8,2 & 1,000 & 0,724 & 0,6 & 0,563 & 0,526 & 0,502 & 0 , & 0, & 0,467 & 0,474 & 0,484 & 0,494 \\
\hline 8,3 & 1,000 & 0,722 & 0,619 & 0,560 & 0,524 & 0,499 & 0 & 0,463 & 0,465 & 0,473 & 0,482 & 0,493 \\
\hline 8,4 & 1,000 & 0,721 & 0,617 & 0,558 & 0,521 & 0,497 & 0,468 & 0,461 & 0,464 & 0,471 & 0,481 & 0,491 \\
\hline 8,5 & 1,000 & 0,719 & 0,615 & 0,556 & 0,519 & 0,495 & 0,466 & 0,459 & 0,462 & 0,470 & 0,480 & 0,490 \\
\hline 8,6 & 1,000 & 0,717 & 0,612 & 0,553 & 0,517 & 0,493 & 0,463 & 0,457 & 0,460 & 0,468 & 0,478 & 0,489 \\
\hline 8,7 & 1,000 & 0,715 & 0,610 & 0,551 & 0,514 & 0,490 & 0,461 & 0,455 & 0,459 & 0,467 & 0,477 & 0,488 \\
\hline 8,8 & 1,000 & 0,713 & 0,608 & 0,549 & 0,512 & 0,488 & 0,459 & 0,453 & 0,457 & 0,466 & 0,476 & 0,487 \\
\hline 8,9 & 1,000 & 0,711 & 0,606 & 0,547 & 0,510 & 0,486 & 0,457 & 0,451 & 0,456 & 0,464 & 0,474 & 0,485 \\
\hline 9,0 & 1,000 & 0,709 & 0,604 & 0,545 & 0,508 & 0,484 & 0,455 & 0,450 & 0,454 & 0,463 & 0,473 & 0,484 \\
\hline 9,1 & 1,000 & 0,707 & 0,602 & 0,542 & 0,506 & 0,482 & 0,454 & 0,448 & 0,453 & 0,461 & 0,472 & 0,483 \\
\hline 9,2 & 1,000 & 0,706 & 0,600 & 0,540 & 0,503 & 0,480 & 0,452 & 0,446 & 0,451 & 0,460 & 0,471 & 0,482 \\
\hline 9,3 & 1,000 & 0,704 & 0,598 & 0,538 & 0,501 & 0,478 & 0,450 & 0,445 & 0,450 & 0,459 & 0,470 & 0,481 \\
\hline 9,4 & 1,000 & 0,702 & 0,596 & 0,536 & 0,499 & 0,476 & 0,448 & 0,443 & 0,448 & 0,457 &, 468 & 0,480 \\
\hline 9,5 & 1,000 & 0,700 & 0,594 & 0,534 & 97 & 474 & 446 & 0,441 & 0,447 &, 456 & 467 & 0,479 \\
\hline 9,6 & 1,000 & 0,699 & 0,592 & 0,532 & 0,495 & 0,472 & 0,444 & 0,440 & 0,445 & 0,455 & 0,466 & 0,478 \\
\hline 9,7 & 1,000 & 0,697 & 0,590 & 0,530 & 0,493 & 0,470 & 0,443 & 0,438 & 0,444 & 0,454 & 0,465 & 0,477 \\
\hline 9,8 & 1,000 & 0,695 & 0,588 & 0,528 & 0,491 & 0,468 & 0,441 & 0,437 & 0,442 & 0,452 & 0,464 & 0,476 \\
\hline $9, \mathrm{~S}$ & 1,000 & 0,694 & 0,586 & 0,526 & 0,489 & 0,466 & 0,439 & 0,435 & 0,441 & 0,451 & 0,463 & 0,475 \\
\hline 10,0 & 1,000 & 0,692 & 0,584 & 0,524 & 0,487 & 0,464 & 0,437 & 0,434 & 0,440 & 0,450 & 0,462 & 0,474 \\
\hline
\end{tabular}

Tabela 67 - Efetividade de temperatura para trocador de calor de fluxo cruzado com dois passes e um tubo por passe (2-1) - Caso 4A - trocador de calor ilustrado na Figura 90 do Anexo A

\begin{tabular}{|c|cccccccccccc|}
\hline NTU & 0,0 & 0,2 & 0,4 & 0,6 & 0,8 & 1,0 & 1,5 & 2,0 & 2,5 & 3,0 & 3,5 & 4,0 \\
\hline 0,0 & 0,000 & 0,000 & 0,000 & 0,000 & 0,000 & 0,000 & 0,000 & 0,000 & 0,000 & 0,000 & 0,000 & 0,000 \\
\hline & & & & & & & \multicolumn{7}{c}{ Continuação na próxima página } \\
\hline
\end{tabular}


Tabela 67 - continuação da página anterior

\begin{tabular}{|c|c|c|c|c|c|c|c|c|c|c|c|c|}
\hline${ }_{N T U}^{R}$ & 0,0 & 0,2 & 0,4 & 0,6 & 0,8 & 1,0 & 1,5 & 2,0 & 2,5 & 3,0 & 3,5 & 4,0 \\
\hline 0,1 & 0,095 & 0,094 & 0,094 & 0,093 & 0,092 & 0,091 & 0,089 & 0,087 & 0,085 & 0,083 & 0,081 & 0,079 \\
\hline 0,2 & 0,181 & 0,178 & 0,175 & 0,172 & 0,169 & 0,167 & 0,160 & 0,153 & 0,147 & 0,141 & 0,136 & 0,130 \\
\hline 0,3 & 0,259 & 0,253 & 0,247 & 0,241 & 0,236 & 0,230 & 0,217 & 0,205 & 0,193 & 0,183 & 0,173 & 0,164 \\
\hline 0,4 & 0,330 & 0,320 & 0,311 & 0,302 & 0,293 & 0,284 & 0,264 & 0,246 & 0,229 & 0,214 & 0,200 & 0,187 \\
\hline 0,5 & 0,394 & 0,380 & 0,367 & 0,355 & 0,343 & 0,331 & 0,304 & 0,279 & 0,257 & 0,237 & 0,219 & 0,203 \\
\hline 0,6 & 0,451 & 0,434 & 0,418 & 0,402 & 0,386 & 0,372 & 0,337 & 0,307 & 0,279 & 0,255 & 0,234 & 0,215 \\
\hline 0,7 & 0,503 & 0,483 & 0,463 & 0,443 & 0,425 & 0,407 & 0,366 & 0,329 & 0,297 & 0,269 & 0,244 & 0,223 \\
\hline 0,8 & 0,551 & 0,527 & 0,503 & 0,481 & 0,459 & 0,438 & 0,390 & 0,348 & 0,311 & 0,280 & 0,252 & 0,229 \\
\hline 0,9 & 0,593 & 0,566 & 0,540 & 0,514 & 0,489 & 0,466 & 0,411 & 0,364 & 0,323 & 0,288 & 0,259 & 0,233 \\
\hline 1,0 & 0,632 & 0,602 & 0,573 & 0,544 & 0,517 & 0,490 & 0,430 & 0,377 & 0,333 & 0,295 & 0,263 & 0,237 \\
\hline 1,1 & 0,667 & 0,635 & 0,603 & 0,571 & 0,541 & 0,512 & 0,446 & 0,389 & 0,341 & 0,301 & 0,267 & 0,239 \\
\hline 1,2 & 0,699 & 0,664 & 0,630 & 0,596 & 0,563 & 0,532 & 0,460 & 0,399 & 0,347 & 0,305 & 0,270 & 0,241 \\
\hline 1,3 & 0,727 & 0,691 & 0,654 & 0,618 & 0,583 & 0,549 & 0,472 & 0,407 & 0,353 & 0,309 & 0,273 & 0,243 \\
\hline 1,4 & 0,753 & 0,715 & 0,677 & 0,638 & 0,601 & 0,565 & 0,484 & 0,415 & 0,358 & 0,312 & 0,275 & 0,244 \\
\hline 1,5 & 0,777 & 0,737 & 0,697 & 0,657 & 0,618 & 0,580 & 0,493 & 0,421 & 0,362 & 0,315 & 0,276 & 0,245 \\
\hline 1,6 & 0,798 & 0,758 & 0,716 & 0,674 & 0,633 & 0,593 & 0,502 & 0,427 & 0,366 & 0,317 & 0,277 & 0,246 \\
\hline 1,7 & 0,817 & 0,776 & 0,733 & 0,689 & 0,646 & 0,605 & 0,510 & 0,432 & 0,369 & 0,318 & 0,278 & 0,246 \\
\hline 1,8 & 0,835 & 0,793 & 0,748 & 0,703 & 0,659 & 0,616 & 0,517 & 0,436 & 0,371 & 0,320 & 0,279 & 0,247 \\
\hline 1,9 & 0,850 & 0,808 & 0,763 & 0,716 & 0,670 & 0,626 & 0,524 & 0,440 & 0,374 & 0,321 & 0,280 & 0,247 \\
\hline 2,0 & 0,865 & 0,822 & 0,776 & 0,728 & 0,681 & 0,635 & 0,530 & 0,444 & 0,376 & 0,322 & 0,281 & 0,248 \\
\hline 2,1 & 0,878 & 0,835 & 0,788 & 0,739 & 0,691 & 0,643 & 0,535 & 0,447 & 0,377 & 0,323 & 0,281 & 0,248 \\
\hline 2,2 & 0,889 & 0,847 & 0,799 & 0,750 & 0,700 & 0,651 & 0,540 & 0,450 & 0,379 & 0,324 & 0,282 & 0,248 \\
\hline 2,3 & 0,900 & 0,857 & 0,810 & 0,759 & 0,708 & 0,658 & 0,544 & 0,452 & 0,380 & 0,325 & 0,282 & 0,248 \\
\hline 2,4 & 0,909 & 0,867 & 0,819 & 0,768 & 0,716 & 0,665 & 0,549 & 0,455 & 0,382 & 0,326 & 0,282 & 0,249 \\
\hline 2,5 & 0,918 & 0,876 & 0,828 & 0,776 & 0,723 & 0,671 & 0,552 & 0,457 & 0,383 & 0,326 & 0,283 & 0,249 \\
\hline 2,6 & 0,926 & 0,884 & 0,836 & 0,783 & 0,729 & 0,676 & 0,556 & 0,458 & 0,384 & 0,327 & 0,283 & 0,249 \\
\hline 2,7 & 0,933 & 0,892 & 0,843 & 0,790 & 0,736 & 0,682 & 0,559 & 0,460 & 0,385 & 0,327 & 0,283 & 0,249 \\
\hline 2,8 & 0,939 & 0,899 & 0,850 & 0,797 & 0,741 & 0,686 & 0,562 & 0,462 & 0,385 & 0,328 & 0,283 & 0,249 \\
\hline 2,9 & 0,945 & 0,905 & 0,857 & 0,803 & 0,747 & 0,691 & 0,564 & 0,463 & 0,386 & 0,328 & 0,284 & 0,249 \\
\hline 3,0 & 0,950 & 0,911 & 0,863 & 0,808 & 0,752 & 0,695 & 0,567 & 0,464 & 0,387 & 0,328 & 0,284 & 0,249 \\
\hline 3,1 & 0,955 & 0,917 & 0,868 & 0,814 & 0,756 & 0,699 & 0,569 & 0,466 & 0,387 & 0,328 & 0,284 & 0,249 \\
\hline 3,2 & 0,959 & 0,922 & 0,873 & 0,818 & 0,761 & 0,703 & 0,571 & 0,467 & 0,388 & 0,329 & 0,284 & 0,249 \\
\hline 3,3 & 0,963 & 0,926 & 0,878 & 0,823 & 0,765 & 0,706 & 0,573 & 0,468 & 0,388 & 0,329 & 0,284 & 0,249 \\
\hline 3,4 & 0,967 & 0,931 & 0,883 & 0,827 & 0,768 & 0,709 & 0,575 & 0,469 & 0,389 & 0,329 & 0,284 & 0,249 \\
\hline 3,5 & 0,970 & 0,934 & 0,887 & 0,831 & 0,772 & 0,712 & 0,577 & 0,470 & 0,389 & 0,329 & 0,284 & 0,249 \\
\hline 3,6 & 0,973 & 0,938 & 0,891 & 0,835 & 0,775 & 0,715 & 0,578 & 0,470 & 0,390 & 0,330 & 0,284 & 0,249 \\
\hline 3,7 & 0,975 & 0,941 & 0,894 & 0,838 & 0,778 & 0,718 & 0,580 & 0,471 & 0,390 & 0,330 & 0,284 & 0,249 \\
\hline 3,8 & 0,978 & 0,945 & 0,898 & 0,842 & 0,781 & 0,720 & 0,581 & 0,472 & 0,390 & 0,330 & 0,284 & 0,250 \\
\hline 3,9 & 0,980 & 0,947 & 0,901 & 0,845 & 0,784 & 0,723 & 0,582 & 0,472 & 0,390 & 0,330 & 0,284 & 0,250 \\
\hline 4,0 & 0,982 & 0,950 & 0,904 & 0,847 & 0,786 & 0,725 & 0,584 & 0,473 & 0,391 & 0,330 & 0,285 & 0,250 \\
\hline 4,1 & 0,983 & 0,952 & 0,906 & 0,850 & 0,789 & 0,727 & 0,585 & 0,473 & 0,391 & 0,330 & 0,285 & 0,250 \\
\hline 4,2 & 0,985 & 0,955 & 0,909 & 0,853 & 0,791 & 0,729 & 0,586 & 0,474 & 0,391 & 0,330 & 0,285 & 0,250 \\
\hline 4,3 & 0,986 & 0,957 & 0,911 & 0,855 & 0,793 & 0,730 & 0,587 & 0,474 & 0,391 & 0,330 & 0,285 & 0,250 \\
\hline 4,4 & 0,988 & 0,959 & 0,914 & 0,857 & 0,795 & 0,732 & 0,588 & 0,475 & 0,392 & 0,330 & 0,285 & 0,250 \\
\hline 4,5 & 0,989 & 0,961 & 0,916 & 0,859 & 0,797 & 0,734 & 0,589 & 0,475 & 0,392 & 0,331 & 0,285 & 0,250 \\
\hline 4,6 & 0,990 & 0,962 & 0,918 & 0,861 & 0,799 & 0,735 & 0,589 & 0,476 & 0,392 & 0,331 & 0,285 & 0,250 \\
\hline 4,7 & 0,991 & 0,964 & 0,919 & 0,863 & 0,801 & 0,737 & 0,590 & 0,476 & 0,392 & 0,331 & 0,285 & 0,250 \\
\hline 4,8 & 0,992 & 0,965 & 0,921 & 0,865 & 0,802 & 0,738 & 0,591 & 0,476 & 0,392 & 0,331 & 0,285 & 0,250 \\
\hline 4,9 & 0,993 & 0,967 & 0,923 & 0,866 & 0,804 & 0,739 & 0,592 & 0,477 & 0,392 & 0,331 & 0,285 & 0,250 \\
\hline 5,0 & 0,993 & 0,968 & 0,924 & 0,868 & 0,805 & 0,740 & 0,592 & 0,477 & 0,393 & 0,331 & 0,285 & 0,250 \\
\hline 5,1 & 0,994 & 0,969 & 0,926 & 0,869 & 0,806 & 0,741 & 0,593 & 0,477 & 0,393 & 0,331 & 0,285 & 0,250 \\
\hline 5,2 & 0,994 & 0,970 & 0,927 & 0,871 & 0,808 & 0,743 & 0,593 & 0,478 & 0,393 & 0,331 & 0,285 & 0,250 \\
\hline \multicolumn{10}{|c|}{$\begin{array}{ccc}0,393 & 0,331 & 0,285 \\
\text { Continuação na póxima página }\end{array}$} & 0,331 & 0,285 & 0,250 \\
\hline
\end{tabular}


Tabela 67 - continuação da página anterior

\begin{tabular}{|c|c|c|c|c|c|c|c|c|c|c|c|c|}
\hline $\mathrm{NTU}^{R}$ & 0,0 & 0,2 & 0,4 & 0,6 & 0,8 & 1,0 & 1,5 & 2,0 & 2,5 & 3,0 & 3,5 & 4,0 \\
\hline 5,4 & 0,995 & 0,972 & 0,929 & 0,873 & 0,810 & 0,744 & 0,594 & 0,478 & 0,393 & 0,331 & 0,285 & 0,250 \\
\hline 5,5 & 0,996 & 0,973 & 0,931 & 0,874 & 0,811 & 0,745 & 0,595 & 0,478 & 0,393 & 0,331 & 0,285 & 0,250 \\
\hline 5,6 & 0,996 & 0,974 & 0,932 & 0,876 & 0,812 & 0,746 & 0,595 & 0,478 & 0,393 & 0,331 & 0,285 & 0,250 \\
\hline 5,7 & 0,997 & 0,975 & 0,933 & 0,877 & 0,813 & 0,747 & 0,596 & 0,479 & 0,393 & 0,331 & 0,285 & 0,250 \\
\hline 5,8 & 0,997 & 0,975 & 0,934 & 0,878 & 0,814 & 0,748 & 0,596 & 0,479 & 0,393 & 0,331 & 0,285 & 0,250 \\
\hline 5,9 & 0,997 & 0,976 & 0,934 & 0,878 & 0,815 & 0,748 & 0,597 & 0,479 & 0,393 & 0,331 & 0,285 & 0,250 \\
\hline 6,0 & 0,998 & 0,977 & 0,935 & 0,879 & 0,815 & 0,749 & 0,597 & 0,479 & 0,393 & 0,331 & 0,285 & 0,250 \\
\hline 6,1 & 0,998 & 0,977 & 0,936 & 0,880 & 0,816 & 0,750 & 0,597 & 0,479 & 0,394 & 0,331 & 0,285 & 0,250 \\
\hline 6,2 & 0,998 & 0,978 & 0,937 & 0,881 & 0,817 & 0,750 & 0,598 & 0,479 & 0,394 & 0,331 & 0,285 & 0,250 \\
\hline 6,3 & 0,998 & 0,978 & 0,937 & 0,882 & 0,817 & 0,751 & 0,598 & 0,480 & 0,394 & 0,331 & 0,285 & 0,250 \\
\hline 6,4 & 0,998 & 0,979 & 0,938 & 0,882 & 0,818 & 0,751 & 0,598 & 0,480 & 0,394 & 0,331 & 0,285 & 0,250 \\
\hline 6,5 & 0,998 & 0,979 & 0,939 & 0,883 & 0,819 & 0,752 & 0,598 & 0,480 & 0,394 & 0,331 & 0,285 & 0,250 \\
\hline 6,6 & 0,999 & 0,980 & 0,939 & 0,884 & 0,819 & 0,752 & 0,599 & 0,480 & 0,394 & 0,331 & 0,285 & 0,250 \\
\hline 6,7 & 0,999 & 0,980 & 0,940 & 0,884 & 0,820 & 0,753 & 0,599 & 0,480 & 0,394 & 0,331 & 0,285 & 0,250 \\
\hline 6,8 & 0,999 & 0,980 & 0,940 & 0,885 & 0,820 & 0,753 & 0,599 & 0,480 & 0,394 & 0,331 & 0,285 & 0,250 \\
\hline 6,9 & 0,999 & 0,981 & 0,941 & 0,885 & 0,821 & 0,754 & 0,599 & 0,480 & 0,394 & 0,331 & 0,285 & 0,250 \\
\hline 7,0 & 0,999 & 0,981 & 0,941 & 0,886 & 0,821 & 0,754 & 0,600 & 0,480 & 0,394 & 0,331 & 0,285 & 0,250 \\
\hline 7,1 & 0,999 & 0,981 & 0,942 & 0,886 & 0,822 & 0,755 & 0,600 & 0,480 & 0,394 & 0,331 & 0,285 & 0,250 \\
\hline 7,2 & 0,999 & 0,982 & 0,942 & 0,887 & 0,822 & 0,755 & 0,600 & 0,480 & 0,394 & 0,331 & 0,285 & 0,250 \\
\hline 7,3 & 0,999 & 0,982 & 0,943 & 0,887 & 0,823 & 0,755 & 0,600 & 0,481 & 0,394 & 0,331 & 0,285 & 0,250 \\
\hline 7,4 & 0,999 & 0,982 & 0,943 & 0,887 & 0,823 & 0,756 & 0,600 & 0,481 & 0,394 & 0,331 & 0,285 & 0,250 \\
\hline 7,5 & 0,999 & 0,982 & 0,943 & 0,888 & 0,823 & 0,756 & 0,600 & 0,481 & 0,394 & 0,331 & 0,285 & 0,250 \\
\hline 7,6 & 0,999 & 0,983 & 0,944 & 0,888 & 0,824 & 0,756 & 0,601 & 0,481 & 0,394 & 0,331 & 0,285 & 0,250 \\
\hline 7,7 & 1,000 & 0,983 & 0,944 & 0,889 & 0,824 & 0,756 & 0,601 & 0,481 & 0,394 & 0,331 & 0,285 & 0,250 \\
\hline 7,8 & 1,000 & 0,983 & 0,944 & 0,889 & 0,824 & 0,757 & 0,601 & 0,481 & 0,394 & 0,332 & 0,285 & 0,250 \\
\hline 7,9 & 1,000 & 0,983 & 0,945 & 0,889 & 0,825 & 0,757 & 0,601 & 0,481 & 0,394 & 0,332 & 0,285 & 0,250 \\
\hline 8,0 & 1,000 & 0,984 & 0,945 & 0,890 & 0,825 & 0,757 & 0,601 & 0,481 & 0,394 & 0,332 & 0,285 & 0,250 \\
\hline 8,1 & 1,000 & 0,984 & 0,945 & 0,890 & 0,825 & 0,757 & 0,601 & 0,481 & 0,394 & 0,332 & 0,285 & 0,250 \\
\hline 8,2 & 1,000 & 0,984 & 0,945 & 0,890 & 0,825 & 0,758 & 0,601 & 0,481 & 0,394 & 0,332 & 0,285 & 0,250 \\
\hline 8,3 & 1,000 & 0,984 & 0,946 & 0,890 & 0,826 & 0,758 & 0,601 & 0,481 & 0,394 & 0,332 & 0,285 & 0,250 \\
\hline 8,4 & 1,000 & 0,984 & 0,946 & 0,891 & 0,826 & 0,758 & 0,602 & 0,481 & 0,394 & 0,332 & 0,285 & 0,250 \\
\hline 8,5 & 1,000 & 0,984 & 0,946 & 0,891 & 0,826 & 0,758 & 0,602 & 0,481 & 0,394 & 0,332 & 0,285 & 0,250 \\
\hline 8,6 & 1,000 & 0,984 & 0,946 & 0,891 & 0,826 & 0,758 & 0,602 & 0,481 & 0,394 & 0,332 & 0,285 & 0,250 \\
\hline 8,7 & 1,000 & 0,985 & 0,946 & 0,891 & 0,826 & 0,758 & 0,602 & 0,481 & 0,394 & 0,332 & 0,285 & 0,250 \\
\hline 8,8 & 1,000 & 0,985 & 0,947 & 0,891 & 0,827 & 0,759 & 0,602 & 0,481 & 0,394 & 0,332 & 0,285 & 0,250 \\
\hline 8,9 & 1,000 & 0,985 & 0,947 & 0,892 & 0,827 & 0,759 & 0,602 & 0,481 & 0,394 & 0,332 & 0,285 & 0,250 \\
\hline 9,0 & 1,000 & 0,985 & 0,947 & 0,892 & 0,827 & 0,759 & 0,602 & 0,481 & 0,394 & 0,332 & 0,285 & 0,250 \\
\hline 9,1 & 1,000 & 0,985 & 0,947 & 0,892 & 0,827 & 0,759 & 0,602 & 0,481 & 0,394 & 0,332 & 0,285 & 0,250 \\
\hline 9,2 & 1,000 & 0,985 & 0,947 & 0,892 & 0,827 & 0,759 & 0,602 & 0,481 & 0,394 & 0,332 & 0,285 & 0,250 \\
\hline 9,3 & 1,000 & 0,985 & 0,947 & 0,892 & 0,827 & 0,759 & 0,602 & 0,481 & 0,394 & 0,332 & 0,285 & 0,250 \\
\hline 9,4 & 1,000 & 0,985 & 0,947 & 0,892 & 0,827 & 0,759 & 0,602 & 0,482 & 0,394 & 0,332 & 0,285 & 0,250 \\
\hline 9,5 & 1,000 & 0,985 & 0,948 & 0,892 & 0,828 & 0,760 & 0,602 & 0,482 & 0,394 & 0,332 & 0,285 & 0,250 \\
\hline 9,6 & 1,000 & 0,985 & 0,948 & 0,893 & 0,828 & 0,760 & 0,602 & 0,482 & 0,394 & 0,332 & 0,285 & 0,250 \\
\hline 9,7 & 1,000 & 0,986 & 0,948 & 0,893 & 0,828 & 0,760 & 0,602 & 0,482 & 0,394 & 0,332 & 0,285 & 0,250 \\
\hline 9,8 & 1,000 & 0,986 & 0,948 & 0,893 & 0,828 & 0,760 & 0,603 & 0,482 & 0,394 & 0,332 & 0,285 & 0,250 \\
\hline 9,9 & 1,000 & 0,986 & 0,948 & 0,893 & 0,828 & 0,760 & 0,603 & 0,482 & 0,394 & 0,332 & 0,285 & 0,250 \\
\hline 10,0 & 1,000 & 0,986 & 0,948 & 0,893 & 0,828 & 0,760 & 0,603 & 0,482 & 0,395 & 0,332 & 0,285 & 0,250 \\
\hline
\end{tabular}


Tabela 68 - Fator de correção para trocador de calor de fluxo cruzado com dois passes e um tubo por passe (2-1) - Caso 4A - trocador de calor ilustrado na Figura 90 do Anexo A

\begin{tabular}{|c|c|c|c|c|c|c|c|c|c|c|c|c|}
\hline${ }_{\text {NTU }}{ }^{R}$ & 0,0 & 0,2 & 0,4 & 0,6 & 0,8 & 1,0 & 1,5 & 2,0 & 2,5 & 3,0 & 3,5 & 4,0 \\
\hline 0,0 & 1,000 & 1,000 & 1,000 & 1,000 & 1,000 & 1,000 & 1,000 & 1,000 & 1,000 & 1,000 & 1,000 & 1,000 \\
\hline 0,1 & 1,000 & 1,000 & 1,000 & 1,000 & 1,000 & 1,000 & 0,999 & 0,999 & 0,999 & 0,999 & 0,999 & 0,998 \\
\hline 0,2 & 1,000 & 1,000 & 0,999 & 0,999 & 0,999 & 0,998 & 0,998 & 0,997 & 0,996 & 0,995 & 0,994 & 0,994 \\
\hline 0,3 & 1,000 & 0,999 & 0,999 & 0,998 & 0,997 & 0,996 & 0,994 & 0,993 & 0,991 & 0,989 & 0,988 & 0,986 \\
\hline 0,4 & 1,000 & 0,999 & 0,997 & 0,996 & 0,995 & 0,993 & 0,990 & 0,987 & 0,984 & 0,981 & 0,979 & 0,976 \\
\hline 0,5 & 1,000 & 0,998 & 0,996 & 0,994 & 0,992 & 0,990 & 0,985 & 0,980 & 0,976 & 0,972 & 0,968 & 0,964 \\
\hline 0,6 & 1,000 & 0,997 & 0,994 & 0,991 & 0,988 & 0,985 & 0,979 & 0,972 & 0,966 & 0,961 & 0,956 & 0,951 \\
\hline 0,7 & 1,000 & 0,996 & 0,992 & 0,988 & 0,984 & 0,980 & 0,971 & 0,963 & 0,956 & 0,949 & 0,942 & 0,937 \\
\hline 0,8 & 1,000 & 0,995 & 0,989 & 0,984 & 0,979 & 0,975 & 0,963 & 0,953 & 0,944 & 0,936 & 0,928 & 0,921 \\
\hline 0,9 & 1,000 & 0,993 & 0,987 & 0,980 & 0,974 & 0,968 & 0,954 & 0,942 & 0,931 & 0,922 & 0,913 & 0,906 \\
\hline 1,0 & 1,000 & 0,992 & 0,984 & 0,976 & 0,968 & 0,961 & 0,945 & 0,931 & 0,918 & 0,907 & 0,898 & 0,890 \\
\hline 1,1 & 1,000 & 0,990 & 0,980 & 0,971 & 0,962 & 0,954 & 0,935 & 0,919 & 0,905 & 0,893 & 0,882 & 0,873 \\
\hline 1,2 & 1,000 & 0,988 & 0,976 & 0,966 & 0,955 & 0,946 & 0,924 & 0,906 & 0,891 & 0,878 & 0,867 & 0,857 \\
\hline 1,3 & 1,000 & 0,986 & 0,973 & 0,960 & 0,948 & 0,937 & 0,913 & 0,893 & 0,877 & 0,863 & 0,851 & 0,841 \\
\hline 1,4 & 1,000 & 0,984 & 0,968 & 0,954 & 0,941 & 0,928 & 0,902 & 0,880 & 0,862 & 0,847 & 0,835 & 0,825 \\
\hline 1,5 & 1,000 & 0,981 & 0,964 & 0,948 & 0,933 & 0,919 & 0,890 & 0,867 & 0,848 & 0,832 & 0,819 & 0,809 \\
\hline 1,6 & 1,000 & 0,979 & 0,959 & 0,941 & 0,924 & 0,910 & 0,878 & 0,853 & 0,833 & 0,817 & 0,804 & 0,793 \\
\hline 1,7 & 1,000 & 0,976 & 0,954 & 0,934 & 0,916 & 0,900 & 0,866 & 0,840 & 0,819 & 0,802 & 0,789 & 0,777 \\
\hline 1,8 & 1,000 & 0,973 & 0,948 & 0,927 & 0,907 & 0,890 & 0,854 & 0,826 & 0,805 & 0,787 & 0,774 & 0,762 \\
\hline 1,9 & 1,000 & 0,970 & 0,943 & 0,919 & 0,898 & 0,879 & 0,841 & 0,813 & 0,790 & 0,773 & 0,759 & 0,747 \\
\hline 2,0 & 1,000 & 0,967 & 0,937 & 0,911 & 0,889 & 0,869 & 0,829 & 0,799 & 0,776 & 0,758 & 0,744 & 0,733 \\
\hline 2,1 & 1,000 & 0,963 & 0,931 & 0,903 & 0,879 & 0,858 & 0,816 & 0,786 & 0,762 & 0,744 & 0,730 & 0,718 \\
\hline 2,2 & 1,000 & 0,960 & 0,925 & 0,895 & 0,869 & 0,847 & 0,804 & 0,772 & 0,749 & 0,730 & 0,716 & 0,704 \\
\hline 2,3 & 1,000 & 0,956 & 0,918 & 0,887 & 0,860 & 0,836 & 0,792 & 0,759 & 0,735 & 0,717 & 0,702 & 0,691 \\
\hline 2,4 & 1,000 & 0,952 & 0,912 & 0,878 & 0,850 & 0,826 & 0,779 & 0,746 & 0,722 & 0,704 & 0,689 & 0,677 \\
\hline 2,5 & 1,000 & 0,948 & 0,905 & 0,869 & 0,840 & 0,815 & 0,767 & 0,734 & 0,709 & 0,690 & 0,676 & 0,664 \\
\hline 2,6 & 1,000 & 0,944 & 0,898 & 0,860 & 0,829 & 0,804 & 0,755 & 0,721 & 0,696 & 0,678 & 0,663 & 0,652 \\
\hline 2,7 & 1,000 & 0,939 & 0,891 & 0,851 & 0,819 & 0,793 & 0,743 & 0,709 & 0,684 & 0,665 & 0,651 & 0,639 \\
\hline 2,8 & 1,000 & 0,935 & 0,883 & 0,842 & 0,809 & 0,782 & 0,731 & 0,697 & 0,672 & 0,653 & 0,639 & 0,627 \\
\hline 2,9 & 1,000 & 0,930 & 0,876 & 0,833 & 0,799 & 0,771 & 0,720 & 0,685 & 0,660 & 0,641 & 0,627 & 0,616 \\
\hline 3,0 & 1,000 & 0,926 & 0,868 & 0,824 & 0,789 & 0,760 & 0,708 & 0,673 & 0,648 & 0,630 & 0,615 & 0,604 \\
\hline 3,1 & 1,000 & 0,921 & 0,861 & 0,815 & 0,779 & 0,749 & 0,697 & 0,662 & 0,637 & 0,618 & 0,604 & 0,593 \\
\hline 3,2 & 1,000 & 0,915 & 0,853 & 0,805 & 0,768 & 0,739 & 0,686 & 0,650 & 0,626 & 0,607 & 0,593 & 0,582 \\
\hline 3,3 & 1,000 & 0,910 & 0,845 & 0,796 & 0,758 & 0,728 & 0,675 & 0,639 & 0,615 & 0,596 & 0,583 & 0,572 \\
\hline 3,4 & 1,000 & 0,905 & 0,837 & 0,787 & 0,748 & 0,718 & 0,664 & 0,629 & 0,604 & 0,586 & 0,572 & 0,561 \\
\hline 3,5 & 1,000 & 0,899 & 0,829 & 0,777 & 0,738 & 0,708 & 0,653 & 0,618 & 0,594 & 0,576 & 0,562 & 0,552 \\
\hline 3,6 & 1,000 & 0,894 & 0,821 & 0,768 & 0,728 & 0,697 & 0,643 & 0,608 & 0,583 & 0,566 & 0,552 & 0,542 \\
\hline 3,7 & 1,000 & 0,888 & 0,813 & 0,759 & 0,719 & 0,687 & 0,633 & 0,598 & 0,574 & 0,556 & 0,543 & 0,532 \\
\hline 3,8 & 1,000 & 0,882 & 0,804 & 0,750 & 0,709 & 0,677 & 0,623 & 0,588 & 0,564 & 0,546 & 0,533 & 0,523 \\
\hline 3,9 & 1,000 & 0,876 & 0,796 & 0,740 & 0,699 & 0,668 & 0,613 & 0,578 & 0,554 & 0,537 & 0,524 & 0,514 \\
\hline 4,0 & 1,000 & 0,870 & 0,788 & 0,731 & 0,690 & 0,658 & 0,603 & 0,569 & 0,545 & 0,528 & 0,515 & 0,505 \\
\hline 4,1 & 1,000 & 0,864 & 0,780 & 0,722 & 0,680 & 0,649 & 0,594 & 0,560 & 0,536 & 0,519 & 0,507 & 0,497 \\
\hline 4,2 & 1,000 & 0,858 & 0,771 & 0,713 & 0,671 & 0,639 & 0,585 & 0,551 & 0,528 & 0,511 & 0,498 & 0,489 \\
\hline 4,3 & 1,000 & 0,852 & 0,763 & 0,704 & 0,662 & 0,630 & 0,576 & 0,542 & 0,519 & 0,502 & 0,490 & 0,481 \\
\hline 4,4 & 1,000 & 0,845 & 0,755 & 0,696 & 0,653 & 0,621 & 0,567 & 0,533 & 0,511 & 0,494 & 0,482 & 0,473 \\
\hline 4,5 & 1,000 & 0,839 & 0,747 & 0,687 & 0,644 & 0,612 & 0,558 & 0,525 & 0,503 & 0,486 & 0,474 & 0,465 \\
\hline 4,6 & 1,000 & 0,832 & 0,739 & 0,678 & 0,636 & 0,604 & 0,550 & 0,517 & 0,495 & 0,479 & 0,467 & 0,458 \\
\hline 4,7 & 1,000 & 0,826 & 0,730 & 0,670 & 0,627 & 0,595 & 0,542 & 0,509 & 0,487 & 0,471 & 0,459 & 0,450 \\
\hline 4,8 & 1,000 & 0,819 & 0,722 & 0,661 & 0,618 & 0,587 & 0,534 & 0,501 & 0,479 & 0,464 & 0,452 & 0,443 \\
\hline
\end{tabular}


Tabela 68 - continuação da página anterior

\begin{tabular}{|c|c|c|c|c|c|c|c|c|c|c|c|c|}
\hline $\mathrm{NTU}^{R}$ & 0,0 & 0,2 & 0,4 & 0,6 & 0,8 & 1,0 & 1,5 & 2,0 & 2,5 & 3,0 & 3,5 & 4,0 \\
\hline 4,9 & 1,000 & 0,812 & 0,714 & 0,653 & 0,610 & 0,578 & 0,526 & 0,494 & 0,472 & 0,456 & 0,445 & 0,436 \\
\hline 5,0 & 1,000 & 0,805 & 0,706 & 0,645 & 0,602 & 0,570 & 0,518 & 0,486 & 0,465 & 0,449 & 0,438 & 0,429 \\
\hline 5,1 & 1,000 & 0,799 & 0,698 & 0,636 & 0,594 & 0,562 & 0,510 & 0,479 & 0,458 & 0,443 & 0,431 & 0,423 \\
\hline 5,2 & 1,000 & 0,792 & 0,690 & 0,628 & 0,586 & 0,555 & 0,503 & 0,472 & 0,451 & 0,436 & 0,425 & 0,417 \\
\hline 5,3 & 1,000 & 0,785 & 0,683 & 0,621 & 0,578 & 0,547 & 0,496 & 0,465 & 0,444 & 0,429 & 0,419 & 0,410 \\
\hline 5,4 & 1,000 & 0,778 & 0,675 & 0,613 & 0,570 & 0,539 & 0,489 & 0,458 & 0,438 & 0,423 & 0,412 & 0,404 \\
\hline 5,5 & 1,000 & 0,771 & 0,667 & 0,605 & 0,563 & 0,532 & 0,482 & 0,451 & 0,431 & 0,417 & 0,406 & 0,398 \\
\hline 5,6 & 1,000 & 0,764 & 0,660 & 0,598 & 0,556 & 0,525 & 0,475 & 0,445 & 0,425 & 0,411 & 0,400 & 0,392 \\
\hline 5,7 & 1,000 & 0,757 & 0,652 & 0,590 & 0,548 & 0,518 & 0,468 & 0,439 & 0,419 & 0,405 & 0,395 & 0,387 \\
\hline 5,8 & 1,000 & 0,750 & 0,645 & 0,583 & 0,541 & 0,511 & 0,462 & 0,433 & 0,413 & 0,399 & 0,389 & 0,381 \\
\hline 5,9 & 1,000 & 0,743 & 0,637 & 0,576 & 0,534 & 0,504 & 0,456 & 0,427 & 0,407 & 0,394 & 0,384 & 0,376 \\
\hline 6,0 & 1,000 & 0,737 & 0,630 & 0,569 & 0,527 & 0,498 & 0,450 & 0,421 & 0,402 & 0,388 & 0,378 & 0,371 \\
\hline 6,1 & 1,000 & 0,730 & 0,623 & 0,562 & 0,521 & 0,491 & 0,443 & 0,415 & 0,396 & 0,383 & 0,373 & 0,365 \\
\hline 6,2 & 1,000 & 0,723 & 0,616 & 0,555 & 0,514 & 0,485 & 0,438 & 0,409 & 0,391 & 0,378 & 0,368 & 0,360 \\
\hline 6,3 & 1,000 & 0,716 & 0,609 & 0,548 & 0,508 & 0,479 & 0,432 & 0,404 & 0,385 & 0,372 & 0,363 & 0,356 \\
\hline 6,4 & 1,000 & 0,709 & 0,602 & 0,541 & 0,501 & 0,472 & 0,426 & 0,398 & 0,380 & 0,367 & 0,358 & 0,351 \\
\hline 6,5 & 1,000 & 0,703 & 0,595 & 0,535 & 0,495 & 0,466 & 0,421 & 0,393 & 0,375 & 0,363 & 0,353 & 0,346 \\
\hline 6,6 & 1,000 & 0,696 & 0,588 & 0,528 & 0,489 & 0,461 & 0,415 & 0,388 & 0,370 & 0,358 & 0,349 & 0,341 \\
\hline 6,7 & 1,000 & 0,689 & 0,582 & 0,522 & 0,483 & 0,455 & 0,410 & 0,383 & 0,365 & 0,353 & 0,344 & 0,337 \\
\hline 6,8 & 1,000 & 0,682 & 0,575 & 0,516 & 0,477 & 0,449 & 0,405 & 0,378 & 0,361 & 0,349 & 0,339 & 0,333 \\
\hline 6,9 & 1,000 & 0,676 & 0,569 & 0,510 & 0,471 & 0,444 & 0,400 & 0,373 & 0,356 & 0,344 & 0,335 & 0,328 \\
\hline 7,0 & 1,000 & 0,669 & 0,563 & 0,504 & 0,466 & 0,438 & 0,395 & 0,369 & 0,352 & 0,340 & 0,331 & 0,324 \\
\hline 7,1 & 1,000 & 0,663 & 0,556 & 0,498 & 0,460 & 0,433 & 0,390 & 0,364 & 0,347 & 0,335 & 0,327 & 0,320 \\
\hline 7,2 & 1,000 & 0,656 & 0,550 & 0,492 & 0,455 & 0,428 & 0,385 & 0,360 & 0,343 & 0,331 & 0,323 & 0,316 \\
\hline 7,3 & 1,000 & 0,650 & 0,544 & 0,487 & 0,449 & 0,423 & 0,380 & 0,355 & 0,339 & 0,327 & 0,319 & 0,312 \\
\hline 7,4 & 1,000 & 0,644 & 0,538 & 0,481 & 0,444 & 0,418 & 0,376 & 0,351 & 0,335 & 0,323 & 0,315 & 0,308 \\
\hline 7,5 & 1,000 & 0,638 & 0,532 & 0,476 & 0,439 & 0,413 & 0,371 & 0,347 & 0,331 & 0,319 & 0,311 & 0,305 \\
\hline 7,6 & 1,000 & 0,631 & 0,527 & 0,470 & 0,434 & 0,408 & 0,367 & 0,343 & 0,327 & 0,315 & 0,307 & 0,301 \\
\hline 7,7 & 0,999 & 0,625 & 0,521 & 0,465 & 0,429 & 0,403 & 0,362 & 0,338 & 0,323 & 0,312 & 0,304 & 0,297 \\
\hline 7,8 & 0,999 & 0,619 & 0,515 & 0,460 & 0,424 & 0,399 & 0,358 & 0,335 & 0,319 & 0,308 & 0,300 & 0,294 \\
\hline 7,9 & 0,999 & 0,613 & 0,510 & 0,455 & 0,419 & 0,394 & 0,354 & 0,331 & 0,315 & 0,304 & 0,297 & 0,290 \\
\hline 8,0 & 0,999 & 0,607 & 0,505 & 0,450 & 0,415 & 0,390 & 0,350 & 0,327 & 0,312 & 0,301 & 0,293 & 0,287 \\
\hline 8,1 & 0,999 & 0,601 & 0,499 & 0,445 & 0,410 & 0,385 & 0,346 & 0,323 & 0,308 & 0,297 & 0,290 & 0,284 \\
\hline 8,2 & 0,999 & 0,596 & 0,494 & 0,440 & 0,406 & 0,381 & 0,342 & 0,319 & 0,305 & 0,294 & 0,286 & 0,281 \\
\hline 8,3 & 0,999 & 0,590 & 0,489 & 0,436 & 0,401 & 0,377 & 0,338 & 0,316 & 0,301 & 0,291 & 0,283 & 0,277 \\
\hline 8,4 & 0,999 & 0,584 & 0,484 & 0,431 & 0,397 & 0,373 & 0,335 & 0,312 & 0,298 & 0,288 & 0,280 & 0,274 \\
\hline 8,5 & 0,999 & 0,579 & 0,479 & 0,426 & 0,393 & 0,369 & 0,331 & 0,309 & 0,295 & 0,284 & 0,277 & 0,271 \\
\hline 8,6 & 0,999 & 0,573 & 0,474 & 0,422 & 0,388 & 0,365 & 0,327 & 0,306 & 0,291 & 0,281 & 0,274 & 0,268 \\
\hline 8,7 & 0,999 & 0,568 & 0,469 & 0,418 & 0,384 & 0,361 & 0,324 & 0,302 & 0,288 & 0,278 & 0,271 & 0,265 \\
\hline 8,8 & 0,999 & 0,562 & 0,464 & 0,413 & 0,380 & 0,357 & 0,321 & 0,299 & 0,285 & 0,275 & 0,268 & 0,263 \\
\hline 8,9 & 0,999 & 0,557 & 0,460 & 0,409 & 0,376 & 0,353 & 0,317 & 0,296 & 0,282 & 0,272 & 0,265 & 0,260 \\
\hline 9,0 & 0,999 & 0,552 & 0,455 & 0,405 & 0,373 & 0,350 & 0,314 & 0,293 & 0,279 & 0,269 & 0,262 & 0,257 \\
\hline 9,1 & 0,999 & 0,547 & 0,451 & 0,401 & 0,369 & 0,346 & 0,311 & 0,290 & 0,276 & 0,267 & 0,260 & 0,254 \\
\hline 9,2 & 0,999 & 0,542 & 0,446 & 0,397 & 0,365 & 0,343 & 0,307 & 0,287 & 0,273 & 0,264 & 0,257 & 0,252 \\
\hline 9,3 & 0,999 & 0,537 & 0,442 & 0,393 & 0,361 & 0,339 & 0,304 & 0,284 & 0,271 & 0,261 & 0,254 & 0,249 \\
\hline 9,4 & 0,999 & 0,532 & 0,438 & 0,389 & 0,358 & 0,336 & 0,301 & 0,281 & 0,268 & 0,259 & 0,252 & 0,247 \\
\hline 9,5 & 0,999 & 0,527 & 0,433 & 0,385 & 0,354 & 0,332 & 0,298 & 0,278 & 0,265 & 0,256 & 0,249 & 0,244 \\
\hline 9,6 & 0,999 & 0,522 & 0,429 & 0,381 & 0,351 & 0,329 & 0,295 & 0,275 & 0,262 & 0,253 & 0,247 & 0,242 \\
\hline 9,7 & 0,999 & 0,517 & 0,425 & 0,378 & 0,347 & 0,326 & 0,292 & 0,273 & 0,260 & 0,251 & 0,244 & 0,239 \\
\hline 9,8 & 0,999 & 0,513 & 0,421 & 0,374 & 0,344 & 0,323 & 0,289 & 0,270 & 0,257 & 0,248 & 0,242 & 0,237 \\
\hline 9,9 & 0,999 & 0,508 & 0,417 & 0,370 & 0,341 & 0,320 & 0,287 & 0,267 & 0,255 & 0,246 & 0,240 & 0,235 \\
\hline 10,0 & 0,999 & 0,504 & 0,413 & 0,367 & 0,337 & 0,317 & 0,284 & 0,265 & 0,252 & 0,244 & 0,237 & 0,232 \\
\hline
\end{tabular}


Tabela 69 - Efetividade de temperatura para trocador de calor de fluxo cruzado com dois passes e dois tubos por passe (2-2) - Caso 4A - trocador de calor ilustrado na Figura 99 do Anexo A

\begin{tabular}{|c|c|c|c|c|c|c|c|c|c|c|c|c|}
\hline $\mathrm{NTU}^{R}$ & 0,0 & 0,2 & 0,4 & 0,6 & 0,8 & 1,0 & 1,5 & 2,0 & 2,5 & 3,0 & 3,5 & 4,0 \\
\hline 0,0 & 1,000 & 1,000 & 1,000 & 1,000 & 1,000 & 1,000 & 1,000 & 1,000 & 1,000 & 1,000 & 1,000 & 1,000 \\
\hline 0,1 & 1,000 & 1,000 & 1,000 & 1,000 & 1,000 & 1,000 & 0,999 & 0,999 & 0,999 & 0,999 & 0,999 & 0,998 \\
\hline 0,2 & 1,000 & 1,000 & 0,999 & 0,999 & 0,999 & 0,998 & 0,998 & 0,997 & 0,996 & 0,995 & 0,994 & 0,994 \\
\hline 0,3 & 1,000 & 0,999 & 0,999 & 0,998 & 0,997 & 0,996 & 0,995 & 0,993 & 0,991 & 0,990 & 0,988 & 0,986 \\
\hline 0,4 & 1,000 & 0,999 & 0,997 & 0,996 & 0,995 & 0,994 & 0,991 & 0,988 & 0,985 & 0,982 & 0,979 & 0,977 \\
\hline 0,5 & 1,000 & 0,998 & 0,996 & 0,994 & 0,992 & 0,990 & 0,986 & 0,981 & 0,977 & 0,973 & 0,969 & 0,966 \\
\hline 0,6 & 1,000 & 0,997 & 0,994 & 0,992 & 0,989 & 0,986 & 0,980 & 0,974 & 0,968 & 0,963 & 0,958 & 0,954 \\
\hline 0,7 & 1,000 & 0,996 & 0,992 & 0,989 & 0,985 & 0,982 & 0,973 & 0,966 & 0,958 & 0,952 & 0,946 & 0,941 \\
\hline 0,8 & 1,000 & 0,995 & 0,990 & 0,985 & 0,981 & 0,976 & 0,966 & 0,957 & 0,948 & 0,940 & 0,934 & 0,927 \\
\hline 0,9 & 1,000 & 0,994 & 0,988 & 0,982 & 0,976 & 0,971 & 0,958 & 0,947 & 0,937 & 0,928 & 0,921 & 0,914 \\
\hline 1,0 & 1,000 & 0,992 & 0,985 & 0,978 & 0,971 & 0,965 & 0,950 & 0,937 & 0,926 & 0,916 & 0,908 & 0,900 \\
\hline 1,1 & 1,000 & 0,991 & 0,982 & 0,974 & 0,966 & 0,958 & 0,941 & 0,927 & 0,914 & 0,903 & 0,894 & 0,887 \\
\hline 1,2 & 1,000 & 0,989 & 0,979 & 0,969 & 0,960 & 0,951 & 0,932 & 0,916 & 0,902 & 0,891 & 0,881 & 0,873 \\
\hline 1,3 & 1,000 & 0,988 & 0,976 & 0,965 & 0,954 & 0,944 & 0,923 & 0,905 & 0,891 & 0,878 & 0,868 & 0,860 \\
\hline 1,4 & 1,000 & 0,986 & 0,972 & 0,960 & 0,948 & 0,937 & 0,914 & 0,894 & 0,879 & 0,866 & 0,856 & 0,847 \\
\hline 1,5 & 1,000 & 0,984 & 0,969 & 0,954 & 0,941 & 0,929 & 0,904 & 0,884 & 0,867 & 0,854 & 0,843 & 0,834 \\
\hline 1,6 & 1,000 & 0,982 & 0,965 & 0,949 & 0,935 & 0,922 & 0,894 & 0,873 & 0,856 & 0,842 & 0,831 & 0,822 \\
\hline 1,7 & 1,000 & 0,980 & 0,961 & 0,943 & 0,928 & 0,914 & 0,885 & 0,862 & 0,844 & 0,830 & 0,819 & 0,810 \\
\hline 1,8 & 1,000 & 0,977 & 0,957 & 0,938 & 0,921 & 0,906 & 0,875 & 0,851 & 0,833 & 0,819 & 0,807 & 0,799 \\
\hline 1,9 & 1,000 & 0,975 & 0,952 & 0,932 & 0,914 & 0,898 & 0,865 & 0,841 & 0,822 & 0,807 & 0,796 & 0,787 \\
\hline 2,0 & 1,000 & 0,973 & 0,948 & 0,926 & 0,907 & 0,890 & 0,855 & 0,830 & 0,811 & 0,796 & 0,785 & 0,776 \\
\hline 2,1 & 1,000 & 0,970 & 0,943 & 0,920 & 0,899 & 0,881 & 0,846 & 0,820 & 0,800 & 0,786 & 0,774 & 0,766 \\
\hline 2,2 & 1,000 & 0,967 & 0,939 & 0,914 & 0,892 & 0,873 & 0,836 & 0,810 & 0,790 & 0,775 & 0,764 & 0,755 \\
\hline 2,3 & 1,000 & 0,965 & 0,934 & 0,907 & 0,885 & 0,865 & 0,827 & 0,800 & 0,780 & 0,765 & 0,754 & 0,745 \\
\hline 2,4 & 1,000 & 0,962 & 0,929 & 0,901 & 0,877 & 0,857 & 0,817 & 0,790 & 0,770 & 0,755 & 0,744 & 0,735 \\
\hline 2,5 & 1,000 & 0,959 & 0,924 & 0,895 & 0,870 & 0,849 & 0,808 & 0,780 & 0,760 & 0,745 & 0,734 & 0,726 \\
\hline 2,6 & 1,000 & 0,956 & 0,919 & 0,888 & 0,862 & 0,840 & 0,799 & 0,771 & 0,750 & 0,736 & 0,725 & 0,717 \\
\hline 2,7 & 1,000 & 0,953 & 0,914 & 0,882 & 0,855 & 0,832 & 0,790 & 0,761 & 0,741 & 0,726 & 0,716 & 0,708 \\
\hline 2,8 & 1,000 & 0,950 & 0,909 & 0,875 & 0,847 & 0,824 & 0,781 & 0,752 & 0,732 & 0,717 & 0,707 & 0,699 \\
\hline 2,9 & 1,000 & 0,947 & 0,904 & 0,869 & 0,840 & 0,816 & 0,773 & 0,743 & 0,723 & 0,709 & 0,698 & 0,690 \\
\hline 3,0 & 1,000 & 0,944 & 0,899 & 0,862 & 0,833 & 0,808 & 0,764 & 0,735 & 0,714 & 0,700 & 0,689 & 0,682 \\
\hline 3,1 & 1,000 & 0,941 & 0,894 & 0,856 & 0,825 & 0,801 & 0,756 & 0,726 & 0,706 & 0,691 & 0,681 & 0,674 \\
\hline 3,2 & 1,000 & 0,938 & 0,888 & 0,849 & 0,818 & 0,793 & 0,747 & 0,718 & 0,697 & 0,683 & 0,673 & 0,666 \\
\hline 3,3 & 1,000 & 0,934 & 0,883 & 0,843 & 0,811 & 0,785 & 0,739 & 0,709 & 0,689 & 0,675 & 0,665 & 0,658 \\
\hline 3,4 & 1,000 & 0,931 & 0,878 & 0,836 & 0,804 & 0,778 & 0,731 & 0,701 & 0,681 & 0,667 & 0,657 & 0,650 \\
\hline 3,5 & 1,000 & 0,928 & 0,872 & 0,830 & 0,797 & 0,770 & 0,723 & 0,693 & 0,673 & 0,659 & 0,650 & 0,643 \\
\hline 3,6 & 1,000 & 0,924 & 0,867 & 0,823 & 0,790 & 0,763 & 0,715 & 0,685 & 0,666 & 0,652 & 0,642 & 0,636 \\
\hline 3,7 & 1,000 & 0,921 & 0,862 & 0,817 & 0,783 & 0,755 & 0,708 & 0,678 & 0,658 & 0,645 & 0,635 & 0,628 \\
\hline 3,8 & 1,000 & 0,917 & 0,856 & 0,811 & 0,776 & 0,748 & 0,700 & 0,670 & 0,651 & 0,637 & 0,628 & 0,621 \\
\hline 3,9 & 1,000 & 0,914 & 0,851 & 0,804 & 0,769 & 0,741 & 0,693 & 0,663 & 0,643 & 0,630 & 0,621 & 0,615 \\
\hline 4,0 & 1,000 & 0,910 & 0,846 & 0,798 & 0,762 & 0,734 & 0,686 & 0,656 & 0,636 & 0,623 & 0,614 & 0,608 \\
\hline 4,1 & 1,000 & 0,907 & 0,840 & 0,792 & 0,755 & 0,727 & 0,678 & 0,649 & 0,629 & 0,616 & 0,607 & 0,601 \\
\hline 4,2 & 1,000 & 0,903 & 0,835 & 0,786 & 0,749 & 0,720 & 0,671 & 0,642 & 0,622 & 0,610 & 0,601 & 0,595 \\
\hline 4,3 & 1,000 & 0,899 & 0,829 & 0,779 & 0,742 & 0,713 & 0,665 & 0,635 & 0,616 & 0,603 & 0,594 & 0,588 \\
\hline 4,4 & 1,000 & 0,896 & 0,824 & 0,773 & 0,736 & 0,707 & 0,658 & 0,628 & 0,609 & 0,597 & 0,588 & 0,582 \\
\hline 4,5 & 1,000 & 0,892 & 0,819 & 0,767 & 0,729 & 0,700 & 0,651 & 0,622 & 0,603 & 0,590 & 0,582 & 0,576 \\
\hline 4,6 & 1,000 & 0,888 & 0,813 & 0,761 & 0,723 & 0,694 & 0,644 & 0,615 & 0,596 & 0,584 & 0,576 & 0,570 \\
\hline 4,7 & 1,000 & 0,884 & 0,808 & 0,755 & 0,717 & 0,687 & 0,638 & 0,609 & 0,590 & 0,578 & 0,570 & 0,564 \\
\hline 4,8 & 1,000 & 0,880 & 0,803 & 0,749 & 0,710 & 0,681 & 0,632 & 0,602 & 0,584 & 0,572 & 0,564 & 0,558 \\
\hline
\end{tabular}


Tabela 69 - continuação da página anterior

\begin{tabular}{|c|c|c|c|c|c|c|c|c|c|c|c|c|}
\hline${ }_{N T U}^{R}$ & 0,0 & 0,2 & 0,4 & 0,6 & 0,8 & 1,0 & 1,5 & 2,0 & 2,5 & 3,0 & 3,5 & 4,0 \\
\hline 4,9 & 1,000 & 0,877 & 0,798 & 0,744 & 0,704 & 0,675 & 0,625 & 0,596 & 0,578 & 0,566 & 0,558 & 0,553 \\
\hline 5,0 & 1,000 & 0,873 & 0,792 & 0,738 & 0,698 & 0,668 & 0,619 & 0,590 & 0,572 & 0,560 & 0,552 & 0,547 \\
\hline 5,1 & 1,000 & 0,869 & 0,787 & 0,732 & 0,692 & 0,662 & 0,613 & 0,584 & 0,566 & 0,555 & 0,547 & 0,542 \\
\hline 5,2 & 1,000 & 0,865 & 0,782 & 0,726 & 0,686 & 0,656 & 0,607 & 0,578 & 0,561 & 0,549 & 0,541 & 0,536 \\
\hline 5,3 & 1,000 & 0,861 & 0,777 & 0,721 & 0,681 & 0,650 & 0,601 & 0,573 & 0,555 & 0,544 & 0,536 & 0,531 \\
\hline 5,4 & 1,000 & 0,857 & 0,772 & 0,715 & 0,675 & 0,645 & 0,595 & 0,567 & 0,549 & 0,538 & 0,531 & 0,526 \\
\hline 5,5 & 1,000 & 0,854 & 0,767 & 0,710 & 0,669 & 0,639 & 0,590 & 0,561 & 0,544 & 0,533 & 0,525 & 0,520 \\
\hline 5,6 & 1,000 & 0,850 & 0,762 & 0,704 & 0,663 & 0,633 & 0,584 & 0,556 & 0,539 & 0,528 & 0,520 & 0,515 \\
\hline 5,7 & 1,000 & 0,846 & 0,757 & 0,699 & 0,658 & 0,628 & 0,579 & 0,551 & 0,533 & 0,522 & 0,515 & 0,510 \\
\hline 5,8 & 1,000 & 0,842 & 0,752 & 0,693 & 0,652 & 0,622 & 0,573 & 0,545 & 0,528 & 0,517 & 0,510 & 0,505 \\
\hline 5,9 & 1,000 & 0,838 & 0,747 & 0,688 & 0,647 & 0,617 & 0,568 & 0,540 & 0,523 & 0,512 & 0,505 & 0,501 \\
\hline 6,0 & 1,000 & 0,834 & 0,742 & 0,683 & 0,641 & 0,611 & 0,563 & 0,535 & 0,518 & 0,507 & 0,500 & 0,496 \\
\hline 6,1 & 1,000 & 0,830 & 0,737 & 0,677 & 0,636 & 0,606 & 0,557 & 0,530 & 0,513 & 0,503 & 0,496 & 0,491 \\
\hline 6,2 & 1,000 & 0,826 & 0,732 & 0,672 & 0,631 & 0,601 & 0,552 & 0,525 & 0,508 & 0,498 & 0,491 & 0,486 \\
\hline 6,3 & 1,000 & 0,822 & 0,727 & 0,667 & 0,626 & 0,595 & 0,547 & 0,520 & 0,503 & 0,493 & 0,486 & 0,482 \\
\hline 6,4 & 1,000 & 0,818 & 0,722 & 0,662 & 0,621 & 0,590 & 0,542 & 0,515 & 0,499 & 0,489 & 0,482 & 0,477 \\
\hline 6,5 & 1,000 & 0,814 & 0,718 & 0,657 & 0,616 & 0,585 & 0,537 & 0,510 & 0,494 & 0,484 & 0,477 & 0,473 \\
\hline 6,6 & 1,000 & 0,810 & 0,713 & 0,652 & 0,611 & 0,580 & 0,532 & 0,506 & 0,490 & 0,479 & 0,473 & 0,469 \\
\hline 6,7 & 1,000 & 0,807 & 0,708 & 0,647 & 0,606 & 0,575 & 0,528 & 0,501 & 0,485 & 0,475 & 0,469 & 0,464 \\
\hline 6,8 & 1,000 & 0,803 & 0,703 & 0,642 & 0,601 & 0,570 & 0,523 & 0,496 & 0,481 & 0,471 & 0,464 & 0,460 \\
\hline 6,9 & 1,000 & 0,799 & 0,699 & 0,638 & 0,596 & 0,566 & 0,518 & 0,492 & 0,476 & 0,466 & 0,460 & 0,456 \\
\hline 7,0 & 1,000 & 0,795 & 0,694 & 0,633 & 0,591 & 0,561 & 0,514 & 0,488 & 0,472 & 0,462 & 0,456 & 0,452 \\
\hline 7,1 & 1,000 & 0,791 & 0,690 & 0,628 & 0,586 & 0,556 & 0,509 & 0,483 & 0,468 & 0,458 & 0,452 & 0,448 \\
\hline 7,2 & 1,000 & 0,787 & 0,685 & 0,623 & 0,582 & 0,552 & 0,505 & 0,479 & 0,463 & 0,454 & 0,448 & 0,444 \\
\hline 7,3 & 1,000 & 0,783 & 0,681 & 0,619 & 0,577 & 0,547 & 0,500 & 0,475 & 0,459 & 0,450 & 0,444 & 0,440 \\
\hline 7,4 & 1,000 & 0,779 & 0,676 & 0,614 & 0,573 & 0,543 & 0,496 & 0,470 & 0,455 & 0,446 & 0,440 & 0,436 \\
\hline 7,5 & 1,000 & 0,775 & 0,672 & 0,610 & 0,568 & 0,538 & 0,492 & 0,466 & 0,451 & 0,442 & 0,436 & 0,432 \\
\hline 7,6 & 1,000 & 0,772 & 0,667 & 0,605 & 0,564 & 0,534 & 0,487 & 0,462 & 0,447 & 0,438 & 0,432 & 0,428 \\
\hline 7,7 & 1,000 & 0,768 & 0,663 & 0,601 & 0,559 & 0,529 & 0,483 & 0,458 & 0,443 & 0,434 & 0,428 & 0,425 \\
\hline 7,8 & 1,000 & 0,764 & 0,659 & 0,596 & 0,555 & 0,525 & 0,479 & 0,454 & 0,440 & 0,431 & 0,425 & 0,421 \\
\hline 7,9 & 1,000 & 0,760 & 0,654 & 0,592 & 0,550 & 0,521 & 0,475 & 0,450 & 0,436 & 0,427 & 0,421 & 0,417 \\
\hline 8,0 & 1,000 & 0,756 & 0,650 & 0,588 & 0,546 & 0,517 & 0,471 & 0,447 & 0,432 & 0,423 & 0,417 & 0,414 \\
\hline 8,1 & 1,000 & 0,752 & 0,646 & 0,583 & 0,542 & 0,513 & 0,467 & 0,443 & 0,428 & 0,420 & 0,414 & 0,410 \\
\hline 8,2 & 1,000 & 0,749 & 0,642 & 0,579 & 0,538 & 0,508 & 0,463 & 0,439 & 0,425 & 0,416 & 0,410 & 0,407 \\
\hline 8,3 & 1,000 & 0,745 & 0,637 & 0,575 & 0,534 & 0,504 & 0,460 & 0,435 & 0,421 & 0,412 & 0,407 & 0,403 \\
\hline 8,4 & 1,000 & 0,741 & 0,633 & 0,571 & 0,530 & 0,500 & 0,456 & 0,432 & 0,418 & 0,409 & 0,404 & 0,400 \\
\hline 8,5 & 1,000 & 0,737 & 0,629 & 0,567 & 0,526 & 0,497 & 0,452 & 0,428 & 0,414 & 0,406 & 0,400 & 0,397 \\
\hline 8,6 & 1,000 & 0,734 & 0,625 & 0,563 & 0,522 & 0,493 & 0,448 & 0,425 & 0,411 & 0,402 & 0,397 & 0,393 \\
\hline 8,7 & 1,000 & 0,730 & 0,621 & 0,559 & 0,518 & 0,489 & 0,445 & 0,421 & 0,407 & 0,399 & 0,394 & 0,390 \\
\hline 8,8 & 1,000 & 0,726 & 0,617 & 0,555 & 0,514 & 0,485 & 0,441 & 0,418 & 0,404 & 0,396 & 0,390 & 0,387 \\
\hline 8,9 & 1,000 & 0,722 & 0,613 & 0,551 & 0,510 & 0,481 & 0,437 & 0,414 & 0,401 & 0,392 & 0,387 & 0,384 \\
\hline 9,0 & 1,000 & 0,719 & 0,609 & 0,547 & 0,506 & 0,478 & 0,434 & 0,411 & 0,397 & 0,389 & 0,384 & 0,381 \\
\hline 9,1 & 1,000 & 0,715 & 0,605 & 0,543 & 0,502 & 0,474 & 0,431 & 0,407 & 0,394 & 0,386 & 0,381 & 0,378 \\
\hline 9,2 & 1,000 & 0,711 & 0,601 & 0,539 & 0,499 & 0,470 & 0,427 & 0,404 & 0,391 & 0,383 & 0,378 & 0,375 \\
\hline 9,3 & 1,000 & 0,708 & 0,598 & 0,535 & 0,495 & 0,467 & 0,424 & 0,401 & 0,388 & 0,380 & 0,375 & 0,372 \\
\hline 9,4 & 1,000 & 0,704 & 0,594 & 0,532 & 0,491 & 0,463 & 0,420 & 0,398 & 0,385 & 0,377 & 0,372 & 0,369 \\
\hline 9,5 & 1,000 & 0,700 & 0,590 & 0,528 & 0,488 & 0,460 & 0,417 & 0,395 & 0,382 & 0,374 & 0,369 & 0,366 \\
\hline 9,6 & 1,000 & 0,697 & 0,586 & 0,524 & 0,484 & 0,456 & 0,414 & 0,392 & 0,379 & 0,371 & 0,366 & 0,363 \\
\hline 9,7 & 1,000 & 0,693 & 0,582 & 0,521 & 0,481 & 0,453 & 0,411 & 0,388 & 0,376 & 0,368 & 0,363 & 0,360 \\
\hline 9,8 & 1,000 & 0,690 & 0,579 & 0,517 & 0,477 & 0,449 & 0,408 & 0,385 & 0,373 & 0,365 & 0,360 & 0,357 \\
\hline 9,9 & 1,000 & 0,686 & 0,575 & 0,513 & 0,474 & 0,446 & 0,404 & 0,382 & 0,370 & 0,362 & 0,357 & 0,354 \\
\hline 10,0 & 1,000 & 0,682 & 0,571 & 0,510 & 0,470 & 0,443 & 0,401 & 0,380 & 0,367 & 0,359 & 0,355 & 0,352 \\
\hline
\end{tabular}


Tabela 70 - Fator de correção para trocador de calor de fluxo cruzado com dois passes e dois tubos por passe (2-2) - Caso 4A - trocador de calor ilustrado na Figura 99 do Anexo $\mathrm{A}$

\begin{tabular}{|c|c|c|c|c|c|c|c|c|c|c|c|c|}
\hline${ }_{N T U}^{R}$ & 0,0 & 0,2 & 0,4 & 0,6 & 0,8 & 1,0 & 1,5 & 2,0 & 2,5 & 3,0 & 3,5 & 4,0 \\
\hline 0,0 & 0,000 & 0,000 & 0,000 & 0,000 & 0,000 & 0,000 & 0,000 & 0,000 & 0,000 & 0,000 & 0,000 & 0,000 \\
\hline 0,1 & 0,095 & 0,094 & 0,094 & 0,093 & 0,092 & 0,091 & 0,089 & 0,087 & 0,085 & 0,083 & 0,081 & 0,079 \\
\hline 0,2 & 0,181 & 0,178 & 0,175 & 0,172 & 0,169 & 0,167 & 0,160 & 0,153 & 0,147 & 0,141 & 0,136 & 0,130 \\
\hline 0,3 & 0,259 & 0,253 & 0,247 & 0,241 & 0,236 & 0,230 & 0,217 & 0,205 & 0,194 & 0,183 & 0,173 & 0,164 \\
\hline 0,4 & 0,330 & 0,320 & 0,311 & 0,302 & 0,293 & 0,284 & 0,264 & 0,246 & 0,229 & 0,214 & 0,200 & 0,187 \\
\hline 0,5 & 0,394 & 0,380 & 0,367 & 0,355 & 0,343 & 0,331 & 0,304 & 0,279 & 0,257 & 0,237 & 0,219 & 0,203 \\
\hline 0,6 & 0,451 & 0,434 & 0,418 & 0,402 & 0,387 & 0,372 & 0,338 & 0,307 & 0,279 & 0,255 & 0,234 & 0,215 \\
\hline 0,7 & 0,503 & 0,483 & 0,463 & 0,444 & 0,425 & 0,407 & 0,366 & 0,329 & 0,297 & 0,269 & 0,245 & 0,223 \\
\hline 0,8 & 0,551 & 0,527 & 0,504 & 0,481 & 0,459 & 0,439 & 0,391 & 0,348 & 0,312 & 0,280 & 0,253 & 0,229 \\
\hline 0,9 & 0,593 & 0,567 & 0,540 & 0,515 & 0,490 & 0,466 & 0,412 & 0,365 & 0,324 & 0,289 & 0,259 & 0,234 \\
\hline 1,0 & 0,632 & 0,602 & 0,573 & 0,545 & 0,517 & 0,491 & 0,431 & 0,378 & 0,334 & 0,296 & 0,264 & 0,237 \\
\hline 1,1 & 0,667 & 0,635 & 0,603 & 0,572 & 0,542 & 0,513 & 0,447 & 0,390 & 0,342 & 0,301 & 0,268 & 0,240 \\
\hline 1,2 & 0,699 & 0,665 & 0,630 & 0,597 & 0,564 & 0,533 & 0,461 & 0,400 & 0,349 & 0,306 & 0,271 & 0,242 \\
\hline 1,3 & 0,727 & 0,691 & 0,655 & 0,620 & 0,585 & 0,551 & 0,474 & 0,409 & 0,355 & 0,310 & 0,273 & 0,243 \\
\hline 1,4 & 0,753 & 0,716 & 0,678 & 0,640 & 0,603 & 0,567 & 0,486 & 0,417 & 0,360 & 0,313 & 0,275 & 0,245 \\
\hline 1,5 & 0,777 & 0,738 & 0,699 & 0,659 & 0,620 & 0,582 & 0,496 & 0,423 & 0,364 & 0,316 & 0,277 & 0,246 \\
\hline 1,6 & 0,798 & 0,759 & 0,718 & 0,676 & 0,635 & 0,596 & 0,505 & 0,429 & 0,368 & 0,318 & 0,278 & 0,246 \\
\hline 1,7 & 0,817 & 0,777 & 0,735 & 0,692 & 0,650 & 0,608 & 0,514 & 0,435 & 0,371 & 0,320 & 0,279 & 0,247 \\
\hline 1,8 & 0,835 & 0,794 & 0,751 & 0,707 & 0,663 & 0,620 & 0,522 & 0,439 & 0,374 & 0,321 & 0,280 & 0,247 \\
\hline 1,9 & 0,850 & 0,810 & 0,766 & 0,720 & 0,675 & 0,630 & 0,528 & 0,444 & 0,376 & 0,323 & 0,281 & 0,248 \\
\hline 2,0 & 0,865 & 0,824 & 0,779 & 0,733 & 0,686 & 0,640 & 0,535 & 0,447 & 0,378 & 0,324 & 0,282 & 0,248 \\
\hline 2,1 & 0,878 & 0,837 & 0,792 & 0,745 & 0,697 & 0,649 & 0,541 & 0,451 & 0,380 & 0,325 & 0,282 & 0,248 \\
\hline 2,2 & 0,889 & 0,849 & 0,803 & 0,755 & 0,706 & 0,658 & 0,546 & 0,454 & 0,382 & 0,326 & 0,283 & 0,249 \\
\hline 2,3 & 0,900 & 0,860 & 0,814 & 0,765 & 0,715 & 0,666 & 0,551 & 0,457 & 0,383 & 0,327 & 0,283 & 0,249 \\
\hline 2,4 & 0,909 & 0,870 & 0,824 & 0,775 & 0,724 & 0,673 & 0,556 & 0,459 & 0,385 & 0,327 & 0,283 & 0,249 \\
\hline 2,5 & 0,918 & 0,879 & 0,833 & 0,783 & 0,731 & 0,680 & 0,560 & 0,462 & 0,386 & 0,328 & 0,284 & 0,249 \\
\hline 2,6 & 0,926 & 0,887 & 0,842 & 0,792 & 0,739 & 0,686 & 0,564 & 0,464 & 0,387 & 0,328 & 0,284 & 0,249 \\
\hline 2,7 & 0,933 & 0,895 & 0,850 & 0,799 & 0,746 & 0,692 & 0,567 & 0,466 & 0,388 & 0,329 & 0,284 & 0,249 \\
\hline 2,8 & 0,939 & 0,903 & 0,857 & 0,806 & 0,752 & 0,698 & 0,571 & 0,468 & 0,389 & 0,329 & 0,284 & 0,249 \\
\hline 2,9 & 0,945 & 0,909 & 0,864 & 0,813 & 0,758 & 0,703 & 0,574 & 0,469 & 0,389 & 0,330 & 0,284 & 0,250 \\
\hline 3,0 & 0,950 & 0,915 & 0,871 & 0,819 & 0,764 & 0,708 & 0,577 & 0,471 & 0,390 & 0,330 & 0,285 & 0,250 \\
\hline 3,1 & 0,955 & 0,921 & 0,877 & 0,825 & 0,770 & 0,713 & 0,580 & 0,472 & 0,391 & 0,330 & 0,285 & 0,250 \\
\hline 3,2 & 0,959 & 0,926 & 0,882 & 0,831 & 0,775 & 0,717 & 0,582 & 0,474 & 0,391 & 0,331 & 0,285 & 0,250 \\
\hline 3,3 & 0,963 & 0,931 & 0,888 & 0,836 & 0,780 & 0,722 & 0,585 & 0,475 & 0,392 & 0,331 & 0,285 & 0,250 \\
\hline 3,4 & 0,967 & 0,935 & 0,893 & 0,841 & 0,784 & 0,726 & 0,587 & 0,476 & 0,392 & 0,331 & 0,285 & 0,250 \\
\hline 3,5 & 0,970 & 0,940 & 0,897 & 0,846 & 0,789 & 0,729 & 0,589 & 0,477 & 0,393 & 0,331 & 0,285 & 0,250 \\
\hline 3,6 & 0,973 & 0,943 & 0,902 & 0,850 & 0,793 & 0,733 & 0,592 & 0,478 & 0,393 & 0,331 & 0,285 & 0,250 \\
\hline 3,7 & 0,975 & 0,947 & 0,906 & 0,855 & 0,797 & 0,736 & 0,593 & 0,479 & 0,394 & 0,331 & 0,285 & 0,250 \\
\hline 3,8 & 0,978 & 0,950 & 0,910 & 0,859 & 0,801 & 0,740 & 0,595 & 0,480 & 0,394 & 0,332 & 0,285 & 0,250 \\
\hline 3,9 & 0,980 & 0,953 & 0,913 & 0,862 & 0,804 & 0,743 & 0,597 & 0,480 & 0,394 & 0,332 & 0,285 & 0,250 \\
\hline 4,0 & 0,982 & 0,956 & 0,917 & 0,866 & 0,808 & 0,746 & 0,599 & 0,481 & 0,395 & 0,332 & 0,285 & 0,250 \\
\hline 4,1 & 0,983 & 0,959 & 0,920 & 0,869 & 0,811 & 0,749 & 0,600 & 0,482 & 0,395 & 0,332 & 0,285 & 0,250 \\
\hline 4,2 & 0,985 & 0,961 & 0,923 & 0,873 & 0,814 & 0,752 & 0,602 & 0,483 & 0,395 & 0,332 & 0,285 & 0,250 \\
\hline 4,3 & 0,986 & 0,963 & 0,926 & 0,876 & 0,817 & 0,754 & 0,603 & 0,483 & 0,395 & 0,332 & 0,285 & 0,250 \\
\hline 4,4 & 0,988 & 0,966 & 0,929 & 0,879 & 0,820 & 0,757 & 0,605 & 0,484 & 0,396 & 0,332 & 0,285 & 0,250 \\
\hline 4,5 & 0,989 & 0,967 & 0,931 & 0,882 & 0,823 & 0,759 & 0,606 & 0,484 & 0,396 & 0,332 & 0,285 & 0,250 \\
\hline 4,6 & 0,990 & 0,969 & 0,934 & 0,884 & 0,825 & 0,761 & 0,607 & 0,485 & 0,396 & 0,332 & 0,285 & 0,250 \\
\hline 4,7 & 0,991 & 0,971 & 0,936 & 0,887 & 0,828 & 0,764 & 0,608 & 0,485 & 0,396 & 0,332 & 0,285 & 0,250 \\
\hline 4,8 & 0,992 & 0,973 & 0,938 & 0,889 & 0,830 & 0,766 & 0,609 & 0,486 & 0,396 & 0,332 & 0,285 & 0,250 \\
\hline
\end{tabular}


Tabela 70 - continuação da página anterior

\begin{tabular}{|c|c|c|c|c|c|c|c|c|c|c|c|c|}
\hline${ }_{N T U}^{R}$ & 0,0 & 0,2 & 0,4 & 0,6 & 0,8 & 1,0 & 1,5 & 2,0 & 2,5 & 3,0 & 3,5 & 4,0 \\
\hline 4,9 & 0,993 & 0,974 & 0,940 & 0,892 & 0,833 & 0,768 & 0,611 & 0,486 & 0,397 & 0,332 & 0,285 & 0,250 \\
\hline 5,0 & 0,993 & 0,975 & 0,942 & 0,894 & 0,835 & 0,770 & 0,612 & 0,487 & 0,397 & 0,333 & 0,286 & 0,250 \\
\hline 5,1 & 0,994 & 0,977 & 0,944 & 0,896 & 0,837 & 0,772 & 0,613 & 0,487 & 0,397 & 0,333 & 0,286 & 0,250 \\
\hline 5,2 & 0,994 & 0,978 & 0,946 & 0,898 & 0,839 & 0,773 & 0,614 & 0,487 & 0,397 & 0,333 & 0,286 & 0,250 \\
\hline 5,3 & 0,995 & 0,979 & 0,948 & 0,900 & 0,841 & 0,775 & 0,614 & 0,488 & 0,397 & 0,333 & 0,286 & 0,250 \\
\hline 5,4 & 0,995 & 0,980 & 0,949 & 0,902 & 0,843 & 0,777 & 0,615 & 0,488 & 0,397 & 0,333 & 0,286 & 0,250 \\
\hline 5,5 & 0,996 & 0,981 & 0,951 & 0,904 & 0,845 & 0,778 & 0,616 & 0,488 & 0,397 & 0,333 & 0,286 & 0,250 \\
\hline 5,6 & 0,996 & 0,982 & 0,952 & 0,906 & 0,846 & 0,780 & 0,617 & 0,489 & 0,397 & 0,333 & 0,286 & 0,250 \\
\hline 5,7 & 0,997 & 0,983 & 0,953 & 0,907 & 0,848 & 0,782 & 0,618 & 0,489 & 0,397 & 0,333 & 0,286 & 0,250 \\
\hline 5,8 & 0,997 & 0,984 & 0,955 & 0,909 & 0,850 & 0,783 & 0,618 & 0,489 & 0,398 & 0,333 & 0,286 & 0,250 \\
\hline 5,9 & 0,997 & 0,985 & 0,956 & 0,911 & 0,851 & 0,784 & 0,619 & 0,489 & 0,398 & 0,333 & 0,286 & 0,250 \\
\hline 6,0 & 0,998 & 0,985 & 0,957 & 0,912 & 0,853 & 0,786 & 0,620 & 0,490 & 0,398 & 0,333 & 0,286 & 0,250 \\
\hline 6,1 & 0,998 & 0,986 & 0,958 & 0,913 & 0,854 & 0,787 & 0,620 & 0,490 & 0,398 & 0,333 & 0,286 & 0,250 \\
\hline 6,2 & 0,998 & 0,987 & 0,960 & 0,915 & 0,856 & 0,788 & 0,621 & 0,490 & 0,398 & 0,333 & 0,286 & 0,250 \\
\hline 6,3 & 0,998 & 0,987 & 0,961 & 0,916 & 0,857 & 0,790 & 0,622 & 0,490 & 0,398 & 0,333 & 0,286 & 0,250 \\
\hline 6,4 & 0,998 & 0,988 & 0,962 & 0,917 & 0,858 & 0,791 & 0,622 & 0,491 & 0,398 & 0,333 & 0,286 & 0,250 \\
\hline 6,5 & 0,998 & 0,988 & 0,963 & 0,919 & 0,860 & 0,792 & 0,623 & 0,491 & 0,398 & 0,333 & 0,286 & 0,250 \\
\hline 6,6 & 0,999 & 0,989 & 0,963 & 0,920 & 0,861 & 0,793 & 0,623 & 0,491 & 0,398 & 0,333 & 0,286 & 0,250 \\
\hline 6,7 & 0,999 & 0,989 & 0,964 & 0,921 & 0,862 & 0,794 & 0,624 & 0,491 & 0,398 & 0,333 & 0,286 & 0,250 \\
\hline 6,8 & 0,999 & 0,990 & 0,965 & 0,922 & 0,863 & 0,795 & 0,624 & 0,491 & 0,398 & 0,333 & 0,286 & 0,250 \\
\hline 6,9 & 0,999 & 0,990 & 0,966 & 0,923 & 0,864 & 0,796 & 0,625 & 0,491 & 0,398 & 0,333 & 0,286 & 0,250 \\
\hline 7,0 & 0,999 & 0,991 & 0,967 & 0,924 & 0,866 & 0,797 & 0,625 & 0,492 & 0,398 & 0,333 & 0,286 & 0,250 \\
\hline 7,1 & 0,999 & 0,991 & 0,968 & 0,925 & 0,867 & 0,798 & 0,626 & 0,492 & 0,398 & 0,333 & 0,286 & 0,250 \\
\hline 7,2 & 0,999 & 0,991 & 0,968 & 0,926 & 0,868 & 0,799 & 0,626 & 0,492 & 0,398 & 0,333 & 0,286 & 0,250 \\
\hline 7,3 & 0,999 & 0,992 & 0,969 & 0,927 & 0,869 & 0,800 & 0,627 & 0,492 & 0,398 & 0,333 & 0,286 & 0,250 \\
\hline 7,4 & 0,999 & 0,992 & 0,970 & 0,928 & 0,870 & 0,801 & 0,627 & 0,492 & 0,398 & 0,333 & 0,286 & 0,250 \\
\hline 7,5 & 0,999 & 0,992 & 0,970 & 0,929 & 0,870 & 0,801 & 0,627 & 0,492 & 0,398 & 0,333 & 0,286 & 0,250 \\
\hline 7,6 & 0,999 & 0,993 & 0,971 & 0,930 & 0,871 & 0,802 & 0,628 & 0,492 & 0,399 & 0,333 & 0,286 & 0,250 \\
\hline 7,7 & 1,000 & 0,993 & 0,971 & 0,931 & 0,872 & 0,803 & 0,628 & 0,493 & 0,399 & 0,333 & 0,286 & 0,250 \\
\hline 7,8 & 1,000 & 0,993 & 0,972 & 0,931 & 0,873 & 0,804 & 0,628 & 0,493 & 0,399 & 0,333 & 0,286 & 0,250 \\
\hline 7,9 & 1,000 & 0,993 & 0,973 & 0,932 & 0,874 & 0,804 & 0,629 & 0,493 & 0,399 & 0,333 & 0,286 & 0,250 \\
\hline 8,0 & 1,000 & 0,994 & 0,973 & 0,933 & 0,875 & 0,805 & 0,629 & 0,493 & 0,399 & 0,333 & 0,286 & 0,250 \\
\hline 8,1 & 1,000 & 0,994 & 0,974 & 0,934 & 0,875 & 0,806 & 0,629 & 0,493 & 0,399 & 0,333 & 0,286 & 0,250 \\
\hline 8,2 & 1,000 & 0,994 & 0,974 & 0,934 & 0,876 & 0,807 & 0,630 & 0,493 & 0,399 & 0,333 & 0,286 & 0,250 \\
\hline 8,3 & 1,000 & 0,994 & 0,974 & 0,935 & 0,877 & 0,807 & 0,630 & 0,493 & 0,399 & 0,333 & 0,286 & 0,250 \\
\hline 8,4 & 1,000 & 0,994 & 0,975 & 0,936 & 0,878 & 0,808 & 0,630 & 0,493 & 0,399 & 0,333 & 0,286 & 0,250 \\
\hline 8,5 & 1,000 & 0,995 & 0,975 & 0,936 & 0,878 & 0,808 & 0,631 & 0,493 & 0,399 & 0,333 & 0,286 & 0,250 \\
\hline 8,6 & 1,000 & 0,995 & 0,976 & 0,937 & 0,879 & 0,809 & 0,631 & 0,493 & 0,399 & 0,333 & 0,286 & 0,250 \\
\hline 8,7 & 1,000 & 0,995 & 0,976 & 0,937 & 0,880 & 0,810 & 0,631 & 0,494 & 0,399 & 0,333 & 0,286 & 0,250 \\
\hline 8,8 & 1,000 & 0,995 & 0,977 & 0,938 & 0,880 & 0,810 & 0,631 & 0,494 & 0,399 & 0,333 & 0,286 & 0,250 \\
\hline 8,9 & 1,000 & 0,995 & 0,977 & 0,939 & 0,881 & 0,811 & 0,632 & 0,494 & 0,399 & 0,333 & 0,286 & 0,250 \\
\hline 9,0 & 1,000 & 0,995 & 0,977 & 0,939 & 0,881 & 0,811 & 0,632 & 0,494 & 0,399 & 0,333 & 0,286 & 0,250 \\
\hline 9,1 & 1,000 & 0,996 & 0,978 & 0,940 & 0,882 & 0,812 & 0,632 & 0,494 & 0,399 & 0,333 & 0,286 & 0,250 \\
\hline 9,2 & 1,000 & 0,996 & 0,978 & 0,940 & 0,883 & 0,812 & 0,632 & 0,494 & 0,399 & 0,333 & 0,286 & 0,250 \\
\hline 9,3 & 1,000 & 0,996 & 0,978 & 0,941 & 0,883 & 0,813 & 0,633 & 0,494 & 0,399 & 0,333 & 0,286 & 0,250 \\
\hline 9,4 & 1,000 & 0,996 & 0,979 & 0,941 & 0,884 & 0,813 & 0,633 & 0,494 & 0,399 & 0,333 & 0,286 & 0,250 \\
\hline 9,5 & 1,000 & 0,996 & 0,979 & 0,941 & 0,884 & 0,814 & 0,633 & 0,494 & 0,399 & 0,333 & 0,286 & 0,250 \\
\hline 9,6 & 1,000 & 0,996 & 0,979 & 0,942 & 0,885 & 0,814 & 0,633 & 0,494 & 0,399 & 0,333 & 0,286 & 0,250 \\
\hline 9,7 & 1,000 & 0,996 & 0,979 & 0,942 & 0,885 & 0,815 & 0,633 & 0,494 & 0,399 & 0,333 & 0,286 & 0,250 \\
\hline 9,8 & 1,000 & 0,996 & 0,980 & 0,943 & 0,886 & 0,815 & 0,633 & 0,494 & 0,399 & 0,333 & 0,286 & 0,250 \\
\hline 9,9 & 1,000 & 0,997 & 0,980 & 0,943 & 0,886 & 0,815 & 0,634 & 0,494 & 0,399 & 0,333 & 0,286 & 0,250 \\
\hline 10,0 & 1,000 & 0,997 & 0,980 & 0,944 & 0,886 & 0,816 & 0,634 & 0,494 & 0,399 & 0,333 & 0,286 & 0,250 \\
\hline
\end{tabular}


Tabela 71 - Efetividade de temperatura para trocador de calor de fluxo cruzado com dois passes e quatro tubos por passe (2-4) - Caso 4A - trocador de calor ilustrado na Figura 103 do Anexo $\mathrm{A}$

\begin{tabular}{|c|c|c|c|c|c|c|c|c|c|c|c|c|}
\hline $\mathrm{NTU}^{R}$ & 0,0 & 0,2 & 0,4 & 0,6 & 0,8 & 1,0 & 1,5 & 2,0 & 2,5 & 3,0 & 3,5 & 4,0 \\
\hline 0,0 & 0,000 & 0,000 & 0,000 & 0,000 & 0,000 & 0,000 & 0,000 & 0,000 & 0,000 & 0,000 & 0,000 & 0,000 \\
\hline 0,1 & 0,095 & 0,094 & 0,094 & 0,093 & 0,092 & 0,091 & 0,089 & 0,087 & 0,085 & 0,083 & 0,081 & 0,079 \\
\hline 0,2 & 0,181 & 0,178 & 0,175 & 0,172 & 0,169 & 0,167 & 0,160 & 0,153 & 0,147 & 0,141 & 0,136 & 0,130 \\
\hline 0,3 & 0,259 & 0,253 & 0,247 & 0,241 & 0,236 & 0,230 & 0,217 & 0,205 & 0,194 & 0,183 & 0,173 & 0,164 \\
\hline 0,4 & 0,330 & 0,320 & 0,311 & 0,302 & 0,293 & 0,284 & 0,264 & 0,246 & 0,229 & 0,214 & 0,200 & 0,187 \\
\hline 0,5 & 0,394 & 0,380 & 0,367 & 0,355 & 0,343 & 0,331 & 0,304 & 0,279 & 0,257 & 0,237 & 0,219 & 0,203 \\
\hline 0,6 & 0,451 & 0,434 & 0,418 & 0,402 & 0,387 & 0,372 & 0,338 & 0,307 & 0,279 & 0,255 & 0,234 & 0,215 \\
\hline 0,7 & 0,503 & 0,483 & 0,463 & 0,444 & 0,425 & 0,407 & 0,366 & 0,330 & 0,297 & 0,269 & 0,245 & 0,223 \\
\hline 0,8 & 0,551 & 0,527 & 0,504 & 0,481 & 0,459 & 0,439 & 0,391 & 0,349 & 0,312 & 0,280 & 0,253 & 0,229 \\
\hline 0,9 & 0,593 & 0,567 & 0,540 & 0,515 & 0,490 & 0,466 & 0,412 & 0,365 & 0,324 & 0,289 & 0,259 & 0,234 \\
\hline 1,0 & 0,632 & 0,603 & 0,573 & 0,545 & 0,518 & 0,491 & 0,431 & 0,378 & 0,334 & 0,296 & 0,264 & 0,237 \\
\hline 1,1 & 0,667 & 0,635 & 0,603 & 0,572 & 0,542 & 0,513 & 0,447 & 0,390 & 0,342 & 0,302 & 0,268 & 0,240 \\
\hline 1,2 & 0,699 & 0,665 & 0,631 & 0,597 & 0,565 & 0,533 & 0,462 & 0,400 & 0,349 & 0,306 & 0,271 & 0,242 \\
\hline 1,3 & 0,727 & 0,692 & 0,656 & 0,620 & 0,585 & 0,552 & 0,475 & 0,409 & 0,355 & 0,310 & 0,274 & 0,244 \\
\hline 1,4 & 0,753 & 0,716 & 0,678 & 0,641 & 0,604 & 0,568 & 0,486 & 0,417 & 0,360 & 0,313 & 0,276 & 0,245 \\
\hline 1,5 & 0,777 & 0,738 & 0,699 & 0,660 & 0,621 & 0,583 & 0,497 & 0,424 & 0,364 & 0,316 & 0,277 & 0,246 \\
\hline 1,6 & 0,798 & 0,759 & 0,718 & 0,677 & 0,636 & 0,597 & 0,506 & 0,430 & 0,368 & 0,318 & 0,279 & 0,246 \\
\hline 1,7 & 0,817 & 0,777 & 0,736 & 0,693 & 0,651 & 0,609 & 0,515 & 0,435 & 0,371 & 0,320 & 0,280 & 0,247 \\
\hline 1,8 & 0,835 & 0,794 & 0,752 & 0,708 & 0,664 & 0,621 & 0,523 & 0,440 & 0,374 & 0,322 & 0,281 & 0,248 \\
\hline 1,9 & 0,850 & 0,810 & 0,766 & 0,721 & 0,676 & 0,632 & 0,530 & 0,445 & 0,377 & 0,323 & 0,281 & 0,248 \\
\hline 2,0 & 0,865 & 0,824 & 0,780 & 0,734 & 0,687 & 0,642 & 0,536 & 0,448 & 0,379 & 0,324 & 0,282 & 0,248 \\
\hline 2,1 & 0,878 & 0,837 & 0,793 & 0,746 & 0,698 & 0,651 & 0,542 & 0,452 & 0,381 & 0,325 & 0,282 & 0,249 \\
\hline 2,2 & 0,889 & 0,849 & 0,804 & 0,757 & 0,708 & 0,659 & 0,548 & 0,455 & 0,382 & 0,326 & 0,283 & 0,249 \\
\hline 2,3 & 0,900 & 0,860 & 0,815 & 0,767 & 0,717 & 0,667 & 0,553 & 0,458 & 0,384 & 0,327 & 0,283 & 0,249 \\
\hline 2,4 & 0,909 & 0,870 & 0,825 & 0,776 & 0,726 & 0,675 & 0,557 & 0,461 & 0,385 & 0,328 & 0,284 & 0,249 \\
\hline 2,5 & 0,918 & 0,880 & 0,835 & 0,785 & 0,734 & 0,682 & 0,562 & 0,463 & 0,387 & 0,328 & 0,284 & 0,249 \\
\hline 2,6 & 0,926 & 0,888 & 0,843 & 0,794 & 0,741 & 0,689 & 0,566 & 0,465 & 0,388 & 0,329 & 0,284 & 0,249 \\
\hline 2,7 & 0,933 & 0,896 & 0,851 & 0,801 & 0,748 & 0,695 & 0,570 & 0,467 & 0,389 & 0,329 & 0,284 & 0,249 \\
\hline 2,8 & 0,939 & 0,903 & 0,859 & 0,809 & 0,755 & 0,701 & 0,573 & 0,469 & 0,390 & 0,330 & 0,284 & 0,250 \\
\hline 2,9 & 0,945 & 0,910 & 0,866 & 0,816 & 0,761 & 0,706 & 0,577 & 0,471 & 0,390 & 0,330 & 0,285 & 0,250 \\
\hline 3,0 & 0,950 & 0,916 & 0,873 & 0,822 & 0,767 & 0,711 & 0,580 & 0,472 & 0,391 & 0,330 & 0,285 & 0,250 \\
\hline 3,1 & 0,955 & 0,922 & 0,879 & 0,828 & 0,773 & 0,716 & 0,583 & 0,474 & 0,392 & 0,331 & 0,285 & 0,250 \\
\hline 3,2 & 0,959 & 0,927 & 0,885 & 0,834 & 0,778 & 0,721 & 0,585 & 0,475 & 0,392 & 0,331 & 0,285 & 0,250 \\
\hline 3,3 & 0,963 & 0,932 & 0,890 & 0,840 & 0,784 & 0,726 & 0,588 & 0,477 & 0,393 & 0,331 & 0,285 & 0,250 \\
\hline 3,4 & 0,967 & 0,937 & 0,895 & 0,845 & 0,788 & 0,730 & 0,591 & 0,478 & 0,393 & 0,331 & 0,285 & 0,250 \\
\hline 3,5 & 0,970 & 0,941 & 0,900 & 0,850 & 0,793 & 0,734 & 0,593 & 0,479 & 0,394 & 0,332 & 0,285 & 0,250 \\
\hline 3,6 & 0,973 & 0,945 & 0,904 & 0,854 & 0,797 & 0,738 & 0,595 & 0,480 & 0,394 & 0,332 & 0,285 & 0,250 \\
\hline 3,7 & 0,975 & 0,948 & 0,909 & 0,859 & 0,802 & 0,742 & 0,597 & 0,481 & 0,395 & 0,332 & 0,285 & 0,250 \\
\hline 3,8 & 0,978 & 0,951 & 0,913 & 0,863 & 0,806 & 0,745 & 0,599 & 0,482 & 0,395 & 0,332 & 0,285 & 0,250 \\
\hline 3,9 & 0,980 & 0,955 & 0,916 & 0,867 & 0,810 & 0,748 & 0,601 & 0,483 & 0,395 & 0,332 & 0,285 & 0,250 \\
\hline 4,0 & 0,982 & 0,957 & 0,920 & 0,871 & 0,813 & 0,752 & 0,603 & 0,483 & 0,396 & 0,332 & 0,285 & 0,250 \\
\hline 4,1 & 0,983 & 0,960 & 0,923 & 0,874 & 0,817 & 0,755 & 0,605 & 0,484 & 0,396 & 0,332 & 0,285 & 0,250 \\
\hline 4,2 & 0,985 & 0,963 & 0,926 & 0,878 & 0,820 & 0,758 & 0,606 & 0,485 & 0,396 & 0,332 & 0,285 & 0,250 \\
\hline 4,3 & 0,986 & 0,965 & 0,929 & 0,881 & 0,823 & 0,761 & 0,608 & 0,485 & 0,396 & 0,332 & 0,285 & 0,250 \\
\hline 4,4 & 0,988 & 0,967 & 0,932 & 0,884 & 0,827 & 0,764 & 0,609 & 0,486 & 0,397 & 0,333 & 0,286 & 0,250 \\
\hline 4,5 & 0,989 & 0,969 & 0,935 & 0,887 & 0,830 & 0,766 & 0,611 & 0,487 & 0,397 & 0,333 & 0,286 & 0,250 \\
\hline 4,6 & 0,990 & 0,971 & 0,937 & 0,890 & 0,832 & 0,769 & 0,612 & 0,487 & 0,397 & 0,333 & 0,286 & 0,250 \\
\hline 4,7 & 0,991 & 0,973 & 0,940 & 0,893 & 0,835 & 0,771 & 0,614 & 0,488 & 0,397 & 0,333 & 0,286 & 0,250 \\
\hline 4,8 & 0,992 & 0,974 & 0,942 & 0,896 & 0,838 & 0,774 & 0,615 & 0,488 & 0,397 & 0,333 & 0,286 & 0,250 \\
\hline
\end{tabular}


Tabela 71 - continuação da página anterior

\begin{tabular}{|c|c|c|c|c|c|c|c|c|c|c|c|c|}
\hline $\mathrm{NTU}^{R}$ & 0,0 & 0,2 & 0,4 & 0,6 & 0,8 & 1,0 & 1,5 & 2,0 & 2,5 & 3,0 & 3,5 & 4,0 \\
\hline 4,9 & 0,993 & 0,976 & 0,944 & 0,898 & 0,841 & 0,776 & 0,616 & 0,489 & 0,398 & 0,333 & 0,286 & 0,250 \\
\hline 5,0 & 0,993 & 0,977 & 0,946 & 0,901 & 0,843 & 0,778 & 0,617 & 0,489 & 0,398 & 0,333 & 0,286 & 0,250 \\
\hline 5,1 & 0,994 & 0,978 & 0,948 & 0,903 & 0,845 & 0,780 & 0,618 & 0,490 & 0,398 & 0,333 & 0,286 & 0,250 \\
\hline 5,2 & 0,994 & 0,980 & 0,950 & 0,905 & 0,848 & 0,782 & 0,619 & 0,490 & 0,398 & 0,333 & 0,286 & 0,250 \\
\hline 5,3 & 0,995 & 0,981 & 0,952 & 0,908 & 0,850 & 0,784 & 0,620 & 0,490 & 0,398 & 0,333 & 0,286 & 0,250 \\
\hline 5,4 & 0,995 & 0,982 & 0,954 & 0,910 & 0,852 & 0,786 & 0,621 & 0,491 & 0,398 & 0,333 & 0,286 & 0,250 \\
\hline 5,5 & 0,996 & 0,983 & 0,955 & 0,912 & 0,854 & 0,788 & 0,622 & 0,491 & 0,398 & 0,333 & 0,286 & 0,250 \\
\hline 5,6 & 0,996 & 0,984 & 0,957 & 0,914 & 0,856 & 0,790 & 0,623 & 0,491 & 0,398 & 0,333 & 0,286 & 0,250 \\
\hline 5,7 & 0,997 & 0,985 & 0,958 & 0,916 & 0,858 & 0,792 & 0,624 & 0,492 & 0,398 & 0,333 & 0,286 & 0,250 \\
\hline 5,8 & 0,997 & 0,986 & 0,960 & 0,917 & 0,860 & 0,794 & 0,625 & 0,492 & 0,398 & 0,333 & 0,286 & 0,250 \\
\hline 5,9 & 0,997 & 0,986 & 0,961 & 0,919 & 0,862 & 0,795 & 0,626 & 0,492 & 0,399 & 0,333 & 0,286 & 0,250 \\
\hline 6,0 & 0,998 & 0,987 & 0,962 & 0,921 & 0,864 & 0,797 & 0,627 & 0,493 & 0,399 & 0,333 & 0,286 & 0,250 \\
\hline 6,1 & 0,998 & 0,988 & 0,964 & 0,922 & 0,866 & 0,799 & 0,628 & 0,493 & 0,399 & 0,333 & 0,286 & 0,250 \\
\hline 6,2 & 0,998 & 0,988 & 0,965 & 0,924 & 0,867 & 0,800 & 0,628 & 0,493 & 0,399 & 0,333 & 0,286 & 0,250 \\
\hline 6,3 & 0,998 & 0,989 & 0,966 & 0,926 & 0,869 & 0,802 & 0,629 & 0,493 & 0,399 & 0,333 & 0,286 & 0,250 \\
\hline 6,4 & 0,998 & 0,990 & 0,967 & 0,927 & 0,871 & 0,803 & 0,630 & 0,493 & 0,399 & 0,333 & 0,286 & 0,250 \\
\hline 6,5 & 0,998 & 0,990 & 0,968 & 0,928 & 0,872 & 0,805 & 0,630 & 0,494 & 0,399 & 0,333 & 0,286 & 0,250 \\
\hline 6,6 & 0,999 & 0,991 & 0,969 & 0,930 & 0,874 & 0,806 & 0,631 & 0,494 & 0,399 & 0,333 & 0,286 & 0,250 \\
\hline 6,7 & 0,999 & 0,991 & 0,970 & 0,931 & 0,875 & 0,807 & 0,632 & 0,494 & 0,399 & 0,333 & 0,286 & 0,250 \\
\hline 6,8 & 0,999 & 0,992 & 0,971 & 0,933 & 0,877 & 0,809 & 0,632 & 0,494 & 0,399 & 0,333 & 0,286 & 0,250 \\
\hline 6,9 & 0,999 & 0,992 & 0,972 & 0,934 & 0,878 & 0,810 & 0,633 & 0,494 & 0,399 & 0,333 & 0,286 & 0,250 \\
\hline 7,0 & 0,999 & 0,992 & 0,973 & 0,935 & 0,879 & 0,811 & 0,634 & 0,495 & 0,399 & 0,333 & 0,286 & 0,250 \\
\hline 7,1 & 0,999 & 0,993 & 0,973 & 0,936 & 0,881 & 0,812 & 0,634 & 0,495 & 0,399 & 0,333 & 0,286 & 0,250 \\
\hline 7,2 & 0,999 & 0,993 & 0,974 & 0,937 & 0,882 & 0,814 & 0,635 & 0,495 & 0,399 & 0,333 & 0,286 & 0,250 \\
\hline 7,3 & 0,999 & 0,993 & 0,975 & 0,938 & 0,883 & 0,815 & 0,635 & 0,495 & 0,399 & 0,333 & 0,286 & 0,250 \\
\hline 7,4 & 0,999 & 0,994 & 0,976 & 0,940 & 0,885 & 0,816 & 0,636 & 0,495 & 0,399 & 0,333 & 0,286 & 0,250 \\
\hline 7,5 & 0,999 & 0,994 & 0,976 & 0,941 & 0,886 & 0,817 & 0,636 & 0,495 & 0,399 & 0,333 & 0,286 & 0,250 \\
\hline 7,6 & 0,999 & 0,994 & 0,977 & 0,942 & 0,887 & 0,818 & 0,637 & 0,495 & 0,399 & 0,333 & 0,286 & 0,250 \\
\hline 7,7 & 1,000 & 0,995 & 0,978 & 0,943 & 0,888 & 0,819 & 0,637 & 0,496 & 0,399 & 0,333 & 0,286 & 0,250 \\
\hline 7,8 & 1,000 & 0,995 & 0,978 & 0,944 & 0,889 & 0,820 & 0,638 & 0,496 & 0,399 & 0,333 & 0,286 & 0,250 \\
\hline 7,9 & 1,000 & 0,995 & 0,979 & 0,944 & 0,890 & 0,821 & 0,638 & 0,496 & 0,399 & 0,333 & 0,286 & 0,250 \\
\hline 8,0 & 1,000 & 0,995 & 0,980 & 0,945 & 0,891 & 0,822 & 0,638 & 0,496 & 0,399 & 0,333 & 0,286 & 0,250 \\
\hline 8,1 & 1,000 & 0,996 & 0,980 & 0,946 & 0,892 & 0,823 & 0,639 & 0,496 & 0,399 & 0,333 & 0,286 & 0,250 \\
\hline 8,2 & 1,000 & 0,996 & 0,981 & 0,947 & 0,893 & 0,824 & 0,639 & 0,496 & 0,399 & 0,333 & 0,286 & 0,250 \\
\hline 8,3 & 1,000 & 0,996 & 0,981 & 0,948 & 0,894 & 0,825 & 0,640 & 0,496 & 0,400 & 0,333 & 0,286 & 0,250 \\
\hline 8,4 & 1,000 & 0,996 & 0,982 & 0,949 & 0,895 & 0,826 & 0,640 & 0,496 & 0,400 & 0,333 & 0,286 & 0,250 \\
\hline 8,5 & 1,000 & 0,996 & 0,982 & 0,950 & 0,896 & 0,827 & 0,640 & 0,496 & 0,400 & 0,333 & 0,286 & 0,250 \\
\hline 8,6 & 1,000 & 0,996 & 0,983 & 0,950 & 0,897 & 0,828 & 0,641 & 0,497 & 0,400 & 0,333 & 0,286 & 0,250 \\
\hline 8,7 & 1,000 & 0,997 & 0,983 & 0,951 & 0,898 & 0,829 & 0,641 & 0,497 & 0,400 & 0,333 & 0,286 & 0,250 \\
\hline 8,8 & 1,000 & 0,997 & 0,983 & 0,952 & 0,899 & 0,830 & 0,642 & 0,497 & 0,400 & 0,333 & 0,286 & 0,250 \\
\hline 8,9 & 1,000 & 0,997 & 0,984 & 0,953 & 0,900 & 0,830 & 0,642 & 0,497 & 0,400 & 0,333 & 0,286 & 0,250 \\
\hline 9,0 & 1,000 & 0,997 & 0,984 & 0,953 & 0,901 & 0,831 & 0,642 & 0,497 & 0,400 & 0,333 & 0,286 & 0,250 \\
\hline 9,1 & 1,000 & 0,997 & 0,985 & 0,954 & 0,902 & 0,832 & 0,643 & 0,497 & 0,400 & 0,333 & 0,286 & 0,250 \\
\hline 9,2 & 1,000 & 0,997 & 0,985 & 0,955 & 0,902 & 0,833 & 0,643 & 0,497 & 0,400 & 0,333 & 0,286 & 0,250 \\
\hline 9,3 & 1,000 & 0,997 & 0,985 & 0,955 & 0,903 & 0,833 & 0,643 & 0,497 & 0,400 & 0,333 & 0,286 & 0,250 \\
\hline 9,4 & 1,000 & 0,998 & 0,986 & 0,956 & 0,904 & 0,834 & 0,643 & 0,497 & 0,400 & 0,333 & 0,286 & 0,250 \\
\hline 9,5 & 1,000 & 0,998 & 0,986 & 0,957 & 0,905 & 0,835 & 0,644 & 0,497 & 0,400 & 0,333 & 0,286 & 0,250 \\
\hline 9,6 & 1,000 & 0,998 & 0,986 & 0,957 & 0,906 & 0,836 & 0,644 & 0,497 & 0,400 & 0,333 & 0,286 & 0,250 \\
\hline 9,7 & 1,000 & 0,998 & 0,987 & 0,958 & 0,906 & 0,836 & 0,644 & 0,497 & 0,400 & 0,333 & 0,286 & 0,250 \\
\hline 9,8 & 1,000 & 0,998 & 0,987 & 0,958 & 0,907 & 0,837 & 0,645 & 0,497 & 0,400 & 0,333 & 0,286 & 0,250 \\
\hline 9,9 & 1,000 & 0,998 & 0,987 & 0,959 & 0,908 & 0,838 & 0,645 & 0,497 & 0,400 & 0,333 & 0,286 & 0,250 \\
\hline 10,0 & 1,000 & 0,998 & 0,988 & 0,959 & 0,908 & 0,838 & 0,645 & 0,498 & 0,400 & 0,333 & 0,286 & 0,250 \\
\hline
\end{tabular}


Tabela 72 - Fator de correção para trocador de calor de fluxo cruzado com dois passes e quatro tubos por passe (2-4) - Caso 4A - trocador de calor ilustrado na Figura 103 do Anexo A

\begin{tabular}{|c|c|c|c|c|c|c|c|c|c|c|c|c|}
\hline $\mathrm{NTU}^{R}$ & 0,0 & 0,2 & 0,4 & 0,6 & 0,8 & 1,0 & 1,5 & 2,0 & 2,5 & 3,0 & 3,5 & 4,0 \\
\hline 0,0 & 1,000 & 1,000 & 1,000 & 1,000 & 1,000 & 1,000 & 1,000 & 1,000 & 1,000 & 1,000 & 1,000 & 1,000 \\
\hline 0,1 & 1,000 & 1,000 & 1,000 & 1,000 & 1,000 & 1,000 & 0,999 & 0,999 & 0,999 & 0,999 & 0,999 & 0,998 \\
\hline 0,2 & 1,000 & 1,000 & 0,999 & 0,999 & 0,999 & 0,998 & 0,998 & 0,997 & 0,996 & 0,995 & 0,994 & 0,994 \\
\hline 0,3 & 1,000 & 0,999 & 0,999 & 0,998 & 0,997 & 0,996 & 0,995 & 0,993 & 0,991 & 0,990 & 0,988 & 0,986 \\
\hline 0,4 & 1,000 & 0,999 & 0,997 & 0,996 & 0,995 & 0,994 & 0,991 & 0,988 & 0,985 & 0,982 & 0,980 & 0,977 \\
\hline 0,5 & 1,000 & 0,998 & 0,996 & 0,994 & 0,992 & 0,990 & 0,986 & 0,981 & 0,977 & 0,973 & 0,970 & 0,966 \\
\hline 0,6 & 1,000 & 0,997 & 0,994 & 0,992 & 0,989 & 0,986 & 0,980 & 0,974 & 0,969 & 0,964 & 0,959 & 0,955 \\
\hline 0,7 & 1,000 & 0,996 & 0,993 & 0,989 & 0,985 & 0,982 & 0,974 & 0,966 & 0,959 & 0,953 & 0,947 & 0,942 \\
\hline 0,8 & 1,000 & 0,995 & 0,990 & 0,986 & 0,981 & 0,977 & 0,967 & 0,957 & 0,949 & 0,942 & 0,935 & 0,929 \\
\hline 0,9 & 1,000 & 0,994 & 0,988 & 0,982 & 0,977 & 0,971 & 0,959 & 0,948 & 0,938 & 0,930 & 0,923 & 0,916 \\
\hline 1,0 & 1,000 & 0,993 & 0,985 & 0,979 & 0,972 & 0,966 & 0,951 & 0,939 & 0,928 & 0,918 & 0,910 & 0,903 \\
\hline 1,1 & 1,000 & 0,991 & 0,983 & 0,975 & 0,967 & 0,959 & 0,943 & 0,929 & 0,917 & 0,906 & 0,897 & 0,890 \\
\hline 1,2 & 1,000 & 0,990 & 0,980 & 0,970 & 0,961 & 0,953 & 0,934 & 0,919 & 0,905 & 0,894 & 0,885 & 0,877 \\
\hline 1,3 & 1,000 & 0,988 & 0,977 & 0,966 & 0,956 & 0,946 & 0,925 & 0,908 & 0,894 & 0,883 & 0,873 & 0,865 \\
\hline 1,4 & 1,000 & 0,986 & 0,973 & 0,961 & 0,950 & 0,939 & 0,916 & 0,898 & 0,883 & 0,871 & 0,861 & 0,853 \\
\hline 1,5 & 1,000 & 0,984 & 0,970 & 0,956 & 0,944 & 0,932 & 0,907 & 0,888 & 0,872 & 0,860 & 0,849 & 0,841 \\
\hline 1,6 & 1,000 & 0,983 & 0,966 & 0,951 & 0,937 & 0,925 & 0,898 & 0,878 & 0,861 & 0,849 & 0,838 & 0,830 \\
\hline 1,7 & 1,000 & 0,981 & 0,962 & 0,946 & 0,931 & 0,917 & 0,889 & 0,868 & 0,851 & 0,838 & 0,827 & 0,819 \\
\hline 1,8 & 1,000 & 0,978 & 0,959 & 0,941 & 0,924 & 0,910 & 0,880 & 0,858 & 0,840 & 0,827 & 0,817 & 0,809 \\
\hline 1,9 & 1,000 & 0,976 & 0,955 & 0,935 & 0,918 & 0,903 & 0,871 & 0,848 & 0,830 & 0,817 & 0,807 & 0,799 \\
\hline 2,0 & 1,000 & 0,974 & 0,951 & 0,930 & 0,911 & 0,895 & 0,862 & 0,838 & 0,820 & 0,807 & 0,797 & 0,789 \\
\hline 2,1 & 1,000 & 0,972 & 0,946 & 0,924 & 0,905 & 0,887 & 0,854 & 0,829 & 0,811 & 0,797 & 0,787 & 0,779 \\
\hline 2,2 & 1,000 & 0,969 & 0,942 & 0,918 & 0,898 & 0,880 & 0,845 & 0,820 & 0,801 & 0,788 & 0,778 & 0,770 \\
\hline 2,3 & 1,000 & 0,967 & 0,938 & 0,913 & 0,891 & 0,872 & 0,836 & 0,811 & 0,792 & 0,779 & 0,769 & 0,762 \\
\hline 2,4 & 1,000 & 0,965 & 0,934 & 0,907 & 0,884 & 0,865 & 0,828 & 0,802 & 0,783 & 0,770 & 0,760 & 0,753 \\
\hline 2,5 & 1,000 & 0,962 & 0,929 & 0,901 & 0,878 & 0,858 & 0,819 & 0,793 & 0,775 & 0,761 & 0,752 & 0,745 \\
\hline 2,6 & 1,000 & 0,959 & 0,925 & 0,895 & 0,871 & 0,850 & 0,811 & 0,785 & 0,766 & 0,753 & 0,744 & 0,737 \\
\hline 2,7 & 1,000 & 0,957 & 0,920 & 0,890 & 0,864 & 0,843 & 0,803 & 0,776 & 0,758 & 0,745 & 0,736 & 0,730 \\
\hline 2,8 & 1,000 & 0,954 & 0,916 & 0,884 & 0,858 & 0,836 & 0,795 & 0,768 & 0,750 & 0,737 & 0,728 & 0,722 \\
\hline 2,9 & 1,000 & 0,951 & 0,911 & 0,878 & 0,851 & 0,829 & 0,788 & 0,761 & 0,742 & 0,730 & 0,721 & 0,715 \\
\hline 3,0 & 1,000 & 0,949 & 0,907 & 0,872 & 0,845 & 0,822 & 0,780 & 0,753 & 0,735 & 0,722 & 0,714 & 0,708 \\
\hline 3,1 & 1,000 & 0,946 & 0,902 & 0,867 & 0,838 & 0,815 & 0,773 & 0,745 & 0,727 & 0,715 & 0,707 & 0,701 \\
\hline 3,2 & 1,000 & 0,943 & 0,897 & 0,861 & 0,832 & 0,808 & 0,765 & 0,738 & 0,720 & 0,708 & 0,700 & 0,695 \\
\hline 3,3 & 1,000 & 0,940 & 0,893 & 0,855 & 0,825 & 0,801 & 0,758 & 0,731 & 0,713 & 0,702 & 0,694 & 0,689 \\
\hline 3,4 & 1,000 & 0,937 & 0,888 & 0,850 & 0,819 & 0,795 & 0,751 & 0,724 & 0,706 & 0,695 & 0,687 & 0,683 \\
\hline 3,5 & 1,000 & 0,935 & 0,884 & 0,844 & 0,813 & 0,788 & 0,744 & 0,717 & 0,700 & 0,689 & 0,681 & 0,677 \\
\hline 3,6 & 1,000 & 0,932 & 0,879 & 0,838 & 0,807 & 0,782 & 0,738 & 0,711 & 0,693 & 0,682 & 0,675 & 0,671 \\
\hline 3,7 & 1,000 & 0,929 & 0,874 & 0,833 & 0,801 & 0,775 & 0,731 & 0,704 & 0,687 & 0,676 & 0,669 & 0,665 \\
\hline 3,8 & 1,000 & 0,926 & 0,870 & 0,827 & 0,795 & 0,769 & 0,725 & 0,698 & 0,681 & 0,670 & 0,664 & 0,660 \\
\hline 3,9 & 1,000 & 0,923 & 0,865 & 0,822 & 0,789 & 0,763 & 0,718 & 0,692 & 0,675 & 0,665 & 0,658 & 0,654 \\
\hline 4,0 & 1,000 & 0,920 & 0,861 & 0,817 & 0,783 & 0,757 & 0,712 & 0,685 & 0,669 & 0,659 & 0,653 & 0,649 \\
\hline 4,1 & 1,000 & 0,917 & 0,856 & 0,811 & 0,777 & 0,751 & 0,706 & 0,680 & 0,663 & 0,653 & 0,647 & 0,644 \\
\hline 4,2 & 1,000 & 0,914 & 0,852 & 0,806 & 0,772 & 0,745 & 0,700 & 0,674 & 0,658 & 0,648 & 0,642 & 0,639 \\
\hline 4,3 & 1,000 & 0,911 & 0,847 & 0,801 & 0,766 & 0,739 & 0,694 & 0,668 & 0,652 & 0,643 & 0,637 & 0,634 \\
\hline 4,4 & 1,000 & 0,908 & 0,843 & 0,796 & 0,761 & 0,734 & 0,689 & 0,663 & 0,647 & 0,638 & 0,632 & 0,629 \\
\hline 4,5 & 1,000 & 0,905 & 0,838 & 0,791 & 0,755 & 0,728 & 0,683 & 0,657 & 0,642 & 0,633 & 0,628 & 0,625 \\
\hline 4,6 & 1,000 & 0,902 & 0,834 & 0,786 & 0,750 & 0,723 & 0,678 & 0,652 & 0,637 & 0,628 & 0,623 & 0,620 \\
\hline 4,7 & 1,000 & 0,899 & 0,830 & 0,781 & 0,745 & 0,717 & 0,672 & 0,647 & 0,632 & 0,623 & 0,618 & 0,616 \\
\hline 4,8 & 1,000 & 0,896 & 0,825 & 0,776 & 0,740 & 0,712 & 0,667 & 0,641 & 0,627 & 0,618 & 0,614 & 0,611 \\
\hline
\end{tabular}


Tabela 72 - continuação da página anterior

\begin{tabular}{|c|c|c|c|c|c|c|c|c|c|c|c|c|}
\hline${ }_{N T U}^{R}$ & 0,0 & 0,2 & 0,4 & 0,6 & 0,8 & 1,0 & 1,5 & 2,0 & 2,5 & 3,0 & 3,5 & 4,0 \\
\hline 4,9 & 1,000 & 0,893 & 0,821 & 0,771 & 0,734 & 0,707 & 0,662 & 0,636 & 0,622 & 0,614 & 0,609 & 0,607 \\
\hline 5,0 & 1,000 & 0,890 & 0,817 & 0,766 & 0,729 & 0,702 & 0,657 & 0,632 & 0,617 & 0,609 & 0,605 & 0,603 \\
\hline 5,1 & 1,000 & 0,887 & 0,813 & 0,762 & 0,724 & 0,697 & 0,652 & 0,627 & 0,613 & 0,605 & 0,601 & 0,599 \\
\hline 5,2 & 1,000 & 0,884 & 0,809 & 0,757 & 0,720 & 0,692 & 0,647 & 0,622 & 0,608 & 0,600 & 0,596 & 0,595 \\
\hline 5,3 & 1,000 & 0,881 & 0,804 & 0,752 & 0,715 & 0,687 & 0,642 & 0,617 & 0,604 & 0,596 & 0,592 & 0,591 \\
\hline 5,4 & 1,000 & 0,878 & 0,800 & 0,748 & 0,710 & 0,682 & 0,637 & 0,613 & 0,599 & 0,592 & 0,588 & 0,587 \\
\hline 5,5 & 1,000 & 0,875 & 0,796 & 0,743 & 0,705 & 0,677 & 0,632 & 0,608 & 0,595 & 0,588 & 0,584 & 0,583 \\
\hline 5,6 & 1,000 & 0,872 & 0,792 & 0,739 & 0,701 & 0,673 & 0,628 & 0,604 & 0,591 & 0,584 & 0,581 & 0,579 \\
\hline 5,7 & 1,000 & 0,869 & 0,788 & 0,734 & 0,696 & 0,668 & 0,623 & 0,600 & 0,587 & 0,580 & 0,577 & 0,576 \\
\hline 5,8 & 1,000 & 0,866 & 0,784 & 0,730 & 0,692 & 0,663 & 0,619 & 0,595 & 0,583 & 0,576 & 0,573 & 0,572 \\
\hline 5,9 & 1,000 & 0,863 & 0,780 & 0,726 & 0,687 & 0,659 & 0,615 & 0,591 & 0,579 & 0,572 & 0,569 & 0,568 \\
\hline 6,0 & 1,000 & 0,860 & 0,777 & 0,722 & 0,683 & 0,655 & 0,610 & 0,587 & 0,575 & 0,568 & 0,566 & 0,565 \\
\hline 6,1 & 1,000 & 0,857 & 0,773 & 0,717 & 0,679 & 0,650 & 0,606 & 0,583 & 0,571 & 0,565 & 0,562 & 0,561 \\
\hline 6,2 & 1,000 & 0,854 & 0,769 & 0,713 & 0,674 & 0,646 & 0,602 & 0,579 & 0,567 & 0,561 & 0,558 & 0,558 \\
\hline 6,3 & 1,000 & 0,852 & 0,765 & 0,709 & 0,670 & 0,642 & 0,598 & 0,575 & 0,563 & 0,557 & 0,555 & 0,555 \\
\hline 6,4 & 1,000 & 0,849 & 0,761 & 0,705 & 0,666 & 0,638 & 0,594 & 0,571 & 0,559 & 0,554 & 0,552 & 0,551 \\
\hline 6,5 & 1,000 & 0,846 & 0,758 & 0,701 & 0,662 & 0,634 & 0,590 & 0,567 & 0,556 & 0,550 & 0,548 & 0,548 \\
\hline 6,6 & 1,000 & 0,843 & 0,754 & 0,697 & 0,658 & 0,630 & 0,586 & 0,564 & 0,552 & 0,547 & 0,545 & 0,545 \\
\hline 6,7 & 1,000 & 0,840 & 0,751 & 0,693 & 0,654 & 0,626 & 0,582 & 0,560 & 0,549 & 0,543 & 0,542 & 0,542 \\
\hline 6,8 & 1,000 & 0,837 & 0,747 & 0,690 & 0,650 & 0,622 & 0,578 & 0,556 & 0,545 & 0,540 & 0,538 & 0,538 \\
\hline 6,9 & 1,000 & 0,834 & 0,743 & 0,686 & 0,646 & 0,618 & 0,574 & 0,553 & 0,542 & 0,537 & 0,535 & 0,535 \\
\hline 7,0 & 1,000 & 0,832 & 0,740 & 0,682 & 0,643 & 0,614 & 0,571 & 0,549 & 0,538 & 0,534 & 0,532 & 0,532 \\
\hline 7,1 & 1,000 & 0,829 & 0,736 & 0,678 & 0,639 & 0,610 & 0,567 & 0,546 & 0,535 & 0,530 & 0,529 & 0,529 \\
\hline 7,2 & 1,000 & 0,826 & 0,733 & 0,675 & 0,635 & 0,607 & 0,564 & 0,542 & 0,532 & 0,527 & 0,526 & 0,526 \\
\hline 7,3 & 1,000 & 0,823 & 0,730 & 0,671 & 0,631 & 0,603 & 0,560 & 0,539 & 0,529 & 0,524 & 0,523 & 0,523 \\
\hline 7,4 & 1,000 & 0,820 & 0,726 & 0,668 & 0,628 & 0,599 & 0,557 & 0,536 & 0,525 & 0,521 & 0,520 & 0,520 \\
\hline 7,5 & 1,000 & 0,818 & 0,723 & 0,664 & 0,624 & 0,596 & 0,553 & 0,532 & 0,522 & 0,518 & 0,517 & 0,517 \\
\hline 7,6 & 1,000 & 0,815 & 0,720 & 0,661 & 0,621 & 0,592 & 0,550 & 0,529 & 0,519 & 0,515 & 0,514 & 0,515 \\
\hline 7,7 & 1,000 & 0,812 & 0,716 & 0,657 & 0,617 & 0,589 & 0,546 & 0,526 & 0,516 & 0,512 & 0,511 & 0,512 \\
\hline 7,8 & 1,000 & 0,810 & 0,713 & 0,654 & 0,614 & 0,585 & 0,543 & 0,523 & 0,513 & 0,509 & 0,508 & 0,509 \\
\hline 7,9 & 1,000 & 0,807 & 0,710 & 0,650 & 0,610 & 0,582 & 0,540 & 0,519 & 0,510 & 0,506 & 0,505 & 0,506 \\
\hline 8,0 & 1,000 & 0,804 & 0,707 & 0,647 & 0,607 & 0,579 & 0,536 & 0,516 & 0,507 & 0,503 & 0,503 & 0,503 \\
\hline 8,1 & 1,000 & 0,802 & 0,703 & 0,644 & 0,604 & 0,575 & 0,533 & 0,513 & 0,504 & 0,500 & 0,500 & 0,501 \\
\hline 8,2 & 1,000 & 0,799 & 0,700 & 0,640 & 0,600 & 0,572 & 0,530 & 0,510 & 0,501 & 0,498 & 0,497 & 0,498 \\
\hline 8,3 & 1,000 & 0,796 & 0,697 & 0,637 & 0,597 & 0,569 & 0,527 & 0,507 & 0,498 & 0,495 & 0,494 & 0,495 \\
\hline 8,4 & 1,000 & 0,794 & 0,694 & 0,634 & 0,594 & 0,565 & 0,524 & 0,504 & 0,495 & 0,492 & 0,492 & 0,493 \\
\hline 8,5 & 1,000 & 0,791 & 0,691 & 0,631 & 0,591 & 0,562 & 0,521 & 0,501 & 0,493 & 0,489 & 0,489 & 0,490 \\
\hline 8,6 & 1,000 & 0,789 & 0,688 & 0,628 & 0,587 & 0,559 & 0,518 & 0,499 & 0,490 & 0,487 & 0,486 & 0,488 \\
\hline 8,7 & 1,000 & 0,786 & 0,685 & 0,625 & 0,584 & 0,556 & 0,515 & 0,496 & 0,487 & 0,484 & 0,484 & 0,485 \\
\hline 8,8 & 1,000 & 0,784 & 0,682 & 0,621 & 0,581 & 0,553 & 0,512 & 0,493 & 0,484 & 0,481 & 0,481 & 0,483 \\
\hline 8,9 & 1,000 & 0,781 & 0,679 & 0,618 & 0,578 & 0,550 & 0,509 & 0,490 & 0,482 & 0,479 & 0,479 & 0,480 \\
\hline 9,0 & 1,000 & 0,779 & 0,676 & 0,615 & 0,575 & 0,547 & 0,506 & 0,487 & 0,479 & 0,476 & 0,476 & 0,478 \\
\hline 9,1 & 1,000 & 0,776 & 0,673 & 0,612 & 0,572 & 0,544 & 0,503 & 0,485 & 0,477 & 0,474 & 0,474 & 0,475 \\
\hline 9,2 & 1,000 & 0,774 & 0,670 & 0,609 & 0,569 & 0,541 & 0,500 & 0,482 & 0,474 & 0,471 & 0,471 & 0,473 \\
\hline 9,3 & 1,000 & 0,771 & 0,668 & 0,607 & 0,566 & 0,538 & 0,498 & 0,479 & 0,471 & 0,469 & 0,469 & 0,470 \\
\hline 9,4 & 1,000 & 0,769 & 0,665 & 0,604 & 0,563 & 0,535 & 0,495 & 0,477 & 0,469 & 0,466 & 0,466 & 0,468 \\
\hline 9,5 & 1,000 & 0,766 & 0,662 & 0,601 & 0,560 & 0,532 & 0,492 & 0,474 & 0,466 & 0,464 & 0,464 & 0,466 \\
\hline 9,6 & 1,000 & 0,764 & 0,659 & 0,598 & 0,558 & 0,530 & 0,490 & 0,471 & 0,464 & 0,461 & 0,462 & 0,463 \\
\hline 9,7 & 1,000 & 0,761 & 0,657 & 0,595 & 0,555 & 0,527 & 0,487 & 0,469 & 0,461 & 0,459 & 0,459 & 0,461 \\
\hline 9,8 & 1,000 & 0,759 & 0,654 & 0,592 & 0,552 & 0,524 & 0,484 & 0,466 & 0,459 & 0,457 & 0,457 & 0,459 \\
\hline 9,9 & 1,000 & 0,757 & 0,651 & 0,590 & 0,549 & 0,521 & 0,482 & 0,464 & 0,457 & 0,454 & 0,455 & 0,456 \\
\hline 10,0 & 1,000 & 0,754 & 0,648 & 0,587 & 0,546 & 0,519 & 0,479 & 0,461 & 0,454 & 0,452 & 0,452 & 0,454 \\
\hline
\end{tabular}


Tabela 73 - Efetividade de temperatura para trocador de calor de fluxo cruzado com três passes e um tubo por passe (3-1) - Caso 4A - trocador de calor ilustrado na Figura 91 do Anexo A

\begin{tabular}{|c|c|c|c|c|c|c|c|c|c|c|c|c|}
\hline $\mathrm{NTU}^{R}$ & 0,0 & 0,2 & 0,4 & 0,6 & 0,8 & 1,0 & 1,5 & 2,0 & 2,5 & 3,0 & 3,5 & 4,0 \\
\hline 0,0 & 0,000 & 0,000 & 0,000 & 0,000 & 0,000 & 0,000 & 0,000 & 0,000 & 0,000 & 0,000 & 0,000 & 0,000 \\
\hline 0,1 & 0,095 & 0,094 & 0,094 & 0,093 & 0,092 & 0,091 & 0,089 & 0,087 & 0,085 & 0,083 & 0,081 & 0,080 \\
\hline 0,2 & 0,181 & 0,178 & 0,175 & 0,172 & 0,169 & 0,167 & 0,160 & 0,153 & 0,147 & 0,141 & 0,136 & 0,131 \\
\hline 0,3 & 0,259 & 0,253 & 0,247 & 0,242 & 0,236 & 0,231 & 0,218 & 0,205 & 0,194 & 0,184 & 0,174 & 0,165 \\
\hline 0,4 & 0,330 & 0,320 & 0,311 & 0,302 & 0,294 & 0,285 & 0,265 & 0,247 & 0,230 & 0,215 & 0,201 & 0,188 \\
\hline 0,5 & 0,394 & 0,381 & 0,368 & 0,356 & 0,344 & 0,332 & 0,305 & 0,281 & 0,259 & 0,239 & 0,221 & 0,204 \\
\hline 0,6 & 0,451 & 0,435 & 0,419 & 0,403 & 0,388 & 0,374 & 0,340 & 0,309 & 0,282 & 0,257 & 0,235 & 0,216 \\
\hline 0,7 & 0,503 & 0,484 & 0,464 & 0,445 & 0,427 & 0,410 & 0,369 & 0,332 & 0,300 & 0,271 & 0,246 & 0,225 \\
\hline 0,8 & 0,551 & 0,528 & 0,505 & 0,483 & 0,462 & 0,442 & 0,394 & 0,352 & 0,315 & 0,283 & 0,255 & 0,231 \\
\hline 0,9 & 0,593 & 0,568 & 0,542 & 0,517 & 0,493 & 0,470 & 0,416 & 0,368 & 0,327 & 0,291 & 0,261 & 0,235 \\
\hline 1,0 & 0,632 & 0,604 & 0,576 & 0,548 & 0,521 & 0,496 & 0,435 & 0,383 & 0,337 & 0,299 & 0,266 & 0,239 \\
\hline 1,1 & 0,667 & 0,637 & 0,606 & 0,576 & 0,547 & 0,518 & 0,452 & 0,395 & 0,346 & 0,304 & 0,270 & 0,241 \\
\hline 1,2 & 0,699 & 0,666 & 0,634 & 0,602 & 0,570 & 0,539 & 0,468 & 0,405 & 0,353 & 0,309 & 0,273 & 0,243 \\
\hline 1,3 & 0,727 & 0,694 & 0,659 & 0,625 & 0,591 & 0,558 & 0,481 & 0,414 & 0,359 & 0,313 & 0,275 & 0,245 \\
\hline 1,4 & 0,753 & 0,718 & 0,682 & 0,646 & 0,610 & 0,575 & 0,493 & 0,422 & 0,364 & 0,316 & 0,277 & 0,246 \\
\hline 1,5 & 0,777 & 0,741 & 0,704 & 0,666 & 0,628 & 0,591 & 0,504 & 0,429 & 0,368 & 0,318 & 0,279 & 0,247 \\
\hline 1,6 & 0,798 & 0,761 & 0,723 & 0,684 & 0,644 & 0,605 & 0,514 & 0,435 & 0,372 & 0,320 & 0,280 & 0,247 \\
\hline 1,7 & 0,817 & 0,780 & 0,741 & 0,700 & 0,659 & 0,618 & 0,522 & 0,441 & 0,375 & 0,322 & 0,281 & 0,248 \\
\hline 1,8 & 0,835 & 0,797 & 0,757 & 0,715 & 0,672 & 0,630 & 0,530 & 0,446 & 0,377 & 0,324 & 0,281 & 0,248 \\
\hline 1,9 & 0,850 & 0,813 & 0,772 & 0,729 & 0,685 & 0,641 & 0,538 & 0,450 & 0,380 & 0,325 & 0,282 & 0,248 \\
\hline 2,0 & 0,865 & 0,828 & 0,786 & 0,742 & 0,697 & 0,651 & 0,544 & 0,454 & 0,382 & 0,326 & 0,283 & 0,249 \\
\hline 2,1 & 0,878 & 0,841 & 0,799 & 0,754 & 0,708 & 0,661 & 0,550 & 0,457 & 0,384 & 0,327 & 0,283 & 0,249 \\
\hline 2,2 & 0,889 & 0,853 & 0,811 & 0,766 & 0,718 & 0,670 & 0,556 & 0,460 & 0,385 & 0,328 & 0,283 & 0,249 \\
\hline 2,3 & 0,900 & 0,864 & 0,822 & 0,776 & 0,728 & 0,678 & 0,561 & 0,463 & 0,386 & 0,328 & 0,284 & 0,249 \\
\hline 2,4 & 0,909 & 0,874 & 0,832 & 0,786 & 0,736 & 0,686 & 0,566 & 0,465 & 0,388 & 0,329 & 0,284 & 0,249 \\
\hline 2,5 & 0,918 & 0,883 & 0,842 & 0,795 & 0,745 & 0,693 & 0,570 & 0,468 & 0,389 & 0,329 & 0,284 & 0,249 \\
\hline 2,6 & 0,926 & 0,892 & 0,851 & 0,803 & 0,752 & 0,700 & 0,574 & 0,470 & 0,390 & 0,330 & 0,284 & 0,250 \\
\hline 2,7 & 0,933 & 0,900 & 0,859 & 0,811 & 0,760 & 0,706 & 0,577 & 0,471 & 0,390 & 0,330 & 0,285 & 0,250 \\
\hline 2,8 & 0,939 & 0,907 & 0,866 & 0,819 & 0,766 & 0,712 & 0,581 & 0,473 & 0,391 & 0,330 & 0,285 & 0,250 \\
\hline 2,9 & 0,945 & 0,914 & 0,874 & 0,826 & 0,773 & 0,717 & 0,584 & 0,474 & 0,392 & 0,331 & 0,285 & 0,250 \\
\hline 3,0 & 0,950 & 0,920 & 0,880 & 0,832 & 0,779 & 0,722 & 0,587 & 0,476 & 0,392 & 0,331 & 0,285 & 0,250 \\
\hline 3,1 & 0,955 & 0,926 & 0,886 & 0,838 & 0,784 & 0,727 & 0,590 & 0,477 & 0,393 & 0,331 & 0,285 & 0,250 \\
\hline 3,2 & 0,959 & 0,931 & 0,892 & 0,844 & 0,790 & 0,732 & 0,592 & 0,478 & 0,393 & 0,331 & 0,285 & 0,250 \\
\hline 3,3 & 0,963 & 0,936 & 0,897 & 0,850 & 0,795 & 0,736 & 0,595 & 0,479 & 0,394 & 0,331 & 0,285 & 0,250 \\
\hline 3,4 & 0,967 & 0,940 & 0,902 & 0,855 & 0,799 & 0,740 & 0,597 & 0,480 & 0,394 & 0,332 & 0,285 & 0,250 \\
\hline 3,5 & 0,970 & 0,944 & 0,907 & 0,859 & 0,804 & 0,744 & 0,599 & 0,481 & 0,395 & 0,332 & 0,285 & 0,250 \\
\hline 3,6 & 0,973 & 0,948 & 0,911 & 0,864 & 0,808 & 0,748 & 0,601 & 0,482 & 0,395 & 0,332 & 0,285 & 0,250 \\
\hline 3,7 & 0,975 & 0,951 & 0,915 & 0,868 & 0,812 & 0,751 & 0,603 & 0,483 & 0,395 & 0,332 & 0,285 & 0,250 \\
\hline 3,8 & 0,978 & 0,955 & 0,919 & 0,872 & 0,816 & 0,754 & 0,604 & 0,483 & 0,395 & 0,332 & 0,285 & 0,250 \\
\hline 3,9 & 0,980 & 0,958 & 0,923 & 0,876 & 0,819 & 0,758 & 0,606 & 0,484 & 0,396 & 0,332 & 0,285 & 0,250 \\
\hline 4,0 & 0,982 & 0,960 & 0,926 & 0,880 & 0,823 & 0,760 & 0,607 & 0,485 & 0,396 & 0,332 & 0,285 & 0,250 \\
\hline 4,1 & 0,983 & 0,963 & 0,929 & 0,883 & 0,826 & 0,763 & 0,609 & 0,485 & 0,396 & 0,332 & 0,285 & 0,250 \\
\hline 4,2 & 0,985 & 0,965 & 0,932 & 0,886 & 0,829 & 0,766 & 0,610 & 0,486 & 0,396 & 0,332 & 0,285 & 0,250 \\
\hline 4,3 & 0,986 & 0,967 & 0,935 & 0,889 & 0,832 & 0,768 & 0,611 & 0,486 & 0,396 & 0,332 & 0,285 & 0,250 \\
\hline 4,4 & 0,988 & 0,969 & 0,938 & 0,892 & 0,835 & 0,771 & 0,613 & 0,487 & 0,397 & 0,332 & 0,285 & 0,250 \\
\hline 4,5 & 0,989 & 0,971 & 0,940 & 0,895 & 0,837 & 0,773 & 0,614 & 0,487 & 0,397 & 0,333 & 0,285 & 0,250 \\
\hline 4,6 & 0,990 & 0,973 & 0,942 & 0,897 & 0,840 & 0,775 & 0,615 & 0,488 & 0,397 & 0,333 & 0,286 & 0,250 \\
\hline 4,7 & 0,991 & 0,975 & 0,945 & 0,900 & 0,842 & 0,777 & 0,616 & 0,488 & 0,397 & 0,333 & 0,286 & 0,250 \\
\hline 4,8 & 0,992 & 0,976 & 0,947 & 0,902 & 0,844 & 0,779 & 0,617 & 0,488 & 0,397 & 0,333 & 0,286 & 0,250 \\
\hline
\end{tabular}


Tabela 73 - continuação da página anterior

\begin{tabular}{|c|c|c|c|c|c|c|c|c|c|c|c|c|}
\hline${ }_{N T U}^{R}$ & 0,0 & 0,2 & 0,4 & 0,6 & 0,8 & 1,0 & 1,5 & 2,0 & 2,5 & 3,0 & 3,5 & 4,0 \\
\hline 4,9 & 0,993 & 0,978 & 0,949 & 0,904 & 0,847 & 0,781 & 0,618 & 0,489 & 0,397 & 0,333 & 0,286 & 0,250 \\
\hline 5,0 & 0,993 & 0,979 & 0,950 & 0,906 & 0,849 & 0,783 & 0,618 & 0,489 & 0,397 & 0,333 & 0,286 & 0,250 \\
\hline 5,1 & 0,994 & 0,980 & 0,952 & 0,908 & 0,851 & 0,784 & 0,619 & 0,489 & 0,397 & 0,333 & 0,286 & 0,250 \\
\hline 5,2 & 0,994 & 0,981 & 0,954 & 0,910 & 0,852 & 0,786 & 0,620 & 0,490 & 0,398 & 0,333 & 0,286 & 0,250 \\
\hline 5,3 & 0,995 & 0,982 & 0,955 & 0,912 & 0,854 & 0,788 & 0,621 & 0,490 & 0,398 & 0,333 & 0,286 & 0,250 \\
\hline 5,4 & 0,995 & 0,983 & 0,957 & 0,914 & 0,856 & 0,789 & 0,621 & 0,490 & 0,398 & 0,333 & 0,286 & 0,250 \\
\hline 5,5 & 0,996 & 0,984 & 0,958 & 0,915 & 0,857 & 0,790 & 0,622 & 0,490 & 0,398 & 0,333 & 0,286 & 0,250 \\
\hline 5,6 & 0,996 & 0,985 & 0,959 & 0,917 & 0,859 & 0,792 & 0,623 & 0,490 & 0,398 & 0,333 & 0,286 & 0,250 \\
\hline 5,7 & 0,997 & 0,986 & 0,961 & 0,918 & 0,860 & 0,793 & 0,623 & 0,491 & 0,398 & 0,333 & 0,286 & 0,250 \\
\hline 5,8 & 0,997 & 0,986 & 0,962 & 0,920 & 0,862 & 0,794 & 0,624 & 0,491 & 0,398 & 0,333 & 0,286 & 0,250 \\
\hline 5,9 & 0,997 & 0,987 & 0,963 & 0,921 & 0,863 & 0,795 & 0,624 & 0,491 & 0,398 & 0,333 & 0,286 & 0,250 \\
\hline 6,0 & 0,998 & 0,988 & 0,964 & 0,922 & 0,865 & 0,797 & 0,625 & 0,491 & 0,398 & 0,333 & 0,286 & 0,250 \\
\hline 6,1 & 0,998 & 0,988 & 0,965 & 0,923 & 0,866 & 0,798 & 0,625 & 0,491 & 0,398 & 0,333 & 0,286 & 0,250 \\
\hline 6,2 & 0,998 & 0,989 & 0,966 & 0,925 & 0,867 & 0,799 & 0,626 & 0,492 & 0,398 & 0,333 & 0,286 & 0,250 \\
\hline 6,3 & 0,998 & 0,989 & 0,967 & 0,926 & 0,868 & 0,800 & 0,626 & 0,492 & 0,398 & 0,333 & 0,286 & 0,250 \\
\hline 6,4 & 0,998 & 0,990 & 0,967 & 0,927 & 0,869 & 0,801 & 0,627 & 0,492 & 0,398 & 0,333 & 0,286 & 0,250 \\
\hline 6,5 & 0,998 & 0,990 & 0,968 & 0,928 & 0,870 & 0,801 & 0,627 & 0,492 & 0,398 & 0,333 & 0,286 & 0,250 \\
\hline 6,6 & 0,999 & 0,991 & 0,969 & 0,929 & 0,871 & 0,802 & 0,627 & 0,492 & 0,398 & 0,333 & 0,286 & 0,250 \\
\hline 6,7 & 0,999 & 0,991 & 0,970 & 0,930 & 0,872 & 0,803 & 0,628 & 0,492 & 0,398 & 0,333 & 0,286 & 0,250 \\
\hline 6,8 & 0,999 & 0,992 & 0,970 & 0,931 & 0,873 & 0,804 & 0,628 & 0,492 & 0,398 & 0,333 & 0,286 & 0,250 \\
\hline 6,9 & 0,999 & 0,992 & 0,971 & 0,931 & 0,874 & 0,805 & 0,628 & 0,492 & 0,398 & 0,333 & 0,286 & 0,250 \\
\hline 7,0 & 0,999 & 0,992 & 0,972 & 0,932 & 0,875 & 0,805 & 0,629 & 0,492 & 0,398 & 0,333 & 0,286 & 0,250 \\
\hline 7,1 & 0,999 & 0,993 & 0,972 & 0,933 & 0,875 & 0,806 & 0,629 & 0,493 & 0,398 & 0,333 & 0,286 & 0,250 \\
\hline 7,2 & 0,999 & 0,993 & 0,973 & 0,934 & 0,876 & 0,807 & 0,629 & 0,493 & 0,399 & 0,333 & 0,286 & 0,250 \\
\hline 7,3 & 0,999 & 0,993 & 0,973 & 0,934 & 0,877 & 0,807 & 0,630 & 0,493 & 0,399 & 0,333 & 0,286 & 0,250 \\
\hline 7,4 & 0,999 & 0,993 & 0,974 & 0,935 & 0,878 & 0,808 & 0,630 & 0,493 & 0,399 & 0,333 & 0,286 & 0,250 \\
\hline 7,5 & 0,999 & 0,994 & 0,974 & 0,936 & 0,878 & 0,809 & 0,630 & 0,493 & 0,399 & 0,333 & 0,286 & 0,250 \\
\hline 7,6 & 0,999 & 0,994 & 0,975 & 0,936 & 0,879 & 0,809 & 0,630 & 0,493 & 0,399 & 0,333 & 0,286 & 0,250 \\
\hline 7,7 & 1,000 & 0,994 & 0,975 & 0,937 & 0,880 & 0,810 & 0,631 & 0,493 & 0,399 & 0,333 & 0,286 & 0,250 \\
\hline 7,8 & 1,000 & 0,994 & 0,976 & 0,937 & 0,880 & 0,810 & 0,631 & 0,493 & 0,399 & 0,333 & 0,286 & 0,250 \\
\hline 7,9 & 1,000 & 0,994 & 0,976 & 0,938 & 0,881 & 0,811 & 0,631 & 0,493 & 0,399 & 0,333 & 0,286 & 0,250 \\
\hline 8,0 & 1,000 & 0,995 & 0,976 & 0,939 & 0,881 & 0,811 & 0,631 & 0,493 & 0,399 & 0,333 & 0,286 & 0,250 \\
\hline 8,1 & 1,000 & 0,995 & 0,977 & 0,939 & 0,882 & 0,812 & 0,632 & 0,493 & 0,399 & 0,333 & 0,286 & 0,250 \\
\hline 8,2 & 1,000 & 0,995 & 0,977 & 0,940 & 0,882 & 0,812 & 0,632 & 0,493 & 0,399 & 0,333 & 0,286 & 0,250 \\
\hline 8,3 & 1,000 & 0,995 & 0,977 & 0,940 & 0,883 & 0,813 & 0,632 & 0,493 & 0,399 & 0,333 & 0,286 & 0,250 \\
\hline 8,4 & 1,000 & 0,995 & 0,978 & 0,940 & 0,883 & 0,813 & 0,632 & 0,494 & 0,399 & 0,333 & 0,286 & 0,250 \\
\hline 8,5 & 1,000 & 0,995 & 0,978 & 0,941 & 0,884 & 0,813 & 0,632 & 0,494 & 0,399 & 0,333 & 0,286 & 0,250 \\
\hline 8,6 & 1,000 & 0,996 & 0,978 & 0,941 & 0,884 & 0,814 & 0,633 & 0,494 & 0,399 & 0,333 & 0,286 & 0,250 \\
\hline 8,7 & 1,000 & 0,996 & 0,979 & 0,942 & 0,885 & 0,814 & 0,633 & 0,494 & 0,399 & 0,333 & 0,286 & 0,250 \\
\hline 8,8 & 1,000 & 0,996 & 0,979 & 0,942 & 0,885 & 0,815 & 0,633 & 0,494 & 0,399 & 0,333 & 0,286 & 0,250 \\
\hline 8,9 & 1,000 & 0,996 & 0,979 & 0,942 & 0,886 & 0,815 & 0,633 & 0,494 & 0,399 & 0,333 & 0,286 & 0,250 \\
\hline 9,0 & 1,000 & 0,996 & 0,979 & 0,943 & 0,886 & 0,815 & 0,633 & 0,494 & 0,399 & 0,333 & 0,286 & 0,250 \\
\hline 9,1 & 1,000 & 0,996 & 0,980 & 0,943 & 0,886 & 0,816 & 0,633 & 0,494 & 0,399 & 0,333 & 0,286 & 0,250 \\
\hline 9,2 & 1,000 & 0,996 & 0,980 & 0,943 & 0,887 & 0,816 & 0,633 & 0,494 & 0,399 & 0,333 & 0,286 & 0,250 \\
\hline 9,3 & 1,000 & 0,996 & 0,980 & 0,944 & 0,887 & 0,816 & 0,634 & 0,494 & 0,399 & 0,333 & 0,286 & 0,250 \\
\hline 9,4 & 1,000 & 0,996 & 0,980 & 0,944 & 0,887 & 0,817 & 0,634 & 0,494 & 0,399 & 0,333 & 0,286 & 0,250 \\
\hline 9,5 & 1,000 & 0,996 & 0,980 & 0,944 & 0,888 & 0,817 & 0,634 & 0,494 & 0,399 & 0,333 & 0,286 & 0,250 \\
\hline 9,6 & 1,000 & 0,996 & 0,981 & 0,945 & 0,888 & 0,817 & 0,634 & 0,494 & 0,399 & 0,333 & 0,286 & 0,250 \\
\hline 9,7 & 1,000 & 0,997 & 0,981 & 0,945 & 0,888 & 0,817 & 0,634 & 0,494 & 0,399 & 0,333 & 0,286 & 0,250 \\
\hline 9,8 & 1,000 & 0,997 & 0,981 & 0,945 & 0,889 & 0,818 & 0,634 & 0,494 & 0,399 & 0,333 & 0,286 & 0,250 \\
\hline 9,9 & 1,000 & 0,997 & 0,981 & 0,945 & 0,889 & 0,818 & 0,634 & 0,494 & 0,399 & 0,333 & 0,286 & 0,250 \\
\hline 10,0 & 1,000 & 0,997 & 0,981 & 0,946 & 0,889 & 0,818 & 0,634 & 0,494 & 0,399 & 0,333 & 0,286 & 0,250 \\
\hline
\end{tabular}


Tabela 74 - Fator de correção para trocador de calor de fluxo cruzado com três passes e um tubo por passe (3-1) - Caso 4A - trocador de calor ilustrado na Figura 91 do Anexo A

\begin{tabular}{|c|c|c|c|c|c|c|c|c|c|c|c|c|}
\hline $\mathrm{NTU}^{R}$ & 0,0 & 0,2 & 0,4 & 0,6 & 0,8 & 1,0 & 1,5 & 2,0 & 2,5 & 3,0 & 3,5 & 4,0 \\
\hline 0,0 & 1,000 & 1,000 & 1,000 & 1,000 & 1,000 & 1,000 & 1,000 & 1,000 & 1,000 & 1,000 & 1,000 & 1,000 \\
\hline 0,1 & 1,000 & 1,000 & 1,000 & 1,000 & 1,000 & 1,000 & 1,000 & 1,000 & 1,000 & 0,999 & 0,999 & 0,999 \\
\hline 0,2 & 1,000 & 1,000 & 1,000 & 1,000 & 0,999 & 0,999 & 0,999 & 0,999 & 0,998 & 0,998 & 0,997 & 0,997 \\
\hline 0,3 & 1,000 & 1,000 & 0,999 & 0,999 & 0,999 & 0,998 & 0,998 & 0,997 & 0,996 & 0,995 & 0,994 & 0,994 \\
\hline 0,4 & 1,000 & 0,999 & 0,999 & 0,998 & 0,998 & 0,997 & 0,996 & 0,994 & 0,993 & 0,991 & 0,990 & 0,989 \\
\hline 0,5 & 1,000 & 0,999 & 0,998 & 0,997 & 0,996 & 0,995 & 0,993 & 0,991 & 0,989 & 0,987 & 0,985 & 0,983 \\
\hline 0,6 & 1,000 & 0,999 & 0,997 & 0,996 & 0,995 & 0,993 & 0,990 & 0,987 & 0,984 & 0,981 & 0,979 & 0,976 \\
\hline 0,7 & 1,000 & 0,998 & 0,996 & 0,995 & 0,993 & 0,991 & 0,987 & 0,983 & 0,979 & 0,975 & 0,972 & 0,968 \\
\hline 0,8 & 1,000 & 0,998 & 0,995 & 0,993 & 0,991 & 0,989 & 0,983 & 0,978 & 0,973 & 0,968 & 0,964 & 0,960 \\
\hline 0,9 & 1,000 & 0,997 & 0,994 & 0,991 & 0,988 & 0,986 & 0,979 & 0,972 & 0,966 & 0,961 & 0,955 & 0,950 \\
\hline 1,0 & 1,000 & 0,996 & 0,993 & 0,989 & 0,986 & 0,982 & 0,974 & 0,966 & 0,959 & 0,952 & 0,946 & 0,940 \\
\hline 1,1 & 1,000 & 0,996 & 0,991 & 0,987 & 0,983 & 0,979 & 0,969 & 0,960 & 0,951 & 0,944 & 0,937 & 0,930 \\
\hline 1,2 & 1,000 & 0,995 & 0,990 & 0,984 & 0,980 & 0,975 & 0,963 & 0,953 & 0,943 & 0,935 & 0,927 & 0,920 \\
\hline 1,3 & 1,000 & 0,994 & 0,988 & 0,982 & 0,976 & 0,971 & 0,958 & 0,946 & 0,935 & 0,925 & 0,917 & 0,909 \\
\hline 1,4 & 1,000 & 0,993 & 0,986 & 0,979 & 0,972 & 0,966 & 0,951 & 0,938 & 0,926 & 0,916 & 0,906 & 0,898 \\
\hline 1,5 & 1,000 & 0,992 & 0,984 & 0,976 & 0,969 & 0,961 & 0,945 & 0,930 & 0,917 & 0,906 & 0,896 & 0,887 \\
\hline 1,6 & 1,000 & 0,991 & 0,982 & 0,973 & 0,964 & 0,956 & 0,938 & 0,922 & 0,908 & 0,896 & 0,885 & 0,876 \\
\hline 1,7 & 1,000 & 0,989 & 0,979 & 0,969 & 0,960 & 0,951 & 0,931 & 0,914 & 0,898 & 0,885 & 0,874 & 0,864 \\
\hline 1,8 & 1,000 & 0,988 & 0,977 & 0,966 & 0,956 & 0,946 & 0,924 & 0,905 & 0,889 & 0,875 & 0,863 & 0,853 \\
\hline 1,9 & 1,000 & 0,987 & 0,974 & 0,962 & 0,951 & 0,940 & 0,916 & 0,896 & 0,879 & 0,865 & 0,852 & 0,842 \\
\hline 2,0 & 1,000 & 0,985 & 0,971 & 0,958 & 0,946 & 0,934 & 0,909 & 0,887 & 0,869 & 0,854 & 0,842 & 0,831 \\
\hline 2,1 & 1,000 & 0,984 & 0,969 & 0,954 & 0,941 & 0,928 & 0,901 & 0,878 & 0,859 & 0,844 & 0,831 & 0,820 \\
\hline 2,2 & 1,000 & 0,982 & 0,966 & 0,950 & 0,936 & 0,922 & 0,893 & 0,869 & 0,849 & 0,833 & 0,820 & 0,809 \\
\hline 2,3 & 1,000 & 0,981 & 0,962 & 0,946 & 0,930 & 0,916 & 0,885 & 0,860 & 0,839 & 0,823 & 0,809 & 0,798 \\
\hline 2,4 & 1,000 & 0,979 & 0,959 & 0,941 & 0,925 & 0,909 & 0,877 & 0,851 & 0,830 & 0,813 & 0,799 & 0,787 \\
\hline 2,5 & 1,000 & 0,977 & 0,956 & 0,937 & 0,919 & 0,903 & 0,868 & 0,841 & 0,820 & 0,802 & 0,788 & 0,777 \\
\hline 2,6 & 1,000 & 0,975 & 0,952 & 0,932 & 0,913 & 0,896 & 0,860 & 0,832 & 0,810 & 0,792 & 0,778 & 0,766 \\
\hline 2,7 & 1,000 & 0,973 & 0,949 & 0,927 & 0,907 & 0,889 & 0,852 & 0,823 & 0,800 & 0,782 & 0,767 & 0,756 \\
\hline 2,8 & 1,000 & 0,971 & 0,945 & 0,922 & 0,901 & 0,882 & 0,843 & 0,813 & 0,790 & 0,772 & 0,757 & 0,746 \\
\hline 2,9 & 1,000 & 0,969 & 0,941 & 0,917 & 0,895 & 0,875 & 0,835 & 0,804 & 0,780 & 0,762 & 0,747 & 0,736 \\
\hline 3,0 & 1,000 & 0,967 & 0,938 & 0,911 & 0,888 & 0,868 & 0,826 & 0,795 & 0,771 & 0,752 & 0,737 & 0,726 \\
\hline 3,1 & 1,000 & 0,965 & 0,934 & 0,906 & 0,882 & 0,861 & 0,818 & 0,786 & 0,761 & 0,743 & 0,728 & 0,716 \\
\hline 3,2 & 1,000 & 0,962 & 0,929 & 0,901 & 0,875 & 0,853 & 0,809 & 0,777 & 0,752 & 0,733 & 0,718 & 0,706 \\
\hline 3,3 & 1,000 & 0,960 & 0,925 & 0,895 & 0,869 & 0,846 & 0,801 & 0,767 & 0,743 & 0,724 & 0,709 & 0,697 \\
\hline 3,4 & 1,000 & 0,958 & 0,921 & 0,889 & 0,862 & 0,839 & 0,792 & 0,758 & 0,733 & 0,714 & 0,699 & 0,688 \\
\hline 3,5 & 1,000 & 0,955 & 0,917 & 0,884 & 0,855 & 0,831 & 0,784 & 0,750 & 0,724 & 0,705 & 0,690 & 0,679 \\
\hline 3,6 & 1,000 & 0,952 & 0,912 & 0,878 & 0,849 & 0,824 & 0,775 & 0,741 & 0,715 & 0,696 & 0,681 & 0,670 \\
\hline 3,7 & 1,000 & 0,950 & 0,908 & 0,872 & 0,842 & 0,816 & 0,767 & 0,732 & 0,707 & 0,687 & 0,673 & 0,661 \\
\hline 3,8 & 1,000 & 0,947 & 0,903 & 0,866 & 0,835 & 0,809 & 0,759 & 0,723 & 0,698 & 0,679 & 0,664 & 0,652 \\
\hline 3,9 & 1,000 & 0,944 & 0,898 & 0,860 & 0,828 & 0,801 & 0,750 & 0,715 & 0,689 & 0,670 & 0,655 & 0,644 \\
\hline 4,0 & 1,000 & 0,941 & 0,893 & 0,854 & 0,821 & 0,794 & 0,742 & 0,706 & 0,681 & 0,662 & 0,647 & 0,635 \\
\hline 4,1 & 1,000 & 0,938 & 0,889 & 0,848 & 0,814 & 0,786 & 0,734 & 0,698 & 0,672 & 0,653 & 0,639 & 0,627 \\
\hline 4,2 & 1,000 & 0,935 & 0,884 & 0,842 & 0,807 & 0,779 & 0,726 & 0,690 & 0,664 & 0,645 & 0,631 & 0,619 \\
\hline 4,3 & 1,000 & 0,932 & 0,879 & 0,835 & 0,800 & 0,771 & 0,718 & 0,682 & 0,656 & 0,637 & 0,623 & 0,611 \\
\hline 4,4 & 1,000 & 0,929 & 0,874 & 0,829 & 0,793 & 0,764 & 0,710 & 0,674 & 0,648 & 0,629 & 0,615 & 0,604 \\
\hline 4,5 & 1,000 & 0,926 & 0,868 & 0,823 & 0,786 & 0,757 & 0,702 & 0,666 & 0,640 & 0,621 & 0,607 & 0,596 \\
\hline 4,6 & 1,000 & 0,923 & 0,863 & 0,817 & 0,779 & 0,749 & 0,695 & 0,658 & 0,632 & 0,614 & 0,600 & 0,589 \\
\hline 4,7 & 1,000 & 0,919 & 0,858 & 0,810 & 0,773 & 0,742 & 0,687 & 0,650 & 0,625 & 0,606 & 0,592 & 0,581 \\
\hline 4,8 & 1,000 & 0,916 & 0,853 & 0,804 & 0,766 & 0,735 & 0,679 & 0,643 & 0,617 & 0,599 & 0,585 & 0,574 \\
\hline 4,9 & 1,000 & 0,913 & 0,847 & 0,798 & 0,759 & 0,728 & 0,672 & 0,635 & 0,610 & 0,592 & 0,578 & 0,567 \\
\hline
\end{tabular}


Tabela 74 - continuação da página anterior

\begin{tabular}{|c|c|c|c|c|c|c|c|c|c|c|c|c|}
\hline $\mathrm{NTU}^{R}$ & 0,0 & 0,2 & 0,4 & 0,6 & 0,8 & 1,0 & 1,5 & 2,0 & 2,5 & 3,0 & 3,5 & 4,0 \\
\hline 5,0 & 1,000 & 0,909 & 0,842 & 0,791 & 0,752 & 0,720 & 0,665 & 0,628 & 0,603 & 0,584 & 0,571 & 0,560 \\
\hline 5,1 & 1,000 & 0,906 & 0,837 & 0,785 & 0,745 & 0,713 & 0,657 & 0,621 & 0,596 & 0,577 & 0,564 & 0,553 \\
\hline 5,2 & 1,000 & 0,902 & 0,831 & 0,779 & 0,738 & 0,706 & 0,650 & 0,614 & 0,589 & 0,570 & 0,557 & 0,547 \\
\hline 5,3 & 1,000 & 0,898 & 0,826 & 0,772 & 0,731 & 0,699 & 0,643 & 0,607 & 0,582 & 0,564 & 0,550 & 0,540 \\
\hline 5,4 & 1,000 & 0,894 & 0,820 & 0,766 & 0,725 & 0,692 & 0,636 & 0,600 & 0,575 & 0,557 & 0,544 & 0,534 \\
\hline 5,5 & 1,000 & 0,891 & 0,815 & 0,760 & 0,718 & 0,686 & 0,629 & 0,593 & 0,568 & 0,551 & 0,537 & 0,527 \\
\hline 5,6 & 1,000 & 0,887 & 0,809 & 0,753 & 0,711 & 0,679 & 0,622 & 0,586 & 0,562 & 0,544 & 0,531 & 0,521 \\
\hline 5,7 & 1,000 & 0,883 & 0,804 & 0,747 & 0,705 & 0,672 & 0,616 & 0,580 & 0,555 & 0,538 & 0,525 & 0,515 \\
\hline 5,8 & 1,000 & 0,879 & 0,798 & 0,741 & 0,698 & 0,665 & 0,609 & 0,573 & 0,549 & 0,532 & 0,519 & 0,509 \\
\hline 5,9 & 1,000 & 0,875 & 0,792 & 0,735 & 0,692 & 0,659 & 0,602 & 0,567 & 0,543 & 0,526 & 0,513 & 0,503 \\
\hline 6,0 & 1,000 & 0,871 & 0,787 & 0,728 & 0,685 & 0,652 & 0,596 & 0,560 & 0,537 & 0,520 & 0,507 & 0,497 \\
\hline 6,1 & 1,000 & 0,867 & 0,781 & 0,722 & 0,679 & 0,646 & 0,590 & 0,554 & 0,531 & 0,514 & 0,501 & 0,492 \\
\hline 6,2 & 1,000 & 0,862 & 0,775 & 0,716 & 0,673 & 0,640 & 0,583 & 0,548 & 0,525 & 0,508 & 0,496 & 0,486 \\
\hline 6,3 & 1,000 & 0,858 & 0,770 & 0,710 & 0,666 & 0,633 & 0,577 & 0,542 & 0,519 & 0,502 & 0,490 & 0,481 \\
\hline 6,4 & 1,000 & 0,854 & 0,764 & 0,704 & 0,660 & 0,627 & 0,571 & 0,536 & 0,513 & 0,497 & 0,484 & 0,475 \\
\hline 6,5 & 1,000 & 0,850 & 0,759 & 0,698 & 0,654 & 0,621 & 0,565 & 0,531 & 0,507 & 0,491 & 0,479 & 0,470 \\
\hline 6,6 & 1,000 & 0,845 & 0,753 & 0,692 & 0,648 & 0,615 & 0,559 & 0,525 & 0,502 & 0,486 & 0,474 & 0,465 \\
\hline 6,7 & 1,000 & 0,841 & 0,747 & 0,686 & 0,642 & 0,609 & 0,553 & 0,519 & 0,497 & 0,480 & 0,469 & 0,460 \\
\hline 6,8 & 1,000 & 0,837 & 0,742 & 0,680 & 0,636 & 0,603 & 0,548 & 0,514 & 0,491 & 0,475 & 0,464 & 0,455 \\
\hline 6,9 & 1,000 & 0,832 & 0,736 & 0,674 & 0,630 & 0,597 & 0,542 & 0,508 & 0,486 & 0,470 & 0,459 & 0,450 \\
\hline 7,0 & 1,000 & 0,828 & 0,731 & 0,668 & 0,624 & 0,591 & 0,536 & 0,503 & 0,481 & 0,465 & 0,454 & 0,445 \\
\hline 7,1 & 1,000 & 0,823 & 0,725 & 0,662 & 0,618 & 0,586 & 0,531 & 0,498 & 0,476 & 0,460 & 0,449 & 0,440 \\
\hline 7,2 & 1,000 & 0,819 & 0,720 & 0,657 & 0,613 & 0,580 & 0,526 & 0,493 & 0,471 & 0,455 & 0,444 & 0,436 \\
\hline 7,3 & 1,000 & 0,814 & 0,714 & 0,651 & 0,607 & 0,574 & 0,520 & 0,488 & 0,466 & 0,451 & 0,439 & 0,431 \\
\hline 7,4 & 1,000 & 0,810 & 0,709 & 0,645 & 0,601 & 0,569 & 0,515 & 0,483 & 0,461 & 0,446 & 0,435 & 0,426 \\
\hline 7,5 & 1,000 & 0,805 & 0,703 & 0,640 & 0,596 & 0,563 & 0,510 & 0,478 & 0,456 & 0,441 & 0,430 & 0,422 \\
\hline 7,6 & 1,000 & 0,800 & 0,698 & 0,634 & 0,590 & 0,558 & 0,505 & 0,473 & 0,452 & 0,437 & 0,426 & 0,418 \\
\hline 7,7 & 1,000 & 0,796 & 0,693 & 0,629 & 0,585 & 0,553 & 0,500 & 0,468 & 0,447 & 0,432 & 0,422 & 0,413 \\
\hline 7,8 & 1,000 & 0,791 & 0,687 & 0,623 & 0,580 & 0,548 & 0,495 & 0,463 & 0,442 & 0,428 & 0,417 & 0,409 \\
\hline 7,9 & 1,000 & 0,786 & 0,682 & 0,618 & 0,575 & 0,542 & 0,490 & 0,459 & 0,438 & 0,424 & 0,413 & 0,405 \\
\hline 8,0 & 1,000 & 0,782 & 0,677 & 0,613 & 0,569 & 0,537 & 0,485 & 0,454 & 0,434 & 0,419 & 0,409 & 0,401 \\
\hline 8,1 & 1,000 & 0,777 & 0,671 & 0,608 & 0,564 & 0,532 & 0,481 & 0,450 & 0,429 & 0,415 & 0,405 & 0,397 \\
\hline 8,2 & 1,000 & 0,772 & 0,666 & 0,602 & 0,559 & 0,527 & 0,476 & 0,445 & 0,425 & 0,411 & 0,401 & 0,393 \\
\hline 8,3 & 1,000 & 0,768 & 0,661 & 0,597 & 0,554 & 0,523 & 0,472 & 0,441 & 0,421 & 0,407 & 0,397 & 0,389 \\
\hline 8,4 & 1,000 & 0,763 & 0,656 & 0,592 & 0,549 & 0,518 & 0,467 & 0,437 & 0,417 & 0,403 & 0,393 & 0,385 \\
\hline 8,5 & 1,000 & 0,758 & 0,651 & 0,587 & 0,544 & 0,513 & 0,463 & 0,433 & 0,413 & 0,399 & 0,389 & 0,382 \\
\hline 8,6 & 1,000 & 0,754 & 0,646 & 0,582 & 0,539 & 0,508 & 0,458 & 0,428 & 0,409 & 0,395 & 0,385 & 0,378 \\
\hline 8,7 & 1,000 & 0,749 & 0,641 & 0,577 & 0,535 & 0,504 & 0,454 & 0,424 & 0,405 & 0,391 & 0,382 & 0,374 \\
\hline 8,8 & 1,000 & 0,744 & 0,636 & 0,572 & 0,530 & 0,499 & 0,450 & 0,420 & 0,401 & 0,388 & 0,378 & 0,371 \\
\hline 8,9 & 1,000 & 0,740 & 0,631 & 0,568 & 0,525 & 0,495 & 0,446 & 0,416 & 0,397 & 0,384 & 0,375 & 0,367 \\
\hline 9,0 & 1,000 & 0,735 & 0,626 & 0,563 & 0,521 & 0,490 & 0,442 & 0,413 & 0,394 & 0,381 & 0,371 & 0,364 \\
\hline 9,1 & 1,000 & 0,730 & 0,621 & 0,558 & 0,516 & 0,486 & 0,438 & 0,409 & 0,390 & 0,377 & 0,368 & 0,360 \\
\hline 9,2 & 1,000 & 0,726 & 0,616 & 0,553 & 0,512 & 0,482 & 0,434 & 0,405 & 0,386 & 0,373 & 0,364 & 0,357 \\
\hline 9,3 & 1,000 & 0,721 & 0,611 & 0,549 & 0,507 & 0,478 & 0,430 & 0,401 & 0,383 & 0,370 & 0,361 & 0,354 \\
\hline 9,4 & 1,000 & 0,716 & 0,607 & 0,544 & 0,503 & 0,473 & 0,426 & 0,398 & 0,379 & 0,367 & 0,357 & 0,351 \\
\hline 9,5 & 1,000 & 0,712 & 0,602 & 0,540 & 0,499 & 0,469 & 0,422 & 0,394 & 0,376 & 0,363 & 0,354 & 0,347 \\
\hline 9,6 & 1,000 & 0,707 & 0,597 & 0,535 & 0,495 & 0,465 & 0,418 & 0,391 & 0,373 & 0,360 & 0,351 & 0,344 \\
\hline 9,7 & 1,000 & 0,702 & 0,593 & 0,531 & 0,490 & 0,461 & 0,415 & 0,387 & 0,369 & 0,357 & 0,348 & 0,341 \\
\hline 9,8 & 1,000 & 0,698 & 0,588 & 0,527 & 0,486 & 0,457 & 0,411 & 0,384 & 0,366 & 0,354 & 0,345 & 0,338 \\
\hline 9,9 & 1,000 & 0,693 & 0,584 & 0,522 & 0,482 & 0,453 & 0,407 & 0,380 & 0,363 & 0,351 & 0,342 & 0,335 \\
\hline 10,0 & 1,000 & 0,689 & 0,579 & 0,518 & 0,478 & 0,450 & 0,404 & 0,377 & 0,360 & 0,347 & 0,339 & 0,332 \\
\hline
\end{tabular}


Tabela 75 - Efetividade de temperatura para trocador de calor de fluxo cruzado com três passes e dois tubos por passe (3-2) - Caso 4A - trocador de calor ilustrado na Figura 105 do Anexo A

\begin{tabular}{|c|c|c|c|c|c|c|c|c|c|c|c|c|}
\hline $\mathrm{NTU}^{R}$ & 0,0 & 0,2 & 0,4 & 0,6 & 0,8 & 1,0 & 1,5 & 2,0 & 2,5 & 3,0 & 3,5 & 4,0 \\
\hline 0,0 & 0,000 & 0,000 & 0,000 & 0,000 & 0,000 & 0,000 & 0,000 & 0,000 & 0,000 & 0,000 & 0,000 & 0,000 \\
\hline 0,1 & 0,095 & 0,094 & 0,094 & 0,093 & 0,092 & 0,091 & 0,089 & 0,087 & 0,085 & 0,083 & 0,081 & 0,080 \\
\hline 0,2 & 0,181 & 0,178 & 0,175 & 0,172 & 0,169 & 0,167 & 0,160 & 0,153 & 0,147 & 0,141 & 0,136 & 0,131 \\
\hline 0,3 & 0,259 & 0,253 & 0,247 & 0,242 & 0,236 & 0,231 & 0,218 & 0,205 & 0,194 & 0,184 & 0,174 & 0,165 \\
\hline 0,4 & 0,330 & 0,320 & 0,311 & 0,302 & 0,294 & 0,285 & 0,265 & 0,247 & 0,230 & 0,215 & 0,201 & 0,188 \\
\hline 0,5 & 0,394 & 0,381 & 0,368 & 0,356 & 0,344 & 0,332 & 0,306 & 0,281 & 0,259 & 0,239 & 0,221 & 0,205 \\
\hline 0,6 & 0,451 & 0,435 & 0,419 & 0,403 & 0,388 & 0,374 & 0,340 & 0,309 & 0,282 & 0,257 & 0,235 & 0,216 \\
\hline 0,7 & 0,503 & 0,484 & 0,464 & 0,445 & 0,427 & 0,410 & 0,369 & 0,332 & 0,300 & 0,271 & 0,246 & 0,225 \\
\hline 0,8 & 0,551 & 0,528 & 0,505 & 0,483 & 0,462 & 0,442 & 0,394 & 0,352 & 0,315 & 0,283 & 0,255 & 0,231 \\
\hline 0,9 & 0,593 & 0,568 & 0,542 & 0,518 & 0,494 & 0,470 & 0,416 & 0,369 & 0,327 & 0,292 & 0,261 & 0,235 \\
\hline 1,0 & 0,632 & 0,604 & 0,576 & 0,548 & 0,522 & 0,496 & 0,436 & 0,383 & 0,337 & 0,299 & 0,266 & 0,239 \\
\hline 1,1 & 0,667 & 0,637 & 0,606 & 0,576 & 0,547 & 0,519 & 0,453 & 0,395 & 0,346 & 0,305 & 0,270 & 0,241 \\
\hline 1,2 & 0,699 & 0,667 & 0,634 & 0,602 & 0,570 & 0,540 & 0,468 & 0,406 & 0,353 & 0,309 & 0,273 & 0,243 \\
\hline 1,3 & 0,727 & 0,694 & 0,660 & 0,625 & 0,591 & 0,558 & 0,482 & 0,415 & 0,359 & 0,313 & 0,275 & 0,245 \\
\hline 1,4 & 0,753 & 0,719 & 0,683 & 0,647 & 0,611 & 0,576 & 0,494 & 0,423 & 0,364 & 0,316 & 0,277 & 0,246 \\
\hline 1,5 & 0,777 & 0,741 & 0,704 & 0,666 & 0,629 & 0,591 & 0,505 & 0,430 & 0,368 & 0,319 & 0,279 & 0,247 \\
\hline 1,6 & 0,798 & 0,762 & 0,724 & 0,684 & 0,645 & 0,606 & 0,515 & 0,436 & 0,372 & 0,321 & 0,280 & 0,247 \\
\hline 1,7 & 0,817 & 0,781 & 0,741 & 0,701 & 0,660 & 0,619 & 0,524 & 0,442 & 0,375 & 0,323 & 0,281 & 0,248 \\
\hline 1,8 & 0,835 & 0,798 & 0,758 & 0,716 & 0,674 & 0,631 & 0,532 & 0,447 & 0,378 & 0,324 & 0,282 & 0,248 \\
\hline 1,9 & 0,850 & 0,814 & 0,773 & 0,731 & 0,687 & 0,643 & 0,539 & 0,451 & 0,381 & 0,325 & 0,282 & 0,249 \\
\hline 2,0 & 0,865 & 0,828 & 0,787 & 0,744 & 0,699 & 0,653 & 0,546 & 0,455 & 0,383 & 0,326 & 0,283 & 0,249 \\
\hline 2,1 & 0,878 & 0,841 & 0,800 & 0,756 & 0,710 & 0,663 & 0,552 & 0,458 & 0,384 & 0,327 & 0,283 & 0,249 \\
\hline 2,2 & 0,889 & 0,853 & 0,812 & 0,767 & 0,720 & 0,672 & 0,558 & 0,462 & 0,386 & 0,328 & 0,284 & 0,249 \\
\hline 2,3 & 0,900 & 0,865 & 0,824 & 0,778 & 0,730 & 0,681 & 0,563 & 0,464 & 0,387 & 0,329 & 0,284 & 0,249 \\
\hline 2,4 & 0,909 & 0,875 & 0,834 & 0,788 & 0,739 & 0,689 & 0,568 & 0,467 & 0,389 & 0,329 & 0,284 & 0,249 \\
\hline 2,5 & 0,918 & 0,884 & 0,844 & 0,797 & 0,748 & 0,696 & 0,573 & 0,469 & 0,390 & 0,330 & 0,284 & 0,250 \\
\hline 2,6 & 0,926 & 0,893 & 0,853 & 0,806 & 0,756 & 0,703 & 0,577 & 0,471 & 0,391 & 0,330 & 0,285 & 0,250 \\
\hline 2,7 & 0,933 & 0,901 & 0,861 & 0,814 & 0,763 & 0,710 & 0,581 & 0,473 & 0,391 & 0,331 & 0,285 & 0,250 \\
\hline 2,8 & 0,939 & 0,908 & 0,869 & 0,822 & 0,770 & 0,716 & 0,584 & 0,475 & 0,392 & 0,331 & 0,285 & 0,250 \\
\hline 2,9 & 0,945 & 0,915 & 0,876 & 0,829 & 0,777 & 0,722 & 0,588 & 0,477 & 0,393 & 0,331 & 0,285 & 0,250 \\
\hline 3,0 & 0,950 & 0,921 & 0,883 & 0,836 & 0,783 & 0,727 & 0,591 & 0,478 & 0,394 & 0,331 & 0,285 & 0,250 \\
\hline 3,1 & 0,955 & 0,927 & 0,889 & 0,842 & 0,789 & 0,732 & 0,594 & 0,479 & 0,394 & 0,332 & 0,285 & 0,250 \\
\hline 3,2 & 0,959 & 0,932 & 0,895 & 0,848 & 0,795 & 0,737 & 0,596 & 0,481 & 0,395 & 0,332 & 0,285 & 0,250 \\
\hline 3,3 & 0,963 & 0,937 & 0,900 & 0,854 & 0,800 & 0,742 & 0,599 & 0,482 & 0,395 & 0,332 & 0,285 & 0,250 \\
\hline 3,4 & 0,967 & 0,941 & 0,906 & 0,859 & 0,805 & 0,747 & 0,601 & 0,483 & 0,395 & 0,332 & 0,285 & 0,250 \\
\hline 3,5 & 0,970 & 0,946 & 0,910 & 0,864 & 0,810 & 0,751 & 0,604 & 0,484 & 0,396 & 0,332 & 0,285 & 0,250 \\
\hline 3,6 & 0,973 & 0,949 & 0,915 & 0,869 & 0,815 & 0,755 & 0,606 & 0,485 & 0,396 & 0,332 & 0,285 & 0,250 \\
\hline 3,7 & 0,975 & 0,953 & 0,919 & 0,874 & 0,819 & 0,759 & 0,608 & 0,485 & 0,396 & 0,332 & 0,285 & 0,250 \\
\hline 3,8 & 0,978 & 0,956 & 0,923 & 0,878 & 0,823 & 0,762 & 0,610 & 0,486 & 0,397 & 0,332 & 0,286 & 0,250 \\
\hline 3,9 & 0,980 & 0,959 & 0,927 & 0,882 & 0,827 & 0,766 & 0,612 & 0,487 & 0,397 & 0,333 & 0,286 & 0,250 \\
\hline 4,0 & 0,982 & 0,962 & 0,930 & 0,886 & 0,831 & 0,769 & 0,613 & 0,488 & 0,397 & 0,333 & 0,286 & 0,250 \\
\hline 4,1 & 0,983 & 0,965 & 0,934 & 0,890 & 0,835 & 0,772 & 0,615 & 0,488 & 0,397 & 0,333 & 0,286 & 0,250 \\
\hline 4,2 & 0,985 & 0,967 & 0,937 & 0,893 & 0,838 & 0,775 & 0,617 & 0,489 & 0,397 & 0,333 & 0,286 & 0,250 \\
\hline 4,3 & 0,986 & 0,969 & 0,940 & 0,897 & 0,841 & 0,778 & 0,618 & 0,489 & 0,398 & 0,333 & 0,286 & 0,250 \\
\hline 4,4 & 0,988 & 0,971 & 0,942 & 0,900 & 0,844 & 0,781 & 0,619 & 0,490 & 0,398 & 0,333 & 0,286 & 0,250 \\
\hline 4,5 & 0,989 & 0,973 & 0,945 & 0,903 & 0,848 & 0,784 & 0,621 & 0,490 & 0,398 & 0,333 & 0,286 & 0,250 \\
\hline 4,6 & 0,990 & 0,975 & 0,948 & 0,906 & 0,850 & 0,786 & 0,622 & 0,491 & 0,398 & 0,333 & 0,286 & 0,250 \\
\hline 4,7 & 0,991 & 0,977 & 0,950 & 0,908 & 0,853 & 0,789 & 0,623 & 0,491 & 0,398 & 0,333 & 0,286 & 0,250 \\
\hline 4,8 & 0,992 & 0,978 & 0,952 & 0,911 & 0,856 & 0,791 & 0,624 & 0,492 & 0,398 & 0,333 & 0,286 & 0,250 \\
\hline
\end{tabular}


Tabela 75 - continuação da página anterior

\begin{tabular}{|c|c|c|c|c|c|c|c|c|c|c|c|c|}
\hline${ }_{N T U}^{R}$ & 0,0 & 0,2 & 0,4 & 0,6 & 0,8 & 1,0 & 1,5 & 2,0 & 2,5 & 3,0 & 3,5 & 4,0 \\
\hline 4,9 & 0,993 & 0,980 & 0,954 & 0,914 & 0,858 & 0,793 & 0,625 & 0,492 & 0,398 & 0,333 & 0,286 & 0,250 \\
\hline 5,0 & 0,993 & 0,981 & 0,956 & 0,916 & 0,861 & 0,796 & 0,626 & 0,492 & 0,398 & 0,333 & 0,286 & 0,250 \\
\hline 5,1 & 0,994 & 0,982 & 0,958 & 0,918 & 0,863 & 0,798 & 0,627 & 0,493 & 0,399 & 0,333 & 0,286 & 0,250 \\
\hline 5,2 & 0,994 & 0,983 & 0,960 & 0,920 & 0,866 & 0,800 & 0,628 & 0,493 & 0,399 & 0,333 & 0,286 & 0,250 \\
\hline 5,3 & 0,995 & 0,984 & 0,961 & 0,922 & 0,868 & 0,802 & 0,629 & 0,493 & 0,399 & 0,333 & 0,286 & 0,250 \\
\hline 5,4 & 0,995 & 0,985 & 0,963 & 0,924 & 0,870 & 0,804 & 0,630 & 0,493 & 0,399 & 0,333 & 0,286 & 0,250 \\
\hline 5,5 & 0,996 & 0,986 & 0,964 & 0,926 & 0,872 & 0,805 & 0,631 & 0,494 & 0,399 & 0,333 & 0,286 & 0,250 \\
\hline 5,6 & 0,996 & 0,987 & 0,966 & 0,928 & 0,874 & 0,807 & 0,632 & 0,494 & 0,399 & 0,333 & 0,286 & 0,250 \\
\hline 5,7 & 0,997 & 0,988 & 0,967 & 0,930 & 0,876 & 0,809 & 0,633 & 0,494 & 0,399 & 0,333 & 0,286 & 0,250 \\
\hline 5,8 & 0,997 & 0,989 & 0,968 & 0,932 & 0,878 & 0,811 & 0,633 & 0,494 & 0,399 & 0,333 & 0,286 & 0,250 \\
\hline 5,9 & 0,997 & 0,989 & 0,970 & 0,933 & 0,879 & 0,812 & 0,634 & 0,495 & 0,399 & 0,333 & 0,286 & 0,250 \\
\hline 6,0 & 0,998 & 0,990 & 0,971 & 0,935 & 0,881 & 0,814 & 0,635 & 0,495 & 0,399 & 0,333 & 0,286 & 0,250 \\
\hline 6,1 & 0,998 & 0,990 & 0,972 & 0,936 & 0,883 & 0,815 & 0,635 & 0,495 & 0,399 & 0,333 & 0,286 & 0,250 \\
\hline 6,2 & 0,998 & 0,991 & 0,973 & 0,938 & 0,884 & 0,817 & 0,636 & 0,495 & 0,399 & 0,333 & 0,286 & 0,250 \\
\hline 6,3 & 0,998 & 0,992 & 0,974 & 0,939 & 0,886 & 0,818 & 0,637 & 0,495 & 0,399 & 0,333 & 0,286 & 0,250 \\
\hline 6,4 & 0,998 & 0,992 & 0,975 & 0,941 & 0,887 & 0,819 & 0,637 & 0,495 & 0,399 & 0,333 & 0,286 & 0,250 \\
\hline 6,5 & 0,998 & 0,992 & 0,976 & 0,942 & 0,889 & 0,821 & 0,638 & 0,496 & 0,399 & 0,333 & 0,286 & 0,250 \\
\hline 6,6 & 0,999 & 0,993 & 0,977 & 0,943 & 0,890 & 0,822 & 0,638 & 0,496 & 0,399 & 0,333 & 0,286 & 0,250 \\
\hline 6,7 & 0,999 & 0,993 & 0,977 & 0,944 & 0,892 & 0,823 & 0,639 & 0,496 & 0,399 & 0,333 & 0,286 & 0,250 \\
\hline 6,8 & 0,999 & 0,994 & 0,978 & 0,945 & 0,893 & 0,824 & 0,639 & 0,496 & 0,399 & 0,333 & 0,286 & 0,250 \\
\hline 6,9 & 0,999 & 0,994 & 0,979 & 0,947 & 0,894 & 0,826 & 0,640 & 0,496 & 0,399 & 0,333 & 0,286 & 0,250 \\
\hline 7,0 & 0,999 & 0,994 & 0,980 & 0,948 & 0,895 & 0,827 & 0,640 & 0,496 & 0,399 & 0,333 & 0,286 & 0,250 \\
\hline 7,1 & 0,999 & 0,995 & 0,980 & 0,949 & 0,897 & 0,828 & 0,641 & 0,496 & 0,399 & 0,333 & 0,286 & 0,250 \\
\hline 7,2 & 0,999 & 0,995 & 0,981 & 0,950 & 0,898 & 0,829 & 0,641 & 0,496 & 0,400 & 0,333 & 0,286 & 0,250 \\
\hline 7,3 & 0,999 & 0,995 & 0,981 & 0,951 & 0,899 & 0,830 & 0,642 & 0,497 & 0,400 & 0,333 & 0,286 & 0,250 \\
\hline 7,4 & 0,999 & 0,996 & 0,982 & 0,952 & 0,900 & 0,831 & 0,642 & 0,497 & 0,400 & 0,333 & 0,286 & 0,250 \\
\hline 7,5 & 0,999 & 0,996 & 0,983 & 0,952 & 0,901 & 0,832 & 0,642 & 0,497 & 0,400 & 0,333 & 0,286 & 0,250 \\
\hline 7,6 & 0,999 & 0,996 & 0,983 & 0,953 & 0,902 & 0,833 & 0,643 & 0,497 & 0,400 & 0,333 & 0,286 & 0,250 \\
\hline 7,7 & 1,000 & 0,996 & 0,984 & 0,954 & 0,903 & 0,834 & 0,643 & 0,497 & 0,400 & 0,333 & 0,286 & 0,250 \\
\hline 7,8 & 1,000 & 0,996 & 0,984 & 0,955 & 0,904 & 0,835 & 0,643 & 0,497 & 0,400 & 0,333 & 0,286 & 0,250 \\
\hline 7,9 & 1,000 & 0,997 & 0,985 & 0,956 & 0,905 & 0,836 & 0,644 & 0,497 & 0,400 & 0,333 & 0,286 & 0,250 \\
\hline 8,0 & 1,000 & 0,997 & 0,985 & 0,957 & 0,906 & 0,837 & 0,644 & 0,497 & 0,400 & 0,333 & 0,286 & 0,250 \\
\hline 8,1 & 1,000 & 0,997 & 0,986 & 0,957 & 0,907 & 0,837 & 0,644 & 0,497 & 0,400 & 0,333 & 0,286 & 0,250 \\
\hline 8,2 & 1,000 & 0,997 & 0,986 & 0,958 & 0,908 & 0,838 & 0,645 & 0,497 & 0,400 & 0,333 & 0,286 & 0,250 \\
\hline 8,3 & 1,000 & 0,997 & 0,986 & 0,959 & 0,909 & 0,839 & 0,645 & 0,497 & 0,400 & 0,333 & 0,286 & 0,250 \\
\hline 8,4 & 1,000 & 0,997 & 0,987 & 0,959 & 0,909 & 0,840 & 0,645 & 0,497 & 0,400 & 0,333 & 0,286 & 0,250 \\
\hline 8,5 & 1,000 & 0,997 & 0,987 & 0,960 & 0,910 & 0,841 & 0,646 & 0,497 & 0,400 & 0,333 & 0,286 & 0,250 \\
\hline 8,6 & 1,000 & 0,998 & 0,987 & 0,961 & 0,911 & 0,841 & 0,646 & 0,498 & 0,400 & 0,333 & 0,286 & 0,250 \\
\hline 8,7 & 1,000 & 0,998 & 0,988 & 0,961 & 0,912 & 0,842 & 0,646 & 0,498 & 0,400 & 0,333 & 0,286 & 0,250 \\
\hline 8,8 & 1,000 & 0,998 & 0,988 & 0,962 & 0,913 & 0,843 & 0,647 & 0,498 & 0,400 & 0,333 & 0,286 & 0,250 \\
\hline 8,9 & 1,000 & 0,998 & 0,988 & 0,962 & 0,913 & 0,843 & 0,647 & 0,498 & 0,400 & 0,333 & 0,286 & 0,250 \\
\hline 9,0 & 1,000 & 0,998 & 0,989 & 0,963 & 0,914 & 0,844 & 0,647 & 0,498 & 0,400 & 0,333 & 0,286 & 0,250 \\
\hline 9,1 & 1,000 & 0,998 & 0,989 & 0,964 & 0,915 & 0,845 & 0,647 & 0,498 & 0,400 & 0,333 & 0,286 & 0,250 \\
\hline 9,2 & 1,000 & 0,998 & 0,989 & 0,964 & 0,915 & 0,845 & 0,647 & 0,498 & 0,400 & 0,333 & 0,286 & 0,250 \\
\hline 9,3 & 1,000 & 0,998 & 0,990 & 0,965 & 0,916 & 0,846 & 0,648 & 0,498 & 0,400 & 0,333 & 0,286 & 0,250 \\
\hline 9,4 & 1,000 & 0,998 & 0,990 & 0,965 & 0,917 & 0,847 & 0,648 & 0,498 & 0,400 & 0,333 & 0,286 & 0,250 \\
\hline 9,5 & 1,000 & 0,998 & 0,990 & 0,966 & 0,917 & 0,847 & 0,648 & 0,498 & 0,400 & 0,333 & 0,286 & 0,250 \\
\hline 9,6 & 1,000 & 0,998 & 0,990 & 0,966 & 0,918 & 0,848 & 0,648 & 0,498 & 0,400 & 0,333 & 0,286 & 0,250 \\
\hline 9,7 & 1,000 & 0,999 & 0,991 & 0,966 & 0,919 & 0,848 & 0,649 & 0,498 & 0,400 & 0,333 & 0,286 & 0,250 \\
\hline 9,8 & 1,000 & 0,999 & 0,991 & 0,967 & 0,919 & 0,849 & 0,649 & 0,498 & 0,400 & 0,333 & 0,286 & 0,250 \\
\hline 9,9 & 1,000 & 0,999 & 0,991 & 0,967 & 0,920 & 0,850 & 0,649 & 0,498 & 0,400 & 0,333 & 0,286 & 0,250 \\
\hline 10,0 & 1,000 & 0,999 & 0,991 & 0,968 & 0,920 & 0,850 & 0,649 & 0,498 & 0,400 & 0,333 & 0,286 & 0,250 \\
\hline
\end{tabular}


Tabela 76 - Fator de correção para trocador de calor de fluxo cruzado com três passes e dois tubos por passe (3-2) - Caso 4A - trocador de calor ilustrado na Figura 105 do Anexo A

\begin{tabular}{|c|c|c|c|c|c|c|c|c|c|c|c|c|}
\hline $\mathrm{NTU}^{R}$ & 0,0 & 0,2 & 0,4 & 0,6 & 0,8 & 1,0 & 1,5 & 2,0 & 2,5 & 3,0 & 3,5 & 4,0 \\
\hline 0,0 & 1,000 & 1,000 & 1,000 & 1,000 & 1,000 & 1,000 & 1,000 & 1,000 & 1,000 & 1,000 & 1,000 & 1,000 \\
\hline 0,1 & 1,000 & 1,000 & 1,000 & 1,000 & 1,000 & 1,000 & 1,000 & 1,000 & 1,000 & 0,999 & 0,999 & 0,999 \\
\hline 0,2 & 1,000 & 1,000 & 1,000 & 1,000 & 0,999 & 0,999 & 0,999 & 0,999 & 0,998 & 0,998 & 0,997 & 0,997 \\
\hline 0,3 & 1,000 & 1,000 & 0,999 & 0,999 & 0,999 & 0,998 & 0,998 & 0,997 & 0,996 & 0,995 & 0,994 & 0,994 \\
\hline 0,4 & 1,000 & 0,999 & 0,999 & 0,998 & 0,998 & 0,997 & 0,996 & 0,994 & 0,993 & 0,992 & 0,990 & 0,989 \\
\hline 0,5 & 1,000 & 0,999 & 0,998 & 0,997 & 0,996 & 0,996 & 0,993 & 0,991 & 0,989 & 0,987 & 0,985 & 0,983 \\
\hline 0,6 & 1,000 & 0,999 & 0,997 & 0,996 & 0,995 & 0,994 & 0,991 & 0,988 & 0,985 & 0,982 & 0,979 & 0,977 \\
\hline 0,7 & 1,000 & 0,998 & 0,997 & 0,995 & 0,993 & 0,992 & 0,988 & 0,984 & 0,980 & 0,976 & 0,973 & 0,970 \\
\hline 0,8 & 1,000 & 0,998 & 0,996 & 0,993 & 0,991 & 0,989 & 0,984 & 0,979 & 0,974 & 0,970 & 0,966 & 0,962 \\
\hline 0,9 & 1,000 & 0,997 & 0,994 & 0,992 & 0,989 & 0,986 & 0,980 & 0,974 & 0,968 & 0,963 & 0,958 & 0,953 \\
\hline 1,0 & 1,000 & 0,997 & 0,993 & 0,990 & 0,987 & 0,983 & 0,976 & 0,968 & 0,962 & 0,955 & 0,950 & 0,944 \\
\hline 1,1 & 1,000 & 0,996 & 0,992 & 0,988 & 0,984 & 0,980 & 0,971 & 0,963 & 0,955 & 0,948 & 0,941 & 0,935 \\
\hline 1,2 & 1,000 & 0,995 & 0,990 & 0,986 & 0,981 & 0,977 & 0,966 & 0,956 & 0,948 & 0,940 & 0,932 & 0,926 \\
\hline 1,3 & 1,000 & 0,994 & 0,989 & 0,983 & 0,978 & 0,973 & 0,961 & 0,950 & 0,940 & 0,931 & 0,923 & 0,916 \\
\hline 1,4 & 1,000 & 0,993 & 0,987 & 0,981 & 0,975 & 0,969 & 0,955 & 0,943 & 0,932 & 0,923 & 0,914 & 0,907 \\
\hline 1,5 & 1,000 & 0,992 & 0,985 & 0,978 & 0,971 & 0,965 & 0,950 & 0,936 & 0,925 & 0,914 & 0,905 & 0,897 \\
\hline 1,6 & 1,000 & 0,992 & 0,983 & 0,975 & 0,968 & 0,961 & 0,944 & 0,929 & 0,917 & 0,906 & 0,896 & 0,888 \\
\hline 1,7 & 1,000 & 0,990 & 0,981 & 0,973 & 0,964 & 0,956 & 0,938 & 0,922 & 0,909 & 0,897 & 0,887 & 0,878 \\
\hline 1,8 & 1,000 & 0,989 & 0,979 & 0,970 & 0,960 & 0,952 & 0,932 & 0,915 & 0,900 & 0,888 & 0,878 & 0,869 \\
\hline 1,9 & 1,000 & 0,988 & 0,977 & 0,966 & 0,956 & 0,947 & 0,926 & 0,907 & 0,892 & 0,880 & 0,869 & 0,860 \\
\hline 2,0 & 1,000 & 0,987 & 0,975 & 0,963 & 0,952 & 0,942 & 0,919 & 0,900 & 0,884 & 0,871 & 0,860 & 0,851 \\
\hline 2,1 & 1,000 & 0,986 & 0,973 & 0,960 & 0,948 & 0,937 & 0,913 & 0,893 & 0,876 & 0,862 & 0,851 & 0,842 \\
\hline 2,2 & 1,000 & 0,985 & 0,970 & 0,956 & 0,944 & 0,932 & 0,906 & 0,885 & 0,868 & 0,854 & 0,843 & 0,833 \\
\hline 2,3 & 1,000 & 0,983 & 0,968 & 0,953 & 0,939 & 0,927 & 0,899 & 0,877 & 0,860 & 0,845 & 0,834 & 0,825 \\
\hline 2,4 & 1,000 & 0,982 & 0,965 & 0,949 & 0,935 & 0,922 & 0,893 & 0,870 & 0,852 & 0,837 & 0,826 & 0,816 \\
\hline 2,5 & 1,000 & 0,981 & 0,962 & 0,946 & 0,930 & 0,916 & 0,886 & 0,862 & 0,844 & 0,829 & 0,817 & 0,808 \\
\hline 2,6 & 1,000 & 0,979 & 0,960 & 0,942 & 0,926 & 0,911 & 0,879 & 0,855 & 0,836 & 0,821 & 0,809 & 0,800 \\
\hline 2,7 & 1,000 & 0,978 & 0,957 & 0,938 & 0,921 & 0,905 & 0,873 & 0,848 & 0,828 & 0,813 & 0,801 & 0,792 \\
\hline 2,8 & 1,000 & 0,976 & 0,954 & 0,934 & 0,916 & 0,900 & 0,866 & 0,840 & 0,820 & 0,805 & 0,793 & 0,784 \\
\hline 2,9 & 1,000 & 0,974 & 0,951 & 0,930 & 0,911 & 0,894 & 0,859 & 0,833 & 0,813 & 0,797 & 0,786 & 0,776 \\
\hline 3,0 & 1,000 & 0,973 & 0,948 & 0,926 & 0,906 & 0,889 & 0,853 & 0,826 & 0,805 & 0,790 & 0,778 & 0,769 \\
\hline 3,1 & 1,000 & 0,971 & 0,945 & 0,922 & 0,901 & 0,883 & 0,846 & 0,818 & 0,798 & 0,782 & 0,771 & 0,762 \\
\hline 3,2 & 1,000 & 0,970 & 0,942 & 0,918 & 0,896 & 0,877 & 0,839 & 0,811 & 0,791 & 0,775 & 0,763 & 0,754 \\
\hline 3,3 & 1,000 & 0,968 & 0,939 & 0,914 & 0,891 & 0,872 & 0,833 & 0,804 & 0,783 & 0,768 & 0,756 & 0,747 \\
\hline 3,4 & 1,000 & 0,966 & 0,936 & 0,910 & 0,886 & 0,866 & 0,826 & 0,797 & 0,776 & 0,761 & 0,749 & 0,741 \\
\hline 3,5 & 1,000 & 0,964 & 0,933 & 0,905 & 0,881 & 0,861 & 0,820 & 0,791 & 0,769 & 0,754 & 0,742 & 0,734 \\
\hline 3,6 & 1,000 & 0,962 & 0,930 & 0,901 & 0,876 & 0,855 & 0,813 & 0,784 & 0,763 & 0,747 & 0,736 & 0,727 \\
\hline 3,7 & 1,000 & 0,961 & 0,926 & 0,897 & 0,871 & 0,849 & 0,807 & 0,777 & 0,756 & 0,740 & 0,729 & 0,721 \\
\hline 3,8 & 1,000 & 0,959 & 0,923 & 0,892 & 0,866 & 0,844 & 0,800 & 0,770 & 0,749 & 0,734 & 0,723 & 0,714 \\
\hline 3,9 & 1,000 & 0,957 & 0,920 & 0,888 & 0,861 & 0,838 & 0,794 & 0,764 & 0,743 & 0,727 & 0,716 & 0,708 \\
\hline 4,0 & 1,000 & 0,955 & 0,916 & 0,884 & 0,856 & 0,832 & 0,788 & 0,757 & 0,736 & 0,721 & 0,710 & 0,702 \\
\hline 4,1 & 1,000 & 0,953 & 0,913 & 0,879 & 0,851 & 0,827 & 0,782 & 0,751 & 0,730 & 0,715 & 0,704 & 0,696 \\
\hline 4,2 & 1,000 & 0,951 & 0,909 & 0,875 & 0,846 & 0,821 & 0,776 & 0,745 & 0,724 & 0,708 & 0,698 & 0,690 \\
\hline 4,3 & 1,000 & 0,949 & 0,906 & 0,870 & 0,841 & 0,816 & 0,770 & 0,739 & 0,717 & 0,702 & 0,692 & 0,684 \\
\hline 4,4 & 1,000 & 0,947 & 0,902 & 0,866 & 0,836 & 0,810 & 0,764 & 0,733 & 0,711 & 0,696 & 0,686 & 0,678 \\
\hline 4,5 & 1,000 & 0,945 & 0,899 & 0,861 & 0,830 & 0,805 & 0,758 & 0,727 & 0,705 & 0,691 & 0,680 & 0,673 \\
\hline 4,6 & 1,000 & 0,943 & 0,895 & 0,857 & 0,825 & 0,799 & 0,752 & 0,721 & 0,699 & 0,685 & 0,675 & 0,667 \\
\hline 4,7 & 1,000 & 0,940 & 0,892 & 0,852 & 0,820 & 0,794 & 0,746 & 0,715 & 0,694 & 0,679 & 0,669 & 0,662 \\
\hline 4,8 & 1,000 & 0,938 & 0,888 & 0,848 & 0,815 & 0,789 & 0,740 & 0,709 & 0,688 & 0,674 & 0,664 & 0,656 \\
\hline
\end{tabular}


Tabela 76 - continuação da página anterior

\begin{tabular}{|c|c|c|c|c|c|c|c|c|c|c|c|c|}
\hline $\mathrm{NTU}^{R}$ & 0,0 & 0,2 & 0,4 & 0,6 & 0,8 & 1,0 & 1,5 & 2,0 & 2,5 & 3,0 & 3,5 & 4,0 \\
\hline 4,9 & 1,000 & 0,936 & 0,885 & 0,844 & 0,810 & 0,783 & 0,735 & 0,703 & 0,682 & 0,668 & 0,658 & 0,651 \\
\hline 5,0 & 1,000 & 0,934 & 0,881 & 0,839 & 0,805 & 0,778 & 0,729 & 0,698 & 0,677 & 0,663 & 0,653 & 0,646 \\
\hline 5,1 & 1,000 & 0,932 & 0,877 & 0,835 & 0,800 & 0,773 & 0,724 & 0,692 & 0,671 & 0,657 & 0,648 & 0,641 \\
\hline 5,2 & 1,000 & 0,929 & 0,874 & 0,830 & 0,796 & 0,768 & 0,718 & 0,687 & 0,666 & 0,652 & 0,643 & 0,636 \\
\hline 5,3 & 1,000 & 0,927 & 0,870 & 0,826 & 0,791 & 0,763 & 0,713 & 0,681 & 0,661 & 0,647 & 0,638 & 0,631 \\
\hline 5,4 & 1,000 & 0,925 & 0,867 & 0,821 & 0,786 & 0,757 & 0,707 & 0,676 & 0,656 & 0,642 & 0,633 & 0,626 \\
\hline 5,5 & 1,000 & 0,922 & 0,863 & 0,817 & 0,781 & 0,752 & 0,702 & 0,671 & 0,650 & 0,637 & 0,628 & 0,621 \\
\hline 5,6 & 1,000 & 0,920 & 0,859 & 0,813 & 0,776 & 0,747 & 0,697 & 0,666 & 0,645 & 0,632 & 0,623 & 0,617 \\
\hline 5,7 & 1,000 & 0,918 & 0,856 & 0,808 & 0,771 & 0,742 & 0,692 & 0,661 & 0,640 & 0,627 & 0,618 & 0,612 \\
\hline 5,8 & 1,000 & 0,915 & 0,852 & 0,804 & 0,767 & 0,737 & 0,687 & 0,656 & 0,636 & 0,622 & 0,613 & 0,607 \\
\hline 5,9 & 1,000 & 0,913 & 0,848 & 0,799 & 0,762 & 0,733 & 0,682 & 0,651 & 0,631 & 0,618 & 0,609 & 0,603 \\
\hline 6,0 & 1,000 & 0,911 & 0,845 & 0,795 & 0,757 & 0,728 & 0,677 & 0,646 & 0,626 & 0,613 & 0,604 & 0,598 \\
\hline 6,1 & 1,000 & 0,908 & 0,841 & 0,791 & 0,753 & 0,723 & 0,672 & 0,641 & 0,621 & 0,608 & 0,600 & 0,594 \\
\hline 6,2 & 1,000 & 0,906 & 0,837 & 0,787 & 0,748 & 0,718 & 0,667 & 0,636 & 0,616 & 0,604 & 0,595 & 0,590 \\
\hline 6,3 & 1,000 & 0,903 & 0,834 & 0,782 & 0,744 & 0,713 & 0,662 & 0,631 & 0,612 & 0,599 & 0,591 & 0,585 \\
\hline 6,4 & 1,000 & 0,901 & 0,830 & 0,778 & 0,739 & 0,709 & 0,658 & 0,627 & 0,607 & 0,595 & 0,587 & 0,581 \\
\hline 6,5 & 1,000 & 0,898 & 0,826 & 0,774 & 0,734 & 0,704 & 0,653 & 0,622 & 0,603 & 0,590 & 0,582 & 0,577 \\
\hline 6,6 & 1,000 & 0,896 & 0,823 & 0,770 & 0,730 & 0,700 & 0,648 & 0,618 & 0,598 & 0,586 & 0,578 & 0,573 \\
\hline 6,7 & 1,000 & 0,893 & 0,819 & 0,765 & 0,726 & 0,695 & 0,644 & 0,613 & 0,594 & 0,582 & 0,574 & 0,569 \\
\hline 6,8 & 1,000 & 0,891 & 0,815 & 0,761 & 0,721 & 0,691 & 0,639 & 0,609 & 0,590 & 0,578 & 0,570 & 0,565 \\
\hline 6,9 & 1,000 & 0,888 & 0,812 & 0,757 & 0,717 & 0,686 & 0,635 & 0,604 & 0,586 & 0,574 & 0,566 & 0,561 \\
\hline 7,0 & 1,000 & 0,886 & 0,808 & 0,753 & 0,713 & 0,682 & 0,630 & 0,600 & 0,581 & 0,569 & 0,562 & 0,557 \\
\hline 7,1 & 1,000 & 0,883 & 0,804 & 0,749 & 0,708 & 0,677 & 0,626 & 0,596 & 0,577 & 0,565 & 0,558 & 0,553 \\
\hline 7,2 & 1,000 & 0,881 & 0,801 & 0,745 & 0,704 & 0,673 & 0,622 & 0,592 & 0,573 & 0,561 & 0,554 & 0,549 \\
\hline 7,3 & 1,000 & 0,878 & 0,797 & 0,741 & 0,700 & 0,669 & 0,617 & 0,587 & 0,569 & 0,558 & 0,550 & 0,545 \\
\hline 7,4 & 1,000 & 0,875 & 0,793 & 0,737 & 0,696 & 0,664 & 0,613 & 0,583 & 0,565 & 0,554 & 0,546 & 0,541 \\
\hline 7,5 & 1,000 & 0,873 & 0,790 & 0,733 & 0,691 & 0,660 & 0,609 & 0,579 & 0,561 & 0,550 & 0,542 & 0,538 \\
\hline 7,6 & 1,000 & 0,870 & 0,786 & 0,729 & 0,687 & 0,656 & 0,605 & 0,575 & 0,557 & 0,546 & 0,539 & 0,534 \\
\hline 7,7 & 1,000 & 0,868 & 0,783 & 0,725 & 0,683 & 0,652 & 0,601 & 0,571 & 0,553 & 0,542 & 0,535 & 0,530 \\
\hline 7,8 & 1,000 & 0,865 & 0,779 & 0,721 & 0,679 & 0,648 & 0,597 & 0,567 & 0,550 & 0,538 & 0,531 & 0,527 \\
\hline 7,9 & 1,000 & 0,862 & 0,776 & 0,717 & 0,675 & 0,644 & 0,593 & 0,563 & 0,546 & 0,535 & 0,528 & 0,523 \\
\hline 8,0 & 1,000 & 0,860 & 0,772 & 0,713 & 0,671 & 0,640 & 0,589 & 0,560 & 0,542 & 0,531 & 0,524 & 0,520 \\
\hline 8,1 & 1,000 & 0,857 & 0,769 & 0,709 & 0,667 & 0,636 & 0,585 & 0,556 & 0,538 & 0,528 & 0,521 & 0,516 \\
\hline 8,2 & 1,000 & 0,854 & 0,765 & 0,706 & 0,663 & 0,632 & 0,581 & 0,552 & 0,535 & 0,524 & 0,517 & 0,513 \\
\hline 8,3 & 1,000 & 0,852 & 0,762 & 0,702 & 0,659 & 0,628 & 0,577 & 0,548 & 0,531 & 0,521 & 0,514 & 0,510 \\
\hline 8,4 & 1,000 & 0,849 & 0,758 & 0,698 & 0,656 & 0,624 & 0,573 & 0,545 & 0,528 & 0,517 & 0,510 & 0,506 \\
\hline 8,5 & 1,000 & 0,846 & 0,755 & 0,694 & 0,652 & 0,620 & 0,570 & 0,541 & 0,524 & 0,514 & 0,507 & 0,503 \\
\hline 8,6 & 1,000 & 0,844 & 0,751 & 0,691 & 0,648 & 0,617 & 0,566 & 0,538 & 0,521 & 0,510 & 0,504 & 0,500 \\
\hline 8,7 & 1,000 & 0,841 & 0,748 & 0,687 & 0,644 & 0,613 & 0,562 & 0,534 & 0,517 & 0,507 & 0,501 & 0,496 \\
\hline 8,8 & 1,000 & 0,838 & 0,744 & 0,683 & 0,640 & 0,609 & 0,559 & 0,531 & 0,514 & 0,504 & 0,497 & 0,493 \\
\hline 8,9 & 1,000 & 0,836 & 0,741 & 0,680 & 0,637 & 0,605 & 0,555 & 0,527 & 0,510 & 0,500 & 0,494 & 0,490 \\
\hline 9,0 & 1,000 & 0,833 & 0,737 & 0,676 & 0,633 & 0,602 & 0,552 & 0,524 & 0,507 & 0,497 & 0,491 & 0,487 \\
\hline 9,1 & 1,000 & 0,830 & 0,734 & 0,672 & 0,630 & 0,598 & 0,548 & 0,520 & 0,504 & 0,494 & 0,488 & 0,484 \\
\hline 9,2 & 1,000 & 0,828 & 0,731 & 0,669 & 0,626 & 0,594 & 0,545 & 0,517 & 0,501 & 0,491 & 0,485 & 0,481 \\
\hline 9,3 & 1,000 & 0,825 & 0,727 & 0,665 & 0,622 & 0,591 & 0,541 & 0,514 & 0,497 & 0,488 & 0,481 & 0,478 \\
\hline 9,4 & 1,000 & 0,822 & 0,724 & 0,662 & 0,619 & 0,587 & 0,538 & 0,510 & 0,494 & 0,484 & 0,478 & 0,475 \\
\hline 9,5 & 1,000 & 0,820 & 0,721 & 0,658 & 0,615 & 0,584 & 0,534 & 0,507 & 0,491 & 0,481 & 0,475 & 0,472 \\
\hline 9,6 & 1,000 & 0,817 & 0,717 & 0,655 & 0,612 & 0,580 & 0,531 & 0,504 & 0,488 & 0,478 & 0,472 & 0,469 \\
\hline 9,7 & 1,000 & 0,814 & 0,714 & 0,651 & 0,608 & 0,577 & 0,528 & 0,501 & 0,485 & 0,475 & 0,469 & 0,466 \\
\hline 9,8 & 1,000 & 0,812 & 0,711 & 0,648 & 0,605 & 0,574 & 0,524 & 0,497 & 0,482 & 0,472 & 0,467 & 0,463 \\
\hline 9,9 & 1,000 & 0,809 & 0,708 & 0,645 & 0,602 & 0,570 & 0,521 & 0,494 & 0,479 & 0,469 & 0,464 & 0,460 \\
\hline 10,0 & 1,000 & 0,806 & 0,704 & 0,641 & 0,598 & 0,567 & 0,518 & 0,491 & 0,476 & 0,466 & 0,461 & 0,457 \\
\hline
\end{tabular}


Tabela 77 - Efetividade de temperatura para trocador de calor de fluxo cruzado com quatro passes e um tubo por passe (4-1) - Caso 4A - trocador de calor ilustrado na Figura 92 do Anexo A

\begin{tabular}{|c|c|c|c|c|c|c|c|c|c|c|c|c|}
\hline $\mathrm{NTU}^{R}$ & 0,0 & 0,2 & 0,4 & 0,6 & 0,8 & 1,0 & 1,5 & 2,0 & 2,5 & 3,0 & 3,5 & 4,0 \\
\hline 0,0 & 0,000 & 0,000 & 0,000 & 0,000 & 0,000 & 0,000 & 0,000 & 0,000 & 0,000 & 0,000 & 0,000 & 0,000 \\
\hline 0,1 & 0,095 & 0,094 & 0,094 & 0,093 & 0,092 & 0,091 & 0,089 & 0,087 & 0,085 & 0,083 & 0,081 & 0,080 \\
\hline 0,2 & 0,181 & 0,178 & 0,175 & 0,172 & 0,169 & 0,167 & 0,160 & 0,153 & 0,147 & 0,141 & 0,136 & 0,131 \\
\hline 0,3 & 0,259 & 0,253 & 0,247 & 0,242 & 0,236 & 0,231 & 0,218 & 0,206 & 0,194 & 0,184 & 0,174 & 0,165 \\
\hline 0,4 & 0,330 & 0,320 & 0,311 & 0,302 & 0,294 & 0,285 & 0,266 & 0,247 & 0,231 & 0,215 & 0,201 & 0,188 \\
\hline 0,5 & 0,394 & 0,381 & 0,368 & 0,356 & 0,344 & 0,333 & 0,306 & 0,282 & 0,259 & 0,239 & 0,221 & 0,205 \\
\hline 0,6 & 0,451 & 0,435 & 0,419 & 0,404 & 0,389 & 0,374 & 0,340 & 0,310 & 0,282 & 0,258 & 0,236 & 0,217 \\
\hline 0,7 & 0,503 & 0,484 & 0,465 & 0,446 & 0,428 & 0,411 & 0,370 & 0,333 & 0,301 & 0,272 & 0,247 & 0,225 \\
\hline 0,8 & 0,551 & 0,528 & 0,506 & 0,484 & 0,463 & 0,443 & 0,395 & 0,353 & 0,316 & 0,284 & 0,256 & 0,232 \\
\hline 0,9 & 0,593 & 0,568 & 0,543 & 0,519 & 0,495 & 0,472 & 0,418 & 0,370 & 0,328 & 0,293 & 0,262 & 0,236 \\
\hline 1,0 & 0,632 & 0,604 & 0,577 & 0,550 & 0,523 & 0,497 & 0,438 & 0,385 & 0,339 & 0,300 & 0,267 & 0,239 \\
\hline 1,1 & 0,667 & 0,637 & 0,607 & 0,578 & 0,549 & 0,521 & 0,455 & 0,397 & 0,347 & 0,306 & 0,271 & 0,242 \\
\hline 1,2 & 0,699 & 0,667 & 0,635 & 0,604 & 0,572 & 0,542 & 0,470 & 0,408 & 0,355 & 0,310 & 0,274 & 0,244 \\
\hline 1,3 & 0,727 & 0,695 & 0,661 & 0,627 & 0,594 & 0,561 & 0,484 & 0,417 & 0,361 & 0,314 & 0,276 & 0,245 \\
\hline 1,4 & 0,753 & 0,719 & 0,684 & 0,649 & 0,613 & 0,579 & 0,497 & 0,425 & 0,366 & 0,317 & 0,278 & 0,246 \\
\hline 1,5 & 0,777 & 0,742 & 0,706 & 0,669 & 0,631 & 0,595 & 0,508 & 0,433 & 0,370 & 0,320 & 0,280 & 0,247 \\
\hline 1,6 & 0,798 & 0,763 & 0,725 & 0,687 & 0,648 & 0,609 & 0,518 & 0,439 & 0,374 & 0,322 & 0,281 & 0,248 \\
\hline 1,7 & 0,817 & 0,782 & 0,744 & 0,704 & 0,663 & 0,623 & 0,527 & 0,444 & 0,377 & 0,324 & 0,282 & 0,248 \\
\hline 1,8 & 0,835 & 0,799 & 0,760 & 0,719 & 0,677 & 0,635 & 0,535 & 0,449 & 0,380 & 0,325 & 0,282 & 0,249 \\
\hline 1,9 & 0,850 & 0,815 & 0,776 & 0,734 & 0,691 & 0,647 & 0,543 & 0,454 & 0,382 & 0,326 & 0,283 & 0,249 \\
\hline 2,0 & 0,865 & 0,829 & 0,790 & 0,747 & 0,703 & 0,658 & 0,550 & 0,458 & 0,384 & 0,327 & 0,283 & 0,249 \\
\hline 2,1 & 0,878 & 0,843 & 0,803 & 0,760 & 0,714 & 0,668 & 0,556 & 0,461 & 0,386 & 0,328 & 0,284 & 0,249 \\
\hline 2,2 & 0,889 & 0,855 & 0,815 & 0,771 & 0,725 & 0,677 & 0,562 & 0,464 & 0,388 & 0,329 & 0,284 & 0,249 \\
\hline 2,3 & 0,900 & 0,866 & 0,826 & 0,782 & 0,735 & 0,686 & 0,568 & 0,467 & 0,389 & 0,329 & 0,284 & 0,250 \\
\hline 2,4 & 0,909 & 0,876 & 0,837 & 0,792 & 0,744 & 0,694 & 0,573 & 0,470 & 0,390 & 0,330 & 0,285 & 0,250 \\
\hline 2,5 & 0,918 & 0,886 & 0,847 & 0,802 & 0,753 & 0,702 & 0,577 & 0,472 & 0,391 & 0,330 & 0,285 & 0,250 \\
\hline 2,6 & 0,926 & 0,894 & 0,856 & 0,811 & 0,761 & 0,709 & 0,581 & 0,474 & 0,392 & 0,331 & 0,285 & 0,250 \\
\hline 2,7 & 0,933 & 0,902 & 0,864 & 0,819 & 0,769 & 0,716 & 0,585 & 0,476 & 0,393 & 0,331 & 0,285 & 0,250 \\
\hline 2,8 & 0,939 & 0,910 & 0,872 & 0,827 & 0,776 & 0,722 & 0,589 & 0,478 & 0,393 & 0,331 & 0,285 & 0,250 \\
\hline 2,9 & 0,945 & 0,916 & 0,879 & 0,834 & 0,783 & 0,728 & 0,592 & 0,479 & 0,394 & 0,332 & 0,285 & 0,250 \\
\hline 3,0 & 0,950 & 0,923 & 0,886 & 0,841 & 0,789 & 0,734 & 0,595 & 0,480 & 0,395 & 0,332 & 0,285 & 0,250 \\
\hline 3,1 & 0,955 & 0,928 & 0,892 & 0,848 & 0,795 & 0,739 & 0,598 & 0,482 & 0,395 & 0,332 & 0,285 & 0,250 \\
\hline 3,2 & 0,959 & 0,934 & 0,898 & 0,854 & 0,801 & 0,744 & 0,601 & 0,483 & 0,395 & 0,332 & 0,285 & 0,250 \\
\hline 3,3 & 0,963 & 0,938 & 0,904 & 0,859 & 0,807 & 0,749 & 0,604 & 0,484 & 0,396 & 0,332 & 0,285 & 0,250 \\
\hline 3,4 & 0,967 & 0,943 & 0,909 & 0,865 & 0,812 & 0,753 & 0,606 & 0,485 & 0,396 & 0,332 & 0,285 & 0,250 \\
\hline 3,5 & 0,970 & 0,947 & 0,914 & 0,870 & 0,817 & 0,758 & 0,608 & 0,486 & 0,396 & 0,332 & 0,285 & 0,250 \\
\hline 3,6 & 0,973 & 0,951 & 0,918 & 0,875 & 0,821 & 0,762 & 0,610 & 0,487 & 0,397 & 0,333 & 0,286 & 0,250 \\
\hline 3,7 & 0,975 & 0,954 & 0,923 & 0,879 & 0,826 & 0,766 & 0,612 & 0,487 & 0,397 & 0,333 & 0,286 & 0,250 \\
\hline 3,8 & 0,978 & 0,958 & 0,927 & 0,884 & 0,830 & 0,769 & 0,614 & 0,488 & 0,397 & 0,333 & 0,286 & 0,250 \\
\hline 3,9 & 0,980 & 0,961 & 0,930 & 0,888 & 0,834 & 0,773 & 0,616 & 0,489 & 0,397 & 0,333 & 0,286 & 0,250 \\
\hline 4,0 & 0,982 & 0,963 & 0,934 & 0,892 & 0,838 & 0,776 & 0,618 & 0,489 & 0,398 & 0,333 & 0,286 & 0,250 \\
\hline 4,1 & 0,983 & 0,966 & 0,937 & 0,895 & 0,841 & 0,779 & 0,619 & 0,490 & 0,398 & 0,333 & 0,286 & 0,250 \\
\hline 4,2 & 0,985 & 0,968 & 0,940 & 0,899 & 0,845 & 0,782 & 0,621 & 0,490 & 0,398 & 0,333 & 0,286 & 0,250 \\
\hline 4,3 & 0,986 & 0,970 & 0,943 & 0,902 & 0,848 & 0,785 & 0,622 & 0,491 & 0,398 & 0,333 & 0,286 & 0,250 \\
\hline 4,4 & 0,988 & 0,973 & 0,946 & 0,905 & 0,851 & 0,788 & 0,623 & 0,491 & 0,398 & 0,333 & 0,286 & 0,250 \\
\hline 4,5 & 0,989 & 0,974 & 0,948 & 0,908 & 0,854 & 0,791 & 0,625 & 0,492 & 0,398 & 0,333 & 0,286 & 0,250 \\
\hline 4,6 & 0,990 & 0,976 & 0,951 & 0,911 & 0,857 & 0,793 & 0,626 & 0,492 & 0,398 & 0,333 & 0,286 & 0,250 \\
\hline 4,7 & 0,991 & 0,978 & 0,953 & 0,914 & 0,860 & 0,795 & 0,627 & 0,492 & 0,398 & 0,333 & 0,286 & 0,250 \\
\hline 4,8 & 0,992 & 0,979 & 0,955 & 0,916 & 0,863 & 0,798 & 0,628 & 0,493 & 0,399 & 0,333 & 0,286 & 0,250 \\
\hline
\end{tabular}


Tabela 77 - continuação da página anterior

\begin{tabular}{|c|c|c|c|c|c|c|c|c|c|c|c|c|}
\hline${ }_{N T U}^{R}$ & 0,0 & 0,2 & 0,4 & 0,6 & 0,8 & 1,0 & 1,5 & 2,0 & 2,5 & 3,0 & 3,5 & 4,0 \\
\hline 4,9 & 0,993 & 0,981 & 0,957 & 0,919 & 0,865 & 0,800 & 0,629 & 0,493 & 0,399 & 0,333 & 0,286 & 0,250 \\
\hline 5,0 & 0,993 & 0,982 & 0,959 & 0,921 & 0,867 & 0,802 & 0,630 & 0,493 & 0,399 & 0,333 & 0,286 & 0,250 \\
\hline 5,1 & 0,994 & 0,983 & 0,961 & 0,923 & 0,870 & 0,804 & 0,631 & 0,493 & 0,399 & 0,333 & 0,286 & 0,250 \\
\hline 5,2 & 0,994 & 0,984 & 0,963 & 0,925 & 0,872 & 0,806 & 0,631 & 0,494 & 0,399 & 0,333 & 0,286 & 0,250 \\
\hline 5,3 & 0,995 & 0,985 & 0,964 & 0,927 & 0,874 & 0,808 & 0,632 & 0,494 & 0,399 & 0,333 & 0,286 & 0,250 \\
\hline 5,4 & 0,995 & 0,986 & 0,966 & 0,929 & 0,876 & 0,810 & 0,633 & 0,494 & 0,399 & 0,333 & 0,286 & 0,250 \\
\hline 5,5 & 0,996 & 0,987 & 0,967 & 0,931 & 0,878 & 0,811 & 0,634 & 0,494 & 0,399 & 0,333 & 0,286 & 0,250 \\
\hline 5,6 & 0,996 & 0,988 & 0,968 & 0,933 & 0,880 & 0,813 & 0,634 & 0,495 & 0,399 & 0,333 & 0,286 & 0,250 \\
\hline 5,7 & 0,997 & 0,989 & 0,970 & 0,935 & 0,882 & 0,815 & 0,635 & 0,495 & 0,399 & 0,333 & 0,286 & 0,250 \\
\hline 5,8 & 0,997 & 0,989 & 0,971 & 0,936 & 0,883 & 0,816 & 0,636 & 0,495 & 0,399 & 0,333 & 0,286 & 0,250 \\
\hline 5,9 & 0,997 & 0,990 & 0,972 & 0,938 & 0,885 & 0,818 & 0,636 & 0,495 & 0,399 & 0,333 & 0,286 & 0,250 \\
\hline 6,0 & 0,998 & 0,991 & 0,973 & 0,939 & 0,887 & 0,819 & 0,637 & 0,495 & 0,399 & 0,333 & 0,286 & 0,250 \\
\hline 6,1 & 0,998 & 0,991 & 0,974 & 0,941 & 0,888 & 0,820 & 0,637 & 0,495 & 0,399 & 0,333 & 0,286 & 0,250 \\
\hline 6,2 & 0,998 & 0,992 & 0,975 & 0,942 & 0,889 & 0,822 & 0,638 & 0,496 & 0,399 & 0,333 & 0,286 & 0,250 \\
\hline 6,3 & 0,998 & 0,992 & 0,976 & 0,943 & 0,891 & 0,823 & 0,638 & 0,496 & 0,399 & 0,333 & 0,286 & 0,250 \\
\hline 6,4 & 0,998 & 0,993 & 0,977 & 0,944 & 0,892 & 0,824 & 0,639 & 0,496 & 0,399 & 0,333 & 0,286 & 0,250 \\
\hline 6,5 & 0,998 & 0,993 & 0,978 & 0,946 & 0,894 & 0,825 & 0,639 & 0,496 & 0,399 & 0,333 & 0,286 & 0,250 \\
\hline 6,6 & 0,999 & 0,993 & 0,978 & 0,947 & 0,895 & 0,826 & 0,640 & 0,496 & 0,399 & 0,333 & 0,286 & 0,250 \\
\hline 6,7 & 0,999 & 0,994 & 0,979 & 0,948 & 0,896 & 0,827 & 0,640 & 0,496 & 0,399 & 0,333 & 0,286 & 0,250 \\
\hline 6,8 & 0,999 & 0,994 & 0,980 & 0,949 & 0,897 & 0,828 & 0,641 & 0,496 & 0,399 & 0,333 & 0,286 & 0,250 \\
\hline 6,9 & 0,999 & 0,994 & 0,980 & 0,950 & 0,898 & 0,829 & 0,641 & 0,496 & 0,399 & 0,333 & 0,286 & 0,250 \\
\hline 7,0 & 0,999 & 0,995 & 0,981 & 0,951 & 0,899 & 0,830 & 0,641 & 0,496 & 0,399 & 0,333 & 0,286 & 0,250 \\
\hline 7,1 & 0,999 & 0,995 & 0,982 & 0,952 & 0,900 & 0,831 & 0,642 & 0,496 & 0,399 & 0,333 & 0,286 & 0,250 \\
\hline 7,2 & 0,999 & 0,995 & 0,982 & 0,952 & 0,901 & 0,832 & 0,642 & 0,497 & 0,399 & 0,333 & 0,286 & 0,250 \\
\hline 7,3 & 0,999 & 0,996 & 0,983 & 0,953 & 0,902 & 0,833 & 0,642 & 0,497 & 0,400 & 0,333 & 0,286 & 0,250 \\
\hline 7,4 & 0,999 & 0,996 & 0,983 & 0,954 & 0,903 & 0,834 & 0,643 & 0,497 & 0,400 & 0,333 & 0,286 & 0,250 \\
\hline 7,5 & 0,999 & 0,996 & 0,984 & 0,955 & 0,904 & 0,835 & 0,643 & 0,497 & 0,400 & 0,333 & 0,286 & 0,250 \\
\hline 7,6 & 0,999 & 0,996 & 0,984 & 0,956 & 0,905 & 0,836 & 0,643 & 0,497 & 0,400 & 0,333 & 0,286 & 0,250 \\
\hline 7,7 & 1,000 & 0,996 & 0,985 & 0,956 & 0,906 & 0,836 & 0,644 & 0,497 & 0,400 & 0,333 & 0,286 & 0,250 \\
\hline 7,8 & 1,000 & 0,997 & 0,985 & 0,957 & 0,907 & 0,837 & 0,644 & 0,497 & 0,400 & 0,333 & 0,286 & 0,250 \\
\hline 7,9 & 1,000 & 0,997 & 0,986 & 0,958 & 0,907 & 0,838 & 0,644 & 0,497 & 0,400 & 0,333 & 0,286 & 0,250 \\
\hline 8,0 & 1,000 & 0,997 & 0,986 & 0,958 & 0,908 & 0,838 & 0,644 & 0,497 & 0,400 & 0,333 & 0,286 & 0,250 \\
\hline 8,1 & 1,000 & 0,997 & 0,986 & 0,959 & 0,909 & 0,839 & 0,645 & 0,497 & 0,400 & 0,333 & 0,286 & 0,250 \\
\hline 8,2 & 1,000 & 0,997 & 0,987 & 0,959 & 0,910 & 0,840 & 0,645 & 0,497 & 0,400 & 0,333 & 0,286 & 0,250 \\
\hline 8,3 & 1,000 & 0,997 & 0,987 & 0,960 & 0,910 & 0,840 & 0,645 & 0,497 & 0,400 & 0,333 & 0,286 & 0,250 \\
\hline 8,4 & 1,000 & 0,997 & 0,987 & 0,961 & 0,911 & 0,841 & 0,645 & 0,497 & 0,400 & 0,333 & 0,286 & 0,250 \\
\hline 8,5 & 1,000 & 0,998 & 0,988 & 0,961 & 0,912 & 0,842 & 0,646 & 0,497 & 0,400 & 0,333 & 0,286 & 0,250 \\
\hline 8,6 & 1,000 & 0,998 & 0,988 & 0,962 & 0,912 & 0,842 & 0,646 & 0,497 & 0,400 & 0,333 & 0,286 & 0,250 \\
\hline 8,7 & 1,000 & 0,998 & 0,988 & 0,962 & 0,913 & 0,843 & 0,646 & 0,497 & 0,400 & 0,333 & 0,286 & 0,250 \\
\hline 8,8 & 1,000 & 0,998 & 0,989 & 0,963 & 0,913 & 0,843 & 0,646 & 0,497 & 0,400 & 0,333 & 0,286 & 0,250 \\
\hline 8,9 & 1,000 & 0,998 & 0,989 & 0,963 & 0,914 & 0,844 & 0,646 & 0,497 & 0,400 & 0,333 & 0,286 & 0,250 \\
\hline 9,0 & 1,000 & 0,998 & 0,989 & 0,963 & 0,914 & 0,844 & 0,646 & 0,497 & 0,400 & 0,333 & 0,286 & 0,250 \\
\hline 9,1 & 1,000 & 0,998 & 0,989 & 0,964 & 0,915 & 0,845 & 0,647 & 0,498 & 0,400 & 0,333 & 0,286 & 0,250 \\
\hline 9,2 & 1,000 & 0,998 & 0,989 & 0,964 & 0,915 & 0,845 & 0,647 & 0,498 & 0,400 & 0,333 & 0,286 & 0,250 \\
\hline 9,3 & 1,000 & 0,998 & 0,990 & 0,965 & 0,916 & 0,846 & 0,647 & 0,498 & 0,400 & 0,333 & 0,286 & 0,250 \\
\hline 9,4 & 1,000 & 0,998 & 0,990 & 0,965 & 0,916 & 0,846 & 0,647 & 0,498 & 0,400 & 0,333 & 0,286 & 0,250 \\
\hline 9,5 & 1,000 & 0,998 & 0,990 & 0,965 & 0,917 & 0,846 & 0,647 & 0,498 & 0,400 & 0,333 & 0,286 & 0,250 \\
\hline 9,6 & 1,000 & 0,998 & 0,990 & 0,966 & 0,917 & 0,847 & 0,647 & 0,498 & 0,400 & 0,333 & 0,286 & 0,250 \\
\hline 9,7 & 1,000 & 0,999 & 0,990 & 0,966 & 0,918 & 0,847 & 0,648 & 0,498 & 0,400 & 0,333 & 0,286 & 0,250 \\
\hline 9,8 & 1,000 & 0,999 & 0,991 & 0,966 & 0,918 & 0,848 & 0,648 & 0,498 & 0,400 & 0,333 & 0,286 & 0,250 \\
\hline 9,9 & 1,000 & 0,999 & 0,991 & 0,967 & 0,919 & 0,848 & 0,648 & 0,498 & 0,400 & 0,333 & 0,286 & 0,250 \\
\hline 10,0 & 1,000 & 0,999 & 0,991 & 0,967 & 0,919 & 0,848 & 0,648 & 0,498 & 0,400 & 0,333 & 0,286 & 0,250 \\
\hline
\end{tabular}


Tabela 78 - Fator de correção para trocador de calor de fluxo cruzado com quatro passes e um tubo por passe (4-1) - Caso 4A - trocador de calor ilustrado na Figura 92 do Anexo $\mathrm{A}$

\begin{tabular}{|c|c|c|c|c|c|c|c|c|c|c|c|c|}
\hline $\mathrm{NTU}^{R}$ & 0,0 & 0,2 & 0,4 & 0,6 & 0,8 & 1,0 & 1,5 & 2,0 & 2,5 & 3,0 & 3,5 & 4,0 \\
\hline 0,0 & 1,000 & 1,000 & 1,000 & 1,000 & 1,000 & 1,000 & 1,000 & 1,000 & 1,000 & 1,000 & 1,000 & 1,000 \\
\hline 0,1 & 1,000 & 1,000 & 1,000 & 1,000 & 1,000 & 1,000 & 1,000 & 1,000 & 1,000 & 1,000 & 1,000 & 1,000 \\
\hline 0,2 & 1,000 & 1,000 & 1,000 & 1,000 & 1,000 & 1,000 & 0,999 & 0,999 & 0,999 & 0,999 & 0,999 & 0,998 \\
\hline 0,3 & 1,000 & 1,000 & 1,000 & 0,999 & 0,999 & 0,999 & 0,999 & 0,998 & 0,998 & 0,997 & 0,997 & 0,996 \\
\hline 0,4 & 1,000 & 1,000 & 0,999 & 0,999 & 0,999 & 0,998 & 0,998 & 0,997 & 0,996 & 0,995 & 0,994 & 0,994 \\
\hline 0,5 & 1,000 & 0,999 & 0,999 & 0,998 & 0,998 & 0,997 & 0,996 & 0,995 & 0,994 & 0,992 & 0,991 & 0,990 \\
\hline 0,6 & 1,000 & 0,999 & 0,999 & 0,998 & 0,997 & 0,996 & 0,994 & 0,993 & 0,991 & 0,989 & 0,987 & 0,986 \\
\hline 0,7 & 1,000 & 0,999 & 0,998 & 0,997 & 0,996 & 0,995 & 0,992 & 0,990 & 0,988 & 0,985 & 0,983 & 0,981 \\
\hline 0,8 & 1,000 & 0,999 & 0,997 & 0,996 & 0,995 & 0,993 & 0,990 & 0,987 & 0,984 & 0,981 & 0,978 & 0,976 \\
\hline 0,9 & 1,000 & 0,998 & 0,997 & 0,995 & 0,993 & 0,992 & 0,988 & 0,984 & 0,980 & 0,977 & 0,973 & 0,970 \\
\hline 1,0 & 1,000 & 0,998 & 0,996 & 0,994 & 0,992 & 0,990 & 0,985 & 0,980 & 0,976 & 0,971 & 0,967 & 0,963 \\
\hline 1,1 & 1,000 & 0,997 & 0,995 & 0,993 & 0,990 & 0,988 & 0,982 & 0,976 & 0,971 & 0,966 & 0,961 & 0,957 \\
\hline 1,2 & 1,000 & 0,997 & 0,994 & 0,991 & 0,988 & 0,985 & 0,979 & 0,972 & 0,966 & 0,960 & 0,955 & 0,950 \\
\hline 1,3 & 1,000 & 0,996 & 0,993 & 0,990 & 0,986 & 0,983 & 0,975 & 0,968 & 0,960 & 0,954 & 0,948 & 0,942 \\
\hline 1,4 & 1,000 & 0,996 & 0,992 & 0,988 & 0,984 & 0,980 & 0,971 & 0,963 & 0,955 & 0,948 & 0,941 & 0,935 \\
\hline 1,5 & 1,000 & 0,995 & 0,991 & 0,986 & 0,982 & 0,977 & 0,967 & 0,958 & 0,949 & 0,941 & 0,933 & 0,927 \\
\hline 1,6 & 1,000 & 0,995 & 0,989 & 0,984 & 0,979 & 0,974 & 0,963 & 0,952 & 0,943 & 0,934 & 0,926 & 0,919 \\
\hline 1,7 & 1,000 & 0,994 & 0,988 & 0,982 & 0,977 & 0,971 & 0,959 & 0,947 & 0,936 & 0,927 & 0,918 & 0,910 \\
\hline 1,8 & 1,000 & 0,993 & 0,987 & 0,980 & 0,974 & 0,968 & 0,954 & 0,941 & 0,930 & 0,919 & 0,910 & 0,902 \\
\hline 1,9 & 1,000 & 0,992 & 0,985 & 0,978 & 0,971 & 0,965 & 0,949 & 0,935 & 0,923 & 0,912 & 0,902 & 0,894 \\
\hline 2,0 & 1,000 & 0,992 & 0,984 & 0,976 & 0,968 & 0,961 & 0,944 & 0,929 & 0,916 & 0,904 & 0,894 & 0,885 \\
\hline 2,1 & 1,000 & 0,991 & 0,982 & 0,973 & 0,965 & 0,957 & 0,939 & 0,923 & 0,909 & 0,897 & 0,886 & 0,877 \\
\hline 2,2 & 1,000 & 0,990 & 0,980 & 0,971 & 0,962 & 0,953 & 0,934 & 0,917 & 0,902 & 0,889 & 0,878 & 0,868 \\
\hline 2,3 & 1,000 & 0,989 & 0,978 & 0,968 & 0,959 & 0,949 & 0,928 & 0,910 & 0,895 & 0,881 & 0,870 & 0,860 \\
\hline 2,4 & 1,000 & 0,988 & 0,976 & 0,966 & 0,955 & 0,945 & 0,923 & 0,904 & 0,887 & 0,873 & 0,861 & 0,851 \\
\hline 2,5 & 1,000 & 0,987 & 0,975 & 0,963 & 0,952 & 0,941 & 0,917 & 0,897 & 0,880 & 0,865 & 0,853 & 0,843 \\
\hline 2,6 & 1,000 & 0,986 & 0,972 & 0,960 & 0,948 & 0,937 & 0,912 & 0,890 & 0,873 & 0,858 & 0,845 & 0,834 \\
\hline 2,7 & 1,000 & 0,985 & 0,970 & 0,957 & 0,944 & 0,932 & 0,906 & 0,884 & 0,865 & 0,850 & 0,837 & 0,826 \\
\hline 2,8 & 1,000 & 0,984 & 0,968 & 0,954 & 0,940 & 0,928 & 0,900 & 0,877 & 0,858 & 0,842 & 0,828 & 0,817 \\
\hline 2,9 & 1,000 & 0,982 & 0,966 & 0,951 & 0,936 & 0,923 & 0,894 & 0,870 & 0,850 & 0,834 & 0,820 & 0,809 \\
\hline 3,0 & 1,000 & 0,981 & 0,964 & 0,947 & 0,932 & 0,918 & 0,888 & 0,863 & 0,842 & 0,826 & 0,812 & 0,801 \\
\hline 3,1 & 1,000 & 0,980 & 0,961 & 0,944 & 0,928 & 0,913 & 0,881 & 0,856 & 0,835 & 0,818 & 0,804 & 0,792 \\
\hline 3,2 & 1,000 & 0,979 & 0,959 & 0,940 & 0,924 & 0,908 & 0,875 & 0,849 & 0,827 & 0,810 & 0,796 & 0,784 \\
\hline 3,3 & 1,000 & 0,977 & 0,956 & 0,937 & 0,919 & 0,903 & 0,869 & 0,842 & 0,820 & 0,802 & 0,788 & 0,776 \\
\hline 3,4 & 1,000 & 0,976 & 0,954 & 0,933 & 0,915 & 0,898 & 0,863 & 0,835 & 0,812 & 0,794 & 0,780 & 0,768 \\
\hline 3,5 & 1,000 & 0,974 & 0,951 & 0,930 & 0,910 & 0,893 & 0,856 & 0,827 & 0,805 & 0,787 & 0,772 & 0,760 \\
\hline 3,6 & 1,000 & 0,973 & 0,948 & 0,926 & 0,906 & 0,888 & 0,850 & 0,820 & 0,797 & 0,779 & 0,764 & 0,752 \\
\hline 3,7 & 1,000 & 0,971 & 0,946 & 0,922 & 0,901 & 0,882 & 0,843 & 0,813 & 0,790 & 0,771 & 0,757 & 0,745 \\
\hline 3,8 & 1,000 & 0,970 & 0,943 & 0,918 & 0,897 & 0,877 & 0,837 & 0,806 & 0,782 & 0,764 & 0,749 & 0,737 \\
\hline 3,9 & 1,000 & 0,968 & 0,940 & 0,914 & 0,892 & 0,872 & 0,830 & 0,799 & 0,775 & 0,756 & 0,741 & 0,730 \\
\hline 4,0 & 1,000 & 0,967 & 0,937 & 0,910 & 0,887 & 0,866 & 0,824 & 0,792 & 0,768 & 0,749 & 0,734 & 0,722 \\
\hline 4,1 & 1,000 & 0,965 & 0,934 & 0,906 & 0,882 & 0,861 & 0,818 & 0,785 & 0,761 & 0,742 & 0,727 & 0,715 \\
\hline 4,2 & 1,000 & 0,963 & 0,931 & 0,902 & 0,877 & 0,855 & 0,811 & 0,778 & 0,753 & 0,734 & 0,719 & 0,707 \\
\hline 4,3 & 1,000 & 0,961 & 0,928 & 0,898 & 0,872 & 0,850 & 0,805 & 0,771 & 0,746 & 0,727 & 0,712 & 0,700 \\
\hline 4,4 & 1,000 & 0,960 & 0,924 & 0,894 & 0,867 & 0,844 & 0,798 & 0,765 & 0,739 & 0,720 & 0,705 & 0,693 \\
\hline 4,5 & 1,000 & 0,958 & 0,921 & 0,890 & 0,862 & 0,839 & 0,792 & 0,758 & 0,732 & 0,713 & 0,698 & 0,686 \\
\hline 4,6 & 1,000 & 0,956 & 0,918 & 0,885 & 0,857 & 0,833 & 0,785 & 0,751 & 0,725 & 0,706 & 0,691 & 0,679 \\
\hline 4,7 & 1,000 & 0,954 & 0,915 & 0,881 & 0,852 & 0,827 & 0,779 & 0,744 & 0,719 & 0,699 & 0,684 & 0,672 \\
\hline 4,8 & 1,000 & 0,952 & 0,911 & 0,876 & 0,847 & 0,822 & 0,773 & 0,738 & 0,712 & 0,692 & 0,677 & 0,666 \\
\hline
\end{tabular}


Tabela 78 - continuação da página anterior

\begin{tabular}{|c|c|c|c|c|c|c|c|c|c|c|c|c|}
\hline${ }_{N T U}^{R}$ & 0,0 & 0,2 & 0,4 & 0,6 & 0,8 & 1,0 & 1,5 & 2,0 & 2,5 & 3,0 & 3,5 & 4,0 \\
\hline 4,9 & 1,000 & 0,950 & 0,908 & 0,872 & 0,842 & 0,816 & 0,766 & 0,731 & 0,705 & 0,686 & 0,671 & 0,659 \\
\hline 5,0 & 1,000 & 0,948 & 0,904 & 0,867 & 0,837 & 0,810 & 0,760 & 0,724 & 0,698 & 0,679 & 0,664 & 0,653 \\
\hline 5,1 & 1,000 & 0,946 & 0,901 & 0,863 & 0,831 & 0,805 & 0,754 & 0,718 & 0,692 & 0,673 & 0,658 & 0,646 \\
\hline 5,2 & 1,000 & 0,944 & 0,897 & 0,858 & 0,826 & 0,799 & 0,747 & 0,711 & 0,685 & 0,666 & 0,651 & 0,640 \\
\hline 5,3 & 1,000 & 0,942 & 0,893 & 0,854 & 0,821 & 0,793 & 0,741 & 0,705 & 0,679 & 0,660 & 0,645 & 0,634 \\
\hline 5,4 & 1,000 & 0,939 & 0,890 & 0,849 & 0,816 & 0,788 & 0,735 & 0,699 & 0,673 & 0,653 & 0,639 & 0,627 \\
\hline 5,5 & 1,000 & 0,937 & 0,886 & 0,845 & 0,810 & 0,782 & 0,729 & 0,692 & 0,666 & 0,647 & 0,633 & 0,621 \\
\hline 5,6 & 1,000 & 0,935 & 0,882 & 0,840 & 0,805 & 0,776 & 0,723 & 0,686 & 0,660 & 0,641 & 0,626 & 0,615 \\
\hline 5,7 & 1,000 & 0,932 & 0,879 & 0,835 & 0,800 & 0,771 & 0,717 & 0,680 & 0,654 & 0,635 & 0,620 & 0,609 \\
\hline 5,8 & 1,000 & 0,930 & 0,875 & 0,830 & 0,795 & 0,765 & 0,711 & 0,674 & 0,648 & 0,629 & 0,614 & 0,603 \\
\hline 5,9 & 1,000 & 0,928 & 0,871 & 0,826 & 0,789 & 0,759 & 0,705 & 0,668 & 0,642 & 0,623 & 0,609 & 0,598 \\
\hline 6,0 & 1,000 & 0,925 & 0,867 & 0,821 & 0,784 & 0,754 & 0,699 & 0,662 & 0,636 & 0,617 & 0,603 & 0,592 \\
\hline 6,1 & 1,000 & 0,923 & 0,863 & 0,816 & 0,779 & 0,748 & 0,693 & 0,656 & 0,630 & 0,611 & 0,597 & 0,586 \\
\hline 6,2 & 1,000 & 0,920 & 0,859 & 0,811 & 0,774 & 0,743 & 0,687 & 0,650 & 0,624 & 0,606 & 0,592 & 0,581 \\
\hline 6,3 & 1,000 & 0,918 & 0,855 & 0,807 & 0,768 & 0,737 & 0,681 & 0,644 & 0,619 & 0,600 & 0,586 & 0,575 \\
\hline 6,4 & 1,000 & 0,915 & 0,851 & 0,802 & 0,763 & 0,732 & 0,676 & 0,639 & 0,613 & 0,594 & 0,581 & 0,570 \\
\hline 6,5 & 1,000 & 0,913 & 0,847 & 0,797 & 0,758 & 0,726 & 0,670 & 0,633 & 0,607 & 0,589 & 0,575 & 0,565 \\
\hline 6,6 & 1,000 & 0,910 & 0,843 & 0,792 & 0,753 & 0,721 & 0,664 & 0,628 & 0,602 & 0,584 & 0,570 & 0,559 \\
\hline 6,7 & 1,000 & 0,907 & 0,839 & 0,787 & 0,747 & 0,716 & 0,659 & 0,622 & 0,597 & 0,578 & 0,565 & 0,554 \\
\hline 6,8 & 1,000 & 0,905 & 0,835 & 0,783 & 0,742 & 0,710 & 0,653 & 0,617 & 0,591 & 0,573 & 0,559 & 0,549 \\
\hline 6,9 & 1,000 & 0,902 & 0,831 & 0,778 & 0,737 & 0,705 & 0,648 & 0,611 & 0,586 & 0,568 & 0,554 & 0,544 \\
\hline 7,0 & 1,000 & 0,899 & 0,827 & 0,773 & 0,732 & 0,700 & 0,643 & 0,606 & 0,581 & 0,563 & 0,549 & 0,539 \\
\hline 7,1 & 1,000 & 0,896 & 0,822 & 0,768 & 0,727 & 0,694 & 0,637 & 0,601 & 0,576 & 0,558 & 0,544 & 0,534 \\
\hline 7,2 & 1,000 & 0,893 & 0,818 & 0,763 & 0,722 & 0,689 & 0,632 & 0,595 & 0,570 & 0,553 & 0,540 & 0,530 \\
\hline 7,3 & 1,000 & 0,890 & 0,814 & 0,759 & 0,717 & 0,684 & 0,627 & 0,590 & 0,565 & 0,548 & 0,535 & 0,525 \\
\hline 7,4 & 1,000 & 0,888 & 0,810 & 0,754 & 0,712 & 0,679 & 0,622 & 0,585 & 0,561 & 0,543 & 0,530 & 0,520 \\
\hline 7,5 & 1,000 & 0,885 & 0,806 & 0,749 & 0,707 & 0,674 & 0,616 & 0,580 & 0,556 & 0,538 & 0,525 & 0,515 \\
\hline 7,6 & 1,000 & 0,882 & 0,801 & 0,744 & 0,702 & 0,669 & 0,611 & 0,575 & 0,551 & 0,533 & 0,521 & 0,511 \\
\hline 7,7 & 1,000 & 0,879 & 0,797 & 0,740 & 0,697 & 0,664 & 0,606 & 0,570 & 0,546 & 0,529 & 0,516 & 0,506 \\
\hline 7,8 & 1,000 & 0,876 & 0,793 & 0,735 & 0,692 & 0,659 & 0,601 & 0,566 & 0,541 & 0,524 & 0,512 & 0,502 \\
\hline 7,9 & 1,000 & 0,873 & 0,789 & 0,730 & 0,687 & 0,654 & 0,597 & 0,561 & 0,537 & 0,520 & 0,507 & 0,498 \\
\hline 8,0 & 1,000 & 0,869 & 0,785 & 0,726 & 0,682 & 0,649 & 0,592 & 0,556 & 0,532 & 0,515 & 0,503 & 0,493 \\
\hline 8,1 & 1,000 & 0,866 & 0,780 & 0,721 & 0,677 & 0,644 & 0,587 & 0,551 & 0,528 & 0,511 & 0,498 & 0,489 \\
\hline 8,2 & 1,000 & 0,863 & 0,776 & 0,716 & 0,672 & 0,639 & 0,582 & 0,547 & 0,523 & 0,506 & 0,494 & 0,485 \\
\hline 8,3 & 1,000 & 0,860 & 0,772 & 0,712 & 0,668 & 0,634 & 0,577 & 0,542 & 0,519 & 0,502 & 0,490 & 0,481 \\
\hline 8,4 & 1,000 & 0,857 & 0,768 & 0,707 & 0,663 & 0,629 & 0,573 & 0,538 & 0,514 & 0,498 & 0,486 & 0,477 \\
\hline 8,5 & 1,000 & 0,854 & 0,763 & 0,702 & 0,658 & 0,625 & 0,568 & 0,533 & 0,510 & 0,494 & 0,482 & 0,473 \\
\hline 8,6 & 1,000 & 0,850 & 0,759 & 0,698 & 0,654 & 0,620 & 0,564 & 0,529 & 0,506 & 0,490 & 0,478 & 0,469 \\
\hline 8,7 & 1,000 & 0,847 & 0,755 & 0,693 & 0,649 & 0,615 & 0,559 & 0,525 & 0,502 & 0,485 & 0,474 & 0,465 \\
\hline 8,8 & 1,000 & 0,844 & 0,751 & 0,689 & 0,644 & 0,611 & 0,555 & 0,520 & 0,497 & 0,481 & 0,470 & 0,461 \\
\hline 8,9 & 1,000 & 0,841 & 0,746 & 0,684 & 0,640 & 0,606 & 0,550 & 0,516 & 0,493 & 0,477 & 0,466 & 0,457 \\
\hline 9,0 & 1,000 & 0,837 & 0,742 & 0,680 & 0,635 & 0,602 & 0,546 & 0,512 & 0,489 & 0,474 & 0,462 & 0,453 \\
\hline 9,1 & 1,000 & 0,834 & 0,738 & 0,675 & 0,631 & 0,597 & 0,542 & 0,508 & 0,485 & 0,470 & 0,458 & 0,450 \\
\hline 9,2 & 1,000 & 0,831 & 0,734 & 0,671 & 0,626 & 0,593 & 0,538 & 0,504 & 0,481 & 0,466 & 0,454 & 0,446 \\
\hline 9,3 & 1,000 & 0,827 & 0,730 & 0,666 & 0,622 & 0,589 & 0,533 & 0,500 & 0,478 & 0,462 & 0,451 & 0,442 \\
\hline 9,4 & 1,000 & 0,824 & 0,725 & 0,662 & 0,618 & 0,584 & 0,529 & 0,496 & 0,474 & 0,458 & 0,447 & 0,439 \\
\hline 9,5 & 1,000 & 0,820 & 0,721 & 0,658 & 0,613 & 0,580 & 0,525 & 0,492 & 0,470 & 0,455 & 0,444 & 0,435 \\
\hline 9,6 & 1,000 & 0,817 & 0,717 & 0,653 & 0,609 & 0,576 & 0,521 & 0,488 & 0,466 & 0,451 & 0,440 & 0,432 \\
\hline 9,7 & 1,000 & 0,814 & 0,713 & 0,649 & 0,605 & 0,572 & 0,517 & 0,484 & 0,463 & 0,448 & 0,437 & 0,428 \\
\hline 9,8 & 1,000 & 0,810 & 0,709 & 0,645 & 0,600 & 0,567 & 0,513 & 0,481 & 0,459 & 0,444 & 0,433 & 0,425 \\
\hline 9,9 & 1,000 & 0,807 & 0,705 & 0,641 & 0,596 & 0,563 & 0,509 & 0,477 & 0,455 & 0,441 & 0,430 & 0,422 \\
\hline 10,0 & 1,000 & 0,803 & 0,700 & 0,636 & 0,592 & 0,559 & 0,506 & 0,473 & 0,452 & 0,437 & 0,426 & 0,418 \\
\hline
\end{tabular}


Tabela 79 - Efetividade de temperatura para trocador de calor de fluxo cruzado com cinco passes e um tubo por passe (5-1) - Caso 4A - trocador de calor ilustrado na Figura 93 do Anexo A

\begin{tabular}{|c|c|c|c|c|c|c|c|c|c|c|c|c|}
\hline $\mathrm{NTU}^{R}$ & 0,0 & 0,2 & 0,4 & 0,6 & 0,8 & 1,0 & 1,5 & 2,0 & 2,5 & 3,0 & 3,5 & 4,0 \\
\hline 0,0 & 0,000 & 0,000 & 0,000 & 0,000 & 0,000 & 0,000 & 0,000 & 0,000 & 0,000 & 0,000 & 0,000 & 0,000 \\
\hline 0,1 & 0,095 & 0,094 & 0,094 & 0,093 & 0,092 & 0,091 & 0,089 & 0,087 & 0,085 & 0,083 & 0,081 & 0,080 \\
\hline 0,2 & 0,181 & 0,178 & 0,175 & 0,172 & 0,170 & 0,167 & 0,160 & 0,153 & 0,147 & 0,141 & 0,136 & 0,131 \\
\hline 0,3 & 0,259 & 0,253 & 0,247 & 0,242 & 0,236 & 0,231 & 0,218 & 0,206 & 0,194 & 0,184 & 0,174 & 0,165 \\
\hline 0,4 & 0,330 & 0,320 & 0,311 & 0,302 & 0,294 & 0,286 & 0,266 & 0,248 & 0,231 & 0,216 & 0,201 & 0,189 \\
\hline 0,5 & 0,394 & 0,381 & 0,368 & 0,356 & 0,344 & 0,333 & 0,306 & 0,282 & 0,260 & 0,240 & 0,222 & 0,205 \\
\hline 0,6 & 0,451 & 0,435 & 0,419 & 0,404 & 0,389 & 0,374 & 0,341 & 0,310 & 0,283 & 0,258 & 0,236 & 0,217 \\
\hline 0,7 & 0,503 & 0,484 & 0,465 & 0,446 & 0,428 & 0,411 & 0,370 & 0,334 & 0,301 & 0,273 & 0,248 & 0,226 \\
\hline 0,8 & 0,551 & 0,528 & 0,506 & 0,485 & 0,464 & 0,443 & 0,396 & 0,354 & 0,317 & 0,284 & 0,256 & 0,232 \\
\hline 0,9 & 0,593 & 0,568 & 0,543 & 0,519 & 0,495 & 0,472 & 0,419 & 0,371 & 0,329 & 0,293 & 0,263 & 0,236 \\
\hline 1,0 & 0,632 & 0,605 & 0,577 & 0,550 & 0,524 & 0,498 & 0,439 & 0,386 & 0,340 & 0,301 & 0,268 & 0,240 \\
\hline 1,1 & 0,667 & 0,638 & 0,608 & 0,579 & 0,550 & 0,522 & 0,456 & 0,398 & 0,348 & 0,306 & 0,271 & 0,242 \\
\hline 1,2 & 0,699 & 0,668 & 0,636 & 0,605 & 0,574 & 0,543 & 0,472 & 0,409 & 0,356 & 0,311 & 0,274 & 0,244 \\
\hline 1,3 & 0,727 & 0,695 & 0,662 & 0,628 & 0,595 & 0,563 & 0,486 & 0,419 & 0,362 & 0,315 & 0,277 & 0,246 \\
\hline 1,4 & 0,753 & 0,720 & 0,685 & 0,650 & 0,615 & 0,580 & 0,498 & 0,427 & 0,367 & 0,318 & 0,279 & 0,247 \\
\hline 1,5 & 0,777 & 0,743 & 0,707 & 0,670 & 0,633 & 0,596 & 0,510 & 0,434 & 0,371 & 0,321 & 0,280 & 0,247 \\
\hline 1,6 & 0,798 & 0,763 & 0,727 & 0,689 & 0,650 & 0,611 & 0,520 & 0,441 & 0,375 & 0,323 & 0,281 & 0,248 \\
\hline 1,7 & 0,817 & 0,782 & 0,745 & 0,706 & 0,665 & 0,625 & 0,529 & 0,446 & 0,378 & 0,324 & 0,282 & 0,248 \\
\hline 1,8 & 0,835 & 0,800 & 0,762 & 0,721 & 0,680 & 0,638 & 0,538 & 0,451 & 0,381 & 0,326 & 0,283 & 0,249 \\
\hline 1,9 & 0,850 & 0,816 & 0,777 & 0,736 & 0,693 & 0,650 & 0,546 & 0,456 & 0,383 & 0,327 & 0,283 & 0,249 \\
\hline 2,0 & 0,865 & 0,830 & 0,792 & 0,750 & 0,706 & 0,661 & 0,553 & 0,460 & 0,385 & 0,328 & 0,284 & 0,249 \\
\hline 2,1 & 0,878 & 0,844 & 0,805 & 0,762 & 0,717 & 0,671 & 0,559 & 0,463 & 0,387 & 0,329 & 0,284 & 0,249 \\
\hline 2,2 & 0,889 & 0,856 & 0,817 & 0,774 & 0,728 & 0,681 & 0,565 & 0,467 & 0,389 & 0,329 & 0,284 & 0,250 \\
\hline 2,3 & 0,900 & 0,867 & 0,829 & 0,785 & 0,738 & 0,690 & 0,571 & 0,469 & 0,390 & 0,330 & 0,285 & 0,250 \\
\hline 2,4 & 0,909 & 0,877 & 0,839 & 0,796 & 0,748 & 0,698 & 0,576 & 0,472 & 0,391 & 0,331 & 0,285 & 0,250 \\
\hline 2,5 & 0,918 & 0,887 & 0,849 & 0,805 & 0,757 & 0,706 & 0,581 & 0,474 & 0,392 & 0,331 & 0,285 & 0,250 \\
\hline 2,6 & 0,926 & 0,896 & 0,858 & 0,814 & 0,765 & 0,714 & 0,585 & 0,476 & 0,393 & 0,331 & 0,285 & 0,250 \\
\hline 2,7 & 0,933 & 0,904 & 0,867 & 0,823 & 0,773 & 0,721 & 0,589 & 0,478 & 0,394 & 0,332 & 0,285 & 0,250 \\
\hline 2,8 & 0,939 & 0,911 & 0,875 & 0,831 & 0,781 & 0,727 & 0,593 & 0,480 & 0,394 & 0,332 & 0,285 & 0,250 \\
\hline 2,9 & 0,945 & 0,918 & 0,882 & 0,838 & 0,788 & 0,733 & 0,597 & 0,481 & 0,395 & 0,332 & 0,285 & 0,250 \\
\hline 3,0 & 0,950 & 0,924 & 0,889 & 0,845 & 0,795 & 0,739 & 0,600 & 0,483 & 0,396 & 0,332 & 0,285 & 0,250 \\
\hline 3,1 & 0,955 & 0,930 & 0,895 & 0,852 & 0,801 & 0,745 & 0,603 & 0,484 & 0,396 & 0,332 & 0,285 & 0,250 \\
\hline 3,2 & 0,959 & 0,935 & 0,901 & 0,858 & 0,807 & 0,750 & 0,606 & 0,485 & 0,396 & 0,332 & 0,285 & 0,250 \\
\hline 3,3 & 0,963 & 0,940 & 0,907 & 0,864 & 0,813 & 0,755 & 0,608 & 0,486 & 0,397 & 0,333 & 0,286 & 0,250 \\
\hline 3,4 & 0,967 & 0,944 & 0,912 & 0,870 & 0,818 & 0,760 & 0,611 & 0,487 & 0,397 & 0,333 & 0,286 & 0,250 \\
\hline 3,5 & 0,970 & 0,948 & 0,917 & 0,875 & 0,823 & 0,764 & 0,613 & 0,488 & 0,397 & 0,333 & 0,286 & 0,250 \\
\hline 3,6 & 0,973 & 0,952 & 0,922 & 0,880 & 0,828 & 0,769 & 0,615 & 0,489 & 0,398 & 0,333 & 0,286 & 0,250 \\
\hline 3,7 & 0,975 & 0,956 & 0,926 & 0,885 & 0,833 & 0,773 & 0,617 & 0,490 & 0,398 & 0,333 & 0,286 & 0,250 \\
\hline 3,8 & 0,978 & 0,959 & 0,930 & 0,889 & 0,837 & 0,777 & 0,619 & 0,490 & 0,398 & 0,333 & 0,286 & 0,250 \\
\hline 3,9 & 0,980 & 0,962 & 0,934 & 0,893 & 0,841 & 0,781 & 0,621 & 0,491 & 0,398 & 0,333 & 0,286 & 0,250 \\
\hline 4,0 & 0,982 & 0,965 & 0,937 & 0,898 & 0,845 & 0,784 & 0,623 & 0,491 & 0,398 & 0,333 & 0,286 & 0,250 \\
\hline 4,1 & 0,983 & 0,967 & 0,941 & 0,901 & 0,849 & 0,788 & 0,625 & 0,492 & 0,398 & 0,333 & 0,286 & 0,250 \\
\hline 4,2 & 0,985 & 0,970 & 0,944 & 0,905 & 0,853 & 0,791 & 0,626 & 0,492 & 0,399 & 0,333 & 0,286 & 0,250 \\
\hline 4,3 & 0,986 & 0,972 & 0,947 & 0,908 & 0,856 & 0,794 & 0,628 & 0,493 & 0,399 & 0,333 & 0,286 & 0,250 \\
\hline 4,4 & 0,988 & 0,974 & 0,950 & 0,912 & 0,860 & 0,797 & 0,629 & 0,493 & 0,399 & 0,333 & 0,286 & 0,250 \\
\hline 4,5 & 0,989 & 0,976 & 0,952 & 0,915 & 0,863 & 0,800 & 0,630 & 0,494 & 0,399 & 0,333 & 0,286 & 0,250 \\
\hline 4,6 & 0,990 & 0,977 & 0,955 & 0,918 & 0,866 & 0,802 & 0,631 & 0,494 & 0,399 & 0,333 & 0,286 & 0,250 \\
\hline 4,7 & 0,991 & 0,979 & 0,957 & 0,921 & 0,869 & 0,805 & 0,633 & 0,494 & 0,399 & 0,333 & 0,286 & 0,250 \\
\hline 4,8 & 0,992 & 0,981 & 0,959 & 0,923 & 0,872 & 0,808 & 0,634 & 0,495 & 0,399 & 0,333 & 0,286 & 0,250 \\
\hline
\end{tabular}


Tabela 79 - continuação da página anterior

\begin{tabular}{|c|c|c|c|c|c|c|c|c|c|c|c|c|}
\hline${ }_{N T U}^{R}$ & 0,0 & 0,2 & 0,4 & 0,6 & 0,8 & 1,0 & 1,5 & 2,0 & 2,5 & 3,0 & 3,5 & 4,0 \\
\hline 4,9 & 0,993 & 0,982 & 0,961 & 0,926 & 0,874 & 0,810 & 0,635 & 0,495 & 0,399 & 0,333 & 0,286 & 0,250 \\
\hline 5,0 & 0,993 & 0,983 & 0,963 & 0,928 & 0,877 & 0,812 & 0,636 & 0,495 & 0,399 & 0,333 & 0,286 & 0,250 \\
\hline 5,1 & 0,994 & 0,984 & 0,965 & 0,931 & 0,880 & 0,815 & 0,637 & 0,495 & 0,399 & 0,333 & 0,286 & 0,250 \\
\hline 5,2 & 0,994 & 0,985 & 0,967 & 0,933 & 0,882 & 0,817 & 0,637 & 0,496 & 0,399 & 0,333 & 0,286 & 0,250 \\
\hline 5,3 & 0,995 & 0,986 & 0,968 & 0,935 & 0,884 & 0,819 & 0,638 & 0,496 & 0,399 & 0,333 & 0,286 & 0,250 \\
\hline 5,4 & 0,995 & 0,987 & 0,970 & 0,937 & 0,886 & 0,821 & 0,639 & 0,496 & 0,399 & 0,333 & 0,286 & 0,250 \\
\hline 5,5 & 0,996 & 0,988 & 0,971 & 0,939 & 0,889 & 0,823 & 0,640 & 0,496 & 0,399 & 0,333 & 0,286 & 0,250 \\
\hline 5,6 & 0,996 & 0,989 & 0,972 & 0,941 & 0,891 & 0,824 & 0,641 & 0,496 & 0,399 & 0,333 & 0,286 & 0,250 \\
\hline 5,7 & 0,997 & 0,990 & 0,974 & 0,942 & 0,893 & 0,826 & 0,641 & 0,497 & 0,400 & 0,333 & 0,286 & 0,250 \\
\hline 5,8 & 0,997 & 0,990 & 0,975 & 0,944 & 0,894 & 0,828 & 0,642 & 0,497 & 0,400 & 0,333 & 0,286 & 0,250 \\
\hline 5,9 & 0,997 & 0,991 & 0,976 & 0,946 & 0,896 & 0,830 & 0,643 & 0,497 & 0,400 & 0,333 & 0,286 & 0,250 \\
\hline 6,0 & 0,998 & 0,992 & 0,977 & 0,947 & 0,898 & 0,831 & 0,643 & 0,497 & 0,400 & 0,333 & 0,286 & 0,250 \\
\hline 6,1 & 0,998 & 0,992 & 0,978 & 0,949 & 0,900 & 0,833 & 0,644 & 0,497 & 0,400 & 0,333 & 0,286 & 0,250 \\
\hline 6,2 & 0,998 & 0,993 & 0,979 & 0,950 & 0,901 & 0,834 & 0,644 & 0,497 & 0,400 & 0,333 & 0,286 & 0,250 \\
\hline 6,3 & 0,998 & 0,993 & 0,980 & 0,952 & 0,903 & 0,836 & 0,645 & 0,497 & 0,400 & 0,333 & 0,286 & 0,250 \\
\hline 6,4 & 0,998 & 0,994 & 0,981 & 0,953 & 0,904 & 0,837 & 0,645 & 0,497 & 0,400 & 0,333 & 0,286 & 0,250 \\
\hline 6,5 & 0,998 & 0,994 & 0,982 & 0,954 & 0,906 & 0,838 & 0,646 & 0,498 & 0,400 & 0,333 & 0,286 & 0,250 \\
\hline 6,6 & 0,999 & 0,994 & 0,982 & 0,955 & 0,907 & 0,840 & 0,646 & 0,498 & 0,400 & 0,333 & 0,286 & 0,250 \\
\hline 6,7 & 0,999 & 0,995 & 0,983 & 0,956 & 0,909 & 0,841 & 0,647 & 0,498 & 0,400 & 0,333 & 0,286 & 0,250 \\
\hline 6,8 & 0,999 & 0,995 & 0,984 & 0,957 & 0,910 & 0,842 & 0,647 & 0,498 & 0,400 & 0,333 & 0,286 & 0,250 \\
\hline 6,9 & 0,999 & 0,995 & 0,984 & 0,959 & 0,911 & 0,843 & 0,647 & 0,498 & 0,400 & 0,333 & 0,286 & 0,250 \\
\hline 7,0 & 0,999 & 0,996 & 0,985 & 0,960 & 0,912 & 0,844 & 0,648 & 0,498 & 0,400 & 0,333 & 0,286 & 0,250 \\
\hline 7,1 & 0,999 & 0,996 & 0,986 & 0,961 & 0,914 & 0,845 & 0,648 & 0,498 & 0,400 & 0,333 & 0,286 & 0,250 \\
\hline 7,2 & 0,999 & 0,996 & 0,986 & 0,961 & 0,915 & 0,847 & 0,649 & 0,498 & 0,400 & 0,333 & 0,286 & 0,250 \\
\hline 7,3 & 0,999 & 0,996 & 0,987 & 0,962 & 0,916 & 0,848 & 0,649 & 0,498 & 0,400 & 0,333 & 0,286 & 0,250 \\
\hline 7,4 & 0,999 & 0,997 & 0,987 & 0,963 & 0,917 & 0,849 & 0,649 & 0,498 & 0,400 & 0,333 & 0,286 & 0,250 \\
\hline 7,5 & 0,999 & 0,997 & 0,988 & 0,964 & 0,918 & 0,849 & 0,650 & 0,498 & 0,400 & 0,333 & 0,286 & 0,250 \\
\hline 7,6 & 0,999 & 0,997 & 0,988 & 0,965 & 0,919 & 0,850 & 0,650 & 0,498 & 0,400 & 0,333 & 0,286 & 0,250 \\
\hline 7,7 & 1,000 & 0,997 & 0,989 & 0,966 & 0,920 & 0,851 & 0,650 & 0,498 & 0,400 & 0,333 & 0,286 & 0,250 \\
\hline 7,8 & 1,000 & 0,997 & 0,989 & 0,966 & 0,921 & 0,852 & 0,650 & 0,498 & 0,400 & 0,333 & 0,286 & 0,250 \\
\hline 7,9 & 1,000 & 0,998 & 0,989 & 0,967 & 0,922 & 0,853 & 0,651 & 0,498 & 0,400 & 0,333 & 0,286 & 0,250 \\
\hline 8,0 & 1,000 & 0,998 & 0,990 & 0,968 & 0,923 & 0,854 & 0,651 & 0,498 & 0,400 & 0,333 & 0,286 & 0,250 \\
\hline 8,1 & 1,000 & 0,998 & 0,990 & 0,968 & 0,923 & 0,855 & 0,651 & 0,498 & 0,400 & 0,333 & 0,286 & 0,250 \\
\hline 8,2 & 1,000 & 0,998 & 0,991 & 0,969 & 0,924 & 0,855 & 0,651 & 0,499 & 0,400 & 0,333 & 0,286 & 0,250 \\
\hline 8,3 & 1,000 & 0,998 & 0,991 & 0,970 & 0,925 & 0,856 & 0,652 & 0,499 & 0,400 & 0,333 & 0,286 & 0,250 \\
\hline 8,4 & 1,000 & 0,998 & 0,991 & 0,970 & 0,926 & 0,857 & 0,652 & 0,499 & 0,400 & 0,333 & 0,286 & 0,250 \\
\hline 8,5 & 1,000 & 0,998 & 0,991 & 0,971 & 0,927 & 0,858 & 0,652 & 0,499 & 0,400 & 0,333 & 0,286 & 0,250 \\
\hline 8,6 & 1,000 & 0,998 & 0,992 & 0,971 & 0,927 & 0,858 & 0,652 & 0,499 & 0,400 & 0,333 & 0,286 & 0,250 \\
\hline 8,7 & 1,000 & 0,998 & 0,992 & 0,972 & 0,928 & 0,859 & 0,653 & 0,499 & 0,400 & 0,333 & 0,286 & 0,250 \\
\hline 8,8 & 1,000 & 0,999 & 0,992 & 0,972 & 0,929 & 0,860 & 0,653 & 0,499 & 0,400 & 0,333 & 0,286 & 0,250 \\
\hline 8,9 & 1,000 & 0,999 & 0,992 & 0,973 & 0,929 & 0,860 & 0,653 & 0,499 & 0,400 & 0,333 & 0,286 & 0,250 \\
\hline 9,0 & 1,000 & 0,999 & 0,993 & 0,973 & 0,930 & 0,861 & 0,653 & 0,499 & 0,400 & 0,333 & 0,286 & 0,250 \\
\hline 9,1 & 1,000 & 0,999 & 0,993 & 0,974 & 0,931 & 0,861 & 0,653 & 0,499 & 0,400 & 0,333 & 0,286 & 0,250 \\
\hline 9,2 & 1,000 & 0,999 & 0,993 & 0,974 & 0,931 & 0,862 & 0,653 & 0,499 & 0,400 & 0,333 & 0,286 & 0,250 \\
\hline 9,3 & 1,000 & 0,999 & 0,993 & 0,975 & 0,932 & 0,863 & 0,654 & 0,499 & 0,400 & 0,333 & 0,286 & 0,250 \\
\hline 9,4 & 1,000 & 0,999 & 0,994 & 0,975 & 0,932 & 0,863 & 0,654 & 0,499 & 0,400 & 0,333 & 0,286 & 0,250 \\
\hline 9,5 & 1,000 & 0,999 & 0,994 & 0,975 & 0,933 & 0,864 & 0,654 & 0,499 & 0,400 & 0,333 & 0,286 & 0,250 \\
\hline 9,6 & 1,000 & 0,999 & 0,994 & 0,976 & 0,933 & 0,864 & 0,654 & 0,499 & 0,400 & 0,333 & 0,286 & 0,250 \\
\hline 9,7 & 1,000 & 0,999 & 0,994 & 0,976 & 0,934 & 0,865 & 0,654 & 0,499 & 0,400 & 0,333 & 0,286 & 0,250 \\
\hline 9,8 & 1,000 & 0,999 & 0,994 & 0,976 & 0,934 & 0,865 & 0,654 & 0,499 & 0,400 & 0,333 & 0,286 & 0,250 \\
\hline 9,9 & 1,000 & 0,999 & 0,994 & 0,977 & 0,935 & 0,866 & 0,654 & 0,499 & 0,400 & 0,333 & 0,286 & 0,250 \\
\hline 10,0 & 1,000 & 0,999 & 0,995 & 0,977 & 0,935 & 0,866 & 0,655 & 0,499 & 0,400 & 0,333 & 0,286 & 0,250 \\
\hline
\end{tabular}


Tabela 80 - Fator de correção para trocador de calor de fluxo cruzado com cinco passes e um tubo por passe (5-1) - Caso 4A - trocador de calor ilustrado na Figura 93 do Anexo $\mathrm{A}$

\begin{tabular}{|c|c|c|c|c|c|c|c|c|c|c|c|c|}
\hline${ }_{\text {NTU }}{ }^{R}$ & 0,0 & 0,2 & 0,4 & 0,6 & 0,8 & 1,0 & 1,5 & 2,0 & 2,5 & 3,0 & 3,5 & 4,0 \\
\hline 0,0 & 1,000 & 1,000 & 1,000 & 1,000 & 1,000 & 1,000 & 1,000 & 1,000 & 1,000 & 1,000 & 1,000 & 1,000 \\
\hline 0,1 & 1,000 & 1,000 & 1,000 & 1,000 & 1,000 & 1,000 & 1,000 & 1,000 & 1,000 & 1,000 & 1,000 & 1,000 \\
\hline 0,2 & 1,000 & 1,000 & 1,000 & 1,000 & 1,000 & 1,000 & 1,000 & 0,999 & 0,999 & 0,999 & 0,999 & 0,999 \\
\hline 0,3 & 1,000 & 1,000 & 1,000 & 1,000 & 1,000 & 0,999 & 0,999 & 0,999 & 0,999 & 0,998 & 0,998 & 0,998 \\
\hline 0,4 & 1,000 & 1,000 & 1,000 & 0,999 & 0,999 & 0,999 & 0,998 & 0,998 & 0,997 & 0,997 & 0,996 & 0,996 \\
\hline 0,5 & 1,000 & 1,000 & 0,999 & 0,999 & 0,999 & 0,998 & 0,998 & 0,997 & 0,996 & 0,995 & 0,994 & 0,994 \\
\hline 0,6 & 1,000 & 1,000 & 0,999 & 0,999 & 0,998 & 0,998 & 0,996 & 0,995 & 0,994 & 0,993 & 0,992 & 0,991 \\
\hline 0,7 & 1,000 & 0,999 & 0,999 & 0,998 & 0,997 & 0,997 & 0,995 & 0,994 & 0,992 & 0,991 & 0,989 & 0,988 \\
\hline 0,8 & 1,000 & 0,999 & 0,998 & 0,997 & 0,997 & 0,996 & 0,994 & 0,992 & 0,990 & 0,988 & 0,986 & 0,984 \\
\hline 0,9 & 1,000 & 0,999 & 0,998 & 0,997 & 0,996 & 0,995 & 0,992 & 0,990 & 0,987 & 0,985 & 0,982 & 0,980 \\
\hline 1,0 & 1,000 & 0,999 & 0,997 & 0,996 & 0,995 & 0,993 & 0,990 & 0,987 & 0,984 & 0,981 & 0,978 & 0,976 \\
\hline 1,1 & 1,000 & 0,998 & 0,997 & 0,995 & 0,994 & 0,992 & 0,988 & 0,985 & 0,981 & 0,977 & 0,974 & 0,971 \\
\hline 1,2 & 1,000 & 0,998 & 0,996 & 0,994 & 0,992 & 0,991 & 0,986 & 0,982 & 0,977 & 0,973 & 0,970 & 0,966 \\
\hline 1,3 & 1,000 & 0,998 & 0,996 & 0,993 & 0,991 & 0,989 & 0,984 & 0,979 & 0,974 & 0,969 & 0,965 & 0,961 \\
\hline 1,4 & 1,000 & 0,997 & 0,995 & 0,992 & 0,990 & 0,987 & 0,981 & 0,975 & 0,970 & 0,965 & 0,960 & 0,955 \\
\hline 1,5 & 1,000 & 0,997 & 0,994 & 0,991 & 0,988 & 0,985 & 0,979 & 0,972 & 0,966 & 0,960 & 0,954 & 0,949 \\
\hline 1,6 & 1,000 & 0,997 & 0,993 & 0,990 & 0,987 & 0,983 & 0,976 & 0,968 & 0,961 & 0,955 & 0,949 & 0,943 \\
\hline 1,7 & 1,000 & 0,996 & 0,992 & 0,989 & 0,985 & 0,981 & 0,973 & 0,965 & 0,957 & 0,950 & 0,943 & 0,937 \\
\hline 1,8 & 1,000 & 0,996 & 0,991 & 0,987 & 0,983 & 0,979 & 0,970 & 0,961 & 0,952 & 0,945 & 0,937 & 0,931 \\
\hline 1,9 & 1,000 & 0,995 & 0,990 & 0,986 & 0,981 & 0,977 & 0,966 & 0,957 & 0,947 & 0,939 & 0,932 & 0,925 \\
\hline 2,0 & 1,000 & 0,995 & 0,989 & 0,984 & 0,979 & 0,975 & 0,963 & 0,952 & 0,942 & 0,934 & 0,925 & 0,918 \\
\hline 2,1 & 1,000 & 0,994 & 0,988 & 0,983 & 0,977 & 0,972 & 0,959 & 0,948 & 0,937 & 0,928 & 0,919 & 0,911 \\
\hline 2,2 & 1,000 & 0,994 & 0,987 & 0,981 & 0,975 & 0,969 & 0,956 & 0,943 & 0,932 & 0,922 & 0,913 & 0,905 \\
\hline 2,3 & 1,000 & 0,993 & 0,986 & 0,979 & 0,973 & 0,967 & 0,952 & 0,939 & 0,927 & 0,916 & 0,906 & 0,898 \\
\hline 2,4 & 1,000 & 0,992 & 0,985 & 0,978 & 0,971 & 0,964 & 0,948 & 0,934 & 0,921 & 0,910 & 0,900 & 0,891 \\
\hline 2,5 & 1,000 & 0,992 & 0,984 & 0,976 & 0,968 & 0,961 & 0,944 & 0,929 & 0,916 & 0,904 & 0,893 & 0,884 \\
\hline 2,6 & 1,000 & 0,991 & 0,982 & 0,974 & 0,966 & 0,958 & 0,940 & 0,924 & 0,910 & 0,898 & 0,887 & 0,877 \\
\hline 2,7 & 1,000 & 0,990 & 0,981 & 0,972 & 0,963 & 0,955 & 0,936 & 0,919 & 0,904 & 0,891 & 0,880 & 0,871 \\
\hline 2,8 & 1,000 & 0,990 & 0,980 & 0,970 & 0,961 & 0,952 & 0,931 & 0,914 & 0,898 & 0,885 & 0,874 & 0,864 \\
\hline 2,9 & 1,000 & 0,989 & 0,978 & 0,968 & 0,958 & 0,949 & 0,927 & 0,909 & 0,893 & 0,879 & 0,867 & 0,857 \\
\hline 3,0 & 1,000 & 0,988 & 0,977 & 0,966 & 0,955 & 0,945 & 0,923 & 0,903 & 0,887 & 0,872 & 0,860 & 0,850 \\
\hline 3,1 & 1,000 & 0,987 & 0,975 & 0,963 & 0,952 & 0,942 & 0,918 & 0,898 & 0,881 & 0,866 & 0,854 & 0,843 \\
\hline 3,2 & 1,000 & 0,986 & 0,973 & 0,961 & 0,949 & 0,938 & 0,913 & 0,892 & 0,875 & 0,860 & 0,847 & 0,836 \\
\hline 3,3 & 1,000 & 0,986 & 0,972 & 0,959 & 0,946 & 0,935 & 0,909 & 0,887 & 0,869 & 0,853 & 0,840 & 0,829 \\
\hline 3,4 & 1,000 & 0,985 & 0,970 & 0,956 & 0,943 & 0,931 & 0,904 & 0,881 & 0,863 & 0,847 & 0,834 & 0,822 \\
\hline 3,5 & 1,000 & 0,984 & 0,968 & 0,954 & 0,940 & 0,927 & 0,899 & 0,876 & 0,856 & 0,840 & 0,827 & 0,816 \\
\hline 3,6 & 1,000 & 0,983 & 0,966 & 0,951 & 0,937 & 0,924 & 0,894 & 0,870 & 0,850 & 0,834 & 0,820 & 0,809 \\
\hline 3,7 & 1,000 & 0,982 & 0,965 & 0,949 & 0,934 & 0,920 & 0,889 & 0,865 & 0,844 & 0,828 & 0,814 & 0,802 \\
\hline 3,8 & 1,000 & 0,981 & 0,963 & 0,946 & 0,930 & 0,916 & 0,885 & 0,859 & 0,838 & 0,821 & 0,807 & 0,796 \\
\hline 3,9 & 1,000 & 0,980 & 0,961 & 0,943 & 0,927 & 0,912 & 0,880 & 0,853 & 0,832 & 0,815 & 0,801 & 0,789 \\
\hline 4,0 & 1,000 & 0,979 & 0,959 & 0,940 & 0,924 & 0,908 & 0,874 & 0,848 & 0,826 & 0,808 & 0,794 & 0,782 \\
\hline 4,1 & 1,000 & 0,978 & 0,957 & 0,938 & 0,920 & 0,904 & 0,869 & 0,842 & 0,820 & 0,802 & 0,788 & 0,776 \\
\hline 4,2 & 1,000 & 0,977 & 0,955 & 0,935 & 0,917 & 0,900 & 0,864 & 0,836 & 0,814 & 0,796 & 0,781 & 0,770 \\
\hline 4,3 & 1,000 & 0,975 & 0,953 & 0,932 & 0,913 & 0,896 & 0,859 & 0,831 & 0,808 & 0,790 & 0,775 & 0,763 \\
\hline 4,4 & 1,000 & 0,974 & 0,951 & 0,929 & 0,909 & 0,892 & 0,854 & 0,825 & 0,802 & 0,783 & 0,769 & 0,757 \\
\hline 4,5 & 1,000 & 0,973 & 0,948 & 0,926 & 0,906 & 0,887 & 0,849 & 0,819 & 0,796 & 0,777 & 0,762 & 0,751 \\
\hline 4,6 & 1,000 & 0,972 & 0,946 & 0,923 & 0,902 & 0,883 & 0,844 & 0,813 & 0,790 & 0,771 & 0,756 & 0,744 \\
\hline 4,7 & 1,000 & 0,971 & 0,944 & 0,920 & 0,898 & 0,879 & 0,839 & 0,808 & 0,784 & 0,765 & 0,750 & 0,738 \\
\hline 4,8 & 1,000 & 0,969 & 0,942 & 0,917 & 0,894 & 0,874 & 0,833 & 0,802 & 0,778 & 0,759 & 0,744 & 0,732 \\
\hline
\end{tabular}


Tabela 80 - continuação da página anterior

\begin{tabular}{|c|c|c|c|c|c|c|c|c|c|c|c|c|}
\hline${ }_{N T U}^{R}$ & 0,0 & 0,2 & 0,4 & 0,6 & 0,8 & 1,0 & 1,5 & 2,0 & 2,5 & 3,0 & 3,5 & 4,0 \\
\hline 4,9 & 1,000 & 0,968 & 0,939 & 0,913 & 0,891 & 0,870 & 0,828 & 0,796 & 0,772 & 0,753 & 0,738 & 0,726 \\
\hline 5,0 & 1,000 & 0,967 & 0,937 & 0,910 & 0,887 & 0,866 & 0,823 & 0,791 & 0,766 & 0,747 & 0,732 & 0,720 \\
\hline 5,1 & 1,000 & 0,965 & 0,934 & 0,907 & 0,883 & 0,861 & 0,818 & 0,785 & 0,760 & 0,741 & 0,726 & 0,714 \\
\hline 5,2 & 1,000 & 0,964 & 0,932 & 0,904 & 0,879 & 0,857 & 0,812 & 0,779 & 0,754 & 0,735 & 0,720 & 0,708 \\
\hline 5,3 & 1,000 & 0,963 & 0,930 & 0,900 & 0,875 & 0,852 & 0,807 & 0,774 & 0,749 & 0,729 & 0,714 & 0,702 \\
\hline 5,4 & 1,000 & 0,961 & 0,927 & 0,897 & 0,871 & 0,848 & 0,802 & 0,768 & 0,743 & 0,724 & 0,709 & 0,697 \\
\hline 5,5 & 1,000 & 0,960 & 0,924 & 0,894 & 0,867 & 0,843 & 0,797 & 0,763 & 0,737 & 0,718 & 0,703 & 0,691 \\
\hline 5,6 & 1,000 & 0,958 & 0,922 & 0,890 & 0,863 & 0,839 & 0,792 & 0,757 & 0,732 & 0,712 & 0,697 & 0,685 \\
\hline 5,7 & 1,000 & 0,957 & 0,919 & 0,887 & 0,859 & 0,834 & 0,786 & 0,752 & 0,726 & 0,707 & 0,692 & 0,680 \\
\hline 5,8 & 1,000 & 0,955 & 0,917 & 0,883 & 0,855 & 0,830 & 0,781 & 0,746 & 0,721 & 0,701 & 0,686 & 0,674 \\
\hline 5,9 & 1,000 & 0,954 & 0,914 & 0,880 & 0,850 & 0,825 & 0,776 & 0,741 & 0,715 & 0,696 & 0,681 & 0,669 \\
\hline 6,0 & 1,000 & 0,952 & 0,911 & 0,876 & 0,846 & 0,821 & 0,771 & 0,736 & 0,710 & 0,690 & 0,675 & 0,663 \\
\hline 6,1 & 1,000 & 0,951 & 0,908 & 0,873 & 0,842 & 0,816 & 0,766 & 0,730 & 0,704 & 0,685 & 0,670 & 0,658 \\
\hline 6,2 & 1,000 & 0,949 & 0,906 & 0,869 & 0,838 & 0,812 & 0,761 & 0,725 & 0,699 & 0,679 & 0,664 & 0,653 \\
\hline 6,3 & 1,000 & 0,947 & 0,903 & 0,865 & 0,834 & 0,807 & 0,756 & 0,720 & 0,694 & 0,674 & 0,659 & 0,648 \\
\hline 6,4 & 1,000 & 0,946 & 0,900 & 0,862 & 0,830 & 0,802 & 0,751 & 0,714 & 0,688 & 0,669 & 0,654 & 0,643 \\
\hline 6,5 & 1,000 & 0,944 & 0,897 & 0,858 & 0,825 & 0,798 & 0,746 & 0,709 & 0,683 & 0,664 & 0,649 & 0,637 \\
\hline 6,6 & 1,000 & 0,942 & 0,894 & 0,854 & 0,821 & 0,793 & 0,741 & 0,704 & 0,678 & 0,659 & 0,644 & 0,632 \\
\hline 6,7 & 1,000 & 0,940 & 0,891 & 0,851 & 0,817 & 0,789 & 0,736 & 0,699 & 0,673 & 0,653 & 0,639 & 0,627 \\
\hline 6,8 & 1,000 & 0,939 & 0,888 & 0,847 & 0,813 & 0,784 & 0,731 & 0,694 & 0,668 & 0,648 & 0,634 & 0,622 \\
\hline 6,9 & 1,000 & 0,937 & 0,885 & 0,843 & 0,808 & 0,780 & 0,726 & 0,689 & 0,663 & 0,643 & 0,629 & 0,618 \\
\hline 7,0 & 1,000 & 0,935 & 0,882 & 0,839 & 0,804 & 0,775 & 0,721 & 0,684 & 0,658 & 0,638 & 0,624 & 0,613 \\
\hline 7,1 & 1,000 & 0,933 & 0,879 & 0,836 & 0,800 & 0,771 & 0,716 & 0,679 & 0,653 & 0,634 & 0,619 & 0,608 \\
\hline 7,2 & 1,000 & 0,931 & 0,876 & 0,832 & 0,796 & 0,766 & 0,711 & 0,674 & 0,648 & 0,629 & 0,614 & 0,603 \\
\hline 7,3 & 1,000 & 0,929 & 0,873 & 0,828 & 0,791 & 0,761 & 0,706 & 0,669 & 0,643 & 0,624 & 0,610 & 0,599 \\
\hline 7,4 & 1,000 & 0,927 & 0,870 & 0,824 & 0,787 & 0,757 & 0,702 & 0,664 & 0,638 & 0,619 & 0,605 & 0,594 \\
\hline 7,5 & 1,000 & 0,925 & 0,867 & 0,820 & 0,783 & 0,752 & 0,697 & 0,660 & 0,634 & 0,615 & 0,600 & 0,590 \\
\hline 7,6 & 1,000 & 0,923 & 0,864 & 0,816 & 0,779 & 0,748 & 0,692 & 0,655 & 0,629 & 0,610 & 0,596 & 0,585 \\
\hline 7,7 & 1,000 & 0,921 & 0,860 & 0,813 & 0,774 & 0,744 & 0,687 & 0,650 & 0,624 & 0,605 & 0,591 & 0,581 \\
\hline 7,8 & 1,000 & 0,919 & 0,857 & 0,809 & 0,770 & 0,739 & 0,683 & 0,645 & 0,620 & 0,601 & 0,587 & 0,576 \\
\hline 7,9 & 1,000 & 0,917 & 0,854 & 0,805 & 0,766 & 0,735 & 0,678 & 0,641 & 0,615 & 0,596 & 0,582 & 0,572 \\
\hline 8,0 & 1,000 & 0,915 & 0,851 & 0,801 & 0,762 & 0,730 & 0,674 & 0,636 & 0,610 & 0,592 & 0,578 & 0,568 \\
\hline 8,1 & 1,000 & 0,913 & 0,848 & 0,797 & 0,758 & 0,726 & 0,669 & 0,632 & 0,606 & 0,587 & 0,574 & 0,563 \\
\hline 8,2 & 1,000 & 0,911 & 0,844 & 0,793 & 0,753 & 0,721 & 0,664 & 0,627 & 0,602 & 0,583 & 0,569 & 0,559 \\
\hline 8,3 & 1,000 & 0,909 & 0,841 & 0,789 & 0,749 & 0,717 & 0,660 & 0,623 & 0,597 & 0,579 & 0,565 & 0,555 \\
\hline 8,4 & 1,000 & 0,907 & 0,838 & 0,786 & 0,745 & 0,713 & 0,656 & 0,618 & 0,593 & 0,575 & 0,561 & 0,551 \\
\hline 8,5 & 1,000 & 0,905 & 0,834 & 0,782 & 0,741 & 0,708 & 0,651 & 0,614 & 0,589 & 0,570 & 0,557 & 0,547 \\
\hline 8,6 & 1,000 & 0,902 & 0,831 & 0,778 & 0,737 & 0,704 & 0,647 & 0,610 & 0,584 & 0,566 & 0,553 & 0,543 \\
\hline 8,7 & 1,000 & 0,900 & 0,828 & 0,774 & 0,733 & 0,700 & 0,642 & 0,605 & 0,580 & 0,562 & 0,549 & 0,539 \\
\hline 8,8 & 1,000 & 0,898 & 0,824 & 0,770 & 0,728 & 0,696 & 0,638 & 0,601 & 0,576 & 0,558 & 0,545 & 0,535 \\
\hline 8,9 & 1,000 & 0,896 & 0,821 & 0,766 & 0,724 & 0,691 & 0,634 & 0,597 & 0,572 & 0,554 & 0,541 & 0,531 \\
\hline 9,0 & 1,000 & 0,893 & 0,818 & 0,762 & 0,720 & 0,687 & 0,630 & 0,593 & 0,568 & 0,550 & 0,537 & 0,527 \\
\hline 9,1 & 1,000 & 0,891 & 0,814 & 0,758 & 0,716 & 0,683 & 0,625 & 0,589 & 0,564 & 0,546 & 0,533 & 0,523 \\
\hline 9,2 & 1,000 & 0,889 & 0,811 & 0,755 & 0,712 & 0,679 & 0,621 & 0,585 & 0,560 & 0,542 & 0,529 & 0,520 \\
\hline 9,3 & 1,000 & 0,886 & 0,808 & 0,751 & 0,708 & 0,675 & 0,617 & 0,581 & 0,556 & 0,538 & 0,526 & 0,516 \\
\hline 9,4 & 1,000 & 0,884 & 0,804 & 0,747 & 0,704 & 0,671 & 0,613 & 0,577 & 0,552 & 0,535 & 0,522 & 0,512 \\
\hline 9,5 & 1,000 & 0,882 & 0,801 & 0,743 & 0,700 & 0,667 & 0,609 & 0,573 & 0,548 & 0,531 & 0,518 & 0,509 \\
\hline 9,6 & 1,000 & 0,879 & 0,797 & 0,739 & 0,696 & 0,663 & 0,605 & 0,569 & 0,544 & 0,527 & 0,514 & 0,505 \\
\hline 9,7 & 1,000 & 0,877 & 0,794 & 0,736 & 0,692 & 0,659 & 0,601 & 0,565 & 0,541 & 0,523 & 0,511 & 0,501 \\
\hline 9,8 & 1,000 & 0,874 & 0,791 & 0,732 & 0,688 & 0,655 & 0,597 & 0,561 & 0,537 & 0,520 & 0,507 & 0,498 \\
\hline 9,9 & 1,000 & 0,872 & 0,787 & 0,728 & 0,684 & 0,651 & 0,593 & 0,557 & 0,533 & 0,516 & 0,504 & 0,494 \\
\hline 10,0 & 1,000 & 0,869 & 0,784 & 0,724 & 0,680 & 0,647 & 0,589 & 0,553 & 0,529 & 0,513 & 0,500 & 0,491 \\
\hline
\end{tabular}


Tabela 81 - Efetividade de temperatura para trocador de calor de fluxo cruzado com dez passes e um tubo por passe (10-1) - Caso 4A - trocador de calor ilustrado na Figura 98 do Anexo A

\begin{tabular}{|c|c|c|c|c|c|c|c|c|c|c|c|c|}
\hline $\mathrm{NTU}^{R}$ & 0,0 & 0,2 & 0,4 & 0,6 & 0,8 & 1,0 & 1,5 & 2,0 & 2,5 & 3,0 & 3,5 & 4,0 \\
\hline 0,0 & 0,000 & 0,000 & 0,000 & 0,000 & 0,000 & 0,000 & 0,000 & 0,000 & 0,000 & 0,000 & 0,000 & 0,000 \\
\hline 0,1 & 0,095 & 0,094 & 0,094 & 0,093 & 0,092 & 0,091 & 0,089 & 0,087 & 0,085 & 0,083 & 0,081 & 0,080 \\
\hline 0,2 & 0,181 & 0,178 & 0,175 & 0,172 & 0,170 & 0,167 & 0,160 & 0,153 & 0,147 & 0,142 & 0,136 & 0,131 \\
\hline 0,3 & 0,259 & 0,253 & 0,247 & 0,242 & 0,236 & 0,231 & 0,218 & 0,206 & 0,195 & 0,184 & 0,174 & 0,165 \\
\hline 0,4 & 0,330 & 0,320 & 0,311 & 0,303 & 0,294 & 0,286 & 0,266 & 0,248 & 0,231 & 0,216 & 0,202 & 0,189 \\
\hline 0,5 & 0,394 & 0,381 & 0,368 & 0,356 & 0,345 & 0,333 & 0,307 & 0,282 & 0,260 & 0,240 & 0,222 & 0,206 \\
\hline 0,6 & 0,451 & 0,435 & 0,419 & 0,404 & 0,389 & 0,375 & 0,341 & 0,311 & 0,283 & 0,259 & 0,237 & 0,218 \\
\hline 0,7 & 0,503 & 0,484 & 0,465 & 0,447 & 0,429 & 0,412 & 0,371 & 0,335 & 0,302 & 0,273 & 0,248 & 0,226 \\
\hline 0,8 & 0,551 & 0,528 & 0,507 & 0,485 & 0,464 & 0,444 & 0,397 & 0,355 & 0,318 & 0,285 & 0,257 & 0,232 \\
\hline 0,9 & 0,593 & 0,569 & 0,544 & 0,520 & 0,496 & 0,473 & 0,420 & 0,372 & 0,330 & 0,294 & 0,263 & 0,237 \\
\hline 1,0 & 0,632 & 0,605 & 0,578 & 0,551 & 0,525 & 0,500 & 0,440 & 0,387 & 0,341 & 0,302 & 0,268 & 0,240 \\
\hline 1,1 & 0,667 & 0,638 & 0,609 & 0,580 & 0,551 & 0,523 & 0,458 & 0,400 & 0,350 & 0,307 & 0,272 & 0,243 \\
\hline 1,2 & 0,699 & 0,668 & 0,637 & 0,606 & 0,575 & 0,545 & 0,474 & 0,411 & 0,357 & 0,312 & 0,275 & 0,245 \\
\hline 1,3 & 0,727 & 0,696 & 0,663 & 0,630 & 0,597 & 0,565 & 0,488 & 0,420 & 0,363 & 0,316 & 0,277 & 0,246 \\
\hline 1,4 & 0,753 & 0,721 & 0,687 & 0,652 & 0,617 & 0,583 & 0,501 & 0,429 & 0,369 & 0,319 & 0,279 & 0,247 \\
\hline 1,5 & 0,777 & 0,743 & 0,708 & 0,672 & 0,635 & 0,599 & 0,513 & 0,436 & 0,373 & 0,322 & 0,281 & 0,248 \\
\hline 1,6 & 0,798 & 0,764 & 0,728 & 0,691 & 0,653 & 0,614 & 0,523 & 0,443 & 0,377 & 0,324 & 0,282 & 0,248 \\
\hline 1,7 & 0,817 & 0,783 & 0,747 & 0,708 & 0,668 & 0,629 & 0,533 & 0,449 & 0,380 & 0,325 & 0,283 & 0,249 \\
\hline 1,8 & 0,835 & 0,801 & 0,764 & 0,724 & 0,683 & 0,642 & 0,542 & 0,454 & 0,383 & 0,327 & 0,283 & 0,249 \\
\hline 1,9 & 0,850 & 0,817 & 0,779 & 0,739 & 0,697 & 0,654 & 0,550 & 0,459 & 0,385 & 0,328 & 0,284 & 0,249 \\
\hline 2,0 & 0,865 & 0,831 & 0,794 & 0,753 & 0,710 & 0,665 & 0,557 & 0,463 & 0,387 & 0,329 & 0,284 & 0,249 \\
\hline 2,1 & 0,878 & 0,845 & 0,807 & 0,766 & 0,722 & 0,676 & 0,564 & 0,466 & 0,389 & 0,330 & 0,284 & 0,250 \\
\hline 2,2 & 0,889 & 0,857 & 0,820 & 0,778 & 0,733 & 0,686 & 0,570 & 0,470 & 0,390 & 0,330 & 0,285 & 0,250 \\
\hline 2,3 & 0,900 & 0,868 & 0,831 & 0,789 & 0,743 & 0,695 & 0,576 & 0,473 & 0,392 & 0,331 & 0,285 & 0,250 \\
\hline 2,4 & 0,909 & 0,879 & 0,842 & 0,800 & 0,753 & 0,704 & 0,581 & 0,475 & 0,393 & 0,331 & 0,285 & 0,250 \\
\hline 2,5 & 0,918 & 0,888 & 0,852 & 0,810 & 0,762 & 0,712 & 0,586 & 0,477 & 0,394 & 0,332 & 0,285 & 0,250 \\
\hline 2,6 & 0,926 & 0,897 & 0,861 & 0,819 & 0,771 & 0,720 & 0,591 & 0,480 & 0,395 & 0,332 & 0,285 & 0,250 \\
\hline 2,7 & 0,933 & 0,905 & 0,870 & 0,828 & 0,780 & 0,727 & 0,595 & 0,481 & 0,395 & 0,332 & 0,285 & 0,250 \\
\hline 2,8 & 0,939 & 0,912 & 0,878 & 0,836 & 0,787 & 0,734 & 0,599 & 0,483 & 0,396 & 0,332 & 0,285 & 0,250 \\
\hline 2,9 & 0,945 & 0,919 & 0,886 & 0,844 & 0,795 & 0,741 & 0,603 & 0,485 & 0,396 & 0,332 & 0,286 & 0,250 \\
\hline 3,0 & 0,950 & 0,926 & 0,893 & 0,851 & 0,802 & 0,747 & 0,606 & 0,486 & 0,397 & 0,333 & 0,286 & 0,250 \\
\hline 3,1 & 0,955 & 0,931 & 0,899 & 0,858 & 0,809 & 0,753 & 0,609 & 0,487 & 0,397 & 0,333 & 0,286 & 0,250 \\
\hline 3,2 & 0,959 & 0,937 & 0,905 & 0,864 & 0,815 & 0,759 & 0,612 & 0,488 & 0,398 & 0,333 & 0,286 & 0,250 \\
\hline 3,3 & 0,963 & 0,942 & 0,911 & 0,871 & 0,821 & 0,764 & 0,615 & 0,489 & 0,398 & 0,333 & 0,286 & 0,250 \\
\hline 3,4 & 0,967 & 0,946 & 0,916 & 0,876 & 0,827 & 0,769 & 0,618 & 0,490 & 0,398 & 0,333 & 0,286 & 0,250 \\
\hline 3,5 & 0,970 & 0,950 & 0,921 & 0,882 & 0,832 & 0,774 & 0,620 & 0,491 & 0,398 & 0,333 & 0,286 & 0,250 \\
\hline 3,6 & 0,973 & 0,954 & 0,926 & 0,887 & 0,837 & 0,779 & 0,623 & 0,492 & 0,399 & 0,333 & 0,286 & 0,250 \\
\hline 3,7 & 0,975 & 0,958 & 0,930 & 0,892 & 0,842 & 0,783 & 0,625 & 0,493 & 0,399 & 0,333 & 0,286 & 0,250 \\
\hline 3,8 & 0,978 & 0,961 & 0,935 & 0,897 & 0,847 & 0,788 & 0,627 & 0,493 & 0,399 & 0,333 & 0,286 & 0,250 \\
\hline 3,9 & 0,980 & 0,964 & 0,938 & 0,901 & 0,852 & 0,792 & 0,629 & 0,494 & 0,399 & 0,333 & 0,286 & 0,250 \\
\hline 4,0 & 0,982 & 0,967 & 0,942 & 0,905 & 0,856 & 0,796 & 0,631 & 0,494 & 0,399 & 0,333 & 0,286 & 0,250 \\
\hline 4,1 & 0,983 & 0,969 & 0,945 & 0,909 & 0,860 & 0,800 & 0,632 & 0,495 & 0,399 & 0,333 & 0,286 & 0,250 \\
\hline 4,2 & 0,985 & 0,971 & 0,949 & 0,913 & 0,864 & 0,803 & 0,634 & 0,495 & 0,399 & 0,333 & 0,286 & 0,250 \\
\hline 4,3 & 0,986 & 0,974 & 0,952 & 0,917 & 0,868 & 0,807 & 0,636 & 0,496 & 0,399 & 0,333 & 0,286 & 0,250 \\
\hline 4,4 & 0,988 & 0,976 & 0,954 & 0,920 & 0,872 & 0,810 & 0,637 & 0,496 & 0,399 & 0,333 & 0,286 & 0,250 \\
\hline 4,5 & 0,989 & 0,977 & 0,957 & 0,924 & 0,875 & 0,813 & 0,638 & 0,496 & 0,400 & 0,333 & 0,286 & 0,250 \\
\hline 4,6 & 0,990 & 0,979 & 0,959 & 0,927 & 0,879 & 0,816 & 0,640 & 0,497 & 0,400 & 0,333 & 0,286 & 0,250 \\
\hline 4,7 & 0,991 & 0,981 & 0,962 & 0,930 & 0,882 & 0,819 & 0,641 & 0,497 & 0,400 & 0,333 & 0,286 & 0,250 \\
\hline 4,8 & 0,992 & 0,982 & 0,964 & 0,933 & 0,885 & 0,822 & 0,642 & 0,497 & 0,400 & 0,333 & 0,286 & 0,250 \\
\hline
\end{tabular}


Tabela 81 - continuação da página anterior

\begin{tabular}{|c|c|c|c|c|c|c|c|c|c|c|c|c|}
\hline $\mathrm{NTU}^{R}$ & 0,0 & 0,2 & 0,4 & 0,6 & 0,8 & 1,0 & 1,5 & 2,0 & 2,5 & 3,0 & 3,5 & 4,0 \\
\hline 4,9 & 0,993 & 0,984 & 0,966 & 0,935 & 0,888 & 0,825 & 0,643 & 0,497 & 0,400 & 0,333 & 0,286 & 0,250 \\
\hline 5,0 & 0,993 & 0,985 & 0,968 & 0,938 & 0,891 & 0,828 & 0,644 & 0,498 & 0,400 & 0,333 & 0,286 & 0,250 \\
\hline 5,1 & 0,994 & 0,986 & 0,970 & 0,940 & 0,894 & 0,830 & 0,645 & 0,498 & 0,400 & 0,333 & 0,286 & 0,250 \\
\hline 5,2 & 0,994 & 0,987 & 0,971 & 0,943 & 0,896 & 0,833 & 0,646 & 0,498 & 0,400 & 0,333 & 0,286 & 0,250 \\
\hline 5,3 & 0,995 & 0,988 & 0,973 & 0,945 & 0,899 & 0,835 & 0,647 & 0,498 & 0,400 & 0,333 & 0,286 & 0,250 \\
\hline 5,4 & 0,995 & 0,989 & 0,975 & 0,947 & 0,901 & 0,838 & 0,648 & 0,498 & 0,400 & 0,333 & 0,286 & 0,250 \\
\hline 5,5 & 0,996 & 0,990 & 0,976 & 0,949 & 0,904 & 0,840 & 0,649 & 0,498 & 0,400 & 0,333 & 0,286 & 0,250 \\
\hline 5,6 & 0,996 & 0,990 & 0,977 & 0,951 & 0,906 & 0,842 & 0,649 & 0,498 & 0,400 & 0,333 & 0,286 & 0,250 \\
\hline 5,7 & 0,997 & 0,991 & 0,979 & 0,953 & 0,908 & 0,844 & 0,650 & 0,499 & 0,400 & 0,333 & 0,286 & 0,250 \\
\hline 5,8 & 0,997 & 0,992 & 0,980 & 0,955 & 0,911 & 0,846 & 0,651 & 0,499 & 0,400 & 0,333 & 0,286 & 0,250 \\
\hline 5,9 & 0,997 & 0,992 & 0,981 & 0,956 & 0,913 & 0,848 & 0,651 & 0,499 & 0,400 & 0,333 & 0,286 & 0,250 \\
\hline 6,0 & 0,998 & 0,993 & 0,982 & 0,958 & 0,915 & 0,850 & 0,652 & 0,499 & 0,400 & 0,333 & 0,286 & 0,250 \\
\hline 6,1 & 0,998 & 0,994 & 0,983 & 0,960 & 0,917 & 0,852 & 0,653 & 0,499 & 0,400 & 0,333 & 0,286 & 0,250 \\
\hline 6,2 & 0,998 & 0,994 & 0,984 & 0,961 & 0,919 & 0,854 & 0,653 & 0,499 & 0,400 & 0,333 & 0,286 & 0,250 \\
\hline 6,3 & 0,998 & 0,994 & 0,985 & 0,963 & 0,920 & 0,855 & 0,654 & 0,499 & 0,400 & 0,333 & 0,286 & 0,250 \\
\hline 6,4 & 0,998 & 0,995 & 0,986 & 0,964 & 0,922 & 0,857 & 0,654 & 0,499 & 0,400 & 0,333 & 0,286 & 0,250 \\
\hline 6,5 & 0,998 & 0,995 & 0,986 & 0,965 & 0,924 & 0,859 & 0,655 & 0,499 & 0,400 & 0,333 & 0,286 & 0,250 \\
\hline 6,6 & 0,999 & 0,996 & 0,987 & 0,967 & 0,926 & 0,860 & 0,655 & 0,499 & 0,400 & 0,333 & 0,286 & 0,250 \\
\hline 6,7 & 0,999 & 0,996 & 0,988 & 0,968 & 0,927 & 0,862 & 0,656 & 0,499 & 0,400 & 0,333 & 0,286 & 0,250 \\
\hline 6,8 & 0,999 & 0,996 & 0,988 & 0,969 & 0,929 & 0,864 & 0,656 & 0,499 & 0,400 & 0,333 & 0,286 & 0,250 \\
\hline 6,9 & 0,999 & 0,996 & 0,989 & 0,970 & 0,930 & 0,865 & 0,656 & 0,499 & 0,400 & 0,333 & 0,286 & 0,250 \\
\hline 7,0 & 0,999 & 0,997 & 0,990 & 0,971 & 0,932 & 0,866 & 0,657 & 0,499 & 0,400 & 0,333 & 0,286 & 0,250 \\
\hline 7,1 & 0,999 & 0,997 & 0,990 & 0,972 & 0,933 & 0,868 & 0,657 & 0,499 & 0,400 & 0,333 & 0,286 & 0,250 \\
\hline 7,2 & 0,999 & 0,997 & 0,991 & 0,973 & 0,934 & 0,869 & 0,658 & 0,500 & 0,400 & 0,333 & 0,286 & 0,250 \\
\hline 7,3 & 0,999 & 0,997 & 0,991 & 0,974 & 0,936 & 0,871 & 0,658 & 0,500 & 0,400 & 0,333 & 0,286 & 0,250 \\
\hline 7,4 & 0,999 & 0,998 & 0,992 & 0,975 & 0,937 & 0,872 & 0,658 & 0,500 & 0,400 & 0,333 & 0,286 & 0,250 \\
\hline 7,5 & 0,999 & 0,998 & 0,992 & 0,976 & 0,938 & 0,873 & 0,658 & 0,500 & 0,400 & 0,333 & 0,286 & 0,250 \\
\hline 7,6 & 0,999 & 0,998 & 0,993 & 0,977 & 0,940 & 0,874 & 0,659 & 0,500 & 0,400 & 0,333 & 0,286 & 0,250 \\
\hline 7,7 & 1,000 & 0,998 & 0,993 & 0,977 & 0,941 & 0,875 & 0,659 & 0,500 & 0,400 & 0,333 & 0,286 & 0,250 \\
\hline 7,8 & 1,000 & 0,998 & 0,993 & 0,978 & 0,942 & 0,877 & 0,659 & 0,500 & 0,400 & 0,333 & 0,286 & 0,250 \\
\hline 7,9 & 1,000 & 0,998 & 0,994 & 0,979 & 0,943 & 0,878 & 0,660 & 0,500 & 0,400 & 0,333 & 0,286 & 0,250 \\
\hline 8,0 & 1,000 & 0,998 & 0,994 & 0,980 & 0,944 & 0,879 & 0,660 & 0,500 & 0,400 & 0,333 & 0,286 & 0,250 \\
\hline 8,1 & 1,000 & 0,999 & 0,994 & 0,980 & 0,945 & 0,880 & 0,660 & 0,500 & 0,400 & 0,333 & 0,286 & 0,250 \\
\hline 8,2 & 1,000 & 0,999 & 0,995 & 0,981 & 0,946 & 0,881 & 0,660 & 0,500 & 0,400 & 0,333 & 0,286 & 0,250 \\
\hline 8,3 & 1,000 & 0,999 & 0,995 & 0,982 & 0,947 & 0,882 & 0,660 & 0,500 & 0,400 & 0,333 & 0,286 & 0,250 \\
\hline 8,4 & 1,000 & 0,999 & 0,995 & 0,982 & 0,948 & 0,883 & 0,661 & 0,500 & 0,400 & 0,333 & 0,286 & 0,250 \\
\hline 8,5 & 1,000 & 0,999 & 0,995 & 0,983 & 0,949 & 0,884 & 0,661 & 0,500 & 0,400 & 0,333 & 0,286 & 0,250 \\
\hline 8,6 & 1,000 & 0,999 & 0,996 & 0,983 & 0,950 & 0,885 & 0,661 & 0,500 & 0,400 & 0,333 & 0,286 & 0,250 \\
\hline 8,7 & 1,000 & 0,999 & 0,996 & 0,984 & 0,951 & 0,886 & 0,661 & 0,500 & 0,400 & 0,333 & 0,286 & 0,250 \\
\hline 8,8 & 1,000 & 0,999 & 0,996 & 0,984 & 0,952 & 0,887 & 0,661 & 0,500 & 0,400 & 0,333 & 0,286 & 0,250 \\
\hline 8,9 & 1,000 & 0,999 & 0,996 & 0,985 & 0,953 & 0,888 & 0,662 & 0,500 & 0,400 & 0,333 & 0,286 & 0,250 \\
\hline 9,0 & 1,000 & 0,999 & 0,996 & 0,985 & 0,953 & 0,889 & 0,662 & 0,500 & 0,400 & 0,333 & 0,286 & 0,250 \\
\hline 9,1 & 1,000 & 0,999 & 0,997 & 0,986 & 0,954 & 0,889 & 0,662 & 0,500 & 0,400 & 0,333 & 0,286 & 0,250 \\
\hline 9,2 & 1,000 & 0,999 & 0,997 & 0,986 & 0,955 & 0,890 & 0,662 & 0,500 & 0,400 & 0,333 & 0,286 & 0,250 \\
\hline 9,3 & 1,000 & 0,999 & 0,997 & 0,987 & 0,956 & 0,891 & 0,662 & 0,500 & 0,400 & 0,333 & 0,286 & 0,250 \\
\hline 9,4 & 1,000 & 0,999 & 0,997 & 0,987 & 0,957 & 0,892 & 0,662 & 0,500 & 0,400 & 0,333 & 0,286 & 0,250 \\
\hline 9,5 & 1,000 & 0,999 & 0,997 & 0,988 & 0,957 & 0,893 & 0,662 & 0,500 & 0,400 & 0,333 & 0,286 & 0,250 \\
\hline 9,6 & 1,000 & 1,000 & 0,997 & 0,988 & 0,958 & 0,893 & 0,663 & 0,500 & 0,400 & 0,333 & 0,286 & 0,250 \\
\hline 9,7 & 1,000 & 1,000 & 0,997 & 0,988 & 0,959 & 0,894 & 0,663 & 0,500 & 0,400 & 0,333 & 0,286 & 0,250 \\
\hline 9,8 & 1,000 & 1,000 & 0,998 & 0,989 & 0,959 & 0,895 & 0,663 & 0,500 & 0,400 & 0,333 & 0,286 & 0,250 \\
\hline 9,9 & 1,000 & 1,000 & 0,998 & 0,989 & 0,960 & 0,896 & 0,663 & 0,500 & 0,400 & 0,333 & 0,286 & 0,250 \\
\hline 10,0 & 1,000 & 1,000 & 0,998 & 0,989 & 0,961 & 0,896 & 0,663 & 0,500 & 0,400 & 0,333 & 0,286 & 0,250 \\
\hline
\end{tabular}


Tabela 82 - Fator de correção para trocador de calor de fluxo cruzado com dez passes e um tubo por passe (10-1) - Caso 4A - trocador de calor ilustrado na Figura 98 do Anexo A

\begin{tabular}{|c|c|c|c|c|c|c|c|c|c|c|c|c|}
\hline${ }_{N T U}^{R}$ & 0,0 & 0,2 & 0,4 & 0,6 & 0,8 & 1,0 & 1,5 & 2,0 & 2,5 & 3,0 & 3,5 & 4,0 \\
\hline 0,0 & 1,000 & 1,000 & 1,000 & 1,000 & 1,000 & 1,000 & 1,000 & 1,000 & 1,000 & 1,000 & 1,000 & 1,000 \\
\hline 0,1 & 1,000 & 1,000 & 1,000 & 1,000 & 1,000 & 1,000 & 1,000 & 1,000 & 1,000 & 1,000 & 1,000 & 1,000 \\
\hline 0,2 & 1,000 & 1,000 & 1,000 & 1,000 & 1,000 & 1,000 & 1,000 & 1,000 & 1,000 & 1,000 & 1,000 & 1,000 \\
\hline 0,3 & 1,000 & 1,000 & 1,000 & 1,000 & 1,000 & 1,000 & 1,000 & 1,000 & 1,000 & 1,000 & 0,999 & 0,999 \\
\hline 0,4 & 1,000 & 1,000 & 1,000 & 1,000 & 1,000 & 1,000 & 1,000 & 0,999 & 0,999 & 0,999 & 0,999 & 0,999 \\
\hline 0,5 & 1,000 & 1,000 & 1,000 & 1,000 & 1,000 & 1,000 & 0,999 & 0,999 & 0,999 & 0,999 & 0,999 & 0,998 \\
\hline 0,6 & 1,000 & 1,000 & 1,000 & 1,000 & 1,000 & 0,999 & 0,999 & 0,999 & 0,999 & 0,998 & 0,998 & 0,998 \\
\hline 0,7 & 1,000 & 1,000 & 1,000 & 1,000 & 0,999 & 0,999 & 0,999 & 0,998 & 0,998 & 0,998 & 0,997 & 0,997 \\
\hline 0,8 & 1,000 & 1,000 & 1,000 & 0,999 & 0,999 & 0,999 & 0,998 & 0,998 & 0,997 & 0,997 & 0,996 & 0,996 \\
\hline 0,9 & 1,000 & 1,000 & 0,999 & 0,999 & 0,999 & 0,999 & 0,998 & 0,997 & 0,997 & 0,996 & 0,995 & 0,995 \\
\hline 1,0 & 1,000 & 1,000 & 0,999 & 0,999 & 0,999 & 0,998 & 0,998 & 0,997 & 0,996 & 0,995 & 0,994 & 0,993 \\
\hline 1,1 & 1,000 & 1,000 & 0,999 & 0,999 & 0,998 & 0,998 & 0,997 & 0,996 & 0,995 & 0,994 & 0,993 & 0,992 \\
\hline 1,2 & 1,000 & 1,000 & 0,999 & 0,999 & 0,998 & 0,998 & 0,996 & 0,995 & 0,994 & 0,993 & 0,992 & 0,991 \\
\hline 1,3 & 1,000 & 0,999 & 0,999 & 0,998 & 0,998 & 0,997 & 0,996 & 0,994 & 0,993 & 0,992 & 0,990 & 0,989 \\
\hline 1,4 & 1,000 & 0,999 & 0,999 & 0,998 & 0,997 & 0,997 & 0,995 & 0,994 & 0,992 & 0,990 & 0,989 & 0,987 \\
\hline 1,5 & 1,000 & 0,999 & 0,999 & 0,998 & 0,997 & 0,996 & 0,994 & 0,993 & 0,991 & 0,989 & 0,987 & 0,986 \\
\hline 1,6 & 1,000 & 0,999 & 0,998 & 0,997 & 0,997 & 0,996 & 0,994 & 0,992 & 0,990 & 0,988 & 0,986 & 0,984 \\
\hline 1,7 & 1,000 & 0,999 & 0,998 & 0,997 & 0,996 & 0,995 & 0,993 & 0,991 & 0,988 & 0,986 & 0,984 & 0,982 \\
\hline 1,8 & 1,000 & 0,999 & 0,998 & 0,997 & 0,996 & 0,995 & 0,992 & 0,989 & 0,987 & 0,984 & 0,982 & 0,980 \\
\hline 1,9 & 1,000 & 0,999 & 0,998 & 0,996 & 0,995 & 0,994 & 0,991 & 0,988 & 0,985 & 0,983 & 0,980 & 0,978 \\
\hline 2,0 & 1,000 & 0,999 & 0,997 & 0,996 & 0,995 & 0,993 & 0,990 & 0,987 & 0,984 & 0,981 & 0,978 & 0,975 \\
\hline 2,1 & 1,000 & 0,999 & 0,997 & 0,996 & 0,994 & 0,993 & 0,989 & 0,986 & 0,982 & 0,979 & 0,976 & 0,973 \\
\hline 2,2 & 1,000 & 0,998 & 0,997 & 0,995 & 0,994 & 0,992 & 0,988 & 0,984 & 0,981 & 0,977 & 0,974 & 0,971 \\
\hline 2,3 & 1,000 & 0,998 & 0,996 & 0,995 & 0,993 & 0,991 & 0,987 & 0,983 & 0,979 & 0,975 & 0,972 & 0,968 \\
\hline 2,4 & 1,000 & 0,998 & 0,996 & 0,994 & 0,992 & 0,991 & 0,986 & 0,982 & 0,977 & 0,973 & 0,969 & 0,965 \\
\hline 2,5 & 1,000 & 0,998 & 0,996 & 0,994 & 0,992 & 0,990 & 0,985 & 0,980 & 0,975 & 0,971 & 0,967 & 0,963 \\
\hline 2,6 & 1,000 & 0,998 & 0,996 & 0,993 & 0,991 & 0,989 & 0,984 & 0,978 & 0,974 & 0,969 & 0,964 & 0,960 \\
\hline 2,7 & 1,000 & 0,998 & 0,995 & 0,993 & 0,990 & 0,988 & 0,982 & 0,977 & 0,972 & 0,967 & 0,962 & 0,957 \\
\hline 2,8 & 1,000 & 0,997 & 0,995 & 0,992 & 0,990 & 0,987 & 0,981 & 0,975 & 0,970 & 0,964 & 0,959 & 0,955 \\
\hline 2,9 & 1,000 & 0,997 & 0,994 & 0,992 & 0,989 & 0,986 & 0,980 & 0,974 & 0,968 & 0,962 & 0,957 & 0,952 \\
\hline 3,0 & 1,000 & 0,997 & 0,994 & 0,991 & 0,988 & 0,985 & 0,978 & 0,972 & 0,965 & 0,960 & 0,954 & 0,949 \\
\hline 3,1 & 1,000 & 0,997 & 0,994 & 0,990 & 0,987 & 0,984 & 0,977 & 0,970 & 0,963 & 0,957 & 0,951 & 0,946 \\
\hline 3,2 & 1,000 & 0,997 & 0,993 & 0,990 & 0,987 & 0,983 & 0,976 & 0,968 & 0,961 & 0,954 & 0,948 & 0,943 \\
\hline 3,3 & 1,000 & 0,996 & 0,993 & 0,989 & 0,986 & 0,982 & 0,974 & 0,966 & 0,959 & 0,952 & 0,945 & 0,940 \\
\hline 3,4 & 1,000 & 0,996 & 0,992 & 0,989 & 0,985 & 0,981 & 0,973 & 0,964 & 0,957 & 0,949 & 0,943 & 0,936 \\
\hline 3,5 & 1,000 & 0,996 & 0,992 & 0,988 & 0,984 & 0,980 & 0,971 & 0,962 & 0,954 & 0,947 & 0,940 & 0,933 \\
\hline 3,6 & 1,000 & 0,996 & 0,991 & 0,987 & 0,983 & 0,979 & 0,969 & 0,960 & 0,952 & 0,944 & 0,937 & 0,930 \\
\hline 3,7 & 1,000 & 0,995 & 0,991 & 0,987 & 0,982 & 0,978 & 0,968 & 0,958 & 0,949 & 0,941 & 0,934 & 0,927 \\
\hline 3,8 & 1,000 & 0,995 & 0,990 & 0,986 & 0,981 & 0,977 & 0,966 & 0,956 & 0,947 & 0,938 & 0,931 & 0,923 \\
\hline 3,9 & 1,000 & 0,995 & 0,990 & 0,985 & 0,980 & 0,976 & 0,964 & 0,954 & 0,944 & 0,936 & 0,927 & 0,920 \\
\hline 4,0 & 1,000 & 0,995 & 0,989 & 0,984 & 0,979 & 0,974 & 0,963 & 0,952 & 0,942 & 0,933 & 0,924 & 0,917 \\
\hline 4,1 & 1,000 & 0,994 & 0,989 & 0,984 & 0,978 & 0,973 & 0,961 & 0,950 & 0,939 & 0,930 & 0,921 & 0,913 \\
\hline 4,2 & 1,000 & 0,994 & 0,988 & 0,983 & 0,977 & 0,972 & 0,959 & 0,947 & 0,937 & 0,927 & 0,918 & 0,910 \\
\hline 4,3 & 1,000 & 0,994 & 0,988 & 0,982 & 0,976 & 0,971 & 0,957 & 0,945 & 0,934 & 0,924 & 0,915 & 0,907 \\
\hline 4,4 & 1,000 & 0,994 & 0,987 & 0,981 & 0,975 & 0,969 & 0,955 & 0,943 & 0,931 & 0,921 & 0,912 & 0,903 \\
\hline 4,5 & 1,000 & 0,993 & 0,987 & 0,980 & 0,974 & 0,968 & 0,953 & 0,940 & 0,929 & 0,918 & 0,908 & 0,900 \\
\hline 4,6 & 1,000 & 0,993 & 0,986 & 0,979 & 0,973 & 0,966 & 0,952 & 0,938 & 0,926 & 0,915 & 0,905 & 0,896 \\
\hline 4,7 & 1,000 & 0,993 & 0,985 & 0,978 & 0,972 & 0,965 & 0,950 & 0,936 & 0,923 & 0,912 & 0,902 & 0,893 \\
\hline 4,8 & 1,000 & 0,992 & 0,985 & 0,978 & 0,970 & 0,964 & 0,948 & 0,933 & 0,920 & 0,909 & 0,898 & 0,889 \\
\hline 4,9 & 1,000 & 0,992 & 0,984 & 0,977 & 0,969 & 0,962 & 0,946 & 0,931 & 0,917 & 0,906 & 0,895 & 0,886 \\
\hline
\end{tabular}


Tabela 82 - continuação da página anterior

\begin{tabular}{|c|c|c|c|c|c|c|c|c|c|c|c|c|}
\hline $\mathrm{NTU}^{R}$ & 0,0 & 0,2 & 0,4 & 0,6 & 0,8 & 1,0 & 1,5 & 2,0 & 2,5 & 3,0 & 3,5 & 4,0 \\
\hline 5,0 & 1,000 & 0,992 & 0,984 & 0,976 & 0,968 & 0,961 & 0,944 & 0,928 & 0,915 & 0,902 & 0,892 & 0,882 \\
\hline 5,1 & 1,000 & 0,991 & 0,983 & 0,975 & 0,967 & 0,959 & 0,942 & 0,926 & 0,912 & 0,899 & 0,888 & 0,879 \\
\hline 5,2 & 1,000 & 0,991 & 0,982 & 0,974 & 0,966 & 0,958 & 0,939 & 0,923 & 0,909 & 0,896 & 0,885 & 0,875 \\
\hline 5,3 & 1,000 & 0,991 & 0,982 & 0,973 & 0,964 & 0,956 & 0,937 & 0,921 & 0,906 & 0,893 & 0,882 & 0,872 \\
\hline 5,4 & 1,000 & 0,990 & 0,981 & 0,972 & 0,963 & 0,955 & 0,935 & 0,918 & 0,903 & 0,890 & 0,878 & 0,868 \\
\hline 5,5 & 1,000 & 0,990 & 0,980 & 0,971 & 0,962 & 0,953 & 0,933 & 0,915 & 0,900 & 0,887 & 0,875 & 0,865 \\
\hline 5,6 & 1,000 & 0,990 & 0,979 & 0,970 & 0,960 & 0,951 & 0,931 & 0,913 & 0,897 & 0,883 & 0,872 & 0,861 \\
\hline 5,7 & 1,000 & 0,989 & 0,979 & 0,969 & 0,959 & 0,950 & 0,929 & 0,910 & 0,894 & 0,880 & 0,868 & 0,858 \\
\hline 5,8 & 1,000 & 0,989 & 0,978 & 0,968 & 0,958 & 0,948 & 0,926 & 0,907 & 0,891 & 0,877 & 0,865 & 0,854 \\
\hline 5,9 & 1,000 & 0,988 & 0,977 & 0,966 & 0,956 & 0,946 & 0,924 & 0,905 & 0,888 & 0,874 & 0,861 & 0,851 \\
\hline 6,0 & 1,000 & 0,988 & 0,976 & 0,965 & 0,955 & 0,945 & 0,922 & 0,902 & 0,885 & 0,870 & 0,858 & 0,847 \\
\hline 6,1 & 1,000 & 0,988 & 0,976 & 0,964 & 0,953 & 0,943 & 0,920 & 0,899 & 0,882 & 0,867 & 0,855 & 0,844 \\
\hline 6,2 & 1,000 & 0,987 & 0,975 & 0,963 & 0,952 & 0,941 & 0,917 & 0,897 & 0,879 & 0,864 & 0,851 & 0,840 \\
\hline 6,3 & 1,000 & 0,987 & 0,974 & 0,962 & 0,950 & 0,940 & 0,915 & 0,894 & 0,876 & 0,861 & 0,848 & 0,837 \\
\hline 6,4 & 1,000 & 0,986 & 0,973 & 0,961 & 0,949 & 0,938 & 0,913 & 0,891 & 0,873 & 0,857 & 0,844 & 0,833 \\
\hline 6,5 & 1,000 & 0,986 & 0,972 & 0,960 & 0,947 & 0,936 & 0,910 & 0,888 & 0,870 & 0,854 & 0,841 & 0,830 \\
\hline 6,6 & 1,000 & 0,985 & 0,972 & 0,958 & 0,946 & 0,934 & 0,908 & 0,885 & 0,867 & 0,851 & 0,838 & 0,826 \\
\hline 6,7 & 1,000 & 0,985 & 0,971 & 0,957 & 0,944 & 0,932 & 0,905 & 0,883 & 0,864 & 0,848 & 0,834 & 0,823 \\
\hline 6,8 & 1,000 & 0,985 & 0,970 & 0,956 & 0,943 & 0,930 & 0,903 & 0,880 & 0,861 & 0,844 & 0,831 & 0,820 \\
\hline 6,9 & 1,000 & 0,984 & 0,969 & 0,955 & 0,941 & 0,929 & 0,901 & 0,877 & 0,857 & 0,841 & 0,827 & 0,816 \\
\hline 7,0 & 1,000 & 0,984 & 0,968 & 0,953 & 0,940 & 0,927 & 0,898 & 0,874 & 0,854 & 0,838 & 0,824 & 0,813 \\
\hline 7,1 & 1,000 & 0,983 & 0,967 & 0,952 & 0,938 & 0,925 & 0,896 & 0,871 & 0,851 & 0,835 & 0,821 & 0,809 \\
\hline 7,2 & 1,000 & 0,983 & 0,966 & 0,951 & 0,936 & 0,923 & 0,893 & 0,869 & 0,848 & 0,831 & 0,817 & 0,806 \\
\hline 7,3 & 1,000 & 0,982 & 0,965 & 0,950 & 0,935 & 0,921 & 0,891 & 0,866 & 0,845 & 0,828 & 0,814 & 0,802 \\
\hline 7,4 & 1,000 & 0,982 & 0,964 & 0,948 & 0,933 & 0,919 & 0,888 & 0,863 & 0,842 & 0,825 & 0,811 & 0,799 \\
\hline 7,5 & 1,000 & 0,981 & 0,964 & 0,947 & 0,931 & 0,917 & 0,886 & 0,860 & 0,839 & 0,822 & 0,807 & 0,796 \\
\hline 7,6 & 1,000 & 0,981 & 0,963 & 0,946 & 0,930 & 0,915 & 0,883 & 0,857 & 0,836 & 0,818 & 0,804 & 0,792 \\
\hline 7,7 & 1,000 & 0,980 & 0,962 & 0,944 & 0,928 & 0,913 & 0,881 & 0,854 & 0,833 & 0,815 & 0,801 & 0,789 \\
\hline 7,8 & 1,000 & 0,980 & 0,961 & 0,943 & 0,926 & 0,911 & 0,878 & 0,851 & 0,830 & 0,812 & 0,797 & 0,786 \\
\hline 7,9 & 1,000 & 0,979 & 0,960 & 0,941 & 0,925 & 0,909 & 0,876 & 0,848 & 0,826 & 0,809 & 0,794 & 0,782 \\
\hline 8,0 & 1,000 & 0,979 & 0,959 & 0,940 & 0,923 & 0,907 & 0,873 & 0,845 & 0,823 & 0,805 & 0,791 & 0,779 \\
\hline 8,1 & 1,000 & 0,978 & 0,958 & 0,939 & 0,921 & 0,905 & 0,870 & 0,843 & 0,820 & 0,802 & 0,788 & 0,776 \\
\hline 8,2 & 1,000 & 0,978 & 0,957 & 0,937 & 0,919 & 0,903 & 0,868 & 0,840 & 0,817 & 0,799 & 0,784 & 0,772 \\
\hline 8,3 & 1,000 & 0,977 & 0,956 & 0,936 & 0,918 & 0,901 & 0,865 & 0,837 & 0,814 & 0,796 & 0,781 & 0,769 \\
\hline 8,4 & 1,000 & 0,976 & 0,955 & 0,934 & 0,916 & 0,899 & 0,863 & 0,834 & 0,811 & 0,793 & 0,778 & 0,766 \\
\hline 8,5 & 1,000 & 0,976 & 0,953 & 0,933 & 0,914 & 0,897 & 0,860 & 0,831 & 0,808 & 0,789 & 0,775 & 0,763 \\
\hline 8,6 & 1,000 & 0,975 & 0,952 & 0,931 & 0,912 & 0,895 & 0,857 & 0,828 & 0,805 & 0,786 & 0,771 & 0,759 \\
\hline 8,7 & 1,000 & 0,975 & 0,951 & 0,930 & 0,910 & 0,893 & 0,855 & 0,825 & 0,802 & 0,783 & 0,768 & 0,756 \\
\hline 8,8 & 1,000 & 0,974 & 0,950 & 0,928 & 0,909 & 0,890 & 0,852 & 0,822 & 0,799 & 0,780 & 0,765 & 0,753 \\
\hline 8,9 & 1,000 & 0,974 & 0,949 & 0,927 & 0,907 & 0,888 & 0,850 & 0,819 & 0,796 & 0,777 & 0,762 & 0,750 \\
\hline 9,0 & 1,000 & 0,973 & 0,948 & 0,925 & 0,905 & 0,886 & 0,847 & 0,816 & 0,793 & 0,774 & 0,759 & 0,747 \\
\hline 9,1 & 1,000 & 0,972 & 0,947 & 0,924 & 0,903 & 0,884 & 0,844 & 0,814 & 0,790 & 0,771 & 0,756 & 0,743 \\
\hline 9,2 & 1,000 & 0,972 & 0,946 & 0,922 & 0,901 & 0,882 & 0,842 & 0,811 & 0,787 & 0,768 & 0,752 & 0,740 \\
\hline 9,3 & 1,000 & 0,971 & 0,945 & 0,921 & 0,899 & 0,880 & 0,839 & 0,808 & 0,784 & 0,764 & 0,749 & 0,737 \\
\hline 9,4 & 1,000 & 0,970 & 0,944 & 0,919 & 0,897 & 0,877 & 0,836 & 0,805 & 0,780 & 0,761 & 0,746 & 0,734 \\
\hline 9,5 & 1,000 & 0,970 & 0,942 & 0,918 & 0,895 & 0,875 & 0,834 & 0,802 & 0,777 & 0,758 & 0,743 & 0,731 \\
\hline 9,6 & 1,000 & 0,969 & 0,941 & 0,916 & 0,893 & 0,873 & 0,831 & 0,799 & 0,774 & 0,755 & 0,740 & 0,728 \\
\hline 9,7 & 1,000 & 0,969 & 0,940 & 0,914 & 0,891 & 0,871 & 0,829 & 0,796 & 0,771 & 0,752 & 0,737 & 0,725 \\
\hline 9,8 & 1,000 & 0,968 & 0,939 & 0,913 & 0,889 & 0,869 & 0,826 & 0,793 & 0,768 & 0,749 & 0,734 & 0,722 \\
\hline 9,9 & 1,000 & 0,967 & 0,938 & 0,911 & 0,888 & 0,866 & 0,823 & 0,791 & 0,766 & 0,746 & 0,731 & 0,719 \\
\hline 10,0 & 1,000 & 0,967 & 0,936 & 0,910 & 0,886 & 0,864 & 0,821 & 0,788 & 0,763 & 0,743 & 0,728 & 0,716 \\
\hline
\end{tabular}





\section{Algoritmos}

O presente apêndice mostra os algoritmos desenvolvimentos para todas as configurações de trocadores de calor de fluxo cruzado desenvolvidos por Pignotti e Cordero (1983a), detalhados por Magazoni e Cabezas-Gómez (2016) e apresentados na Seção 4.1. No total, são sete algoritmos desenvolvidos:

- Caso 1A: trocador de calor de fluxo cruzado em escoamento paralelo com os fluidos quente e frio completamente misturados entre os passes;

- Casos 1B e 1C: trocador de calor de fluxo cruzado em escoamento paralelo com fluido frio completamente misturado entre os passes e com fluido quente não misturado com uma ordem idêntica das fileiras (caso 1B) e não misturado com uma ordem inversa das fileiras (caso 1C);

- Caso 2A: trocador de calor de fluxo cruzado em escoamento contracorrente com os fluidos quente e frio completamente misturados entre os passes;

- Caso 2B e 2C: trocador de calor de fluxo cruzado em escoamento contracorrente com fluido frio completamente misturado entre os passes e com fluido quente não misturado com uma ordem idêntica das fileiras (caso 2B) e não misturado com uma ordem inversa das fileiras (caso 2C);

- Caso 3A, 3B e 3C: trocador de calor de fluxo cruzado em escoamento paralelo com fluido frio não misturado entre os passes e com fluido quente misturado (caso $3 \mathrm{~A}$ ), não misturado com uma ordem idêntica das fileiras (caso 3B) e não misturado com uma ordem inversa das fileiras (caso 3C);

- Caso 4A: trocador de calor de fluxo cruzado em escoamento contracorrente com fluido frio não misturado entre os passes e fluido quente misturado;

- Caso 4B e 4C: trocador de calor de fluxo cruzado em escoamento contracorrente com fluido frio não misturado entre os passes e com fluido quente não misturado com uma ordem idêntica das fileiras (caso 4B) e não misturado com uma ordem inversa das fileiras (caso 4C).

\section{C.1 Caso $1 \mathrm{~A}$}

$\mathrm{N}=\mathrm{N} \_\mathrm{p} * \mathrm{~N} \_\mathrm{r}$;

$\mathrm{rho}=\exp (-\mathrm{NTU} / \mathrm{N})$; 


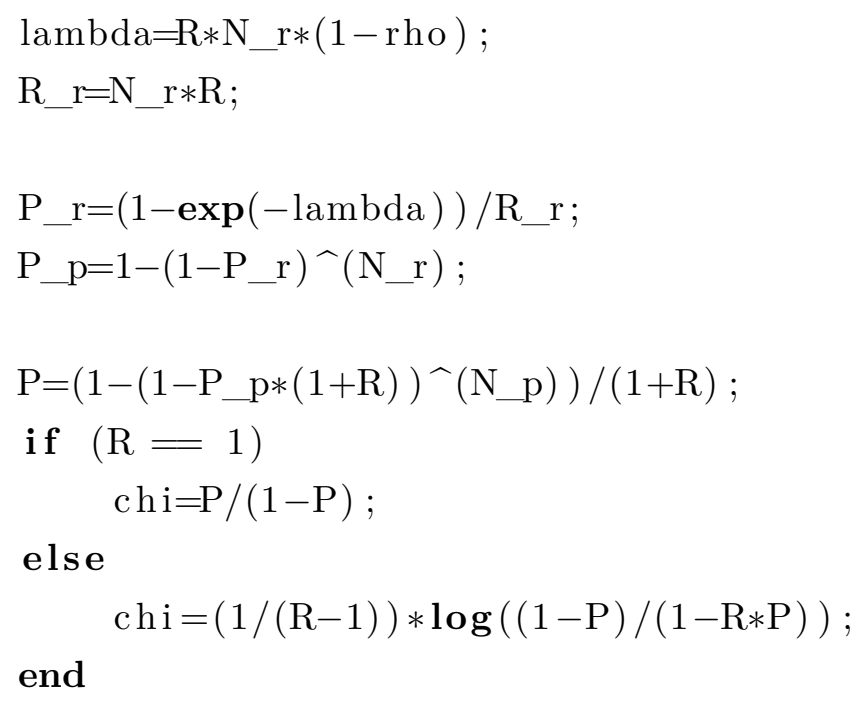

$\mathrm{F}=\mathrm{chi} / \mathrm{NTU}$;

\section{C.2 Casos 1B e $1 \mathrm{C}$}

$\mathrm{N}=\mathrm{N} \_\mathrm{p} * \mathrm{~N} \_\mathrm{r}$;

$\mathrm{rho}=\exp (-\mathrm{NTU} / \mathrm{N})$;

lambda $=\mathrm{R} * \mathrm{~N} \_\mathrm{r} *(1-\mathrm{rho})$;

$\mathrm{R} \_\mathrm{r}=\mathrm{N} \_\mathrm{r} * \mathrm{R}$;

$\mathrm{P} \_\mathrm{r}=(1-\exp (-\mathrm{lambda})) / \mathrm{R} \_\mathrm{r}$;

$\mathrm{P} \_\mathrm{p}=1-\left(1-\mathrm{P} \_\mathrm{r}\right)^{\wedge}\left(\mathrm{N} \_\mathrm{r}\right)$;

$\mathrm{Pt} \_\mathrm{r}=\mathrm{P} \_\mathrm{r} * \mathrm{R} \_\mathrm{r}$;

theta_I $(1,1)=0$;

for $\mathrm{q}=1$ :N_r tau_I $(1, q)=1$;

end

for $\mathrm{p}=1: \mathrm{N} \_\mathrm{p}$

for $q=1: N \_r$

tau_F $(p, q)=P t \_r * t h e t a \_I(p, q)+\left(1-P t \_r\right) * t a u \_I(p, q)$;

theta_F $(\mathrm{p}, \mathrm{q})=\left(1-\mathrm{P} \_\mathrm{r}\right) * \operatorname{theta} \_\mathrm{I}(\mathrm{p}, \mathrm{q})+\mathrm{P} \_\mathrm{r} * \operatorname{tau} \_\mathrm{I}(\mathrm{p}, \mathrm{q})$;

if $\left(q \sim=N \_r\right)$

theta_I $(p, q+1)=$ theta_F $(p, q)$;

end

end

for $q=1: N \_r$

if $\left(\mathrm{p} \sim \mathrm{N} \_\mathrm{p}\right)$

switch caso

case '1B'

tau_I $(p+1, q)=t a u \_F(p, q) ;$ 


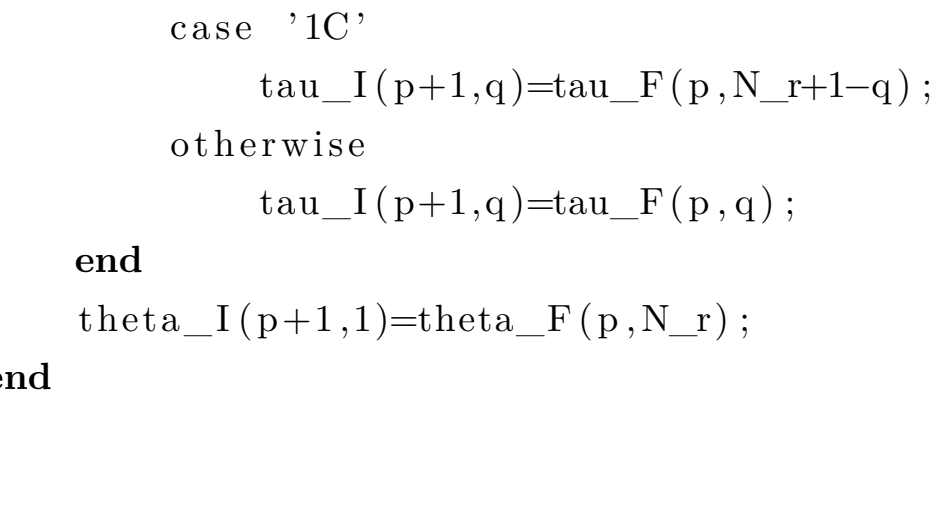

$\mathrm{P}=$ theta_F (N_p, N_r $)$;

if $(\mathrm{R}=1)$ $\operatorname{chi}=\mathrm{P} /(1-\mathrm{P})$;

else $\operatorname{chi}=(1 /(\mathrm{R}-1)) * \log ((1-\mathrm{P}) /(1-\mathrm{R} * \mathrm{P})) ;$

end

$\mathrm{F}=\mathrm{chi} / \mathrm{NTU}$;

\section{C.3 Caso 2A}

$\mathrm{N}=\mathrm{N} \_\mathrm{p} * \mathrm{~N} \_\mathrm{r} ;$

$\mathrm{rho}=\exp (-\mathrm{NTU} / \mathrm{N})$;

lambda $=\mathrm{R} * \mathrm{~N} \_\mathrm{r} *(1-\mathrm{rho})$;

$\mathrm{R} \_\mathrm{r}=\mathrm{N} \_\mathrm{r} * \mathrm{R}$;

$\mathrm{P} \_\mathrm{r}=(1-\exp (-\operatorname{lambda})) / \mathrm{R} \_\mathrm{r}$;

$\mathrm{P} \_\mathrm{p}=1-\left(1-\mathrm{P} \_\mathrm{r}\right) \hat{\wedge}\left(\mathrm{N} \_\mathrm{r}\right)$;

if $(\mathrm{R}=1)$

$\mathrm{P}=\mathrm{P} \_\mathrm{p} /\left(\mathrm{P} \_\mathrm{p}+\left(1-\mathrm{P} \_\mathrm{p}\right) / \mathrm{N} \_\mathrm{p}\right)$;

$\operatorname{chi}=\mathrm{P} /(1-\mathrm{P})$;

else

$\left.\left.\left.\mathrm{P}=\left(1-\left(\left(1-\mathrm{P} \_\mathrm{p}\right) /\left(1-\mathrm{R} * \mathrm{P} \_\mathrm{p}\right)\right)\right)^{\wedge}\left(\mathrm{N} \_\mathrm{p}\right)\right) /\left(1-\mathrm{R} *\left(\left(1-\mathrm{P} \_\mathrm{p}\right) /\left(1-\mathrm{R} * \mathrm{P} \_\mathrm{p}\right)\right)\right)^{\wedge} \mathrm{N} \_\mathrm{p}\right)\right)$; $\operatorname{chi}=(1 /(\mathrm{R}-1)) * \log ((1-\mathrm{P}) /(1-\mathrm{R} * \mathrm{P}))$;

end

$\mathrm{F}=\mathrm{chi} / \mathrm{NTU}$;

\section{C.4 Casos 2B e 2C}

$\mathrm{N}=\mathrm{N} \_\mathrm{p} * \mathrm{~N} \_\mathrm{r} ;$

$\mathrm{rho}=\exp (-\mathrm{NTU} / \mathrm{N})$;

lambda $=\mathrm{R} * \mathrm{~N} \_\mathrm{r} *(1-\mathrm{rho})$; 


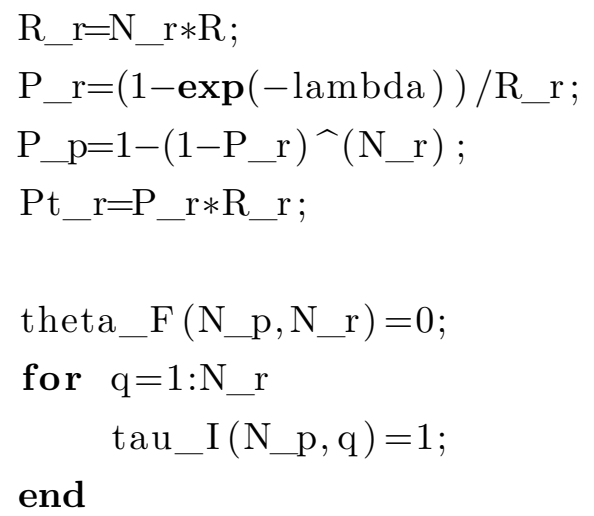

for $\mathrm{p}=\mathrm{N} \_\mathrm{p}:-1: 1$

for $q=\mathrm{N} \_r:-1: 1$

theta_I $(p, q)=$ theta_ $F(p, q) /\left(1-P_{\_} r\right)-\left(t a u_{-} I(p, q) * P_{\_} r\right) /\left(1-P_{\_} r\right)$;

tau_F $(p, q)=P t \_r * t h e t a \_I(p, q)+\left(1-P t \_r\right) * t a u \_I(p, q)$;

if $\quad(q \sim=1)$

theta_F $(\mathrm{p}, \mathrm{q}-1)=$ theta_I $(\mathrm{p}, \mathrm{q})$;

end

end

for $q=1: N_{-} r$

if $\quad(\mathrm{p} \sim=1)$

switch caso

case ' $2 \mathrm{~B}$ '

tau_I $(p-1, q)=$ tau_F $(p, q) ;$

case ' $2 \mathrm{C}$ '

tau_I $(p-1, q)=t a u \_F\left(p, N_{-} r+1-q\right) ;$

otherwise

tau_I $(p-1, q)=$ tau_F $(p, q)$;

end

theta_F $\left(\mathrm{p}-1, \mathrm{~N} \_\mathrm{r}\right)=$ theta__ $(\mathrm{p}, 1)$;

end

end

end

$\mathrm{P}=$ theta_I $(1,1) /($ theta_I $(1,1)-1)$;

if $(\mathrm{R}=1)$

$\operatorname{chi}=\mathrm{P} /(1-\mathrm{P})$;

else

$\operatorname{chi}=(1 /(\mathrm{R}-1)) * \log ((1-\mathrm{P}) /(1-\mathrm{R} * \mathrm{P})) ;$

end

$\mathrm{F}=\mathrm{chi} / \mathrm{NTU}$; 


\section{5 Casos 3A, 3B e 3C}

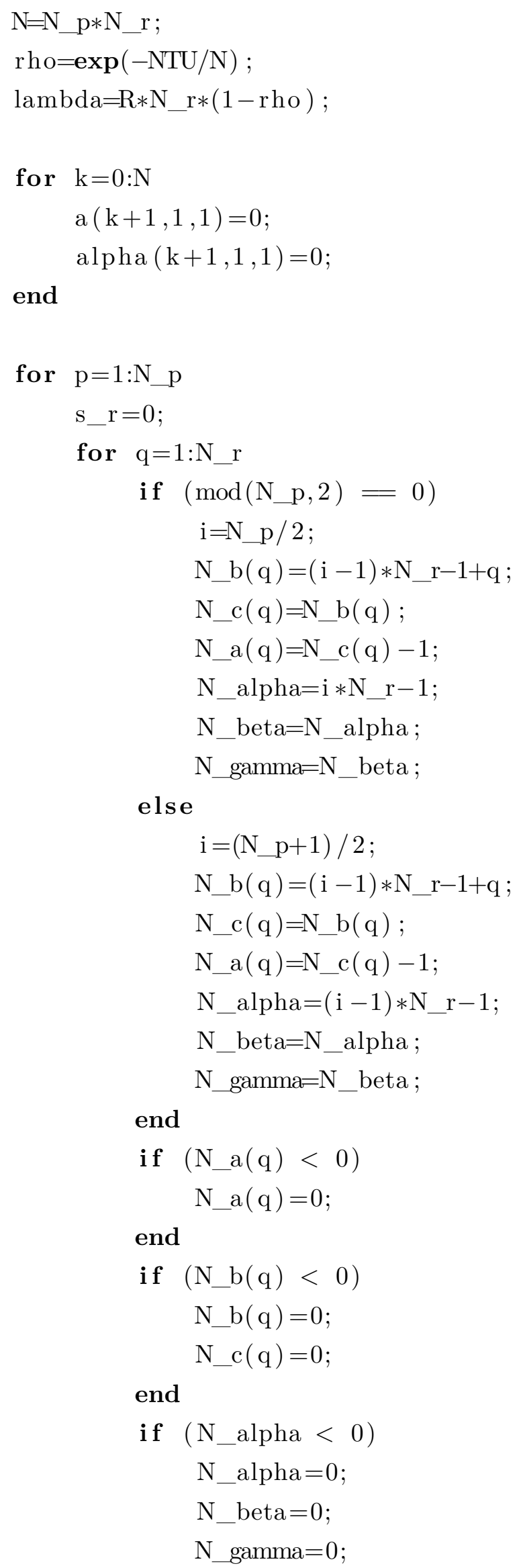


end

if $\quad(\mathrm{p}==1)$

$\operatorname{tau}(1, q, 1)=1$

end

s_beta $(p, q)=0$;

for $\mathrm{k}=0: \mathrm{N} \_$beta

$\mathrm{s} \_$beta $1=0$;

for $\mathrm{j}=\mathrm{k}: \mathrm{N} \_$beta

s_beta $1=$ s_beta $1+(\operatorname{alpha}(\mathrm{j}+1, \mathrm{p}, \mathrm{q})) *($ factorial $(\mathrm{j})$

$\left.*(-1 /(2 * \text { lambda }))^{\wedge}(\mathrm{j}-\mathrm{k})\right)$;

end

$\operatorname{beta}(\mathrm{k}+1, \mathrm{p}, \mathrm{q})=(1 /(2 *$ factorial $(\mathrm{k}))) * \mathrm{~s} \_$beta 1 ;

$\mathrm{s} \_$beta $(\mathrm{p}, \mathrm{q})=\mathrm{s} \_$beta $(\mathrm{p}, \mathrm{q})+\operatorname{beta}(\mathrm{k}+1, \mathrm{p}, \mathrm{q})$;

$\operatorname{gamma}(\mathrm{k}+1, \mathrm{p}, \mathrm{q})=\mathrm{rho} * \operatorname{alpha}(\mathrm{k}+1, \mathrm{p}, \mathrm{q})+(1-\mathrm{rho}) * \operatorname{beta}(\mathrm{k}+1, \mathrm{p}, \mathrm{q})$;

if $\left(q \sim=N \_r\right)$

alpha $(k+1, p, q+1)=\operatorname{gamma}(k+1, p, q)$;

end

end

for $\mathrm{k}=0: \mathrm{N} \_\mathrm{a}(\mathrm{q})$

s_beta $1=0$;

for $\mathrm{j}=\mathrm{k}: \mathrm{N} \_$beta

s_beta $1=$ s_beta $1+(\operatorname{alpha}(\mathrm{j}+1, \mathrm{p}, \mathrm{q})) *($ factorial $(\mathrm{j})$ $\left.*(-1 /(2 * \text { lambda }))^{\wedge}(\mathrm{j}-\mathrm{k})\right)$;

end

beta $(\mathrm{k}+1, \mathrm{p}, \mathrm{q})=(1 /(2 *$ factorial $(\mathrm{k}))) * \mathrm{~s} \_$beta 1 ;

$\operatorname{gamma}(\mathrm{k}+1, \mathrm{p}, \mathrm{q})=\mathrm{rho} * \operatorname{alpha}(\mathrm{k}+1, \mathrm{p}, \mathrm{q})+(1-\mathrm{rho}) * \operatorname{beta}(\mathrm{k}+1, \mathrm{p}, \mathrm{q})$;

if $\left(q \sim=N \_r\right)$

alpha $(\mathrm{k}+1, \mathrm{p}, \mathrm{q}+1)=\operatorname{gamma}(\mathrm{k}+1, \mathrm{p}, \mathrm{q})$;

end

end

$\mathrm{s} \_\mathrm{b}(\mathrm{p}, \mathrm{q})=0$

for $k=0: N \_b(q)$

if $(\mathrm{k}>=1)$

$\mathrm{b}(\mathrm{k}+1, \mathrm{p}, \mathrm{q})=(\operatorname{lambda} * \mathrm{a}(\mathrm{k}, \mathrm{p}, \mathrm{q})) / \mathrm{k} ;$

else

$$
\mathrm{b}(1, \mathrm{p}, \mathrm{q})=\operatorname{tau}(\mathrm{p}, \mathrm{q}, 1)-\operatorname{beta}(1, \mathrm{p}, \mathrm{q}) ;
$$

end

$\mathrm{s} \_\mathrm{b}(\mathrm{p}, \mathrm{q})=\mathrm{s} \_\mathrm{b}(\mathrm{p}, \mathrm{q})+\mathrm{b}(\mathrm{k}+1, \mathrm{p}, \mathrm{q})$; 


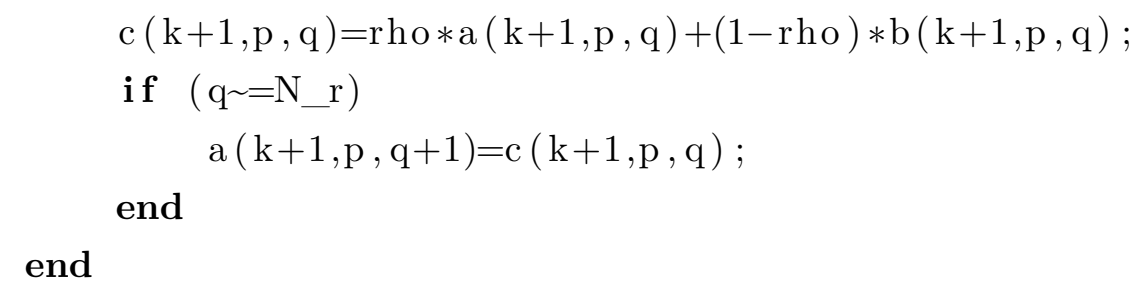




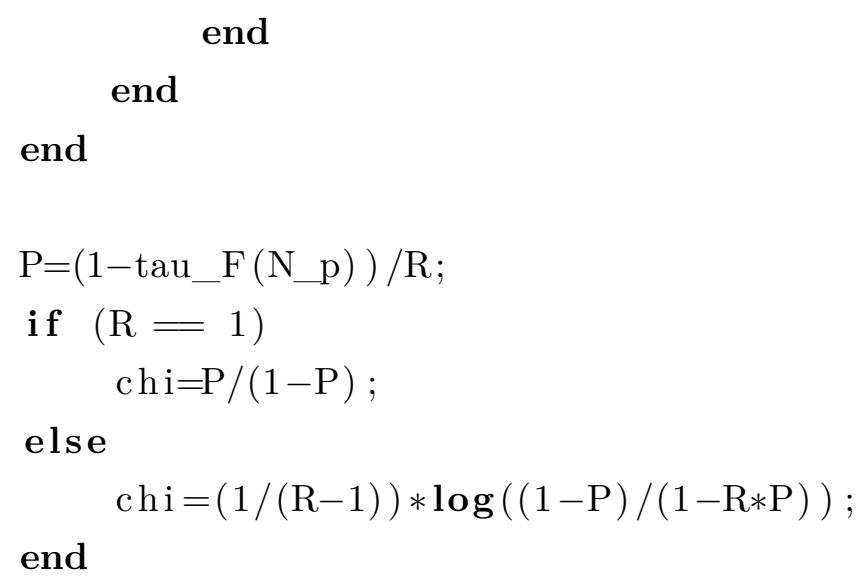

